\title{
METADISCOURSE IN POSTGRADUATE WRITING
}

PANSA PROMMAS

A thesis submitted to the Victoria University of Wellington

in fulfilment of the requirements for the degree of

Doctor of Philosophy in Applied Linguistics

Victoria University of Wellington 



\begin{abstract}
This thesis investigates metadiscourse in master's theses and the relationship between metadiscourse frequencies and quality of thesis writing. Metadiscourse has been a major research focus in various genres and contexts, but only a small proportion of this work has compared metadiscourse in postgraduate writing across educational contexts and disciplines. While previous studies of metadiscourse have reported a positive correlation between metadiscourse frequencies and writing quality, all of these studies focused on undergraduate writing. Little is known about the relationship between metadiscourse frequencies and quality of thesis writing.

This thesis includes two main studies to address the gaps in literature. Study 1 examined use of metadiscourse (i.e., frequencies, types, and functions) in master's thesis discussion and conclusion chapters written in English by New Zealand and Thai postgraduates in the disciplines of English language teaching and business administration. Four subcorpora with a total of 116 thesis samples were compiled: 26 New Zealand students' theses in English language teaching (NZ-ELT), 30 New Zealand students' theses in business administration (NZBA), 30 Thai students' theses in English language teaching (TH-ELT), and 30 Thai students' theses in business administration (TH-BA). Hyland's (2005) metadiscourse taxonomy was adopted for this study.
\end{abstract}

Study 2 explored the relationship between metadiscourse frequencies and quality of thesis writing. Forty eight theses (twelve theses with highest and lowest frequencies of metadiscourse markers in each of the four subcorpora in Study 1) were selected for this study. Semi-structured interviews were conducted with twenty four disciplinary supervisors in New Zealand and Thailand in order to investigate supervisors' attitudes towards and expectations of good thesis writing in their disciplines. This information was used to design a rating scale specifically for thesis quality assessment. Two New Zealand and Thai raters in English language teaching and business administration, four raters altogether, rated twenty four discussion and conclusion chapters in their own disciplines.

The findings of Study 1 reveal a higher frequency of metadiscourse in New Zealand theses than Thai theses. While both New Zealand and Thai students use more textual metadiscourse than interpersonal metadiscourse, New Zealand students show a greater reliance on the use of 
interpersonal metadiscourse (all interpersonal subcategories, except for boosters) than Thai students. By contrast, Thai students show a greater reliance on the use of textual metadiscourse (especially transition markers and frame markers) than New Zealand students. With regard to disciplinary variation, English language teaching students use more metadiscourse than business administration students, in both textual and interpersonal metadiscourse categories. Transition markers and hedges are the most prominent metadiscourse features, contributing the preponderance of textual and interpersonal metadiscourse in this study. Despite palpable differences in frequencies, the analysis of individual types across the four subcorpora reveals similarities of New Zealand and Thai students in the two disciplines. They use similar markers, rely heavily on a small cluster of high frequency markers, and make scarce use of lower frequency ones in all subcategories. The functional analysis indicates that there are six subcategories whose functions contribute to differences between New Zealand and Thai theses, namely transition markers, frame markers, evidentials, attitude markers, engagement markers, and self-mentions.

The findings of Study 2 reveal a positive correlation between metadiscourse frequencies and thesis quality scores in both English language teaching and business administration disciplines. However, a major difference between the two disciplines is that in business administration, the frequency of textual metadiscourse is more highly related to the quality scores when compared to interpersonal metadiscourse. In English language teaching, the frequency of interpersonal metadiscourse is more closely related to the quality scores. In the comparison of quality scores between high and low frequency groups, a statistically significant difference is found in business administration, but not in English language teaching. Insights gained from this study are that (1) business administration raters are likely to focus more on textual features which directly affect readers' comprehension, while English language teaching raters seem to have more expectations towards interactional features (e.g., explicit expression of students' attitudes towards their own research propositions), (2) not all metadiscourse subcategories affect thesis quality scores, and (3) apart from frequencies, factors such as appropriate use of a wide variety of markers in different subcategories may contribute to better quality scores.

Based on these findings, this thesis also provides theoretical, methodological, and pedagogical implications, laying out a framework for postgraduate writing instructors in developing English for Postgraduate Academic Writing lessons and materials based on actual language use and expectations of members in specific disciplinary communities and educational contexts in order to improve postgraduate writing quality. 


\section{DEDICATION}

Dedicated to my teachers at

Thaksin University

Prince of Songkla University

and

Victoria University of Wellington 


\section{ACKNOWLEDGEMENTS}

This thesis has been completed because of the encouragement and assistance of many individuals.

My deepest gratitude goes to my supervisors, Dr. Jean Parkinson and Dr. Rachael Ruegg, for devoting a huge amount of time reading my thesis drafts and providing constructive comments on my work. Not only their academic guidance but also their friendly discussions, warmest encouragement, and trust were meaningful for me to complete this thesis. I would also like to thank Dr. Lisa Woods for her great support in the statistical part of my work.

I am greatly grateful to the thesis authors for granting permission to use their theses for this research purpose and to the supervisor informants for participating in the interviews and providing useful information to support this study.

I owe a deep debt of gratitude to the four supervisor raters who devoted their time to rate theses in my study. Without their generosity and assistance, this thesis would not have been possible.

I would like to express my sincerest thanks to all my friends in Thailand and New Zealand for giving me abiding friendship and making my $\mathrm{PhD}$ journey more enjoyable and memorable.

My heartfelt thank goes to my father (นฤพนธ์ พรหมมาศ), my mother (อมรา อ่วมละออ), my brother (นฤเบศ พรหมมาศ), my sister (อัจฉรา พรหมมาศ), and my husband (สุทัศน์ ษัฏเสน). Without their wholehearted love and unfailing belief in me, I would not have come this far. They truly are the wind beneath my wings.

Pansa Prommas 


\section{TABLE OF CONTENTS}

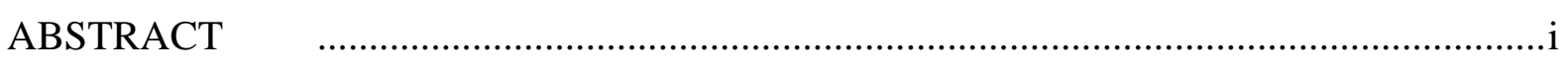

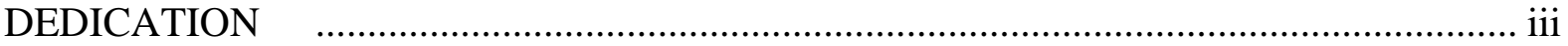

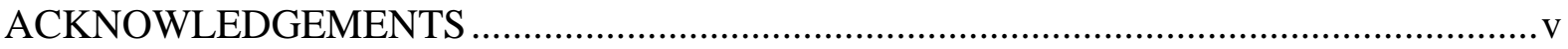

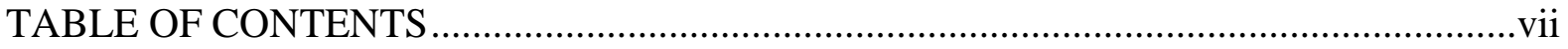

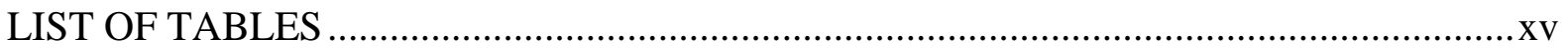

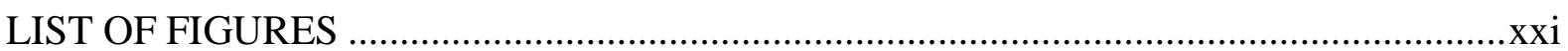

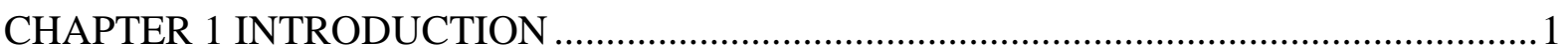

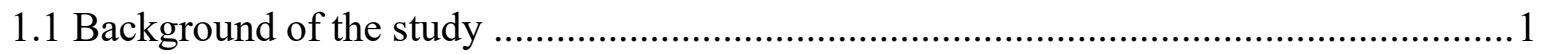

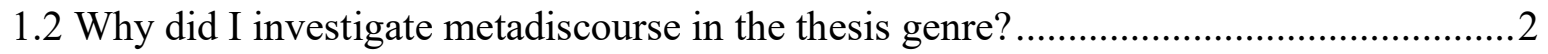

1.3 Why did I compare the use of metadiscourse between New Zealand and Thai

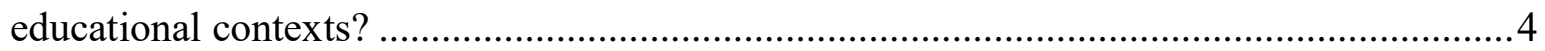

1.4 Why did I compare the use of metadiscourse between English language teaching and

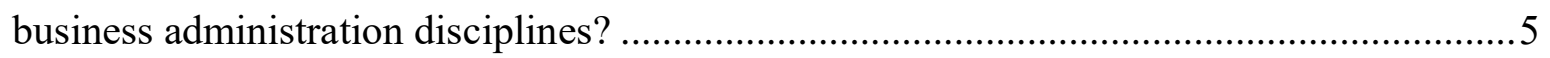

1.5 Why did I investigate the relationship between use of metadiscourse and quality of

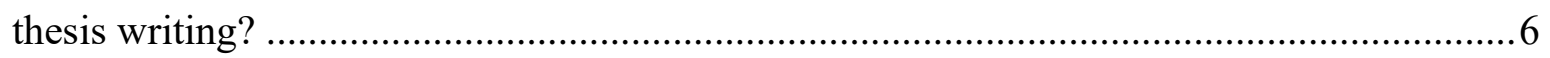

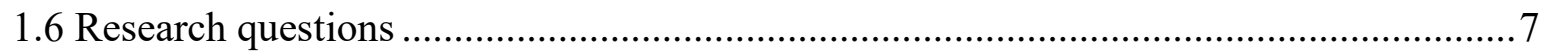

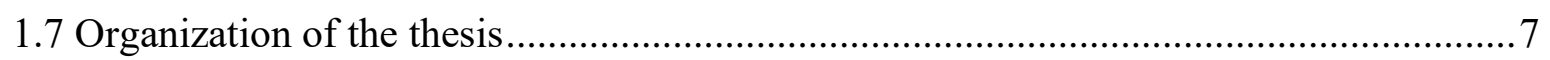

CHAPTER 2 LITERATURE REVIEW …................................................................. 9

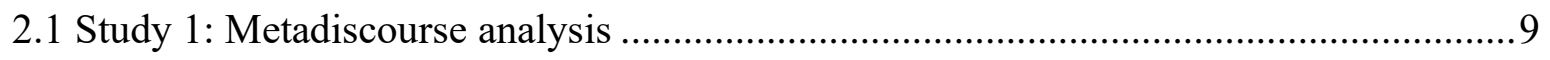

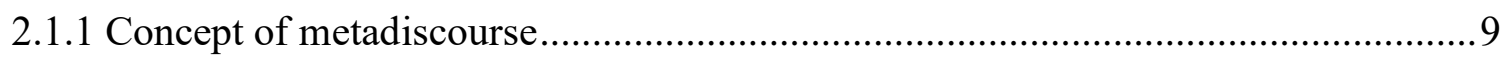

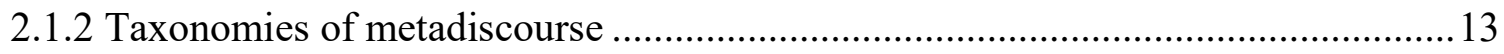

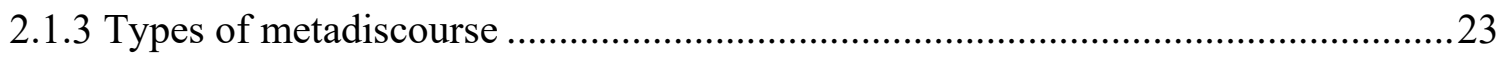

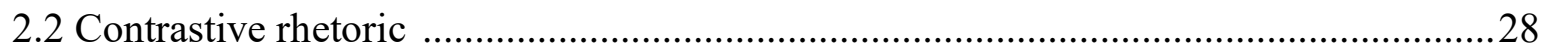

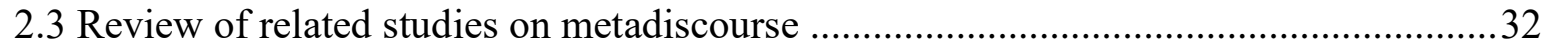

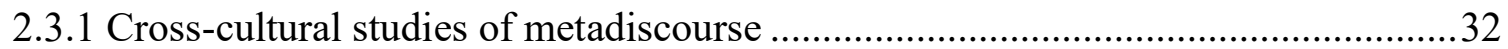

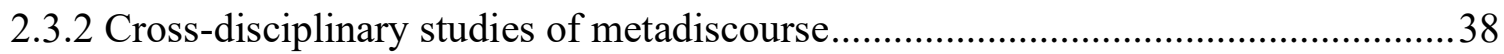

2.4 Study 2: Metadiscourse frequency and thesis quality ...............................................43 
2.4.1 Types of rating

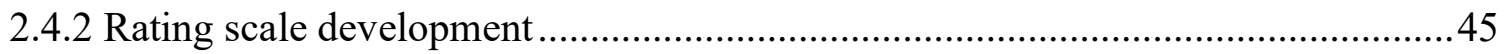

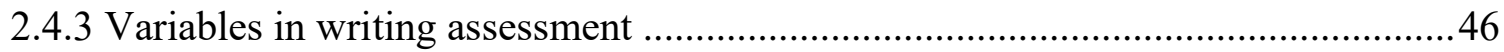

2.5 Review of related studies on metadiscourse and quality of writing ............................48

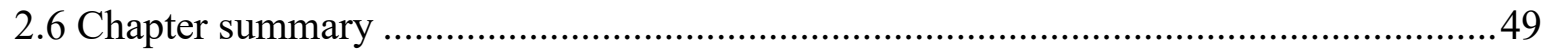

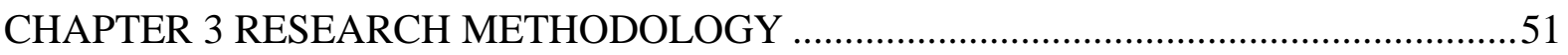

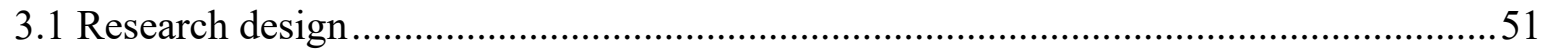

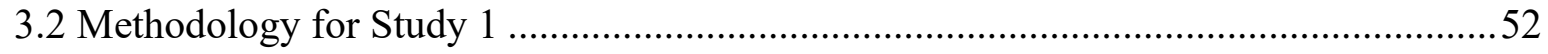

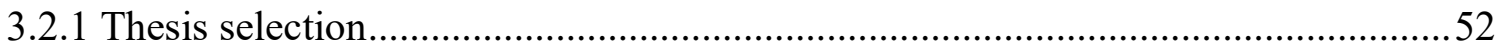

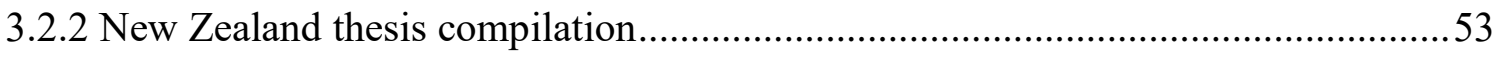

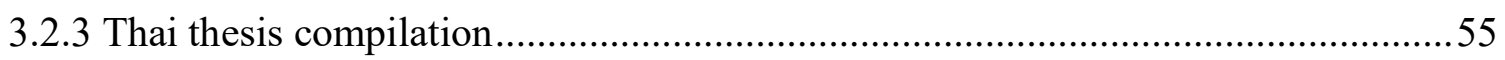

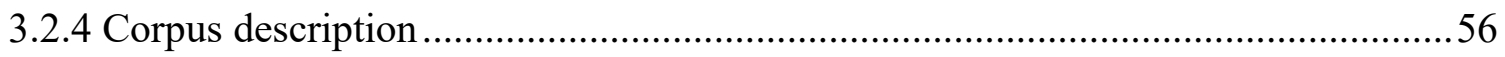

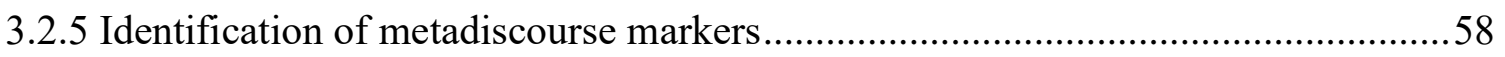

3.2.6 Calculation of metadiscourse marker frequencies ............................................62

3.2.7 Comparison of metadiscourse frequencies, types, and functions .........................63

3.2.8 Subjectivity in metadiscourse identification and my justification.........................65

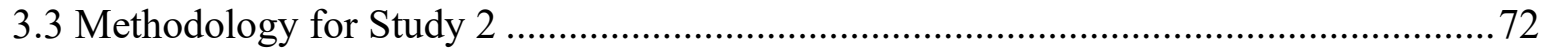

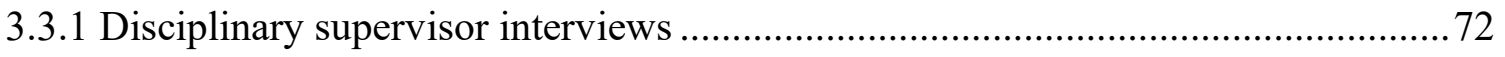

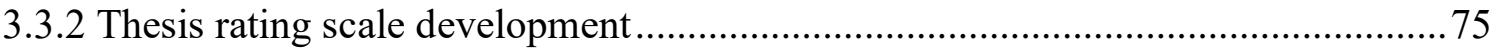

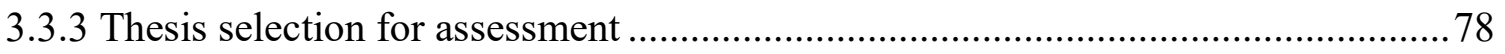

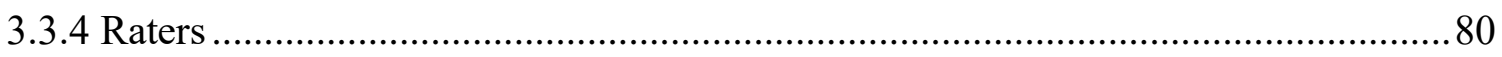

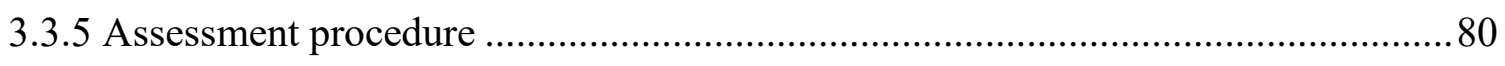

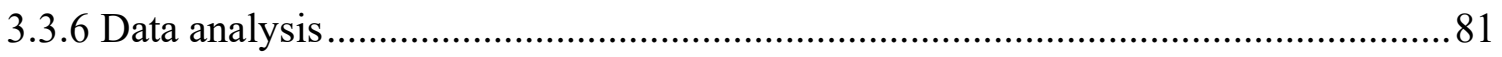

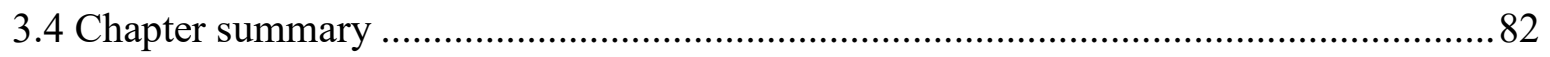

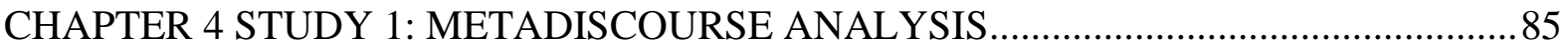

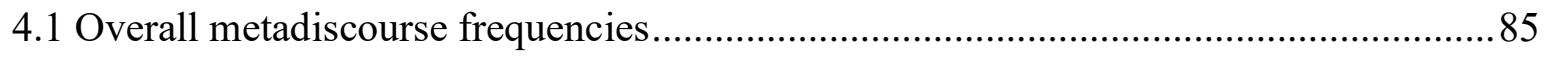

4.2 Comparison of metadiscourse frequencies between NZ and TH corpora ....................86

4.3 Comparison of metadiscourse frequencies between ELT and BA corpora .................89 
4.4 Chapter summary

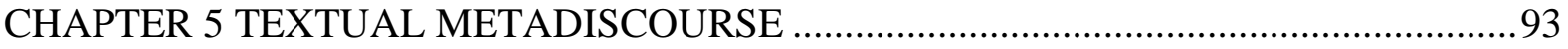

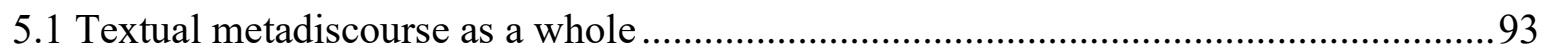

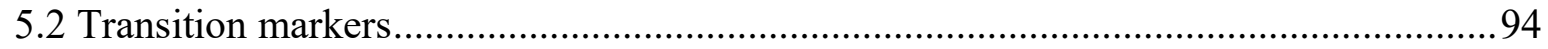

5.2.1 Frequencies of transition markers in $\mathrm{NZ}$ and $\mathrm{TH}$ corpora ..................................94

5.2.2 Frequencies of transition markers in ELT and BA corpora..................................95

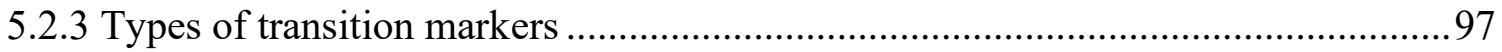

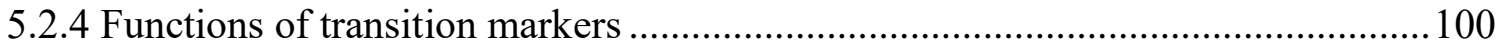

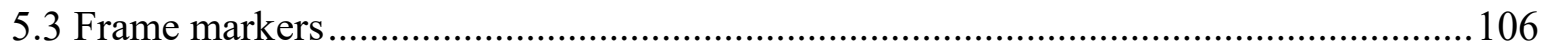

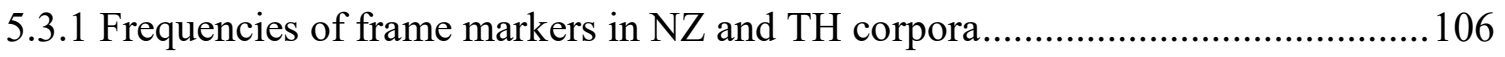

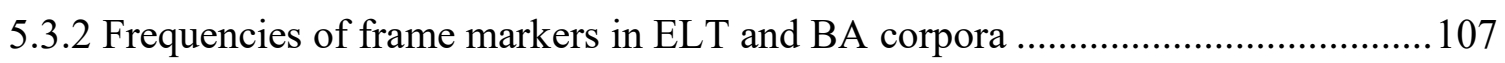

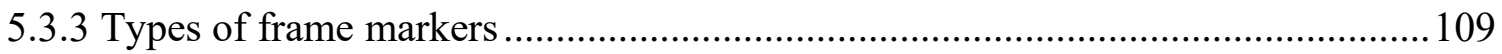

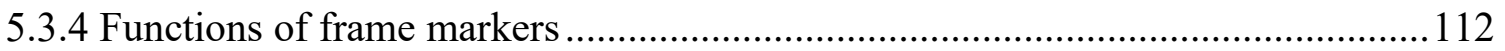

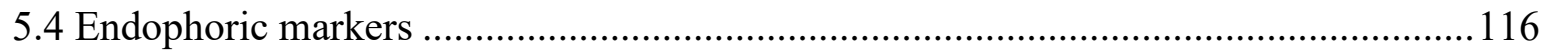

5.4.1 Frequencies of endophoric markers in NZ and TH corpora .............................116

5.4.2 Frequencies of endophoric markers in ELT and BA corpora..............................118

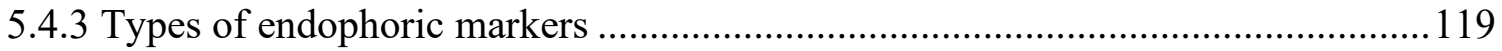

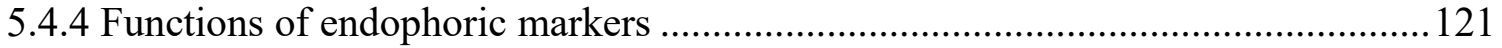

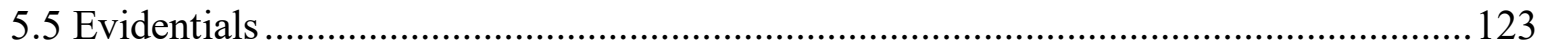

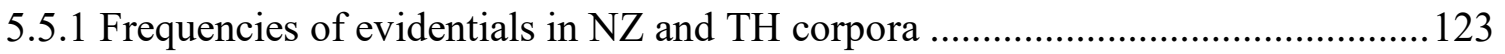

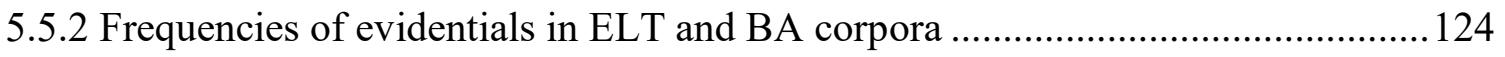

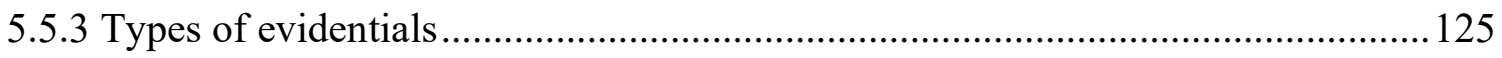

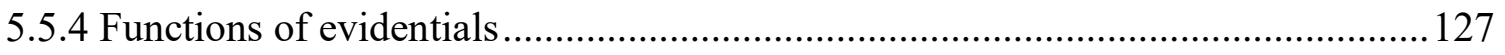

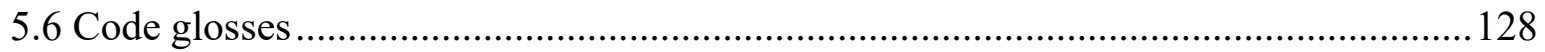

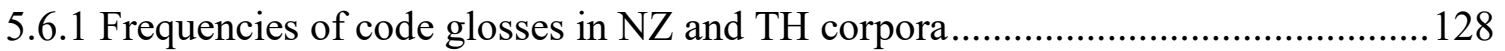

5.6.2 Frequencies of code glosses in ELT and BA corpora .......................................129

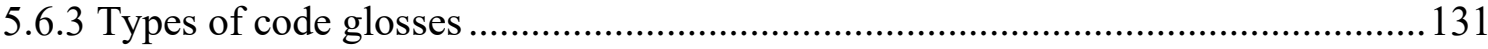


5.6.4 Functions of code glosses

5.7 Chapter summary ………………………………………………………………... 134

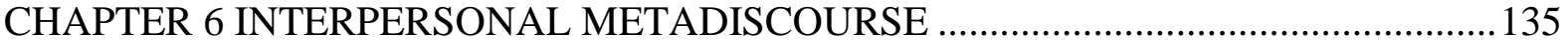

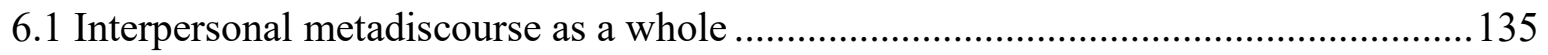

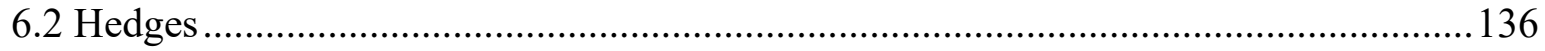

6.2.1 Frequencies of hedges in NZ and TH corpora ...............................................136

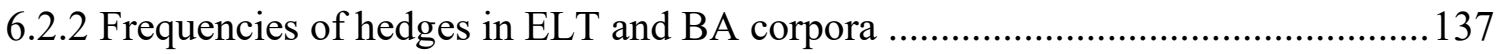

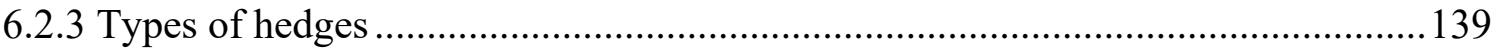

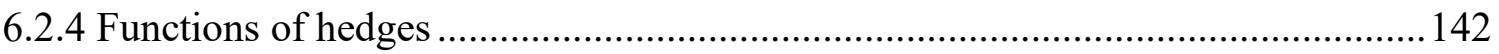

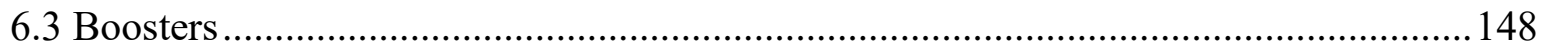

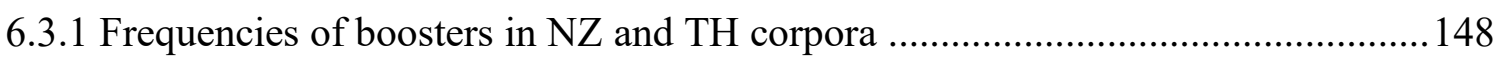

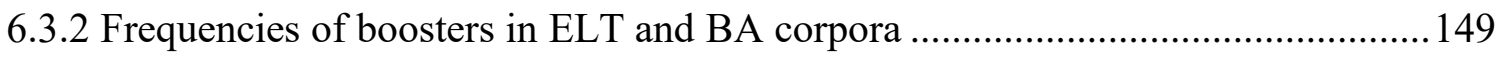

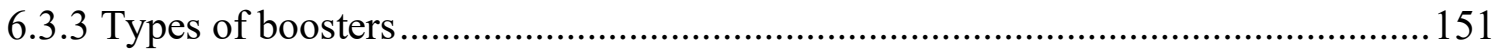

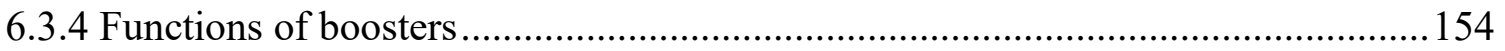

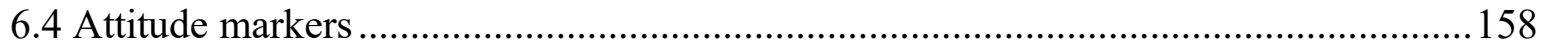

6.4.1 Frequencies of attitude markers in NZ and TH corpora ....................................158

6.4.2 Frequencies of attitude markers in ELT and BA corpora..................................159

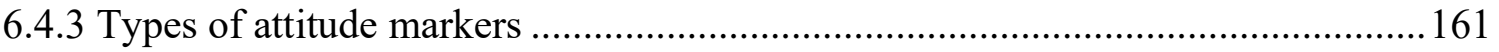

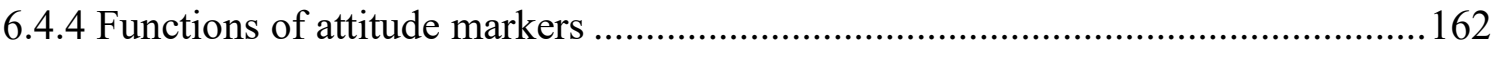

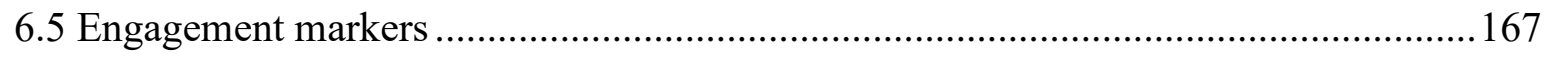

6.5.1 Frequencies of engagement markers in NZ and TH corpora............................... 167

6.5.2 Frequencies of engagement markers in ELT and BA corpora .............................. 168

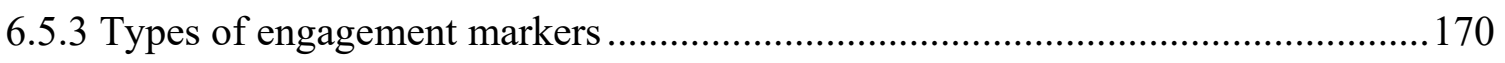

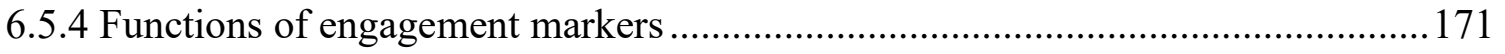

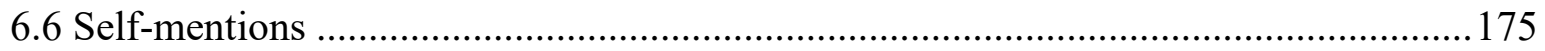

6.6.1 Frequencies of self-mentions in NZ and TH corpora ....................................... 175

6.6.2 Frequencies of self-mentions in ELT and BA corpora ....................................176 


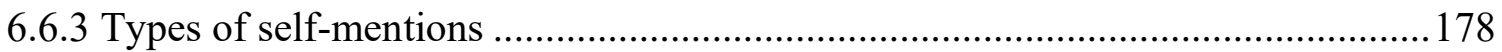

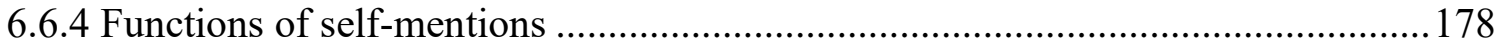

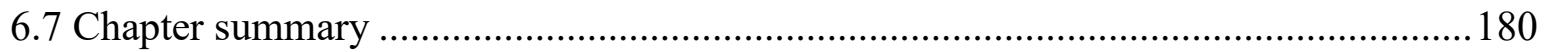

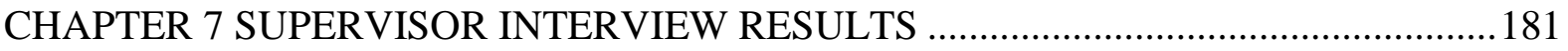

7.1 Writing disciplinary theses in New Zealand and Thai contexts .................................182

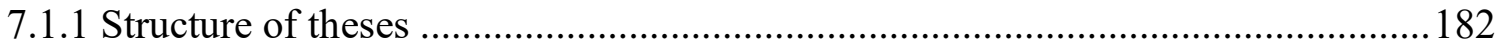

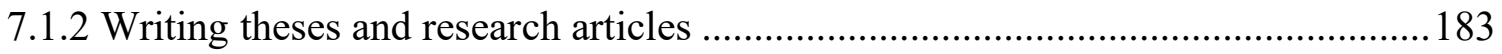

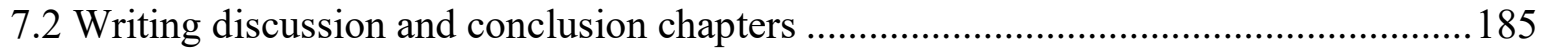

7.2.1 Functional elements of the discussion chapter .............................................. 185

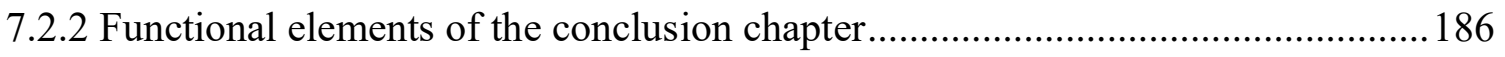

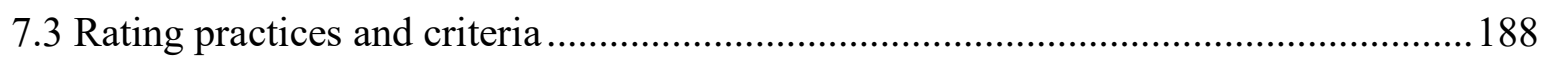

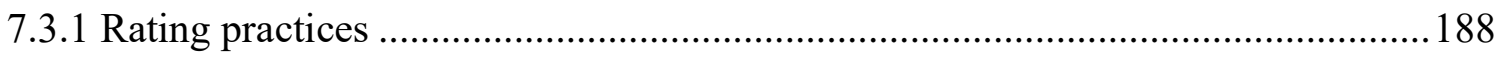

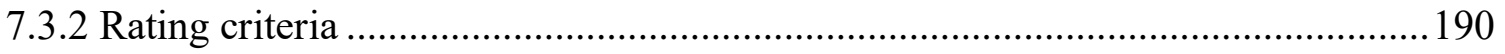

7.4 Supervisors' attitudes towards use of metadiscourse in theses .................................200

7.4.1 Supervisors' comments on use of hedges and boosters.....................................202

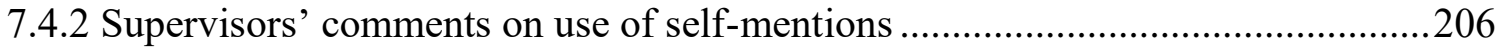

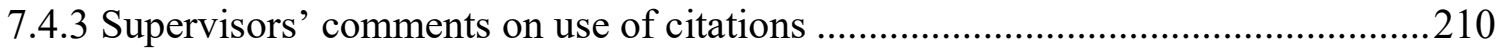

7.5 Rating scale designed for thesis quality assessment in Study 2 .............................211

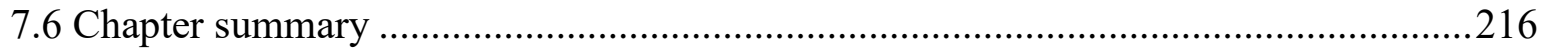

CHAPTER 8 STUDY 2: METADISCOURSE FREQUENCY AND THESIS QUALITY .217

8.1 Quality scores and metadiscourse frequencies in English language teaching theses ...217

8.1.1 Interrater agreement in assessing English language teaching theses...................217

8.1.2 Correlations between quality scores and overall metadiscourse in English language

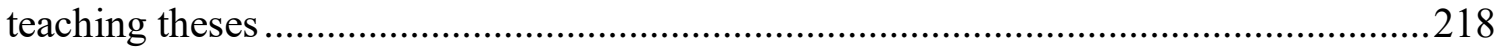

8.1.3 Correlations between quality scores and subcategories of textual and interpersonal metadiscourse in English language teaching theses ...................................................224

8.2 Quality scores and metadiscourse frequencies in business administration theses .......228

8.2.1 Interrater agreement in assessing business administration theses .......................229 
8.2.2 Correlations between quality scores and overall metadiscourse in business administration theses

8.2.3 Correlations between quality scores and subcategories of textual and interpersonal metadiscourse in business administration theses

8.3 Comparison of quality scores in high and low frequency groups in English language teaching and business administration....

8.3.1 Comparison of quality scores in high and low frequency groups in English language teaching

8.3.2 Comparison of quality scores in high and low frequency groups in business administration

8.4 Chapter summary

CHAPTER 9 DISCUSSION 251

9.1 Variation of metadiscourse frequency 251

9.1.1 Textual and interpersonal metadiscourse in New Zealand and Thai theses 251

9.1.2 Textual and interpersonal metadiscourse in English language teaching and business administration theses 258

9.1.3 Textual and interpersonal metadiscourse in the four subcorpora 262

9.2 Variation of metadiscourse types 265

9.2.1 Types of textual markers .265

9.2.2 Types of interpersonal markers 269

9.3 Variation of metadiscourse functions.... 273

9.4 Relationship between the use of metadiscourse and quality of thesis writing 278

9.4.1 English language teaching theses 279

9.4.2 Business administration theses 280

9.4.3 Quality scores in high and low frequency groups 281

9.5 Chapter summary 284

CHAPTER 10 CONCLUSION AND IMPLICATIONS 285

10.1 Summary of Study 1 285

10.1.1 Frequencies of metadiscourse. 285 
10.1.2 Types of metadiscourse

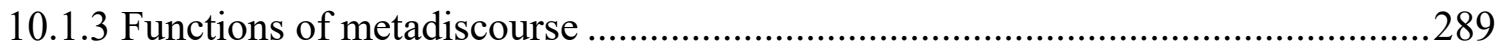

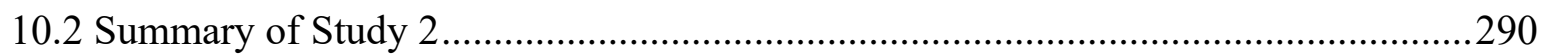

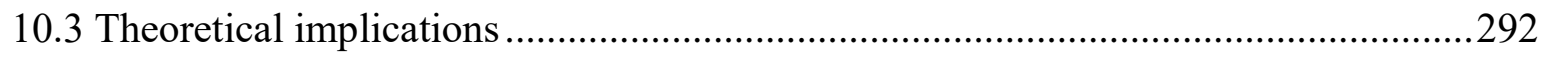

10.3.1 Providing more rigorous criteria for identifying some ambiguous metadiscourse markers

10.3.2 Proposing further description of writer-responsible and reader-responsible writing cultures based on metadiscourse perspectives. 294

10.3.3 Proposing rating criteria for thesis quality assessment....................................295

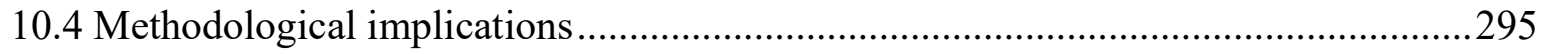

10.4.1 Taking into account both contextual and disciplinary factors ..........................295

10.4.2 Developing a list of markers from different sources .....................................296

10.4.3 Conducting interviews with disciplinary supervisors ...................................297

10.4.4 Assessing quality of thesis writing and use of metadiscourse ...........................297

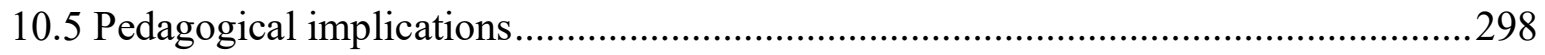

10.5.1 Developing postgraduate students' genre, intercultural, and interdisciplinary knowledge through authentic materials from different sources ...................................298

10.5.2 Developing postgraduate students and instructors' awareness and knowledge of

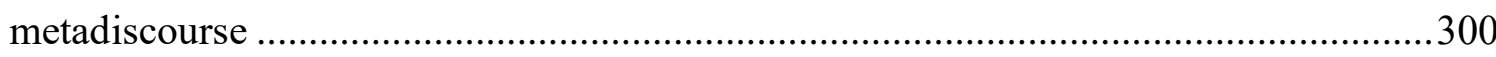

10.6 Limitations and recommendations for future research .........................................301

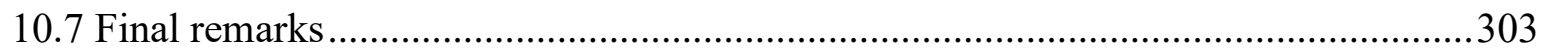

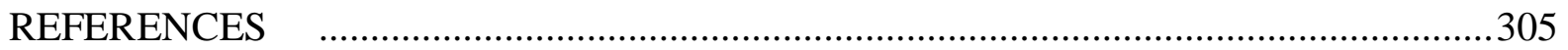

APPENDICES 


\section{LIST OF TABLES}

Table 2.1. Metadiscourse identification principles .............................................................. 12

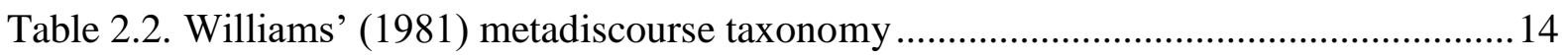

Table 2.3. Vande Kopple's (1985) metadiscourse taxonomy ...............................................15

Table 2.4. Vande Kopple's (1997) metadiscourse taxonomy .................................................16

Table 2.5. Crismore et al.'s (1993) metadiscourse taxonomy .............................................17

Table 2.6. Hyland's (2005) metadiscourse taxonomy ........................................................... 19

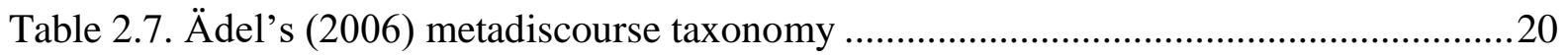

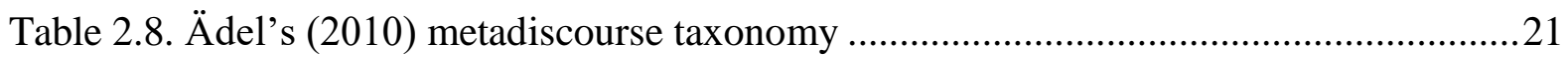

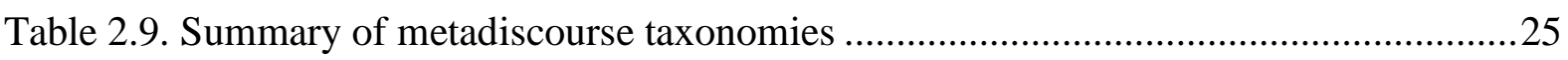

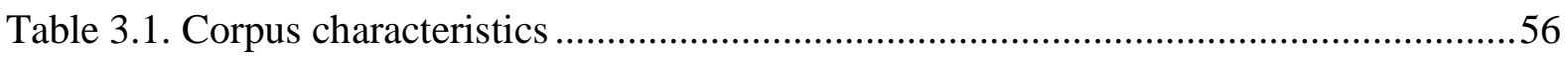

Table 3.2. Formats of discussion and conclusion chapters .................................................57

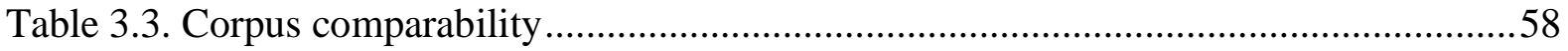

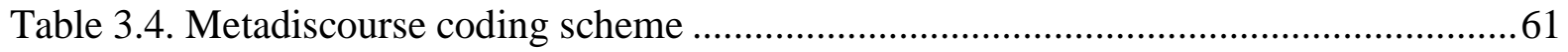

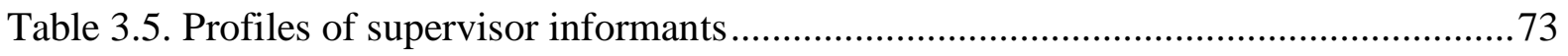

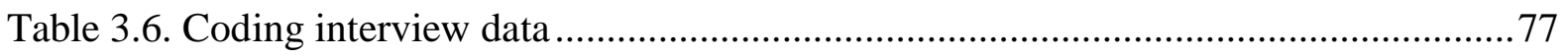

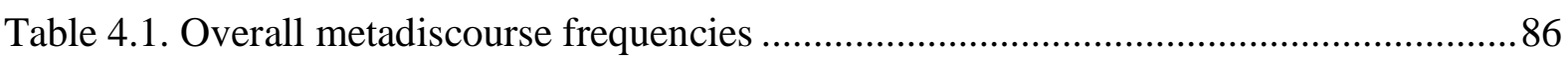

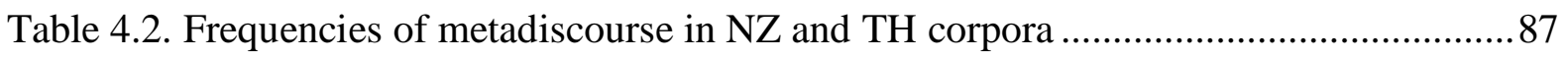

Table 4.3. Frequencies of metadiscourse in NZ-ELT and NZ-BA subcorpora ......................88

Table 4.4. Frequencies of metadiscourse in TH-ELT and TH-BA subcorpora ......................89

Table 4.5. Frequencies of metadiscourse in ELT and BA corpora ......................................90

Table 4.6. Frequencies of metadiscourse in NZ-ELT and TH-ELT subcorpora ...................91

Table 4.7. Frequencies of metadiscourse in NZ-BA and TH-BA subcorpora .......................91

Table 5.1. Textual metadiscourse subcategories in NZ and TH corpora ..............................93

Table 5.2. Textual metadiscourse subcategories in ELT and BA corpora.............................94

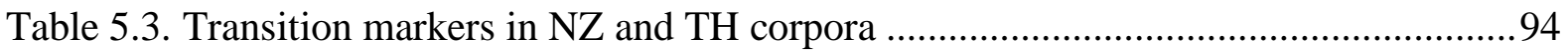

Table 5.4. Transition markers in NZ-ELT and NZ-BA subcorpora ...................................95

Table 5.5. Transition markers in TH-ELT and TH-BA subcorpora .....................................95

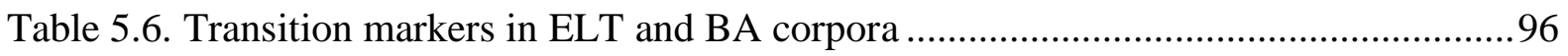

Table 5.7. Transition markers in NZ-ELT and TH-ELT subcorpora ..................................96

Table 5.8. Transition markers in NZ-BA and TH-BA subcorpora .....................................96

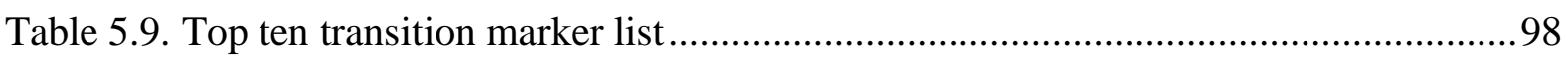


Table 5.10. High frequency additive transition markers 100

Table 5.11. High frequency adversative transition markers .............................................. 103

Table 5.12. High frequency causative and resultative transition markers ............................. 104

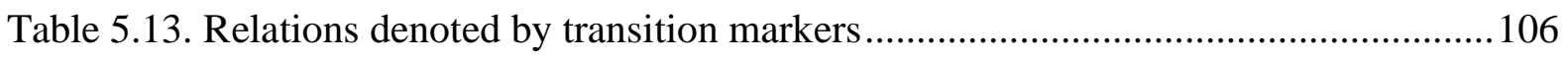

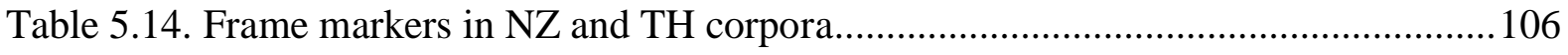

Table 5.15. Frame markers in NZ-ELT and NZ-BA subcorpora .....................................107

Table 5.16. Frame markers in TH-ELT and TH-BA subcorpora ...................................... 107

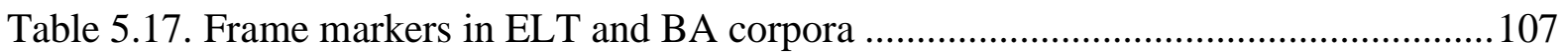

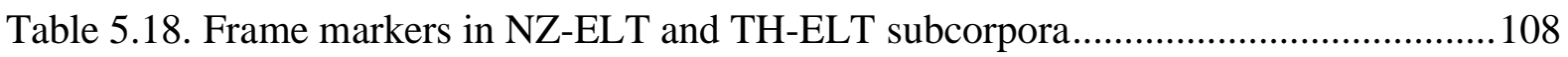

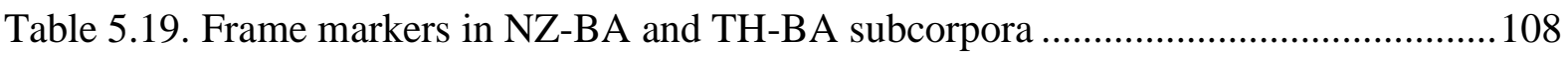

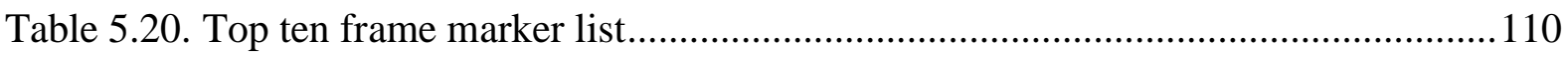

Table 5.21. High frequency frame markers for sequencing arguments ..............................113

Table 5.22. High frequency frame markers for labelling discourse acts ............................113

Table 5.23. High frequency frame markers for announcing discourse goals ........................114

Table 5.24. High frequency frame markers for signposting topic shifts .............................115

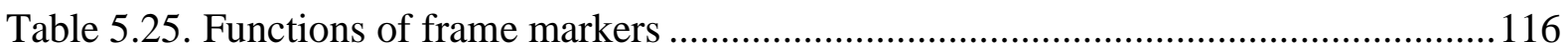

Table 5.26. Endophoric markers in NZ and TH corpora ............................................... 117

Table 5.27. Endophoric markers in NZ-ELT and NZ-BA subcorpora ................................117

Table 5.28. Endophoric markers in TH-ELT and TH-BA subcorpora ...............................117

Table 5.29. Endophoric markers in ELT and BA corpora ................................................118

Table 5.30. Endophoric markers in NZ-ELT and TH-ELT subcorpora ...............................118

Table 5.31. Endophoric markers in NZ-BA and TH-BA subcorpora.................................119

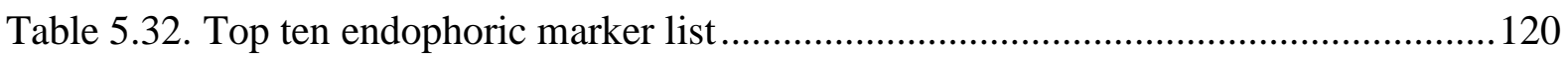

Table 5.33. High frequency endophoric markers for linear text references ......................... 121

Table 5.34. High frequency endophoric markers for non-linear text references ...................123

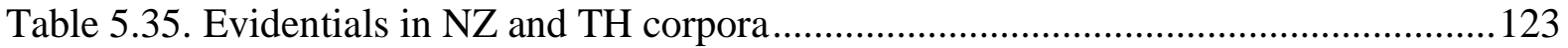

Table 5.36. Evidentials in NZ-ELT and NZ-BA subcorpora..........................................123

Table 5.37. Evidentials in TH-ELT and TH-BA subcorpora............................................ 124

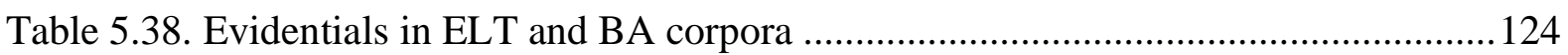

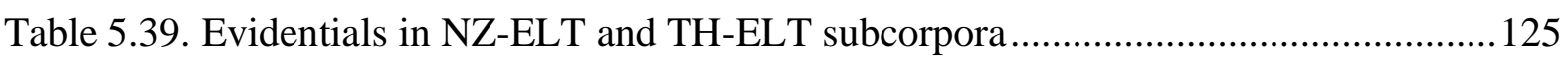

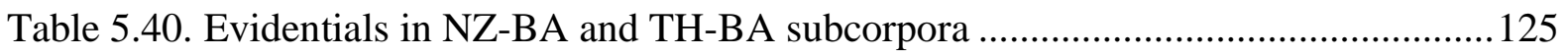

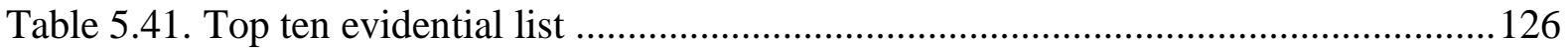

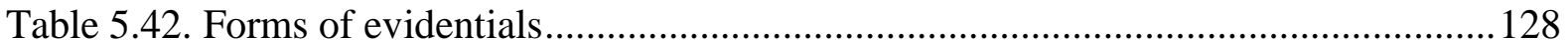

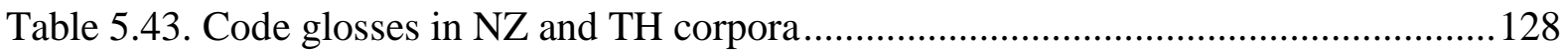


Table 5.44. Code glosses in NZ-ELT and NZ-BA subcorpora.

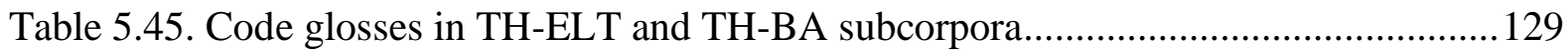

Table 5.46. Code glosses in ELT and BA corpora ............................................................130

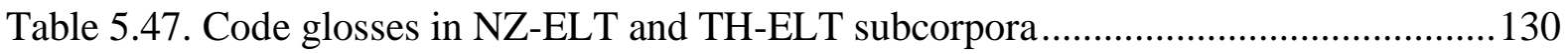

Table 5.48. Code glosses in NZ-BA and TH-BA subcorpora .........................................130

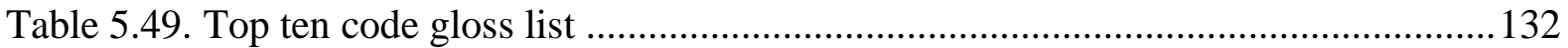

Table 5.50. High frequency code glosses for exemplifying ............................................. 133

Table 5.51. High frequency code glosses for rephrasing ..................................................... 134

Table 6.1. Interpersonal metadiscourse subcategories in NZ and TH corpora .....................135

Table 6.2. Interpersonal metadiscourse subcategories in ELT and BA corpora...................136

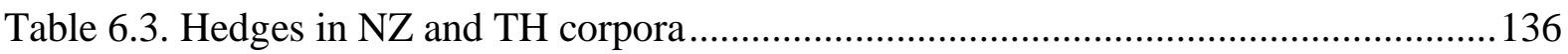

Table 6.4. Hedges in NZ-ELT and NZ-BA subcorpora................................................. 137

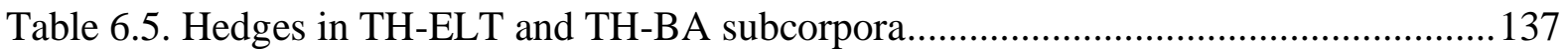

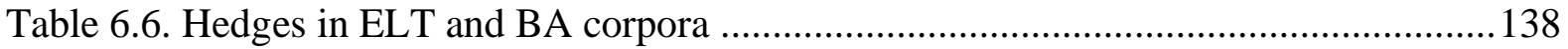

Table 6.7. Hedges in NZ-ELT and TH-ELT subcorpora.................................................. 138

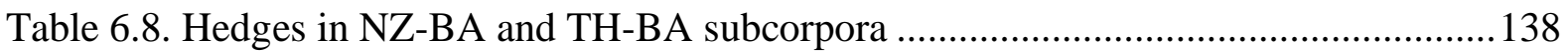

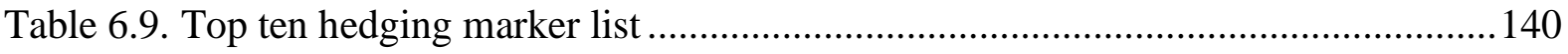

Table 6.10. High frequency hedges in different grammatical categories .............................142

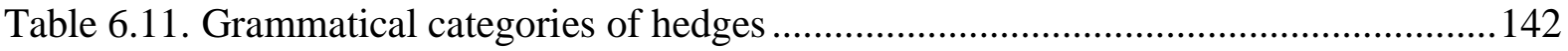

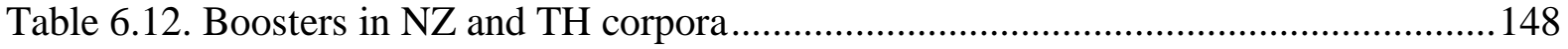

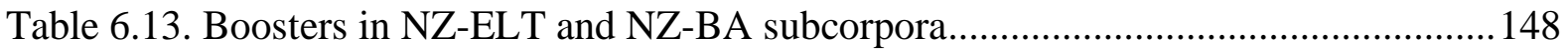

Table 6.14. Boosters in TH-ELT and TH-BA subcorpora................................................ 149

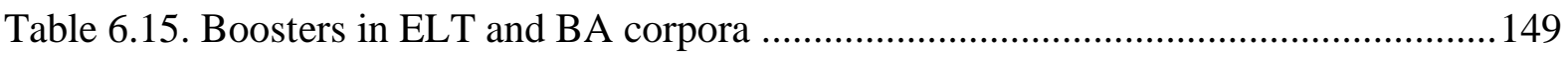

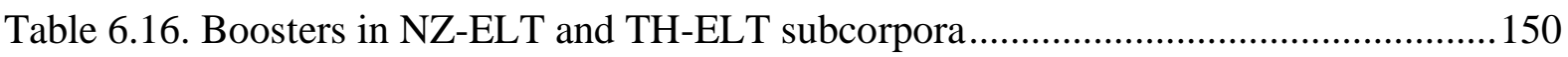

Table 6.17. Boosters in NZ-BA and TH-BA subcorpora …..........................................150

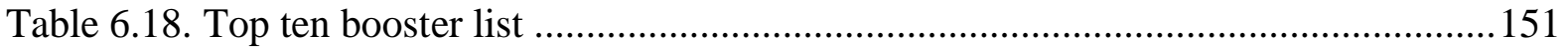

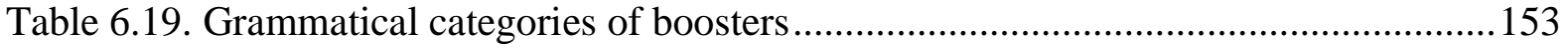

Table 6.20. Frequencies of boosters in four grammatical forms ........................................153

Table 6.21. Attitude markers in NZ and TH corpora ........................................................ 158

Table 6.22. Attitude markers in NZ-ELT and NZ-BA subcorpora.....................................158

Table 6.23. Attitude markers in TH-ELT and TH-BA subcorpora....................................159

Table 6.24. Attitude markers in ELT and BA corpora …...............................................159

Table 6.25. Attitude markers in NZ-ELT and TH-ELT subcorpora ...................................160

Table 6.26. Attitude markers in NZ-BA and TH-BA subcorpora .....................................160 
Table 6.27. Top ten attitude marker list 161

Table 6.28. High frequency attitude markers in different aspects .....................................163

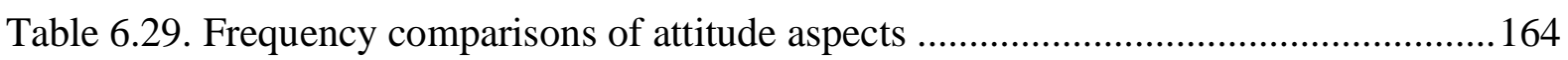

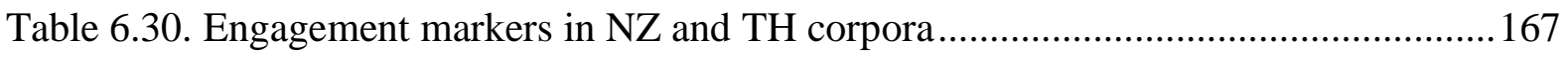

Table 6.31. Engagement markers in NZ-ELT and NZ-BA subcorpora................................168

Table 6.32. Engagement markers in TH-ELT and TH-BA subcorpora............................... 168

Table 6.33. Engagement markers in ELT and BA corpora................................................169

Table 6.34. Engagement markers in NZ-ELT and TH-ELT subcorpora ..............................169

Table 6.35. Engagement markers in NZ-BA and TH-BA subcorpora ................................ 169

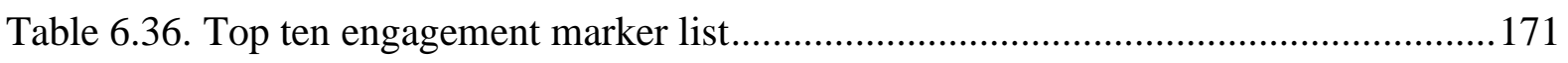

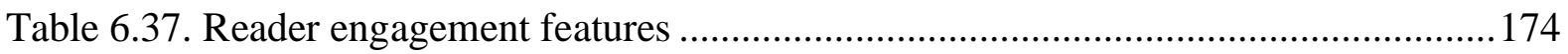

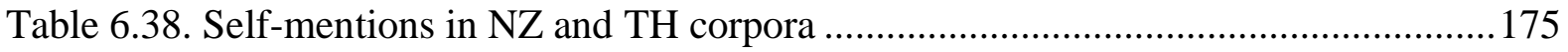

Table 6.39. Self-mentions in NZ-ELT and NZ-BA subcorpora ........................................ 175

Table 6.40. Self-mentions in TH-ELT and TH-BA subcorpora ........................................ 176

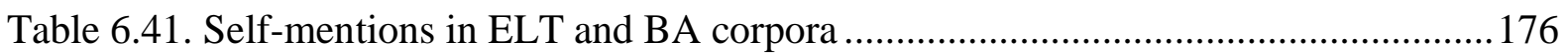

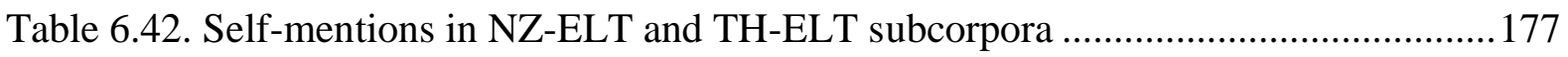

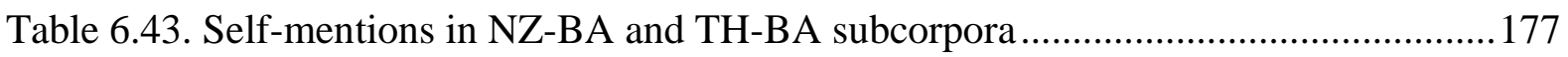

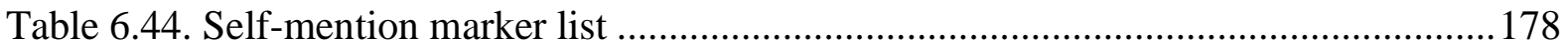

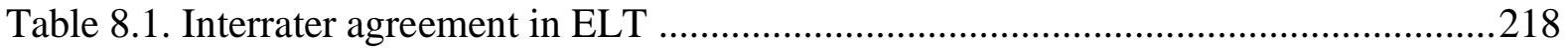

Table 8.2. Descriptive statistics of quality scores in ELT theses........................................219

Table 8.3. Descriptive statistics of metadiscourse frequencies in ELT theses ....................219

Table 8.4. Correlations between quality scores and overall metadiscourse in ELT theses ...220

Table 8.5. Regression model for overall metadiscourse in ELT theses ...............................222

Table 8.6. Regression model for textual and interpersonal metadiscourse in ELT theses ....223

Table 8.7. Correlations between quality scores and subcategories of textual and interpersonal

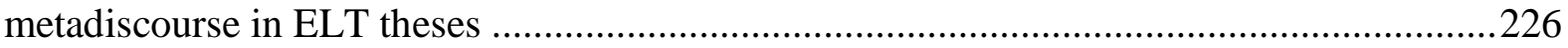

Table 8.8. Regression model for evidentials and code glosses in ELT theses.....................227

Table 8.9. Regression model for hedges, attitude markers, engagement markers, and self-

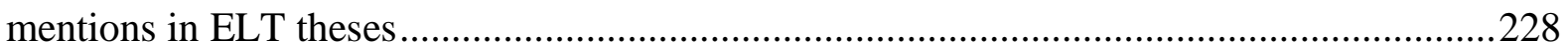

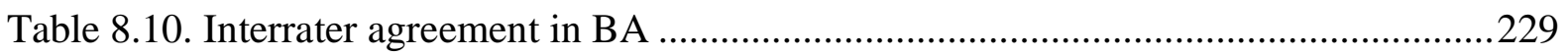

Table 8.11. Descriptive statistics of quality scores in BA theses .....................................230

Table 8.12. Descriptive statistics of metadiscourse frequencies in BA theses .....................230

Table 8.13. Correlations between quality scores and overall metadiscourse in BA theses ...231

Table 8.14. Regression model for overall metadiscourse in BA theses..... .233 
Table 8.15. Regression model for textual and interpersonal metadiscourse in BA theses ....234

Table 8.16. Correlations between quality scores and subcategories of textual and

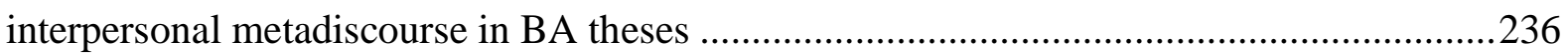

Table 8.17. Regression model for the five types of textual metadiscourse in BA theses ......237

Table 8.18. Regression model for hedges and boosters in BA theses .................................238

Table 8.19. Quality scores in high and low frequency groups in ELT theses ......................239

Table 8.20. Top ten marker list in high and low frequency groups in ELT.........................243

Table 8.21. Quality scores in high and low frequency groups in BA theses ........................244

Table 8.22. Top ten marker list in high and low frequency groups in BA ..........................248

Table 9.1. Summary of comparisons of textual and interpersonal metadiscourse categories and subcategories between educational contexts and disciplines .....................................252

Table 9.2. Summary of key functions of metadiscourse subcategories ..............................274 


\section{LIST OF FIGURES}

Figure 2.1. Writer-responsible and reader-responsible writing styles based on metadiscourse

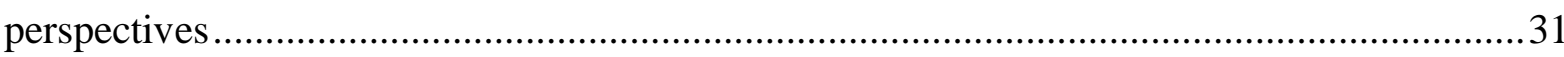

Figure 3.1. Auckland University of Technology digital repository …...................................54

Figure 3.2. Thammasat University digital repository ….......................................................56

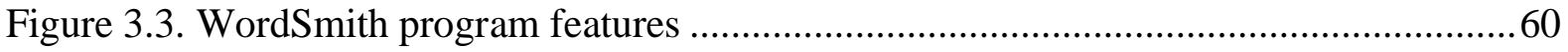

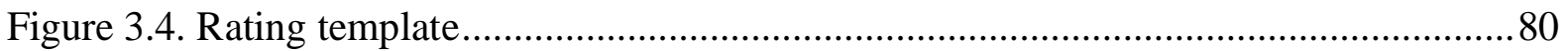

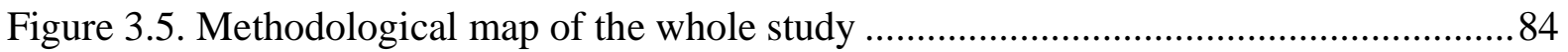

Figure 5.1. Distribution of higher and lower frequency transition markers ..........................100

Figure 5.2. Distribution of higher and lower frequency frame markers ...............................112

Figure 5.3. Distribution of higher and lower frequency endophoric markers ......................121

Figure 5.4. Distribution of higher and lower frequency evidentials ................................... 127

Figure 5.5. Distribution of higher and lower frequency code glosses ................................132

Figure 6.1. Distribution of higher and lower frequency hedges ....................................... 141

Figure 6.2. Distribution of higher and lower frequency boosters ........................................ 154

Figure 6.3. Distribution of higher and lower frequency attitude markers ............................162

Figure 7.1. Rating scale for thesis quality assessment ..................................................214

Figure 8.1. Histogram and normal P-P plot of quality score residual (ELT).......................222

Figure 8.2. Histogram and normal P-P plot of quality score residual (BA) ........................233

Figure 8.3. Distribution of metadiscourse in high and low frequency groups in ELT .........240

Figure 8.4. Distribution of metadiscourse in high and low frequency groups in BA ...........245 


\section{CHAPTER 1 \\ INTRODUCTION}

\subsection{Background of the study}

When I first saw the term "metadiscourse analysis" in a research article, I asked myself what it was and how it differed from "discourse analysis" and "textual analysis," which are the terms I am more familiar with. At the time, having no intention to study for a $\mathrm{PhD}$ yet, I quickly read the author's definition of metadiscourse. The only idea I retained from the author's lengthy definition was "interaction in academic texts." Then when I subsequently decided to study for a $\mathrm{PhD}$ and had to reflect on possible areas of research, the idea of "interaction in academic texts" came to mind. Since then, I seriously read more about metadiscourse to find out its concrete meaning and significance in academic writing.

To begin with, what is the difference between primary discourse and metadiscourse? In a general sense, if primary discourse is academic language used to convey information about the subject matter (propositional content) (Vande Kopple, 1985) and mainly concerns textual features, metadiscourse is a combination of "primary discourse" and "interaction" between writer and reader in academic texts. What makes metadiscourse distinct from the primary discourse concerning the textual features is its interactional features. Metadiscourse is therefore the use of language to organize information and to establish an interaction between writer, reader, and the text itself. In this sense, metadiscourse analysis has attracted my particular attention in the way that it not only examines textual features in a written text but also strategies of authorial self-reference and reader engagement in the text. It extends an analytical focus on the text to the writer and reader and weights interpersonal features on a par with textual features. In metadiscourse analysis, all discourse components - text, writer, and reader-are fully taken into consideration.

This thesis, therefore, covers the examination of both textual and interpersonal (interactional) metadiscourse in the thesis genre in terms of frequencies, types, and functions. Following the widely-used metadiscourse taxonomy of Hyland (2005), this study examines how master's students in New Zealand and Thai educational contexts and in English language teaching and business administration disciplines organize their thesis discussion and conclusion chapters and how they facilitate readers' comprehension by considering their use of textual 
metadiscourse. This study also investigates master's students' argumentation strategies, i.e., how and to what extent master's students manage knowledge claims and allow themselves and readers to engage with the theses, by considering their use of interpersonal metadiscourse. Moreover, this thesis addresses an underexplored area of the relationship between the use of metadiscourse and thesis writing quality.

\subsection{Why did I investigate metadiscourse in the thesis genre?}

Earlier work on metadiscourse sheds light on the fact that interaction is embedded in both written and spoken language. Both writers and readers take part in the written text just as speakers and listeners do in conversation. Hyland (2009) claims that, in the process of reading, the readers usually draw on assumptions about what the writers are trying to convey. In the process of writing, the writers need to create a text in ways that are facilitative of readers' interpretation and convincing enough to gain positive responses from the readers. Thus, this writer-reader interaction is viewed as a key feature in successful academic writing.

In particular, writing lengthy academic texts such as theses does not entail just gathering propositional content together. It involves a social and communicative engagement where the thesis writers employ an array of linguistic devices to assist the readers in organizing, understanding, interpreting, evaluating, and reacting to thesis argument in alignment with the writers' goals (Crismore, Markkanen, \& Steffensen, 1993; Hyland, 2005; Vande Kopple, 1985). Postgraduate students and scholars alike need to write a text by using language and writing conventions that they assume target readers (e.g., supervisors, examiners, journal reviewers, and other members in their disciplinary communities) are familiar with, expect, and accept (Hyland, 2009). Indeed, it is essential for postgraduate students to have genre-specific knowledge and adopt a metadiscourse perspective for creating writer-reader interactional features, apart from concentrating on content and surface textual features, in their theses. Therefore, the investigation of the degree to which metadiscourse is used in theses is significant to postgraduate writing pedagogy because it informs postgraduate students' knowledge of metadiscourse options and awareness of using appropriate rhetorical strategies to foster the readers' interpretation and evaluation of the theses. It also shows recurrent patterns of metadiscourse and style of thesis writing which are associated with cultural conventions of a particular discourse community (Ädel, 2006; Hyland, 2005). 
Given the significance of the use of metadiscourse in academic writing, numerous studies from various theoretical perspectives have been conducted to investigate metadiscourse in a variety of genres-essays (Li \& Wharton, 2012; Rustipa, 2014), newspapers (Dafouz-Milne, 2008), textbooks (Hyland, 1999), and research articles (Blagojevic, 2004; Hyland, 1998a, 1998b). However, only a scant number of studies have analyzed metadiscourse features in thesis writing partly due to the daunting size of typical theses (Bunton, 1999). Theses are a valuable genre for metadiscourse analysis because in this lengthy writing genre an orientation to readers is crucial in securing rhetorical objectives, and a wide range of metadiscourse features are likely to be found (Bunton, 1999, 2005; Hyland, 2004).

Research on postgraduate writing (e.g., Akbas \& Hardman, 2018; Bitchener \& Basturkmen, 2006; Johns \& Swales, 2002) indicates that both native and non-native English speaking students (hereafter L1 and L2) are likely to experience difficulties in understanding the thesis genre and meeting disciplinary requirements because it is usually the first time that they are writing this high stakes research report. Writing at undergraduate and postgraduate levels is understood to be different in terms of length, rhetorical complexity, and sophistication expected by a department or a discipline (Johns \& Swales, 2002). This means that although some students may have taken academic writing courses or tried small research projects at undergraduate level, this does not guarantee that they will be able to apply it to thesis writing at postgraduate level (Bitchener \& Basturkmen, 2006).

Writing theses, particularly discussion and conclusion chapters, is difficult for postgraduate students because these are the chapters where the research writers are expected to give critical justifications for findings in relation to the reviewed literature, prove the writers' knowledge claims based on evidence from the collected data, and deal with implications or generalizations of the findings for a larger field (Bunton, 2005; Parkinson, 2011). Writing these chapters is then likely to make greater cognitive demands on students than other thesis chapters and be problematic for students in some contexts where critical perspectives are not encouraged (Bitchener \& Basturkmen, 2006).

Because of the above, it is of interest to investigate rhetorical strategies that postgraduate students use to present their knowledge claims and to make their theses convincing and appealing to their supervisors, examiners, and other members in their research communities. This thesis, therefore, aims to offer a closer examination of metadiscourse in thesis discussion and conclusion chapters which may result in new findings and a better 
understanding of rhetorical features used specifically for the thesis genre in the disciplines examined.

\subsection{Why did I compare the use of metadiscourse between New Zealand and Thai educational contexts?}

Metadiscourse research generally takes a contrastive approach (Hyland, 2005). Literature has shown that writing academic texts and using metadiscourse not only varies across different genres but also systematically across cultural contexts and disciplines (Alshahrani, 2015; Bruce, 2009, 2010; Burneikaite, 2008; Hyland, 2004, 2005, 2009; Mauranen, 1993). That is, members of the same discourse community are likely to use language to formulate texts and manage their interaction in particular ways, so texts produced by the community members often display a certain degree of homogeneity and specificity (Hyland, 2009; Johns \& Swales, 2002).

Previous cross-cultural and cross-linguistic studies have been conducted to compare frequency of metadiscourse in academic writing produced by L1 and L2 writers in different contexts, e.g., Finnish vs. American (Crismore et al., 1993; Mauranen, 1993), Lithuanian vs. English (Burneikaitè, 2008), Arabic vs. English (Alshahrani, 2015), Turkish vs. American (Ozdemir \& Longo, 2014), and Turkish vs. English (Akbas, 2012; Akbas \& Hardman, 2018). However, these studies have come up with contradictory findings, i.e., some studies found a higher incidence of metadiscourse in L1 students' texts than in L2 students' texts and some found the opposite. This suggests that L1 and L2 writers in different contexts may exhibit a variety of rhetorical preferences and writing styles. Regardless of other potential factors, it might be too incautious to conclude that L1 writers are more likely to use metadiscourse than L2 writers, or vice versa. Hence, it seems to be more sensible to explore metadiscourse variation and writing conventions in other individual L1 and L2 contexts so as to investigate underlying factors within the contexts contributing to either similarities or differences in the use of metadiscourse. Despite a growing number of cross-contextual studies of metadiscourse in different contexts as mentioned above, theses written by students in New Zealand (L1) and Thai (L2) contexts do not appear to have attracted much attention. To fill this gap, the present study was proposed to investigate thesis writing and the use of metadiscourse, in two educational contexts. 


\subsection{Why did I compare the use of metadiscourse between English language teaching and business administration disciplines?}

While investigations of metadiscourse across disciplines have markedly increased in recent years, few studies (if any) have compared the use of metadiscourse across disciplines in New Zealand and Thai contexts. A series of Hyland's publications (e.g., Hyland, 1998a, 1998b, 1999, 2004, 2005) has offered a well-known framework for examining similarities and differences between hard and soft disciplines and between pure and applied disciplines. Particularly, his study in 2004, which compared metadiscourse in master's and doctoral dissertations written by Chinese students between soft and hard disciplines, provides a groundbreaking finding. It indicates that more soft knowledge disciplines (e.g., applied linguistics) are likely to employ more interactive (textual) and interactional (interpersonal) metadiscourse features than hard knowledge disciplines (e.g., physics, medicine). This finding has attracted much attention from metadiscourse researchers to further explore variation between soft and hard disciplines in their own contexts. However, to date, most of the existing studies of metadiscourse across disciplines seem to concentrate on a comparison between soft and hard disciplines and provide broad findings in terms of frequencies only. While it is predictable to find significant differences between soft and hard disciplines, subtle variations within either soft disciplines or hard disciplines have been underexplored. One study that concerns both contextual and disciplinary factors is that of Li and Wharton (2012). This study investigated the use of metadiscourse by Chinese students in the United Kingdom and China and in literary criticism and translation studies disciplines. However, Li and Wharton's work focuses on metadiscourse variation in undergraduate writing. The present study, therefore, took into account both cross-contextual and cross-disciplinary variation of metadiscourse in postgraduate writing. To provide a detailed picture of metadiscourse, the emphasis of this study is not merely on frequencies but also types and functions of metadiscourse in the discussion and conclusion chapters. The findings from this study are anticipated to contribute to the literature on both disciplinary and contextual variation and pedagogical implications at postgraduate level.

In order to find out which disciplines should be first examined in Thai and New Zealand contexts, I started a survey of popular disciplines in Thailand. According to statistical information of enrollment from the Office of the Higher Education Commission of Thailand (OHEC), language teaching and business disciplines (Faculties of Business Administration and 
Liberal Arts) have received much attention from master's students and obtained the highest number of enrollments. Despite the popularity, literature has shown little detailed discussion on thesis writing and rhetorical features used by members in the two disciplines. Given that the two disciplines are representative of the soft knowledge branch (humanities and social sciences), a close examination of theses in English language teaching and business administration may reveal some subtle variations between the two disciplines and complement the literature to a greater extent.

In addition, the discipline selection is also based on my profession as a Business English teacher at undergraduate level. About ten years ago, when I was a university student, I studied pure English as my major. All courses I learnt were about English such as British and American Literature, English Essay Writing, so on and so forth. When I became a teacher, I noticed that a number of curriculums in Thailand have been increasingly developed to offer courses in English for Specific Purposes like English for Business Communication and English for Medical Professionals. With this emerging trend, it is therefore necessary for language teachers like me to extend our knowledge beyond our own language field. Also, I noticed that academic writing colleagues in Thailand have never explicitly taught or even mentioned metadiscourse features such as hedging and boosting argument in their classes. The frequent topic discussed in their classes is coherence and cohesion or using connectors. With these reasons, I would like to extend my knowledge of metadiscourse and offer more detailed discussion on thesis writing and rhetorical features used by members in language teaching and business disciplines in order to share such knowledge with academic writing teachers in Thailand and New Zealand as a key contribution of this study.

\subsection{Why did I investigate the relationship between use of metadiscourse and quality of thesis writing?}

Despite the stress on the importance of metadiscourse in prior research, the issue of the relationship between the use of metadiscourse and the quality of thesis writing has been underexplored. As will be discussed in detail in Chapter 2, there have been a small number of studies investigating the association of metadiscourse with writing quality. Researchers (Chang, 2014; Intaraprawat \& Steffensen, 1995; Noble, 2010) share a commonality in that they assessed the quality of undergraduate essays in relation to the use of metadiscourse. They also reveal the same robust trend that high scoring essays demonstrate a higher frequency and a broader range of metadiscourse markers than low scoring essays. However, no studies have 
attempted to examine the correlation between metadiscourse frequencies and quality of thesis writing at postgraduate level. Therefore, this study aimed to report trends with respect to the overall quality of thesis writing.

\subsection{Research questions}

To address the gaps mentioned above, this thesis includes two main studies. Study 1 examines frequencies, types, and functions of metadiscourse in master's thesis discussion and conclusion chapters written by New Zealand and Thai students in the disciplines of English language teaching and business administration. Study 2 proceeds with investigating the relationship between metadiscourse frequencies and quality of thesis writing. The research questions are as follows:

(1) To what extent do New Zealand and Thai postgraduates use metadiscourse markers in their master's theses?

(2) What are the similarities and differences in frequencies, types, and functions of metadiscourse markers across the New Zealand and Thai corpora?

(3) What are the similarities and differences in frequencies, types, and functions of metadiscourse markers across the English language teaching and business administration corpora?

(4) How does metadiscourse affect the quality of postgraduate writing? What kinds of metadiscourse have the biggest impact?

\subsection{Organization of the thesis}

The present thesis has ten chapters. Following this introductory chapter, Chapter 2 is a review of literature. The first part of Chapter 2 describes key concepts and classifications of metadiscourse and previous metadiscourse studies, and the second part reviews theories on writing quality assessment and previous studies on the relationship between metadiscourse frequencies and writing quality.

Chapter 3 provides a detailed account of methodology for both Study 1 and Study 2. It describes how the New Zealand and Thai students' master's theses were collected and how metadiscourse was analyzed in Study 1. As Study 2 involved development of a thesis rating scale based on disciplinary supervisor interviews, this chapter also describes details of the interview process and how a rating scale for thesis quality assessment was constructed prior to 
the examination of the relationship between metadiscourse frequencies and thesis writing quality scores.

Chapter 4 reports on the overall results of metadiscourse frequencies in thesis discussion and conclusion chapters written by New Zealand and Thai students in English language teaching and business administration.

Chapters 5 and 6 report on the results of frequencies, types, and functions of textual metadiscourse (i.e., transition markers, frame markers, endophoric markers, evidentials, and code glosses) and interpersonal metadiscourse (i.e., hedges, boosters, attitude markers, engagement markers, and self-mentions), respectively.

Chapters 7 and 8 present the supervisor interview results and a thesis quality rating scale specifically designed based on disciplinary supervisors' expectations and then report on the relationship between metadiscourse frequencies and thesis quality scores.

Chapter 9 discusses the use of metadiscourse in New Zealand and Thai contexts and also in English language teaching and business administration disciplines. It also discusses the extent to which metadiscourse affects the quality of theses in the two disciplines.

Chapter 10 concludes the main findings of Study 1 and Study 2 and discusses theoretical, methodological, and pedagogical implications. It also discusses important limitations and proposes future research directions. 


\section{CHAPTER 2 \\ LITERATURE REVIEW}

This chapter reviews literature in relation to Study 1 (Metadiscourse analysis) and Study 2 (Metadiscourse frequency and thesis quality). For Study 1, Section 2.1 discusses key concepts and taxonomies of metadiscourse. Section 2.2 explores a contrastive approach in order to set the scope and direction for the present study. Section 2.3 reviews previous metadiscourse studies across educational contexts and across disciplines. For Study 2, Section 2.4 explores the area of academic writing assessment with a focus on types of rating and rating scale development. Section 2.5 reviews previous studies related to impacts of metadiscourse on academic writing quality.

\subsection{Study 1: Metadiscourse analysis}

\subsubsection{Concept of metadiscourse}

Premised on Halliday's (1973) notion that language has three communicative functions, namely ideational, textual, and interpersonal functions, metadiscourse is an umbrella term for linguistic elements fulfilling either textual or interpersonal function in discourse (Hyland, 2005; Vande Kopple, 1985, 2012; Williams, 1981).

Vande Kopple $(1985,2012)$ explains that on the first level of writing a text, writers basically try to convey ideational meaning or propositional content, but on the second level writers deal with using linguistic elements such as metadiscourse markers to organize discourse and interact with readers. Crismore et al. (1993) refer to metadiscourse as linguistic material used by the writers to help the readers organize, interpret, and evaluate the propositional content. Williams (1981) defines metadiscourse as "discourse about discourse, writing about writing, or whatever does not refer to the subject matter being addressed." Linguistic items regarded as metadiscourse exhibit one of the following features: connecting different parts of writing, presenting the writer's attitude, indicating the writer's confidence in his assertion, and referring to the readers (p. 212). Williams suggests that if the writer includes metadiscourse features in either short words or longer phrases and clauses, e.g., therefore, seem to, I would like to turn your attention to the subject of, the whole sentences and paragraphs become more direct and facilitative of the reader's comprehension. 
To get a clearer view of metadiscourse definitions, a dichotomy of metadiscourse is presented

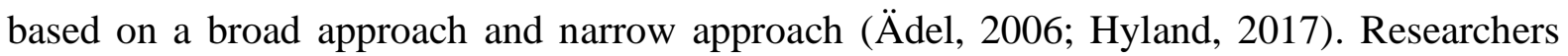
favoring the former approach (e.g., Hyland, 2004; Vande Kopple, 1985; Williams, 1981) include as metadiscourse a large array of linguistic items which do not concern the communicative content of discourse. In this broader approach, employment of metadiscourse is viewed as a reflection of how the writer organizes information, presents himself in discourse, and signals attitudes towards the content and reader. It influences the degree of reader involvement and the level of formality, for example by frequent use of commentary markers with the pronouns $I$ and you, in a particular genre such as emails, essays, lectures, talks, textbooks, journal articles, theses, and so on. In addition to agreeing with Williams and Vande Kopple concerning the textual and interpersonal functions of metadiscourse, Hyland (2005) further suggests that not only is interpersonal metadiscourse related to interaction. The socalled textual metadiscourse is also used by the writer with the purpose of guiding the reader to comprehend and interpret the text in his/ her preferable ways. In this sense, both types of metadiscourse are interpersonal in that they reflect the writer's awareness and assessment of imagined readers' needs for elaboration, clarification, guidance, and interaction (Hyland, 2017; Li \& Wharton, 2012). Thus, Hyland uses Thompson's (2001) terms "interactive" and "interactional" to convey textual and interpersonal functions, respectively, with an emphasis that textual metadiscourse can play an interactive role in discourse apart from its primary textual role.

On the other hand, the narrow approach - also known as non-integrative approach (Mauranen, 1993) and reflexive model (Ädel, 2006) — restricts the boundary of metadiscourse to the textorganizing function only. Mauranen (1993), for example, labels elements of textual organization as "metatext" which literally refers to the text itself. In other words, metatext is viewed as rhetorical strategies which organize the propositional content of the text. Similarly, Ädel (2006) views metadiscourse as a form of linguistic reflexivity which mainly explicates the writer's awareness of the text itself rather than of the reader's and the writer's own stances. She, however, extends Mauranen's non-integrative approach and takes a "middle ground" (Ädel, 2006, p. 180) by including explicit references to the writer ( $I$, we) and to the imagined reader (you) of the current text yet ignoring references to events and agents in the world outside discourse. This new framework closely aligns with Jakobson's (1998) three basic language functions-metalinguistic, expressive, and directive-referring to the text components "text 
per se, writer, and reader," respectively. That is, metadiscourse in Ädel's perspective must refer to one of the text components.

One important distinction between Hyland's broad model and Ädel's reflexive model is that the latter does not include stance markers or participation markers as metadiscourse. Ädel explains that stance markers (I think, I believe, I am convinced, I agree) and participation markers (we, usually found in narrative or descriptive passages) overtly express personal feelings and judgments of the writer as an experiencer in the real world and do not refer to any components of the current text. Moreover, with stance markers, readers hardly have an opportunity to make their own inferences and judgments (Ädel, 2006, p. 38-39). As in Ädel's examples, the marker we in "We all make mistakes..." is not counted as a metadiscourse marker as it presents the writer's experience in the real world, rather than referring to the current text, but the marker we in "We must now consider the pros and cons..." is a metadiscourse marker used by the writer to comment on his/ her own discourse actions, namely introducing a topic or stating an aim.

Hyland (2017, p. 19) argues that this model, especially the inclusion of authorial self-reference and relational markers, leads metadiscourse to a different conception of metatext in the narrow approach, by taking a broader definition but focusing selectively on a narrow range of features. Nevertheless, he concludes that we should view metadiscourse as a long continuum on which different studies possibly occupy different points rather than two opposed positions and thus contribute different aspects to our understanding of discourse.

After having a closer look at both broad and narrow approaches, I tried to bridge the two strands and found that there is in fact some overlap between the principles used to determine what is metadiscourse and what is not. Hyland (2005, p. 38-45) considers a linguistic element as metadiscourse when (1) "it is distinct from propositional aspects of discourse; (2) it refers to expressions that embody writer-reader interactions; and (3) it refers only to discourse-internal relations." In Ädel's (2006, p. 27-29) framework of identifying metadiscourse, a linguistic element qualifies as metadiscourse when (1) it displays the "explicitness" feature in the form of wording, not typographical marking such as italics and boldface; (2) it refers to "current discourse" or current text; (3) it refers to "writer qua writer" and "reader qua reader" of the current discourse rather than experiencers in the real world; and (4) it refers to "world of discourse" or discourse-internal phenomena rather than discourse-external phenomena. It is worth noting that even though Hyland theoretically considers typographical marking as 
metadiscourse, for the practical purposes of identification, he only deals with overt surface features of metadiscourse like Ädel because he believes that explicitness can indicate presence in discourse and reflect the writer's awareness of self and readers (p. 58).

Table 2.1. Metadiscourse identification principles

\begin{tabular}{ll}
\hline Hyland (2005) & Ädel (2006) \\
\hline Explicitness (in practice) & Explicitness \\
\hline $\begin{array}{l}\text { Metadiscourse is distinct from propositional aspects } \\
\text { of discourse }\end{array}$ & Current discourse \\
\hline $\begin{array}{l}\text { Metadiscourse refers to expressions that embody } \\
\text { writer-reader interactions }\end{array}$ & Writer qua writer and reader qua reader \\
\hline $\begin{array}{l}\text { Metadiscourse refers only to discourse-internal } \\
\text { relations }\end{array}$ & World of discourse \\
\hline
\end{tabular}

In summary, this study broadly defines metadiscourse as any linguistic elements concerning text organization and fostering writer-reader interactions in a text. Three important keywords drawing the boundaries of metadiscourse are a current text, writer, and reader. The criteria proposed by Hyland (2005) and Ädel (2006) were used as a main basis in coding potential items as metadiscourse. I use Hyland's (2005) examples below to illustrate the features of metadiscourse (ranging from short words to whole sentences) being distinguished from primary discourse and counted as metadiscourse in this study.

(2.1) Results suggest that rapid freeze and thaw rates during artificial experiments in the laboratory may cause artificial formation of embolism. (p. 145)

(2.2) In contrast, these findings were not found among the low collectivists. (p. 46)

(2.3) It is certainly true that many arguments involve multiple premises. (p. 146)

(2.4) Is it, in fact, necessary to choose between nurture and nature? My contention is that it is not. (p. 153)

The bolded markers such as suggest and may are identified as hedging markers (Excerpt 2.1), in contrast as a transition marker (Excerpt 2.2), it is true as an attitude marker and certainly as a boosting marker (Excerpt 2.3), and the whole rhetorical question as an engagement marker (Excerpt 2.4). These examples shed light on how metadiscourse markers were identified whose functions involve textual organization and interaction in a text rather than ideational content. 


\subsubsection{Taxonomies of metadiscourse}

According to the two main traditions in defining and classifying metadiscourse, analysts adopting either a broad or narrow approach have presented taxonomies which appropriately align with their own studies. This section starts from reviewing metadiscourse classifications based on the broad approach like taxonomies of Williams (1981), Vande Kopple (1985, 1997), Crismore et al. (1993), and Hyland (2005) and then distinctive taxonomies in the narrow approach like Ädel $(2006,2010)$. These taxonomies exhibit a list of pre-identified markers and open for more and more markers to be added according to findings from the studies. As you will see, most types of markers, albeit with different names in different taxonomies, are similar in terms of functions and individual items (e.g., commentaries in Vande Kopple vs. engagement markers in Hyland). It is important to note that individual items shown as examples in the taxonomies are not solely from studies in written genres but also spoken genres like lectures, talks, etc.

\section{(i) Williams' (1981) metadiscourse taxonomy}

Williams (1981) classifies metadiscourse into six types of markers with textual and interpersonal functions. The textual category includes sequencers and topicalizers, while hedges, emphatics, narrators, and attributors are in the interpersonal category. As can be seen in Table 2.2, narrators and attributors are similar in that they are used to suggest to the reader that the propositional ideas are from another source. However, a difference between the two types of marker is that narrators explicitly specify the source while attributors do not. Usually, the latter is expressed in the form of active voice. 
Table 2.2. Williams' (1981) metadiscourse taxonomy

1. Sequencers - used to move readers through a text and make a discourse cohesive; used to lay out introductions of the plan of the paper (in the next section of the chapter, it is my intention to discuss the problem of; the first thing I want to say about this subject is)

2. Topicalizers - used to indicate the main topic of a sentence, paragraph, or whole section; used to announce that writers are moving on to a new idea (in regard to; in the matter of; turning now to; where $x$ is concerned; there are five reasons why)

3. Hedges - used to show readers the degree of uncertainty that writers have about an assertion and would like to leave room for making exceptions (possibly; seemingly; sort of; perhaps; may; tend)

4. Emphatics - used to show readers the degree of certainty (as everyone knows; it is clear that; the fact is; obviously; certainly; of course; indeed; major)

5. Narrators - used to tell readers where writers' ideas or facts or opinions come from; used to determine what writers really want to say by offering a narrative of thinking (I was concerned with; so I attempted to; I have concluded; I think)

6. Attributors - used to indirectly state that the observer or idea/ opinion source is unspecified (... is found to exist; ... is seen/noticed/ noted/ determined)

(ii) Vande Kopple's (1985) metadiscourse taxonomy

Vande Kopple (1985) considers text connectives and code glosses as textual metadiscourse and validity markers (i.e., hedges, emphatics, and attributors), narrators, illocution markers, attitude markers, and commentaries as interpersonal metadiscourse. In this taxonomy, Vande Kopple creates new categories, namely text connectives and validity markers, and places topicalizers, hedges, emphatics, and attributors from William's (1981) as subcategories. Even though Vande Kopple separates attributors from narrators by putting the former under the set of validity markers with his stress that attributors are used with the writer's intention to indicate the validity of the content, functional meanings of the two types remain unclear. Moreover, individual items like according to still appear in both types of marker, as seen in Table 2.3. This indicates that distinguishing the two types of marker has not been consistent yet and thus should be done in sentential context with considerable care. What is interesting about this taxonomy is the subcategories of code glosses, illocution markers, attitude markers, and commentaries are firstly introduced here. 
Table 2.3. Vande Kopple's (1985) metadiscourse taxonomy

Textual metadiscourse

-used to show how different parts or individual propositions are linked in order to form a cohesive and coherent text

-related to the overall semantic structure of the texts

1. Text connectives - used to guide readers throughout texts by explicitly establishing sequences (first; next; in the third place) as well as logical or temporal relationship (however; nevertheless; as a consequence; at the same time)

Subcategories:

1.1 Reminders about material presented earlier and announcements of forthcoming material (as $I$ noted in Chapter One; as we shall see in the next section)

1.2 Statements of what material one is on the verge of presenting (what I wish to do now is to develop the idea that)

1.3 Topicalizers - used to connect new information to information already presented and to mark changes in topic (for example; there are; as for; in regard to; in connection with)

2. Code glosses - used to help readers understand and interpret the meanings of some elements for example by defining or explaining words/phrases possibly in parentheses; used to re-phrase (I'll put it this way; What I mean to say is ...); used to add explanatory details about figures or charts often in postmodifying or parenthetical elements (as in "See figure 4, which displays these dipole resonances")

\section{Interpersonal metadiscourse}

-used to express writers' personalities and reactions to the propositional content of texts -used to characterize the interaction writers would like to have with readers about the content

3. Validity markers - used to express how writers assess the validity of the content being conveyed Subcategories:

3.1 Hedges - used to allow readers register necessary doubts (perhaps; might; may; seem; to a certain extent)

3.2 Emphatics - used to emphasize what writers really believe (clearly; undoubtedly; it's obvious that)

3.3 Attributors - used to lead readers to believe or to judge the propositional content in the way writers would like them to by claiming the support of a credible other (according to Einstein)

4. Narrators - used to indicate the source of the information being referred to (according to James; Mrs. Wilson announced that; the principal reported that)

5. Illocution markers - used to express the discourse act writers are performing at certain points in texts (I hypothesize that; to sum up; to conclude; we claim that; I promise to; we predict that)

6. Attitude markers - used to reveal writers' attitudes toward the propositional content (surprisingly; I find it interesting that; it is alarming to note that; unfortunately; interestingly; I wish that)

7. Commentaries - used to address readers directly and have them engaged in a dialogue by commenting on the readers' probable moods, views, or reaction to the content (most of you will oppose the idea that; you will certainty agree that; you might wish to read the last chapter first; you will probably find the following material difficult at first) 


\section{(iii) Vande Kopple's (1997) metadiscourse taxonomy}

In 1997, Vande Kopple developed his 1985 taxonomy by removing validity markers (i.e., hedges, emphatics, and attributors), introducing epistemology markers, and adding modality markers and evidentials as their subcategories. From examples of metadiscourse items given in the following table, it is possible that the terms modality markers and evidentials are presented to substitute for hedges and attributors respectively, but emphatics have been removed.

Table 2.4. Vande Kopple's (1997) metadiscourse taxonomy

\section{Textual metadiscourse}

\section{Text connectives (see Table 2.3)}

Subcategories:

1.1 Reminders

1.2 Statements of what material one is on the verge of presenting

1.3 Topicalizers

\section{Code glosses}

\section{Interpersonal metadiscourse}

\section{Illocution markers}

4. Epistemology markers - used to indicate some stance on the part of writer toward the epistemological status of the referential material conveyed

Subcategories:

4.1 Modality markers - used to express writers' degree of commitment to the truth of that content/ material and to show a cautious assessment (in other words, to shield discourse actions) by means of combining not/ un-/ in-, adding adverbs, modal auxiliary verbs, phrases, or clauses as well as using tag questions (not unlikely; not impossible; perhaps; possibly; might; may; seem; appear; think; guess; suppose; to our knowledge; at this preliminary stage of research; to a certain degree; it is possible that; I find it possible that; there is the possibility that; that $x$ is $y$ is a possibility; they are thought to be; it's thought that; if I am not mistaken)

4.2 Evidentials - used to indicate bases writers have for referential material. These bases can stem from personal beliefs (I believe that), an induction (I induce that; evidently), sensory experience (it sounds like; it feels like; it looks like), other people's work (reportedly; Sarah told me; according to Professor Snythe; the principal reported that; cf. Maxwell, 1987), and a deduction (should; presumably; I deduce that; of course; oddly)

\section{Attitude markers}

\section{Commentaries}




\section{(iv) Crismore et al.'s (1993) metadiscourse taxonomy}

In Crismore et al.'s (1993) classification, Vande Kopple's (1985) model is used as a basis for classifying metadiscourse. Textual metadiscourse is divided into two main categories: textual markers referring to items which help organize a text (i.e., logical connectives, sequencers, reminders, and topicalizers) and interpretive markers referring to items which help the reader better understand the writer's proposition (i.e., code glosses, illocution markers, and announcements). Interpersonal metadiscourse includes hedges, certainty markers (or emphatics in Vande Kopple's (1985) model), attributors, attitude markers, and commentary. In this model, Crismore et al. combine narrators with attributors because both can be used to convince the reader by explicitly and implicitly claiming the source of ideas.

Table 2.5. Crismore et al.’s (1993) metadiscourse taxonomy

\section{Textual metadiscourse}

\section{Textual markers}

Subcategories:

1.1 Logical connectives - used to show connections between ideas (therefore; so; in addition; and)

1.2 Sequencers - used to indicate sequence/ordering of material (first; next; finally; 1, 2, 3)

1.3 Reminders - used to refer to earlier text material (as we saw in Chapter one)

1.4 Topicalizers - used to indicate a shift in topic (well; now I will discuss)

\section{Interpretive markers}

Subcategories:

2.1 Code glosses - used to explain text material (for example; that is)

2.2 Illocution markers - used to name the act performed (to conclude; in sum; I predict)

2.3 Announcements - used to announce upcoming material (in the next section)

\section{Interpersonal metadiscourse}

3. Hedges - used to show uncertainty to truth of assertion (might; possible; likely)

4. Certainty markers - used to express full commitment to assertion (certainly; know; show)

5. Attributors - used to give source/ support of information (Smith claims that)

6. Attitude markers - used to display writer's affective values (I hope; I agree; surprisingly)

7. Commentary - used to build relationship with reader (you may not agree that)

Adapted from Metadiscourse: Exploring interaction in writing, Hyland, K., (2005, p. 34), Continuum, an imprint of Bloomsbury Publishing Plc. Reprinted with permission. 


\section{(v) Hyland's (2005) metadiscourse taxonomy}

As mentioned earlier, Hyland (2005) employs the terms "interactive" and "interactional" to emphasize that not only interpersonal metadiscourse reflects the writer's interaction with the reader but also textual metadiscourse. Interactive metadiscourse here overtly marks the organization of a text for readers through signaling sequences, pointing out topic shifts, previewing or reviewing information, and so on. Metadiscourse markers that Hyland puts in this category are transitions, frame markers, endophoric markers, evidentials, and code glosses. On the other hand, interactional metadiscourse focuses on writers' effort to express their explicit views on propositional information and establish writer-reader relationships by resorting to hedges, boosters, attitude markers, self-mentions, and engagement markers.

Compared with Crismore et al.'s (1993) classification, Hyland relabels the following subcategories from logical connectives to transitions, illocution markers to frame markers, reminders and announcements to endophoric markers, certainty markers to boosters, and commentary to engagement markers. It is notable that he shifts evidentials from the interpersonal resource in Crismore et al.'s system to the textual one in his system. From his explanation about interpersonal features (Hyland, 2005, p. 51-52), it can be implied that for him interactional features like attitude markers clearly concern how the writer engages with positions and reaction of others, whereas evidentials involve only an indication of who is responsible for a proposition and thus should be assigned as interactive metadiscourse rather than interactional metadiscourse.

Hyland, similar to Vande Kopple (1997), does not include attributors in his taxonomy. He argues that attributors can be subcategorized within evidentials and used interchangeably by the writer to convince readers of the credibility of the propositional content. Another slight difference between aforementioned taxonomies is the emphasis on self-mentions in Hyland's system, an innovation not present in Vande Kopple's and others' taxonomies. 
Table 2.6. Hyland's (2005) metadiscourse taxonomy

\begin{tabular}{l} 
Interactive metadiscourse \\
\hline used to guide the reader through the text
\end{tabular}

1. Transitions - used to express relations between main clauses (in addition; but; thus; and)

2. Frame markers - used to refer to discourse acts, sequences or stages (finally; to conclude; my purpose is)

3. Endophoric markers - used to refer to information in other parts of the text (noted above; see Fig; in section 2)

4. Evidentials - used to refer to information from other texts and provide a reliable source to support arguments (according to $X$; $Z$ states)

5. Code glosses - used to elaborate propositional meanings (namely; e.g.; such as; in other words)

\section{Interactional metadiscourse}

used to involve the reader in the text

6. Hedges - used to withhold commitment and open dialogue (might; perhaps; possible; about)

7. Boosters - used to emphasize certainty or close dialogue (in fact; definitely; it is clear that)

8. Attitude markers - used to express writer's attitude to proposition (unfortunately; I agree; surprisingly)

9. Engagement markers - used to explicitly build relationship with reader (consider; note; you can see that)

10. Self-mentions - used to explicit reference to author(s) $(I ;$ we; my; me; our $)$

Adapted from Metadiscourse: Exploring interaction in writing, Hyland, K., (2005, p. 49), Continuum, an imprint of Bloomsbury Publishing Plc. Reprinted with permission.

\section{(vi) Ädel's (2006) metadiscourse taxonomy}

Clearly deviating from the previous taxonomies, Ädel (2006) takes a narrow approach to define and classify metadiscourse. She defines metadiscourse as explicit linguistic elements marking references to the current text itself (text-oriented metadiscourse), references to the writer of the current text (writer-oriented metadiscourse), references to the reader of the current text (readeroriented metadiscourse), and references to both the writer and reader of the current text (participant-oriented metadiscourse). 
Table 2.7. Ädel's (2006) metadiscourse taxonomy

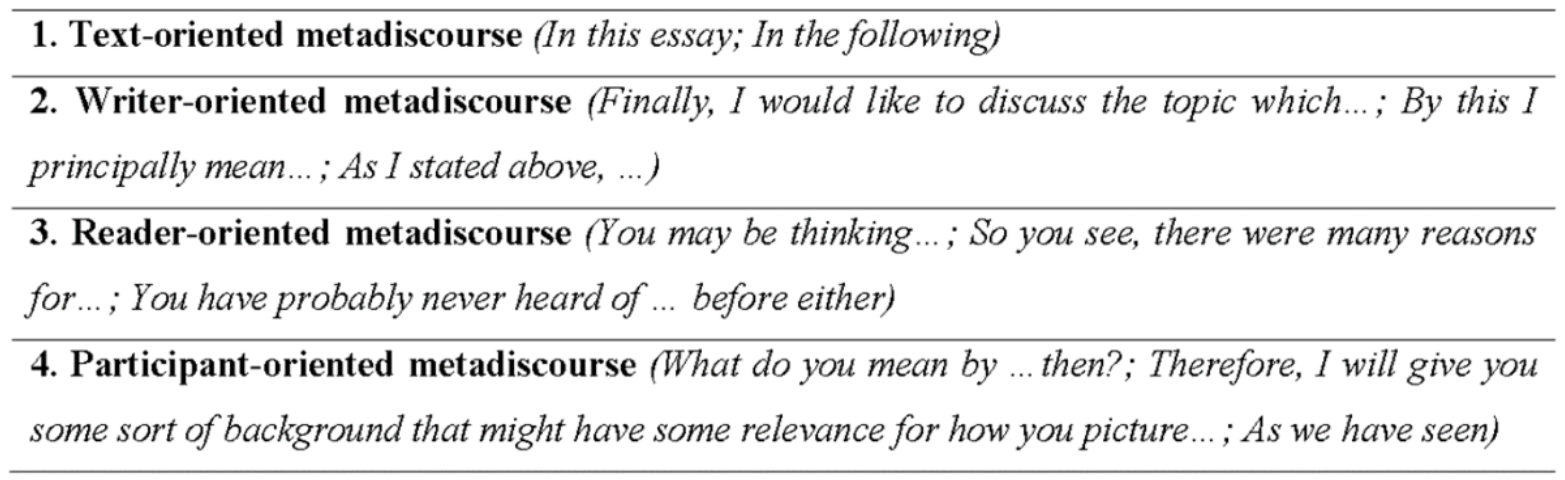

Adapted from Metadiscourse in L1 and L2 English, Ädel, A. (2006, p. 20), an imprint of John Benjamins Publishing Company. Reprinted with permission.

\section{(vii) Ädel's (2010) metadiscourse taxonomy}

In Ädel's (2010) publication, she presents a revised taxonomy of metadiscourse in both spoken and written English. She states that metadiscourse is a discourse-functional category which can be realized in different forms and structures. To categorize and label metadiscourse, we should not mix forms and functions. For instance, in her model, she calls the functional category "discourse organization" (e.g., concluding topic, previewing) instead of logical connectives which are labelled based on grammatical status in Crismore et al.'s (1993) taxonomy. Therefore, her present taxonomy consists of four main categories labelled with respect to their specific discourse functions: metalinguistic comments, discourse organization, speech act labels, and references to audience. The first three categories focus on textual aspects, while the last one concerns audience interaction. Some types of interpersonal markers (evaluation in Ädel's terms) like validity markers (i.e., hedges and emphatics) and attitude markers are excluded from this taxonomy. Her argument is that the writer/ speaker uses evaluation markers to express his/ her attitudes toward the content as an experiencer in the real world, so the markers do not refer to the current text or interact with the reader. 
Table 2.8. Ädel's (2010) metadiscourse taxonomy

\section{Metalinguistic comments}

1. Repairing - used to refer to self- and other-initiated suggestions or alterations which correct or cancel a preceding contribution (no example in written data)

2. Reformulating - used to offer an alternative term or expression (not because of the erroneous preceding contribution) (or... if you want)

3. Commenting on linguistic form/ meaning - used to refer to linguistic form, word choice and/ or meaning (To put it in Fregean language, we can therefore say that...)

4. Clarifying - used to spell out the addresser's intentions in order to avoid misinterpretation (I do not mean to say that .., I should note for the sake of clarity that ...; I will not necessarily be trying to ...; I am by no means trying to ...; I wish simply to...)

5. Managing terminology — used to give definitions and provide terms or labels for phenomena that are talked about (When we use the term Creole in this paper, we will be using the following definition:..; I define ... as ...; what I shall call ...)

\section{Discourse organization}

1. Introducing topic — used to open the topic (In this paper; I explore...)

2. Delimiting topic - used to explicitly state how the topic is constrained (... is outside the scope of this paper; I have restricted my discussion to...; I will focus on...)

3. Adding to topic - used to explicitly comment on the addition of a topic or subtopic (We might add that...)

4. Concluding topic — used to close the topic (We conclude that... ; I have attempted in this paper to...)

5. Marking asides - used to open or close a topic sidetrack or digression (no example in written data)

6. Enumerating - used to show how different parts of the discourse are ordered (In the following section I will ..., followed by ... ; Finally; First of all)

7. Endophoric marking - used to point to a specific location in the discourse which is not clear whether what is referred to occurs before or after the current point (As we can see in (5); From these map points, we see that...)

8. Previewing - used to point forward in the discourse in order to announce what is to come (As I discuss below, ... ; In Section 5, I evaluate...; Below, I give a very brief history of ...; As we will see later...; Before we examine ..., let's briefly look at...)

9. Reviewing - used to point backward in the discourse in order to remind readers what has already taken place (We have seen two different arguments... ; As we have seen, ... ; As I discussed above, ... ; As I mentioned above in the discussion of ...)

10. Contextualizing - used to comment on the situation/conditions of writing or speaking (Larson does not go into great detail on this and I will not do so here either; I have said little about...; I have reused the examples because...; In keeping with the intended scope of this project, I have decided to ...) 
Table 2.8. Ädel's (2010) metadiscourse taxonomy (continued)

\begin{tabular}{|c|c|}
\hline \multirow{4}{*}{ 武 } & 3. Speech act labels \\
\hline & $\begin{array}{l}\text { 1. Arguing - used to stress the action of arguing for or against an issue (I am postulating that ...; I } \\
\text { argue that ...) }\end{array}$ \\
\hline & 2. Exemplifying - used to introduce examples (I will use the embezzlement example to examine...) \\
\hline & $\begin{array}{l}\text { 3. Other speech act labelling (no explanation) (I am suggesting that ... I I am just mentioning it here } \\
\text { as...; I cannot answer that...; I want to emphasize...) }\end{array}$ \\
\hline \multirow{6}{*}{ 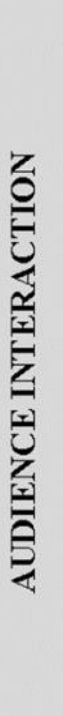 } & 4. References to the audience \\
\hline & $\begin{array}{l}\text { 1. Managing comprehension/ channel — used to ensure the addresser and addressee are on the same } \\
\text { page (no example in the written data) }\end{array}$ \\
\hline & $\begin{array}{l}\text { 2. Managing audience discipline - used to address readers directly and instruct them to do something } \\
\text { (no example in the written data) }\end{array}$ \\
\hline & $\begin{array}{l}\text { 3. Anticipating the audience's response —used to predict readers' reaction to what is said (You might } \\
\text { still think that...; I of course acknowledge that...; You might then wonder how...) }\end{array}$ \\
\hline & $\begin{array}{l}\text { 4. Managing the message - used to emphasize the core message in what is being conveyed (I hope } \\
\text { that the reader has arrived at similar positions after reading this paper; I hope you enjoy reading } \\
\text { materials; I have attempted to present the reader with...) }\end{array}$ \\
\hline & $\begin{array}{l}\text { 5. Imagining scenarios - used to ask readers to see something from a specific perspective and engage } \\
\text { readers into texts (Suppose I say that ...; If I say that...; Imagine the following situation. You have to...) }\end{array}$ \\
\hline
\end{tabular}

Adapted from Metadiscourse in L1 and L2 English, Ädel, A. (2006, p. 60-61), an imprint of John Benjamins Publishing Company. Reprinted with permission.

From a review of taxonomies presented by Williams (1981), Vande Kopple (1985, 1997), Crismore et al. (1993), Hyland (2005), and Ädel (2006, 2010), most of the metadiscourse taxonomies are similar, except for Ädel's taxonomies, in that they all restrict the boundaries of metadiscourse by considering its roles as either textual or interpersonal elements. As discussed above, the narrow approach is more likely to delimit subcategories of metadiscourse to the textual features only. Although Ädel includes some interpersonal features like audience interaction in her recent taxonomy, most of interpersonal features like stance markers are neglected. In my opinion, what makes metadiscourse distinct from the primary discourse concerning the content of a topic is its interpersonal function, so this should be maintained as a key feature for metadiscourse. If a text is viewed as an instance of communication between a writer and a reader, the interaction between these discourse participants should be on a par with the textual features. Moreover, stance markers should be counted as metadiscourse since they give guidance to the reader with respect to the writer's attitudes toward the content and leave 
room for discussion and differences of opinion, thus fostering participatory interaction in discourse.

\subsubsection{Types of metadiscourse}

The previous section reviews how taxonomies of metadiscourse have evolved over time and indicates absence and presence of particular types of metadiscourse in the taxonomies. This section focuses on the definition and primary functions of each metadiscourse subcategory. Table 2.9 compares types of metadiscourse from the pioneering model of Williams (1981) to the most recent one of Hyland (2005). It illustrates that there are five subcategories of metadiscourse markers labelled within the textual category and five subcategories in the interpersonal category. Metadiscourse subcategories in this study are labelled in accordance with Hyland's (2005) taxonomy as the labels inclusively convey nuances of marker functions in each category and also help me anticipate which markers should or should not be classified under the labels. Since this study adopts the broad approach for inclusive definition and classification of metadiscourse markers in order to leave some room for new contextualized markers to be added later on, only metadiscourse features in taxonomies using the same approach are shown in the table to track variation of subcategories within the same approach and also to narrow the scope of classification. Based on the explicitness criterion proposed by Hyland (2005) and Ädel (2006), only explicit markers or overt surface features which can be clearly identified in the text will be the focus in this study, so markers like bolds and italics are not included.

Metadiscourse is divided in two main functional categories: textual metadiscourse and interpersonal metadiscourse. Textual metadiscourse includes transition markers, frame markers, endophoric markers, evidentials, and code glosses. Interpersonal metadiscourse includes hedges, boosters, attitude markers, engagement markers, and self-mentions. A more detailed description of each of the ten subcategories is provided as follows:

\section{(i) Transition markers}

Transition markers are used to organize discourse and create cohesion and coherence. When markers explicitly express logical or temporal relationships between ideas or clauses and help readers interpret links between ideas, these markers are called logical connectives (Crismore et al., 1993) and transitions (Hyland, 2005). These markers are mainly conjunctions and 
adverbials used to mark addition, comparison, and consequence in the discourse (and, however, due to).

\section{(ii) Frame markers}

Frame markers in Hyland (2005) include sequencers, topicalizers, and illocution markers (first, finally, in regard to, my purpose is) (Crismore et al., 1993; Vande Kopple, 1985, 1997; Williams, 1981) under the same label. It is interesting that Crismore et al. (1993) include illocution markers as textual metadiscourse with an argument that the markers are used to guide the reader by indicating what the writer is performing yet do not involve reader participation. In contrast, Vande Kopple $(1985,1997)$ views illocution markers as interpersonal metadiscourse due to the possibility that some of the illocution markers (I must ask that you...; I hate to have to do this, but I must ask that) can convey interpersonal meaning and encourage readers to collaborate in the discourse. This means that not all illocution markers function as textual devices but also interpersonal devices, depending on contexts and metadiscourse analysts' perspectives. As we can see from Ädel's (2010) model, she underlines speech act labelling as a main function of textual metadiscourse-metatext. She includes arguing, exemplifying and other speech act labelling markers under the functional category of speech act labels in order to suggest to the reader what speech acts the writer intends to perform at a given moment.

\section{(iii) Endophoric markers}

Hyland (2005) and Ädel (2010) use the term endophoric markers, while Crismore et al. (1993) and Vande Kopple $(1985,1997)$ favour the term reminders and announcements when they refer to markers that remind readers of preceding or following information in other parts of the text (as I noted in Chapter One, in Table 9). 
Table 2.9. Summary of metadiscourse taxonomies

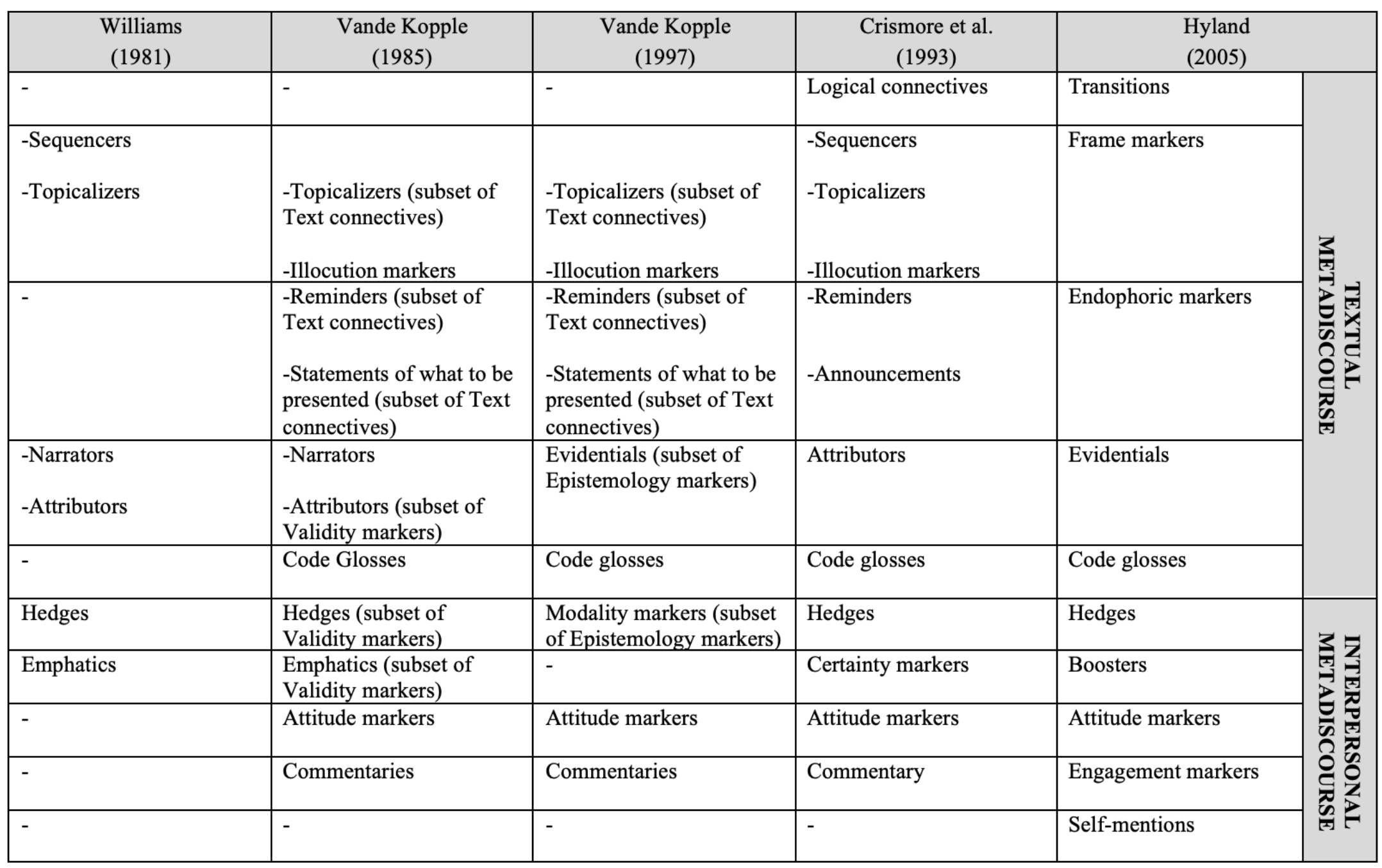




\section{(iv) Evidentials}

Evidentials (Hyland, 2005; Vande Kopple, 1997) or narrators (Vande Kopple, 1985; Williams, 1981) are markers that indicate a source of information being referred to (according to James, the participant suggested that). Regarding their functions, both narrators and evidentials are similar. However, evidentials in Hyland's (2005) monograph differ from other taxonomies in that they are coded as interactive (textual) metadiscourse rather than interactional (interpersonal) metadiscourse since they provide important support for arguments by indicating a source of information which is outside the current text rather than indicating the writer's stance towards the content.

\section{(v) Code glosses}

Code glosses are used to elaborate propositional meanings in order to help readers understand and interpret the meanings of some elements, for example by defining, re-phrasing, explaining words/ phrases possibly in parentheses, or even adding explanatory details about figures and charts often in postmodifying or parenthetical elements (for example, namely, in other words, e.g.) (Crismore et al., 1993; Hyland, 2005; Vande Kopple, 1985, 1997).

\section{(vi) Hedges}

Hedges are used to shield discourse actions and show readers the degree of uncertainty and approximation, so writers use hedges when they have doubts about an assertion and would like to leave room for alternative viewpoints (may, likely, it is possible that) (Crismore et al., 1993; Hyland, 2005; Vande Kopple, 1985; Williams, 1981). Vande Kopple (1997) uses the term modality markers instead of hedges to emphasize that this type of marker can include prefixes (un-, in- and not), adding adverbs, modal auxiliary verbs, phrases, or clauses as well as using tag questions.

\section{(vii) Boosters}

Boosters (Hyland, 2005) or emphatics (Vande Kopple, 1985; Williams, 1981) are used to suggest to readers the degree of certainty or validity of an assertion and narrow conflicting views or diverse positions rather than enlarge them (obviously, in fact, it is clear that) (Vande Kopple, 1985; Williams, 1981). Hyland (2005) uses the term boosters to indicate that these 
markers not only express certainty but also construct rapport by marking involvement with the topic and solidarity with readers.

(viii) Attitude markers

Attitude markers are words or clauses used by writers to reveal attitudes, e.g., surprise, agreement, importance, obligation, or frustration, toward the propositional content (surprisingly, unfortunately, I agree) (Crismore et al., 1993; Hyland, 2005; Vande Kopple, 1985, 1997).

\section{(ix) Engagement markers}

Engagement markers (Hyland, 2005) and commentaries (Crismore et al., 1993; Vande Kopple, $1985,1997)$ are used to address readers directly and have them engaged in a dialogue by predicting or commenting on the reader's probable moods, views, or reaction to the content (you will certainly agree that, it is important to note that). A distinction between attitude markers and engagement markers is that the former expresses the writer's appraisal of information, while the latter focuses on reader participation by addressing readers as participants in an argument with reader pronouns like you, your, or inclusive we (Ädel, 2010; Crismore et al., 1993; Hyland, 2005; Vande Kopple, 1985, 1997).

\section{(x) Self-mentions}

Self-mentions are newly introduced as interactional metadiscourse in Hyland's (2005) monograph. These markers refer to the degree of explicit authorial presence in the text (I, exclusive us, the researcher).

Given that the boundaries of metadiscourse remain vague and in dispute in terms of functional categories and types of markers, this study took Hyland's (2005) direction to define and classify metadiscourse since it covers all explicit markers like self-mentions which are not found in other taxonomies. Moreover, it is the taxonomy most widely adopted in previous studies which the present study can draw on and make comparisons with. However, although Hyland relabels and uses the terms "interactive metadiscourse" and "interactional metadiscourse," it must be noted that my study employed the original terms "textual metadiscourse" and "interpersonal metadiscourse" for the major division within metadiscourse in order to distinguish and recognize the two key functions of metadiscourse. That is, the former covers all textual 
features, and the latter particularly deals with writer-reader participation in discourse. Both the original terms and the relabeled terms are accepted by metadiscourse analysts as long as writerreader interaction is involved as part of their functions.

\subsection{Contrastive rhetoric}

Studies with different aims and foci employ several approaches to examine metadiscourse and contribute to the discourse field in different ways. The main purpose of the present study is to investigate similarities and dissimilarities in the use of metadiscourse of New Zealand and Thai postgraduates between two disciplines. This section, therefore, reviews a contrastive approach, also known as contrastive rhetoric, dominantly adopted in metadiscourse studies and which corresponds to the purpose of this study.

Contrastive rhetoric is conceptualized by Robert Kaplan (1966) based on the notion that "language and writing are cultural phenomena." Each language has unique linguistic and rhetorical conventions which possibly interfere with writing in the second language. Therefore, contrastive rhetoric analysis aims to provide descriptions of second language writing patterns by speculating about the first language or cross-linguistic influence (Connor, 1998, 2002).

Contrastive rhetoricians included linguistic text analysis as a tool to describe the conventions of writing in English and to compare writing in students' first and second languages, especially in terms of cohesion, coherence, and discourse structure of texts across cultures and genres (Connor, 2002). However, according to Leki (1991), this traditional contrastive rhetoric has been subject to some criticism. It was regarded as a product-oriented approach ignoring both the processes and the context of producing the text. Concerning a comparison of native and non-native writing, traditional contrastive analysts seemingly overlooked the fact that writers of a particular ethnicity invariably used particular discourse patterns, so writing of native English speakers was privileged as a standard model and that of non-native speakers as poorer: "In English we write like this, those who would write well in English must look at this pattern and imitate it" (p. 123).

As a result of such criticism, Connor $(1998,2002)$ has provided new directions of contrastive rhetoric which move from examining only products to studying processes as well products written for readers in different situations such as journal editors, proposal reviewers, and prospective employers. Thus, four domains of new contrastive rhetoric include: (1) contrastive text linguistics/ text analysis which compares discourse features, super-structures of argument, 
rhetorical moves, metatext, etc., across languages and cultures; (2) study of writing as a cultural and educational activity which compares the processes of learning to write in different cultures; (3) classroom-based studies which examine cross-cultural patterns in process writing, collaborative revisions, and teacher-student conferences; and (4) contrastive genre-specific studies which investigate writing in a variety of academic and professional genres for a variety of purposes such as journal articles, business reports, and letters of application.

The present study involves the first and fourth domains of contrastive rhetoric, contrastive text analysis and contrastive genre-specific analysis, since it aims to compare textual and interpersonal features in the thesis genre written by New Zealand and Thai postgraduates in two disciplinary communities. It must be noted here that this contrastive study will not privilege English speaking students' writing over that of Thai speaking students, or vice versa, but see and describe different writing characteristics and conventions (if any) of students with different ethnicities in different educational contexts. Sharing the same idea with Connor (1998), I think that "the driving force behind contrastive rhetoric research is pedagogical" (p. 108), not a matter of superiority. If a comparison or contrast is the case, this study is meant to point out areas that students in the two contexts are similar or different from each other in using rhetorical strategies in their theses rather than to privilege one over another. In terms of pedagogical implications, the findings of this contrastive study will advance both L1 and L2 students' understanding of thesis writing conventions according to specific educational contexts and disciplinary communities. It will lay out a framework for postgraduate writing instructors in developing writing lessons and materials based on the norms of actual language use of people in specific communities, so that students can learn to use the language conforming to the expectations of members in their communities.

Hinds (1987) proposed a new direction for contrastive analysis, i.e., investigating characteristics of writing by L1 and L2 writers based on the distribution of responsibility between readers and writers. He considers the degree of writers' effort to make texts cohere through transitions and other types of metatext and refers to the texts as writer-responsible, as opposed to reader-responsible texts. In writer-responsible cultures such as English, writers play an important role in producing well-organized texts through explicit textual-organizing devices, with an awareness and evaluation of readers' need for elaboration. In readerresponsible cultures such as Japanese (Mok, 1993) and Chinese (Qi \& Liu, 2007), writers tend not to make explicit the textual organization and rhetorical acts. They tend to leave their 
argument implicit, so that the readers have room for their own personal interpretations. Based on this account, the definitions of writer-responsible and reader-responsible cultures seem to be given on the basis of textual features in a text, but interpersonal features have not been specifically defined as part of the writing cultures.

As the present study also concerns interpersonal features in the thesis genre, it proposes use of interpersonal metadiscourse markers as a further way to describe writer-responsible and readerresponsible writing cultures. Given that writing academic texts involves not only textual features but also writer-reader participation in the texts, there is a possibility that writers assume an unequal degree of responsibility for textual organization and writer-reader interaction. To describe the two writing styles based on metadiscourse perspectives, in writer-responsible cultures, writers produce their writing with an orientation to readers. In reader-responsible cultures, writers are likely to be implicit in participating in the texts and interacting with the readers. Figure 2.1 illustrates writers' responsibilities for textual organization and writer-reader interaction through their use of textual metadiscourse (Bar A) and interpersonal metadiscourse (Bar B). The movement towards each end of the metadiscourse frequency continuum, reflecting a more writer-responsible writing style and a more reader-responsible style, may vary from one discourse community to another. The darker side of Bar A represents a high frequency of textual metadiscourse, portraying a higher degree of writer responsibility for textual organization and elaboration of propositional meanings. The lighter side of Bar A represents a low frequency of textual metadiscourse, portraying a higher degree of reader responsibility for interpretation of meanings.

Focusing on the interpersonal metadiscourse frequency continuum, the darker side of Bar B represents a high frequency of interpersonal metadiscourse. It reflects a higher degree of writer responsibility for explicitly engaging themselves and readers in the texts and managing claims to hint to the readers whether propositions are certain facts or tentative opinions, so that the readers can interpret and evaluate the propositions with more careful consideration. The lighter side of Bar B represents a low frequency of interpersonal metadiscourse. This indicates a lower degree of writer responsibility for creating writer-reader interaction in academic texts and informing the readers about the level of (un)certainty of knowledge claims, resulting in a higher degree of reader responsibility for evaluating claims and interpreting the writers' attitudes towards the content. Writers in different discourse communities may assume high responsibility for textual features but less responsibility for building relationships between 
writers and readers in academic texts, or vice versa.

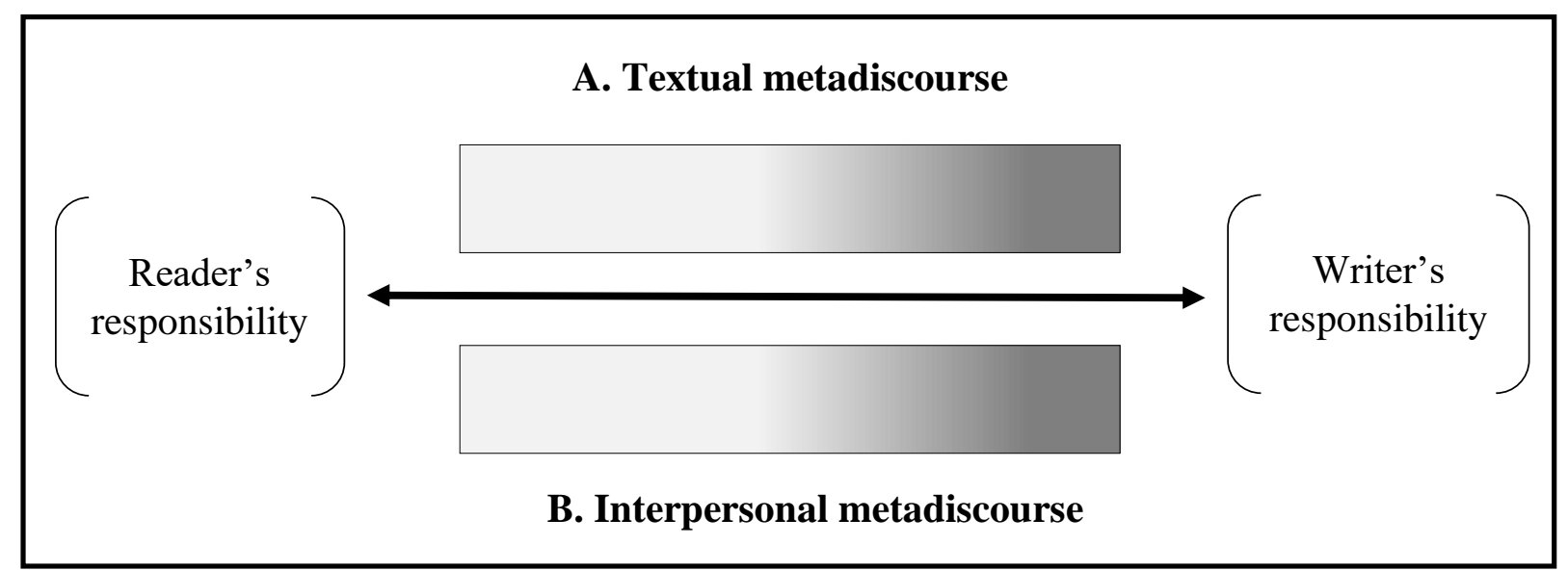

Figure 2.1. Writer-responsible and reader-responsible writing styles based on metadiscourse perspectives

On the subject of contrastive rhetoric methods, Moreno (2008) suggests the necessity for contrastive rhetoric researchers to ensure that corpora to be analyzed are parallel and research is rigorous, reliable, and explanatory. In her paper, she defines a corpus as a sample of texts representing the population of texts and parallel corpora as sets of comparable original texts written independently in two or more languages. She highlights that to design comparable or equivalent corpora, they do not need to be exactly the same but similar as far as possible. Contrastive rhetoric studies usually compare rhetorical features of written texts across languages and cultures and inevitably investigate the effects of a contextual factor which is likely to be the "language code" associated with norms, values, common practices, educational and training factors, etc. It may be said that the language code is the independent variable and the text form (rhetorical/ semantic/ linguistic features) is the dependent variable. In order to achieve valid and reliable results in contrastive rhetoric research, other relevant contextual factors, known as confounding variables, should be manipulated. The confounding variables such as genre (essays/ newspapers), mode (written language/ spoken language), participant expertise (students/ professors), unit of analysis (entire texts), etc. can be used as criteria to determine whether the corpora are equivalent to the maximum degree of similarity and thus comparable.

To ensure comparability, thesis subcorpora in the present study were therefore manipulated based on Moreno's criteria of genre (thesis), mode (written language), the writers' level of 
expertise (master's students), and textual unit of analysis (discussion and conclusion chapters) (see Table 3.3 in the next chapter for corpus comparability of the present study).

\subsection{Review of related studies on metadiscourse}

Applying a contrastive approach, previous studies underline variation in use of metadiscourse across L1 and L2 contexts (e.g., Kobayashi, 2016; Lee \& Casal, 2014; Mauranen, 1993; Ozdemir \& Longo, 2014; Tarrayo, 2011) and across disciplines (e.g., Hyland, 1998a, 1998b, 1999, 2004). As this section shows, metadiscourse studies involve both frequency and functional approaches. Below, I provide an overview of how metadiscourse studies have been done and what they have discovered so far.

\subsubsection{Cross-cultural studies of metadiscourse}

Research on the issue of variation across cultures and languages has received much attention. Contrastive research has compared English texts written by L1 and L2 students, English texts written by different groups of L2 students, and English and non-English texts. These studies have been conducted using different genres, ranging from essays to research articles (RAs) and doctoral dissertations. I now review cross-cultural studies of each genre in turn.

Starting with essays, many studies have compared use of metadiscourse in academic essays of students of different language backgrounds, e.g., Finnish vs. American (Crismore et al., 1993), Indonesian vs. British (Rustipa, 2014), and across six groups of Asian students (Kobayashi, 2016). The comparison between L1 and L2 students' essays suggested that L2 students (Finnish and Indonesian students) used metadiscourse more often than L1 students (American and British students). Comparing the use of textual and interpersonal metadiscourse, Crismore and colleagues found a higher frequency of interpersonal metadiscourse than textual metadiscourse in both Finnish and American students' essays, but Rustipa found a higher frequency of textual metadiscourse than interpersonal metadiscourse in both Indonesian and British students' essays. A considerable difference was the less frequent use of endophoric markers, hedges, boosters, and engagement markers in Indonesian students' writing compared to British students' writing. The results of Kobayashi's (2016) study also revealed substantial differences in terms of frequencies and writing characteristics between East Asian groups (Chinese, Japanese, Korean, and Taiwanese) and Southeast Asian groups (Indonesian and Thai). For instance, focusing on the writer and reader visibility, Japanese students focused more on making authorial self-references (I, my, me) and using boosters (I think), whereas Thai students 
focused more on addressing the readers through frequent use of engagement markers (especially second-person pronouns) and clarifying propositions with examples (such as, for example). These studies emphasized the prominent role of language and cultural conventions, not only between L1 and L2 cultures but also within L2 cultures, in shaping discourse structures and rhetorical strategies (e.g., implicity vs. explicity of authorial presence).

Apart from essays, numerous metadiscourse studies have examined research articles. For example, Mauranen (1993) investigated metatext (i.e., connectors, reviews, previews, and illocution/ action markers) in economics RAs written by Finnish and American writers. This study revealed a higher incidence of metatext in the American writers' RAs. In the Finnish writers' RAs, authorial presence was implicit and previewing markers were not adequately provided. Tarrayo (2011) adopted Mauranen's (1993) metatext model to examine results and discussion sections of RAs written by Philippine, Taiwanese, and Iranian writers. In this study, previewing markers were more frequently used than reviewing markers in the three groups of RAs. Philippine ESL writers used all types of metatext more often than Iranian and Taiwanese EFL writers. Taken together, the American English and Philippine English RAs seemed to be more writer-responsible when compared to the Finnish, Taiwanese, and Iranian English RAs. However, these studies took the narrow approach and did not include interpersonal features for analysis.

Using Hyland's (2005) model, Mu, Zhang, Ehrich, and Hong (2015) examined metadiscourse in English and Chinese RA introductions in applied linguistics and found more metadiscourse overall in the English RAs than in the Chinese RAs. While both English and Chinese RAs used more textual metadiscourse than interpersonal metadiscourse, the use of interpersonal metadiscourse was more frequent in the English RAs than in the Chinese RAs. Transition markers and hedges were the most frequent markers in both English and Chinese corpora. Comparing the two corpora, Chinese authors tended to use evidentials, boosters, and selfmentions (we) more often than English authors, whereas English authors hedged more often than Chinese authors. Although Gholamit and Ilghamit (2016) found no significant difference in the frequency of using metadiscourse between Iranian and American authors' RAs in biology, this study was similar to Mu et al.'s (2015) study, indicating more frequent use of interpersonal markers (especially hedges) in L1 authors' RAs than in L2 authors' RAs with more frequent use of boosters. 
The metadiscourse studies described above rely on the quantitative (frequency-based) approach with a focus on comparing frequencies across corpora as a whole. What has been neglected in the studies is an in-depth analysis of individual types and functions to provide a full picture of how metadiscourse markers are used by writers in different contexts to achieve certain communicative purposes in a particular genre.

Some studies have extended their analytical focus from frequencies only to functions and usage patterns (e.g., word collocations, grammatical forms) and concentrated on certain subcategories of metadiscourse. For instance, Mur Dueñas (2007) conducted a detailed analysis of frequencies and functions of self-mentions in English and Spanish RAs in business administration. The frequency of self-mentions was higher in the English RAs than in the Spanish RAs. American scholars writing single-authored RAs were more likely to use singular personal references $(I, m y)$, whereas Spanish scholars writing single-authored RAs seemed to favor plural personal references (exclusive we, us, our). The functional analysis of exclusive we in this study revealed eight different rhetorical functions: (1) explaining a procedure (we used); (2) making a claim, elaborating on an argument (we suggest); (3) stating a hypothesis, an expectation, or a wish (we predicted); (4) stating a goal or purpose (we focus); (5) showing results (we found); (6) assessing limitations of research (we were unable to); (7) assessing the strengths of research (we report); and (8) outlining the steps followed in the RAs (we develop).

Focusing on hedging, Nguyen Thi Thuy (2018) examined RA results and discussion sections written by Vietnamese and English authors. The frequency of hedges was significantly lower in the Vietnamese authors' RAs than in the English authors' RAs. Besides overall frequencies, this study accounted for grammatical categories of hedges. The two groups of authors showed the same inclination to use epistemic verb forms (indicate, seem, suggest) for hedging arguments, when compared to modal auxiliaries (may, would, could, might, should) and epistemic adverbs and adjectives (probably, possible, likely).

With regard to postgraduate writing, cross-cultural research has compared use of metadiscourse by postgraduate students in different contexts. Comparing Lithuanian and British students' master's theses, Burneikaitè (2008) classified metadiscourse into three categories (textorganizing metadiscourse, participant-oriented metadiscourse, and evaluative metadiscourse). This study found no significant difference in the overall frequency of metadiscourse between the two groups of students. This study also revealed extensive use of text-connectives (firstly, however, so), rather limited use of endophoric markers (in Section X, in Chapter X) and reader- 
oriented markers (you, the reader, see), and sparse use of evaluative markers (especially emphatic markers we believe that) in the Lithuanian students' theses compared to the British students' theses.

Following Hyland's (2005) taxonomy, Alshahrani (2015) compared Arab and English students' doctoral dissertations in linguistics, and Lee and Casal (2014) compared Spanish and English students' master's theses in engineering. Not only metadiscourse frequencies in general, these two studies also refered to different writing styles based on frequent types of markers. The studies found more occurrences of textual and interpersonal metadiscourse in the English students' texts, when compared to the Arab and Spanish students' texts. Both Arab and English doctoral students made greater use of additive markers than comparative and consequential markers, showing their preference for a progressive writing style (adding arguments in the same direction by means of additive markers) over a retrogressive style (explicitly showing contrasts and consequences of ideas by means of comparative and consequential markers). In Lee and Casal's (2014) study, English writers preferred a progressive style, but Spanish writers preferred a retrogressive style. Mestre-Mestre (2017), who also compared Spanish and American students' master's theses, found more occurrences and types of textual metadiscourse in the Spanish students' theses but more occurrences and types of interpersonal metadiscourse in the American students' theses. A difference between the two groups was the types of frame markers that they preferred. Spanish students showed great emphasis on sequencing arguments with heavy use of finally and to conclude, whereas American students made substantial use of the marker my purpose is... to announce major discourse goals.

Comparing Persian and English students' master's thesis discussion and conclusion chapters, Mirshamsi and Allami (2013) suggested that native English speaking students used more metadiscourse than Persian students. The two groups were similar in that they used more textual metadiscourse than interpersonal metadiscourse. Transition markers and hedges constituted the highest frequencies in the corpora.

Comparing Turkish and American students' abstracts, Ozdemir and Longo (2014) found more textual and interpersonal metadiscourse in the American students' abstracts than those of Turkish students. While both Turkish and American students used more textual metadiscourse than interpersonal metadiscourse, the use of interpersonal metadiscourse was more frequent in the American students' abstracts than in the Turkish students' abstracts. Transition markers 
and frame markers were most frequent textual metadiscourse used in both Turkish and American writing corpora. The incidence of evidentials, endophoric markers, code glosses, boosters, attitude markers, and self-mentions was higher in the American students' abstracts, whereas the incidence of transition markers, frame markers, and hedges was higher in the Turkish students' abstracts.

With a particular focus on hedges and boosters, Akbas and Hardman (2018) compared master's thesis discussion sections written by native speakers of Turkish (TL1) and English (EL1) and Turkish speakers of English (EL2). This study reported that the Turkish L1 writers preferred using boosters to hedges when writing theses in Turkish. In contrast, when writing theses in English, the Turkish writers of English were similar to their English L1 counterparts in making greater use of hedges than boosters. Both EL2 and the EL1 writers preferred using modal verbs to verbs and the formulaic expressions (is likely due to, it is possible that).

In the Thai context, Getkham (2014) examined discussion sections of research papers produced by Thai postgraduate students, focusing on the use of positive politeness strategies (e.g., engagement markers like rhetorical questions and inclusive we, certainty markers, attitude markers) used to gain approval from the community and negative politeness strategies (e.g., hedging markers, impersonality markers like passive voice) used to mitigate imposition. The results suggested that Thai students used more negative politeness strategies (especially impersonality devices (passive voice) and hedges (may, likely)) than the positive ones and seemed to have a limited repertoire of rhetorical strategies.

In addition, there have been some studies examining metadiscourse bundles, analytical units larger than single word level. Ädel and Erman (2012) compared use of four-word lexical bundles in Swedish and English students' writing and found that Swedish students used fewer types of metadiscourse bundles and had a more restricted repertoire of recurrent word combinations than English students. $\mathrm{Li}$ (2016) also examined four-word metadiscourse bundles at the beginning of sentences (e.g., on the other hand, it should be noted) in master's and $\mathrm{PhD}$ theses of Chinese and New Zealand students. This study revealed more occurrences and types of sentence initial bundles in the Chinese students' theses than in the New Zealand students' theses. In the textual category, code gloss bundles (for example, in other words) and condition bundles (with regard to the, on the basis of) were found to be more frequent in Chinese students' writing than in New Zealand students' writing. In the interpersonal category, Chinese 
students showed a heavy use of booster bundles and a relatively low use of attitude bundles, hedging bundles, and self-mention bundles.

Due to space limitations, I conclude this section by identifying common themes related to methodological frameworks often used in previous studies and evaluating key findings. Apart from genres examined, metadiscourse studies differ from each other in that some studies investigated a full range of metadiscourse (Crismore et al., 1993; Lee \& Casal, 2014; Mu et al., 2015), whereas some devoted attention to certain subcategories such as hedges and boosters (Akbas \& Hardman, 2018; Nguyen Thi Thuy, 2018). While some studies took bundle-based analysis to see metadiscourse use in a big picture (Ädel \& Erman, 2012; Li, 2016), most metadiscourse studies started from examining single markers and further analyzed words and phrases that co-occur with the examined markers (Akbas \& Hardman, 2018; Burneikaite, 2008; Mestre-Mestre, 2017; Mur Dueñas, 2007). As noted earlier, most metadiscourse research was undertaken using the frequency approach to investigate metadiscourse occurrences in each context. Individual types and functions within each subcategory have been underresearched. Finally, the observation of taxonomies adopted in previous studies indicates that taxonomies in the narrow model (e.g., Ädel, 2006, 2010; Mauranen, 1993) were not widely used in studies of academic writing genre (RA and postgraduate writing). It is possible that the taxonomies were generalized from both spoken and written data and contain functions that have little relevance to academic writing (see examples of spoken language markers in Table 2.8). Taxonomies in the broad model (e.g., Crismore et al., 1993; Hyland, 2005) are researchoriented and therefore widely adopted in several studies of advanced academic writing (Alshahrani, 2015; Gholamit \& Ilghamit, 2016; Lee \& Casal, 2014; Mu et al., 2015).

Regarding key findings, the above cross-cultural studies of the three genres (essays, RAs, and theses) exhibit the following trends: (1) L1 students tend to use more metadiscourse than L2 students (e.g., Alshahrani, 2015; Mauranen, 1993; Mirshamsi \& Allami, 2013; Ozdemir \& Longo, 2014); (2) L1 students tend to use more interpersonal metadiscourse than L2 students who tend to use more textual metadiscourse (e.g., Alshahrani, 2015; Burneikaite, 2008; Gholami \& Ilghami, 2016; Mestre-Mestre, 2017; Mu et al., 2015; Ozdemir \& Longo, 2014); and (3) different groups of L1 and L2 students have different preferences for particular metadiscourse subcategories, e.g., more frequent use of hedges by L1 students and more frequent use of boosters by L2 students (e.g., Akbas \& Hardman, 2018; Gholami \& Ilghami, 
2016; $\mathrm{Mu}$ et al., 2015). Moreover, the literature review has indicated an insufficiency of research on metadiscourse in New Zealand and Thai students' postgraduate writing.

\subsubsection{Cross-disciplinary studies of metadiscourse}

The considerable attention to variation of metadiscourse across disciplines began with the seminal work of Hyland. He carried out a number of studies investigating disciplinary variation of metadiscourse in essays (Hyland \& Milton, 1997), research articles (Hyland, 1998a, 1998b; Hyland \& Jiang, 2018a, 2018b), textbooks (Hyland, 1999), and theses (Hyland, 2004; Hyland $\&$ Tse, 2004). With limited space, this section discusses some of the studies.

Hyland (1998a) examined hedges and boosters in RAs in eight disciplines (mechanical engineering, electrical engineering, marketing, philosophy, sociology, applied linguistics, physics, and microbiology). RAs in humanities and social sciences (philosophy, marketing, applied linguistics, and sociology) contained more interpersonal strategies like hedges and boosters than RAs in the sciences (physics and engineering). The most frequent hedging markers were may, would, and possible, and the most frequent boosters were will, show, and the fact that. Epistemic verbs such as suggest, indicate, assume, and seem were also heavily used as hedges. Hyland (1998b) further examined a full range of metadiscourse in four disciplines (microbiology, marketing, astrophysics, and applied linguistics). This study found more textual metadiscourse than interpersonal metadiscourse in the RA corpus. Hedges and connectives were the most frequent markers in this RA corpus. Writers in the soft disciplines (marketing and applied linguistics) used interpersonal markers more often than writers in the hard disciplines (astrophysics and biology).

In 1999, Hyland compared textbooks and RAs in microbiology, marketing, and applied linguistics. The findings suggested that in all disciplines, RAs contained more interpersonal metadiscourse, especially hedges, than textbooks. Textbooks contained more textual features, particularly connectives, code glosses, and endophoric markers, than RAs. Hedges, attitude markers, emphatics, evidentials, person markers, and frame markers were more frequently used in RAs than textbooks. This genre-based study indicated that writers of different genres tended to use different rhetorical choices to organize discourse.

Hyland (2004) focused on the comparison between master's and doctoral dissertations written by Hong Kong Chinese students and between soft disciplines (applied linguistics, business studies, and public administration) and hard disciplines (biology, computer science, and 
electronic engineering). This study found that hedges and transitions were the most frequent markers in the thesis corpus. Doctoral writers used substantially more textual metadiscourse (especially evidentials and transition markers) and interpersonal metadiscourse (especially engagement markers and self-mentions) than master's student writers. Between soft and hard disciplines, more soft knowledge social science disciplines were more likely to employ more metadiscourse features, especially interpersonal metadiscourse. The marked difference was that the soft disciplines tended to make more frequent use of hedges, attitude markers, and selfmentions than the hard disciplines because the soft disciplines required more explicit personal interpretation. As this study pointed out, the use of metadiscourse features not only varied according to discipline but also levels of writers' writing proficiency and experience.

Recently, Hyland and Jiang paid particular attention to certain features of metadiscourse and changes in the use of metadiscourse over the past 50 years. Hyland and Jiang (2018a), investigating RAs published over the past 50 years in applied linguistics, sociology, electrical engineering, and biology, revealed a significant increase in textual features and a significant decrease in interpersonal features. Hedges and transitions were the most frequent markers in the corpus over the five decades. Salient changes were the decline of boosters and attitude markers, indicating a shift to less explicit expression of strong claims and authorial standpoints on content, and the marked increase of evidentials and code glosses, indicating the RA writers' greater attempt to make texts more transparent and persuasive to less specialized readers. Divided by soft and hard knowledge, this study found a marked decrease of interpersonal metadiscourse in the soft knowledge disciplines and a substantial increase of interpersonal metadiscourse in the hard knowledge disciplines.

Using the same corpus and disciplines as described above, Hyland and Jiang (2018b) further explored changes in the expression of authorial stance (the evaluative that-structure) over decades. They found that the that-structure was extensively used in RAs over the time. The most important change was a shift to less explicit authorial presence (think that, believe that). To reduce authorial intervention, writers, especially in applied linguistics, largely preferred to conceal sources with a dummy it subject (it is believed that) and attribute evaluations to inanimate subjects (data, results, tables) and other researchers rather than themselves.

There were three limitations in Hyland's studies that should be taken into account. First, while a wide range of academic writing genres such as RAs, textbooks, and postgraduate theses were covered in his studies, the major focus was on rhetorical features in RAs. Second, although his 
disciplinary study in 2004 examined metadiscourse features in master's and doctoral dissertations, this study drew conclusions mainly on a clear-cut line between soft and hard disciplines, providing superficial discussion on subtle variations between disciplines within either soft or hard domains. Third, his studies exhibited the same fashion as pointed out in the the review of cross-cultural studies, that is, comparing metadiscourse frequencies across corpora. A detailed examination of particular types of markers and functions in certain thesis chapters has been neglected to envisage pedagogical materials based on salient markers and functions in thesis chapters.

In addition to Hyland's work, there have been other metadiscourse studies investigating crossdisciplinary variation. Chan (2015) examined stance expressions in acknowledgements of $\mathrm{PhD}$ dissertations written by Hong Kong Chinese students across the six disciplines examined in Hyland's (2004) study. Although this study was conducted with $\mathrm{PhD}$ dissertations like Hyland's (2004) study, the corpus size was rather small (totalling almost 80,000 words) when compared to Hyland's four-million-word corpus. Stance features were found more in the soft disciplines than the hard disciplines. Various stance devices served many different social functions such as expressing personal feelings about research experiences, contributions made by different thanked addressees, etc.

$\mathrm{Hu}$ and Cao (2015) examined interpersonal metadiscourse in the post-method sections of quantitative and qualitative RAs in applied linguistics, education, and psychology. This study suggested that RAs in applied linguistics and education used boosters more often than RAs in psychology. Furthermore, RAs in applied linguistics used more reader references but fewer self-mentions than RAs in psychology. Cross-paradigmatic comparisons revealed that quantitative RAs made more frequent use of hedges, boosters, attitude markers, engagement markers (reader references and directives such as see and refer to) than qualitative RAs. Reader references in this study were most frequently realized by inclusive we, followed by the indefinite pronoun one, the inclusive determiner our, the pronoun you, and the referent reader. Similarly, Blagojevic (2004) found that writers in psychology had fewer expressions of their attitudes and rarely made direct commentaries on the propositional content either by asking a question or addressing the reader directly, when compared to writers in philosophy and sociology.

Dahl (2004) analyzed Norwegian, French, and English RAs in economics, linguistics, and medicine. Less metatext was found in medicine articles in all three languages. This suggested 
a possibility that writers in medicine had a more fixed pattern of text structure which members in the discipline were very familiar with and thus metatext devices were less necessary when compared to the texts in economics and linguistics.

Bruce (2009) examined results sections of RAs in sociology and organic chemistry. A substantial difference between the two disciplines was the extensive use of hedging markers in RAs in sociology but very limited use in RAs in chemistry. Then Bruce (2010) compared essays between sociology and English taken from the British Academic Written English (BAWE) Corpus and found more metadiscourse (especially endophoric markers and frame markers) in the sociology essays. Frame markers such as I will now focus on ... and [new topic] shall now be discussed are used to signal major rhetorical shifts in the body section of sociology essays. The English essays made greater use of evidentials (direct quotes from commentators or salient sources).

From these studies, it is quite evident that writers in the hard disciplines like medicine (Dahl, 2004) and chemistry (Bruce, 2009) are less likely to use both textual and interpersonal metadiscourse when compared to the writers in the soft disciplines possibly because of a more fixed pattern of text structure and less interpretative nature of research in the hard disciplines. Apart from language backgrounds and disciplines, previous studies pointed out writers' writing proficiency (Hyland, 2004) and research paradigms (Hu \& Cao, 2015) as influential factors affecting choices of rhetorical strategies and writing styles. However, no further analysis of the factors was undertaken.

Among the studies that have examined metadiscourse across disciplines, Li and Wharton (2012) conducted a cross-contextual and cross-disciplinary study to examine metadiscourse used by Chinese students in China and the United Kingdom in the disciplines of literary criticism and translation studies. However, this study was conducted with essays rather than postgraduate writing. The findings suggested that Chinese students in the United Kingdom used metadiscourse more often than Chinese students in China. Chinese students in both contexts and both disciplines used more textual metadiscourse than interpersonal metadiscourse. A distinction of Chinese students in the two contexts was the use of selfmentions, hedges, and boosters. This study suggested that patterns of metadiscourse use were associated with both disciplinary and contextual factors, and contextual factors (local institutional culture) seemed to have a more considerable influence on Chinese students' use of metadiscourse than disciplinary factors. 
Some studies have explored rhetorical patterns used in a specific discipline, e.g., engineering (Koutsantoni, 2006), physics (Parkinson, 2011), accounting (Alyousef, 2015), and applied linguistics (Kawase, 2015). Looking at the disciplines that were examined in previous studies, there is a paucity of research on rhetorical patterns in business administration. In Koutsantoni's (2006) genre-based study, rhetorical strategies (personal and impersonal expression of hedges) in engineering theses and RAs were compared, following Hyland's (1998a, 1998c) hedging classification. The results indicated that thesis authors hedged more often than RA authors. Thesis authors preferred impersonal attribution (attributing all claims to data) as a crucial means for hedging and distancing themselves from their claims, whereas RA authors tended to use personal attribution through collective pronouns we and our being referred to their team of researchers/ authors. This study argued that the possibility of differences in the frequency and types of hedging was not only due to genre requirements but also the power asymmetries between thesis authors and disciplinary gatekeepers (examiners).

Parkinson's (2011) work focused on the lexico-grammar for expressions of causal, conditional, and purposive meanings and proof in the discussion section of RAs and undergraduate laboratory reports in physics. This study revealed student writers' greater reliance on the use of conjunctions to express causal, conditional and purposive meanings, whereas RA writers relied more on adverbial phrases, nouns, and verbs. Because was the most frequent marker of expressing causal meaning in students' laboratory reports, with other frequent conjunctions such as therefore and since. For the expression of proof, student writers tended to make strong claims of proof rather than weaker claims through strong verbs such as show, prove, confirm, demonstrate, and reveal, which refer to a result already published and accepted as fact by the research community in the literature.

Alyousef (2015) analyzed management reports of university students in accounting. This study showed a higher frequency of textual markers than interpersonal markers. In the textual category, transition markers (on the other hand, however) obtained the highest use, followed by code glosses (the punctuation mark colon, the abbreviation i.e.) and frame markers (first, second, third, fourth, finally). In the interpersonal category, hedges (assume) and engagement markers (we) obtained the highest use.

Kawase (2015) compared metadiscourse in introduction sections of $\mathrm{PhD}$ theses and subsequently published RAs written by Japanese student writers in applied linguistics at Australian universities. This study found more occurrences of metadiscourse in RA 
introductions than in thesis introductions. When thesis writers wrote RAs, they made more frequent use of evidentials, code glosses, and hedges but less frequent use of endophoric markers and authorial presence. Code glosses were more frequently used in RA introductions to describe and clarify methodological information from the beginning. Endophoric markers were more frequently used in $\mathrm{PhD}$ theses to present chapter previews and summaries of the chapters. The differences between theses and RAs were explained in relation to genre-related factors, viewing $\mathrm{PhD}$ theses as an educational genre and $\mathrm{RAs}$ as a professional genre with higher competition to get their manuscripts published.

In sum, some trends can be elicited from the above disciplinary studies: (1) the majority of research has paid attention to a comparison between soft and hard knowledge disciplines; (2) the key finding was more frequent use of interpersonal metadiscourse (e.g., hedges, boosters, attitude markers) in RAs and postgraduate writing in the soft disciplines than the hard disciplines; (3) RAs have been a major research focus in disciplinary studies, but research on postgraduate texts (especially in English language teaching and business administration) is rare; and (4) few studies have explored the distribution of high and low frequency types of markers and their prominent functions in particular sections of theses. Given that there might be some subtle variation within either soft disciplines or hard disciplines, a close examination of variation within soft or hard disciplines is likely to yield in-depth findings for members in the examined disciplines in terms of disciplinary-specific rhetorical patterns. Thus, this study focused on two disciplines in the soft knowledge branch (English language teaching and business administration in humanities and social sciences). Although the two disciplines have been part of the comparison between soft and hard disciplines in the previous studies (e.g., Chan, 2015; Hyland, 2004), information of thesis writing conventions and rhetorical practices in the disciplines has been broadly and inadequately documented since the emphasis of those studies was on the broad disciplinary "soft and hard" grouping.

\subsection{Study 2: Metadiscourse frequency and thesis quality}

Study 2 aims to investigate the relationship between the use of metadiscourse and overall quality of postgraduate writing. The following section reviews topics relevant to academic writing assessment (i.e., types of rating, rating scale development, and variables in writing assessment) as well as related studies of metadiscourse and academic writing quality. 


\subsubsection{Types of rating}

Traditionally, according to Knoch (2009), a norm-referenced method was used to evaluate students' performance by comparing the performance with that of others. More recently, a criterion-referenced method is more likely to be used in assessing students' writing ability based on specific external criteria like vocabulary, grammar or coherence. Knoch suggests four forms of criterion-referenced assessment (i.e., holistic, analytic, primary trait, and multipletrait scoring) as follows:

\section{(i) Holistic scoring}

Holistic scoring requires raters to read each writing assignment quickly, evaluate the writing as a whole based on their general impression and assign a single, integrated score. This method aims to determine whether the writing performance is good or poor. Based on a holistic impression, raters will not focus on one aspect of writing (e.g., grammatical accuracy) and not specify areas of weaknesses and strengths. Although this kind of scoring can save a lot time and cost, on the negative side, it is likely to produce unfair results and a loss of reliability and validity especially when rating a large number of assignments (Knoch, 2009).

\section{(ii) Analytic scoring}

The analytical scoring procedure makes use of separate scales and descriptors. Each scale is weighted and prescribed to assess a different writing trait. For instance, a rating scale includes five aspects of writing: content, organization, vocabulary, language use, and mechanics. Often, scores for each aspect are either averaged or summed, and the final score is used to determine the overall writing quality. A rating scale with multiple criteria contributes to higher reliability and standardization (Weigle, 2002; Weir, 1990), but it is definitely more time consuming and expensive. One example of internationally accepted tests using the analytical rating procedure is the International English Language Testing System (IELTS) (Uysal, 2010).

\section{(iii) Primary trait scoring}

Primary trait scoring uses predetermined criteria for writing on a particular topic. The criteria must be sharp and narrow depending on the context, so that the rating scale can fit the specific writing task (Cohen, 1994; Fulcher, 2003). As this method focuses on one primary aspect of writing, the criteria designed for this aspect may not be applicable to assessing other writing 
tasks on different topics. Because it is time consuming to develop this kind of rating scale for each task, primary trait scoring has not been readily adopted (Knoch, 2009, p. 41).

\section{(iv) Multi-trait scoring}

Multi-trait scoring is the final type of rating scale. Both primary and multi-trait scoring methods are more task-specific, but multi-trait scoring allows for attention to several aspects of writing and can provide a lot of diagnostic information. Rating rubrics must be developed according to the requirements of the given task. However, to develop valid scales for one particular task is very time consuming. It is also difficult to ensure that raters will apply the multi-trait scoring procedure instead of their traditional way of rating.

As Knoch $(2009,2011)$ suggests, primary and multiple trait scoring are specific to a particular writing task and designing a new scale for each writing task is not practical. Holistic and analytic rating systems then seem to be better suited for this study. Although the focus of this study is to investigate the overall quality of theses and the density of metadiscourse, analytic rating is still needed for reliability in assessment and pedagogical information. By doing this, key elements that supervisor raters in each discipline take into account when reading a thesis and quality aspects that are associated with metadiscourse frequencies can be investigated.

\subsubsection{Rating scale development}

Rating scales or rating rubrics can be developed based on intuition, empirical, and theoretical methods (Knoch, 2009). First, "an intuitive rating scale" can be developed or refined by an expert or a group of experts (e.g., experienced teachers) based on already existing scales, raters' feedback, a syllabus or a needs analysis. In "empirically-based scale" development, rating rubrics and descriptors are created through observation of learner behavior and a corpus of scale descriptors. And third, a "theory-based rating scale" is constructed commonly based on one of four theory-based models: (1) Four Skills Model laying the ground that each of the four language skills consists of phonology/ orthography, lexicon and grammar; (2) Communicative Competence Model assessing grammatical, discourse, sociolinguistic and strategic competencies; (3) Model of Writing Theories adopting a scholar's writing theory as a main basis, e.g., using Grabe and Kaplan's (1996) model of text construction which includes criteria such as syntactic structures, cohesion signaling, lexical forms, etc.; and (4) Model of DecisionMaking by Expert Judges devising criteria based on the rater's focused features and actual rating process. 
With regard to the possibility and validity of assessment on communicative competence of professionals in different fields, Jacoby and McNamara (1999) and Knoch and Macqueen (2016) discuss the issue by referring to two kinds of performance-based tests. Weak performance tests are tests in which criteria are designed to focus on field-specific language use, but assessors of the tests are language experts who use linguistic criteria. Strong performance tests include criteria based on real-world tasks, and language-based criteria are not included or focused. However, the scholars suggest that, in assessment for several professions, test developers and assessors consider the two kinds of tests as a continuum, not a dichotomy. This means that criteria such as content can range from very general to very (field) specific (Knoch \& Macqueen, 2016). Also, criteria should be indigenous, a mixture of linguistic criteria and professionally relevant. In developing indigneous criteria, both linguists and field insiders (e.g., members of the field to be assessed) should be engaged in order to reflect what is valued by professionals in the field rather than focusing on linguistic criteria only.

Since there has been no study assessing quality of theses in terms of language use, rating scales and criteria for thesis writing assessment have never been constructed. As Knoch (2009) indicates, the fact that "rating scales for writing are usually based on what scale developers 'think' represents the construct of writing proficiency" (p. 42) leads me to implement the expert decision-making method (interviewing experts) and intuition-based method to create a generic rating scale for thesis quality assessment in this study. It should be noted here that published theses have been quality-assured, so criteria like grammatical accuracy and text length for existing tests may not be useful to the assessment in this study. In addition, as this study involves assessment on quality of theses in two different disciplines, as suggested in the literature above, rating criteria will be developed to cover both linguistic and professionally relevant criteria (Jacoby \& McNamara, 1999; Knoch \& Macqueen, 2016). It is therefore worth adopting the expectations of thesis examiners as criteria for assessment. However, it is important to note that the rating criteria will be generic rather than very specific to language or business disciplines, so that non-linguists can use the criteria to assess overall quality of thesis writing in their own disciplines.

\subsubsection{Variables in writing assessment}

Besides scoring rubrics, the issue which should be taken into consideration in writing assessment is the suitability of the number of bands and raters. As Weigle (2002) points out, 
the number of points or scoring levels depends on the use or the purpose of the test. If the test is used primarily to make pass and fail decisions, fewer points may be needed. If the test is used to place students in different courses, more score points will be needed. Many large-scale assessment programs such as Test of English as a Foreign Language (TOEFL) and Michigan Writing Assessment use a six-point scale and others like IELTS may use a nine-point scale in order to determine the range of performances that can be reasonably expected of the population of test takers. Research has shown that raters can only differentiate between seven (plus or minus two) levels to make reasonable distinctions. So scales ranging from five to nine points can maintain the highest reliability in assessment (Myford, 2002, cited in Knoch, 2009, p. 57).

Concerning rater selection, Weigle (2002) points out five variables about raters that should be considered: raters' attributes, disciplines, cultural backgrounds, assessment training, and expectations. First, attributes of raters (composition teaching and rating experience) may greatly affect their rating. Second, as Knoch and Macqueen (2016) suggest, raters from different disciplines have different background experience and are likely to give value to different quality aspects and apply different criteria in assigning scores to compositions. Third, raters who are familiar with common L1 rhetorical patterns tend to be more accepting of L2 compositions with those patterns than other raters. Fourth, training is a significant variable in regard to rater reliability. In order to get raters accustomed to working with designed criteria, a training or orientation session should be organized. The last factor is raters' expectations. For example, raters tend to score handwritten essays higher than word-processed essays because their expectations of formatting, grammatical and spelling accuracy are higher in wordprocessed essays and errors are more noticeable and glaring in these essays (Weigle, 2002).

The design and use of the rating scale in this study are discussed at length in Chapter 3. However, I note here that guided by the above findings, I used a five-point scale for each rating criterion. More scoring levels could cause more difficulty to raters in distinguishing each level of traits and make the task too demanding. Fewer score points will facilitate raters' ability to determine the quality level of each trait more easily and reliably. The purpose of assessment in this study was to measure the overall quality of theses and divide them into high and low score groups, so fewer score points were more suitable for this study.

All rater variables mentioned above were controlled. Only expert raters with similar attributes were recruited. Theses in each discipline were rated by experts in both L1 and L2 contexts and in their own disciplines. In the pilot study, there was an orientation session for raters to get 
familiar with the rating scales and to trial rating to ensure that all raters proceeded with the same rating procedure. All the rating criteria used in this study were based on experienced supervisors and examiners' expectations of thesis writing in their disciplines.

\subsection{Review of related studies on metadiscourse and quality of writing}

This section reviews prominent studies on the relationship between the use of metadiscourse and academic writing quality.

Using Vande Kopple's (1985) system, Intaraprawat and Steffensen (1995) compared the density and types of metadiscourse in 6 good and 6 poor essays of ESL students at a large Midwestern university. Noble (2010) examined 80 argumentative essays written by ESL students at an Australian university. However, only 10 high and 10 low scoring essays were used to compare types in depth, and only 2 essays were used to observe how metadiscourse operated in the context. In these studies, the high scoring essays had a higher frequency and a greater variety of metadiscourse features within each subcategory than the low scoring essays. Connectives were the most frequent subcategory in both sets of essays. Good essays had a higher percentage of interpersonal features, while the poorer ones had a higher percentage of textual features (Intaraprawat \& Steffensen, 1995) and tended to rely more heavily on markers common in spoken English (Noble, 2010).

Mohamed and Rashid (2017) explored metadiscourse features in 269 high scoring essays written by Malaysian ESL undergraduates. In this study, good essays showed the highest frequency of transition markers and the lowest frequency of endophoric markers and evidentials.

Sanford (2012), using Hyland's (2005) framework, observed a correlation between the frequency of metadiscourse markers in essays written by 69 adolescent students and the standard score of Subtest 8, Story Construction of the Test of Written Language-Third Edition (TOWL-3). The Pearson's correlation coefficient test indicated a linear positive relationship between the frequency of metadiscourse markers and writing quality scores.

Unlike the above studies, Cheng and Steffensen (1996) conducted an experimental study with 46 native English speaking students in their first-year at a large Midwestern university, equally divided into the Control Class (CC) and the Experimental Class (EC). This study indicated that explicit instruction in metadiscourse resulted in higher scores in the EC. Students in the EC used metadiscourse more effectively and received better grades than students in the CC. The 
in-depth analysis focused on the use of metadiscourse in two papers from the CC and two papers from the EC. Considerable differences between the two groups were that (1) the two EC writers used more textual metadiscourse than the CC writers, while the latter used more interpersonal metadiscourse than the former; (2) the EC writers used certainty markers more than hedging markers, while the $\mathrm{CC}$ writers used more hedging markers; and (3) the EC writers used significantly more attributors than the $\mathrm{CC}$ writers. The findings suggested that the higher use of certainty markers in the EC papers (higher scoring group) was supported by their frequent references to authorities to increase the force of their argument.

Another experimental study of metadiscourse was conducted by Chang (2014). This study investigated the teaching of metadiscourse to 60 Chinese students at Qilu University of Technolgy and found that the explicit instruction in metadiscourse contributed to better writing scores of the EC group. This study indicated that after instruction, students were able to recognize different kinds of metadiscourse markers, interpret the functions performed by them, and use metadiscourse in a more appropriate way. However, it is important to note that this study revealed no significant correlation between the writing quality and the frequency of textual metadiscourse, given that students used colloquial textual connectives redundantly. By contrast, the significant correlation between the writing quality and the frequency of interpersonal metadiscourse suggested that appropriate use of interpersonal metadiscourse in argumentative essays could improve the writing quality to some extent.

This section has shown that studies examining the relationship between the use of metadiscourse and academic writing quality are not only limited in number, but those focusing on the impact of metadiscourse on thesis writing are even rarer. Assumptions gained from prior work are that metadiscourse frequency is likely to be positively correlated with academic quality scores and that explicit instruction in metadiscourse is likely to improve students' ability in using metadiscourse in a more appropriate way. The present study therefore aims to examine the correlation between quality scores and use of metadiscourse in thesis writing.

\subsection{Chapter summary}

The first part of this chapter has provided better understanding of the theoretical concepts of metadiscourse, including key principles for metadiscourse identification and methodological frameworks that underlie this study. A key contribution after reviewing a contrastive approach for metadiscourse studies is providing a further way to reflect different academic writing styles based on different degrees of writer and reader responsibility for establishing interactions in 
the texts besides their responsibility for organizing texts (Section 2.2). Based on the interest of this study in delineating both textual and interpersonal features in master's theses, Hyland's (2005) broad approach was adopted to classify metadiscourse in this study. The review of previous metadiscourse studies has not only indicated the insufficiency of metadiscourse research in New Zealand and Thai contexts and the in-depth investigation of certain disciplines within either soft or hard disciplines but has also shown some trends in the use of metadiscourse by academic writers in other contexts and disciplines, which the present study can draw on. The second part of this chapter has reviewed studies of academic writing assessment and laid out practical frameworks for rating scale development (e.g., rating types, scoring level, and potential rating criteria). Drawing upon the literature review in this chapter, the next chapter will discuss the methodological approaches used in Study 1 and Study 2 in detail. 


\section{CHAPTER 3 \\ RESEARCH METHODOLOGY}

This chapter concerns the methodology used in Study 1 regarding frequencies and functions of metadiscourse. It also describes the methodology used in Study 2 investigating the relationship between the use of metadiscourse and quality of thesis writing. Section 3.1 presents an overview of the research design of the whole study. Section 3.2 describes the procedures used to collect master's theses in New Zealand and Thailand and the methods for metadiscourse analysis, including the discussion of difficulty and subjectivity issues in identifying ambiguous markers. Section 3.3 describes the procedures used to conduct supervisor interviews, develop a thesis rating scale, assess quality of theses, and analyze the relationship between metadiscourse frequencies and quality scores.

\subsection{Research design}

This research was divided into two studies. Study 1 aimed to answer the first three research questions, and Study 2 corresponded to the fourth research question below:

(1) To what extent do New Zealand and Thai postgraduates use metadiscourse markers in their master's theses?

(2) What are the similarities and differences in frequencies, types, and functions of metadiscourse markers across the New Zealand and Thai corpora?

(3) What are the similarities and differences in frequencies, types, and functions of metadiscourse markers across the English language teaching and business administration corpora?

(4) How does metadiscourse affect the quality of postgraduate writing? What kinds of metadiscourse have the biggest impact?

In Study 1, I compiled four small subcorpora of thesis discussion and conclusion chapters written by New Zealand and Thai students in the disciplines of English language teaching and business administration. Then I examined frequencies, types, and functions of metadiscourse markers across the four subcorpora. In Study 2, I conducted semi-structured interviews with New Zealand and Thai supervisors in the two disciplines and utilized information from the interviews for two main purposes: firstly to supplement the discussion of metadiscourse findings in Study 1 and secondly to design a thesis rating scale based on supervisors' 
expectations. After designing rating scale, I asked experienced raters to rate the quality of selected thesis discussion and conclusion chapters and then compared quality scores with frequencies of metadiscourse markers. The following sections explain the methodology for the two studies in detail.

\subsection{Methodology for Study 1}

In order to make a comparison between metadiscourse in master's theses in New Zealand and Thai contexts and between English language teaching and business administration disciplines, four small subcorpora with a total of 116 samples were built up for the present study: $26 \mathrm{New}$ Zealand students' theses in English language teaching (NZ-ELT), 30 New Zealand students' theses in business administration (NZ-BA), 30 Thai students' theses in English language teaching (TH-ELT), and 30 Thai students' theses in business administration (TH-BA). It should be noted that the initial aim was to construct the subcorpora of the same size (i.e., 30 theses in every corpus), but the number of New Zealand students' theses in English language teaching which complied with the selection criteria was not sufficient (see Section 3.2.2, New Zealand thesis compilation). However, despite having fewer theses, this corpus yielded the largest number of words and was eligible for a comparison in the present study. The data selection and collection procedures are presented in three stages: thesis selection, New Zealand thesis collection, and Thai thesis collection.

\subsubsection{Thesis selection}

The discussion and conclusion chapters in master's theses were selected for metadiscourse analysis as in these chapters the writer summarizes the whole thesis, integrates the writer's interpretation of findings and discusses them in relation to the reviewed literature in order to establish new claims with professional credentials. In these chapters, the writer must persuade readers, especially supervisors and examiners, to view the validity of new claims from the writer's perspective by comparing their findings with previous literature and offering potential explanations for findings (Bunton, 2005; Thompson, 2013). Metadiscourse is particularly important in these chapters in the sense that it fosters the persuasive function and the links made to previous chapters.

A thesis in this study is referred to as research writing work of more than 10,000 words submitted in partial fulfillment of the requirements for the master's degree. To compile the four subcorpora, purposive selection of theses was as follows: 
(1) theses written in English;

(2) theses submitted between 2000 and 2017;

(3) theses including both discussion and conclusion sections;

(4) theses written by New Zealand postgraduates (L1) in New Zealand in English language teaching and business administration;

(5) theses written by Thai postgraduates (L2) in Thailand in English language teaching and business administration.

As different universities offer similar programs with different names, the English language teaching discipline may be under other names such as applied linguistics, sociolinguistics, Teaching English to Speakers of Other Languages (TESOL), Teaching English as an International Language (TEIL), and so forth. Business administration theses may be selected from business management and business studies programs.

\subsubsection{New Zealand thesis compilation}

In this study, New Zealand theses refer to theses written by native English speaking students in the New Zealand educational context. However, as there is a wide variety of English, this study included only theses written by New Zealanders and Australians studying in New Zealand in order to control variables of language background and cultural diversity which might affect writing conventions and use of metadiscourse within the New Zealand corpus itself.

Collecting New Zealand students' theses took a series of steps. I firstly explored many New Zealand university websites and made a list of universities offering master's programs in both English language teaching and business administration disciplines. Importantly, these universities must be able to provide digital copies of theses. At first, I intended to collect data from two universities on the list. However, I later found that despite a large collection of theses available online, not many of them were written by New Zealand students. In this case, an expansion from two universities to six universities was necessary.

Finally, 56 New Zealand theses (26 in English language teaching and 30 in business administration) were collected from six universities in New Zealand (Victoria University of Wellington, Auckland University of Technology, University of Otago, Massey University, University of Waikato, and University of Canterbury). Thanks to these universities allowing open access to their digital repositories for research outputs, I could do an online search for 
prospective theses by using keywords like master's thesis + business administration (see Figure 3.1). After I had compiled a large collection of theses, I checked authors' first language backgrounds and searched for their current contact details on search engines like Google and other online academic hubs like ResearchGate and LinkedIn. According to copyright guidelines provided by university librarians, thesis authors in New Zealand hold the copyright to their own work. Even though the theses are open-access, it is possible that some thesis authors might not appreciate use of their theses without permission. As a courtesy I contacted each individual author and requested permission to use their theses. The outcome of this process was that only theses for which consent had been given by the authors were included in this study. After the authors' profiles were confirmed by means of the direct contact, a total of 56 New Zealand theses was contributed from 53 New Zealanders and 3 Australians. According to a signed agreement with authors not to reveal their identities, theses in this group do not appear in the reference list.

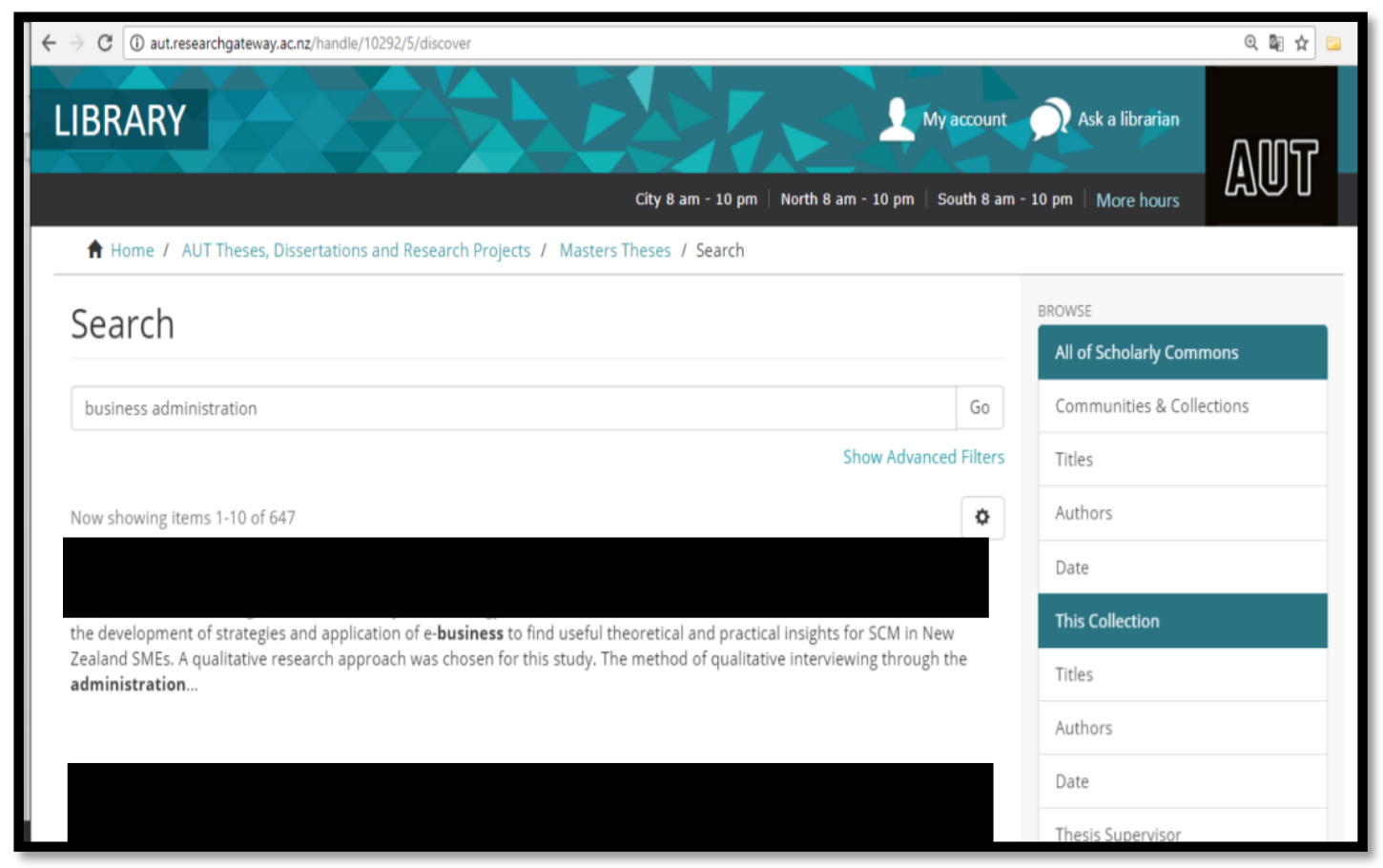

Figure 3.1. Auckland University of Technology digital repository

Regarding some constraints in collecting New Zealand students' theses, two issues arose when the data collection process began. The first difficulty occurred when I tried to preliminarily check authors' profiles and find their current contact details. Some of them did not use any social media and their profiles were unavailable on the Internet. This means that even though I could find a lot of theses in the repositories, I could not use any until I was able to contact the 
authors and obtain their consent. Second, from the step of checking identities of authors, the result of contacting each author appeared to be that some of them, even with English names, did not speak English as their first language and were not originally from New Zealand or Australia. This suggested that using names as an indicator to determine authors' ethnicity and language backgrounds was not effective enough in this comparative study. As a result of these constraints, I needed to exclude theses for which authors were not able to be contacted for consent and identity confirmation and were not New Zealanders or Australians. In an attempt to achieve the desired number of theses written by New Zealand students, I increased the New Zealand universities from two to six universities as indicated above. Nonetheless, the number of New Zealand theses in English language teaching included in this study was 26, although contributing the highest number of words compared to those in other subcorpora.

\subsubsection{Thai thesis compilation}

Sixty Thai students' theses were obtained from two universities in Thailand (Thammasat University and Prince of Songkla University). Before arriving at these two universities, I surveyed postgraduate programs offered by the top ten universities in Thailand. I found that at some universities which offer postgraduate programs in English language teaching and business administration, their theses are written in Thai and there is closed access to the theses (only available to their staff and students). The two selected universities have shared features in that they are research-led national universities and offer international postgraduate programs in English language teaching and business administration, so theses from these Thai universities were written in English and could be collected through their online databases. However, as the Thai theses are under the copyright of the universities, I contacted each university and requested written consent from them before utilizing their theses. Similar to the searching procedure for New Zealand theses, I logged into the Thai universities' online libraries and used keywords to search for theses in each discipline. 


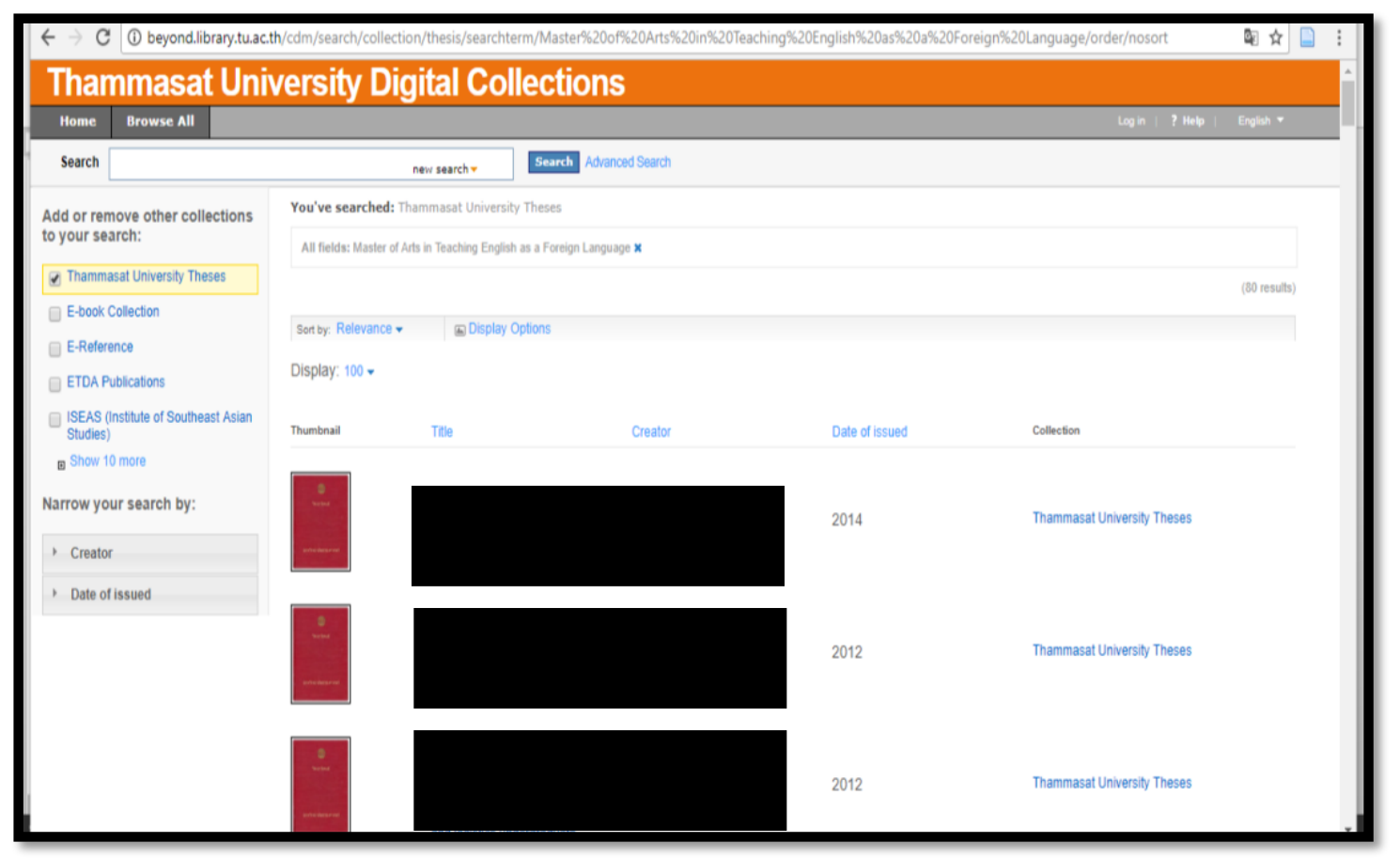

Figure 3.2. Thammasat University digital repository

\subsubsection{Corpus description}

As presented in Table 3.1, the whole corpus contained 116 discussion and conclusion chapters with a total of 599,599 words and an average length of 5,169 words.

Table 3.1. Corpus characteristics

\begin{tabular}{lccccc}
\hline Context & \multicolumn{2}{c}{ NEW ZEALAND } & \multicolumn{2}{c}{ THAI } & Total \\
\cline { 1 - 2 } Discipline & NZ-ELT & NZ-BA & TH-ELT & TH-BA & \\
\hline $\begin{array}{l}\text { Number of theses } \\
\text { Total number of words }\end{array}$ & 26 & 30 & 30 & 30 & 116 \\
$\begin{array}{l}\text { Average length of selected } \\
\text { chapters }\end{array}$ & 201,099 & 144,178 & 125,631 & 128,691 & 599,599 \\
\hline
\end{tabular}

To gain an understanding of how New Zealand and Thai master's students in the two disciplines organize their theses, I analyzed the overall structure of the theses in my study by drawing upon Swales' (1990) Introduction-Method-Results-Discussion (IMRD) macrostructure of research genre. The finding reveals that theses in the four subcorpora are organized following the traditional IMRD pattern, but all of them also have a separate chapter of literature review. However, headings of chapters might be titled differently according to the writers' intentions and institutional conventions. 
Focusing on the structure of discussion and conclusion chapters, the theses share three different formats of discussion and conclusion chapters. As seen in Table 3.2, most theses (70 out of 116 theses) in the four subcorpora combine discussion and conclusion chapters, and 33 theses separate the two chapters. The third format (13 theses) has a separate discussion section in the result chapter. I excluded the result reporting part and counted only the separate discussion section.

Table 3.2. Formats of discussion and conclusion chapters

\begin{tabular}{|c|c|c|c|c|c|}
\hline Format & NZ-ELT & NZ-BA & TH-ELT & TH-BA & Total \\
\hline $\begin{array}{l}\text { (1) Separating discussion and } \\
\text { conclusion chapters }\end{array}$ & 13 & 20 & 0 & 0 & 33 \\
\hline $\begin{array}{l}\text { (2) Combining discussion and } \\
\text { conclusion chapters }\end{array}$ & 13 & 10 & 17 & 30 & 70 \\
\hline $\begin{array}{l}\text { (3) Including the discussion section } \\
\text { in the result chapter }\end{array}$ & 0 & 0 & 13 & 0 & 13 \\
\hline
\end{tabular}

After collecting Thai theses in business administration, it was found that not all the theses are research-oriented; some are business case study-oriented. However, this study included only research-oriented theses because the two types of theses vary in terms of length, communicative purposes, and structural organization, and there is a possibility that these variations will skew the results. Business case study theses aim to report and suggest a business plan for a particular case or company, whereas empirical research theses usually discuss results by refering to literature in several contexts and considering wider implications.

After collecting data and analyzing the overall structure of thesis chapters, Moreno's (2008) criteria of corpus comparability were used as a checklist to guarantee that the four small subcorpora in this study were equivalent to the maximum degree of similarity and therefore comparable. Table 3.3 shows similar qualities of corpora possible for a comparison. All the theses in the current study were research-oriented and written in English by master's students. They shared the same group of readers in general (i.e., supervisors, examiners, other scholars). However, theses in each discipline had their own specific readers. For instance, theses in English language teaching included implications for language teachers and students while theses in business administration included implications for companies, policy makers, etc. Textual units for analysis were only the discussion and conclusion chapters where students needed to interpret and critically discuss their findings and provide the readers with a brief summary of research. 
Table 3.3. Corpus comparability

\begin{tabular}{|c|c|}
\hline Criteria of corpus comparability & $\begin{array}{l}\text { Prototypical features across four subcorpora of } \\
\text { the current study }\end{array}$ \\
\hline Text form & Research-oriented exposition \\
\hline Genre & Theses \\
\hline Mode & Written language \\
\hline Participant/ level of expertise & $\begin{array}{l}\text { Writers: master's students } \\
\text { Targeted readers: supervisors, examiners, researchers, } \\
\text { teachers, etc. }\end{array}$ \\
\hline Format features & $\begin{array}{l}\text { Average length: } 3,000-7,000 \text { words } \\
\text { excluding graphs, tables, and footnotes }\end{array}$ \\
\hline Global communication event & $\begin{array}{l}\text {-Interpreting and discussing key research findings } \\
\text {-Summarizing the whole research }\end{array}$ \\
\hline Setting & A library, home, university, etc. \\
\hline General purpose of communication & $\begin{array}{l}\text {-To present underlying meanings of key findings and engage } \\
\text { readers in evaluating what have been found } \\
\text {-To succinctly restate what has been done and found in } \\
\text { research and highlight significant messages for readers }\end{array}$ \\
\hline $\begin{array}{l}\text { Overall subject-matter or topic or } \\
\text { discipline }\end{array}$ & English language teaching and business administration \\
\hline Textual unit of analysis & Discussion and conclusion chapters \\
\hline Global superstructure & Discussion of key findings - research summary \\
\hline
\end{tabular}

\subsubsection{Identification of metadiscourse markers}

Both quantitative and qualitative analyses were performed in Study 1. The quantitative analysis provided results with regard to frequencies of metadiscourse overall and its subcategories. The qualitative analysis was concerned with prominent types and functions of textual and interpersonal markers in the four subcorpora.

Taking a top-down approach, a marker list in this study was developed based on three sources. I used Hyland's (2005) list of metadiscourse markers as a starting point for creating a preidentified marker list and data coding. By using the pre-identified marker list, the process of recognizing potential items of particular subcategories is more facilitative for a coder dealing 
with a large number of items in lengthy texts. According to Hyland's list, there are ten functional subcategories of metadiscourse with a wide range of markers in each subcategory.

However, I also expanded Hyland's list by finding potential markers from my own data as well as from The Academic Word List (AWL) (https://www.victoria.ac.nz/lals/resources/ academicwordlist/most-frequent) (Coxhead, 2000). To do so, I used the tool "WordList" in WordSmith (version 7.0) to create a list of common words extracted from the theses in my corpus. The outcome of this process was that the program generated a list of more than 10,000 common words used in my corpus and from this list I found some potential markers which are not present on Hyland's list especially in the subcategories of evidentials (e.g., $X$ claim, $X$ assert, following $X$ ), hedges (e.g., incline, imply, basically), and attitude markers (e.g., valuable, unique, ideally). To cover as many markers as possible before the actual search, I also looked for other items in the AWL and double checked whether they were used in my data as metadiscourse markers. I chose the AWL because it is claimed that all academic words of the AWL are from academic texts at tertiary level (e.g., book chapters, journal articles, lab notes) across a wide range of disciplines (e.g., arts, commerce). The level of texts and disciplines are therefore suitable for this study. After all the processes, I added all potential markers found in the AWL and in my corpus to the initial pre-identified marker list and used this refined list in the next step. A complete list of pre-identified metadiscourse markers is provided in Appendix 1.

For the frequency retrieval step, a semi-automatic coding procedure was adopted. I used the tool "Concord" in WordSmith to do an automatic search for pre-identified metadiscourse markers in the corpus and took a manual coding step to eliminate irrelevant ones. The tool was used to find instances and generate a concordance for metadiscourse markers found in the corpus. As this program only works with plain text files, all PDF thesis files were converted into .txt files. They were renamed using abbreviations of the subcorpora to indicate original sources of data and numbered from one to thirty. For example, "NZ-BA-01" refers to a New Zealand student's thesis in business administration, and "TH-ELT-15" refers to a Thai student's thesis in English language teaching. I started my search with the first pre-identified marker in the first subcategory "transition markers" and continued until the last marker in the tenth subcategory "self-mentions." When the tool displayed a concordance of markers, I inserted an extra column named "Function" at the right end of window so as to carry out a manual identification of metadiscourse markers in the context, as illustrated in Figure 3.3. 


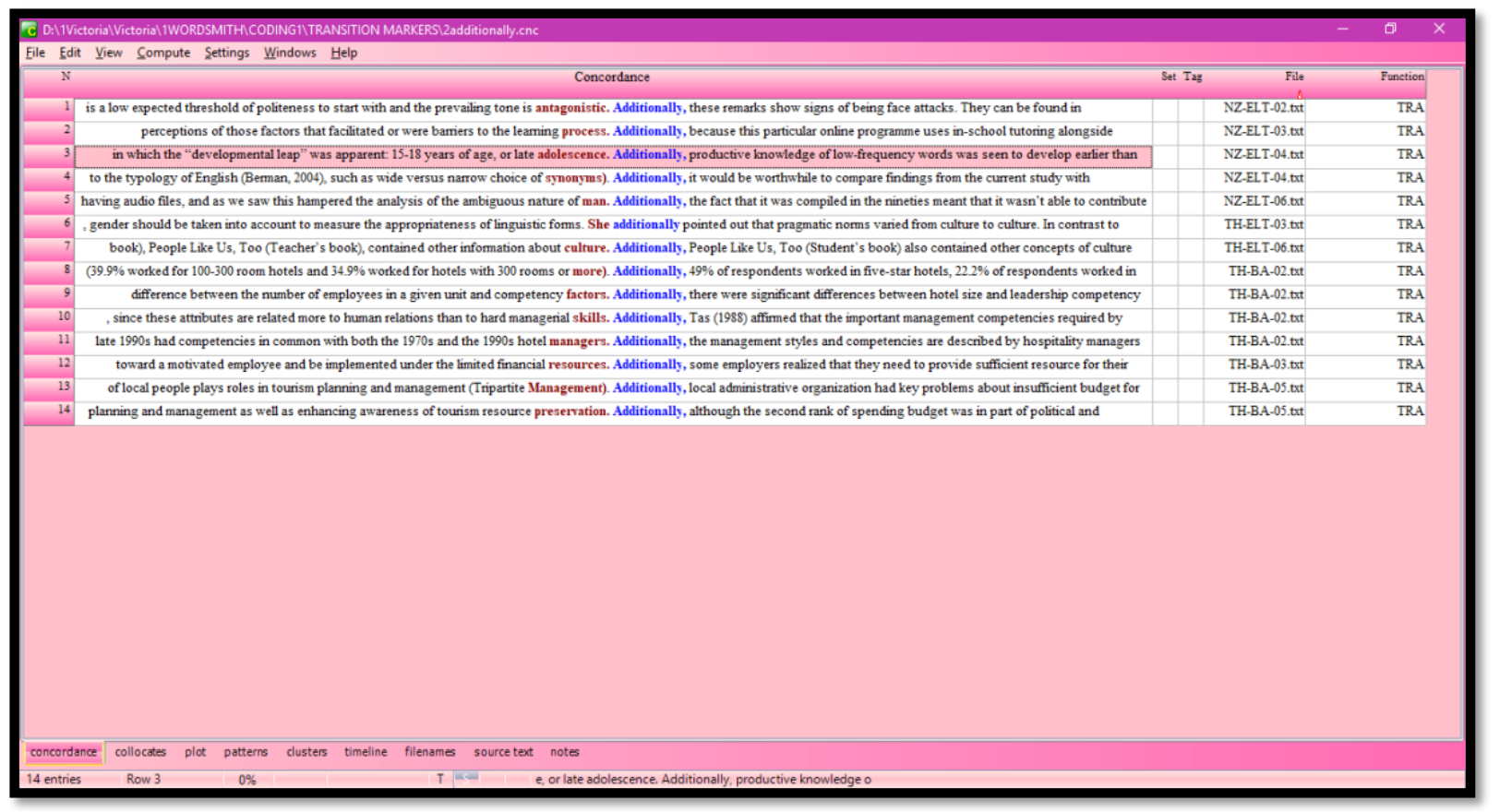

Figure 3.3. WordSmith program features

The examination of metadiscourse in this step needed to be done manually since metadiscourse can perform different functions in different parts of a text. Manual coding is generally the best way to accurately specify functions being performed and classify markers to appropriate subcategories. By doing so in this study, I identified whether the displayed markers were metadiscourse or not and what functions they performed by using the coding scheme in Table 3.4 .

Since metadiscourse is an open category to which new items can be added (Hyland, 2005) and can be put in different categories based on their contextual functions, in the actual process of reading and identifying markers in context, I looked for new markers in addition to the ones pre-identified on the list. For example, I added the markers regarding and concerning to my coding scheme as they function as frame markers and frequently occur in my Thai corpus.

With regard to the reliability and consistency of coding, an ideal methodology is taking an inter-coding method, that is, having at least two coders working separately and comparing consistency of results. However, the feasibility of doing so in this study is limited for the following reasons. First, no potential second coders (my $\mathrm{PhD}$ colleagues) are familiar with metadiscourse concepts. Coding a wide range of individual types of markers yielding a number of hits would be an overwhelming task for them to complete. 
Table 3.4. Metadiscourse coding scheme

\begin{tabular}{|c|c|c|c|}
\hline Category & Code & Function & Example \\
\hline \multicolumn{4}{|l|}{ Textual metadiscourse } \\
\hline 1. Transition markers & TRA & express logical relationships between complete ideas or clauses & $\begin{array}{l}\text { Adverbials: moreover, in contrast, also } \\
\text { Subordinating conjunctions: although, } \\
\text { because, while } \\
\text { Coordinating conjunctions (linking main } \\
\text { clauses, sentences or larger units): and, but, so }\end{array}$ \\
\hline 2. Frame markers & FRA & $\begin{array}{l}\text { indicate introductions and sequences of information; } \\
\text { explicitly refer to text stages; } \\
\text { indicate discourse acts; } \\
\text { mark topic shift }\end{array}$ & $\begin{array}{l}\text { first of all, next, finally } \\
\text { at this point, to conclude, in summary } \\
\text { aim to, focus, purpose } \\
\text { with regard to, concerning, turn to }\end{array}$ \\
\hline 3. Endophoric markers & END & refer to preceding or following information in other parts of the text & in chapter $\mathrm{X}$, table $\mathrm{X}$, in the previous section \\
\hline 4. Evidentials & EVI & indicate an outside source of information & $\begin{array}{l}\text { according to } X \text {, as } X \text { suggested, “...” }(X \text {, } \\
2015)\end{array}$ \\
\hline 5. Code glosses & COD & $\begin{array}{l}\text { elaborate propositional meanings by defining, re-phrasing } \\
\text { words/phrases or providing examples }\end{array}$ & in other words, for example, namely \\
\hline \multicolumn{4}{|l|}{ Interpersonal metadiscourse } \\
\hline 6. Hedges & HED & express the writer's degree of uncertainty and approximation & may, suggest, tend to \\
\hline 7. Boosters & $\mathrm{BOO}$ & $\begin{array}{l}\text { emphasize the writer's degree of certainty and full commitment to a } \\
\text { proposition }\end{array}$ & must, show, certainly \\
\hline 8. Attitude markers & ATT & reveal the writer's attitudes or expectation & important, interestingly, ideally \\
\hline 9. Engagement markers & ENG & $\begin{array}{l}\text { engage the readers into the text by directing to actions, asking } \\
\text { rhetorical questions or inserting personal comments }\end{array}$ & you, see,,$\ldots$ ? \\
\hline 10. Self-mentions & SEM & mark the writer's presence in the text & I, we (inclusive), the researcher \\
\hline *Non-metadiscourse marker & Non-1 & & \\
\hline
\end{tabular}


Second, provision of a coding scheme with examples as well as training could not guarantee that it would be easy for the unfamiliar coder to deal with the non-straightforward task since some metadiscourse items can convey different meanings and overlap in different subcategories. Reading and identifying functions of markers in context not only requires the second coder's time but also his/ her dedication to complete the work. As the identification itself is very time consuming, training people who are unfamiliar with metadiscourse to comprehend metadiscourse concepts and be able to assign a function for each item is not feasible in this study.

Therefore, I undertook four main steps to ensure the intra-coding reliability of this study. First, I divided data and scheduled coding in three rounds. By doing so, the number of markers and occurrences in each round would be more manageable for me to precisely and accurately examine. In the first round, I selected and coded only $20 \%$ of all data or 24 out of 116 theses from the four subcorpora. From this round, I could probe difficulties and ambiguity in coding some types of markers, especially the multi-functional ones like conjunctions and adverbials. Second, I set my own coding scheme and noted reasons why I included and excluded some types of markers. I applied findings from the reviewed literature to set inclusive criteria for the ambiguous markers (see Section 3.2.8). Examples were also elicited from the corpus of this study and used as a guideline for coding in the next rounds.

Third, after the first-round coding had been done, a considerable amount of time in meetings with supervisors was dedicated to in-depth discussion of the overall results and each type of marker in sentential context before making decisions together and refining criteria for the inclusion of ambiguous markers in the next rounds of coding. When I reached agreement with my supervisors, I proceeded with coding $40 \%$ of data in the second round and the other $40 \%$ in the third round by repeating the same process including discussion sessions. Finally, I rechecked the results by selecting five high frequency markers from each of the ten subcategories, recoding them based on the decisions and coding scheme in the previous steps, and comparing the two sets of results. When the difference in coding some types of markers was significant, I recoded those markers and brought them to a discussion with supervisors until agreement was achieved.

\subsubsection{Calculation of metadiscourse marker frequencies}

As pointed out by Gries (2010), a higher frequency occurrence of some element in a corpus 
does not automatically mean that the element is more frequent because the frequencies depend on the sizes of the corpora being compared as well. Hence, to compare frequencies across different corpora of unequal sizes, absolute frequencies of identified metadiscourse markers in each corpus were normalized to occurrences per 10,000 words to facilitate statistical treatment. This study compared frequencies of markers from four data sets, yielding the total number of 599,599 words. The normalization per 10,000 words was selected because it contributed the comparable (i.e., not too small) values for comparison. I tried normalization by using two common bases, per 1,000 words and 10,000 words, to find which base fitted my data better. For instance, in the TH-ELT corpus with the total of 125,631 words, the calculation of 39 selfmention markers per 1,000 words and 10,000 words offered the normalized values of 0.31 and 3.10 , respectively. It seems to be more practical to report the frequencies of more than 1 , for example, approximately 3 tokens of self-mentions per 10,000 words rather than 0.31 token per 1,000 words. The normalizing equation I used is as follows: Normalized frequency $=$ [raw frequency $\div$ number of words in corpus $] \times 10,000$.

\subsubsection{Comparison of metadiscourse frequencies, types, and functions}

Comparisons were undertaken based on the aims and research questions of this study which emphasized both similarities and differences in frequencies, types, and functions of metadiscourse in the theses between the two educational contexts and disciplines.

For macro-level comparisons, the quantitative results were compared to determine the similarities and differences in frequencies of textual and interpersonal metadiscourse in ten subcategories between New Zealand and Thai thesis corpora and between English language teaching and business administration thesis corpora. This study comprised four subcorpora categorized by educational contexts and disciplines, namely NZ-ELT, NZ-BA, TH-ELT and TH-BA. To make a comparison across New Zealand and Thai corpora, I combined NZ-ELT and NZ-BA data sets for the New Zealand corpus and TH-ELT and TH-BA data sets for the Thai corpus. To make a comparison between the two disciplines, I combined NZ-ELT and THELT data sets for the English language teaching corpus and NZ-BA and TH-BA data sets for the business administration corpus.

In addition, micro-level comparisons were performed to investigate variation within each educational context (NZ-ELT vs. NZ-BA, TH-ELT vs. TH-BA) and within each discipline (NZ-ELT vs. TH-ELT, NZ-BA vs. TH-BA). All in all, the comparisons were run from the first 
metadiscourse subcategory to the tenth subcategory. In each subcategory, types of markers were also investigated and compared across thesis subcorpora.

With regard to the statistical test, I employed a log-likelihood test to perform significance testing for both macro- and micro-level comparisons (http://ucrel.lancs.ac.uk/llwizard.html). Although many statistical tests are proposed to deal with the quantitative aspect of corpusbased studies, not all corpus-based studies utilize the available statistical methods to their fullest extent (Gries, 2010, p. 5). From a statistician's perspective, it is likely that significance of comparisons between two independent variables is expected to be measured by a factorial analysis like Analysis of Variance Test (ANOVA). However, before using this kind of test, we have to ensure that our data meet assumptions of homogeneity of variances and normality of data distribution. At this point, corpus-based studies typically concerning frequencies or uneven distributions fail to meet the assumptions and need an alternative significance testing method specifically for corpus data. Log-likelihood was therefore selected for comparisons of corpus data in this study.

Practices in reporting quantitative results vary in metadiscourse research dealing with frequency comparisons ( $\mathrm{Li} \&$ Wharton, 2012). Many prominent studies (e.g., Crismore et al., 1993; Hyland, 1998a, 1998b, 1999, 2004; Li \& Wharton, 2012) took a traditional approach for statistical treatments (i.e., providing only raw and normalized frequencies and percentage to compare patterns of occurrence in corpora). However, Ädel and Erman (2012, p. 85) argue that, departing from the tradition, log-likelihood is useful for contrastive studies because it compares the raw frequency of metadiscourse items between unequal corpora and determines whether a frequency is statistically higher or lower in one corpus compared to in another.

More recent metadiscourse studies (e.g., Ädel \& Erman, 2012; Chan, 2015; Jiang \& Hyland, 2015) added more detailed statistical analysis using log-likelihood values to indicate statistical significance of differences. The presentation of frequency results in this study was consistent with these studies. Raw frequencies, normalized frequencies, and log-likelihood values were reported for describing trends and significance of variation as well as indicating the areas in which variation between subcorpora should be further explored and qualitatively discussed. Using the web-based log-likelihood calculator, the critical value was set at 3.84 or more (95th percentile; $5 \%$ level; $p<.05)$. This value shows that the probability of the findings of this study occurring by chance is less than 5\% (Chan, 2015; Parkinson, 2011). It is important to note that using log-likelihood to support significance of frequency differences between two data sets at 
macro level (e.g., NZ vs. TH) and micro level (e.g., NZ-ELT vs. NZ-BA), this study did not account for subject-to-subject variability.

In addition to observing trends in the use of metadiscourse between contexts and disciplines based on frequencies, a qualitative analysis was performed to examine types and functions of metadiscourse markers in greater detail. As Mauranen (1993, p. 49) suggests, there is an intensity in text analysis because the context of metadiscourse markers must be taken into serious consideration starting from the coding stage to a more qualitative analysis stage. With a wide range of metadiscourse markers identified in this study, I therefore decided to analyze functions of metadiscourse markers by concentrating on the top ten high frequency markers in each subcategory. Confining the analysis to a smaller, more focused, number of identified markers was effective in the sense that it made the analysis manageable in scale and helped demonstrate strategic functions or communicative purposes of metadiscourse in the thesis chapters more obviously. By this means, patterns of use across thesis corpora were also able to be analyzed. It should be noted that error analysis is beyond the scope of this study.

\subsubsection{Subjectivity in metadiscourse identification and my justification}

In this section, I describe difficulties and subjectivity issues in identifying some types of metadiscourse and then conclude with my decision to include or exclude ambiguous types of markers and justification.

Given that metadiscourse is a functional category (Hyland, 2005), identifying a linguistic item as metadiscourse or not is subjective in nature. Therefore, conflicting views may arise as to whether items should be considered as metadiscourse in a particular context. Most previous studies have provided categories of metadiscourse markers, yet provided no explanation of the decision as to why they assigned some ambiguous markers as metadiscourse. Thus, it seems crucial for metadiscourse analysts to give a full account for criteria in assigning linguistic items as metadiscourse in order to minimize the subjectivity and ensure coding consistency within a study.

After I did the preliminary analysis of metadiscourse markers, I found that there was ambiguity and difficulties in operationalizing the metadiscourse concept with transition markers which can be realized in different syntactic forms like linking adverbials and conjunctions as well as hedges which can be realized in the form of modal verbs. These markers caused internal conflict for me while coding. 


\section{(i) Transition markers}

I found myself asking whether all forms of transition markers should be counted as metadiscourse. Based on their distribution in sentences, transition markers in this study can be mainly classified in three syntactic categories: linking adverbials, coordinating conjunctions, and subordinating conjunctions.

First, linking adverbials modify an independent clause or a verb phrase. According to Biber, Johansson, Leech, Conrad, and Finegan (1999, p. 884), linking adverbials themselves can be realized in five different forms: single adverbs (anyway, however, thus, and), adverb phrases (last but not least, more precisely), prepositional phrases (as a consequence, in contrast, on the other hand), finite clauses (that is, that is to say), and non-finite clauses (added to that, given that, to summarize). From the given definition and examples of linking adverbials, it seems to me that all linking adverbials can be metadiscourse markers since they mark pragmatic connections between ideas in order to facilitate readers' interpretation. In fact, there might be some restrictions to count linking adverbials as metadiscourse when they are used with other linguistic elements to form a sentence or paragraph. I illustrate this using the following examples.

(3.1) In contrast to Western culture, Asian societies put emphasis on an interdependent view of self and collectivism. (Hyland, 2005, p. 46)

(3.2) In contrast to Mei-Chen's finding, this relationship was lacking for the group of Thai English teachers in the present study because of their lack of linguistic ability and pragmatic knowledge. (TH-ELT-03)

Excerpt 3.1 is from Hyland (2005, p. 46). He explains that the marker in contrast to is not considered as metadiscourse because it expresses an external relation between activities and processes by comparing the characteristics of two cultures. When I found similar examples (e.g., Excerpt 3.2) in my corpus, I first coded the marker without looking at the form and recognized the marker as metadiscourse in the sense that it is expressing a relationship and creating connectedness between current and previous statements. However, I then questioned whether prepositional phrase markers followed by a noun (in contrast to + noun, as a result of + noun) should be counted as textual metadiscourse. Do they convey an ideational meaning rather than textual meaning when they appear in a sentence with a noun? 
In my study, I decided to include prepositional phrases followed by a noun (in contrast to, as a result of) insofar as they mark a reference between information in the previous segment and the current one. I think the identification of metadiscourse should not focus only on a specific element accompanying the markers. We should also pay attention to the surrounding context, so that we can see what functions the writers intentionally use the markers to perform.

It seems to me that Hyland's exclusion of In contrast to Western culture is rather contradictory to his principle suggesting a focus on functions. He argues that the element conveys an ideational meaning by comparing two activities outside the current discourse. In my opinion, even though the marker primarily conveys ideational meaning, on a second level it explicitly indicates the writer's intention to relate the current utterance with the previous one and to facilitate the reader's comprehension by marking a contrast of arguments. However, it should be noted that Hyland has not provided what came before the sentence (surrounding context). It is hard to predict whether "western culture" had been previously mentioned. If it had not been mentioned before, I would definitely agree with Hyland that the marker In contrast to Western culture is not metadiscourse because it does not create any relationship with another part of the text.

As seen in the similar example In contrast to Mei-Chen's finding found in my corpus, the thesis writer had already mentioned Mei-Chen's study before using this marker. Therefore, I think that the marker explicitly performs the textual function by linking different segments of the text and creates cohesion in discourse either at sentence or paragraph levels.

In accordance with Halliday and Hasan (1976, p. 231), both as a result and as a result of are conjunctive adjuncts and do exhibit cohesion because both of them make an anaphoric reference in discourse. In other words, although the prepositional phrase is followed by a noun, the marker still refers back and forth to the previous and current statements and demonstrates the textual metadiscourse function.

The second syntactic form of transition markers was coordinating conjunctions, coordinators for short. They combine two independent clauses together, usually accompanied with a comma, as in Excerpt 3.3. However, coordinators (and, but, or, so) can also function as a linking adverbial at the beginning of sentence, as in Excerpt 3.4. To put it simply, coordinators can be used as inter- and intra-sentential linking devices. 
(3.3) It could be argued that...more children could be offered greater opportunities to engage in natural and meaningful learning through play, and the negative effects of the hurried child could be minimised. (NZ-ELT-01)

(3.4) The study revealed a second area of cognitive development... And alongside that awareness was an increasing orientation towards vocabulary... (NZ-ELT-04)

Some metadiscourse analysts (see Mu et al., 2015; Noble, 2010) clearly state that "sentenceinternal connectors" are not included as metadiscourse in their studies. Hyland (2005) and Mauranen (1993), on the other hand, place connectors linking independent clauses in their textual category. Here, my second question arose as to whether metadiscourse identification should also rely on discourse units. If so, do coordinators at clause level qualify enough to be metadiscourse?

In this study, coordinators linking main clauses were included. It seems to me that coordinate and conjunctive items are different in terms of grammatical status or discourse units but very similar in terms of function. Moreover, the use of coordinators can signify the writer's intention to maintain a continuity of "arguments" in the text.

In reference to Hyland and Ädel's principles, although some transition markers can be realized in different forms (coordinate or conjunctive items), we should focus our attention not on the structural relation, but the functional relation. According to my view of metadiscourse, the examples below do not differ in terms of discourse units. That is, if we consider the marker for example elaborating ideas between clauses in Excerpt 3.5 as metadiscourse, the marker and in Excerpt 3.6 should be regarded as metadiscourse as well.

(3.5) Someone comes along with a great idea for an expedition-for example, I did a book called Sand Rivers, just before the Indian books... (Halliday, 2014, p. 610)

(3.6) It could be argued that... more children could be offered greater opportunities to engage in natural and meaningful learning through play, and the negative effects of the hurried child could be minimised. (NZ-ELT-01)

Based on functions, coordinators make explicit the semantic relationship between clauses while keeping their status as independent clauses (Markkanen, Steffensen, \& Crismore, 1993). As 
Hyland (2005) suggests, coordinate items can mark both external and internal relations in discourse. Hence, it should be stressed that only coordinators marking an internal relation by adding, comparing, or concluding "arguments of the current text" rather than activities, qualities, or events outside the current text are included. This clearly excludes items connecting a group of nouns and verbs (cable TV and audio-visual aids).

The last form of transition markers was subordinating conjunctions or subordinators. They generally connect a main clause with a dependent clause, as in Excerpt 3.7. Previous studies (e.g., Gardezi \& Nesi, 2009, p. 244) avoid using the grammatical terms like coordinating conjunctions and subordinating conjunctions. Rather, they use the inclusive term "conjunctions" but only refer to the conjunctions marking inter-sentential relations. In other words, for markers such as and, but, however, thus, etc. only those that mark inter-sentential relations are included as transition markers in the studies, as in Excerpt 3.8.

(3.7) Although this analysis provided some information about the construct validity of the scale, further psychometric testing is recommended in order to measure both the reliability of the scale and the other types of validity. (NZ-ELT-01)

(3.8) This type of report has a role which appears to be a termly summative assessment... However, this cannot be considered a developmental tool and does not fit with the educative mentoring model. (NZ-ELT-08)

Markkanen and colleagues (1993, p. 143) exclude subordinators from their study because subordinators perform a syntactic function by changing the grammatical relationship between clauses. In contrast, Hyland (2005, p. 31) counts subordinators as metadiscourse because they establish a "hierarchy" and signal the writer's evaluation of significance between ideas in the main clause and dependent clause. My question was whether items linking a main clause with a subordinate clause (marking intra-sentential relations) should be counted as metadiscourse in my study.

The explanation about the inclusion of coordinators is also applied to that of subordinators. Even though subordinators mark a relationship between a main clause and dependent clause, the use of subordinators explicitly indicates the writer's evaluation of the importance of propositional information (Hyland, 2005). It can be implied that a metadiscursive function of subordinators is to signal a hierarchy of propositional content. As mentioned earlier, some previous studies exclude items marking intra-sentential relations (subordinators). This means 
that a key criterion to include or exclude markers in the studies is based on the structural relation (intra- and inter-sentential structures). However, this current study concentrated on functions of the items, so subordinators like because and although were investigated in this study. If they mark a logical relation between "ideas" or "arguments" of the writer as in Excerpt 3.9, they are counted as transition markers. However, although in Excerpt 3.10 is excluded.

(3.9) Although this analysis provided some information about..., further psychometric testing is recommended... (NZ-ELT-01)

(3.10) Another participant (S11) said that although she had expected them weekly, she was happy they were monthly... (NZ-ELT-13)

\section{(ii) Hedges}

One important issue which should be addressed is modality markers in the subcategories of hedges (may, could, should) and boosters (must). Modal verbs can convey multiple meanings (epistemic, deontic, and dynamic meanings) (Huddleston \& Pullum, 2002), thus causing variation across different metadiscourse studies as to which meaning should be included as metadiscourse. According to Jiang and Hyland's (2017) metadiscourse study, epistemic modals convey possibility and certainty; deontic modals concern obligation and necessity; dynamic modals describe ability and opportunity. The problem is a single modal marker can convey more than one meaning. As in the following examples, the same modal verb could can express possibility of a proposition in Excerpt 3.11, necessity of an action in Excerpt 3.12, and ability of agents in Excerpt 3.13.

(3.11) This could be due to more recent exposure to these terms at university during initial teacher education courses. (NZ-ELT-08)

(3.12) Further research could investigate a common definition to enable a fuller understanding and appreciation of Maori entrepreneurship. (NZ-BA-16)

(3.13) The subjects in their study could use the concordances for error-correction effectively in the first three weeks of the training period. (TH-ELT-02)

However, attention has mostly been paid to epistemic modality and deontic or root modality. In the literature on metadiscourse, there seems to be conflicting views on the inclusion of the deontic meaning of modal verbs. Some studies of hedges (e.g., Hyland, 2000a; Nguyen Thi Thuy, 2018; Vázquez \& Giner, 2008) explicitly state that cases of modal verbs expressing the 
deontic meaning are excluded. Other studies (e.g., Chan, 2015) include both epistemic and deontic functions of modality but prefer using functional labels, for example, modal verbs expressing probability and possibility and modal verbs expressing necessity. As treatments of modality vary in different studies and there is no explicit indication of which meanings of modal verbs are included as metadiscourse and why, it is quite dubious to me whether all the meanings of the same modal item like could should be counted as metadiscourse. If not all, which of the above meanings should be included?

In more recent studies (e.g., Jiang \& Hyland, 2017), modality concerning possibility and certainty is categorized in the epistemic category, whereas modality concerning necessity is categorized in the root/deontic category. Based on this categorization, I would definitely include both epistemic and deontic modal meanings in my study. However, when looking at the following paraphrases given by Coates and Leech (1980, p. 4), both epistemic and deontic modality in fact concern "possibility" and "necessity."

\author{
Epistemic meaning \\ ' $\mathrm{X}$ may $\mathrm{Y}^{\prime}$ = 'it is possible that $\mathrm{X}$ [will] $\mathrm{Y}^{\prime}$ = 'perhaps $\mathrm{X}$ [will] $\mathrm{Y}^{\prime}$. \\ 'X must $\mathrm{Y}^{\prime}=$ ' $\mathrm{X}$ must necessarily $\mathrm{Y}^{\prime}$ = 'it must be that $\mathrm{Y}$ '. \\ Root meaning \\ ' $\mathrm{X}$ may $\mathrm{Y}^{\prime}=$ 'it is possible for $\mathrm{X}$ to $\mathrm{Y}^{\prime}$ \\ 'X must $\mathrm{Y}^{\prime}$ = 'it is necessary for $\mathrm{X}$ to $\mathrm{Y}^{\prime}$
}

That is to say, from Coates and Leech's (1980) perspective, epistemic and deontic meanings can convey possibility and necessity of a proposition. A distinction between epistemic and deontic modals is based on the principle as to whether "circumstances constrain the speaker/ writer to believe that X" or "circumstances constrain the occurrence of X". In other words, deontic modal meanings refer to the occurrence of $\mathrm{X}$ which is influenced by a phenomenon or external circumstances. Epistemic modal meanings, on the other hand, refer to the writer's assumptions or evaluation of possibility and necessity of a proposition as well as indicate the writer's confidence or lack of confidence in the truth of the proposition expressed (Coates, 1987).

In the light of metadiscourse analysis, I decided to include only epistemic modal meanings as the notion of epistemic modals proposed by Coates and Leech (1980) and Coates (1987) is much closer to the notion of hedges and boosters which mainly concern the writer's evaluation 
and confidence or lack of confidence in a proposition. Therefore, in this study, epistemic modals which convey tentativeness, possibility, uncertainty, and cautious commitment were counted in the hedging subcategory. Epistemic modals which convey the writer's confidence in making claims and evaluation of certainty and necessity of a proposition were counted in the boosting subcategory. Modal verbs which concern obligation, permission and ability were omitted. This means that could denoting epistemic possibility and necessity in Excerpts 3.113.12 above was included as a hedging marker in this study, but could denoting ability of an agent rather than the writer's evaluation in Excerpt 3.13 was excluded.

\subsection{Methodology for Study 2}

Study 2 involved thesis quality assessment. No previous research has attempted to investigate the quality of postgraduate writing, particularly theses, in relation to the use of metadiscourse. Because of this limitation, no appropriate rubrics have been formulated to assess the quality of thesis writing, especially discussion and conclusion chapters. This raises the need for this study to create thesis rating rubrics prior to assessment of quality and investigation of the relationship between the use of metadiscourse markers and the overall quality.

In this study, a set of criteria used to assess thesis writing was constructed based on information obtained from disciplinary supervisor interviews. Sections 3.3.1 and 3.3.2 describe the procedures used to conduct supervisor interviews and the procedures used to develop a thesis rating scale. Sections 3.3.3-3.3.5 describe the procedures used to select high and low frequency theses from Study 1, to assess the theses, and to analyze quality scores and metadiscourse frequencies.

\subsubsection{Disciplinary supervisor interviews}

Conducting interviews with disciplinary supervisors was necessary for this study because thesis supervisors and examiners in the investigated disciplines were regarded as target expert readers who read the theses and evaluate the quality. The main purpose of the interviews was to perceive supervisors' expectations of good theses in their disciplines and what elements they took into consideration when examining the theses. This information was used as a foundation for creating an analytic rating scale which specifically represented the thesis genre. In addition to the assessment-related purpose, it was expected that information from the supervisor interviews would supplement the discussion of findings in Study 1. 


\section{(i) Supervisor informants}

In Study 1, master's theses in New Zealand and Thailand were collected for metadiscourse analysis. Experienced supervisors who were familiar with thesis writing practices in the disciplines of English language teaching and business administration were recruited from the New Zealand and Thai universities that were the main sources of theses for the first study. I searched for supervisors' profiles and contact details on the universities' websites and sent them an invitation email together with an information sheet (see Appendix 5). Initially, I received a very low rate of positive responses partly due to their busy working schedules or some other reasons impeding their agreement to participate. I then sought assistance from supervisors who had already accepted my invitation. I requested them to forward my email to their colleagues or pass the invitation by word of mouth.

Finally, a total of twenty four supervisors agreed to participate in the interviews: twelve from New Zealand universities and twelve from Thai universities. In New Zealand, seven English language teaching supervisors and five business administration supervisors agreed to participate. They were from Auckland University of Technology and Victoria University of Wellington. In terms of their supervision experience, the number of theses they had supervised ranged from two to forty, including both master's and doctoral theses. In Thailand, seven English language teaching supervisors and five business administration supervisors agreed to participate. They were from Thammasat University and Prince of Songkla University. The number of theses supervised by the Thai supervisors ranged from two to fourteen, including both master's and doctoral theses. It should be noted that all of the supervisors had experience examining theses and/ or reviewing journal articles either at national or international level.

Table 3.5. Profiles of supervisor informants

\begin{tabular}{lcccc}
\hline \multirow{2}{*}{ Discipline } & \multicolumn{2}{c}{ NEW ZEALAND } & THAI \\
\cline { 2 - 5 } & $\begin{array}{c}\text { Number of } \\
\text { informants }\end{array}$ & $\begin{array}{c}\text { Number of theses } \\
\text { supervised }\end{array}$ & $\begin{array}{c}\text { Number of } \\
\text { informants }\end{array}$ & $\begin{array}{c}\text { Number of theses } \\
\text { supervised }\end{array}$ \\
\hline English language teaching & 7 & $8-24$ theses & 7 & $3-14$ theses \\
Business administration & 5 & $2-40$ theses & 5 & $2-11$ theses \\
\hline
\end{tabular}




\section{(ii) Interview arrangement}

As the interviews involved human informants, prior to conducting interviews, my human ethics application was reviewed and approved by the Victoria University of Wellington Human Ethics Committee on 9 May 2017 (Application 24600). After recruiting supervisor informants, faceto-face interviews were arranged rather than interviews via electronic channels for the following three reasons. First, my prospective informants were senior supervisors from different faculties, universities and countries, and I did not have any professional or personal relationship with them. So it was difficult for me to obtain their consent to participate in my research interviews. Once they granted me an opportunity to interview, making an effort to meet them in person was more appropriate than using electronic channels (e.g., Skype) which probably would have worked with more familiar participants like colleagues and students. Second, face-to-face interviews enabled me to elicit more data both in terms of quantity and quality from the supervisor informants because it is likely that supervisors would feel more at ease to share some aspects and cases when we meet in person. Third, through face-to-face interviews, I could develop rapport with informants and take the opportunity after the interviews to invite some of them to participate as raters in the later stage of assessment; they also had the opportunity to ask questions and discuss the assessment details with me before deciding to take part as raters.

The actual interviews were semi-structured with a list of indicative questions. Semi-structured interviews were used as it allowed both flexibility and consistency across informants in sharing their experience and ideas on essential criteria for considering a thesis. The questions for the interviews were divided into four parts: (1) general overarching topics of thesis writing at their institutions, (2) more specific concerns on writing discussion and conclusion chapters, (3) rating practices and criteria for rating master's thesis discussion and conclusion chapters, and (4) attitudes towards use of metadiscourse in thesis writing (Appendix 7, Interview questions).

With regard to interview settings, the one-on-one interviews with supervisors in New Zealand were conducted in their offices according to their confirmation of availability during June to July 2018. Subsequently, one-on-one interviews with Thai supervisors were also conducted in their offices in August 2018. One Thai supervisor was interviewed in a café because it was more convenient for him. Each interview lasted forty minutes to one hour.

With the consent of the supervisor informants, all the interviews were audio-recorded and 
manually transcribed. As the interviews with Thai supervisors were conducted in their first language Thai, the transcriptions of the Thai supervisor interviews were made in Thai. Only important parts including information related to my questions were translated into English. I used NVivo 12 for storing audio-recordings and transcribing because it facilitated the data coding process at the analysis stage. After each transcription, I re-read and took notes on the highlights of each interview and used these notes to aid my memory after all the twenty four transcriptions had been completed. As some informants chose not to review the interview transcripts, only informants who made a request to review their transcripts were sent the transcripts for verification.

\subsubsection{Thesis rating scale development}

A thesis rating scale was developed in two stages: identifying rating criteria and writing score descriptors. In the first stage, I read and coded interview data into different categories in NVivo 12. The reading and coding process was repeated several times in order to identify salient themes related to rating criteria (see Table 3.6, Coding interview data). The program was very useful at this stage as it helped track themes that recurred frequently and neatly summarized the number of theme recurrences. Therefore, a set of generic criteria used for assessing thesis discussion and conclusion chapters in English language teaching and business administration was mainly developed on the basis of the recurring themes of the interviews, in other words frequent mentions by the disciplinary supervisors.

As a result of the interviews, there were four aspects that most disciplinary supervisors frequently referred to when they examined thesis discussion and conclusion chapters. The four main aspects were content, organization and presentation, language use, and genre knowledge. I used these four aspects as rating criteria in this study. Even though the finding of these aspects was not surprising because they were basic elements of writing in any genre as indicated in literature, the details of how the supervisor informants described each aspect were different from those of writing in other genres. A full report on the interview results and a complete rating scale will be in a separate chapter (Chapter 7).

In the second stage, after identifying the four criteria, I used a five-point rating scale and wrote descriptors for each point of the four criteria using wording from the coded interview data (see Table 3.6). I chose the five-point scale format for rating thesis discussion and conclusion chapters because a review of assessment literature (e.g., Knoch, 2009; Weigle, 2002) suggests 
that raters can only differentiate between seven (plus or minus two) levels in order to make reasonable distinctions. More scoring levels would cause more difficulties and confusion to raters in distinguishing each level of rubrics and make the task too demanding, and a scale of fewer points like a three-point scale was suitable for the assessment to make a pass or fail decision (Weigle, 2002, p. 123).

Before making a final decision to use the five-point scale format, I ensured the validity of the scale through a pilot study with two Thai supervisors, one from English language teaching and one from business administration. They were required to read over the score descriptors and rate discussion and conclusion chapters of a thesis in their field using the template. Their overall feedback was that they had no difficulty in differentiating each level of the rubrics because it was clear what aspects and to which extent they should be included or excluded in a thesis to obtain Point 5 (excellent) or Point 1 (very poor), or vice versa. Supervisors in the pilot study also provided three useful suggestions as follows. First, some of the scale descriptors should be shortened, and some terms should be simplified in order that raters in different fields could have the same understanding. Second, raters should be allowed to give a half point $(0.5)$ because it was likely that theses might have some aspects overlapping between two levels. Third, an instruction requiring raters to take notes should be made optional. Given that the purpose of this assessment was to rate the overall quality of thesis writing rather than providing constructive feedback to revise the theses, it would be too demanding and stressful if raters were asked to provide detailed notes when reading and rating each of the twenty four theses. Finally, the rating scale was revised according to the suggestions and given to four actual raters who were four of my interviewees from the previous stage for consideration and actual assessment. 
Table 3.6. Coding interview data

\begin{tabular}{|c|c|c|}
\hline Excerpt from interview data & Code & Category \\
\hline $\begin{array}{l}\text { So in some circumstances if they make outlandish claims without enough evidence } \\
\text { to support it, I don't think that positions them particularly well. I mean a thesis is an } \\
\text { argument providing evidence from your analysis. (Supervisor-NZ-ELT-05) }\end{array}$ & $\begin{array}{l}\text {-Have enough evidence to support } \\
\text { argument } \\
\text {-Develop argument in theses based on } \\
\text { evidence }\end{array}$ & Rubric 4: Genre knowledge \\
\hline $\begin{array}{l}\text { It's really critical process when you are looking at the thesis ...reading it ...you've } \\
\text { got a very critical focus... you're asking yourself 'have they really got enough } \\
\text { evidence to demonstrate the answer to this question?' and yes I got a lot of evidence } \\
\text { and it's very well discussed... that I think that's fantastic... that's a really interesting } \\
\text { finding. If they don't have... or have less evidence and this is a bit of a gap in the } \\
\text { argument, this is the case then you think that I'm not quite convinced by that. So } \\
\text { actually I'm coming at a conclusion that it's the strength of the convincing...the } \\
\text { strength of the argument... (Supervisor-NZ-ELT-02) }\end{array}$ & $\begin{array}{l}\text {-Have enough evidence to support } \\
\text { argument } \\
\text {-Have enough evidence to support } \\
\text { argument } \\
\text {-Strength of conviction }\end{array}$ & Rubric 4: Genre knowledge \\
\hline $\begin{array}{l}\text { The discussion is sort of critical assessment of your findings and linking them to } \\
\text { the existing literature/ theory, and showing what can be taken away, what is the } \\
\text { added value in terms of theories, you know, have you supported the existing } \\
\text { theories, have you shown that the existing theory does not apply in every context. } \\
\text { (Supervisor-NZ-BA-08) }\end{array}$ & $\begin{array}{l}\text {-Make critical assessment of findings } \\
\text {-Link findings to literature/theories }\end{array}$ & Rubric 1: Content \\
\hline $\begin{array}{l}\text {.. That is the main thing we look at when we examine a thesis. Can students make } \\
\text { a critical discussion beyond repeating the results? This is common in reviewer's } \\
\text { feedback. (Supervisor-NZ-BA-09) }\end{array}$ & $\begin{array}{l}\text {-Make a critical discussion beyond } \\
\text { repeating findings }\end{array}$ & Rubric 1: Content \\
\hline
\end{tabular}




\subsubsection{Thesis selection for assessment}

The purpose of thesis assessment in Study 2 was to investigate the relationship between metadiscourse frequencies and quality scores. The previous section has presented the procedures used to conduct supervisor interviews and develop a rating scale. This section describes the thesis selection procedures.

In Study 1, four small subcorpora with a total of 116 master's theses were compiled for metadiscourse analysis. These theses were written by Thai and New Zealand postgraduates in the disciplines of English language teaching and business administration (NZ-ELT, NZ-BA, TH-ELT and TH-BA theses for short). In order to investigate whether high and low frequencies of metadiscourse markers affected high and low thesis quality scores, forty eight theses (twelve theses from each of the four subcorpora) were selected based on the findings of high and low frequencies of metadiscourse markers in Study 1. The reason for reducing the number of theses from the original corpus to forty eight for the assessment phase was based on the principles of feasibility and availability since raters were able to read and assess a limited number of texts without the task becoming too demanding. As mentioned earlier, the NZ-ELT corpus contained the smallest number of theses $(\mathrm{N}=26)$. Fifty percent of the theses in this corpus was thirteen, but thirteen was an odd number and hard to divide into high and low metadiscourse frequency groups. So twelve theses (six in the high frequency group and six in the low frequency group) were selected from each corpus. In total, each rater was required to assess twenty four theses in his/ her own discipline, either English language teaching or business administration.

Metadiscourse in this study was functionally categorized as textual and interpersonal metadiscourse with ten types of markers altogether. Textual metadiscourse included transition markers, frame markers, endophoric markers, evidentials, and code glosses. Interpersonal metadiscourse included hedges, boosters, attitude markers, engagement markers, and selfmentions. To find out which theses had high and low metadiscourse frequencies, normalized frequencies of the ten types of markers were used to rank the theses in each corpus.

In Corpus 1 (NZ-ELT), the five types of markers in the textual metadiscourse category were processed in a series of steps, as follows. Because a thesis may have high frequency in using a certain type of textual marker and low frequency in another, it was important to generate an average rank of a thesis in each of the five types of textual markers first. To do so, normalized frequencies of the first type of markers (transition markers) were sorted from high to low in an Excel template, and then the twenty six theses in this corpus were ranked from 1 (highest) to 
26 (lowest) according to the normalized frequencies of transition markers. The same process was repeated in the second type of marker (frame markers) until the last one (code glosses) in the textual metadiscourse category. After that, ranks of each thesis from the previous process were averaged. For example, Thesis NZ-ELT-01 was ranked the 19th, 10th, 25th, 10th, and 19th based on the normalized frequencies of transition markers, frame markers, endophoric markers, evidentials, and code glosses, respectively. The five ranks of Thesis NZ-ELT-01 were averaged as 16.6, meaning that this thesis had an average rank of 16.6 based on the frequencies of textual metadiscourse. Then the five types of markers in the interpersonal metadiscourse category were processed the same way, starting from hedges to self-mentions, until all the theses in this corpus had an average rank based on the frequencies of interpersonal metadiscourse. For example, the five ranks of Thesis NZ-ELT-01 were averaged as 17.8, meaning that this thesis had an average rank of 17.8 based on the frequencies of interpersonal metadiscourse. After that, the two average ranks of each thesis generated from textual and interpersonal metadiscourse categories were combined and divided by two. It should be noted that I initially put attempts in finding theses with high and low frequencies of textual and interpersonal metadiscourse separately in order to investigate which category had bigger impacts on the quality of thesis writing. The result was that theses with high frequencies in the textual metadiscourse category were likely to have high frequencies in the interpersonal metadiscourse category. The same tendency also happened to theses with low frequencies in the textual and interpersonal metadiscourse categories. So it was impossible to completely distinguish theses with high and low frequencies of textual metadiscourse from theses with high and low frequencies of interpersonal metadiscourse. All the theses in this corpus, therefore, had an average rank based on the frequencies of metadiscourse overall and were finally sorted from high to low rank. Six theses from the top of the list and six theses from the bottom of the list were selected for quality assessment. The twelve theses represented the theses which had highest and lowest frequencies of metadiscourse markers in the NZ-ELT corpus. The whole process was repeated with theses in Corpus 2 (NZ-BA), Corpus 3 (TH-ELT), and Corpus 4 (TH-BA).

After twelve theses from each corpus had been selected, theses in the same discipline (twelve NZ-ELT theses and twelve TH-ELT theses) were mixed, relabeled from one to twenty four without identifying NZ or TH (e.g., BA-04), and packed together with a rating template for delivery to raters. 
Assessor:

Please score each rubric following the rating scales attached (from $5=$ =highest to $1=$ =lowest).

\begin{tabular}{|l|c|c|c|c|c|}
\hline Thesis ID & $\begin{array}{c}\text { Content } \\
\text { (5 points) }\end{array}$ & $\begin{array}{c}\text { Organization } \\
\text { and } \\
\text { presentation } \\
\text { (5 points) }\end{array}$ & $\begin{array}{c}\text { Language } \\
\text { Use } \\
\text { (5 points) }\end{array}$ & $\begin{array}{c}\text { Genre } \\
\text { knowledge } \\
\text { (5 points) }\end{array}$ & Total \\
\hline Example & 4 & 3.5 & 4 & 2 & 13.5 \\
\hline BA-01 & & & & & \\
\hline BA-02 & & & & & \\
\hline BA-03 & & & & & \\
\hline BA-04 & & & & & \\
\hline BA-05 & & & & & \\
\hline
\end{tabular}

Figure 3.4. Rating template

\subsubsection{Raters}

As described in the previous section, the forty eight theses (twenty four in English language teaching and twenty four in business administration) were selected for quality assessment. Two raters from each discipline, four raters altogether, were recruited to take part in the assessment phase. At the end of the supervisor interview sessions, I presented a rater information sheet to some of the supervisor informants and invited them to participate as raters (see Appendix 8).

Four raters who agreed to take part were from New Zealand and Thai universities. The first rater was a senior lecturer in English language teaching at Auckland University of Technology. The second rater was a senior lecturer in business administration at Victoria University of Wellington. The third and fourth raters were senior lecturers in English language teaching and business administration at Prince of Songkla University. All of them had many years' experience supervising and examining both master's and doctoral theses as well as being journal reviewers in their fields.

\subsubsection{Assessment procedure}

Before the actual assessment took place, I arranged an orientation session with each rater individually in order to familiarize the raters with the rating scale and rating process. The raters were not trained in rating thesis quality since they had high experience themselves as thesis examiners, and this also reflects real life practice where examiners have implicit rating criteria in mind and do not have specific rubrics for examining theses (as indicated in the interviews 
with supervisors/ examiners. After the discussion-based session, I provided a pack of rating materials which included twenty four discussion and conclusion chapters and a rating template (see Appendix 3). To avoid aprioristic influences on thesis authors, the names of the authors and universities were omitted. The theses were labelled only with the name of the discipline and number one to twenty four. New Zealand and Thai raters in English language teaching were required to rate twenty four discussion and conclusion chapters in their field, and the other two raters in business administration were also required to rate twenty four chapters in their field. The raters were required to rate quality of the thesis chapters from 1 (the lowest score) to 5 (the highest score) based on the given criteria, their own expectations and general impression within one month. After the assessment task had been done, two raters returned the scoring sheets along with their notes on assessment via email. I met the other two raters in person and discussed the assessment process and difficulties.

\subsubsection{Data analysis}

Study 2 addressed the last research question: How does metadiscourse affect the quality of postgraduate writing? What kinds of metadiscourse have the biggest impact? The analysis of data focused on two main parts: correlations between frequencies of metadiscourse and thesis quality scores and comparisons of quality scores between high and low frequency groups in each discipline.

As there were two pairs of raters rating theses in their disciplines, the analysis and presentation of scoring data were divided by discipline. Individual scores of the twenty four theses in each discipline were firstly calculated using Pearson's correlation coefficient test to measure the interrater reliability of the two raters. Also, the agreement of the raters in assessing each of the four quality aspects (content, organization and presentation, language use, and genre knowledge) was measured using the same statistical test.

The first part of analysis focused on correlations between frequencies of metadiscourse and thesis quality scores. Because the distribution of frequencies in different metadiscourse subcategories was not normal, this study resorted to using Spearman's rank-order correlation test to measure the correlations between frequencies of metadiscourse overall and quality scores and subsequently between frequencies of metadiscourse subcategories and quality scores. Since the Spearman's rank-order correlation test can only determine whether there are correlations between scores and frequencies, a simple linear regression was further conducted 
to explore whether frequencies of overall metadiscourse and subcategories are significant predictors for thesis quality scores. The average change in thesis quality scores resulting from one unit change in metadiscourse frequency was also estimated from the regression.

As this study was preliminary research assessing quality of thesis writing in relation to metadiscourse frequencies, the focus of this study was on providing evidence of trends rather than trying to improve the correlations. In experimental studies, it is recommended to adjust $p$ values to strictly control a familywise error-rate (the possibility of making a Type 1 error) (Larson-Hall, 2009; Pallant, 2001). However, with little discussion in literature specifically on adjusting $p$-values with correlation tests (Spearman's test or even Pearson's test), when a $p$ value adjustment is applied in correlation tests, the significance level might be too stringent, and correlations are unlikely to be found. This possibly leads to a Type 2 error (e.g., truth is there is a correlation, but we reject it by claiming that there is no correlation).

Thus, despite having a concern about the possibility of committing a Type 1 error when making multiple comparisons, this study intended not to set the alpha level too high to avoid neglecting correlations which may exist. This study set significance levels at .05 and .01 to detect correlations which may exist between quality of thesis writing and frequencies of metadiscourse and its subcategories. However, a replication of the study is encouraged for more robust measurement of correlation strengths.

The second part of analysis focused on comparisons of quality scores between high and low frequency groups. Twenty four theses in each discipline were divided into two groups: twelve theses with a high frequency of metadiscourse (HFG) and twelve theses with a low frequency of metadiscourse (LFG). To examine the difference in quality scores between high and low frequency groups, an independent samples $t$-test was performed.

In order to gain more insight into differences and similarities between theses in high and low frequency groups, this study also examined metadiscourse distribution and ranges of types of markers within each subcategory between the two groups.

\subsection{Chapter summary}

This thesis includes two main studies. This chapter has provided a detailed explanation of collecting New Zealand and Thai theses and analyzing metadiscourse in Study 1 and the detail of selecting high and low frequency theses from Study 1 for quality assessment and finally 
examining the correlation between metadiscourse frequencies and quality scores in Study 2 . Study 1 examined use of metadiscourse (i.e., frequencies, types, and functions) in four subcorpora (NZ-ELT, NZ-BA, TH-ELT, and TH-BA). Hyland's (2005) metadiscourse model was adopted for metadiscourse classification in this study. Log-likelihood was used to indicate significance of frequency differences between each pair of subcorpora. Study 2 explored the relationship between metadiscourse frequencies and quality of thesis writing. Forty eight theses (twelve theses with highest and lowest frequencies of metadiscourse markers in each of the four subcorpora in Study 1) were selected for this study. Semi-structured interviews were conducted with twenty four disciplinary supervisors in New Zealand and Thailand. The interview data was used to design a rating scale specifically for thesis quality assessment. Two New Zealand and Thai raters in English language teaching and business administration rated twenty four discussion and conclusion chapters in their own disciplines. Spearman's rank-order correlation tests and regression were undertaken to gauge the correlations. The methodology of the whole study is summarized in Figure 3.5. Following this, Chapters 4-6 will report the findings of Study 1. Chapters 7-8 will report the findings of Study 2, including interview results. 


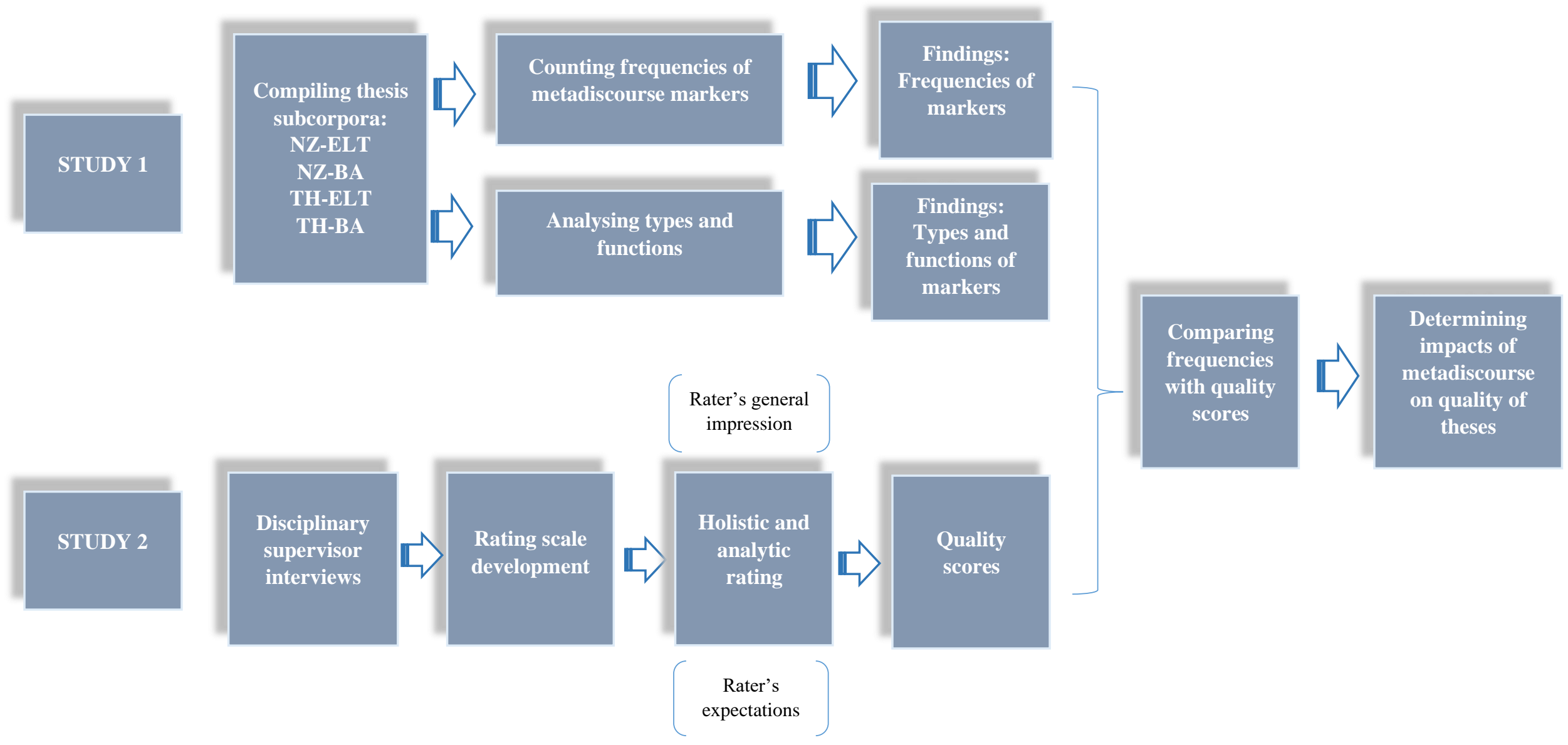

Figure 3.5. Methodological map of the whole study 


\section{CHAPTER 4 \\ STUDY 1: METADISCOURSE ANALYSIS}

The findings of Study 1 cover two dimensions of metadiscourse analysis: frequency analysis and functional analysis. Chapter 4 aims to give a general overview of metadiscourse frequencies in New Zealand and Thai theses and in English language teaching and business administration theses before moving on to more nuanced comparisons in each subcategory in the following chapters. Chapter 5 discusses textual metadiscourse (i.e., transition markers, frame markers, endophoric markers, evidentials, and code glosses) in terms of frequencies, types, and functions. Chapter 6 discusses interpersonal metadiscourse (i.e., hedges, boosters, attitude markers, engagement markers, and self-mentions) in terms of frequencies, types, and functions.

In this chapter, Section 4.1 presents the overall frequencies of textual and interpersonal metadiscourse occurrences in all four subcorpora. Then Sections 4.2 and 4.3 report findings of comparisons between New Zealand and Thai theses and between English language teaching and business administration theses.

\subsection{Overall metadiscourse frequencies}

In accordance with Hyland's (2005) metadiscourse taxonomy, metadiscourse is classified into two main categories, textual and interpersonal categories. Table 4.1 provides raw frequencies, normalized frequencies, and the ratio of textual and interpersonal metadiscourse across all four subcorpora. The frequency counts indicate that there are 26,255 metadiscourse occurrences from the total 599,599 running words in the master's thesis corpora, or approximately one token every 23 words. Overall, master's students employ substantially more textual markers $(\mathrm{Nf}=230.8$ accounting for $52.7 \%$ of all metadiscourse occurrences) than interpersonal markers $(\mathrm{Nf}=207.1$ accounting for $47.3 \%$ of all metadiscourse occurrences). The textual metadiscourse count is approximately $5 \%$ higher than the interpersonal category. 
Table 4.1. Overall metadiscourse frequencies

\begin{tabular}{lcccccc}
\hline \multirow{2}{*}{ Corpus } & \multicolumn{3}{c}{ Textual metadiscourse } & \multicolumn{3}{c}{ Interpersonal metadiscourse } \\
\cline { 2 - 7 } & Raw & Nf* & $\%$ & Raw & Nf & $\%$ \\
\hline NZ-ELT & 4611 & 229.3 & $48.5 \%$ & 4903 & 243.8 & $51.5 \%$ \\
NZ-BA & 3167 & 219.7 & $53.6 \%$ & 2742 & 190.2 & $46.4 \%$ \\
TH-ELT & 3062 & 243.7 & $56.9 \%$ & 2319 & 184.6 & $43.1 \%$ \\
TH-BA & 2999 & 233.0 & $55.0 \%$ & 2452 & 190.5 & $45.0 \%$ \\
All & 13839 & 230.8 & $52.7 \%$ & 12416 & 207.1 & $47.3 \%$ \\
\hline
\end{tabular}

*Nf = Normalized frequencies per 10,000 words

\subsection{Comparison of metadiscourse frequencies between $\mathrm{NZ}$ and TH corpora}

Table 4.2 shows the extent to which New Zealand and Thai postgraduate students use textual and interpersonal metadiscourse in master's theses. To make a comparison across New Zealand and Thai thesis corpora, I combined NZ-ELT and NZ-BA data sets for the New Zealand corpus and TH-ELT and TH-BA data sets for the Thai corpus. Raw and normalized frequencies of textual and interpersonal markers in New Zealand and Thai students' theses are used to reflect the actual number of metadiscourse occurrences and facilitate the application of the loglikelihood test using the raw data to determine significance of the difference between the two corpora. When comparing the overall occurrences based on the normalized frequencies of metadiscourse markers between the New Zealand and Thai corpora, it was found that New Zealand master's students use more metadiscourse markers $(\mathrm{Nf}=446.7)$ in their theses than Thai students $(\mathrm{Nf}=425.9)$. The log-likelihood calculation of 14.46 determines statistical significance of the higher metadiscourse incidence in the New Zealand corpus at the level of $p$ $<.001$. It should be noted that using the log-likelihood calculation, exact $p$-values are not provided.

It can also be seen in Table 4.2 that the two groups of students share the same trend in using more textual metadiscourse than interpersonal metadiscourse. That is, in every 10,000 words, New Zealand students use textual markers 225.3 times and interpersonal markers 221.4 times. Thai students use textual markers 238.3 times and interpersonal markers 187.6 times. However, as measured by the normalized frequencies of textual markers, it is noticeable that the reliance of Thai students on textual markers $(\mathrm{Nf}=238.3)$ is higher than that of New Zealand students $(\mathrm{Nf}=225.3)$. The log-likelihood calculation of 10.78 reveals statistical significance of the higher frequency of textual markers in the Thai corpus at the level of $p<.01$. On the other hand, the 
New Zealand group makes more frequent use of interpersonal metadiscourse $(\mathrm{Nf}=221.4)$, when compared to the Thai group $(\mathrm{Nf}=187.6)$. The log-likelihood calculation of 81.66 determines statistical significance of the higher frequency of interpersonal markers in the New Zealand group at the level of $p<.0001$.

Table 4.2. Frequencies of metadiscourse in NZ and TH corpora

\begin{tabular}{|c|c|c|c|c|c|c|}
\hline \multirow[b]{2}{*}{ Category } & \multicolumn{2}{|c|}{$\begin{array}{l}\text { NEW ZEALAND } \\
(345,277 \text { words) }\end{array}$} & \multicolumn{2}{|c|}{$\begin{array}{c}\text { THAI } \\
(254,322 \text { words) }\end{array}$} & \multicolumn{2}{|c|}{ Log-likelihood } \\
\hline & Raw & $\mathrm{Nf}$ & Raw & $\mathrm{Nf}$ & LL & $p$-value \\
\hline $\begin{array}{l}\text { Textual } \\
\text { metadiscourse }\end{array}$ & 7778 & 225.3 & 6061 & 238.3 & 10.78 & $p<.01$ \\
\hline $\begin{array}{l}\text { Interpersonal } \\
\text { metadiscourse }\end{array}$ & 7645 & 221.4 & 4771 & 187.6 & 81.66 & $p<.0001$ \\
\hline All & 15423 & 446.7 & 10832 & 425.9 & 14.46 & $p<.001$ \\
\hline
\end{tabular}

To examine disciplinary variation within each educational context, metadiscourse frequencies between English language teaching and business administration disciplines within the New Zealand context (NZ-ELT vs. NZ-BA) and then between the two disciplines within the Thai context (TH-ELT vs. TH-BA) were compared.

Table 4.3 presents frequencies of metadiscourse between two disciplines within the New Zealand corpus (NZ-ELT vs. NZ-BA). Overall, New Zealand students in English language teaching include more metadiscourse markers in their theses $(\mathrm{Nf}=473.1)$ than their compatriots in business administration ( $\mathrm{Nf}=409.9)$. The higher incidence of metadiscourse markers in the NZ-ELT corpus is significant, as indicated by the log-likelihood value of 75.89 at the level of $p<.0001$.

Moreover, New Zealand students in English language teaching make more frequent use of interpersonal than textual metadiscourse, while their compatriots in business administration more often use textual metadiscourse. Comparing frequencies between the two groups, New Zealand students in English language teaching show higher frequencies of using both textual markers $(\mathrm{Nf}=229.3$ in NZ-ELT, $\mathrm{Nf}=219.7$ in NZ-BA) and interpersonal markers $(\mathrm{Nf}=243.8$ in NZ-ELT, Nf=190.2 in NZ-BA) than their counterparts in business administration. The loglikelihood calculation of 3.47 , however, indicates that the higher frequency of textual markers in the NZ-ELT corpus is not statistically significant $(p>.05)$. Yet, the higher frequency of 
interpersonal markers in the NZ-ELT corpus is significant, as indicated by the log-likelihood value of 110.83 at the level of $p<.0001$. This suggests that New Zealand students in English language teaching noticeably have a greater degree of preference in the use of interpersonal markers than New Zealand students in business administration, but they are quite similar in terms of using textual markers.

Table 4.3. Frequencies of metadiscourse in NZ-ELT and NZ-BA subcorpora

\begin{tabular}{lcccccc}
\hline & \multicolumn{4}{c}{ NEW ZEALAND } & & Log-likelihood \\
\cline { 2 - 6 } & \multicolumn{2}{c}{$\begin{array}{c}\text { NZ-ELT } \\
(201,099 \text { words })\end{array}$} & NZ-BA \\
& Raw & Nf & Raw & Nf & LL & $p$-value \\
\hline $\begin{array}{l}\text { Category } \\
\begin{array}{l}\text { Textual } \\
\text { metadiscourse }\end{array}\end{array}$ & 4611 & 229.3 & 3167 & 219.7 & 3.47 & $p>.05$ \\
$\begin{array}{l}\text { Interpersonal } \\
\text { metadiscourse }\end{array}$ & 4903 & 243.8 & 2742 & 190.2 & 110.83 & $p<.0001$ \\
All & 9514 & 473.1 & 5909 & 409.9 & 75.89 & $p<.0001$ \\
\hline
\end{tabular}

Table 4.4 presents frequencies of metadiscourse between two disciplines within the Thai corpus (TH-ELT vs. TH-BA). Overall, Thai students in the disciplines of English language teaching and business administration do not show a significant difference in the use of metadiscourse markers in their theses ( $\mathrm{Nf}=428.3$ in $\mathrm{TH}-\mathrm{ELT}, \mathrm{Nf}=423.5$ in $\mathrm{TH}-\mathrm{BA})$. The log-likelihood value is 0.34 , which is below the level of statistical significance $(p>.05)$.

Thai students in the two disciplines employ more textual than interpersonal metadiscourse. When comparing the use of textual and interpersonal metadiscourse between the two groups, Thai students in English language teaching show a slightly higher frequency in the use of textual markers $(\mathrm{Nf}=243.7)$ than Thai students in business administration $(\mathrm{Nf}=233)$. The latter, however, has more frequent use of interpersonal markers $(\mathrm{Nf}=190.5)$ than the former $(\mathrm{Nf}=184.6)$. By looking at the log-likelihood values of 3.05 for textual metadiscourse and 1.20 for interpersonal metadiscourse, the differences between the two disciplines in the Thai corpus are below the level of statistical significance $(p>.05)$. The result suggests that the use of textual and interpersonal markers by Thai students do not seem to vary according to their disciplines. 
Table 4.4. Frequencies of metadiscourse in TH-ELT and TH-BA subcorpora

\begin{tabular}{|c|c|c|c|c|c|c|}
\hline \multirow[b]{4}{*}{ Category } & \multicolumn{4}{|c|}{ THAI } & & \\
\hline & \multirow{2}{*}{\multicolumn{2}{|c|}{$\begin{array}{c}\text { TH-ELT } \\
\text { (125,631 words) }\end{array}$}} & \multirow{2}{*}{\multicolumn{2}{|c|}{$\begin{array}{c}\text { TH-BA } \\
(128,691 \text { words })\end{array}$}} & \multirow{2}{*}{\multicolumn{2}{|c|}{ Log-likelihood }} \\
\hline & & & & & & \\
\hline & Raw & $\mathrm{Nf}$ & Raw & $\mathrm{Nf}$ & LL & $p$-value \\
\hline $\begin{array}{l}\text { Textual } \\
\text { metadiscourse }\end{array}$ & 3062 & 243.7 & 2999 & 233.0 & 3.05 & $p>.05$ \\
\hline $\begin{array}{l}\text { Interpersonal } \\
\text { metadiscourse }\end{array}$ & 2319 & 184.6 & 2452 & 190.5 & 1.20 & $p>.05$ \\
\hline All & 5381 & 428.3 & 5451 & 423.5 & 0.34 & $p>.05$ \\
\hline
\end{tabular}

\subsection{Comparison of metadiscourse frequencies between ELT and BA corpora}

Table 4.5 shows the extent to which postgraduate students in English language teaching and business administration include textual and interpersonal metadiscourse in their master's theses. To perform a comparison between the two disciplines, I combined NZ-ELT and THELT data sets for the English language teaching corpus as well as NZ-BA and TH-BA data sets for the business administration corpus. Based on the normalized frequencies, students in English language teaching employ more metadiscourse markers $(\mathrm{Nf}=455.8)$ than students in business administration $(\mathrm{Nf}=416.3)$. The log-likelihood calculation of 53.32 reveals statistical significance of the higher incidence of metadiscourse in the English language teaching corpus at the level of $p<.0001$.

In a comparison of textual with interpersonal metadiscourse, students in both disciplines have the same inclination to use more textual markers than interpersonal ones. That is, in every 10,000 words, English language teaching students use textual markers 234.8 times and interpersonal markers 221 times. Business administration students use textual markers 226 times and interpersonal markers 190.3 times. When comparing the frequencies of each category between the two disciplines, English language teaching students use textual metadiscourse $(\mathrm{Nf}=234.8)$ more often than business administration students $(\mathrm{Nf}=226)$. The log-likelihood value of 5.08 indicates the higher frequency of textual markers in English language teaching is significant at the level of $p<.05$. In the same way, English language teaching students also use interpersonal markers $(\mathrm{Nf}=221)$ more often than business administration students $(\mathrm{Nf}=190.3)$. The log-likelihood value of 68 indicates the higher incidence of interpersonal markers in the English language teaching discipline is significant at the level of $p<.0001$. 
Table 4.5. Frequencies of metadiscourse in ELT and BA corpora

\begin{tabular}{lcccccc}
\hline & \multicolumn{2}{c}{ ELT } & \multicolumn{2}{c}{ BA } & & Log-likelihood \\
& $(326,730$ words $)$ & & \multicolumn{2}{c}{$(272,869$ words $)$} & & \\
\hline Category & Raw & $\mathrm{Nf}$ & Raw & $\mathrm{Nf}$ & LL & $p$-value \\
\hline $\begin{array}{l}\text { Textual } \\
\text { metadiscourse }\end{array}$ & 7673 & 234.8 & 6166 & 226.0 & 5.08 & $p<.05$ \\
$\begin{array}{l}\text { Interpersonal } \\
\text { metadiscourse }\end{array}$ & 7222 & 221.0 & 5194 & 190.3 & 68.00 & $p<.0001$ \\
All & 14895 & 455.8 & 11360 & 416.3 & 53.32 & $p<.0001$ \\
\hline
\end{tabular}

With regard to contextual variation of metadiscourse within each discipline, metadiscourse frequencies between New Zealand and Thai theses within the English language teaching discipline (NZ-ELT vs. TH-ELT) and then between New Zealand and Thai theses within the business administration discipline (NZ-BA vs. TH-BA) were compared.

Table 4.6 provides a comparison of metadiscourse frequencies between New Zealand and Thai theses within the English language teaching discipline (NZ-ELT vs. TH-ELT). Overall, New Zealand students in English language teaching make considerably more frequent use of metadiscourse markers $(\mathrm{Nf}=473.1)$ than Thai students in the same discipline $(\mathrm{Nf}=428.3)$. The log-likelihood calculation of 34.29 indicates that the higher frequency of metadiscourse markers in the NZ-ELT corpus is significant at the level of $p<.0001$.

Furthermore, Thai students in English language teaching employ more textual markers $(\mathrm{Nf}=243.7)$ than interpersonal markers $(\mathrm{Nf}=184.6)$, whereas New Zealand students in the same discipline employ more interpersonal markers $(\mathrm{Nf}=243.8)$ than textual markers $(\mathrm{Nf}=229.3)$. The higher incidence of the textual category in the TH-ELT corpus is significant, as determined by the log-likelihood value of 6.83 at the level of $p<.01$. Moreover, the higher frequency of the interpersonal category in the NZ-ELT corpus is highly significant, as determined by the $\log$-likelihood value of 125.68 at the level of $p<.0001$. 
Table 4.6. Frequencies of metadiscourse in NZ-ELT and TH-ELT subcorpora

\begin{tabular}{|c|c|c|c|c|c|c|}
\hline \multirow[b]{3}{*}{ Category } & \multicolumn{4}{|c|}{ ENGLISH LANGUAGE TEACHING } & \multirow{2}{*}{\multicolumn{2}{|c|}{ Log-likelihood }} \\
\hline & \multicolumn{2}{|c|}{$\begin{array}{c}\text { NZ-ELT } \\
(201,099 \text { words })\end{array}$} & \multicolumn{2}{|c|}{$\begin{array}{c}\text { TH-ELT } \\
\text { (125,631 words) }\end{array}$} & & \\
\hline & Raw & $\mathrm{Nf}$ & Raw & $\mathrm{Nf}$ & LL & $p$-value \\
\hline $\begin{array}{l}\text { Textual } \\
\text { metadiscourse }\end{array}$ & 4611 & 229.3 & 3062 & 243.7 & 6.83 & $p<.01$ \\
\hline $\begin{array}{l}\text { Interpersonal } \\
\text { metadiscourse }\end{array}$ & 4903 & 243.8 & 2319 & 184.6 & 125.68 & $p<.0001$ \\
\hline All & 9514 & 473.1 & 5381 & 428.3 & 34.29 & $p<.0001$ \\
\hline
\end{tabular}

Table 4.7 offers a comparison of metadiscourse frequencies between New Zealand and Thai theses within the business administration discipline (NZ-BA vs. TH-BA). The finding shows that New Zealand and Thai students in business administration do not significantly differ in the frequency of using metadiscourse markers in their theses $(\mathrm{Nf}=409.9$ in NZ-BA, $\mathrm{Nf}=423.5$ in TH-BA), as determined by the log-likelihood value of $3.08(p>.05)$.

For the textual markers identified in business theses, Thai students in this discipline exhibit more frequent use of textual markers $(\mathrm{Nf}=233)$ than New Zealand students $(\mathrm{Nf}=219.7)$. The log-likelihood value of 5.38 indicates statistical significance of the higher frequency in the THBA corpus at the level of $p<.05$. For the interpersonal markers in business theses, Thai students in this discipline also employ slightly more interpersonal markers $(\mathrm{Nf}=190.5)$ than $\mathrm{New}$ Zealand students $(\mathrm{Nf}=190.2)$, but the difference is not significant based on the log-likelihood value of $0.00(p>.05)$.

Table 4.7. Frequencies of metadiscourse in NZ-BA and TH-BA subcorpora

\begin{tabular}{|c|c|c|c|c|c|c|}
\hline \multirow[b]{3}{*}{ Category } & \multicolumn{4}{|c|}{ BUSINESS ADMINISTRATION } & \multirow{2}{*}{\multicolumn{2}{|c|}{ Log-likelihood }} \\
\hline & \multicolumn{2}{|c|}{$\begin{array}{c}\text { NZ-BA } \\
(144,178 \text { words })\end{array}$} & \multicolumn{2}{|c|}{$\begin{array}{c}\text { TH-BA } \\
\text { (128,691 words) }\end{array}$} & & \\
\hline & Raw & $\mathrm{Nf}$ & Raw & $\mathrm{Nf}$ & LL & $p$-value \\
\hline $\begin{array}{l}\text { Textual } \\
\text { metadiscourse }\end{array}$ & 3167 & 219.7 & 2999 & 233.0 & 5.38 & $p<.05$ \\
\hline $\begin{array}{l}\text { Interpersonal } \\
\text { metadiscourse }\end{array}$ & 2742 & 190.2 & 2452 & 190.5 & 0.00 & $p>.05$ \\
\hline All & 5909 & 409.9 & 5451 & 423.5 & 3.08 & $p>.05$ \\
\hline
\end{tabular}




\subsection{Chapter summary}

This chapter has reported the overall results of metadiscourse in New Zealand and Thai theses and in English language teaching and business administration theses. The cross-contextual comparison indicates that New Zealand students use significantly more metadiscourse than Thai students. While both New Zealand and Thai students use more textual markers than interpersonal markers in their theses, Thai students use more textual metadiscourse than New Zealand students. New Zealand students use more interpersonal metadiscourse than Thai students. Within the New Zealand corpus (NZ-ELT vs. NZ-BA), New Zealand students in English language teaching include significantly more metadiscourse than their compatriots in business administration. New Zealand students in the two disciplines are significantly different in the use of interpersonal metadiscourse, but not in the use of textual metadiscourse. Within the Thai corpus (TH-ELT vs. TH-BA), Thai students in the two disciplines do not differ in the frequency of metadiscourse in their theses, neither textual nor interpersonal markers.

The cross-disciplinary comparison indicates that English language teaching students use more metadiscourse than business administration students, both textual and interpersonal metadiscourse. Comparing students in English language teaching between the two contexts (NZ-ELT vs. TH-ELT), New Zealand students in this discipline use significantly more metadiscourse, especially interpersonal metadiscourse, than Thai students. However, Thai students in the language teaching discipline use significantly more textual metadiscourse than New Zealand students in the same discipline. Within the business administration discipline (NZ-BA vs. TH-BA), students in the two contexts are not significantly different in the frequency of using metadiscourse overall or interpersonal metadiscourse. Yet, Thai-business students use significantly more textual metadiscourse than New Zealand-business students. The following chapters will explore which subcategories are more and less frequently used and likely to have a big influence on the overall results. 


\section{CHAPTER 5}

\section{TEXTUAL METADISCOURSE}

Chapter 5 discusses textual metadiscourse in New Zealand and Thai theses and in English language teaching and business administration theses. Section 5.1 reports frequencies of textual metadiscourse as a whole. From Section 5.2 to Section 5.6, transition markers, frame markers, endophoric markers, evidentials, and code glosses are discussed in terms of frequencies, types, and functions.

\subsection{Textual metadiscourse as a whole}

Table 5.1 reports the extent to which New Zealand and Thai postgraduate students use each textual metadiscourse subcategory. Normalized frequencies per 10,000 words of textual subcategories suggest that transition markers and evidentials are most frequently used by both New Zealand and Thai postgraduates to form cohesive and coherent theses and provide a reliable source to support their arguments. Similar to New Zealand students, Thai students moderately employ frame markers and code glosses to organize propositional content and elaborate meanings. The lowest frequency textual subcategory in both corpora is endophoric markers.

Table 5.1. Textual metadiscourse subcategories in NZ and TH corpora

\begin{tabular}{|c|c|c|c|c|c|c|}
\hline \multirow[b]{2}{*}{ Subcategory } & \multicolumn{2}{|c|}{$\begin{array}{c}\text { NEW ZEALAND } \\
(345,277 \text { words })\end{array}$} & \multicolumn{2}{|c|}{$\begin{array}{c}\text { THAI } \\
(254,322 \text { words })\end{array}$} & \multicolumn{2}{|c|}{$\begin{array}{c}\text { All } \\
(599,599 \text { words })\end{array}$} \\
\hline & Raw & $\mathrm{Nf}$ & Raw & $\mathrm{Nf}$ & Raw & $\mathrm{Nf}$ \\
\hline Transition markers & 3752 & $108.7(1)$ & 3601 & $141.6(1)$ & 7353 & 122.6 \\
\hline Evidentials & 1812 & $52.5(2)$ & 780 & $30.7(2)$ & 2592 & 43.2 \\
\hline Code glosses & 1105 & $32.0(3)$ & 640 & $25.2(4)$ & 1745 & 29.1 \\
\hline Frame markers & 663 & $19.2(4)$ & 720 & $28.3(3)$ & 1383 & 23.1 \\
\hline Endophoric markers & 446 & $12.9(5)$ & 320 & $12.6(5)$ & 766 & 12.8 \\
\hline
\end{tabular}

The bracketed numbers indicate the ranks of each subcategory.

Table 5.2 shows a comparison of textual metadiscourse subcategories in English language teaching and business administration disciplines. According to the ranks of textual subcategories, master's students in the two disciplines show the same disposition in the use of textual markers in their theses. Transition markers and evidentials are the two most frequent 
textual markers in the two disciplines, followed by code glosses, frame markers, and endophoric markers, respectively.

Table 5.2. Textual metadiscourse subcategories in ELT and BA corpora

\begin{tabular}{|c|c|c|c|c|c|c|}
\hline \multirow[b]{2}{*}{ Subcategory } & \multicolumn{2}{|c|}{$\begin{array}{c}\text { ELT } \\
(326,730 \text { words })\end{array}$} & \multicolumn{2}{|c|}{$\begin{array}{c}\text { BA } \\
(272,869 \text { words })\end{array}$} & \multicolumn{2}{|c|}{$\begin{array}{c}\text { All } \\
(599,599 \text { words })\end{array}$} \\
\hline & Raw & $\mathrm{Nf}$ & Raw & $\mathrm{Nf}$ & Raw & $\mathrm{Nf}$ \\
\hline Transition markers & 3914 & $119.8(1)$ & 3439 & $126.0(1)$ & 7353 & 122.6 \\
\hline Evidentials & 1578 & $48.3(2)$ & 1014 & $37.2(2)$ & 2592 & 43.2 \\
\hline Code glosses & 924 & $28.3(3)$ & 821 & $30.1(3)$ & 1745 & 29.1 \\
\hline Frame markers & 789 & $24.1(4)$ & 594 & $21.8(4)$ & 1383 & 23.1 \\
\hline Endophoric markers & 468 & $14.3(5)$ & 298 & $10.9(5)$ & 766 & 12.8 \\
\hline
\end{tabular}

The bracketed numbers indicate the ranks of each subcategory.

\subsection{Transition markers}

\subsubsection{Frequencies of transition markers in $\mathrm{NZ}$ and $\mathrm{TH}$ corpora}

Table 5.3 reports frequencies of transition markers in the New Zealand and Thai corpora. As measured by the normalized frequencies, transition markers occur more frequently in the Thai corpus $(\mathrm{Nf}=141.6)$ than in the New Zealand corpus $(\mathrm{Nf}=108.7)$. The log-likelihood calculation of 128.11 indicates statistical significance of the higher incidence of transition markers in the Thai corpus at the level of $p<.0001$.

Table 5.3. Transition markers in NZ and TH corpora

\begin{tabular}{|c|c|c|c|c|c|c|}
\hline & \multicolumn{2}{|c|}{$\begin{array}{l}\text { NEW ZEALAND } \\
(345,277 \text { words })\end{array}$} & \multicolumn{2}{|c|}{$\begin{array}{c}\text { THAI } \\
(254,322 \text { words })\end{array}$} & \multicolumn{2}{|c|}{ Log-likelihood } \\
\hline & Raw & $\mathrm{Nf}$ & Raw & $\mathrm{Nf}$ & LL & $p$-value \\
\hline Transition markers & 3752 & 108.7 & 3601 & 141.6 & 128.11 & $p<.0001$ \\
\hline
\end{tabular}

Further analysis of transition markers between two disciplines within the New Zealand corpus (NZ-ELT vs. NZ-BA) reveals that there is no significant difference in the occurrence of transitions between the two subcorpora, as determined by the log-likelihood value of 0.21 ( $p>$ .05). The normalized frequency of transition markers used by New Zealand students in the language teaching discipline $(\mathrm{Nf}=109.3)$ is nearly the same as the frequency in the business discipline $(\mathrm{Nf}=107.7)$, as presented in Table 5.4 below. 
Table 5.4. Transition markers in NZ-ELT and NZ-BA subcorpora

\begin{tabular}{|c|c|c|c|c|c|c|}
\hline & \multicolumn{4}{|c|}{ NEW ZEALAND } & \multirow{3}{*}{\multicolumn{2}{|c|}{ Log-likelihood }} \\
\hline & \multirow{2}{*}{\multicolumn{2}{|c|}{$\begin{array}{c}\text { NZ-ELT } \\
\text { (201,099 words) }\end{array}$}} & \multirow{2}{*}{\multicolumn{2}{|c|}{$\begin{array}{c}\text { NZ-BA } \\
(144,178 \text { words) }\end{array}$}} & & \\
\hline & & & & & & \\
\hline & Raw & $\mathrm{Nf}$ & Raw & $\mathrm{Nf}$ & LL & $p$-value \\
\hline Transition markers & 2199 & 109.3 & 1553 & 107.7 & 0.21 & $p>.05$ \\
\hline
\end{tabular}

When comparing frequencies of transitions between two disciplines within the Thai corpus (TH-ELT vs. TH-BA), the result in the Thai corpus contrasts with that in the New Zealand corpus. Thai-business students employ significantly more transition markers $(\mathrm{Nf}=146.6)$ than their compatriots in English language teaching $(\mathrm{Nf}=136.5)$. As presented in Table 5.5, the loglikelihood value of 4.53 indicates that the higher incidence of transition markers in the TH-BA corpus is statistically significant at the level of $p<.05$.

Table 5.5. Transition markers in TH-ELT and TH-BA subcorpora

\begin{tabular}{|c|c|c|c|c|c|c|}
\hline & & & & & & \\
\hline & & & & & & g-likelihood \\
\hline & $(12$ & & $(12$ & & & \\
\hline & Raw & $\mathrm{Nf}$ & Raw & $\mathrm{Nf}$ & LL & $p$-value \\
\hline Transition markers & 1715 & 136.5 & 1886 & 146.6 & 4.53 & $p<.05$ \\
\hline
\end{tabular}

\subsubsection{Frequencies of transition markers in ELT and BA corpora}

Table 5.6 compares transition marker frequencies between the English language teaching and business administration corpora. Overall, transition markers occur more frequently in business administration theses $(\mathrm{Nf}=126)$ than in English language teaching theses $(\mathrm{Nf}=119.8)$. As determined by the log-likelihood value of 4.71 , the higher frequency of transition markers in the business administration discipline is significant at the level of $p<.05$. 
Table 5.6. Transition markers in ELT and BA corpora

\begin{tabular}{|c|c|c|c|c|c|c|}
\hline & \multicolumn{2}{|c|}{$\begin{array}{c}\text { ELT } \\
\text { (326,730 words) }\end{array}$} & \multicolumn{2}{|c|}{$\begin{array}{c}\text { BA } \\
(272,869 \text { words })\end{array}$} & \multicolumn{2}{|c|}{ Log-likelihood } \\
\hline & Raw & $\mathrm{Nf}$ & Raw & $\mathrm{Nf}$ & LL & $p$-value \\
\hline Transition markers & 3914 & 119.8 & 3439 & 126.0 & 4.71 & $p<.05$ \\
\hline
\end{tabular}

An exploration of transition markers in New Zealand and Thai theses within the English language teaching corpus (NZ-ELT vs. TH-ELT) suggests that 109.3 and 136.5 transition markers are likely to appear in every 10,000 words in the NZ-ELT corpus and the TH-ELT corpus, respectively. This means that Thai students in English language teaching use transition markers more often than New Zealand students in the same discipline. The log-likelihood calculation of 46.90 determines the higher frequency of transition markers in the TH-ELT corpus is significant at the level of $p<.0001$, as presented in Table 5.7.

Table 5.7. Transition markers in NZ-ELT and TH-ELT subcorpora

\begin{tabular}{|c|c|c|c|c|c|c|}
\hline & \multicolumn{4}{|c|}{ ENGLISH LANGUAGE TEACHING } & \multirow{3}{*}{\multicolumn{2}{|c|}{ Log-likelihood }} \\
\hline & \multirow{2}{*}{\multicolumn{2}{|c|}{$\begin{array}{c}\text { NZ-ELT } \\
(201,099 \text { words })\end{array}$}} & \multirow{2}{*}{\multicolumn{2}{|c|}{$\begin{array}{c}\text { TH-ELT } \\
\text { (125,631 words) }\end{array}$}} & & \\
\hline & & & & & & \\
\hline & Raw & $\mathrm{Nf}$ & Raw & $\mathrm{Nf}$ & LL & $p$-value \\
\hline Transition markers & 2199 & 109.3 & 1715 & 136.5 & 46.90 & $p<.0001$ \\
\hline
\end{tabular}

Table 5.8 presents frequencies of transition markers identified in New Zealand and Thai students' theses in business administration (NZ-BA vs. TH-BA). Thai-business students include more transition markers $(\mathrm{Nf}=146.6)$ in their theses than New Zealand-business students $(\mathrm{Nf}=107.7)$. The log-likelihood value of 81.23 reveals the higher frequency of transition markers in the TH-BA corpus is significant at the level of $p<.0001$.

Table 5.8. Transition markers in NZ-BA and TH-BA subcorpora

\begin{tabular}{|c|c|c|c|c|c|c|}
\hline & \multicolumn{4}{|c|}{ BUSINESS ADMINISTRATION } & \multirow{3}{*}{\multicolumn{2}{|c|}{ Log-likelihood }} \\
\hline & \multirow{2}{*}{\multicolumn{2}{|c|}{$\begin{array}{c}\text { NZ-BA } \\
(144,178 \text { words) }\end{array}$}} & \multirow{2}{*}{\multicolumn{2}{|c|}{$\begin{array}{c}\text { TH-BA } \\
\text { (128,691 words) }\end{array}$}} & & \\
\hline & & & & & & \\
\hline & Raw & $\mathrm{Nf}$ & Raw & $\mathrm{Nf}$ & LL & $p$-value \\
\hline Transition markers & 1553 & 107.7 & 1886 & 146.6 & 81.23 & $p<.0001$ \\
\hline
\end{tabular}


This section concludes that overall Thai students employ significantly more transition markers than New Zealand students. The cross-disciplinary comparison in the New Zealand corpus (NZ-ELT vs. NZ-BA) indicates that there is no significant difference in the incidence of transition markers between the two disciplines in the New Zealand corpus. The crossdisciplinary comparison in the Thai corpus (TH-ELT vs. TH-BA) indicates a significantly higher frequency of transition markers in the TH-BA corpus. As for the overall comparison between two disciplines, business administration students employ significantly more transition markers than English language teaching students. The cross-contextual comparison between New Zealand and Thai theses in English language teaching (NZ-ELT vs. TH-ELT) and business administration (NZ-BA vs. TH-BA) suggests a significantly higher frequency of transition markers in Thai theses compared to New Zealand theses in both disciplines (THELT and TH-BA).

\subsubsection{Types of transition markers}

In terms of individual types in the transition subcategory, 37 and 41 types of transition markers are identified in NZ-ELT and NZ-BA, respectively. Similarly, in the Thai corpus, 41 and 42 types are identified in TH-ELT and TH-BA, respectively. Out of these 42 types, 33 types are shared in all four subcorpora. This suggests that New Zealand and Thai students in both disciplines opt for similar types of transition markers in thesis writing.

A complete list of metadiscourse markers identified in the four subcorpora is provided in Appendix 2. Table 5.9 displays the top ten transition markers in the New Zealand and Thai corpora in a descending order to make high frequency transition markers more obvious. Six high frequency transition markers consistently found on the top ten list across the four subcorpora are also, however, because, while, and, and therefore. Also, however, and because are the most prominent markers on the top five shared over the four subcorpora.

Moreover, there are a few transition markers which appear only on the top ten list of one single corpus but are absent from other subcorpora, namely the presence of furthermore and consequently in NZ-BA and in addition in TH-BA. Some markers are not found on the top ten list of one corpus, namely the absence of although in TH-BA, but in TH-ELT, and thus in NZBA. The resultative marker so is found only on the top ten list of business thesis subcorpora (NZ-BA and TH-BA), but not on the top ten list of language teaching thesis subcorpora (NZELT and TH-ELT). The additive marker moreover is found only on the top ten list of Thai 
students' thesis subcorpora (TH-ELT and TH-BA), but not on the list of New Zealand students' thesis subcorpora (NZ-ELT and NZ-BA).

When investigating transition markers only in the New Zealand corpus (NZ-ELT and NZ-BA), although and but are the two markers shared by New Zealand students in both disciplines in addition to the six markers shared over the four subcorpora. In the Thai corpus (TH-ELT and TH-BA), moreover and thus are shared by Thai students in both disciplines in addition to the six markers mentioned earlier.

Table 5.9. Top ten transition marker list

\begin{tabular}{|c|c|c|c|c|c|c|c|c|}
\hline & \multicolumn{4}{|c|}{ NEW ZEALAND } & \multicolumn{4}{|c|}{ THAI } \\
\hline & \multicolumn{2}{|c|}{ NZ-ELT } & \multicolumn{2}{|c|}{ NZ-BA } & \multicolumn{2}{|c|}{ TH-ELT } & \multicolumn{2}{|c|}{ TH-BA } \\
\hline & Type & $\mathrm{Nf}$ & Type & $\mathrm{Nf}$ & Type & $\mathrm{Nf}$ & Type & $\mathrm{Nf}$ \\
\hline 1 & also & 27.1 & also & 20.7 & also & 23.9 & also & 30.8 \\
\hline 2 & however & 15.6 & however & 18.0 & however & 13.2 & because & 15.5 \\
\hline 3 & because & 8.1 & while & 10.8 & because & 11.9 & however & 14.0 \\
\hline 4 & although & 7.5 & therefore & 8.7 & moreover & 8.9 & therefore & 9.2 \\
\hline 5 & while & 7.0 & because & 6.9 & therefore & 7.3 & but & 9.1 \\
\hline 6 & but & 6.1 & although & 5.9 & while & 6.8 & moreover & 8.5 \\
\hline 7 & and & 5.9 & and & 5.6 & so & 5.7 & and & 8.4 \\
\hline 8 & therefore & 5.6 & furthermore & 3.4 & thus & 5.7 & thus & 5.9 \\
\hline 9 & so & 2.9 & but & 3.1 & although & 5.3 & while & 5.7 \\
\hline \multirow[t]{2}{*}{10} & thus & 2.1 & consequently & 2.8 & and & 5.3 & in addition & 4.4 \\
\hline & SUM NF=109.3 & $\begin{array}{c}87.9 \\
(80.4 \%)\end{array}$ & SUM NF $=107.7$ & $\begin{array}{c}85.9 \\
(79.8 \%)\end{array}$ & SUM NF=136.5 & $\begin{array}{c}94.0 \\
(68.9 \%)\end{array}$ & SUM NF=146.6 & $\begin{array}{c}111.5 \\
(76.1 \%)\end{array}$ \\
\hline
\end{tabular}

Bolded markers represent the popular markers on the top ten list shared across the four subcorpora.

Italic markers represent the popular markers shared by two disciplines within each context.

As for the lower frequency transition markers outside the provided list, there are a few markers found in only one corpus. In the same way and by the same token appear only in TH-ELT (Excerpts 5.1-5.2), and thereby appears only in TH-BA (Excerpt 5.3). These markers are completely absent from the New Zealand corpus.

(5.1) Both students and English teachers indicated various needs in order to increase the effectiveness in English teaching and learning... In the same way, almost all of the teachers agreed that such course should be held for the first year students before the beginning of the first semester. (TH-ELT-O1) 
(5.2) In some cases, where the new vocabulary is surrounded by information that the subjects are familiar with, guessing meaning from context clue is the strategy chosen. By the same token, the meaning of an unknown word is guessed from the available graphics such as charts, diagram, illustrations, or tables, wherever available. (TH-ELT-17)

(5.3) To focus on Gen Y characteristics, they voted tech-savvy and family-centric as the most exactly, this implied that online shopping can be another efficient distribution channel for OTOP brand. Thereby, social media such as Facebook will be one of the most effective channels attracting Gen Y community today as long as they automatically promote OTOP Facebook Fanpage to their peers and family members. (TH-BA-11)

With regard to the distribution of higher and lower frequency transition markers, a sum of normalized frequencies and percentage of the ten high frequency transitions in each corpus show a dense distribution of the ten markers in NZ-ELT and NZ-BA theses, as illustrated in Figure 5.1. This indicates that New Zealand students in both disciplines are overwhelmingly reliant on the ten transition markers when they try to cohere elements and create information flow in the thesis discussion and conclusion chapters. In NZ-ELT and NZ-BA, the top ten transition markers occupy 87.9 out of 109.3 occurrences and 85.9 out of 107.7 occurrences per 10,000 words, accounting for $80.4 \%$ and $79.8 \%$ of the total occurrences, respectively. Approximately $20 \%$ is made up of 27 types of transition markers outside the top ten list in NZELT and 31 types in NZ-BA, suggesting very sparse use of lower frequency transition markers in the two disciplines in the New Zealand corpus. As for the Thai corpus, the top ten transition markers in TH-ELT and TH-BA occur 94 out of 136.5 times and 111.5 out of 146.6 times per 10,000 words, accounting for $68.9 \%$ and $76.1 \%$ of the total occurrences, respectively. $31.1 \%$ in TH-ELT and $23.9 \%$ in TH-BA are made up of 31 types of transition markers outside the top ten list in each corpus. These findings suggest that although the four subcorpora exhibit a similar number of transition types, they differ in terms of proportions of use. It is important to note that New Zealand students in the two disciplines have a greater proportion of use of the ten high frequency transitions and very sparse use of other lower frequency markers, compared to Thai students. In the Thai corpus, although the percentage of high frequency markers is also high in both disciplines, Thai students especially in the English language teaching discipline make more frequent use of lower frequency transition markers than other groups. 


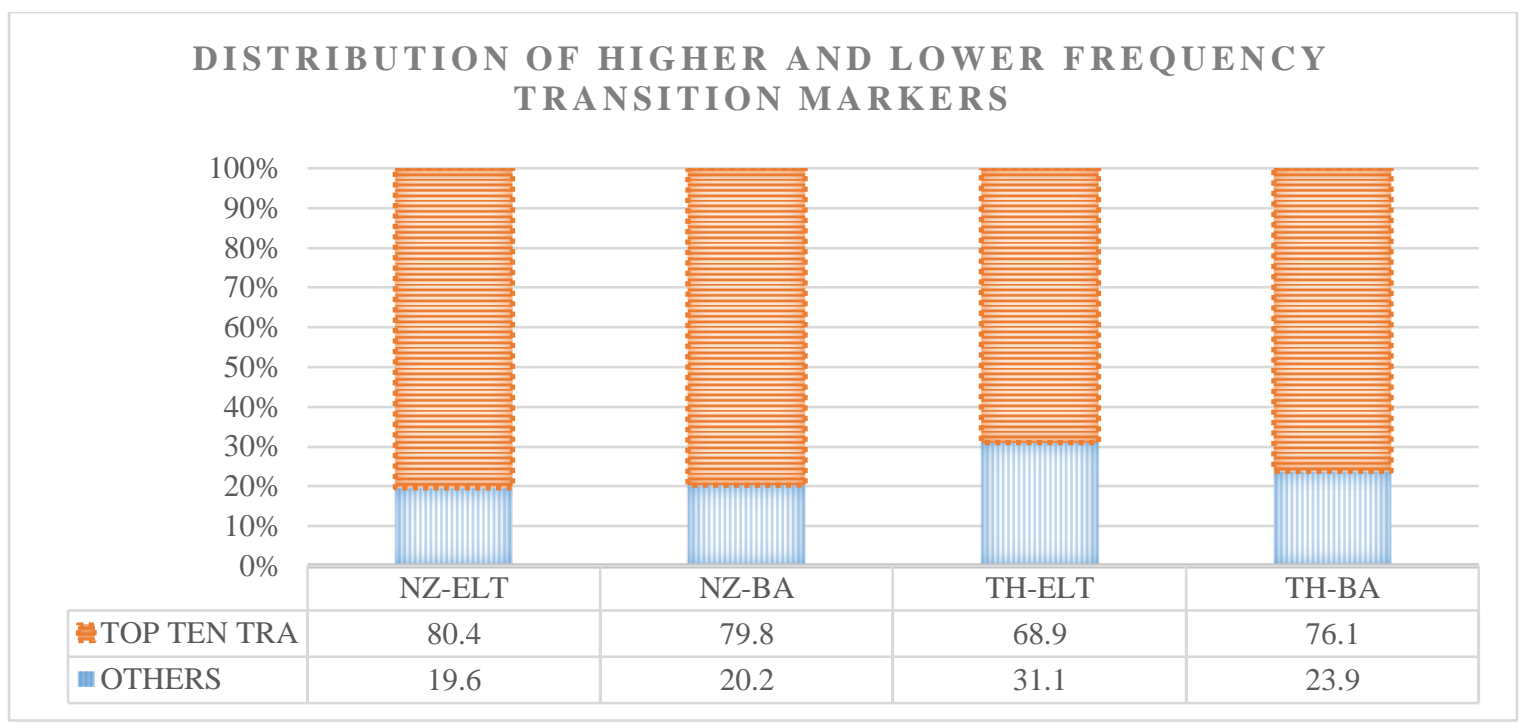

Figure 5.1. Distribution of higher and lower frequency transition markers

\subsubsection{Functions of transition markers}

\section{(i) Adding arguments}

As shown in Table 5.10, high frequency transition markers which New Zealand and Thai students use to mark an addition of new arguments are also, and, moreover, furthermore, and in addition. Also and and are present on the top ten list in the four subcorpora. This suggests that New Zealand and Thai students in the two disciplines are familiar with the two common markers and tend to use them when adding new arguments which have a connection with the previous ones. Although the additive markers like moreover, furthermore, and in addition are also used by New Zealand and Thai students in the two disciplines, each of these markers seems to be preferred by a certain group of students. That is, Thai students in both disciplines make greater use of moreover, while the marker is far below the high frequency list in the New Zealand thesis corpus. With an array of transition markers, furthermore appears to be a salient transition marker for New Zealand students in business administration as well as in addition for Thai students in business administration.

Table 5.10. High frequency additive transition markers

\begin{tabular}{ll}
\hline Corpus & Additive transition markers \\
\hline NZ-ELT & also, and \\
NZ-BA & also, and, furthermore \\
TH-ELT & also, and, moreover \\
TH-BA & also, and, moreover, in addition \\
\hline
\end{tabular}


According to a functional analysis of theses in this study, additive transition markers play important roles in adding arguments in areas of adding results, adding suggestions for further research, and adding implications to target readers in the field.

Firstly, when summarizing key findings in the discussion and conclusion chapters, also as well as and are frequently used as connective devices to mark an addition of findings in the four thesis subcorpora, as seen in Excerpts 5.4-5.6. The high occurrence of the two additive markers in the discussion and conclusion chapters is possibly owing to the fact that in the chapters thesis writers need to concisely write a series of key findings by using short and easy-to-use markers like also which can appear in different positions in a sentence to mark a connection from the first finding to another as well as and whose function is clearly to coordinate clauses and add ideas. Importantly, the two markers can establish both intra-clausal and inter-clausal relationships in discourse.

(5.4) This study also found that tourists who had been aged from between 35 years and above were more "Brand conscious" than the tourists who had the age group of 18-34 years of age. (TH-BA-28)

(5.5) It was also noted that turnover rates are relatively low and this was attributed to the fact that universities are generally good employers and offer attractive staff benefits. (NZ-BA-17)

(5.6) The view also emerged that teachers were concerned about how to help students who did not possess or struggled to develop the requisite vocabulary, given the rate at which those demands continued to increase. And a significant dimension that emerged through the study was that individual attitudes and orientation to vocabulary varied... (NZ-ELT-04)

Secondly, New Zealand and Thai students prominently use additive transition markers when they offer several suggestions for further research and would like to point out where new information is added to a long list of suggestions. However, for such purpose, Thai students in both disciplines often use moreover, whereas New Zealand students especially in business administration use furthermore, besides also and and.

(5.7) It would be worthwhile to conduct a cross-sectional study comparing high and low proficiency groups in order to see any differences between the two groups in producing 
English passive voice. Moreover, it would also be interesting to conduct an experimental study comparing students that receive form-focused instruction and students that receive meaning-focused instruction ... (TH-ELT-23)

(5.8) ... it is interesting to investigate the essential competencies required by full service hotels in Phuket because upscale hotels may require leadership competencies for success more or less than 3 or less star hotels. Moreover, it is interesting to identify the leadership competencies needs for five-star hotels in Phuket. It would be interesting to replicate this study every few years to assess whether changes in perception occur over time. $($ TH-BA-02)

(5.9) For example, the inclusion of interview participants outside of the Auckland region, and those of non-English or fluent Maori speaking backgrounds, could extend the current research into new lines of enquiry. Furthermore, research could be conducted into the entrepreneurial process or framework of Maori entrepreneurs in overseas markets, or as specific to certain industry sectors, such as the tourism industry within Aotearoa. (NZ-BA-16)

And thirdly, transition markers are useful for thesis writing when drawing implications from present studies to target readers in the field. Since it is necessary for thesis writers to highlight how their studies contribute to the field, the writers often include a long list of implications and use additive markers to mark the additional information.

(5.10) It would be useful to integrate additional exercises of dictionary skills into the curriculum. Training students to become more familiar with using dictionaries not only can enrich language skills but also make them have good attitudes toward the reference tool in the long term. Moreover, the teachers should frequently train the students to understand dictionary features and how to use these useful resources appropriately. (TH-ELT-11)

(5.11) Hence, it is recommended that research should be encouraged as part of the post-crisis management in all kinds of organizations. This supports Laws et al. 's (2007) study that all stakeholders should operate by learning from experience and researching about information required for effective pre-planning. In addition, they should work collaboratively with other stakeholders to obtain much needed information to help them at post-crisis. (TH-BA-18) 
(ii) Marking contrasting ideas

In Table 5.11, high frequency transition markers which New Zealand and Thai postgraduate writers use to express adversative senses in their arguments are however, while, although, and but. The presence of however and while on the top list in all the subcorpora indicates that when New Zealand and Thai students contrast ideas, these two markers are more likely to be used to signal the contrastive relations. They are commonly used across New Zealand and Thai contexts and across English language teaching and business administration disciplines. In the New Zealand corpus, it is interesting that there is no variation in terms of types of adversative markers between English language teaching and business administration. Students in the two disciplines show the same preference for choosing adversative markers however, while, although, and but. In the Thai corpus, students in the two disciplines are somewhat different. Besides the markers however and while, Thai students in English language teaching make frequent use of the subordinator although, while their compatriots in business administration are more likely to use the simpler coordinator but.

Table 5.11. High frequency adversative transition markers

\begin{tabular}{ll}
\hline Corpus & Adversative transition markers \\
\hline NZ-ELT & however, while, although, but \\
NZ-BA & however, while, although, but \\
TH-ELT & however, while, although \\
TH-BA & however, while, but \\
\hline
\end{tabular}

Adversative transition markers in this study express a contrastive meaning of propositions in different segments. The markers are used to signal both a contrast of ideas within the same study (Excerpt 5.12) and a contrast to the literature (Excerpts 5.13-5.14). This might be attributed to the fact that thesis writers usually discuss findings by referring to earlier studies, so adversative transition markers play an important role here to indicate findings or practices of current studies which are different from those in earlier studies.

(5.12) The qualitative data showed that the awareness of language use of the teachers was at a high level. The statistical results, however, reported that this high degree of awareness did not lead to a corresponding degree of the teachers' pragmatic competence in the three aspects of requests. (TH-ELT-03) 
(5.13) Sharpe et al. (2006) surmise from numerous research studies that redesign becomes more difficult if it is conducted during the implementation rather than planned for in advance, yet they conceded that "an emphasis on design [first] is probably not the norm for either traditional or blended courses" (p. 25). However, I maintain that the order in which the development happened was vital... (NZ-ELT-15)

(5.14) Knowing and understanding one's own culture as well as those of others are very important in intercultural communication (Akutsu, 2008; Bardovi-Harlig \& Hartford 1990, cited in Chick 1996; Jung, 2005). Therefore, cultural information was assumed to be the pragmatic feature found in every book. However, the findings did not support this assumption. (TH-ELT-06)

\section{(iii) Specifying causes and results of actions}

From Table 5.12, a segment transition in a causative and resultative sense is often expressed through the markers because, therefore, thus, so, and consequently. In the four subcorpora, because and therefore frequently occur to denote cause-effect relationships between segments. So appears as a high frequency marker in the New Zealand and Thai students' theses but only in the language teaching discipline (NZ-ELT and TH-ELT). Thus appears as a high frequency resultative marker in Thai students' theses in both disciplines and New Zealand students' theses in the language teaching discipline (TH-ELT, TH-BA, and NZ-ELT). As for New Zealand students in business administration (NZ-BA), they show a greater tendency to use the adverbial consequently rather than thus or so to present their arguments on a cause and effect basis.

Table 5.12. High frequency causative and resultative transition markers

\begin{tabular}{ll}
\hline Corpus & Causative and resultative transition markers \\
\hline NZ-ELT & because, therefore, thus, so \\
NZ-BA & because, therefore, consequently \\
TH-ELT & because, therefore, thus, so \\
TH-BA & because, therefore, thus \\
\hline
\end{tabular}

It can be said that an important function of transition markers is to provide justification for what has been discovered or rationale for arguments being made. To gain acceptance from supervisors or readers in the field, thesis writers must be able to show the ability in justifying results, not only reporting the results. In Excerpt 5.15, the writers use direct markers such as therefore and because to indicate the rationale of the research process. In Excerpt 5.16, they 
use causative markers to discuss findings and reasons for findings. And, in Excerpt 5.17, they provide reasons to support their claims of implications of the studies.

(5.15) The participants in this thesis were chosen based on purposive and convenience sampling methods...the findings of this thesis are not generalisable to the average Màori entrepreneur. Caution should therefore be applied when interpreting the profile of the Māori entrepreneur. (NZ-BA-16)

(5.16) As noted by Phillips (2011), trolls say their practice is about getting "lulz" - laughs gained from antagonising people. So we can presume that the board's users share a belief that antagonising people is funny. (NZ-ELT-12)

(5.17) For OTOP entrepreneurs and marketers, they should consider undertaking a Supply Chain Management (SCM) towards overseas countries because a good supply chain will help to synchronize the organic production and sales more effectively. (TH-BA-15)

To scrutinize similarities and differences in the extent to which postgraduate students in different contexts and disciplines use transition markers to represent each function, normalized frequencies and ratios of additive markers, adversative markers, and causative and resultative markers are utilized. Table 5.13 below suggests that New Zealand students tend to employ transition markers to signal adversative relationships between segments, while Thai students use them for adding arguments. To elaborate, New Zealand students in English language teaching and business administration most frequently use transition markers to denote adversative relations $(\mathrm{Nf}=44.9$ accounting for $41.1 \%$ in $\mathrm{NZ}$-ELT, $\mathrm{Nf}=46.4$ accounting for $43.1 \%$ in NZ-BA), followed by additive relations ( $\mathrm{Nf}=41.7$ accounting for $38.1 \%$ in NZ-ELT, $\mathrm{Nf}=37.9$ accounting for $35.2 \%$ in $\mathrm{NZ}-\mathrm{BA})$ and causative and resultative relations $(\mathrm{Nf}=22.8$ accounting for $20.8 \%$ in NZ-ELT, $\mathrm{Nf}=23.4$ accounting for $21.7 \%$ in NZ-BA), respectively. In contrast, Thai students in the two disciplines tend to include transition markers in their theses mostly for the additive function $(\mathrm{Nf}=52.2$ accounting for $38.2 \%$ in $\mathrm{TH}-\mathrm{ELT}, \mathrm{Nf}=63.6$ accounting for $43.4 \%$ in TH-BA), with a slight difference between adversative and causative functions. Thai students in English language teaching use transition markers slightly more often for consequence relations ( $\mathrm{Nf}=42.6$ accounting for $31.2 \%$ ) than adversative relations $(\mathrm{Nf}=41.7$ accounting for $30.6 \%$ ), whereas their compatriots in business administration prefer to use transition markers to mark adversative relations ( $\mathrm{Nf}=42.5$ accounting for $29 \%$ ) than consequence relations $(\mathrm{Nf}=40.5$ accounting for $27.6 \%)$. 
Table 5.13. Relations denoted by transition markers

\begin{tabular}{lccccccccc}
\hline \multirow{2}{*}{ Corpus } & \multicolumn{3}{c}{ Additive } & \multicolumn{3}{c}{ Adversative } & \multicolumn{3}{c}{ Causative } \\
\cline { 2 - 11 } & Raw & Nf & $\%$ & Raw & Nf & $\%$ & Raw & Nf & $\%$ \\
\hline NZ-ELT & 838 & 41.7 & $38.1 \%$ & 903 & 44.9 & $41.1 \%$ & 458 & 22.8 & $20.8 \%$ \\
NZ-BA & 547 & 37.9 & $35.2 \%$ & 669 & 46.4 & $43.1 \%$ & 337 & 23.4 & $21.7 \%$ \\
TH-ELT & 656 & 52.2 & $38.2 \%$ & 524 & 41.7 & $30.6 \%$ & 535 & 42.6 & $31.2 \%$ \\
TH-BA & 818 & 63.6 & $43.4 \%$ & 547 & 42.5 & $29.0 \%$ & 521 & 40.5 & $27.6 \%$ \\
\hline
\end{tabular}

\subsection{Frame markers}

\subsubsection{Frequencies of frame markers in $\mathrm{NZ}$ and $\mathrm{TH}$ corpora}

Table 5.14 indicates that Thai students are inclined to make more frequent use of frame markers $(\mathrm{Nf}=28.3)$ compared to New Zealand students $(\mathrm{Nf}=19.2)$. The log-likelihood calculation of 51.97 indicates that the higher incidence of frame markers in the Thai corpus is significant at the level of $p<.0001$.

Table 5.14. Frame markers in NZ and TH corpora

\begin{tabular}{|c|c|c|c|c|c|c|}
\hline & \multicolumn{2}{|c|}{$\begin{array}{l}\text { NEW ZEALAND } \\
(345,277 \text { words })\end{array}$} & \multicolumn{2}{|c|}{$\begin{array}{c}\text { THAI } \\
(254,322 \text { words })\end{array}$} & \multicolumn{2}{|c|}{ Log-likelihood } \\
\hline & Raw & $\mathrm{Nf}$ & Raw & $\mathrm{Nf}$ & LL & $p$-value \\
\hline Frame markers & 663 & 19.2 & 720 & 28.3 & 51.97 & $p<.0001$ \\
\hline
\end{tabular}

A cross-disciplinary comparison was subsequently performed in the New Zealand corpus (NZELT vs. NZ-BA). The finding is that New Zealand students in English language teaching and business administration do not differ in the frequency of using frame markers in their theses. The former and the latter tend to use only 20.3 and 18.4 frame markers in every 10,000 words. The log-likelihood value of 1.42 indicates a non-significant difference between the two disciplinary groups $(p>.05)$, as shown in Table 5.15 . 
Table 5.15. Frame markers in NZ-ELT and NZ-BA subcorpora

\begin{tabular}{|c|c|c|c|c|c|c|}
\hline & \multicolumn{4}{|c|}{ NEW ZEALAND } & \multirow{2}{*}{\multicolumn{2}{|c|}{ Log-likelihood }} \\
\hline & \multicolumn{2}{|c|}{$\begin{array}{c}\text { NZ-ELT } \\
(201,099 \text { words })\end{array}$} & \multicolumn{2}{|c|}{$\begin{array}{c}\text { NZ-BA } \\
(144,178 \text { words })\end{array}$} & & \\
\hline & Raw & $\mathrm{Nf}$ & Raw & $\mathrm{Nf}$ & LL & $p$-value \\
\hline Frame markers & 371 & 18.4 & 292 & 20.3 & 1.42 & $p>.05$ \\
\hline
\end{tabular}

Considering frame markers in the two disciplines within the Thai corpus (TH-ELT vs. THBA), Thai students in business administration show less frequent use of frame markers $(\mathrm{Nf}=23.5)$ than Thai students in English language teaching $(\mathrm{Nf}=33.3)$. The log-likelihood value of 21.67 shows that the higher incidence of frame markers in the TH-ELT corpus is significant at the level of $p<.0001$, as presented in Table 5.16.

Table 5.16. Frame markers in TH-ELT and TH-BA subcorpora

\begin{tabular}{|c|c|c|c|c|c|c|}
\hline & \multicolumn{4}{|c|}{ THAI } & \multirow{3}{*}{\multicolumn{2}{|c|}{ Log-likelihood }} \\
\hline & \multirow{2}{*}{\multicolumn{2}{|c|}{$\begin{array}{c}\text { TH-ELT } \\
\text { (125,631 words) }\end{array}$}} & \multirow{2}{*}{\multicolumn{2}{|c|}{$\begin{array}{c}\text { TH-BA } \\
(128,691 \text { words })\end{array}$}} & & \\
\hline & & & & & & \\
\hline & Raw & $\mathrm{Nf}$ & Raw & $\mathrm{Nf}$ & LL & $p$-value \\
\hline Frame markers & 418 & 33.3 & 302 & 23.5 & 21.67 & $p<.0001$ \\
\hline
\end{tabular}

\subsubsection{Frequencies of frame markers in ELT and BA corpora}

As shown in Table 5.17, the English language teaching corpus contains more frame markers $(\mathrm{Nf}=24.1)$ compared to the business administration corpus $(\mathrm{Nf}=21.8)$. However, the frequency in the language teaching corpus is not significantly different from that in the business corpus, as indicated by the log-likelihood value of $3.66(p>.05)$.

Table 5.17. Frame markers in ELT and BA corpora

\begin{tabular}{|c|c|c|c|c|c|c|}
\hline & \multicolumn{2}{|c|}{$\begin{array}{c}\text { ELT } \\
(326,730 \text { words) }\end{array}$} & \multicolumn{2}{|c|}{$\begin{array}{c}\text { BA } \\
(272,869 \text { words })\end{array}$} & \multicolumn{2}{|c|}{ Log-likelihood } \\
\hline & Raw & $\mathrm{Nf}$ & Raw & $\mathrm{Nf}$ & LL & $p$-value \\
\hline Frame markers & 789 & 24.1 & 594 & 21.8 & 3.66 & $p>.05$ \\
\hline
\end{tabular}


With regard to a comparison of frame markers between New Zealand and Thai theses in the English language teaching discipline (NZ-ELT vs. TH-ELT), Thai students in the language teaching discipline include 33.3 frame markers in every 10,000 words, while New Zealand students include only 18.4 frame markers. The higher incidence of frame markers in the THELT corpus is significant, as determined by the log-likelihood calculation of 68.17 at the level of $p<.0001$.

Table 5.18. Frame markers in NZ-ELT and TH-ELT subcorpora

\begin{tabular}{|c|c|c|c|c|c|c|}
\hline & \multicolumn{4}{|c|}{ ENGLISH LANGUAGE TEACHING } & \multirow{3}{*}{\multicolumn{2}{|c|}{ Log-likelihood }} \\
\hline & \multirow{2}{*}{\multicolumn{2}{|c|}{$\begin{array}{c}\text { NZ-ELT } \\
\text { (201,099 words) }\end{array}$}} & \multirow{2}{*}{\multicolumn{2}{|c|}{$\begin{array}{c}\text { TH-ELT } \\
\text { (125,631 words) }\end{array}$}} & & \\
\hline & & & & & & \\
\hline & Raw & $\mathrm{Nf}$ & Raw & $\mathrm{Nf}$ & LL & $p$-value \\
\hline Frame markers & 371 & 18.4 & 418 & 33.3 & 68.17 & $p<.0001$ \\
\hline
\end{tabular}

In contrast, a comparison within the business administration discipline (NZ-BA vs. TH-BA) reveals that there is no significant difference in the incidence of frame markers between New Zealand and Thai theses in the business administration corpus. The normalized frequency of frame markers in the TH-BA corpus $(\mathrm{Nf}=23.5)$ is slightly higher than in the NZ-BA corpus $(\mathrm{Nf}=20.3)$. The log-likelihood value is 3.22 determining a non-significant difference between the two groups $(p>.05)$.

Table 5.19. Frame markers in NZ-BA and TH-BA subcorpora

\begin{tabular}{|c|c|c|c|c|c|c|}
\hline & \multicolumn{4}{|c|}{ BUSINESS ADMINISTRATION } & \multirow{3}{*}{\multicolumn{2}{|c|}{ Log-likelihood }} \\
\hline & \multirow{2}{*}{\multicolumn{2}{|c|}{$\begin{array}{c}\text { NZ-BA } \\
(144,178 \text { words) }\end{array}$}} & \multirow{2}{*}{\multicolumn{2}{|c|}{$\begin{array}{c}\text { TH-BA } \\
\text { (128,691 words) }\end{array}$}} & & \\
\hline & & & & & & \\
\hline & Raw & $\mathrm{Nf}$ & Raw & $\mathrm{Nf}$ & LL & $p$-value \\
\hline Frame markers & 292 & 20.3 & 302 & 23.5 & 3.22 & $p>.05$ \\
\hline
\end{tabular}

This section concludes that Thai students use markedly more frame markers than New Zealand students. The cross-disciplinary comparison within the New Zealand context (NZ-ELT vs. NZBA) indicates that there is no significant difference in the incidence of frame markers between the two disciplines in the New Zealand corpus. The cross-disciplinary comparison within the Thai corpus (TH-ELT vs. TH-BA) indicates a significantly higher frequency of frame markers in the TH-ELT corpus. Furthermore, overall English language teaching students do not 
significantly differ from business administration students in the frequency of frame markers. The comparison between New Zealand and Thai theses within the English language teaching discipline (NZ-ELT vs. TH-ELT) suggests a significantly higher frequency of frame markers in the TH-ELT corpus. In the business administration discipline (NZ-BA vs. TH-BA), there is no significant difference in the incidence of frame markers between the two subcorpora.

\subsubsection{Types of frame markers}

Among a wide range of frame markers on the pre-identified list, 38 types of frame markers are used in NZ-ELT, 32 types in NZ-BA, 46 types in TH-ELT, and 38 types in TH-BA. There are 21 markers overlapping in all subcorpora. The small number of shared types of markers indicates that New Zealand and Thai students include different types of markers in their disciplinary theses.

Table 5.20 lists the top ten frame markers found in the four subcorpora. There are only three markers shared by students in the four groups: firstly, (in) this chapter, and finally. In addition to these markers, divided by educational context, New Zealand students in the two disciplines (NZ-ELT and NZ-BA) share three other markers, namely (in) this section, overall, and listing $(a, b, c)$. Thai students in the two disciplines (TH-ELT and TH-BA) share five other types of frame markers, namely numbering $(1,2,3)$, regarding, secondly, second, and lastly. This means that eight of ten high frequency frame markers used by Thai students in the two disciplines are the same.

From the top ten frame marker list, there are some markers which appear as high frequency frame markers in three subcorpora but do not appear in one corpus, namely the absence of (in) this section in TH-BA, second in NZ-BA, and secondly, numbering $(1,2,3)$ and lastly in NZELT. Furthermore, some markers are found on the top ten list of a corpus, namely the presence of then and now in NZ-ELT, purpose in NZ-BA, with regard to in TH-ELT, and in conclusion in TH-BA. 
Table 5.20. Top ten frame marker list

\begin{tabular}{|c|c|c|c|c|c|c|c|c|}
\hline & \multicolumn{4}{|c|}{ NEW ZEALAND } & \multicolumn{4}{|c|}{ THAI } \\
\hline & \multicolumn{2}{|c|}{ NZ-ELT } & \multicolumn{2}{|c|}{ NZ-BA } & \multicolumn{2}{|c|}{ TH-ELT } & \multicolumn{2}{|l|}{ TH-BA } \\
\hline & Type & $\mathrm{Nf}$ & Type & $\mathrm{Nf}$ & Type & $\mathrm{Nf}$ & Type & $\mathrm{Nf}$ \\
\hline 1 & first & 1.5 & firstly & 2.2 & numbering & 5.4 & numbering & 2.7 \\
\hline 2 & firstly & 1.2 & finally & 2.1 & regarding & 3.1 & lastly & 1.9 \\
\hline 3 & (in) this chapter & 1.2 & secondly & 1.8 & (in) this chapter & 2.3 & finally & 1.8 \\
\hline 4 & (in) this section & 1.2 & (in) this chapter & 1.8 & firstly & 2.1 & first & 1.6 \\
\hline 5 & second & 1.1 & numbering & 1.2 & secondly & 2.0 & secondly & 1.3 \\
\hline 6 & then & 0.9 & overall & 1.0 & (in) this section & 1.4 & in conclusion & 1.2 \\
\hline 7 & now & 0.9 & listing & 0.9 & finally & 1.3 & second & 1.2 \\
\hline 8 & overall & 0.9 & (in) this section & 0.9 & second & 1.2 & regarding & 1.2 \\
\hline 9 & finally & 0.9 & purpose & 0.9 & with regard to & 1.2 & (in) this chapter & 1.1 \\
\hline 10 & listing & 0.8 & lastly & 0.8 & lastly & 1.1 & firstly & 0.9 \\
\hline & SUM NF=18.4 & $\begin{array}{c}10.6 \\
(57.6 \%)\end{array}$ & SUM NF=20.3 & $\begin{array}{c}13.6 \\
(67.0 \%)\end{array}$ & SUM NF=33.3 & $\begin{array}{c}21.1 \\
(63.4 \%)\end{array}$ & SUM NF=23.5 & $\begin{array}{c}14.9 \\
(63.4 \%)\end{array}$ \\
\hline
\end{tabular}

Bolded markers represent the popular markers on the top ten list shared across the four subcorpora.

Italic markers represent the popular markers shared by two disciplines within each context.

Some types of frame markers are more likely to be found in the New Zealand corpus (NZ-ELT and NZ-BA) or the Thai corpus (TH-ELT and TH-BA). Subsequently and (in) the X section are only found in NZ-ELT and NZ-BA (Excerpts 5.18-5.19). The markers which occur solely in TH-ELT and TH-BA are regarding, with regard to, and concerning (Excerpts 5.20-5.22).

(5.18) Initial analysis was conducted inductively at the individual participant level. Subsequently, to provide a greater level of abstraction and focus for this research study the SCOT model was applied deductively... (NZ-ELT-15)

(5.19) The first section presents a summarised description of the dissertation chapters and the main findings of this study. The second section highlights the limitations of this research and provides suggestions for future research; while the third section covers recommendations. (NZ-BA-30)

(5.20) Less than half have taken consulting in preventive maintenance which helps them reduce costs. Regarding the need for consulting services, quantitative results revealed that... (TH-BA-04) 
(5.21) This finding, therefore, fully supports the contribution of reading to incidental vocabulary acquisition. With regard to the effect of content familiarity, out of 15 texts, the effect of this factor was showed in two texts... (TH-ELT-09)

(5.22) The successful students used all six strategy categories significantly more often than unsuccessful ones did. Concerning the most preferred strategy categories, all 4 proficiency groups identified the metacognitive strategy category as the most frequently used. (TH-ELT-12)

This section discusses the distribution of higher and lower frequency frame markers. As presented in Table 5.20 and Figure 5.2, the top ten frame markers in NZ-BA occupy 13.6 out of 20.3 occurrences, accounting for $67 \%$ of all the occurrences of frame markers in this corpus. In TH-ELT and TH-BA, the top ten frame markers occur 21.1 out of 33.3 times (63.4\% of all the occurrences) and 14.9 out of 23.5 times (63.4\% of all the occurrences), respectively. In NZELT, the top ten frame markers occupy 10.6 out of 18.4 occurrences, accounting for $57.6 \%$ of all the occurrences of frame markers in this corpus.

Considering variation between two disciplines in the New Zealand corpus (NZ-ELT and NZBA), New Zealand students in business administration rely heavily on the top ten frame markers on the list (67:33 for higher and lower frequency frame markers) when structuring the discussion and conclusion chapters. As illustrated in Figure 5.2, their compatriots in English langauge teaching are more likely to maintain a similar proportion in the use of higher and lower frequency frame markers in their theses (57.6:42.4 for higher and lower frequency frame markers). Within the Thai corpus (TH-ELT and TH-BA), Thai students in the two disciplines similarly make greater use of higher frequency frame markers in their theses (63.4:36.6 for higher and lower frequency frame markers). In other words, New Zealand students in English language teaching maintain a similar proportion of use of higher and lower frequency frame markers, while other groups of students are more likely to focus on the top ten markers, although not to the same extent as transition markers. 


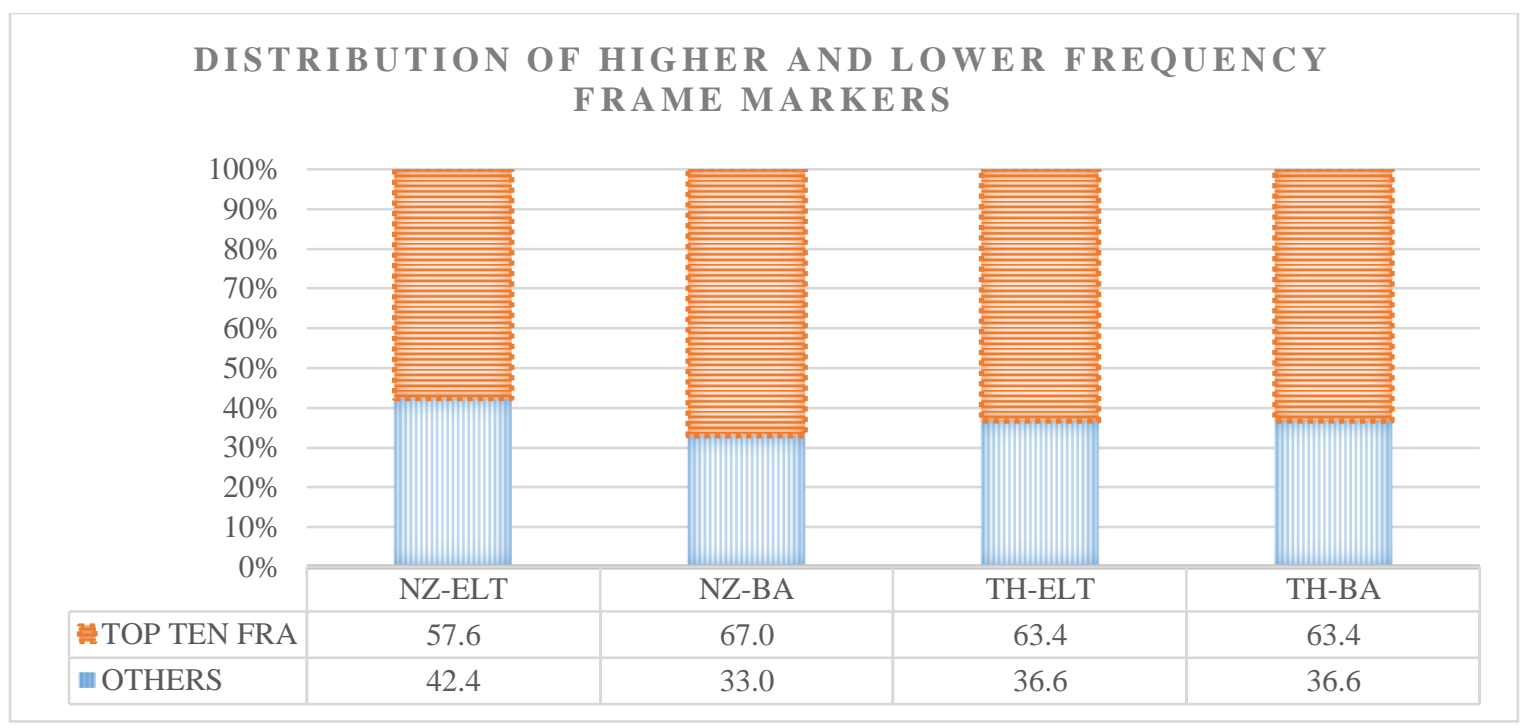

Figure 5.2. Distribution of higher and lower frequency frame markers

\subsubsection{Functions of frame markers}

\section{(i) Sequencing arguments}

As shown in Table 5.21, New Zealand and Thai students use similar types of frame markers to show sequences of arguments and organize the chapter structure in a way which is easier for readers to perceive. Based on the top ten frame marker list, high frequency sequencers are firstly, finally, first, second, secondly, then, lastly, listing ( $a, b, c)$, and numbering (1, 2, 3). The markers firstly and finally are found to be the most salient sequencers to mark the first and last orders of propositional content in a topic across the four subcorpora. Often, New Zealand students in both disciplines (NZ-ELT and NZ-BA) make a list of propositional content in their discussion and conclusion chapters by using letters a, b, c, etc., but this textual feature is not frequently found in the Thai thesis corpus. Thai students in both disciplines and New Zealand students in business administration (TH-ELT, TH-BA, and NZ-BA) often use a list of Arabic numbers $(1,2,3)$ or Roman numbers $(i, i i, i i)$ to order units of arguments. This enumeration feature is not very apparent in NZ-ELT. The use of alphabetical and enumerative listing in New Zealand and Thai students' theses is mainly for the purpose of summarizing key research findings, suggesting future research directions, and indicating limitations of present research in the discussion and conclusion chapters. 
Table 5.21. High frequency frame markers for sequencing arguments

\begin{tabular}{ll}
\hline Corpus & Frame markers for sequencing arguments \\
\hline NZ-ELT & firstly, finally, first, second, then, listing \\
NZ-BA & firstly, finally, secondly, lastly, listing, numbering \\
TH-ELT & firstly, finally, second, secondly, lastly, numbering \\
TH-BA & firstly, finally, first, second, secondly, lastly, numbering \\
\hline
\end{tabular}

(ii) Labelling discourse acts

Based on the top ten list, there are a few markers which New Zealand and Thai postgraduates frequently employ to signpost a certain stage of text. As seen in Table 5.22, high frequency discourse-label markers in New Zealand and Thai students' theses are now, overall, and in conclusion.

Table 5.22. High frequency frame markers for labelling discourse acts

\begin{tabular}{ll}
\hline Corpus & Frame markers for labelling discourse acts \\
\hline NZ-ELT & overall, now \\
NZ-BA & overall \\
TH-ELT & - \\
TH-BA & in conclusion \\
\hline
\end{tabular}

Overall is frequently used in New Zealand students' theses in both disciplines. Now appears as a high frequency frame marker to label current discourse in NZ-ELT as well as in conclusion in TH-BA. It is interesting that there is no discourse-label marker appearing on the high frequency marker list in TH-ELT. Nonetheless, it should be stressed that in conclusion is also used in TH-ELT but below the top ten list.

(5.23) Overall, the important finding that emerged in this study for me was the importance of what Gilbert (2006) calls "catching the knowledge wave” ... (NZ-ELT-17)

(5.24) I will now discuss those aspects that arose, namely time and participants' perceptions of their roles. (NZ-ELT-03)

(5.25) In conclusion, educational universities and institutions, as well as national, regional and local governments must engage in attracting international students by... (TH-BA08) 


\section{(iii) Announcing discourse goals}

As for frame markers used to indicate a specific goal of current discourse, New Zealand and Thai students are likely to specify a goal within a boundary or level of discourse (e.g., section, chapter) and use similar markers such as (in) this chapter and (in) this section (Excerpts 5.265.28). Specifying goals at sentence and paragraph levels is not found.

Table 5.23. High frequency frame markers for announcing discourse goals

\begin{tabular}{ll}
\hline Corpus & Frame markers for announcing discourse goals \\
\hline NZ-ELT & (in) this chapter, (in) this section \\
NZ-BA & (in) this chapter, (in) this section, purpose \\
TH-ELT & (in) this chapter, (in) this section \\
TH-BA & (in) this chapter \\
\hline
\end{tabular}

It is apparent that New Zealand students in business administration tend to use a direct marker like purpose to announce intended goals. Nevertheless, the marker purpose usually co-occurs with discourse boundary markers like this chapter and this section (Excerpt 5.29).

(5.26) This chapter examines how aspects of mentoring have assisted the Maori tertiary students to prepare for employment. (NZ-ELT-16)

(5.27) In this chapter, I summarise my study, discuss its limitations and consider transferability. (NZ-ELT-03)

(5.28) This section discusses the findings of the study in relation to the South Korean ethnolinguistic context. (NZ-ELT-23)

(5.29) The purpose of this chapter was to discuss the different implications (i.e. theoretical, managerial, and public policy) of the present study findings. (NZ-BA-30)

\section{(iv) Signposting topic shifts}

Frame markers for topic shifts are absent from the top ten list in NZ-ELT and NZ-BA. This suggests that New Zealand students are likely to shift from one topic to another without giving a signpost for readers or use other means to shift topics such as new headings. 
Table 5.24. High frequency frame markers for signposting topic shifts

\begin{tabular}{ll}
\hline Corpus & Frame markers for signposting topic shifts \\
\hline NZ-ELT & - \\
NZ-BA & - \\
TH-ELT & regarding, with regard to \\
TH-BA & regarding \\
\hline
\end{tabular}

On the other hand, Thai students in both disciplines seem to frequently include a topic shift marker like regarding and with regard to (Excerpts 5.30-5.31). This reflects that Thai students place a high priority on accommodating the readers to comprehend their theses.

(5.30) With regard to the attitudes towards lesson features provided in vocabulary learning package, it is remarkable that all the lesson features in the package were helpful to them in learning and retaining vocabulary. (TH-ELT-10)

(5.31) Regarding the students' vocabulary sizes, the research subjects gained high score on vocabulary levels test at the 1000 - and 2000 -word levels ( $86.5 \%$ and $74 \%$ respectively). (TH-ELT-07)

Table 5.25 below shows both similarities and differences of New Zealand and Thai postgraduates in functional use of frame markers. Identified frame markers in all four subcorpora are mainly employed by New Zealand and Thai postgraduates to sequence arguments and structure the thesis discussion and conclusion chapters. However, a clear difference between New Zealand and Thai students is that Thai students in both disciplines exhibit considerable use of frame markers for signposting topic shifts, but this feature is rarely used in NZ-ELT $(\mathrm{Nf}=0.2$ accounting for $1.1 \%)$ and completely omitted from NZ-BA $(\mathrm{Nf}=0$ accounting for $0 \%$ in NZ-BA).

Investigating disciplinary variation within each context, New Zealand students in English language teaching and business administration share the same preference for the use of frame markers mainly to sequence arguments $(\mathrm{Nf}=10.8$ accounting for $59 \%$ in NZ-ELT, $\mathrm{Nf}=13.5$ accounting for $66.5 \%$ in NZ-BA), to announce discourse goals ( $\mathrm{Nf}=4.2$ accounting for $23 \%$ in NZ-ELT, Nf=4.4 accounting for $21.7 \%$ in NZ-BA), and to label different stages of discourse $(\mathrm{Nf}=3.1$ accounting for $16.9 \%$ in $\mathrm{NZ}-\mathrm{ELT}, \mathrm{Nf}=2.4$ accounting for $11.8 \%$ in NZ-BA), respectively. 
Within the Thai corpus, there is slight variation between the two disciplines. That is, Thai students in English language teaching tend to use frame markers for the purpose of sequencing arguments $(\mathrm{Nf}=18.7$ accounting for $56.3 \%)$, signposting topic shifts $(\mathrm{Nf}=5.8$ accounting for $17.5 \%)$, announcing discourse goals ( $\mathrm{Nf}=5$ accounting for $15.1 \%)$, and labelling discourse acts $(\mathrm{Nf}=3.7$ accounting for $11.1 \%$ ), respectively. Thai students in business administration, on the other hand, prefer to use frame markers for the purpose of sequencing arguments $(\mathrm{Nf}=15.1$ accounting for $64.5 \%$ ), announcing goals ( $\mathrm{Nf}=3.7$ accounting for $15.8 \%$ ), labelling discourse acts $(\mathrm{Nf}=2.6$ accounting for $11.1 \%)$, and signposting topic shifts $(\mathrm{Nf}=2$ accounting for $8.6 \%)$, respectively. In other words, the topic shift function of frame markers is more salient in Thai students' theses in English language teaching, compared to other Thai and New Zealand corpora.

Table 5.25. Functions of frame markers

\begin{tabular}{|c|c|c|c|c|c|c|c|c|c|c|c|c|}
\hline \multirow[t]{2}{*}{ Corpus } & \multicolumn{3}{|c|}{$\begin{array}{l}\text { Sequencing } \\
\text { arguments }\end{array}$} & \multicolumn{3}{|c|}{$\begin{array}{l}\text { Labelling discourse } \\
\text { acts }\end{array}$} & \multicolumn{3}{|c|}{$\begin{array}{c}\text { Announcing discourse } \\
\text { goals }\end{array}$} & \multicolumn{3}{|c|}{ Signposting topic shifts } \\
\hline & Raw & $\mathrm{Nf}$ & $\%$ & Raw & $\mathrm{Nf}$ & $\%$ & Raw & $\mathrm{Nf}$ & $\%$ & Raw & $\mathrm{Nf}$ & $\%$ \\
\hline NZ-ELT & 218 & 10.8 & $59.0 \%$ & 63 & 3.1 & $16.9 \%$ & 85 & 4.2 & $23.0 \%$ & 5 & 0.2 & $1.1 \%$ \\
\hline NZ-BA & 194 & 13.5 & $66.5 \%$ & 34 & 2.4 & $11.8 \%$ & 64 & 4.4 & $21.7 \%$ & 0 & 0.0 & $0.0 \%$ \\
\hline TH-ELT & 235 & 18.7 & $56.3 \%$ & 47 & 3.7 & $11.1 \%$ & 63 & 5.0 & $15.1 \%$ & 73 & 5.8 & $17.5 \%$ \\
\hline TH-BA & 194 & 15.1 & $64.5 \%$ & 34 & 2.6 & $11.1 \%$ & 48 & 3.7 & $15.8 \%$ & 26 & 2.0 & $8.6 \%$ \\
\hline
\end{tabular}

\subsection{Endophoric markers}

\subsubsection{Frequencies of endophoric markers in NZ and TH corpora}

Table 5.26 shows normalized frequencies of endophoric markers in the New Zealand and Thai corpora. New Zealand and Thai students exhibit similar frequencies in the use of endophoric markers $(\mathrm{Nf}=12.9$ in $\mathrm{NZ}, \mathrm{Nf}=12.6$ in $\mathrm{TH})$. Accordingly, there is no significant difference overall in the use of endophoric markers between New Zealand and Thai students, as indicated by the log-likelihood value of $0.13(p>.05)$. 
Table 5.26. Endophoric markers in NZ and TH corpora

\begin{tabular}{|c|c|c|c|c|c|c|}
\hline & \multicolumn{2}{|c|}{$\begin{array}{l}\text { NEW ZEALAND } \\
(345,277 \text { words })\end{array}$} & \multicolumn{2}{|c|}{$\begin{array}{c}\text { THAI } \\
\text { (254,322 words) }\end{array}$} & \multicolumn{2}{|c|}{ Log-likelihood } \\
\hline & Raw & $\mathrm{Nf}$ & Raw & $\mathrm{Nf}$ & LL & $p$-value \\
\hline $\begin{array}{l}\text { Endophoric } \\
\text { markers }\end{array}$ & 446 & 12.9 & 320 & 12.6 & 0.13 & $p>.05$ \\
\hline
\end{tabular}

With regard to a comparison between two disciplines in the New Zealand context (NZ-ELT vs. NZ-BA), Table 5.27 shows that New Zealand students in English language teaching and business administration exhibit a similarity in the frequency of using endophoric markers in their theses. Although New Zealand students in business administration have slightly more frequent use of endophoric markers $(\mathrm{Nf}=13.9)$ than their compatriots in the language teaching discipline $(\mathrm{Nf}=12.2)$, this frequency difference is not statistically significant, as determined by the log-likelihood value of $1.74(p>.05)$.

Table 5.27. Endophoric markers in NZ-ELT and NZ-BA subcorpora

\begin{tabular}{|c|c|c|c|c|c|c|}
\hline & \multicolumn{4}{|c|}{ NEW ZEALAND } & \multirow{3}{*}{\multicolumn{2}{|c|}{ Log-likelihood }} \\
\hline & \multirow{2}{*}{\multicolumn{2}{|c|}{$\begin{array}{c}\text { NZ-ELT } \\
\text { (201,099 words) }\end{array}$}} & \multirow{2}{*}{\multicolumn{2}{|c|}{$\begin{array}{c}\text { NZ-BA } \\
(144,178 \text { words })\end{array}$}} & & \\
\hline & & & & & & \\
\hline & Raw & $\mathrm{Nf}$ & Raw & $\mathrm{Nf}$ & LL & $p$-value \\
\hline $\begin{array}{l}\text { Endophoric } \\
\text { markers }\end{array}$ & 246 & 12.2 & 200 & 13.9 & 1.74 & $p>.05$ \\
\hline
\end{tabular}

As for a cross-disciplinary comparison within the Thai corpus (TH-ELT vs. TH-BA), Thai theses in business administration contain fewer endophoric markers $(\mathrm{Nf}=7.6)$ than Thai theses in English language teaching $(\mathrm{Nf}=17.7)$. The log-likelihood calculation of 52.36 indicates statistical significance of the higher incidence of endophoric markers in the TH-ELT corpus at the level of $p<.0001$.

Table 5.28. Endophoric markers in TH-ELT and TH-BA subcorpora

\begin{tabular}{lcccccc}
\hline & \multicolumn{3}{c}{ THAI } & & \\
\cline { 2 - 5 } & \multicolumn{2}{c}{$\begin{array}{c}\text { TH-ELT } \\
(125,631 \text { words })\end{array}$} & TH-BA & Log-likelihood \\
& Raw & Nf & Raw & Nf & LL & $p$-value \\
\cline { 2 - 5 } $\begin{array}{l}\text { Endophoric } \\
\text { markers }\end{array}$ & 222 & 17.7 & 98 & 7.6 & 52.36 & $p<.0001$ \\
\hline
\end{tabular}




\subsubsection{Frequencies of endophoric markers in ELT and BA corpora}

A comparison of endophoric markers between English language teaching and business administration disciplines indicates a higher frequency of endophoric markers in the English language teaching discipline. Based on the frequency normalization per 10,000 words, 14.3 endophoric markers are found in the language teaching corpus and 10.9 markers in the business corpus. The higher frequency of endophoric markers in the language teaching corpus is significant, as determined by the log-likelihood value of 13.63 at the level of $p<.001$.

Table 5.29. Endophoric markers in ELT and BA corpora

\begin{tabular}{|c|c|c|c|c|c|c|}
\hline & \multicolumn{2}{|c|}{$\begin{array}{c}\text { ELT } \\
(326,730 \text { words })\end{array}$} & \multicolumn{2}{|c|}{$\begin{array}{c}\text { BA } \\
(272,869 \text { words })\end{array}$} & \multicolumn{2}{|c|}{ Log-likelihood } \\
\hline & Raw & $\mathrm{Nf}$ & Raw & $\mathrm{Nf}$ & LL & $p$-value \\
\hline $\begin{array}{l}\text { Endophoric } \\
\text { markers }\end{array}$ & 468 & 14.3 & 298 & 10.9 & 13.63 & $p<.001$ \\
\hline
\end{tabular}

When investigating variation between New Zealand and Thai theses within the language teaching corpus (NZ-ELT vs. TH-ELT), a higher frequency of endophoric markers is found in Thai students' English language teaching theses. In every 10,000 words, 12.2 and 17.7 endophoric markers are likely to be found in the NZ-ELT corpus and the TH-ELT corpus, respectively. The log-likelihood calculation of 15.60 determines statistical significance of the higher incidence of endophoric markers in the TH-ELT corpus at the level of $p<.0001$.

Table 5.30. Endophoric markers in NZ-ELT and TH-ELT subcorpora

\begin{tabular}{|c|c|c|c|c|c|c|}
\hline & \multicolumn{4}{|c|}{ ENGLISH LANGUAGE TEACHING } & \multirow{3}{*}{\multicolumn{2}{|c|}{ Log-likelihood }} \\
\hline & \multirow{2}{*}{\multicolumn{2}{|c|}{$\begin{array}{c}\text { NZ-ELT } \\
\text { (201,099 words) }\end{array}$}} & \multirow{2}{*}{\multicolumn{2}{|c|}{$\begin{array}{c}\text { TH-ELT } \\
(125,631 \text { words) }\end{array}$}} & & \\
\hline & & & & & & \\
\hline & Raw & $\mathrm{Nf}$ & Raw & $\mathrm{Nf}$ & LL & $p$-value \\
\hline $\begin{array}{l}\text { Endophoric } \\
\text { markers }\end{array}$ & 246 & 12.2 & 222 & 17.7 & 15.60 & $p<.0001$ \\
\hline
\end{tabular}

As for variation between New Zealand and Thai theses in the business administration corpus (NZ-BA vs. TH-BA), New Zealand students in business administration use endophoric markers 13.9 times, while Thai students in the business discipline use them only 7.6 times in every 10,000 words. The log-likelihood calculation of 25 determines the higher frequency in the NZ-BA corpus is significant at the level of $p<.0001$. 
Table 5.31. Endophoric markers in NZ-BA and TH-BA subcorpora

\begin{tabular}{lcccccc}
\hline & \multicolumn{4}{c}{ BUSINESS ADMINISTRATION } & & Log-likelihood \\
\cline { 2 - 5 } & \multicolumn{2}{c}{$\begin{array}{c}\text { NZ-BA } \\
(144,178 \text { words })\end{array}$} & \multicolumn{2}{c}{$\begin{array}{c}\text { TH-BA } \\
(128,691 \text { words })\end{array}$} & & \\
\cline { 2 - 6 } & Raw & Rf & Raw & Nf & LL & $p$-value \\
\hline $\begin{array}{l}\text { Endophoric } \\
\text { markers }\end{array}$ & 200 & 13.9 & 98 & 7.6 & 25.00 & $p<.0001$ \\
\hline
\end{tabular}

This section concludes that overall New Zealand and Thai students have the same frequency in using endophoric markers. The cross-disciplinary comparison within the New Zealand corpus (NZ-ELT vs. NZ-BA) indicates that there is no significant difference in the incidence of endophoric markers between the two disciplines in the New Zealand corpus. The crossdisciplinary comparison within the Thai corpus (TH-ELT vs. TH-BA) indicates a significantly higher frequency of endophoric markers in the TH-ELT corpus. Furthermore, overall English language teaching students make more frequent use of endophoric markers than business administration students. The comparison between New Zealand and Thai theses within the English language teaching discipline (NZ-ELT vs. TH-ELT) suggests a significantly higher frequency of endophoric markers in the TH-ELT corpus. In the business administration discipline (NZ-BA vs. TH-BA), the NZ-BA corpus has a significantly higher frequency of endophoric markers.

\subsubsection{Types of endophoric markers}

Overall, there are not many types or tokens of endophoric markers used in the four subcorpora. Twelve types of endophoric markers are found in NZ-ELT, 13 types in NZ-BA, 12 types in TH-ELT, and 8 types in TH-BA. All 8 types of endophoric markers identified in TH-BA are found in the other three subcorpora. This result suggests that Thai students in business administration rely on a smaller cluster of endophoric markers, when compared to other groups of students.

Table 5.32 provides the top ten endophoric markers in the four subcorpora. There are eight types of endophoric markers shared over all the subcorpora, namely Table X, (In) Chapter X, $X$ above, Figure X, X below, X earlier, (In) the X section, and (In) the X chapter.

Divided by context, New Zealand students in the two disciplines share two other types of markers, (In) Section $X$ and Page $X$. This means that New Zealand students in the two 
disciplines frequently use the same types of endophoric markers to refer to information in earlier or forthcoming parts of the text. The abbreviation $P$. $X$ for Page $\mathrm{X}$ and Example $X$ are found only in TH-ELT.

Table 5.32. Top ten endophoric marker list

\begin{tabular}{|c|c|c|c|c|c|c|c|c|}
\hline & \multicolumn{4}{|c|}{ NEW ZEALAND } & \multicolumn{4}{|c|}{ THAI } \\
\hline & \multicolumn{2}{|l|}{ NZ-ELT } & \multicolumn{2}{|l|}{ NZ-BA } & \multicolumn{2}{|l|}{ TH-ELT } & \multicolumn{2}{|l|}{ TH-BA } \\
\hline & Type & $\mathrm{Nf}$ & Type & $\mathrm{Nf}$ & Type & $\mathrm{Nf}$ & Type & $\mathrm{Nf}$ \\
\hline 1 & Table X & 2.2 & Figure $\mathrm{X}$ & 2.7 & Table X & 5.2 & Table X & 2.4 \\
\hline 2 & (In) Chapter X & 1.7 & (In) Section $X$ & 2.2 & $\mathbf{X}$ below & 3.2 & $\mathbf{X}$ above & 2.4 \\
\hline 3 & (In) Section $X$ & 1.6 & $\mathbf{X}$ below & 1.7 & $\mathrm{X}$ above & 2.5 & $\mathbf{X}$ below & 0.9 \\
\hline 4 & $\mathrm{X}$ above & 1.4 & Table X & 1.3 & P. $\mathrm{X}$ & 1.9 & Figure $\mathrm{X}$ & 0.6 \\
\hline 5 & Figure $\mathbf{X}$ & 1.1 & (In) the $X$ section & 1.2 & Example X & 1.8 & (In) Chapter X & 0.5 \\
\hline 6 & Page X & 1.0 & $\mathbf{X}$ earlier & 1.2 & (In) Chapter X & 1.4 & $\mathbf{X}$ earlier & 0.4 \\
\hline 7 & $\mathbf{X}$ below & 0.7 & (In) Chapter X & 1.0 & (In) the $X$ chapter & 0.6 & (In) the $X$ chapter & 0.2 \\
\hline 8 & $\mathbf{X}$ earlier & 0.7 & (In) the $X$ chapter & 0.9 & $\mathbf{X}$ earlier & 0.4 & (In) the $X$ section & 0.2 \\
\hline 9 & (In) the $X$ section & 0.6 & $\mathrm{X}$ above & 0.9 & (In) the $\mathrm{X}$ section & 0.3 & - & - \\
\hline 10 & (In) the $X$ chapter & 0.5 & Page $X$ & 0.3 & Figure X & 0.2 & - & - \\
\hline & SUM NF $=12.2$ & $\begin{array}{l}11.5 \\
(94.3 \%)\end{array}$ & SUM NF=13.9 & $\begin{array}{l}13.4 \\
(96.4 \%)\end{array}$ & SUM NF=17.7 & $\begin{array}{l}17.5 \\
(98.9 \%)\end{array}$ & SUM NF=7.6 & $\begin{array}{l}7.6 \\
(100 \%)\end{array}$ \\
\hline
\end{tabular}

Bolded markers represent the popular markers on the top ten list shared across the four subcorpora.

Italic markers represent the popular markers shared by two disciplines within each context.

A sum of normalized frequencies and percentage of the top ten endophoric markers reveal a similar proportion in the use of the ten markers across all subcorpora. The top ten endophoric markers in the four subcorpora occupy more than $90 \%$ of the total occurrences in each corpus. As illustrated in Figure 5.3, the ten high frequency endophoric markers occur 11.5 out of 12.2 times $(94.3 \%)$ in NZ-ELT, 13.4 out of 13.9 times (96.4\%) in NZ-BA, and 17.5 out of 17.7 times $(98.9 \%)$ in TH-ELT. As TH-BA theses contain only eight types of endophoric markers, the markers on the list account for $100 \%$ of the total occurrences in this corpus. These findings suggest that New Zealand and Thai students have a great reliance on the top ten markers when making a reference to other parts of their theses. The lower frequency endophoric markers like as I noted in..., as we saw in..., and as we shall see in... are rarely employed in New Zealand or Thai students' theses. 


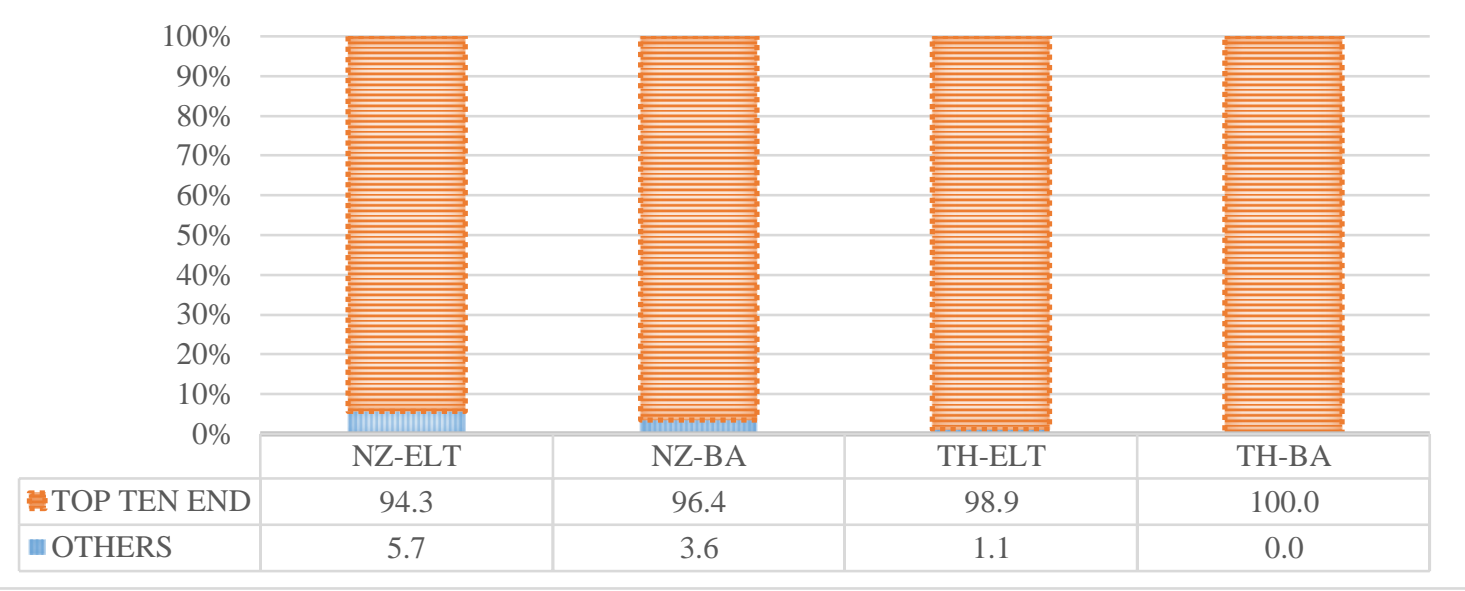

Figure 5.3. Distribution of higher and lower frequency endophoric markers

\subsubsection{Functions of endophoric markers}

\section{(i) Linear text references}

Table 5.33 compares high frequency endophoric markers used by New Zealand and Thai students in the two disciplines for linear text references in their theses. The linear text reference function can be either backward reference or forward reference. The backward reference markers take the readers back to previous arguments and remind them of what has been discussed. The forward reference markers preview for the readers what will be discussed in the following parts of the text.

Table 5.33. High frequency endophoric markers for linear text references

\begin{tabular}{ll}
\hline Corpus & Endophoric markers for linear text references \\
\hline NZ-ELT & (In) Chapter X, (In) the X chapter, (In) Section X, (In) the X section, X above, X earlier, X below, Page X \\
NZ-BA & (In) Chapter X, (In) the X chapter, (In) Section X, (In) the X section, X above, X earlier, X below, Page X \\
TH-ELT & (In) Chapter X, (In) the X chapter, (In) the X section, X above, X earlier, X below, P. X \\
TH-BA & (In) Chapter X, (In) the X chapter, (In) the X section, X above, X earlier, X below \\
\hline
\end{tabular}

However, it is hard to identify the functions of some endophoric markers by only looking at forms, e.g., Chapter 4, In Section 2.6, Page 67, (Excerpts 5.32-5.33). These forms can denote a function of frame markers such as Chapter 6 discusses and Section 3.1 reports. The location where the markers appear (whether before or after current discourse), together with a bigger chunk of markers (Excerpt 5.34), can reveal a more accurate function of such markers. 
(5.32) In section 2.6, a theory of entrepreneurship was defined as a verifiable and logically coherent formulation of relationships... (NZ-BA-16)

(5.33) The third observation feedback from the recorded meeting was positive and affirming of what was happening...(see page $67 \& 68)$. (NZ-ELT-08)

(5.34) Additionally, allocation of these themes was also based on the original conceptual model as presented in section 2.6. (NZ-BA-13)

The endophoric markers whose functions can be identified by forms are the markers like $X$ above and $X$ earlier expressing the backward reference function and $X$ below expressing the forward reference function. As mentioned earlier, New Zealand and Thai postgraduates in the two disciplines have a close similarity in terms of types of endophoric markers to express the two functions (i.e., (In) Chapter X, (In) the X chapter, (In) Section X, (In) the X section, $X$ above, $X$ earlier, $X$ below, Page $X$, and $P . X$ ). According to the high incidence of the markers like Chapter $X$ and Section $X$ in the four subcorpora, it can be assumed that New Zealand and Thai students are inclined to use linear text markers in reference to discourse at chapter and section levels.

\section{(ii) Non-linear text references}

Non-linear text reference markers are the markers used to direct the readers to visual elements (e.g., table, figure, appendix). As shown in Table 5.34, across the four thesis subcorpora, the non-linear reference function is most frequently expressed through the use of Table $X$ and Figure $X$. Based on the normalized frequencies of the two visual markers, all groups of thesis writers are more likely to direct the readers to provided tables than figures, except for New Zealand students in business administration. In addition to these markers, Example $X$ is a high frequency endophoric marker in Thai theses in English language teaching, from which it can be assumed that Thai students in the language teaching field tend to include a number of examples in the discussion and conclusion chapters. 
Table 5.34. High frequency endophoric markers for non-linear text references

\begin{tabular}{ll}
\hline Corpus & Endophoric markers for non-linear text references \\
\hline NZ-ELT & Table X, Figure X \\
NZ-BA & Table X, Figure X, \\
TH-ELT & Table X, Figure X, Example X \\
TH-BA & Table X, Figure X \\
\hline
\end{tabular}

\subsection{Evidentials}

\subsubsection{Frequencies of evidentials in $\mathrm{NZ}$ and $\mathrm{TH}$ corpora}

Table 5.35 presents frequencies of evidentials in the New Zealand and Thai thesis corpora. As measured by the normalized frequencies of evidentials, New Zealand students use evidentials $(\mathrm{Nf}=52.5)$ significantly more often than Thai students $(\mathrm{Nf}=30.7)$. The log-likelihood value of 167.31 determines statistical significance of the higher frequency of evidentials in the New Zealand corpus at the level of $p<.0001$.

Table 5.35. Evidentials in NZ and TH corpora

\begin{tabular}{|c|c|c|c|c|c|c|}
\hline & \multicolumn{2}{|c|}{$\begin{array}{c}\text { NEW ZEALAND } \\
(345,277 \text { words })\end{array}$} & \multicolumn{2}{|c|}{$\begin{array}{c}\text { THAI } \\
\text { (254,322 words) }\end{array}$} & \multicolumn{2}{|c|}{ Log-likelihood } \\
\hline & Raw & $\mathrm{Nf}$ & Raw & $\mathrm{Nf}$ & $\mathrm{LL}$ & $p$-value \\
\hline Evidentials & 1812 & 52.5 & 780 & 30.7 & 167.31 & $p<.0001$ \\
\hline
\end{tabular}

Taking variation between two disciplines within the New Zealand group into consideration (NZ-ELT vs. NZ-BA), New Zealand students in English language teaching exhibit a higher frequency in using evidentials. They include evidentials 57.4 times in every 10,000 words, while their compatriots in the business discipline include them 45.6 times. The log-likelihood value of 22.86 indicates statistical significance of the higher incidence of evidentials in the NZELT corpus at the level of $p<.0001$.

Table 5.36. Evidentials in NZ-ELT and NZ-BA subcorpora

\begin{tabular}{|c|c|c|c|c|c|c|}
\hline & \multicolumn{4}{|c|}{ NEW ZEALAND } & \multirow{3}{*}{\multicolumn{2}{|c|}{ Log-likelihood }} \\
\hline & \multirow{2}{*}{\multicolumn{2}{|c|}{$\begin{array}{c}\text { NZ-ELT } \\
\text { (201,099 words) }\end{array}$}} & \multirow{2}{*}{\multicolumn{2}{|c|}{$\begin{array}{c}\text { NZ-BA } \\
(144,178 \text { words) }\end{array}$}} & & \\
\hline & & & & & & \\
\hline & Raw & $\mathrm{Nf}$ & Raw & $\mathrm{Nf}$ & LL & $p$-value \\
\hline Evidentials & 1155 & 57.4 & 657 & 45.6 & 22.86 & $p<.0001$ \\
\hline
\end{tabular}


As for disciplinary variation within the Thai group (TH-ELT vs. TH-BA), a similar result is discovered. That is, Thai students in the language teaching discipline use evidentials $(\mathrm{Nf}=33.7)$ more often than their compatriots in the business discipline $(\mathrm{Nf}=27.7)$. The log-likelihood calculation of 7.29 indicates the higher frequency of evidentials in the TH-ELT corpus is significant at the level of $p<.01$.

Table 5.37. Evidentials in TH-ELT and TH-BA subcorpora

\begin{tabular}{|c|c|c|c|c|c|c|}
\hline & & & & & & \\
\hline & & & & & & -likelihood \\
\hline & $(12$ & & & & & \\
\hline & Raw & $\mathrm{Nf}$ & Raw & $\mathrm{Nf}$ & LL & $p$-value \\
\hline Evidentials & 423 & 33.7 & 357 & 27.7 & 7.29 & $p<.01$ \\
\hline
\end{tabular}

\subsubsection{Frequencies of evidentials in ELT and BA corpora}

Table 5.38 shows a comparison of frequencies of evidentials between English language teaching and business administration disciplines. Based on the normalized frequencies, English language teaching students use evidentials $(\mathrm{Nf}=48.3)$ more often than business administration students $(\mathrm{Nf}=37.2)$. The log-likelihood calculation of 43.11 reveals that the higher frequency of evidentials in the English language teaching discipline is significant at the level of $p<.0001$.

Table 5.38. Evidentials in ELT and BA corpora

\begin{tabular}{|c|c|c|c|c|c|c|}
\hline & \multicolumn{2}{|c|}{$\begin{array}{c}\text { ELT } \\
(326,730 \text { words) }\end{array}$} & \multicolumn{2}{|c|}{$\begin{array}{c}\text { BA } \\
(272,869 \text { words })\end{array}$} & \multicolumn{2}{|c|}{ Log-likelihood } \\
\hline & Raw & $\mathrm{Nf}$ & Raw & $\mathrm{Nf}$ & LL & $p$-value \\
\hline Evidentials & 1578 & 48.3 & 1014 & 37.2 & 43.11 & $p<.0001$ \\
\hline
\end{tabular}

In regard to a comparison of evidentials between New Zealand and Thai theses within the English language teaching corpus (NZ-ELT vs. TH-ELT), New Zealand students in the language teaching field employ more evidentials $(\mathrm{Nf}=57.4)$ than Thai students in the same field $(\mathrm{Nf}=33.7)$. As indicated by the log-likelihood value of 95.07, the higher frequency of evidentials in the NZ-ELT corpus is significant at the level of $p<.0001$. 
Table 5.39. Evidentials in NZ-ELT and TH-ELT subcorpora

\begin{tabular}{|c|c|c|c|c|c|c|}
\hline & \multicolumn{4}{|c|}{ ENGLISH LANGUAGE TEACHING } & \multirow{3}{*}{\multicolumn{2}{|c|}{ Log-likelihood }} \\
\hline & \multirow{2}{*}{\multicolumn{2}{|c|}{$\begin{array}{c}\text { NZ-ELT } \\
\text { (201,099 words) }\end{array}$}} & \multirow{2}{*}{\multicolumn{2}{|c|}{$\begin{array}{c}\text { TH-ELT } \\
\text { (125,631 words) }\end{array}$}} & & \\
\hline & & & & & & \\
\hline & Raw & $\mathrm{Nf}$ & Raw & $\mathrm{Nf}$ & LL & $p$-value \\
\hline Evidentials & 1155 & 57.4 & 423 & 33.7 & 95.07 & $p<.0001$ \\
\hline
\end{tabular}

Similarly, a comparison between New Zealand and Thai theses within the business field (NZBA vs. TH-BA) reveals that New Zealand students in the business field use evidentials $(\mathrm{Nf}=45.6)$ more often than Thai students in the same field $(\mathrm{Nf}=27.7)$. The higher incidence of evidentials in the NZ-BA corpus is significant, as determined by the log-likelihood value of 59.28 at the level of $p<.0001$.

Table 5.40. Evidentials in NZ-BA and TH-BA subcorpora

\begin{tabular}{|c|c|c|c|c|c|c|}
\hline & & NESS & TRAT & & & \\
\hline & & & & & & g-likelihood \\
\hline & (14 & & $(12$ & & & \\
\hline & Raw & $\mathrm{Nf}$ & Raw & $\mathrm{Nf}$ & LL & $p$-value \\
\hline Evidentials & 657 & 45.6 & 357 & 27.7 & 59.28 & $p<.0001$ \\
\hline
\end{tabular}

This section concludes that New Zealand students use evidential markers significantly more often than Thai students. The cross-disciplinary comparison of evidentials within the New Zealand context (NZ-ELT vs. NZ-BA) and the Thai context (TH-ELT vs. TH-BA) reveals a significantly higher frequency of evidentials in English language teaching theses than business administration theses in both contexts (NZ-ELT and TH-ELT). As for the overall comparison between two disciplines, English language teaching students show significantly more frequent use of evidentials than business administration students. The comparison between New Zealand and Thai theses in the English language teaching discipline (NZ-ELT vs. TH-ELT) and the business administration discipline (NZ-BA vs. TH-BA) suggests a significantly higher frequency of evidentials in New Zealand theses compared to Thai theses in both disciplines (NZ-ELT and NZ-BA).

\subsubsection{Types of evidentials}

There are 29 types of evidential markers identified in NZ-ELT, 24 types in NZ-BA, 25 types in TH-ELT and 20 types in TH-BA. Among these, 17 types of evidentials are found in all four 
subcorpora.

Table 5.41 presents the top ten evidential markers. There are four high frequency evidential markers shared over the four subcorpora: parenthetical citations, $X$ find, $X$ suggest, and $X$ support. Divided by context, New Zealand students in the two disciplines share three other types of evidentials, namely $X$ note, $X$ describe, and $X$ assert. As for Thai students in the two disciplines, they share five other types of evidentials in addition to the four types shared over the four subcorpora, namely according to, cited, $X$ state, $X$ show, and $X$ indicate. This means that nine of ten high frequency evidential markers used by Thai students in the two disciplines are the same.

Moreover, some evidential markers appear on the top ten list in three subcorpora but are absent from one corpus, namely the presence of according to, cited, and $X$ state in NZ-ELT, TH-ELT and TH-BA. These three markers are absent from the top ten list of NZ-BA. There are markers which appear on the high frequency evidential list of a particular corpus but are absent from other three subcorpora, namely the presence of $X$ argue, $X$ identify, and ... is determined by in NZ-BA, $X$ report in TH-ELT, and $X$ mention in TH-BA.

Table 5.41. Top ten evidential list

\begin{tabular}{|c|c|c|c|c|c|c|c|c|}
\hline & \multicolumn{4}{|c|}{ NEW ZEALAND } & \multicolumn{4}{|c|}{ THAI } \\
\hline & \multicolumn{2}{|c|}{ NZ-ELT } & \multicolumn{2}{|c|}{ NZ-BA } & \multicolumn{2}{|c|}{ TH-ELT } & \multicolumn{2}{|c|}{ TH-BA } \\
\hline & Type & $\mathrm{Nf}$ & Type & $\mathrm{Nf}$ & Type & $\mathrm{Nf}$ & Type & $\mathrm{Nf}$ \\
\hline 1 & $\begin{array}{l}\text { non-integral } \\
\text { citation }\end{array}$ & 40.7 & $\begin{array}{l}\text { non-integral } \\
\text { citation }\end{array}$ & 35.2 & $\begin{array}{l}\text { non-integral } \\
\text { citation }\end{array}$ & 10.8 & $\begin{array}{l}\text { non-integral } \\
\text { citation }\end{array}$ & 10.9 \\
\hline 2 & $X$ find & 3.6 & $\mathrm{X}$ suggest & 1.4 & $X$ find & 5.6 & X support & 3.0 \\
\hline 3 & $X$ suggest & 1.7 & Xnote & 1.2 & according to $X$ & 2.2 & $X$ find & 2.9 \\
\hline 4 & according to $\mathrm{X}$ & 1.4 & X support & 1.2 & $X$ state & 1.9 & Xstate & 2.8 \\
\hline 5 & X support & 1.1 & $X$ find & 1.0 & X support & 1.8 & cited & 2.0 \\
\hline 6 & cited & 0.8 & $X$ assert & 1.0 & cited & 1.8 & $X$ indicate & 0.9 \\
\hline 7 & Xnote & 0.7 & $\mathrm{X}$ argue & 0.9 & $\mathrm{X}$ suggest & 1.2 & $\mathrm{X}$ mention & 0.9 \\
\hline 8 & $X$ describe & 0.7 & X identify & 0.8 & Xshow & 1.1 & according to $X$ & 0.9 \\
\hline 9 & X assert & 0.6 & is determined & 0.5 & $\mathrm{X}$ report & 0.9 & Xshow & 0.7 \\
\hline 10 & X state & 0.6 & $X$ describe & 0.5 & $X$ indicate & 0.8 & $\mathrm{X}$ suggest & 0.6 \\
\hline & $\mathrm{SUM} N \mathrm{NF}=57.4$ & $\begin{array}{l}51.9 \\
(90.4 \%)\end{array}$ & $\mathrm{SUM} N F=45.6$ & $\begin{array}{l}43.7 \\
(95.8 \%)\end{array}$ & SUM NF=33.7 & $\begin{array}{l}28.1 \\
(83.4 \%)\end{array}$ & SUM NF $=27.7$ & $\begin{array}{l}25.6 \\
(92.4 \%)\end{array}$ \\
\hline
\end{tabular}

Bolded markers represent the popular markers on the top ten list shared across the four subcorpora. Italic markers represent the popular markers shared by two disciplines within each context. 
A sum of the top ten markers reveals that the four groups of students rely heavily on the top ten markers, accounting for more than $80 \%$ of all citations in each corpus. The top ten evidential markers in TH-ELT occur 28.1 out of 33.7 times per 10,000 words, accounting for $83.4 \%$ of all the occurrences. About $17 \%$ is accounted for by 15 other types of evidentials in this corpus. In TH-BA, the top ten markers occur 25.6 out of 27.7 times, accounting for $92.4 \%$ of all the occurrences. Only $8 \%$ is accounted for by lower frequency evidential markers in this corpus. In NZ-ELT and NZ-BA, the top ten markers occur 51.9 out of 57.4 times $(90.4 \%$ of all the occurrences) and 43.7 out of 45.6 times (95.8\% of all the occurrences), respectively. Figure 5.4 illustrates that although the four groups of students have a great reliance on the ten evidential markers, Thai students in the language teaching discipline exhibit a wider distribution of lower frequency evidentials when compared to other groups of students.

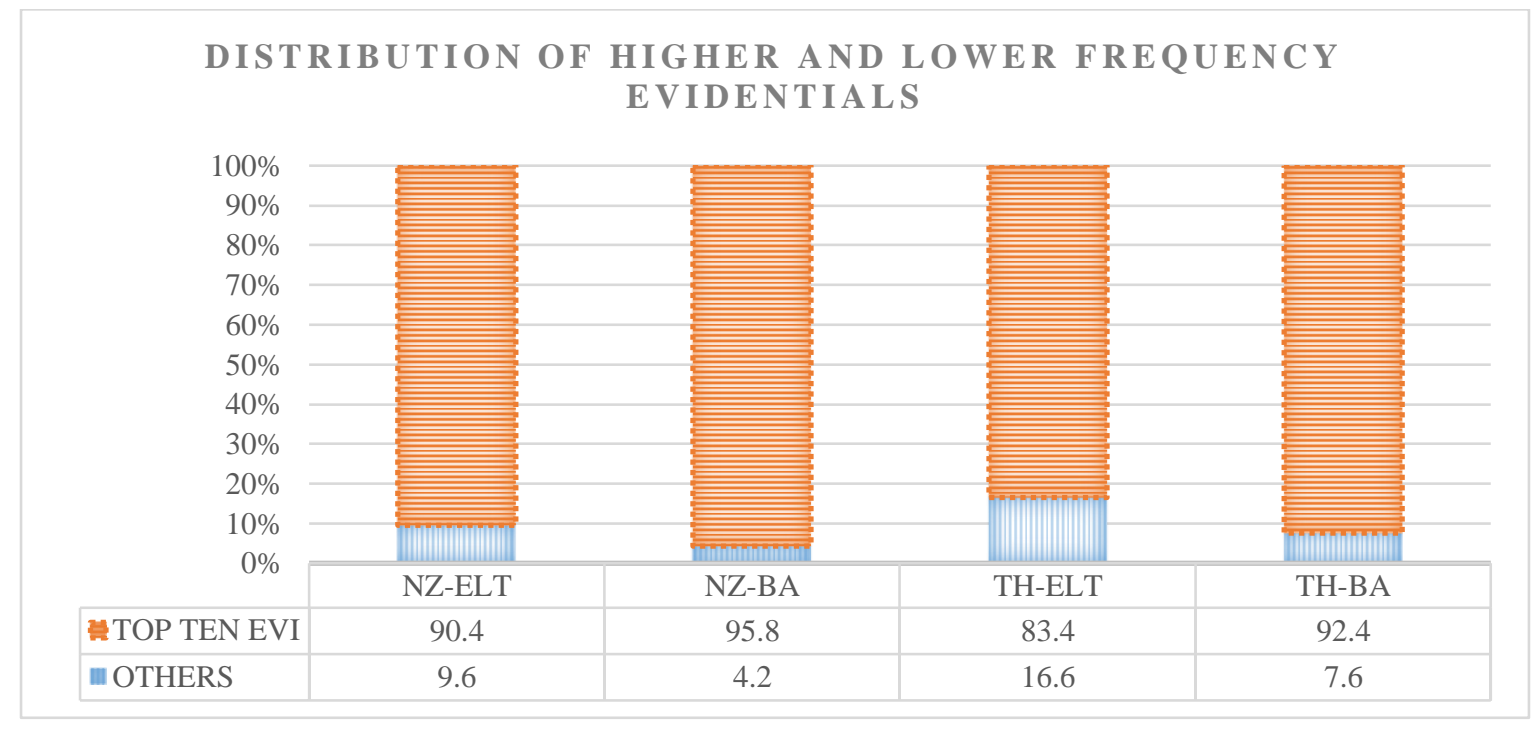

Figure 5.4. Distribution of higher and lower frequency evidentials

\subsubsection{Functions of evidentials}

A key function of evidential markers is to provide a source attribution for arguments which are not originally derived from the writer of the current text. The inclusion of evidentials in thesis writing is a means of giving credit to the original source and establishing thesis credibility. The evidential function can be expressed in two forms: integral citations and non-integral citations. According to the top ten evidential list in Table 5.41 in the previous section, it is apparent that in all four subcorpora, non-integral citations are the most frequent type of evidentials, compared to other evidential markers. However, a combination of all the integral citation occurrences reveals that there is a difference in the use of citations between New Zealand and Thai students, as presented in Table 5.42 below. 
Table 5.42. Forms of evidentials

\begin{tabular}{lcccccc}
\hline \multirow{2}{*}{ Corpus } & \multicolumn{3}{c}{ Integral citations } & \multicolumn{3}{c}{ Non-integral citations } \\
\cline { 2 - 7 } & Raw & Nf & $\%$ & Raw & Nf & $\%$ \\
\hline NZ-ELT & 337 & 16.8 & $29.1 \%$ & 818 & 40.7 & $70.9 \%$ \\
NZ-BA & 150 & 10.4 & $22.8 \%$ & 507 & 35.2 & $77.2 \%$ \\
TH-ELT & 287 & 22.8 & $67.7 \%$ & 136 & 10.8 & $32.3 \%$ \\
TH-BA & 217 & 16.9 & $61.0 \%$ & 140 & 10.9 & $39.0 \%$ \\
\hline
\end{tabular}

When comparing the use of citations across contexts, New Zealand postgraduates in English language teaching and business administration have a greater preference for non-integral citations $(\mathrm{Nf}=40.7$ or $70.9 \%$ in $\mathrm{NZ}-\mathrm{ELT}, \mathrm{Nf}=35.2$ or $77.2 \%$ in NZ-BA) than integral citations $(\mathrm{Nf}=16.8$ or $29.1 \%$ in NZ-ELT, $\mathrm{Nf}=10.4$ or $22.8 \%$ in NZ-BA). In contrast, Thai postgraduates in both disciplines are more inclined to use integral citations $(\mathrm{Nf}=22.8$ or $67.7 \%$ in $\mathrm{TH}-\mathrm{ELT}$, $\mathrm{Nf}=16.9$ or $61 \%$ in $\mathrm{TH}-\mathrm{BA})$ than non-integral citations $(\mathrm{Nf}=10.8$ or $32.3 \%$ in TH-ELT, $\mathrm{Nf}=10.9$ or $39 \%$ in TH-BA). This means that Thai postgraduates in both disciplines tend to integrate source attributions in sentences along with propositional content rather than separating them in parentheses, indicating a different practice in the use of evidentials between students in the two contexts.

\subsection{Code glosses}

\subsubsection{Frequencies of code glosses in $\mathrm{NZ}$ and $\mathrm{TH}$ corpora}

Table 5.43 presents frequencies of code glosses used in New Zealand and Thai students' master's theses. New Zealand students use code glosses $(\mathrm{Nf}=32)$ more often than Thai students $(\mathrm{Nf}=25.2)$. The log-likelihood calculation of 23.87 indicates that the higher frequency of code glosses in the New Zealand corpus is significant at the level of $p<.0001$.

Table 5.43. Code glosses in NZ and TH corpora

\begin{tabular}{|c|c|c|c|c|c|c|}
\hline & \multicolumn{2}{|c|}{$\begin{array}{l}\text { NEW ZEALAND } \\
(345,277 \text { words })\end{array}$} & \multicolumn{2}{|c|}{$\begin{array}{c}\text { THAI } \\
(254,322 \text { words })\end{array}$} & \multicolumn{2}{|c|}{ Log-likelihood } \\
\hline & Raw & $\mathrm{Nf}$ & Raw & $\mathrm{Nf}$ & LL & $p$-value \\
\hline Code glosses & 1105 & 32.0 & 640 & 25.2 & 23.87 & $p<.0001$ \\
\hline
\end{tabular}


Comparing code glosses between two disciplines within the New Zealand corpus (NZ-ELT vs. NZ-BA), the two New Zealand groups do not significantly differ. New Zealand students in English language teaching and business administration show almost the same frequency in using code glosses ( $\mathrm{Nf}=31.8$ in NZ-ELT, $\mathrm{Nf}=32.3$ in NZ-BA). The log-likelihood calculation of 0.05 indicates that there is no significant difference in the use of code glosses in NZ-ELT and NZ-BA corpora $(p>.05)$, as in Table 5.44.

Table 5.44. Code glosses in NZ-ELT and NZ-BA subcorpora

\begin{tabular}{|c|c|c|c|c|c|c|}
\hline & & $\mathrm{NE}$ & ND & & & \\
\hline & & & & & & -likelihood \\
\hline & & & (14 & & & \\
\hline & Raw & $\mathrm{Nf}$ & Raw & $\mathrm{Nf}$ & LL & $p$-value \\
\hline Code glosses & 640 & 31.8 & 465 & 32.3 & 0.05 & $p>.05$ \\
\hline
\end{tabular}

Within the Thai corpus (TH-ELT vs. TH-BA), Thai students in the business field use code glosses $(\mathrm{Nf}=27.7)$ more often than Thai students in the language teaching field $(\mathrm{Nf}=22.6)$. The log-likelihood calculation of 6.48 indicates the higher frequency of code glosses in the TH-BA corpus is significant at the level of $p<.05$, as seen in Table 5.45 below.

Table 5.45. Code glosses in TH-ELT and TH-BA subcorpora

\begin{tabular}{|c|c|c|c|c|c|c|}
\hline & & & & & & \\
\hline & & & & & & g-likelihood \\
\hline & & & & & & \\
\hline & Raw & $\mathrm{Nf}$ & Raw & $\mathrm{Nf}$ & LL & $p$-value \\
\hline Code glosses & 284 & 22.6 & 356 & 27.7 & 6.48 & $p<.05$ \\
\hline
\end{tabular}

\subsubsection{Frequencies of code glosses in ELT and BA corpora}

Table 5.46 shows frequencies of code glosses in English language teaching and business administration disciplines. The normalized frequencies of code glosses in the language teaching corpus and the business corpus are 28.3 and 30.1 times in every 10,000 words, respectively. The log-likelihood value of 1.67 suggests that there is no significant difference in the use of code glosses between the two disciplines $(p>.05)$. 
Table 5.46. Code glosses in ELT and BA corpora

\begin{tabular}{llccccc}
\hline & \multicolumn{2}{c}{ ELT } & \multicolumn{2}{c}{ BA } & & Log-likelihood \\
& \multicolumn{2}{c}{$(326,730$ words $)$} & Nf & $(272,869$ words $)$ & & \\
\cline { 2 - 7 } & Raw & Nf & Raw & Nf & LL & $p$-value \\
\hline Code glosses & 924 & 28.3 & 821 & 30.1 & 1.67 & $p>.05$ \\
\hline
\end{tabular}

In regard to a comparison between New Zealand and Thai theses within the English language teaching corpus (NZ-ELT vs. TH-ELT), code glosses occur more frequently in the NZ-ELT corpus $(\mathrm{Nf}=31.8)$ than in the $\mathrm{TH}-\mathrm{ELT}$ corpus $(\mathrm{Nf}=22.6)$. The log-likelihood value of 23.95 reveals that the higher frequency of code glosses in the NZ-ELT corpus is significant at the level of $p<.0001$.

Table 5.47. Code glosses in NZ-ELT and TH-ELT subcorpora

\begin{tabular}{|c|c|c|c|c|c|c|}
\hline & \multicolumn{4}{|c|}{ ENGLISH LANGUAGE TEACHING } & \multirow{2}{*}{\multicolumn{2}{|c|}{ Log-likelihood }} \\
\hline & \multicolumn{2}{|c|}{$\begin{array}{c}\text { NZ-ELT } \\
\text { (201,099 words) }\end{array}$} & \multicolumn{2}{|c|}{$\begin{array}{c}\text { TH-ELT } \\
(125,631 \text { words })\end{array}$} & & \\
\hline & Raw & $\mathrm{Nf}$ & Raw & $\mathrm{Nf}$ & LL & $p$-value \\
\hline Code glosses & 640 & 31.8 & 284 & 22.6 & 23.95 & $p<.0001$ \\
\hline
\end{tabular}

A comparison between New Zealand and Thai theses within the business administration corpus (NZ-BA vs. TH-BA) also suggests that code glosses occur more frequently in the NZ-BA corpus $(\mathrm{Nf}=32.3)$ than in the $\mathrm{TH}-\mathrm{BA}$ corpus $(\mathrm{Nf}=27.7)$. The $\log$-likelihood value of 4.78 determines the higher incidence of code glosses in the NZ-BA corpus is significant at the level of $p<.05$.

Table 5.48. Code glosses in NZ-BA and TH-BA subcorpora

\begin{tabular}{|c|c|c|c|c|c|c|}
\hline & \multicolumn{4}{|c|}{ BUSINESS ADMINISTRATION } & \multirow{3}{*}{\multicolumn{2}{|c|}{ Log-likelihood }} \\
\hline & \multirow{2}{*}{\multicolumn{2}{|c|}{$\begin{array}{c}\text { NZ-BA } \\
(144,178 \text { words })\end{array}$}} & \multirow{2}{*}{\multicolumn{2}{|c|}{$\begin{array}{c}\text { TH-BA } \\
(128,691 \text { words) }\end{array}$}} & & \\
\hline & & & & & & \\
\hline & Raw & $\mathrm{Nf}$ & Raw & $\mathrm{Nf}$ & LL & $p$-value \\
\hline Code glosses & 465 & 32.3 & 356 & 27.7 & 4.78 & $p<.05$ \\
\hline
\end{tabular}


This section concludes that New Zealand students employ code glosses significantly more often than Thai students. The cross-disciplinary comparison of code glosses within the New Zealand context (NZ-ELT vs. NZ-BA) reveals that New Zealand students in the two disciplines do not differ much in using code glosses. However, the cross-disciplinary comparison within the Thai context (TH-ELT vs. TH-BA) indicates a significantly higher frequency of code glosses in the TH-BA corpus. As for the overall comparison between two disciplines, there is no significant difference in the use of code glosses between English language teaching and business administration. The comparison between New Zealand and Thai theses in the English language teaching discipline (NZ-ELT vs. TH-ELT) and the business discipline (NZ-BA vs. TH-BA) suggests a significantly higher frequency of code glosses in New Zealand theses compared to Thai theses in both disciplines (NZ-ELT and NZ-BA).

\subsubsection{Types of code glosses}

In the New Zealand corpus, 19 types of code glosses are identified in NZ-ELT and NZ-BA each. In the Thai corpus, there are 18 types of code glosses identified in TH-ELT and 19 types in TH-BA. Among these, 12 types of code glosses are shared across all four subcorpora. These findings suggest that New Zealand and Thai students in the two disciplines are very similar in terms of using a small cluster of code glosses.

Table 5.49 presents ten high frequency code glosses in the four subcorpora. There are five types of code glosses shared over the four subcorpora, namely such as, for example, parenthetical gloss (...), e.g., and for instance. Divided by context, New Zealand students in the two disciplines share three other types of code glosses (i.e., in fact, indeed) in addition to the five types mentioned earlier. Thai students in the two disciplines share two other types (in other words, namely). Three markers are found as high frequency markers on the list of three subcorpora but absent from one corpus, namely the absence of i.e. and in fact in TH-ELT and in other words in NZ-BA. Specifically is a high frequency code gloss marker which appears only on the top ten marker list of NZ-BA. This means only appears on the list of TH-BA. 
Table 5.49. Top ten code gloss list

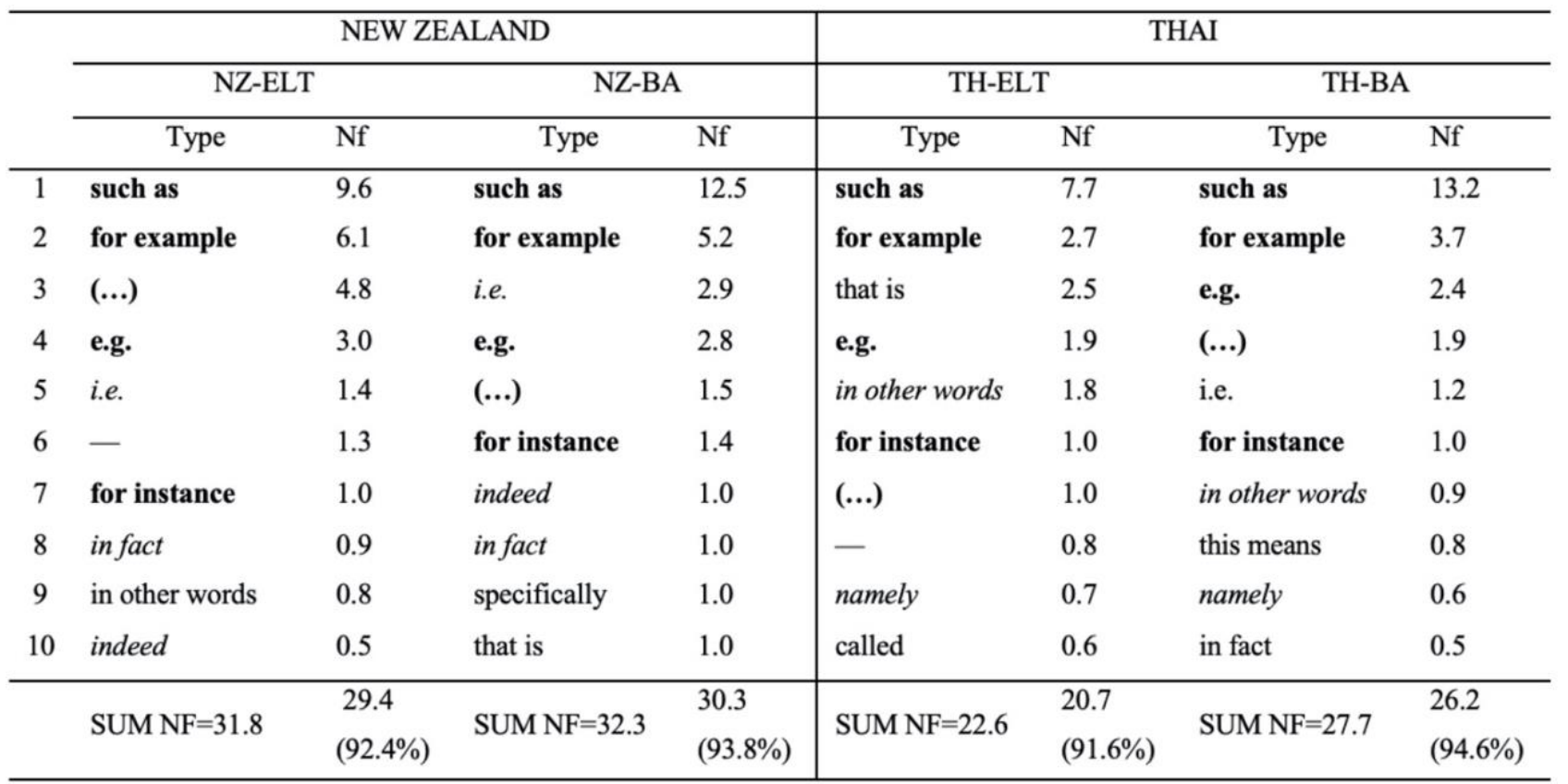

Bolded markers represent the popular markers on the top ten list shared across the four subcorpora.

Italic markers represent the popular markers shared by two disciplines within each context.

A sum of normalized frequencies and percentage of the top ten code gloss markers indicate that New Zealand and Thai students in the two disciplines make far greater use of the top ten code glosses and very sparse use of lower frequency markers (e.g., put another way, as a matter of fact). The top ten code glosses in each corpus occupy more than $90 \%$ of all the occurrences of code glosses. However, TH-ELT theses have a slightly wider distribution of lower frequency code glosses when compared to other subcorpora.

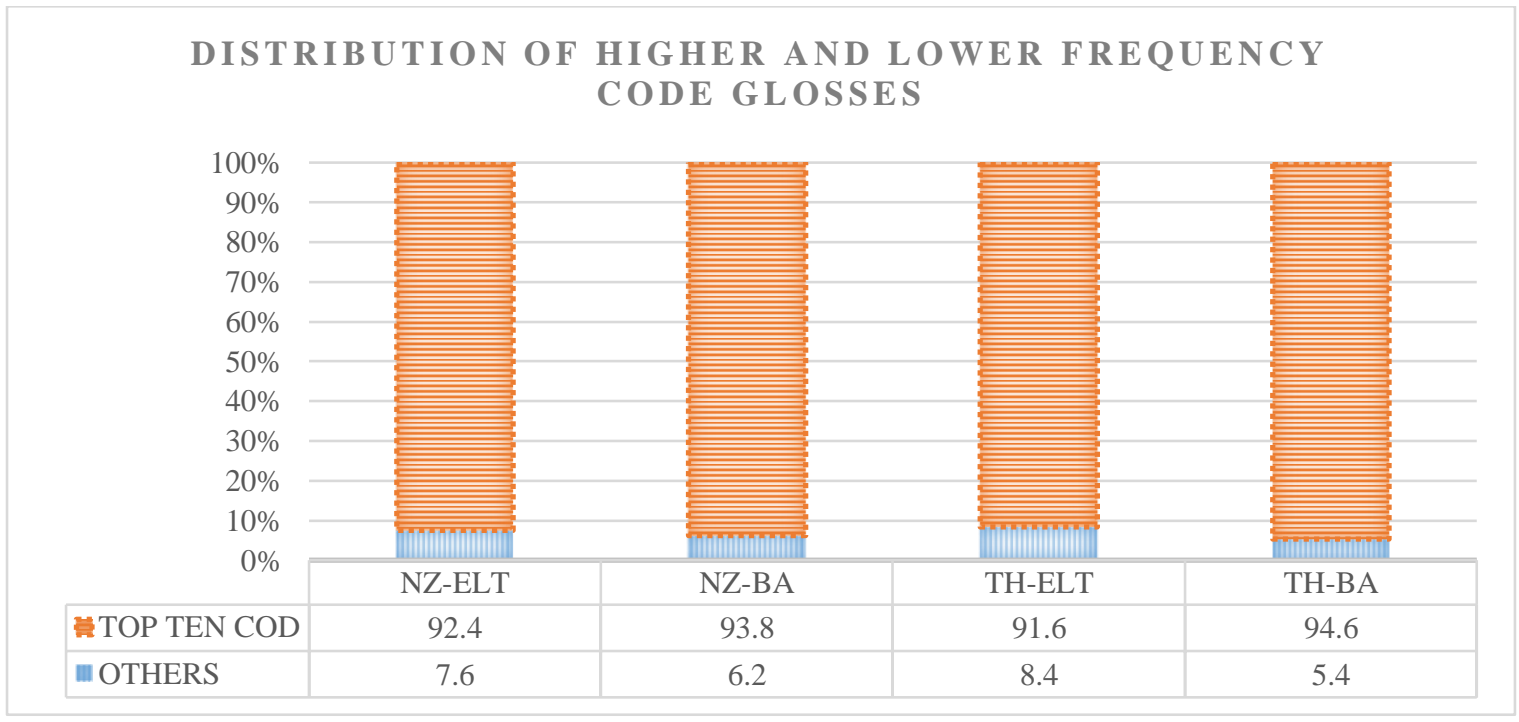

Figure 5.5. Distribution of higher and lower frequency code glosses 


\subsubsection{Functions of code glosses}

\section{(i) Exemplifying}

As seen in Table 5.50, such as, for example, for instance, e.g., and parenthetical glosses are five common expressions that New Zealand and Thai postgraduates use to provide the readers with examples to illustrate preceding arguments. The code gloss i.e. high-frequently occurs in three subcorpora, except in TH-ELT. It should be noted that although i.e. has almost exactly the same meaning as that is and can be used for rephrasing statements, in this study it is frequently used as an exemplification marker like namely. In English language teaching, New Zealand and Thai students are likely to provide examples of students' writing assignments and dialogues and direct the thesis readers to those examples to clarify preceding arguments. And in business administration theses, given examples are related to highlights of interviews with participants in the business field as well as some questions and responses in a survey.

Table 5.50. High frequency code glosses for exemplifying

\begin{tabular}{ll}
\hline Corpus & Code glosses for exemplifying \\
\hline NZ-ELT & such as, for example, for instance, e.g., $(\ldots)$, i.e. \\
NZ-BA & such as, for example, for instance, e.g., $(\ldots)$, i.e. \\
TH-ELT & such as, for example, for instance, e.g., $(\ldots)$, namely \\
TH-BA & such as, for example, for instance, e.g., $(\ldots)$, i.e., namely \\
\hline
\end{tabular}

(ii) Rephrasing

Another key function of code glosses is to elaborate meanings that the writers intend to convey to the readers. The meaning elaboration can be expressed by using such rephrasing markers as in other words, that is and this means to make the meanings clearer to the readers. There is no code gloss on the high frequency list shared across the four subcorpora. In fact is a high frequency code gloss found on the top ten list of three subcorpora, except in TH-ELT, to give more detailed information of preceded arguments. TH-ELT theses are more likely to include alternative definitions with the bundle It is called. In other words appears in three subcorpora, except in NZ-BA whose the appearance of the adverbial specifically is more dominant. That is appears on the top ten list of NZ-BA and TH-ELT. This means is found on the list of TH-BA. Indeed is found on the top ten list of the New Zealand corpus (both NZ-ELT and NZ-BA), yet this feature is not frequently used in the Thai theses. 
Table 5.51. High frequency code glosses for rephrasing

\begin{tabular}{ll}
\hline Corpus & Code glosses for rephrasing \\
\hline NZ-ELT & in fact, in other words, indeed, - \\
NZ-BA & in fact, indeed, that is, specifically \\
TH-ELT & in other words, that is, - , called \\
TH-BA & in fact, in other words, this means \\
\hline
\end{tabular}

\subsection{Chapter summary}

This chapter has reported the findings of five subcategories of textual metadiscourse (i.e., transition markers, frame markers, endophoric markers, evidentials, and code glosses). The cross-contextual comparison reveals the significantly higher incidence of transition markers and frame markers in Thai theses and of evidentials and code glosses in New Zealand theses. Theses in the two contexts do not significantly differ in the frequency of endophoric markers. The cross-disciplinary comparison reveals the significantly higher incidence of transition markers in business administration theses and of endophoric markers and evidentials in English language teaching theses. The two disciplinary groups do not significantly differ in the use of frame markers or code glosses. Despite differences in frequencies, both New Zealand and Thai students in the two disciplines share similarities in relying on a very small cluster of high frequency markers and making scarce use of lower frequency ones in all textual subcategories. 


\section{CHAPTER 6 \\ INTERPERSONAL METADISCOURSE}

Chapter 6 discusses interpersonal metadiscourse in New Zealand and Thai theses and in English language teaching and business administration theses. Section 6.1 reports frequencies of interpersonal metadiscourse as a whole. From Section 6.2 to Section 6.6, hedges, boosters, attitude markers, engagement markers, and self-mentions are discussed in terms of frequencies, types, and functions.

\subsection{Interpersonal metadiscourse as a whole}

Table 6.1 shows distributions of interpersonal metadiscourse subcategories in New Zealand and Thai students' theses. As measured by normalized frequencies per 10,000 words, hedges and boosters are the most frequent interpersonal subcategories in both New Zealand and Thai corpora. However, New Zealand and Thai students differ slightly in the frequency of using self-mentions and attitude markers. That is, self-mention markers seem to be more frequently used by the New Zealand group, thus ranking as the third most frequent interpersonal subcategory, followed by attitude markers. In the Thai corpus, attitude markers rank third, followed by self-mentions. The least frequent interpersonal subcategory in both New Zealand and Thai corpora is engagement markers.

Table 6.1. Interpersonal metadiscourse subcategories in $\mathrm{NZ}$ and $\mathrm{TH}$ corpora

\begin{tabular}{|c|c|c|c|c|c|c|}
\hline \multirow[b]{2}{*}{ Subcategory } & \multicolumn{2}{|c|}{$\begin{array}{c}\text { NEW ZEALAND } \\
(345,277 \text { words) }\end{array}$} & \multicolumn{2}{|c|}{$\begin{array}{c}\text { THAI } \\
\text { (254,322 words) }\end{array}$} & \multicolumn{2}{|c|}{$\begin{array}{c}\text { All } \\
(599,599 \text { words })\end{array}$} \\
\hline & Raw & $\mathrm{Nf}$ & Raw & $\mathrm{Nf}$ & Raw & $\mathrm{Nf}$ \\
\hline Hedges & 4606 & $133.4(1)$ & 3085 & $121.3(1)$ & 7691 & 128.3 \\
\hline Boosters & 935 & $27.1(2)$ & 1104 & $43.4(2)$ & 2039 & 34.0 \\
\hline Self-mentions & 879 & $25.5(3)$ & 152 & $6.0(4)$ & 1031 & 17.2 \\
\hline Attitude markers & 713 & 20.7 (4) & 302 & $11.9(3)$ & 1015 & 16.9 \\
\hline Engagement markers & 512 & $14.8(5)$ & 128 & $5.0(5)$ & 640 & 10.7 \\
\hline
\end{tabular}

The bracketed numbers indicate the ranks of each subcategory.

Table 6.2 presents distributions of interpersonal metadiscourse subcategories in English language teaching and business administration disciplines. Hedges and boosters rank as the first two high frequency interpersonal subcategories in both English language teaching and 
business administration corpora. Distributions of three other interpersonal subcategories are somewhat different. In the English language teaching corpus, self-mentions rank third, followed by attitude markers and engagement markers, respectively. On the other hand, attitude markers rank third in the business administration corpus, followed by engagement markers and self-mentions, respectively.

Table 6.2. Interpersonal metadiscourse subcategories in ELT and BA corpora

\begin{tabular}{|c|c|c|c|c|c|c|}
\hline \multirow[b]{2}{*}{ Subcategory } & \multicolumn{2}{|c|}{$\begin{array}{c}\text { ELT } \\
(326,730 \text { words })\end{array}$} & \multicolumn{2}{|c|}{$\begin{array}{c}\text { BA } \\
(272,869 \text { words })\end{array}$} & \multicolumn{2}{|c|}{$\begin{array}{c}\text { All } \\
(599,599 \text { words })\end{array}$} \\
\hline & Raw & $\mathrm{Nf}$ & Raw & $\mathrm{Nf}$ & Raw & $\mathrm{Nf}$ \\
\hline Hedges & 4324 & $132.3(1)$ & 3367 & $123.4(1)$ & 7691 & 128.3 \\
\hline Boosters & 1116 & $34.2(2)$ & 923 & $33.8(2)$ & 2039 & 34.0 \\
\hline Self-mentions & 831 & $25.4(3)$ & 200 & $7.3(5)$ & 1031 & 17.2 \\
\hline Attitude markers & 533 & $16.3(4)$ & 482 & $17.7(3)$ & 1015 & 16.9 \\
\hline Engagement markers & 418 & $12.8(5)$ & 222 & $8.1(4)$ & 640 & 10.7 \\
\hline
\end{tabular}

The bracketed numbers indicate the ranks of each subcategory.

\subsection{Hedges}

\subsubsection{Frequencies of hedges in $\mathrm{NZ}$ and $\mathrm{TH}$ corpora}

Table 6.3 describes a comparison of hedges in the New Zealand and Thai corpora. Based on the normalized frequencies per 10,000 words, New Zealand students show significantly more frequent use of hedges $(\mathrm{Nf}=133.4)$ when compared to Thai students $(\mathrm{Nf}=121.3)$. The $\log$ likelihood calculation of 16.80 indicates that the higher frequency of hedges in the New Zealand corpus is significant at the level of $p<.0001$.

Table 6.3. Hedges in NZ and TH corpora

\begin{tabular}{|c|c|c|c|c|c|c|}
\hline & \multicolumn{2}{|c|}{$\begin{array}{l}\text { NEW ZEALAND } \\
(345,277 \text { words })\end{array}$} & \multicolumn{2}{|c|}{$\begin{array}{c}\text { THAI } \\
\text { (254,322 words) }\end{array}$} & \multicolumn{2}{|c|}{ Log-likelihood } \\
\hline & Raw & $\mathrm{Nf}$ & Raw & $\mathrm{Nf}$ & LL & $p$-value \\
\hline Hedges & 4606 & 133.4 & 3085 & 121.3 & 16.80 & $p<.0001$ \\
\hline
\end{tabular}

A cross-disciplinary comparison subsequently performed in the New Zealand corpus (NZ-ELT vs. NZ-BA) reveals that New Zealand students in English language teaching tend to use hedges 137.4 times per 10,000 words, while their compatriots in business administration are likely to 
use hedges 127.8 times. The log-likelihood value of 5.93 reveals that the higher frequency of hedges in the NZ-ELT corpus is significant at the level of $p<.05$, as shown in Table 6.4.

Table 6.4. Hedges in NZ-ELT and NZ-BA subcorpora

\begin{tabular}{|c|c|c|c|c|c|c|}
\hline & \multicolumn{4}{|c|}{ NEW ZEALAND } & \multirow{3}{*}{\multicolumn{2}{|c|}{ Log-likelihood }} \\
\hline & \multirow{2}{*}{\multicolumn{2}{|c|}{$\begin{array}{c}\text { NZ-ELT } \\
(201,099 \text { words) }\end{array}$}} & \multirow{2}{*}{\multicolumn{2}{|c|}{$\begin{array}{c}\text { NZ-BA } \\
(144,178 \text { words })\end{array}$}} & & \\
\hline & & & & & & \\
\hline & Raw & $\mathrm{Nf}$ & Raw & $\mathrm{Nf}$ & LL & $p$-value \\
\hline Hedges & 2764 & 137.4 & 1842 & 127.8 & 5.93 & $p<.05$ \\
\hline
\end{tabular}

With regard to a cross-disciplinary comparison of hedges within the Thai corpus (TH-ELT vs. TH-BA), Table 6.5 shows that Thai students in the two disciplines exhibit a slight difference in the frequency of hedging. Thai students in the language teaching discipline use hedges 124.2 times in every 10,000 words, while their compatriots in the business discipline use hedges 118.5 times. The log-likelihood value of 1.69 indicates that there is no significant difference in the incidence of hedges between Thai students in the two disciplines $(p>.05)$.

Table 6.5. Hedges in TH-ELT and TH-BA subcorpora

\begin{tabular}{|c|c|c|c|c|c|c|}
\hline & & & & & & \\
\hline & & & & & & -likelihood \\
\hline & (12 & & $(12$ & & & \\
\hline & Raw & $\mathrm{Nf}$ & Raw & $\mathrm{Nf}$ & LL & $p$-value \\
\hline Hedges & 1560 & 124.2 & 1525 & 118.5 & 1.69 & $p>.05$ \\
\hline
\end{tabular}

\subsubsection{Frequencies of hedges in ELT and BA corpora}

As seen in Table 6.6, the English language teaching corpus contains more hedging markers $(\mathrm{Nf}=132.3)$ than the business administration corpus $(\mathrm{Nf}=123.4)$. As determined by the loglikelihood value of 9.30, the higher incidence of hedges in the English language teaching corpus is significant at the level of $p<.01$. 
Table 6.6. Hedges in ELT and BA corpora

\begin{tabular}{|c|c|c|c|c|c|c|}
\hline & \multicolumn{2}{|c|}{$\begin{array}{c}\text { ELT } \\
(326,730 \text { words) }\end{array}$} & \multicolumn{2}{|c|}{$\begin{array}{c}\text { BA } \\
(272,869 \text { words })\end{array}$} & \multicolumn{2}{|c|}{ Log-likelihood } \\
\hline & Raw & $\mathrm{Nf}$ & Raw & $\mathrm{Nf}$ & LL & $p$-value \\
\hline Hedges & 4324 & 132.3 & 3367 & 123.4 & 9.30 & $p<.01$ \\
\hline
\end{tabular}

Table 6.7 presents a comparison of hedges between New Zealand and Thai theses in the English language teaching discipline (NZ-ELT vs. TH-ELT). According to the normalized frequencies in the two groups, New Zealand students in English language teaching include more hedging markers $(\mathrm{Nf}=137.4)$ in their theses than Thai students in the same discipline $(\mathrm{Nf}=124.2)$. The higher incidence of hedges in the NZ-ELT corpus is significant, as determined by the loglikelihood value of 10.38 at the level of $p<.01$.

Table 6.7. Hedges in NZ-ELT and TH-ELT subcorpora

\begin{tabular}{|c|c|c|c|c|c|c|}
\hline & \multicolumn{4}{|c|}{ ENGLISH LANGUAGE TEACHING } & \multirow{3}{*}{\multicolumn{2}{|c|}{ Log-likelihood }} \\
\hline & \multirow{2}{*}{\multicolumn{2}{|c|}{$\begin{array}{c}\text { NZ-ELT } \\
\text { (201,099 words) }\end{array}$}} & \multirow{2}{*}{\multicolumn{2}{|c|}{$\begin{array}{c}\text { TH-ELT } \\
(125,631 \text { words })\end{array}$}} & & \\
\hline & & & & & & \\
\hline & Raw & $\mathrm{Nf}$ & Raw & $\mathrm{Nf}$ & LL & $p$-value \\
\hline Hedges & 2764 & 137.4 & 1560 & 124.2 & 10.38 & $p<.01$ \\
\hline
\end{tabular}

A comparison of hedges between New Zealand and Thai theses in the business administration discipline (NZ-BA vs. TH-BA) reveals that New Zealand-business students employ hedging markers $(\mathrm{Nf}=127.8)$ more often than Thai-business students $(\mathrm{Nf}=118.5)$. The log-likelihood calculation of 4.73 indicates that the higher incidence of hedges in the NZ-BA corpus is significant at the level of $p<.05$.

Table 6.8. Hedges in NZ-BA and TH-BA subcorpora

\begin{tabular}{|c|c|c|c|c|c|c|}
\hline & \multicolumn{4}{|c|}{ BUSINESS ADMINISTRATION } & \multirow{3}{*}{\multicolumn{2}{|c|}{ Log-likelihood }} \\
\hline & \multirow{2}{*}{\multicolumn{2}{|c|}{$\begin{array}{c}\text { NZ-BA } \\
(144,178 \text { words })\end{array}$}} & \multirow{2}{*}{\multicolumn{2}{|c|}{$\begin{array}{c}\text { TH-BA } \\
(128,691 \text { words) }\end{array}$}} & & \\
\hline & & & & & & \\
\hline & Raw & $\mathrm{Nf}$ & Raw & $\mathrm{Nf}$ & LL & $p$-value \\
\hline Hedges & 1842 & 127.8 & 1525 & 118.5 & 4.73 & $p<.05$ \\
\hline
\end{tabular}


This section concludes that New Zealand postgraduates hedge their thesis arguments more often than Thai postgraduates. The cross-disciplinary comparison within the New Zealand context (NZ-ELT vs. NZ-BA) indicates a significantly higher frequency of hedging markers in the NZ-ELT corpus. The cross-disciplinary comparison within the Thai corpus (TH-ELT vs. TH-BA) indicates that there is no significant difference in the incidence of hedging markers between Thai theses in the two disciplines. The overall comparison between English language teaching and business administration reveals a significantly higher frequency in the use of hedging markers in English language teaching theses. The comparison between New Zealand and Thai theses in the English language teaching discipline (NZ-ELT vs. TH-ELT) and the business administration discipline (NZ-BA vs. TH-BA) suggests a significantly higher frequency of hedging markers in New Zealand theses compared to Thai theses in both disciplines (NZ-ELT and NZ-BA).

\subsubsection{Types of hedges}

In the New Zealand corpus, there are 52 types of hedging markers identified in NZ-ELT and NZ-BA each. In the Thai corpus, 52 types are identified in TH-ELT and 51 types in TH-BA. Among these types, 40 types are shared in the four subcorpora. The findings suggest that even though the incidence of hedges in the New Zealand corpus is higher than in the Thai corpus, New Zealand and Thai students in the two disciplines include a similar number and similar types of hedging markers in their theses.

Table 6.9 displays the top ten hedging markers in each corpus. The high frequency hedges on the list can be grouped into four grammatical categories expressing the writer's evaluation of possibility, uncertainty, and necessity of propositions: modal verbs (may, would, could, should, might), verbs (suggest, indicate, appear, tend to), adjectives (likely, possible), and adverbs (mostly, frequently, often). 
Table 6.9. Top ten hedging marker list

\begin{tabular}{|c|c|c|c|c|c|c|c|c|}
\hline & \multicolumn{4}{|c|}{ NEW ZEALAND } & \multicolumn{4}{|c|}{ THAI } \\
\hline & \multicolumn{2}{|c|}{ NZ-ELT } & \multicolumn{2}{|c|}{ NZ-BA } & \multicolumn{2}{|c|}{ TH-ELT } & \multicolumn{2}{|c|}{ TH-BA } \\
\hline & Type & $\mathrm{Nf}$ & Type & $\mathrm{Nf}$ & Type & $\mathrm{Nf}$ & Type & $\mathrm{Nf}$ \\
\hline 1 & may & 26.3 & may & 19.9 & should & 24.2 & should & 36.1 \\
\hline 2 & would & 14.0 & could & 19.8 & may & 16.2 & could & 13.8 \\
\hline 3 & could & 12.5 & would & 13.9 & might & 12.7 & may & 11.3 \\
\hline 4 & suggest & 11.5 & suggest & 8.5 & could & 8.9 & would & 10.0 \\
\hline 5 & might & 10.0 & should & 4.9 & indicate & 7.0 & might & 6.3 \\
\hline 6 & likely & 7.4 & appear & 4.4 & suggest & 6.3 & indicate & 5.9 \\
\hline 7 & appear & 7.1 & indicate & 4.4 & would & 6.1 & tend to & 3.9 \\
\hline 8 & should & 5.3 & likely & 4.1 & possible & 3.6 & mostly & 3.3 \\
\hline 9 & indicate & 4.6 & often & 3.3 & frequently & 2.5 & suggest & 2.9 \\
\hline 10 & often & 4.6 & possible & 2.9 & mostly & 2.5 & likely & 2.4 \\
\hline & SUM NF=137.4 & $\begin{array}{c}103.3 \\
(75.2 \%)\end{array}$ & SUM NF=127.8 & $\begin{array}{c}86.1 \\
(67.4 \%)\end{array}$ & SUM NF $=124.2$ & $\begin{array}{c}90 \\
(72.5 \%)\end{array}$ & SUM NF $=118.5$ & $\begin{array}{c}95.9 \\
(80.9 \%)\end{array}$ \\
\hline
\end{tabular}

Bolded markers represent the popular markers on the top ten list shared across the four subcorpora.

Italic markers represent the popular markers shared by two disciplines within each context.

Six high frequency hedging markers overlapping on the top ten list across all subcorpora are may, would, could, should, suggest, and indicate. There are a couple of hedging markers which appear on the top list of three subcorpora but are absent from one corpus, namely the absence of might in NZ-BA and likely in TH-ELT. The hedging markers which appear only on the top ten list of one corpus are frequently in TH-ELT and tend to in TH-BA.

When investigating hedges shared between the two disciplines only in the New Zealand corpus (NZ-ELT and NZ-BA), New Zealand postgraduates in English language teaching and business administration share three other types of hedges, namely likely, appear, and often, in addition to the six types of hedging markers already discussed. This means that nine out of ten high frequency types of hedges are shared between the two disciplines within the New Zealand corpus. It is also interesting that the top four types of hedges in NZ-ELT and NZ-BA are exactly the same (i.e., may, would, could, and suggest), emphasizing that New Zealand students in the two disciplines share a similarity in the use of high frequency hedges in their theses. As for hedges shared within the Thai corpus (TH-ELT and TH-BA), the markers might and mostly are frequently used by Thai students in both disciplines in addition to the six types of hedges shared over the four subcorpora. 
With regard to the distribution of higher and lower frequency hedges, a sum of normalized frequencies and percentage of the ten high frequency hedges in each corpus show a high density of the ten markers in TH-BA, as illustrated in Figure 6.1. This indicates that Thai students in business administration heavily depend on the ten hedging markers when they shield their arguments and signal uncertainty of propositional content to the readers. In this corpus, the top ten hedges occupy 95.9 out of 118.5 occurrences per 10,000 words, accounting for $80.9 \%$ of the total hedging occurrences. About $19 \%$ are accounted for by 41 lower frequency hedging markers in the corpus. In TH-ELT, the top ten markers occur 90 out of 124.2 times, accounting for $72.5 \%$ of the total occurrences of hedges in this corpus. As for NZ-ELT and NZ-BA, the top ten hedges occur 103.3 out of 137.4 times and 86.1 out of 127.8 times, accounting for $75.2 \%$ and $67.4 \%$ of the total occurrences, respectively. Concerning the distribution of hedges across the four subcorpora, Thai students in business administration make far greater use of high frequency hedges and have sparse use of lower frequency hedges, whereas New Zealand students in business administration have a greater proportion in the use of lower frequency hedges in their theses.

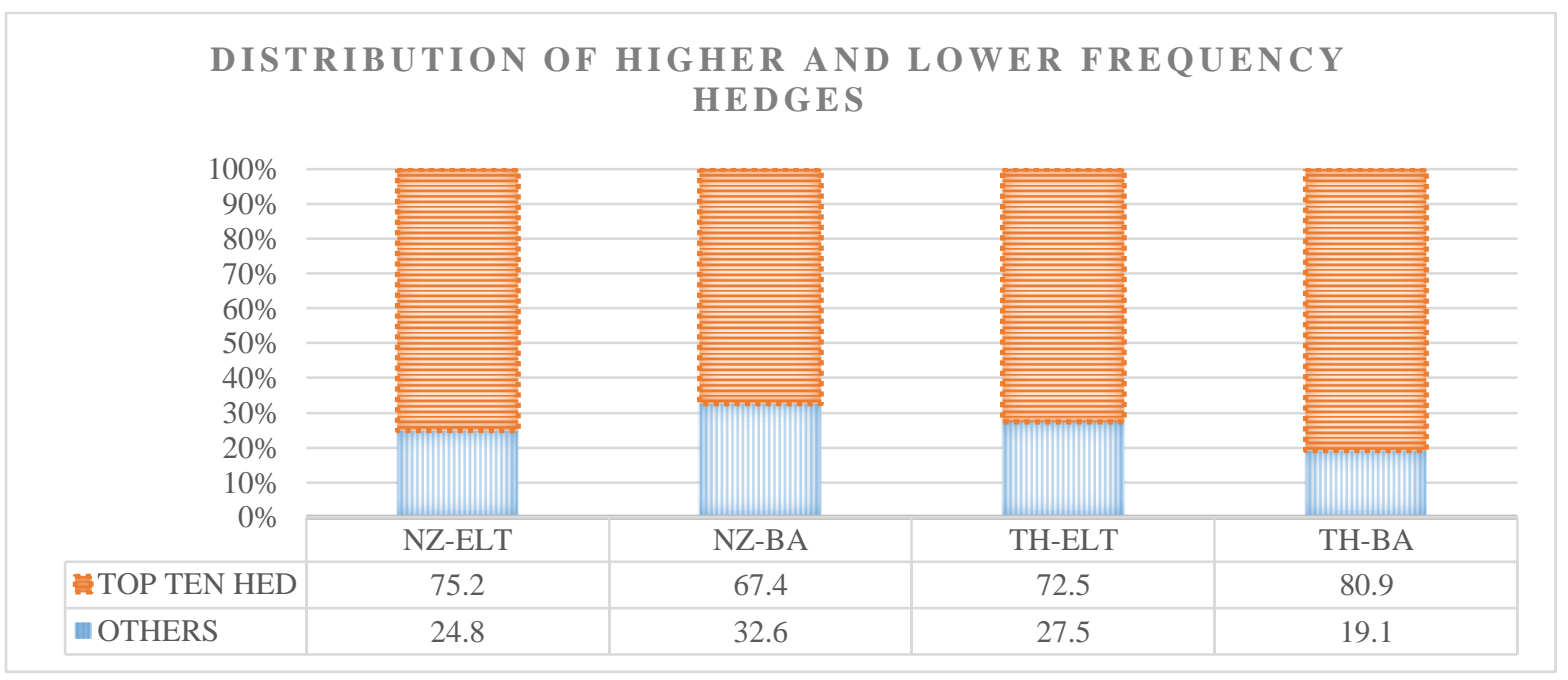

Figure 6.1. Distribution of higher and lower frequency hedges

Table 6.10 below provides a summary of New Zealand and Thai students' preferences for particular grammatical forms of hedging. New Zealand and Thai students in the two disciplines show a similarity in hedging their arguments mostly through the employment of several types of modal verbs, the most frequent one being may. The most frequent verbs used for hedging by all groups of students in the present study are suggest and indicate. The adjective likely is frequently employed by all groups, except TH-ELT students. Similar to NZ-BA students, THELT students are likely to use possible rather than other types of adjectives. As for adverbs, it 
is quite clear that the adverb of frequency often is more likely to be used by New Zealand students in the two disciplines, whereas Thai students in the two disciplines seem to more frequently use mostly for a maximum estimation. Additionally, Thai students in the language teaching discipline show their frequent use of the adverb frequently in the theses.

Table 6.10. High frequency hedges in different grammatical categories

\begin{tabular}{|c|c|c|c|c|}
\hline Corpus & Modal verbs & Verbs & Adjectives & Adverbs \\
\hline NZ-ELT & $\begin{array}{l}\text { may, would, could, should, } \\
\text { might }\end{array}$ & $\begin{array}{l}\text { suggest, indicate, } \\
\text { appear }\end{array}$ & likely & often \\
\hline NZ-BA & may, would, could, should & suggest, indicate, appear & likely, possible & often \\
\hline TH-ELT & $\begin{array}{l}\text { may, would, could, should, } \\
\text { might }\end{array}$ & suggest, indicate & possible & mostly, frequently \\
\hline TH-BA & $\begin{array}{l}\text { may, would, could, should, } \\
\text { might }\end{array}$ & $\begin{array}{l}\text { suggest, indicate, tend } \\
\text { to }\end{array}$ & likely & mostly \\
\hline
\end{tabular}

When classifying all the hedging markers found in the data sets according to the four grammatical forms and comparing frequencies, an interesting finding is that although New Zealand and Thai students show the same tendency to hedge their arguments mostly through modal verbs, their preferences for other forms are different. As seen in Table 6.11 below, New Zealand students in the two disciplines prefer hedging through the verb form rather than adverbs and adjectives. In contrast, Thai students in the two disciplines prefer hedging through adverbs rather than verbs and adjectives.

Table 6.11. Grammatical categories of hedges

\begin{tabular}{lcccccccccccc}
\hline \multirow{2}{*}{ Corpus } & \multicolumn{3}{c}{ Modal verbs } & \multicolumn{3}{c}{ Verbs } & \multicolumn{3}{c}{ Adjectives } & \multicolumn{3}{c}{ Adverbs } \\
\cline { 2 - 14 } & Raw & Nf & $\%$ & Raw & Nf & $\%$ & Raw & Nf & $\%$ & Raw & Nf & $\%$ \\
\hline NZ-ELT & 1375 & 68.4 & $49.7 \%$ & 623 & 31.0 & $22.5 \%$ & 275 & 13.7 & $10.0 \%$ & 491 & 24.4 & $17.8 \%$ \\
NZ-BA & 943 & 65.4 & $51.2 \%$ & 432 & 30.0 & $23.4 \%$ & 123 & 8.5 & $6.7 \%$ & 344 & 23.9 & $18.7 \%$ \\
TH-ELT & 860 & 68.5 & $55.2 \%$ & 297 & 23.6 & $19.0 \%$ & 80 & 6.4 & $5.1 \%$ & 323 & 25.7 & $20.7 \%$ \\
TH-BA & 1016 & 78.9 & $66.6 \%$ & 211 & 16.4 & $13.9 \%$ & 49 & 3.8 & $3.2 \%$ & 249 & 19.3 & $16.3 \%$ \\
\hline
\end{tabular}

\subsubsection{Functions of hedges}

\section{(i) Expressing tentativeness of research findings}

As conclusions and discussions of findings in either English language teaching or business administration theses are usually drawn from specific cases, thesis writers tend to include 
hedging markers in order to express tentativeness of their findings and circumspectly report the findings "in ways that are likely to be accepted and persuasive to their examiners and supervisors" (Hyland, 2004, p. 140).

Despite the higher frequency of hedging in the New Zealand corpus, New Zealand and Thai students employ similar types of hedges, e.g., the findings suggest that, to explicitly advise the readers with a gentle caution that the findings being presented are derived from the current study's data and they might be true or not true in other studies or cases. Making overly certain claims of research findings probably causes the readers' suspicion about overstatement and subjectivity of such claims. A prominent hedging strategy in the thesis corpora is making a reference to an inanimate subject (e.g., research itself, results, analyses) or human agent (e.g., previous researchers, research participants) as a source attribution rather than the writers themselves. As exemplified in the following excerpts, New Zealand and Thai students frequently collocate epistemic verbs (suggest, indicate) with research elements, namely research results (Excerpt 6.1), research instruments (progress reports, observation forms, interview comments) (Excerpt 6.2), and research participants (Excerpt 6.3). By so doing, the student writers have room for negotiation and are more likely to achieve acceptance for their claims than immediate refutation.

(6.1) This result, thus, may suggest that linguistic competence was a necessary tool for this group of Thai English teachers... (TH-ELT-03)

(6.2) An analysis of meeting documents, progress reports and observation feedback documents indicated a lack of goal setting of personal goals with a view to improving teaching practice. (NZ-ELT-08)

(6.3) Three students indicated that less than half their expectations of course activities had been met, or in other words, that the course had not fully met their expectations. (NZELT-13)

\section{(ii) Making possible justifications}

Not only do hedges express tentativeness of findings, but the markers also allow the writers to criticize findings based on a plausible rationale rather than proven facts or certain knowledge purely. New Zealand and Thai thesis writers employ hedging markers to present their epistemic views about findings so as to gain recognition and acceptance from readers in their 
communities. The discussion and conclusion chapters are parts of theses which not only require the writers to compare findings with the literature but also show their abilities in justifying the findings and clarifying propositions based on their own epistemological assumptions. So, the inclusion of hedges in thesis statements opens opportunities for apprentice writers like master's students to express their own views and debate with more knowledgeable examiners and supervisors in a cautious way.

To justify their claims or make opinion-based statements, New Zealand and Thai students in this study similarly use epistemic adjectives (possible, likely) in the two following patterns: epistemic adjective + noun phrase (Excerpt 6.4) and the anticipatory-it + verb to be + epistemic adjective clause (Excerpts 6.5-6.6). It is likely that the thesis writers repeatedly use these patterns to directly communicate with the readers their evaluation of the most likely explanation for a particular finding.

(6.4) One possible explanation for prevalence and acceptance of aggressive or competitive behaviour here is that, on an anonymous imageboard such as $/ \mathrm{cwc} /$, the potential for face loss is very small. (NZ-ELT-02)

(6.5) It is possible that when high proficiency learners encountered words that rarely appear in texts, they may prefer to learn those vocabulary items by taking note of word meanings, using verbal or written repetition and so on. (TH-ELT-07)

(6.6) It also seems likely that, like in the blue-collar workplace, there are other communities of practice, and indeed communities, where bro is largely unmarked for gender. (NZELT-06)

Besides using epistemic adjectives, another prominent pattern found in New Zealand and Thai students' theses is a combination between the demonstrative pronoun this representing a particular finding and the epistemic modal verb may followed by a causative marker, as in Excerpts 6.7-6.8.

(6.7) This may be because most participants perceived their respective organisations as independent entities with strong existing organisational identities. (NZ-BA-13)

(6.8) This may be due to the inadequate exposure to English practice. (TH-ELT-01) 


\section{(iii) Reducing frankness of assertions}

An important function of hedges is to tone down the writer's assertions (Hyland, 2005) particularly when the results contradict previous studies or triangulated data. It is noticeable in my data that when New Zealand and Thai students have contradictory results, they often hedge their arguments as an important rhetorical means to soften the statements and maintain solidarity with readers. In this case, the employment of hedges reflects the thesis writers' anticipation of possible opposition and criticism towards their assertions. This is viewed as a politeness strategy (Myers, 1989) conventionalized in academic writing and often used when academic writers need to challenge and criticize existing assumptions or work without imposing on the readers.

A collocation of an epistemic verb (suggest, indicate) with research elements (findings, interview data, survey responses) is a salient hedging pattern used by New Zealand and Thai students for presenting contradictory results. As in Excerpts 6.9-6.10, the presence of the markers like the findings suggest that (compared to the findings prove or the results show) reduces force of claims by indicating that such claims are not based on the writers' personal views but the discovery from existing data. This means of hedging not only conveys respect for alternative views (Hyland, 2005) but to me it also avoids threatening the face of participants and other scholars being referred to.

(6.9) All mentors identified as mentoring in the educative manner in the initial survey. They espoused enacting educative practices but the findings suggest that this was not always happening. (NZ-ELT-08)

(6.10) The findings from this study indicate that Bennett's (1986) basic model may be too blunt an instrument to measure sensitivity. (NZ-ELT-18)

Moreover, when they need to reject some existing assumptions, New Zealand writers alternatively front-load their statements with the there + be + evidence clause (There is no/little evidence to suggest that...) to avoid responsibility for their claims by positioning themselves as distant from the statements and attributing the claims to research elements (Excerpts 6.116.12). This hedging feature is hardly found in Thai students' thesis writing. 
(6.11) Furthermore, there was no evidence to suggest that participants had made connections between textual elements or related the information they had read to their own personal experiences and background knowledge. (NZ-ELT-20)

(6.12) There appears to be little evidence to suggest that any significant distinctions between multi-sector organisations exist in the New Zealand fitness industry. (NZ-BA-13)

\section{(iv) Discussing theoretical and practical implications}

Traditionally, thesis writers include a section in the discussion and conclusion chapters for which they discuss the implications of their present studies. Based on an analysis of theses of this study, in business administration theses, New Zealand writers frequently employ hedges for the purpose of suggesting a possible solution for a problem and predicting an outcome of business and management plans (Excerpt 6.13). Thai students in the business discipline also employ hedges for the purpose of suggesting a predictable outcome but not as frequently as New Zealand students do. In English language teaching theses, both New Zealand and Thai students make frequent use of hedges to emphasize advantages of using particular language teaching and learning strategies as in Excerpts 6.14-6.15.

(6.13) Collaboration with larger firms, where experienced and capable IT specialists could be seconded to work on projects... or provide guidance and training to graduate and junior developers as part of an apprenticeship or mentoring arrangement, may yield broader benefits across the market. (NZ-BA-01)

(6.14) Another implication that the current study has indicated is that IELTS preparation courses need to include language skill development in tandem with IELTS test-taking skills, in order to help prepare students for tertiary education. (NZ-ELT-13)

(6.15) The results from this group of Thai English teachers suggest that Thai English teachers in general should be encouraged to develop their pragmatic and linguistic ability because these teachers may be the only available source students can rely on for pragmatic development. (TH-ELT-03)

\section{(v) Commenting on research limitations}

Based on the fact that research has its own specific limitations impeding a conduct of research to some extent, thesis writers use hedges to address the anticipated limitations. This is to 
negotiate with the readers that they are aware of such factors but cannot avoid them when conducting their study. As in Excerpt 6.16, the writer hedges his/ her statements when acknowledging contextual constraints which possibly influence on the results of the study. In Excerpt 6.17, the use of hedge indicates the writer's awareness of issues around generalizing findings for other cases.

(6.16) Difficulty expressing themselves in English may have been a factor for three of the sets of parents not wanting to be interviewed. A lack of English proficiency may also have affected the depth of communication in the interviews with the remaining parents who did consent. (NZ-ELT-03)

(6.17) The scope of distribution of the questionnaires was limited to the international medical tourists in Phuket and Bangkok, Thailand. Therefore, the result of this study may not generalize with regard to any other medical tourism destinations countries. (TH-BA25)

\section{(vi) Suggesting alternative methods for further research}

As thesis students are encouraged to provide alternative directions for further research, the employment of hedging markers in this thesis section enables the writers to express their personal views without taking full responsibility for the suggestions. Modal verbs like may, would, should, and could are the most frequent hedging markers used by both New Zealand and Thai students when giving suggestions of alternative methods to undertake further research. The frequent use of modal verbs for hedging is possibly attributed to semantic functions of modal verbs which allow the writers to express possibility, probability, and necessity in writing. Also, making use of modal verbs is a facilitative and economical way of claiming with fewer words when compared to an evaluative that construction (Hyland \& Jiang, 2018b).

(6.18) Further research in this area may include the collective nature of physical working environments and the benefits of group efficacy. (NZ-BA-07)

(6.19) Further study may explore why more frequent strategies use does not promote vocabulary development in low proficiency learners. (TH-ELT-07) 


\subsection{Boosters}

\subsubsection{Frequencies of boosters in $\mathrm{NZ}$ and $\mathrm{TH}$ corpora}

Table 6.12 shows the extent to which New Zealand and Thai students use boosters in their master's theses. As measured by the normalized frequencies of boosters, the Thai group exhibits considerably more frequent use of boosters $(\mathrm{Nf}=43.4)$ than the New Zealand group $(\mathrm{Nf}=27.1)$. The log-likelihood calculation of 113.16 reveals statistical significance of the higher incidence of boosters in the Thai corpus at the level of $p<.0001$.

Table 6.12. Boosters in NZ and TH corpora

\begin{tabular}{llcrlrc}
\hline & \multicolumn{2}{c}{$\begin{array}{c}\text { TEW ZEALAND } \\
(345,277 \text { words })\end{array}$} & \multicolumn{2}{c}{$\begin{array}{c}\text { THAI } \\
(254,322 \text { words })\end{array}$} & Log-likelihood \\
\cline { 2 - 6 } & Raw & Nf & Raw & Nf & LL & $p$-value \\
\hline Boosters & 935 & 27.1 & 1104 & 43.4 & 113.16 & $p<.0001$ \\
\hline
\end{tabular}

Regarding cross-disciplinary variation of boosters in the New Zealand corpus (NZ-ELT vs. NZ-BA), New Zealand students in the language teaching field employ more boosters $(\mathrm{Nf}=29.5)$ than their compatriots in the business field $(\mathrm{Nf}=23.7)$. The log-likelihood value of 10.90 indicates that the higher frequency of boosters in the NZ-ELT corpus is highly significant at the level of $p<.001$, as shown in Table 6.13.

Table 6.13. Boosters in NZ-ELT and NZ-BA subcorpora

\begin{tabular}{|c|c|c|c|c|c|c|}
\hline & \multicolumn{4}{|c|}{ NEW ZEALAND } & \multirow{3}{*}{\multicolumn{2}{|c|}{ Log-likelihood }} \\
\hline & \multirow{2}{*}{\multicolumn{2}{|c|}{$\begin{array}{c}\text { NZ-ELT } \\
\text { (201,099 words) }\end{array}$}} & \multirow{2}{*}{\multicolumn{2}{|c|}{$\begin{array}{c}\text { NZ-BA } \\
\text { (144,178 words) }\end{array}$}} & & \\
\hline & & & & & & \\
\hline & Raw & $\mathrm{Nf}$ & Raw & $\mathrm{Nf}$ & LL & $p$-value \\
\hline Boosters & 594 & 29.5 & 341 & 23.7 & 10.90 & $p<.001$ \\
\hline
\end{tabular}

As for cross-disciplinary variation of boosters in the Thai corpus (TH-ELT vs. TH-BA), Thai students in the two disciplines show similar frequencies in using boosters. That is, Thai students in the language teaching and business disciplines are likely to use boosters 41.6 times and 45.2 times per 10,000 words, respectively. The log-likelihood value of 1.98 suggests that there is no significant difference in the use of boosters between Thai students in the two disciplines $(p>$ $.05)$. 
Table 6.14. Boosters in TH-ELT and TH-BA subcorpora

\begin{tabular}{|c|c|c|c|c|c|c|}
\hline & \multicolumn{4}{|c|}{ THAI } & \multirow{3}{*}{\multicolumn{2}{|c|}{ Log-likelihood }} \\
\hline & \multirow{2}{*}{\multicolumn{2}{|c|}{$\begin{array}{c}\text { TH-ELT } \\
\text { (125,631 words) }\end{array}$}} & \multirow{2}{*}{\multicolumn{2}{|c|}{$\begin{array}{c}\text { TH-BA } \\
(128,691 \text { words) }\end{array}$}} & & \\
\hline & & & & & & \\
\hline & Raw & $\mathrm{Nf}$ & Raw & $\mathrm{Nf}$ & LL & $p$-value \\
\hline Boosters & 522 & 41.6 & 582 & 45.2 & 1.98 & $p>.05$ \\
\hline
\end{tabular}

\subsubsection{Frequencies of boosters in ELT and BA corpora}

Table 6.15 shows frequencies of boosters between English language teaching and business administration disciplines. Overall, English language teaching students do not differ from business administration students in the frequency of using boosters. In every 10,000 words, boosters occur 34.2 times in the language teaching corpus and 33.8 times in the business corpus. The log-likelihood value of 0.05 indicates that there is no significant difference in the use of boosters between English language teaching and business administration disciplines ( $p$ $>.05)$.

Table 6.15. Boosters in ELT and BA corpora

\begin{tabular}{|c|c|c|c|c|c|c|}
\hline & \multicolumn{2}{|c|}{$\begin{array}{c}\text { ELT } \\
(326,730 \text { words) }\end{array}$} & \multicolumn{2}{|c|}{$\begin{array}{c}\text { BA } \\
(272,869 \text { words })\end{array}$} & \multicolumn{2}{|c|}{ Log-likelihood } \\
\hline & Raw & $\mathrm{Nf}$ & Raw & $\mathrm{Nf}$ & LL & $p$-value \\
\hline Boosters & 1116 & 34.2 & 923 & 33.8 & 0.05 & $p>.05$ \\
\hline
\end{tabular}

With regard to a comparison of boosters between New Zealand and Thai theses in the English language teaching discipline (NZ-ELT vs. TH-ELT), Table 6.16 shows that Thai students in the language teaching discipline use boosters 41.6 times in every 10,000 words, while New Zealand students in the same discipline use only 29.5 times. The log-likelihood calculation of 31.96 reveals that the higher incidence of boosters in the TH-ELT corpus is significant at the level of $p<.0001$. 
Table 6.16. Boosters in NZ-ELT and TH-ELT subcorpora

\begin{tabular}{lcccccc}
\hline & \multicolumn{4}{c}{ ENGLISH LANGUAGE TEACHING } & & Log-likelihood \\
\cline { 2 - 5 } & \multicolumn{2}{c}{$\begin{array}{c}\text { NZ-ELT } \\
(201,099 \text { words })\end{array}$} & \multicolumn{2}{c}{$\begin{array}{c}\text { TH-ELT } \\
(125,631 \text { words })\end{array}$} & & \\
\cline { 2 - 5 } & Raw & Nf & Raw & Nf & LL & $p$-value \\
\hline Boosters & 594 & 29.5 & 522 & 41.6 & 31.96 & $p<.0001$ \\
\hline
\end{tabular}

Similarly, a cross-cultural comparison in the business administration discipline (NZ-BA vs. TH-BA) reveals that Thai students in the business discipline use boosters $(\mathrm{Nf}=45.2)$ more often than New Zealand students in the business discipline $(\mathrm{Nf}=23.7)$. The higher frequency of boosters in the TH-BA corpus is significant, as determined by the log-likelihood value of 94.03 at the level of $p<.0001$.

Table 6.17. Boosters in NZ-BA and TH-BA subcorpora

\begin{tabular}{|c|c|c|c|c|c|c|}
\hline & \multicolumn{4}{|c|}{ BUSINESS ADMINISTRATION } & \multirow{2}{*}{\multicolumn{2}{|c|}{ Log-likelihood }} \\
\hline & \multirow{2}{*}{\multicolumn{2}{|c|}{$\begin{array}{c}\text { NZ-BA } \\
\text { (144,178 words) }\end{array}$}} & \multirow{2}{*}{\multicolumn{2}{|c|}{$\begin{array}{c}\text { TH-BA } \\
(128,691 \text { words) }\end{array}$}} & & \\
\hline & & & & & \multirow[b]{2}{*}{ LL } & \multirow[b]{2}{*}{$p$-value } \\
\hline & Raw & $\mathrm{Nf}$ & Raw & $\mathrm{Nf}$ & & \\
\hline Boosters & 341 & 23.7 & 582 & 45.2 & 94.03 & $p<.0001$ \\
\hline
\end{tabular}

This section concludes that Thai students use boosters more often than New Zealand students. The cross-disciplinary comparison within the New Zealand context (NZ-ELT vs. NZ-BA) indicates a significantly higher frequency of boosters in the NZ-ELT corpus. The crossdisciplinary comparison within the Thai corpus (TH-ELT vs. TH-BA) suggests that the incidence of boosters between the two disciplines in the Thai corpus is not significantly different. Overall, there is no significant difference in the frequency of boosters in English language teaching and business administration theses. The comparison between New Zealand and Thai theses in the English language teaching discipline (NZ-ELT vs. TH-ELT) and the business discipline (NZ-BA vs. TH-BA) suggests a significantly higher frequency of boosters in Thai theses compared to New Zealand theses in both disciplines (TH-ELT and TH-BA). 


\subsubsection{Types of boosters}

The four subcorpora have similar numbers of booster types, namely 23 types in NZ-ELT, 26 types in NZ-BA, 27 types in TH-ELT, and 26 types in TH-BA. Sixteen types of these markers are shared over the four subcorpora.

Table 6.18 provides the top ten booster list. Show, find, must, certainly, clearly, and always are six high frequency boosters shared over the four subcorpora. Similar to hedges, high frequency boosters can be realized in the grammatical form of modal verbs (must), verbs (show, find, demonstrate, prove, think), adjectives (evident, clear, obvious), and adverbs (certainly, clearly, always, indeed, in fact, obviously, actually). The verbs show and find are the most frequent boosters which New Zealand and Thai students in the two disciplines employ to express their certainty of knowledge claims.

Table 6.18. Top ten booster list

\begin{tabular}{|c|c|c|c|c|c|c|c|c|}
\hline & \multicolumn{4}{|c|}{ NEW ZEALAND } & \multicolumn{4}{|c|}{ THAI } \\
\hline & \multicolumn{2}{|c|}{ NZ-ELT } & \multicolumn{2}{|c|}{ NZ-BA } & \multicolumn{2}{|c|}{ TH-ELT } & \multicolumn{2}{|c|}{ TH-BA } \\
\hline & Type & $\mathrm{Nf}$ & Type & $\mathrm{Nf}$ & Type & $\mathrm{Nf}$ & Type & $\mathrm{Nf}$ \\
\hline 1 & show & 8.4 & find & 4.8 & find & 18.0 & show & 15.4 \\
\hline 2 & find & 4.0 & show & 4.6 & show & 11.9 & find & 15.1 \\
\hline 3 & certainly & 3.5 & must & 2.8 & certainly & 2.4 & must & 4.0 \\
\hline 4 & demonstrate & 1.8 & evident & 2.1 & demonstrate & 1.6 & always & 2.7 \\
\hline 5 & must & 1.4 & certainly & 1.6 & must & 1.0 & certainly & 1.2 \\
\hline 6 & evident & 1.4 & clear & 1.3 & always & 0.7 & clear & 0.9 \\
\hline 7 & clearly & 1.2 & demonstrate & 1.2 & obvious & 0.7 & think & 0.9 \\
\hline 8 & always & 1.1 & always & 0.9 & evident & 0.6 & clearly & 0.8 \\
\hline 9 & clear & 1.0 & clearly & 0.8 & prove & 0.6 & obviously & 0.6 \\
\hline 10 & indeed & 0.9 & in fact & 0.6 & clearly & 0.6 & actually & 0.5 \\
\hline & SUM NF $=29.5$ & $\begin{array}{c}24.7 \\
(83.7 \%)\end{array}$ & SUM NF $=23.7$ & $\begin{array}{c}20.7 \\
(87.3 \%)\end{array}$ & SUM NF=41.6 & $\begin{array}{c}38.1 \\
(91.6 \%)\end{array}$ & SUM NF $=45.2$ & $\begin{array}{c}42.1 \\
\text { (93.1\%) }\end{array}$ \\
\hline
\end{tabular}

Bolded markers represent the popular markers on the top ten list shared across the four subcorpora.

Italic markers represent the popular markers shared by two disciplines within each context.

From the top ten list of boosters, there are some markers which appear on the top ten list of three subcorpora but are absent from one corpus, namely the absence of clear in TH-ELT as well as demonstrate and evident in TH-BA. However, there are some boosters which are found only on the top list of one corpus but are absent from other three subcorpora, namely the 
presence of obvious and prove in TH-ELT, think, obviously and actually in TH-BA, indeed in NZ-ELT, and in fact in NZ-BA.

Divided by context, disciplinary theses in the New Zealand corpus share three other boosters (demonstrate, evident, clear) in addition to the six boosters shared across the four subcorpora. This means that New Zealand students in the two disciplines are similar in terms of using the same nine high frequency boosters on the top ten list in their disciplinary theses. By contrast, Thai students in the two disciplines seem to differ from each other by including different types of high frequency boosters in their theses.

According to data in the present study, similar to hedges, boosters are realized in four grammatical forms: modal verbs, verbs, adjectives, and adverbs. Table 6.19 below shows both similar and different preferences of New Zealand and Thai students for particular forms of boosters. In terms of similarities, New Zealand and Thai students in the two disciplines seem to express their degree of confidence and certainty of research claims mostly through the use of verbs and adverbs. The least frequent form of boosters is modal verbs. The only high frequency boosting modal verb shared across the four subcorpora is must. New Zealand and Thai students frequently use the same types of boosting adverbs (certainly, always, clearly) and adjectives (evident, clear). The most frequent verbs in the thesis chapters in all the four subcorpora are show and find.

In terms of differences in the use of boosters between New Zealand and Thai students, Table 6.19 also illustrates that New Zealand students in the two disciplines use almost the same types of high frequency boosters in the four grammatical forms. Only in the adverb form, the marker indeed is preferred by New Zealand students in English language teaching and in fact preferred by New Zealand students in business administration. There is clear variation between the two disciplines of Thai students' theses. Thai students in English language teaching are more likely to use verbs (e.g., demonstrate, prove) to boost their claims, while Thai students in business administration seem to prefer boosters in the adverb form (e.g., obviously, actually). 
Table 6.19. Grammatical categories of boosters

\begin{tabular}{lllll}
\hline Corpus & Modal verbs & Verbs & Adjectives & Adverbs \\
\hline NZ-ELT & must & show, find, demonstrate & evident, clear & $\begin{array}{l}\text { certainly, always, clearly, } \\
\text { indeed } \\
\text { NZ-BA }\end{array}$ \\
& must & show, find, demonstrate & evident, clear & $\begin{array}{l}\text { certainly, always, clearly, } \\
\text { in fact }\end{array}$ \\
TH-ELT & must & show, find, demonstrate, & evident, obvious & certainly, always, clearly \\
& & prove & clear & certainly, always, clearly, \\
TH-BA & must & show, find, think & & obviously, actually \\
\hline
\end{tabular}

When comparing frequencies of all the boosters in the four grammatical forms, boosters in the verb form account for the highest proportion in all subcorpora, followed by adverbs. Looking at percentages of verbs across the subcorpora, Thai students in the two disciplines show a greater degree of preference for boosting arguments through verbs, when compared to New Zealand students whose the incidence of boosting adverbs is higher.

Table 6.20. Frequencies of boosters in four grammatical forms

\begin{tabular}{lcccccccccccc}
\hline \multirow{2}{*}{ Corpus } & \multicolumn{3}{c}{ Modal verbs } & \multicolumn{3}{c}{ Verbs } & \multicolumn{3}{c}{ Adjectives } & \multicolumn{3}{c}{ Adverbs } \\
\cline { 2 - 12 } & Raw & Nf & $\%$ & Raw & Nf & $\%$ & Raw & Nf & $\%$ & Raw & Nf & $\%$ \\
\hline NZ-ELT & 29 & 1.4 & $4.9 \%$ & 309 & 15.4 & $52.1 \%$ & 66 & 3.3 & $11.1 \%$ & 189 & 9.4 & $31.9 \%$ \\
NZ-BA & 40 & 2.8 & $11.8 \%$ & 168 & 11.7 & $49.2 \%$ & 57 & 4.0 & $16.7 \%$ & 76 & 5.3 & $22.3 \%$ \\
TH-ELT & 13 & 1.0 & $2.5 \%$ & 416 & 33.1 & $80.2 \%$ & 23 & 1.8 & $4.4 \%$ & 67 & 5.3 & $12.9 \%$ \\
TH-BA & 52 & 4.0 & $9.0 \%$ & 419 & 32.6 & $72.0 \%$ & 19 & 1.5 & $3.3 \%$ & 91 & 7.1 & $15.7 \%$ \\
\hline
\end{tabular}

With regard to the distribution of higher and lower frequency boosters, the ten high frequency markers in NZ-ELT occur 24.7 out of 29.5 times in every 10,000 words, accounting for $83.7 \%$ of the total occurrences of boosters in this corpus. In NZ-BA, the ten high frequency boosters are present 20.7 out of 23.7 times, accounting for $87.3 \%$ of the total occurrences. In the Thai corpus, the top ten high frequency boosters occur 38.1 out of 41.6 times in TH-ELT and 42.1 out of 45.2 times in TH-BA, accounting for $91.6 \%$ and $93.1 \%$ of the total occurrences of boosters in each corpus. As illustrated in Figure 6.2, New Zealand and Thai students in both disciplines overwhelmingly rely on the top ten high frequency boosters and have very sparse use of lower frequency boosters. Nonetheless, the distribution of lower frequency boosters in NZ-ELT is wider than in other subcorpora, suggesting slightly more frequent use of lower frequency boosters by New Zealand students in the language teaching discipline. 


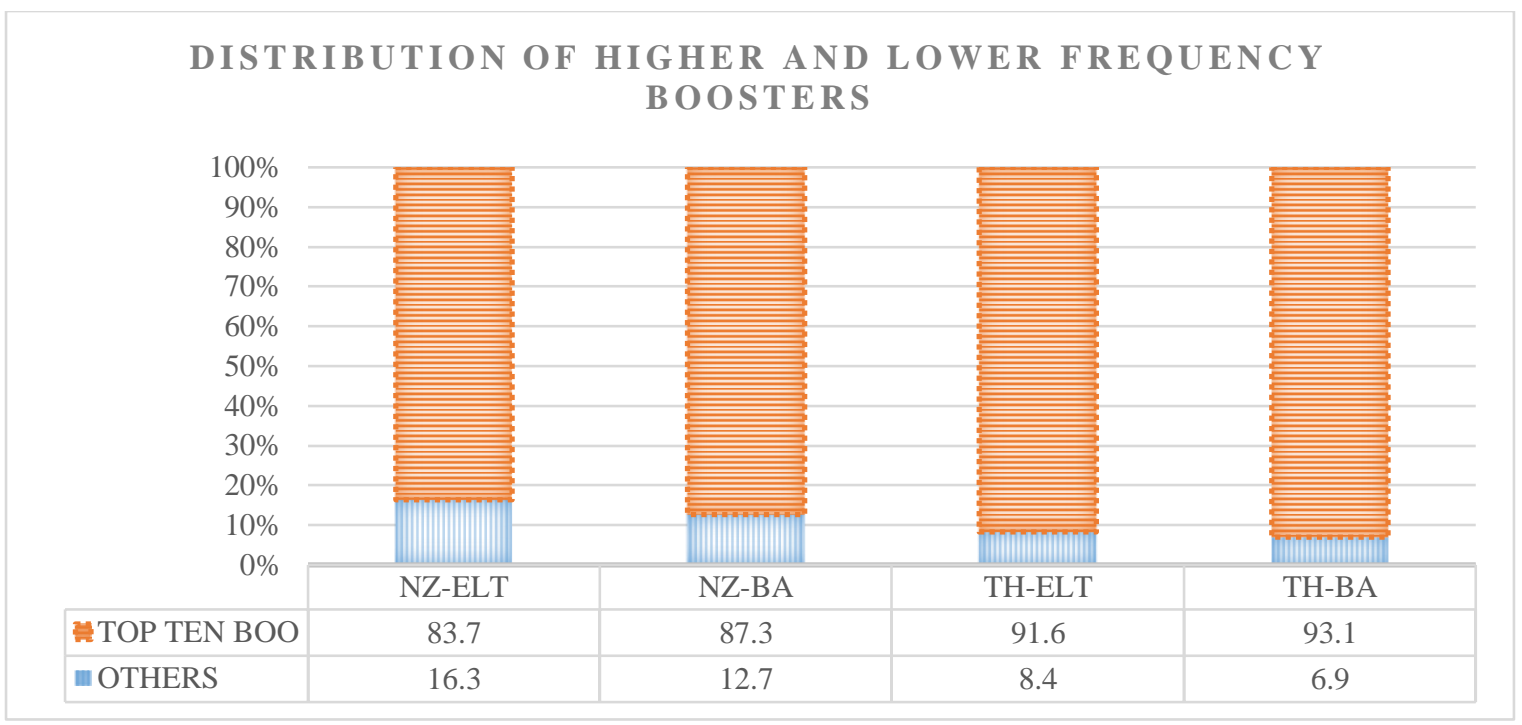

Figure 6.2. Distribution of higher and lower frequency boosters

\subsubsection{Functions of boosters}

\section{(i) Warranting certainty of research findings}

A principal function of boosters used in thesis writing is to warrant certainty of research findings and establish strong claims. New Zealand and Thai students strategically attribute the knowledge claims to strong evidence like research elements (e.g., data, results, research procedures, research participants) and allow such elements to build trustworthiness and speak for themselves. By this means, the writers can promote the appearance of objectivity and avoid the appearance of bias in the eyes of readers who have different perspectives. As seen in the following excerpts, in order to establish strong, impersonal claims, New Zealand and Thai thesis writers employ boosting verbs, predominantly find and show, in conjunction with research findings and procedures, for example the findings show that, qualitative data in this study found that, and multiple narratives show that (Excerpts 6.20-6.22).

(6.20) This finding showed that there was indeed evidence of productive lexical development occurring during early adolescence in this study... (NZ-ELT-04)

(6.21) Qualitative data in this study found that screen time was only deemed appropriate for infants and toddlers in limited amounts... (NZ-ELT-01)

(6.22) Multiple narratives show, in an economic climate largely made up of small to medium enterprises (SMEs), there is an enormous potential to foster social enterprise growth and develop the Māori economy. (NZ-BA-08) 
In addition to this, the employment of boosters by Thai students is more evident when they make claims based on statistical performance results (Excerpts 6.23-6.24). In other words, Thai students are likely to express confidence in their claims particularly when they have objective evidence like statistical results to support their judgment and drop the issue of subjectivity of making too certain claims.

(6.23) The results from a statistical performance show that the teachers with higher linguistic proficiency are likely to possess higher pragmatic competence in the three aspects of requests in question ( $r=.404, p<0.05)$. (TH-ELT-03)

(6.24) Based on the independent sample t-test between respondents' demographic characteristics and pull factors, the results showed that there were statistically significant differences in gender, nationality, resident and non-resident status, and resources affecting decision. The results showed that there was a significant difference in the pull factor labeled "Cost and financial aid”.... (TH-BA-08)

While the incidence of boosting verbs is higher in the Thai students' theses, New Zealand students in both disciplines more commonly use adverbs like indeed and in fact to intensify actions or degree of certainty of research results. The two markers are less frequently found in Thai students' theses. Common adverbs shared by both New Zealand and Thai students are clearly, certainly, and always.

(6.25) However, despite being the participant to refer to the individual 'leader' the most, it was indeed clear that this was embedded in a very collaborative, shared, and social perspective of leadership. (NZ-BA-23)

(6.26) The results clearly reveal that instrumental motivation is the most powerful type of motivation in English extensive reading of students. (TH-ELT-30)

Based on normalized frequencies of adjectives for boosting claims, New Zealand students especially in the discipline of business administration make more frequent use of adjectives than other groups of students in the present study. Clear and evident are the most salient adjectives with the highest occurrence in the four subcorpora. 
(6.27) From this study it is evident that while lexical development is a feature of adolescence, it is within the later period that marked growth in lexical resources takes place. (NZELT-04)

(6.28) It is clear that the quality and sensory aspects of the coffee, convenience, and price are all key aspects of business competition and coffee shops should focus on these areas as areas for customer improvement. (TH-BA-10)

\section{(ii) Adding persuasion}

Given that hedges allow apprentice writers to make research claims based on their own opinions, boosters also help the apprentice writers establish strong claims with a confident voice. Referring back to the top ten boosters in each corpus in the previous section, it is noticeable that Thai students especially in English language teaching often opt for boosting words with more strength like prove and obviously, while New Zealand students seem to avoid these strong words in their writing. One plausible explanation is that Thai students use more powerful words with an attempt to enhance the degree of persuasion and close down opportunities that skeptical readers will reject their claims. By contrast, New Zealand students tend to select soft or neutral boosting options (demonstrate), or even hedges, in order to avoid overstating and attracting negative reaction from the readers.

(6.29) The result of the current study proves that the CAVL package provided students with an opportunity to learn unknown word at any time. (TH-ELT-10)

(6.30) The finding of item 6 obviously reflects the characteristic of teacher dependence of the students in their learning. (TH-ELT-27)

A strategy New Zealand students use to promote the credibility of their assertions is to combine boosting markers with self-mentions (first-person pronouns) as in Excerpt 6.31. A combination of boosters and self-mentions not only reflects complete commitment and responsibility of the writers for the knowledge claims but also establishes an authorial involvement in discourse. Even though the combination is also found in Thai students' theses, it should be noted that Thai students make far less frequent use of this feature when compared to English speaking students in this study, as indicated by the frequencies of self-mentions across the corpora. A more prominent pattern in the Thai corpus is the use of boosting markers in the anticipatory it or 
extraposition form which refers to clauses in which it is inserted in the normal subject position (Hewings \& Hewings, 2002), as exemplified in Excerpt 6.32.

(6.31) Given the evidence from the online survey, interviews, meeting and documentation, I have found that the role of the mentor and what mentors understood their role to be was the critical element for establishing a relationship. (NZ-ELT-08)

(6.32) It was found that during the training sessions, students with low proficiency in English seemed to have difficulty comprehending the presentation of the content being offered. (TH-ELT-16)

The difference between the use of I found that and It was found that (or It is likely that in the subcategory of hedges) lies in the extent to which thesis writers would like to present their claims in a personal or impersonal way, taking or avoiding responsibility for the claims.

\section{(iii) Indicating necessity of an action}

A key function of boosters in thesis writing is to indicate the writers' judgement about necessity of an action as part of research contributions. To emphasize a message the writers hope readers in their communities to take into consideration and practice, New Zealand and Thai students similarly use the obligatory modal verb must and directly mention the target readers like educative mentors, entrepreneurs, language teachers, and tourism organizations, as in Excerpts 6.33-6.36. Here must is counted as an interpersonal metadiscourse marker because it plays an important role in expressing the writers' evaluation of propositions in terms of necessity and the writers' willingness to talk to the target readers about the evaluated propositions. The presence of reader reference together with the modal must here manifests writer-reader interaction in thesis discourse.

(6.33) To optimise results for deliberate educative mentoring the mentor must understand what educative mentoring is and establish a relationship in order for the practice to occur. (NZ-ELT-08)

(6.34) The entrepreneur must continuously maintain their growth strategy, and then create a new growth strategy, then maintain this strategy, and so forth. (NZ-BA-16)

(6.35) In addition, teachers must consider using CAVL package both in and out of the class to assist learners to learn on their own. (TH-ELT-10) 
(6.36) Authorities must create a culture of consciousness especially towards the environment and benefit of Phuket. (TH-BA-07)

\subsection{Attitude markers}

\subsubsection{Frequencies of attitude markers in NZ and TH corpora}

Table 6.21 reports frequencies of attitude markers in New Zealand and Thai theses. Based on the normalized frequencies per 10,000 words, attitude markers are more frequently found in New Zealand students' theses $(\mathrm{Nf}=20.7)$ than in Thai students' theses $(\mathrm{Nf}=11.9)$. The loglikelihood calculation of 69.27 reveals statistical significance of the higher occurrence of attitude markers in the New Zealand corpus at the level of $p<.0001$.

Table 6.21. Attitude markers in NZ and TH corpora

\begin{tabular}{|c|c|c|c|c|c|c|}
\hline & \multicolumn{2}{|c|}{$\begin{array}{l}\text { NEW ZEALAND } \\
(345,277 \text { words })\end{array}$} & \multicolumn{2}{|c|}{$\begin{array}{c}\text { THAI } \\
(254,322 \text { words })\end{array}$} & \multicolumn{2}{|c|}{ Log-likelihood } \\
\hline & Raw & $\mathrm{Nf}$ & Raw & $\mathrm{Nf}$ & LL & $p$-value \\
\hline Attitude markers & 713 & 20.7 & 302 & 11.9 & 69.27 & $p<.0001$ \\
\hline
\end{tabular}

Comparing attitude markers between the two disciplines in the New Zealand corpus (NZ-ELT vs. NZ-BA), New Zealand theses in business administration contain slightly more attitude markers $(\mathrm{Nf}=22.3)$ than theses in English language teaching $(\mathrm{Nf}=19.5)$. However, the loglikelihood value of 3.10 indicates that there is no significant difference in the incidence of attitude markers between New Zealand theses in the two disciplines $(p>.05)$, as shown in Table 6.22

Table 6.22. Attitude markers in NZ-ELT and NZ-BA subcorpora

\begin{tabular}{|c|c|c|c|c|c|c|}
\hline & \multicolumn{4}{|c|}{ NEW ZEALAND } & \multirow{3}{*}{\multicolumn{2}{|c|}{ Log-likelihood }} \\
\hline & \multirow{2}{*}{\multicolumn{2}{|c|}{$\begin{array}{c}\text { NZ-ELT } \\
\text { (201,099 words) }\end{array}$}} & \multirow{2}{*}{\multicolumn{2}{|c|}{$\begin{array}{c}\text { NZ-BA } \\
(144,178 \text { words })\end{array}$}} & & \\
\hline & & & & & & \\
\hline & Raw & $\mathrm{Nf}$ & Raw & $\mathrm{Nf}$ & LL & $p$-value \\
\hline Attitude markers & 392 & 19.5 & 321 & 22.3 & 3.10 & $p>.05$ \\
\hline
\end{tabular}

As for disciplinary variation in the Thai corpus (TH-ELT vs. TH-BA), Thai students in the two disciplines share a similarity in the frequency of using attitude markers. From Table 6.23, Thai 
students in the language teaching and business disciplines are likely to use attitude markers 11.2 times and 12.5 times per 10,000 words, respectively. The log-likelihood value of 0.89 indicates that there is no significant difference between Thai students in the two disciplines ( $p$ $>.05)$.

Table 6.23. Attitude markers in TH-ELT and TH-BA subcorpora

\begin{tabular}{|c|c|c|c|c|c|c|}
\hline & & & & & & \\
\hline & & & & & & g-likelihood \\
\hline & $(12$ & & $(12$ & & & \\
\hline & Raw & $\mathrm{Nf}$ & Raw & $\mathrm{Nf}$ & LL & $p$-value \\
\hline Attitude markers & 141 & 11.2 & 161 & 12.5 & 0.89 & $p>.05$ \\
\hline
\end{tabular}

\subsubsection{Frequencies of attitude markers in ELT and BA corpora}

Table 6.24 shows frequencies of attitude markers found in English language teaching and business administration theses. English language teaching theses contain slightly fewer attitude markers $(\mathrm{Nf}=16.3)$ than business administration theses $(\mathrm{Nf}=17.7)$. Overall, there is no significant difference in the incidence of attitude markers between English language teaching and business administration disciplines, as determined by the log-likelihood value of 1.60 ( $p$ > $.05)$.

Table 6.24. Attitude markers in ELT and BA corpora

\begin{tabular}{|c|c|c|c|c|c|c|}
\hline & \multicolumn{2}{|c|}{$\begin{array}{c}\text { ELT } \\
(326,730 \text { words })\end{array}$} & \multicolumn{2}{|c|}{$\begin{array}{c}\text { BA } \\
(272,869 \text { words })\end{array}$} & \multicolumn{2}{|c|}{ Log-likelihood } \\
\hline & Raw & $\mathrm{Nf}$ & Raw & $\mathrm{Nf}$ & $\mathrm{LL}$ & $p$-value \\
\hline Attitude markers & 533 & 16.3 & 482 & 17.7 & 1.60 & $p>.05$ \\
\hline
\end{tabular}

Comparing frequency of attitude markers in New Zealand and Thai theses in the English language teaching discipline (NZ-ELT vs. TH-ELT), Table 6.25 shows that New Zealand students in the language teaching field employ attitude markers $(\mathrm{Nf}=19.5)$ more often than Thai students in the same field $(\mathrm{Nf}=11.2)$. The log-likelihood calculation of 34.15 indicates that the higher incidence of attitude markers in the NZ-ELT corpus is significant at the level of $p<$ .0001 . 
Table 6.25. Attitude markers in NZ-ELT and TH-ELT subcorpora

\begin{tabular}{|c|c|c|c|c|c|c|}
\hline & \multicolumn{4}{|c|}{ ENGLISH LANGUAGE TEACHING } & \multirow{3}{*}{\multicolumn{2}{|c|}{ Log-likelihood }} \\
\hline & \multirow{2}{*}{\multicolumn{2}{|c|}{$\begin{array}{c}\text { NZ-ELT } \\
(201,099 \text { words })\end{array}$}} & \multirow{2}{*}{\multicolumn{2}{|c|}{$\begin{array}{c}\text { TH-ELT } \\
\text { (125,631 words) }\end{array}$}} & & \\
\hline & & & & & & \\
\hline & Raw & $\mathrm{Nf}$ & Raw & $\mathrm{Nf}$ & LL & $p$-value \\
\hline Attitude markers & 392 & 19.5 & 141 & 11.2 & 34.15 & $p<.0001$ \\
\hline
\end{tabular}

Similarly, comparing frequency of attitude markers in New Zealand and Thai theses in business administration (NZ-BA vs. TH-BA) reveals that New Zealand students in the business field use attitude markers $(\mathrm{Nf}=22.3)$ more often than Thai students in the same field $(\mathrm{Nf}=12.5)$. The higher frequency of attitude markers in the NZ-BA corpus is significant, as determined by the log-likelihood value of 37.51 at the level of $p<.0001$.

Table 6.26. Attitude markers in NZ-BA and TH-BA subcorpora

\begin{tabular}{|c|c|c|c|c|c|c|}
\hline & \multicolumn{4}{|c|}{ BUSINESS ADMINISTRATION } & \multirow{2}{*}{\multicolumn{2}{|c|}{ Log-likelihood }} \\
\hline & \multicolumn{2}{|c|}{$\begin{array}{c}\text { NZ-BA } \\
(144,178 \text { words })\end{array}$} & \multicolumn{2}{|c|}{$\begin{array}{c}\text { TH-BA } \\
(128,691 \text { words })\end{array}$} & & \\
\hline & Raw & $\mathrm{Nf}$ & Raw & $\mathrm{Nf}$ & LL & $p$-value \\
\hline Attitude markers & 321 & 22.3 & 161 & 12.5 & 37.51 & $p<.0001$ \\
\hline
\end{tabular}

This section concludes that attitude markers occur more frequently in New Zealand students' theses compared to Thai students' theses. The cross-disciplinary comparison within the New Zealand context (NZ-ELT vs. NZ-BA) and the Thai context (TH-ELT vs. TH-BA) indicates that there is no significant difference in the use of attitude markers between the two disciplines in both contexts. Overall, the incidence of attitude markers in English language teaching and business administration theses is not significantly different. The comparison between New Zealand and Thai theses in the English language teaching discipline (NZ-ELT vs. TH-ELT) and the business administration discipline (NZ-BA vs. TH-BA) suggests a significantly higher frequency of attitude markers in New Zealand theses compared to Thai theses in both disciplines (NZ-ELT and NZ-BA). 


\subsubsection{Types of attitude markers}

Among a wide range of attitude markers on the pre-identified marker list, 27 types of attitude markers are found in NZ-ELT, 28 types in NZ-BA, 19 types in TH-ELT, and 26 types in THBA. Only 13 types are shared over the four subcorpora.

Table 6.27 indicates that important, interesting, valuable, and significant are the most salient attitude markers which are shared over the four subcorpora. Divided by context, New Zealand students in the two disciplines share three more types of attitude markers, necessarily, interestingly and unique, in addition to the four markers mentioned earlier. Thai students in the two disciplines further share essential and crucial.

There are some attitude markers which appear on the top ten list of three of the subcorpora but are absent from one corpus, namely the absence of essential in NZ-ELT, crucial in NZ-BA, necessarily and unique in TH-ELT, and interestingly in TH-BA. The markers which are present on the top list of one corpus are essentially and prominent in NZ-BA, salient and outstanding in TH-ELT, and unfortunately in TH-BA.

Table 6.27. Top ten attitude marker list

\begin{tabular}{|c|c|c|c|c|c|c|c|c|}
\hline & \multicolumn{4}{|c|}{ NEW ZEALAND } & \multicolumn{4}{|c|}{ THAI } \\
\hline & \multicolumn{2}{|c|}{ NZ-ELT } & \multicolumn{2}{|c|}{ NZ-BA } & \multicolumn{2}{|c|}{ TH-ELT } & \multicolumn{2}{|c|}{ TH-BA } \\
\hline & Type & $\mathrm{Nf}$ & Type & $\mathrm{Nf}$ & Type & $\mathrm{Nf}$ & Type & $\mathrm{Nf}$ \\
\hline 1 & important & 5.3 & important & 6.1 & important & 3.9 & important & 5.3 \\
\hline 2 & necessarily & 1.8 & interesting & 3.3 & interestingly & 1.1 & interesting & 1.4 \\
\hline 3 & interesting & 1.6 & valuable & 1.5 & interesting & 0.8 & essential & 1.1 \\
\hline 4 & significant & 1.6 & significant & 1.4 & significant & 0.8 & unique & 0.8 \\
\hline 5 & valuable & 1.2 & unique & 1.3 & essential & 0.7 & necessarily & 0.5 \\
\hline 6 & crucial & 0.9 & necessarily & 1.2 & importantly & 0.6 & expected & 0.4 \\
\hline 7 & interestingly & 0.8 & interestingly & 1.0 & crucial & 0.6 & crucial & 0.4 \\
\hline 8 & unique & 0.7 & essentially & 0.9 & salient & 0.5 & unfortunately & 0.3 \\
\hline 9 & expected & 0.6 & prominent & 0.8 & valuable & 0.4 & significant & 0.3 \\
\hline 10 & importantly & 0.6 & essential & 0.8 & outstanding & 0.4 & valuable & 0.2 \\
\hline & SUM NF $=19.5$ & $\begin{array}{c}15.1 \\
(77.4 \%)\end{array}$ & SUM NF=22.3 & $\begin{array}{c}18.3 \\
(82 \%)\end{array}$ & SUM NF $=11.2$ & $\begin{array}{c}9.8 \\
(87.5 \%)\end{array}$ & SUM NF=12.5 & $\begin{array}{c}10.7 \\
(85.6 \%)\end{array}$ \\
\hline
\end{tabular}

Bolded markers represent the popular markers on the top ten list shared across the four subcorpora.

Italic markers represent the popular markers shared by two disciplines within each context. 
With regard to the proportion in the use of higher and lower frequency attitude markers, Figure 6.3 illustrates that Thai students in English language teaching and business administration are heavily reliant on the top ten markers when they evaluate propositional content and intend to present their personal evaluation to the readers. The top ten markers in TH-ELT are present 9.8 out of 11.2 times, accounting for $87.5 \%$ of the total occurrences of attitude markers in this corpus. In TH-BA, the top ten markers occur 10.7 out of 12.5 times, accounting for $85.6 \%$ of the total occurrences. In the New Zealand corpus, New Zealand students in English language teaching are more likely to make greater use of lower frequency attitude markers when compared to other groups of students. The occurrences of high frequency attitude markers in NZ-ELT are 15.1 out of 19.5 times, accounting for $77.4 \%$ of the total occurrences. The top ten markers in NZ-BA occur 18.3 out of 22.3 times, accounting for $82 \%$ of the total occurrences. The results suggest that New Zealand and Thai students in the two disciplines, especially Thai students in English language teaching, have a heavy reliance on a small cluster of attitude markers and do not make frequent use of the attitude markers to express their personal sentiments in theses.

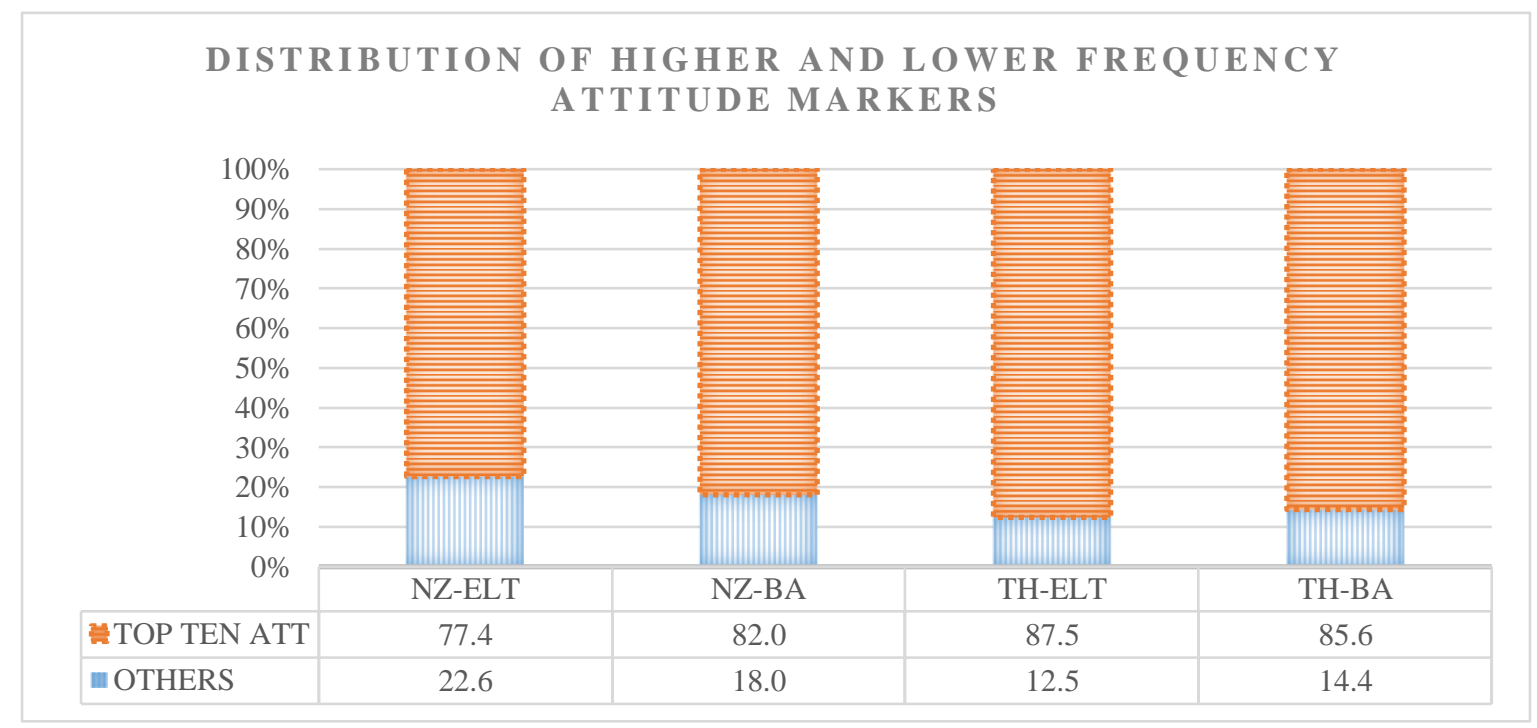

Figure 6.3. Distribution of higher and lower frequency attitude markers

\subsubsection{Functions of attitude markers}

In order to examine how attitude markers are used in master's theses, I categorized types of attitude markers found in the four subcorpora based on their functions being performed in the present study into five aspects, namely importance, interestingness, quality, predictability, and acceptability. For instance, when I found the markers salient and outstanding, I categorized them into the aspect of "quality" attitude markers since they are often used by thesis writers to 
express their evaluation of quality of research materials and so on. In Table 6.28 below, the categorization focuses on the ten high frequency markers in the four subcorpora because other attitude markers are far less frequently found in the corpus and thus provide little evidence to analyze their functions. The table also shows that New Zealand and Thai students similarly employ high frequency attitude markers in the grammatical form of adjectives and adverbs to express their perceptions on content in four of the five aspects.

Table 6.28. High frequency attitude markers in different aspects

\begin{tabular}{|c|c|c|c|c|c|}
\hline Corpus & Importance & Interestingness & Quality & Predictability & Acceptability \\
\hline NZ-ELT & $\begin{array}{l}\text { important } \\
\text { significant } \\
\text { valuable } \\
\text { crucial } \\
\text { importantly } \\
\text { necessarily }\end{array}$ & $\begin{array}{l}\text { interesting } \\
\text { interestingly }\end{array}$ & unique & expected & - \\
\hline NZ-BA & $\begin{array}{l}\text { important } \\
\text { significant } \\
\text { valuable } \\
\text { essential } \\
\text { essentially } \\
\text { necessarily }\end{array}$ & $\begin{array}{l}\text { interesting } \\
\text { interestingly }\end{array}$ & $\begin{array}{l}\text { unique } \\
\text { prominent }\end{array}$ & - & - \\
\hline TH-ELT & $\begin{array}{l}\text { important } \\
\text { significant } \\
\text { valuable } \\
\text { crucial } \\
\text { essential } \\
\text { importantly }\end{array}$ & $\begin{array}{l}\text { interesting } \\
\text { interestingly }\end{array}$ & $\begin{array}{l}\text { salient } \\
\text { outstanding }\end{array}$ & - & - \\
\hline TH-BA & $\begin{array}{l}\text { important } \\
\text { significant } \\
\text { valuable } \\
\text { crucial } \\
\text { essential } \\
\text { necessarily }\end{array}$ & interesting & unique & $\begin{array}{l}\text { expected } \\
\text { unfortunately }\end{array}$ & - \\
\hline
\end{tabular}

Considering to which extent New Zealand and Thai students in the two disciplines employ attitude markers to denote their stance in the five aspects, normalized frequencies of attitude markers representing each aspect reveal that most of the attitude markers identified in this study are used by New Zealand and Thai students for the expression of importance and interestingness of topics or actions which cannot be addressed in current studies as a suggestion for readers who may be interested in making practical use of the research. As presented in Table 6.29 below, among five aspects, New Zealand and Thai students show the same tendency in making less frequent use of attitude markers to demonstrate their personal point of view in terms of quality, predictability, and acceptability of propositional content. In particular, Thai students in English language teaching do not use attitude markers to express their stance in terms of acceptability. 
Table 6.29. Frequency comparisons of attitude aspects

\begin{tabular}{|c|c|c|c|c|c|c|c|c|c|c|c|c|c|c|c|}
\hline \multirow{2}{*}{ Corpus } & \multicolumn{3}{|c|}{ Importance } & \multicolumn{3}{|c|}{ Interestingness } & \multicolumn{3}{|c|}{ Quality } & \multicolumn{3}{|c|}{ Predictability } & \multicolumn{3}{|c|}{ Acceptability } \\
\hline & Raw & $\mathrm{Nf}$ & $\%$ & Raw & $\mathrm{Nf}$ & $\%$ & Raw & $\mathrm{Nf}$ & $\%$ & Raw & $\mathrm{Nf}$ & $\%$ & Raw & $\mathrm{Nf}$ & $\%$ \\
\hline NZ-ELT & 241 & 12.0 & $62.2 \%$ & 48 & 2.4 & $12.4 \%$ & 44 & 2.2 & $11.4 \%$ & 46 & 2.3 & $11.9 \%$ & 8 & 0.4 & $2.1 \%$ \\
\hline NZ-BA & 185 & 12.8 & $57.7 \%$ & 63 & 4.4 & $19.8 \%$ & 42 & 2.9 & $13.1 \%$ & 26 & 1.8 & $8.1 \%$ & 5 & 0.3 & $1.3 \%$ \\
\hline TH-ELT & 92 & 7.3 & $65.2 \%$ & 24 & 1.9 & $17.0 \%$ & 18 & 1.4 & $12.5 \%$ & 7 & 0.6 & $5.3 \%$ & 0 & 0.0 & $0.0 \%$ \\
\hline TH-BA & 103 & 8.0 & $64.0 \%$ & 20 & 1.6 & $12.8 \%$ & 16 & 1.2 & $9.6 \%$ & 18 & 1.4 & $11.2 \%$ & 4 & 0.3 & $2.4 \%$ \\
\hline
\end{tabular}

\section{(i) Claiming the value of research}

Even though New Zealand students' theses have a higher incidence of attitude markers, New Zealand and Thai students in the two disciplines make use of similar types of attitude markers. They include adjectives like important, significant, and valuable in order to claim the value of their research. Two important sections in the conclusion chapter which show extensive use of adjectives are the sections of contributions of present research and further research direction. In Excerpt 6.37, the writer claims the value of current research, and in Excerpts 6.38-6.39 the writers stress the importance of future developments which the present study does not cover and use such remarks to point towards a direction for further research.

(6.37) This study has provided valuable insights for research regarding senior leader influence on organisational learning. (NZ-BA-14)

(6.38) Further projects or research driven by teachers exploring the 'what' and 'how' of ICLT in the language classroom would provide language teachers with a larger tool kit of ideas for practical implementation of ICLT. The dissemination of this knowledge is crucial ... (NZ-ELT-07)

(6.39) Additionally, a wider variety of push-pull factors should be considered to understand the motivational factors more precisely. The results of this will have a significant implication for destination competitiveness and type of product development which will help the marketing departments of universities. Further study in this area could help Thailand ... (TH-BA-08)

In Excerpts 6.40-6.41, New Zealand and Thai students frequently employ signal words like (most) importantly and essentially in the sentence-initial position for the purposes of 
attracting the reader' attention and signaling the writers' evaluation of current propositions as important matters.

(6.40) Most importantly, students themselves should be aware of the limitations of their own vocabulary knowledge and try every possible way to improve their vocabulary knowledge to a sufficient level for effective language use. (TH-ELT-03)

(6.41)Essentially, most research participants perceive that REPs NZ's lacking public profile is having little legitimating impact on their respective organisations... (NZ$B A-13)$

\section{(ii) Indicating interestingness in different findings}

Excerpt 6.42 shows how the thesis writer employs the direct marker interestingly to express the interestingness of the new result in the present study different from literature. In Excerpts 6.43-6.44, the writers also employ the markers interestingly and interesting to emphasize an interesting point of two different results.

(6.42) Interestingly, the result of this study indicated that self-confidence to learn autonomously was at a low level which is in contrast to the previous research finding of Rosukhon Swatevacharkul (2010) who reported the moderate level of self-confidence to learn autonomously. (TH-ELT-27)

(6.43) Interestingly, while most affiliated participants believed that other affiliated organisations behaved accordingly, four of these affiliates exhibited some form of symbolic behaviour themselves. (NZ-BA-13)

(6.44) Doctors Bonning, Harris, and Whittaker all discussed that capacity is an issue for any new systems - it is interesting that St John employees did not make similar comments, which may highlight a lack of awareness. (NZ-BA-03)

\section{(iii) Commenting on research methods and findings}

Based on the top ten attitude marker list, thesis writers in the present study, except Thai students in English language teaching, use the marker unique when expressing stance on quality of research methods as well as prominent findings, while salient is used by Thai students in the language teaching discipline for the same purpose. 
(6.45) The unique feature of this research study was that there were no rigid mentoring criteria or check-box processes for the mentor and mentee to follow. (NZ-ELT-16)

(6.46) The context of this study, the New Zealand sport sector, is a unique setting comprised of a variety of organisations and contributors. (NZ-BA-23)

(6.47) Significantly, one of the most salient findings emerging from the table was the absence of Move 1: Situating the research, Sub-move I B - Citing previous research. (TH-ELT20)

(6.48) Touchstone 4A (Student's book) was salient in terms of Speech act information, compared to the other books. (TH-ELT-O6)

\section{(iv) Emphasizing (un)expected outcome}

Thesis writers express their predictability of propositional content through the employment of mood markers like expected and unfortunately. In Excerpt 6.49, the writer expresses a state of discovering an anticipated result. In Excerpt 6.50, the writer uses unfortunately to indicate that the finding is revealed in a direction different from the writer's initial assumption.

(6.49) The findings also showed that ICT innovations, such as social networking media, blogs and e-portfolios improved relationships, communication and documentation highly. I expected this as these ICT initiatives provided more avenues for spontaneous dialogue... (NZ-ELT-17)

(6.50) It shows that his Majesty did not deny economic progress and globalization... Unfortunately, the in-depth interview results from the home stay owners show that the community has the knowledge about the philosophy but they rarely put it into practice although they realize it is good for living. (TH-BA-09)

\section{(v) Projecting (un)acceptance of claims}

The last aspect of the writer's stance is acceptability. As the incidence of acceptability markers is very low, the excerpts below are provided to give some flavour of this aspect. Based on data of the present study, New Zealand and Thai students, except Thai students in English language teaching, project their evaluative judgement about propositions from previous studies or 
theories through the direct markers like agree and do not agree and also show their acceptance of present findings through the marker understandable.

(6.51) I do not fully agree with Nishumura's assertions about the egalitarian nature of CMC communities because... (NZ-ELT-02)

(6.52) This is an understandable concern because there are noticeable expectations in workplaces, which I myself have seen as a Māori female working in this environment. (NZ-ELT-16)

(6.53) The results of t-test also revealed that hotels in Bangkok faced this challenge more than hotels in Phuket, which is quite understandable because... (TH-BA-04)

\subsection{Engagement markers}

\subsubsection{Frequencies of engagement markers in $\mathrm{NZ}$ and $\mathrm{TH}$ corpora}

Table 6.30 shows a comparison of engagement marker occurrences in New Zealand and Thai students' theses. As measured by the normalized frequencies, the New Zealand corpus contains considerably more engagement markers $(\mathrm{Nf}=14.8)$ than the Thai corpus $(\mathrm{Nf}=5)$. The $\log$ likelihood calculation of 144.21 reveals statistical significance of the higher incidence of engagement markers in the New Zealand corpus at the level of $p<.0001$.

Table 6.30. Engagement markers in NZ and TH corpora

\begin{tabular}{|c|c|c|c|c|c|c|}
\hline & \multicolumn{2}{|c|}{$\begin{array}{l}\text { NEW ZEALAND } \\
(345,277 \text { words })\end{array}$} & \multicolumn{2}{|c|}{$\begin{array}{c}\text { THAI } \\
(254,322 \text { words })\end{array}$} & \multicolumn{2}{|c|}{ Log-likelihood } \\
\hline & Raw & $\mathrm{Nf}$ & Raw & $\mathrm{Nf}$ & LL & $p$-value \\
\hline $\begin{array}{l}\text { Engagement } \\
\text { markers }\end{array}$ & 512 & 14.8 & 128 & 5.0 & 144.21 & $p<.0001$ \\
\hline
\end{tabular}

Regarding cross-disciplinary variation of engagement markers in the New Zealand corpus (NZELT vs. NZ-BA), New Zealand students in the language teaching field more frequently employ engagement markers $(\mathrm{Nf}=18)$ than their compatriots in the business field $(\mathrm{Nf}=10.5)$. The loglikelihood calculation of 32.96 indicates that the higher frequency of engagement markers in the NZ-ELT corpus is significant at the level of $p<.0001$, as shown in Table 6.31 . 
Table 6.31. Engagement markers in NZ-ELT and NZ-BA subcorpora

\begin{tabular}{llccccc}
\hline & \multicolumn{4}{c}{ NEW ZEALAND } & & Log-likelihood \\
\cline { 2 - 5 } & \multicolumn{2}{c}{$\begin{array}{c}\text { NZ-ELT } \\
(201,099 \text { words })\end{array}$} & NZ-BA \\
& Raw & Nf & Raw & Nf & LL & $p$-value \\
\cline { 2 - 5 } $\begin{array}{l}\text { Engagement } \\
\text { markers }\end{array}$ & 361 & 18.0 & 151 & 10.5 & 32.96 & $p<.0001$ \\
\hline
\end{tabular}

As for cross-disciplinary variation of engagement markers in the Thai corpus (TH-ELT vs. THBA), Thai students in the two disciplines have a similarity in the limited use of engagement markers. From Table 6.32, in every 10,000 words, engagement markers are found 4.5 times in the TH-ELT corpus and 5.5 times in the TH-BA corpus. The log-likelihood value of 1.22 indicates that there is no significant difference in the use of engagement markers between Thai students in the two disciplines $(p>.05)$.

Table 6.32. Engagement markers in TH-ELT and TH-BA subcorpora

\begin{tabular}{|c|c|c|c|c|c|c|}
\hline & \multicolumn{4}{|c|}{ THAI } & \multirow{2}{*}{\multicolumn{2}{|c|}{ Log-likelihood }} \\
\hline & \multicolumn{2}{|c|}{$\begin{array}{c}\text { TH-ELT } \\
(125,631 \text { words })\end{array}$} & \multicolumn{2}{|c|}{$\begin{array}{c}\text { TH-BA } \\
\text { (128,691 words) }\end{array}$} & & \\
\hline & Raw & $\mathrm{Nf}$ & Raw & $\mathrm{Nf}$ & $\mathrm{LL}$ & $p$-value \\
\hline $\begin{array}{l}\text { Engagement } \\
\text { markers }\end{array}$ & 57 & 4.5 & 71 & 5.5 & 1.22 & $p>.05$ \\
\hline
\end{tabular}

\subsubsection{Frequencies of engagement markers in ELT and BA corpora}

Table 6.33 offers frequencies of engagement markers in English language teaching and business administration theses. Engagement markers occur more frequently in English language teaching theses $(\mathrm{Nf}=12.8)$ than in business administration theses $(\mathrm{Nf}=8.1)$. As indicated by the log-likelihood value of 30.88 , the higher frequency of engagement markers in the English language teaching theses is significant at the level of $p<.0001$. 
Table 6.33. Engagement markers in ELT and BA corpora

\begin{tabular}{|c|c|c|c|c|c|c|}
\hline & & & $(27$ & & & g-likelihood \\
\hline & Raw & $\mathrm{Nf}$ & Raw & $\mathrm{Nf}$ & LL & $p$-value \\
\hline $\begin{array}{l}\text { Engagement } \\
\text { markers }\end{array}$ & 418 & 12.8 & 222 & 8.1 & 30.88 & $p<.0001$ \\
\hline
\end{tabular}

With regard to a comparison of engagement markers between New Zealand and Thai theses in the English language teaching discipline (NZ-ELT vs. TH-ELT), Table 6.34 shows that New Zealand students in the language teaching discipline include more engagement markers $(\mathrm{Nf}=18)$ than Thai students in the same discipline $(\mathrm{Nf}=4.5)$. The log-likelihood calculation of 126.39 determines statistical significance of the higher incidence of engagement markers in the NZ-ELT corpus at the level of $p<.0001$.

Table 6.34. Engagement markers in NZ-ELT and TH-ELT subcorpora

\begin{tabular}{lcccccc}
\hline & \multicolumn{4}{c}{ ENGLISH LANGUAGE TEACHING } & & Log-likelihood \\
\cline { 2 - 5 } & \multicolumn{2}{c}{$\begin{array}{c}\text { NZ-ELT } \\
(201,099 \text { words })\end{array}$} & \multicolumn{2}{c}{$\begin{array}{c}\text { TH-ELT } \\
(125,631 \text { words })\end{array}$} \\
\cline { 2 - 5 } & Raw & Nf & Raw & Nf & LL & $p$-value \\
\hline $\begin{array}{l}\text { Engagement } \\
\text { markers }\end{array}$ & 361 & 18.0 & 57 & 4.5 & 126.39 & $p<.0001$ \\
\hline
\end{tabular}

A subsequent comparison between New Zealand and Thai theses within the business administration discipline (NZ-BA vs. TH-BA) also suggests that New Zealand students in the business discipline include more engagement markers $(\mathrm{Nf}=10.5)$ than Thai students in the same discipline $(\mathrm{Nf}=5.5)$. The higher frequency of engagement markers in the NZ-BA corpus is significant, as determined by the log-likelihood value of 21.11 at the level of $p<.0001$, as presented in Table 6.35 .

Table 6.35. Engagement markers in NZ-BA and TH-BA subcorpora

\begin{tabular}{lcccccc}
\hline & \multicolumn{4}{c}{ BUSINESS ADMINISTRATION } & & Log-likelihood \\
\cline { 2 - 5 } & \multicolumn{2}{c}{$\begin{array}{c}\text { NZ-BA } \\
(144,178 \text { words })\end{array}$} & \multicolumn{2}{c}{$\begin{array}{c}\text { TH-BA } \\
(128,691 \text { words })\end{array}$} & & \\
\cline { 2 - 5 } & Raw & Nf & Raw & Nf & LL & $p$-value \\
\hline $\begin{array}{l}\text { Engagement } \\
\text { markers }\end{array}$ & 151 & 10.5 & 71 & 5.5 & 21.11 & $p<.0001$ \\
\hline
\end{tabular}


This section concludes that New Zealand students use engagement markers more often than Thai students. The cross-disciplinary comparison within the New Zealand context (NZ-ELT vs. NZ-BA) indicates a significantly higher frequency of engagement markers in the NZ-ELT corpus. The cross-disciplinary comparison within the Thai corpus (TH-ELT vs. TH-BA) indicates that there is no significant difference in the incidence of engagement markers between Thai theses in the two disciplines. Overall, English language teaching students use engagement markers more often than business administration students. The comparison between New Zealand and Thai theses in the English language teaching discipline (NZ-ELT vs. TH-ELT) and the business administration discipline (NZ-BA vs. TH-BA) suggests a significantly higher frequency of engagement markers in New Zealand theses compared to Thai theses in both disciplines (NZ-ELT and NZ-BA).

\subsubsection{Types of engagement markers}

In terms of types of engagement markers, 19 types of engagement markers are identified in NZ-ELT, 15 types in NZ-BA, 11 types in TH-ELT, and 13 types in TH-BA. Only 7 types of engagement markers are shared over the four subcorpora. The result suggests that not many types of engagement markers are employed by either New Zealand or Thai students, and Thai students in English language teaching employ the smallest cluster of engagement markers when compared to other groups of students.

There are five engagement markers overlapping across the four subcorpora, namely see, we (inclusive), our (inclusive), us (inclusive) and note (be noted). The marker assume appears in three subcorpora but does not appear in NZ-ELT. There are markers which appear in one corpus but do not appear in other subcorpora, namely the presence of let's and the reader in NZ-ELT, the pronouns your and you in NZ-BA, investigate, bear in mind and integrate in TH-ELT, and consider, keep in mind and notice in TH-BA.

In addition to the five markers shared over the four subcorpora, divided by context, New Zealand students in English language teaching and business administration share two other types of engagement markers, namely interrogative markers (rhetorical questions) and personal asides in parentheses/ dashes. In Thai students' theses, the markers should and assume are shared between the two disciplines. 
Table 6.36. Top ten engagement marker list

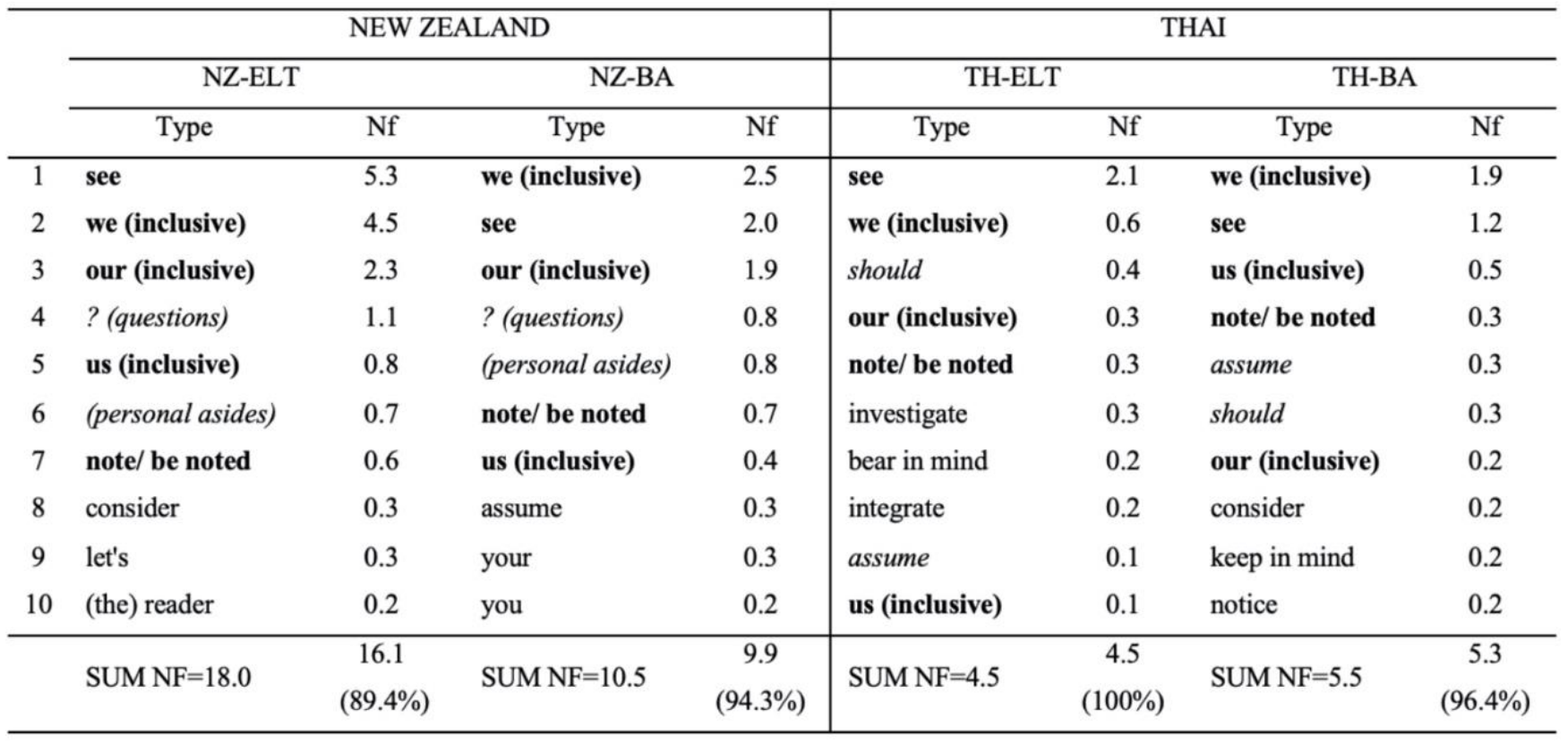

Bolded markers represent the popular markers on the top ten list shared across the four subcorpora.

Italic markers represent the popular markers shared by two disciplines within each context.

\subsubsection{Functions of engagement markers}

As we have seen from the beginning of Chapter 6, engagement markers rank second last of five interpersonal metadiscourse subcategories both in New Zealand and Thai corpora. As the normalized frequencies of engagement markers in all four subcorpora are very low, I adopted Hyland's (2005) analytical framework to identify distinctive features of types of engagement markers found in this study. The finding is that engagement markers occurring in New Zealand and Thai students' theses are expressed in the four following features: reader references, interrogatives, directives, and personal asides. Excerpts shown below exemplify some of the cases where engagement markers are found in theses examined in this study.

\section{(i) Reader references}

In general, the reader reference feature of engagement markers is realized in the grammatical form of the inclusive first-person pronouns we and $u s$, the inclusive determiner our, the secondperson pronoun you, the determiner your, and also the noun reader. As we have seen in Table 6.36, the inclusive first-person pronoun we is the most prominent marker used in all the subcorpora to address the readers. It is far more frequently used by New Zealand and Thai 
students in the two disciplines, when compared to the second-pronoun you and the determiner your which are found only in the corpus of New Zealand students in business administration.

New Zealand and Thai thesis writers directly address the readers and engage them as participants of discourse through the use of we. In Excerpts 6.54-6.55, the writers use we to guide the readers towards a preferred interpretation. The pronoun $u s$ in Excerpts 6.56-6.57 is also used to establish the solidarity with the readers in drawing significant contributions from the present studies.

(6.54) In this sense, we might argue that Hue's identity work and strong levels of classroom investment aligned with Julia's sense of imagined community for the ELTOs (cf Kanno, 2003)... (NZ-ELT-05)

(6.55) We may conclude that such roads and streets were built to serve both local people and tourists in line with the tourism destination development concept of Gunn and Var (2002). (TH-BA-30)

(6.56) These findings are valuable as they give us some insight into what is happening linguistically, but also potentially highlight some shifts in attitude and New Zealand identity in a broader sense. (NZ-ELT-06)

(6.57) Thus the analysis of authentic texts in this study has allowed us to more accurately gauge the extent of their productive knowledge, and accordingly, assess the gaps between different sets of students' abilities. (NZ-ELT-04)

\section{(ii) Directives}

The directive expressions are usually realized by the grammatical form of imperatives, modal verbs, and predicative adjectives. New Zealand and Thai students tend to make frequent use of these features in order to advise the readers to take an action (Excerpts 6.58-6.59) or emphasize what should be particularly taken into account (Excerpt 6.60).

(6.58) If we look at the group means for the unfamiliar data, the female-female dyads used quotative like the most at 0.70 times per 100 words, followed by the female-male dyads (0.47) and finally the male-male dyads (0.23). (NZ-ELT-19) 
(6.59) As identified in the literature review, we shouldn't underestimate the importance of culture in the international education environment (Richards \& Lee, 2004). (NZ-BA06)

(6.60) It is also worthy to note that perhaps the participants were humble about the transformative nature of their work and had high standards for what they would consider as transformative. (NZ-ELT-15)

\section{(iii) Interrogatives}

Another explicit strategy the writers use to invite the readers to participate in discourse is to construct interrogatives or rhetorical questions. The presence of questions, found only in New Zealand students' theses in the two disciplines, encourages the readers to take an issue into consideration. It reflects the writers' intention to communicate with disciplinary readers and reinforce their involvement in the discourse. This rhetorical question feature is completely omitted from Thai students' theses.

(6.61) So does the "impolite" behaviour constitute some form of mock impoliteness? (NZ-ELT-02)

(6.62) Should the New Zealand ITP sector be focusing on lower level trades training to low skilled workers in developing countries? (NZ-BA-06)

\section{(iv) Personal asides}

The last feature found in the present study's corpus is personal asides, or personal comments of the writers on what is being discussed. These comments are usually located in either parentheses or dashes appearing to interrupt information flow and send personal messages from the writers to the readers (Excerpts 6.63-6.64). There is only one instance of this feature in the Thai corpus (Excerpt 6.65).

(6.63) Although there were very few tokens of bro by and to females in the media data, I speculate that I would get different results (to what degree I'm not sure) with access to spontaneous speech in natural environments, i.e. not from media sources. (NZ-ELT-06) 
(6.64) A mentor whose dialogue is in the form of a monologue about how things should be done, with which the PCT is obliged to agree (which seems the case here), is unlikely to promote reflective thinking and learning for improvement (Brookbank \& McGill, 2006). (NZ-ELT-08)

(6.65) However, in fact, the students seemed not to rehearse or practice word meanings frequently enough until the word meanings are remembered - they may do it but just a few times. (TH-ELT-07)

In regard to the extent to which New Zealand and Thai thesis writers use engagement markers in the four features discussed above, Table 6.37 below reveals that overall engagement markers identified in this study mostly occur in the features of reader references and directives. An interesting finding is that students in the two disciplines within each context seem to have different preferences for the two engagement features. That is, New Zealand students in the language teaching field make more frequent use of the directive or imperative feature in their theses, while New Zealand students in the business field tend to make more direct references to the readers. In the same way, Thai students in the language teaching field tend to interact with the readers through the imperative feature, while their compatriots in the business field prefer direct references to the readers. This finding indicates that students in the same disciplines are more likely to use the same engagement features (reader references and directives) in their disciplinary theses. When considering interrogative and personal aside features, it is interesting that these two features are substantially used by New Zealand students in the two disciplines but almost completely avoided by Thai students. The result suggests that not only do New Zealand and Thai students have a significant difference in the frequency of using engagement markers, but they also use different features to encourage readers to engage with their theses.

Table 6.37. Reader engagement features

\begin{tabular}{|c|c|c|c|c|c|c|c|c|c|c|c|c|}
\hline \multirow{2}{*}{ Corpus } & \multicolumn{3}{|c|}{ Reader references } & \multicolumn{3}{|c|}{ Directives } & \multicolumn{3}{|c|}{ Interrogatives } & \multicolumn{3}{|c|}{ Personal asides } \\
\hline & Raw & $\mathrm{Nf}$ & $\%$ & Raw & $\mathrm{Nf}$ & $\%$ & Raw & $\mathrm{Nf}$ & $\%$ & Raw & $\mathrm{Nf}$ & $\%$ \\
\hline NZ-ELT & 158 & 7.9 & $43.9 \%$ & 166 & 8.3 & $46.1 \%$ & 23 & 1.1 & $6.1 \%$ & 14 & 0.7 & $3.9 \%$ \\
\hline NZ-BA & 77 & 5.3 & $51.0 \%$ & 51 & 3.5 & $33.6 \%$ & 12 & 0.8 & $7.7 \%$ & 11 & 0.8 & $7.7 \%$ \\
\hline TH-ELT & 12 & 1.0 & $21.7 \%$ & 44 & 3.5 & $76.1 \%$ & 0 & 0.0 & $0.0 \%$ & 1 & 0.1 & $2.2 \%$ \\
\hline TH-BA & 36 & 2.8 & $50.9 \%$ & 35 & 2.7 & $49.1 \%$ & 0 & 0.0 & $0.0 \%$ & 0 & 0.0 & $0.0 \%$ \\
\hline
\end{tabular}




\subsection{Self-mentions}

\subsubsection{Frequencies of self-mentions in $\mathrm{NZ}$ and $\mathrm{TH}$ corpora}

Table 6.38 reports frequencies of self-mention markers in New Zealand and Thai theses. Based on the normalized frequencies between the two groups, New Zealand students make more frequent use of self-mention markers than Thai students. New Zealand students tend to use self-mentions 25.5 times per 10,000 words, whereas Thai students use self-mentions only 6 times. The log-likelihood calculation of 368.61 indicates a significantly higher incidence of self-mention markers in the New Zealand corpus at the level of $p<.0001$.

Table 6.38. Self-mentions in NZ and TH corpora

\begin{tabular}{llccccc}
\hline & $\begin{array}{c}\text { NEW ZEALAND } \\
(345,277 \text { words })\end{array}$ & THAI & & Log-likelihood \\
& Raw & Nf & Raw & Nf & LL & $p$-value \\
\hline Self-mentions & 879 & 25.5 & 152 & 6.0 & 368.61 & $p<.0001$ \\
\hline
\end{tabular}

In regard to a cross-disciplinary comparison in the New Zealand corpus (NZ-ELT vs. NZ-BA), New Zealand students in the language teaching discipline make far more frequent use of selfmention markers $(\mathrm{Nf}=39.4)$ than their compatriots in the business discipline $(\mathrm{Nf}=6)$. The loglikelihood value of 440.65 determines a significantly higher incidence of self-mentions in the NZ-ELT corpus at the level of $p<.0001$, as shown in Table 6.39.

Table 6.39. Self-mentions in NZ-ELT and NZ-BA subcorpora

\begin{tabular}{|c|c|c|c|c|c|c|}
\hline & \multicolumn{4}{|c|}{ NEW ZEALAND } & \multirow{3}{*}{\multicolumn{2}{|c|}{ Log-likelihood }} \\
\hline & \multirow{2}{*}{\multicolumn{2}{|c|}{$\begin{array}{c}\text { NZ-ELT } \\
(201,099 \text { words })\end{array}$}} & \multirow{2}{*}{\multicolumn{2}{|c|}{$\begin{array}{c}\text { NZ-BA } \\
(144,178 \text { words })\end{array}$}} & & \\
\hline & & & & & & \\
\hline & Raw & $\mathrm{Nf}$ & Raw & $\mathrm{Nf}$ & LL & $p$-value \\
\hline Self-mentions & 792 & 39.4 & 87 & 6.0 & 440.65 & $p<.0001$ \\
\hline
\end{tabular}

As for a cross-disciplinary comparison of self-mentions in the Thai corpus (TH-ELT vs. THBA), Thai students in the business discipline use self-mention markers $(\mathrm{Nf}=8.8)$ more often than their compatriots in the language teaching discipline $(\mathrm{Nf}=3.1)$. The log-likelihood value 
of 35.85 determines statistical significance of the higher incidence of self-mentions in the THBA corpus at the level of $p<.0001$, as shown in Table 6.40 .

Table 6.40. Self-mentions in TH-ELT and TH-BA subcorpora

\begin{tabular}{|c|c|c|c|c|c|c|}
\hline & \multicolumn{4}{|c|}{ THAI } & \multirow{2}{*}{\multicolumn{2}{|c|}{ Log-likelihood }} \\
\hline & \multicolumn{2}{|c|}{$\begin{array}{c}\text { TH-ELT } \\
(125,631 \text { words })\end{array}$} & \multicolumn{2}{|c|}{$\begin{array}{c}\text { TH-BA } \\
\text { (128,691 words) }\end{array}$} & & \\
\hline & Raw & $\mathrm{Nf}$ & Raw & $\mathrm{Nf}$ & LL & $p$-value \\
\hline Self-mentions & 39 & 3.1 & 113 & 8.8 & 35.85 & $p<.0001$ \\
\hline
\end{tabular}

\subsubsection{Frequencies of self-mentions in ELT and BA corpora}

Table 6.41 offers frequencies of self-mentions in English language teaching and business administration disciplines. English language teaching theses contain more self-mention markers than business administration theses. In every 10,000 words, self-mentions are found 25.4 times in English language teaching theses and 7.3 times in business administration theses. The log-likelihood value of 309.55 reveals that the higher incidence of self-mentions in English language teaching theses is significant at the level of $p<.0001$.

Table 6.41. Self-mentions in ELT and BA corpora

\begin{tabular}{|c|c|c|c|c|c|c|}
\hline & \multicolumn{2}{|c|}{$\begin{array}{c}\text { ELT } \\
(326,730 \text { words })\end{array}$} & \multicolumn{2}{|c|}{$\begin{array}{c}\text { BA } \\
(272,869 \text { words })\end{array}$} & \multicolumn{2}{|c|}{ Log-likelihood } \\
\hline & Raw & $\mathrm{Nf}$ & Raw & $\mathrm{Nf}$ & LL & $p$-value \\
\hline Self-mentions & 831 & 25.4 & 200 & 7.3 & 309.55 & $p<.0001$ \\
\hline
\end{tabular}

With regard to variation of self-mentions between New Zealand and Thai theses in the English language teaching discipline (NZ-ELT vs. TH-ELT), Table 6.42 indicates that New Zealand students in the language teaching discipline use significantly more self-mention markers than Thai students in the same discipline. In every 10,000 words, self-mention markers are found 39.4 times in the NZ-ELT corpus and 3.1 times in the TH-ELT corpus. The log-likelihood calculation of 528.58 suggests that the higher incidence of self-mentions in the NZ-ELT corpus is significant at the level of $p<.0001$. 
Table 6.42. Self-mentions in NZ-ELT and TH-ELT subcorpora

\begin{tabular}{lcccccc}
\hline & \multicolumn{4}{c}{ ENGLISH LANGUAGE TEACHING } & & Log-likelihood \\
\cline { 2 - 6 } & \multicolumn{2}{c}{$\begin{array}{c}\text { NZ-ELT } \\
(201,099 \text { words })\end{array}$} & \multicolumn{2}{c}{$\begin{array}{c}\text { TH-ELT } \\
(125,631 \text { words })\end{array}$} & & \\
\cline { 2 - 6 } & Raw & Nf & Raw & Nf & LL & $p$-value \\
\hline Self-mentions & 792 & 39.4 & 39 & 3.1 & 528.58 & $p<.0001$ \\
\hline
\end{tabular}

As shown in Table 6.43, a comparison between New Zealand and Thai theses in the business administration discipline (NZ-BA vs. TH-BA) reveals that Thai students in the business discipline make more frequent use of self-mentions $(\mathrm{Nf}=8.8)$ than New Zealand students in the same discipline $(\mathrm{Nf}=6)$. The higher frequency of self-mentions in the TH-BA corpus is significant, as suggested by the log-likelihood value of 6.99 at the level of $p<.01$.

Table 6.43. Self-mentions in NZ-BA and TH-BA subcorpora

\begin{tabular}{|c|c|c|c|c|c|c|}
\hline & \multicolumn{4}{|c|}{ BUSINESS ADMINISTRATION } & \multirow{3}{*}{\multicolumn{2}{|c|}{ Log-likelihood }} \\
\hline & \multirow{2}{*}{\multicolumn{2}{|c|}{$\begin{array}{c}\text { NZ-BA } \\
\text { (144,178 words) }\end{array}$}} & \multirow{2}{*}{\multicolumn{2}{|c|}{$\begin{array}{c}\text { TH-BA } \\
(128,691 \text { words) }\end{array}$}} & & \\
\hline & & & & & & \\
\hline & Raw & $\mathrm{Nf}$ & Raw & $\mathrm{Nf}$ & LL & $p$-value \\
\hline Self-mentions & 87 & 6.0 & 113 & 8.8 & 6.99 & $p<.01$ \\
\hline
\end{tabular}

This section concludes that New Zealand students use significantly more self-mentions than Thai students. The cross-disciplinary comparison within the New Zealand context (NZ-ELT vs. NZ-BA) indicates a significantly higher frequency of self-mentions in the NZ-ELT corpus. The cross-disciplinary comparison within the Thai corpus (TH-ELT vs. TH-BA) indicates a significantly higher frequency of self-mentions in the TH-BA corpus. Overall, English language teaching students use more self-mentions than business administration students. The comparison between New Zealand and Thai theses in the English language teaching discipline (NZ-ELT vs. TH-ELT) suggests a significantly higher frequency of self-mentions in the NZELT corpus. In the business administration discipline (NZ-BA vs. TH-BA), the TH-BA corpus has a significantly higher frequency of self-mentions. 


\subsubsection{Types of self-mentions}

NZ-ELT and NZ-BA theses contain 7 types of self-mentions each. TH-ELT and TH-BA theses contain 3 types and 4 types of self-mentions, respectively. This means that Thai students not only have fewer occurrences of self-mentions but also fewer types of self-mentions when compared to New Zealand students.

The noun researcher is shared over the four subcorpora. Divided by context, New Zealand students in the two disciplines also share other types of self-mentions, namely the researcher's, I, $m y, m e$, and we. Three markers overlap across three subcorpora but are absent from one corpus, namely the absence of $I$ and the researcher's in TH-BA and we in TH-ELT. The markers which appear in only one corpus are the writer in NZ-BA and the author's in TH-BA. New Zealand-business students tend to use the writer to represent themselves in their theses, whereas Thai-business students are more likely to use the author's. The possessive pronoun our is occasionally present in NZ-ELT and TH-BA.

Table 6.44. Self-mention marker list

\begin{tabular}{|c|c|c|c|c|c|c|c|c|}
\hline & \multicolumn{4}{|c|}{ NEW ZEALAND } & \multicolumn{4}{|c|}{ THAI } \\
\hline & \multicolumn{2}{|c|}{ NZ-ELT } & \multicolumn{2}{|c|}{ NZ-BA } & \multicolumn{2}{|c|}{ TH-ELT } & \multicolumn{2}{|c|}{ TH-BA } \\
\hline & Type & $\mathrm{Nf}$ & Type & $\mathrm{Nf}$ & Type & $\mathrm{Nf}$ & Type & $\mathrm{Nf}$ \\
\hline 1 & $I$ & 21.2 & researcher & 2.1 & researcher & 2.9 & researcher & 6.9 \\
\hline 2 & my & 12.3 & $I$ & 1.5 & I & 0.1 & we & 1.6 \\
\hline 3 & me & 4.1 & $m y$ & 0.8 & the researcher's & 0.1 & our & 0.2 \\
\hline 4 & researcher & 1.2 & the researcher's & 0.6 & - & - & the author's & 0.1 \\
\hline 5 & we & 0.2 & me & 0.5 & - & - & - & - \\
\hline 6 & the researcher's & 0.2 & we & 0.4 & - & - & - & - \\
\hline 7 & our & 0.1 & the writer & 0.1 & - & - & - & - \\
\hline 8 & - & - & - & - & - & - & - & - \\
\hline 9 & - & - & - & - & - & - & - & - \\
\hline 10 & - & - & - & - & - & - & - & - \\
\hline & SUM NF=39.4 & $\begin{array}{c}39.4 \\
(100 \%)\end{array}$ & SUM NF $=6.0$ & $\begin{array}{c}6.0 \\
(100 \%)\end{array}$ & $\mathrm{SUM} N F=3.1$ & $\begin{array}{c}3.1 \\
(100 \%)\end{array}$ & $\mathrm{SUM} \mathrm{NF}=8.8$ & $\begin{array}{c}8.8 \\
(100 \%)\end{array}$ \\
\hline
\end{tabular}

Bolded markers represent the popular markers on the top ten list shared across the four subcorpora.

Italic markers represent the popular markers shared by two disciplines within each context.

\subsubsection{Functions of self-mentions}

Pronouns and nouns which refer to the writers are found to collocate with other types of markers like the hedging markers suggest and argue as well as the boosting markers believe 
and found. Self-mentions focus on the writers' involvement in theses with several purposes depending on types of markers being collocated.

\section{(i) Self-mentions + frame markers for labelling discourse acts}

(6.66) In the following chapter, I will make some recommendations for practice... (NZ-ELT-03)

(6.67) In this part, the researcher discusses online marketing communications in the perspectives of customers... (TH-BA-12)

\section{(ii) Self-mentions + attitude markers for expressing attitudes}

(6.68) I hope that this research will contribute to 'the archaeology of the future' of our knowledge and practice of online teaching with ELLs in New Zealand (Richards, 2003, p. 21). (NZ-ELT-03)

(6.69) I expect that I have become more reflective throughout this research, because of the process that I went through. (NZ-ELT-17)

(6.70) The researcher agrees with these authors' point of view. In particular, it is the continuous interaction between tacit and explicit knowledge that is stimulated by informal interactions. (NZ-BA-11)

\section{(iii) Self-mentions + hedges/boosters for making cautious and assertive}

\section{arguments}

(6.71) I argue that the dual consumer-producer role afforded to internet users can lead users to put effort into designing their contributions with entertainment value in mind... (NZ-ELT-02)

(6.72) The researcher suggests that the telecom industry should emphasize its position on quality and differentiate its product on sustainable development. (TH-BA-13)

(6.73) From the results of the interview, the researcher found that some of the learners still believed that error-correction was the teachers' task... (TH-ELT-02) 


\section{(iv) Self-mentions + action verbs/nouns for describing research procedures}

(6.74) After collecting all the information during the field work, the researcher collated the data from the questionnaires as illustrated in Table A. (NZ-ELT-11)

(6.75) In this study, the researcher designed the three tasks of error-correction by including one type of grammatical errors in one sentence... (TH-ELT-02)

(6.76) The study was primarily motivated by the researcher's personal interest in changing consumption and production behaviour on a global scale... (NZ-BA-26)

(6.77) From the researcher's observation during the training...they took less time in the looking-up process and could select the meanings of the target words to fit the context. (TH-ELT-21)

\subsection{Chapter summary}

Chapter 6 has reported the findings of five subcategories of interpersonal metadiscourse (hedges, boosters, attitude markers, engagement markers, and self-mentions). This study reveals that New Zealand theses use significantly more interpersonal metadiscourse in all subcategories, except for boosters, than Thai theses. English language teaching theses use significantly more interpersonal metadiscourse in the subcategories of hedges, engagement markers, and self-mentions than business administration theses. Theses in the two disciplines are not significantly different in the frequencies of boosters and attitude markers. The detailed analysis shows some subtle variations in terms of types and functions of each interpersonal subcategory. 


\section{CHAPTER 7 \\ SUPERVISOR INTERVIEW RESULTS}

Semi-structured interviews were conducted with twenty four disciplinary supervisors in New Zealand and Thailand. Interview data were used to design a rating scale for thesis quality assessment and to supplement the discussion of metadiscourse findings in Study 1. Questions for the interviews were divided into four parts:

Part 1 pertained to supervisors' past and present supervision experience and general overarching topics of theses and research articles at their institutions. This part aimed to offer insight into disciplinary practices in terms of structuring master's theses and research articles in New Zealand and Thai educational contexts.

Part 2 focused on what supervisors considered important elements of discussion and conclusion chapters. As the present study investigated use of metadiscourse and quality assessment particularly in the discussion and conclusion chapters, it was essential to understand what elements supervisors took into consideration when examining the two chapters.

Part 3 elicited information relating to rating practices and criteria for examining master's thesis discussion and conclusion chapters. The information from this part was used as a foundation for creating an analytic rating scale which specifically represented the thesis genre. This part contributed a thesis rating scale used in Study 2.

Part 4 aimed to understand supervisors' attitudes towards use of metadiscourse in thesis writing. Previous metadiscourse studies included interviews with metadiscourse users, either research article authors or postgraduate students (e.g., Hyland, 2004; Li, 2016), in order to provide reasons behind their use of metadiscourse. The present study aimed to provide insight into use of metadiscourse from the reader dimension.

Therefore, the following section presents interview results in conjunction with the four areas of questions. Acronyms of supervisor informants are used in the presentation of interview results. For example, Supervisor-TH-ELT-01 refers to a Thai supervisor in English language teaching, and Supervisor-NZ-BA-03 refers to a New Zealand supervisor in business administration. In the interviews the informants sometimes differentiated their roles either as a supervisor or examiner, so both terms are used in this chapter to specify the roles being referred to. The presentation of interview results starts with a brief description of writing disciplinary 
theses in the New Zealand and Thai contexts in Section 7.1, followed by elements of discussion and conclusion chapters in Section 7.2, rating practices and criteria in Section 7.3, and supervisors' attitudes towards use of metadiscourse in theses in Section 7.4. At the end of this chapter, a rating scale designed for thesis quality assessment is presented in Section 7.5. Given that the interviews were semi-structured and recursive in nature, the exact questions asked and points discussed varied slightly between interviewees. The questions are therefore not presented along with the texts in this chapter. Underlined parts in excerpts are key words which were coded and used to identify themes.

\subsection{Writing disciplinary theses in New Zealand and Thai contexts}

\subsubsection{Structure of theses}

To provide a better understanding of the nature of research and writing research-based papers (theses and articles) in each discipline, supervisor informants started from describing the overall structure of theses in their disciplines based on their past and present supervision experience. New Zealand and Thai supervisors in both disciplines reported that theses in their fields follow a very traditional research reporting framework, the Introduction-MethodologyResult-Discussion (IMRD) structure with the inclusion of the literature review chapter. In the interviews, Thai informants frequently used the term "five-chapter thesis" to represent the structure. Even though it is possible for theses in the two disciplines and contexts to deviate from the traditional pattern, most of them still follow this structure.

There is a flexibility to deviate the structure from this five-chapter thesis, but $\underline{\text { rarely see }}$ master's theses here have Chapter 6. (Supervisor-TH-BA-22)

With regard to nuances between the two disciplines, it was evident that the structure of theses in the English language teaching discipline, especially in the Thai context, is not deviant from the traditional one. In the interviews, almost all of the supervisors in business administration stressed the inclusion of context background (e.g., industry sector) and conceptual/ hypothesis development as important parts in business theses. These additional chapters are commonly called the conceptual/ hypothesis development chapter and contextual chapter. 
In terms of conceptual or hypothesis development which is part of this chapter, some people have a separate chapter for this and some people include hypothesis development in the literature review chapter. Either is fine...Some people do the next chapter based on the context...S Some people have this chapter (contextual chapter), small descriptive chapter. And some people include this in the research methodology chapter... (Supervisor-NZ-BA-09)

This does not necessarily mean that theses in English language teaching do not include context background and conceptual development. There might be these two sections within one of the chapters (e.g., introduction chapter or methodology chapter) in some English language teaching theses as well, but the English language teaching informants of the present study did not explicitly mention so since the sections (if any) seem to be small parts just to give an overview of the context in general. One plausible reason was gained from the way supervisors described the nature of research in their disciplines, as indicated in the interview excerpts below. That is, English language teaching theses are more likely to be theory-based research which requires an extensive review of different theories and discovers gaps in the literature, whereas business theses are likely to be operation-based research which requires a detailed analysis of a particular context before trialing a business administration plan most suitable for the context.

The next part is literature review which discusses previous studies - what has been studied and what has been neglected. We try to review as many related studies as we can. But we cannot just report who said what. We need to be critical to point out what and why we would like to add or contribute to literature. This leads us to think about the methodology or procedures to address gaps in the literature and research questions. (Supervisor-TH-ELT-18) We take a practical approach, so theses must be based more on real business plans and practical implications than theories... for me, I let students explore the subject first. I assign them some projects to explore, observe, make video clips, etc. Put simply, let students learn from doing or trying something. Let them draw their own conclusions and implications on such experience. (Supervisor-TH-BA-24)

\subsubsection{Writing theses and research articles}

Questions about research articles were brought up in the interviews because some supervisors mentioned that a strategy they use in thesis supervision is to encourage their students to look at previous theses and research articles published in good journals. By this means, students can review relevant literature and also familiarize themselves with the conventions of the research 
reporting genre in their particular fields. When supervisors were asked about similarities and differences between writing theses and research articles, they stated that theses and research articles are similar in terms of overall structure but different in terms of the scale of writing and target audience.

There's not much difference between theses and RAs. They might be different in terms of the number of words and pages. Therefore, some parts in RAs must be shortened to make the writing concise. Some parts might be long for clarification. When writing RAs, we must be aware that we are presenting our work to a wider audience who might not be much familiar with things/ terms in our field. When writing theses, we present our work to 5 supervisors/ examiners who are very knowledgeable in the field of our research. Therefore, I think when we publish part of our theses in a journal, I think we must revise it just a bit. (Supervisor-THELT-18)

Elaboration and conciseness are two key words frequently used by the informants to represent the difference in the scale of writing between theses and research articles, respectively. A thesis is a large document with approximately 40,000 words as it needs to precisely provide justification of every aspect in research methodology and elaborately report quantitative results with plenty of tables. Research articles are more concise and normally take some aspects from a thesis. On the whole, empirical research articles have the same structure as a thesis: introduction, literature review, methodology, results, discussion and conclusion. However, all the sections must be condensed into 8,000 words in a research article, and with the word limit emphasis on each component or section is different. Research articles do not need to develop the literature review to any great extent, and it is common for research articles to merge the relevant literature into the introduction part. Most often, the results and discussion parts are emphasized, but these parts still need to be written in a concise way.

In terms of audience, theses are read by a particular group of readers like examiners and supervisors who are very knowledgeable about the research project, while research articles are targeted at a much wider academic audience both inside and outside the field. The purposes of their reading are different. Supervisors and examiners read theses for accuracy and quality assurance, but article readers are scholars in the same or relevant fields who read articles with the expectation of gaining some implications from the reading and applying the implications to their own work. With supervisors and examiners, the writers have the chance to negotiate and clarify unclear points in the lengthy texts. But with limited space in research articles, the 
writers need to make every point concise but clear enough to convince the unknown audience with whom the writers have no chance to negotiate.

Therefore, the writing scale and target audience are the two main factors that supervisors advise students to take into account when they write theses but use research articles as a writing model.

\subsection{Writing discussion and conclusion chapters}

\subsubsection{Functional elements of the discussion chapter}

The discussion chapter is where thesis writers provide their critical interpretations and comments on research findings presented in the previous chapter. Often, supervisor informants used the term "thread" to describe a quality of the discussion and conclusion chapters. A good discussion chapter draws threads from sections, chapters, and the whole thesis. This chapter brings together the findings of the research into the reviewed literature and moves forward to the contributions and suggestions in the conclusion chapter. The writers are expected to develop a line of argument based on data or evidence from the present study and establish a stand in the discussion along with logical reasons. This means that the discussion not only refers to the literature in order to compare whether the findings contradict or complement the previous studies, but also needs to show the writers' critical thoughts in answering the "so what" question for the findings. In case the results are not significant or the trialed business plans are not successful, the writers are expected to discuss factors and provide possible reasons rather than distorting the data and making them significant.

So then the discussion is reflecting on the findings of your analysis. It's drawing all the threads together to make sort of some comments on either the common themes or what you have found through your analysis... so you are not repeating the analysis. You're looking at it more holistically of what you analysis is showing you. So again that's a critical review of your research, but also tying it in with the literature... (Supervisor-NZ-ELT-05)

But of course the discussion chapter, it's where you have to develop an argument, based on your data. It's got to be justified by your data, but also the literature... It's bringing the $\underline{\text { threads }}$ together that they find difficult. Particularly doing so in a coherent and logical way. (Supervisor-NZ-ELT-07)

Thai students have difficulties in discussions. When they have findings, they simply say whether it is the same or different from those in literature. Then so what? They need to explain their reasoning as to why it agrees or disagrees. It might be because of the differences in contexts, timings, or human behaviors. If you find something new or it does not support your hypotheses, do not try to manipulate or twist the results. (Supervisor-TH-BA-21) 
So, I really want to see in the discussion that they are laying out the so what. So, I want to see first of all where are the areas of the literature that are in agreement with their research but really that is only the first step... What I really want to see, that's the discussion is where I want to see the students' own thinking. (Supervisor-NZ-BA-11)

\subsubsection{Functional elements of the conclusion chapter}

The conclusion chapter is the chapter where thesis writers summarize the entire thesis and show highlights of their research. Supervisors in the interviews mentioned that students sometimes think that the conclusion chapter is not important because it is the last chapter in the thesis and they would like to complete the thesis as soon as possible. However, supervisors indicated that in fact the conclusion chapter is very important because it is the first or second chapter (after introduction chapter) where the readers read to gain an overall picture of the whole study with highlighted findings and implications.

Besides giving a summary of the entire thesis, the conclusion chapter is the chapter where the writers show transparency of the research by reviewing their research and acknowledging actual limitations, for example, the issues that prevent the research from going according to initial plans or the issues that might restrict generalization of the findings and how the writers deal with the issues. This limitation section in the conclusion chapter reflects the writers' awareness of the limitations and interpretation of the revealed findings with caution as well as the writers' willingness to impart knowledge to the readers as a key contribution of their research.

Moreover, supervisors in the interviews suggested thesis writers close their theses with positive notes, in other words the feeling of the contributions of the research, like recommendations for future research or final reflective thoughts of the research journey. It is a means to inspire other people to move forward from current research and to establish a connection and impression between the writer and reader before the final closure. Thai and New Zealand supervisors noted the same problem in writing implications and recommendations. That is, students provide broad recommendations to the readers, for example, suggesting use of qualitative approach instead of quantitative approach or vice-versa. The implications they give are sometimes drawn from other similar studies, rather than specifically based on their own findings and covering all groups of stakeholders involved in their studies. 
The conclusion chapter, it seems to me, is a more overall conclusion of the thesis. So what all have you learnt through the thesis? And that is going to be covered in the conclusion chapter, briefly. The highlights. And the conclusion chapter would include an indication of future research. It would include shortcomings of the present thesis. (Supervisor-NZ-ELT06)

By all means, you are required to say what the limitations were, but I like to see people leave the examiner with the feeling of contribution of the research... And I think if you can impress an examiner, you give your discussion but leave on a positive note. Just don't write down, Oh these are the limitations of my research and it's just like...oh really. I mean... they should talk about potential future research in line with the limitations. Because then you're showing that not only has your own study contributed to the area, but it's now hopefully going to encourage other people to read your research and use it as well. (Supervisor-NZ-ELT-05)

Most often, in the conclusion chapter, students just include a summary of their research without discussing implications and recommendations. If they include implications, the implications are not based on their current research. They are too general. Sometimes I feel like students just include the implication part as an element of the chapter but do not give much importance to that part. Maybe, for them, the conclusion is not much important. They just would like to finish it. In fact, the conclusion is important for the readers to understand why they study this and what the readers can benefit from the research. Recommendations or directions for further research are not solid enough... not based on the current research... not well-grounded... and no link to the literature. Also, they don't specify limitations they experienced and provide broad suggestions similar to those in other studies. (SupervisorTH-ELT-17)

It consists of many elements. It should concern implications of the studies. As I said earlier, implications should be drawn from your findings. You cannot imply things you have not found in your research, or what you have imagined before conducting the study. Implications should cover all stakeholders related to the study. (Supervisor-TH-ELT-18)

In the conclusion, no new information is provided. It is just a wrap-up... a good conclusion is short, very concise.....and has to be inspirational. I think it has to provide some sort of closure for the readers. The concluding section is more about the readers and you know offering the readers some sort of general ideas and also key take-away from the research. (Supervisor-NZ-BA-08) 


\subsection{Rating practices and criteria}

\subsubsection{Rating practices}

As this study involved thesis quality assessment and all of the supervisor informants have experience examining theses and reviewing journal articles, they were asked in the interviews to describe the examination practice and criteria they take into consideration when examining the quality of theses.

The interview data suggest that almost all of Thai and New Zealand informants view thesis assessment as a holistic process. They look at all aspects in the theses in a big picture and mark the theses holistically rather than focusing on an individual aspect and criticizing it. As seen in the interview excerpts below, the informants explained that a thesis is like a narrative or telling a story of the thesis. So they expect thesis writers to write the theses in the way of telling a story and show a good development and flow of the argument. That is, they expect a very clear beginning of the story, for example, what the thesis is about and what the motivation or significance of doing this research is. And then in the middle of the story, they expect to read an explanation and justification about the methods used in the study, so that they can evaluate whether the methods are efficient enough to develop solid evidence and answer the questions. At the end of the thesis story, they expect to read useful findings of what has been done, the writers' critical thoughts about the findings, and key messages of thesis contributions for the readers to take away after reading the whole thesis story.

But at the end of the day, well it's a narrative as well...you're telling a story. (SupervisorNZ-ELT-05)

I am a big picture person. I like big pictures, and so I always look for the line of argument. So when I start reading a thesis, I think what the motivation for the thesis is... And so I'm looking in the methodology... So you can see a line of argument developing, I know what they're doing, I know why they're doing it, and I know how they're doing it... And then in the conclusion, I'm looking for a real kind of putting it up putting the story together ....bring it to an end by saying this is what I've done, this is what I found, these are the limitations... (Supervisor-NZ-ELT-02)

Some of the informants differentiate their roles as a supervisor and examiner. Performing the supervisor's role, they make a very careful consideration of every single detail in a thesis, ranging from validating content and correcting grammatical errors. As an examiner, they are 
likely to consider the thesis holistically and look for some deficits in the thesis. Taking the holistic consideration, they do not have any fixed criteria for thesis assessment. However, the informants stated that common aspects they automatically take into account when reading are content, overall formatting or macro-structure of the thesis, and the way the writers use the language to convey the content and develop their thesis argument.

There are holistic things that I am going to do it systematically. When you read a thesis, you want to finish thinking this person knows a lot about the subject ...also knows a lot about thinking through an argument. And when you read it, you think that the person really achieves the standard which is needed...that they have come up with something interesting. And then that's the holistic thing at the end of reading a thesis and you think it's good...I like that. (Supervisor-NZ-ELT-02)

I rate it holistically based on my impression. As I said before, I look for flow between ideas. Not only the flow because they use a lot of markers but the flow of ideas and so on and so forth. (Supervisor-TH-ELT-13)

Not using fixed criteria. My consideration is based on feeling after reading the whole thing... whether there is cohesion in the thesis. This is because we do not need to assign a score or grade for each chapter... I assess theses holistically. I do not have fixed or detailed rubrics. When I read a thesis, I would like to make sure it is clear and understandable and answers all the research questions. They ask a few questions at the beginning and at the end I find answers for all the questions. (Supervisor-TH-ELT-15)

Experience and impression are integral parts of their judgment after reading the whole story of a thesis. It is important to note that usually examiners are not required to grade each chapter individually. Only a single grade for the whole thesis is required. When universities are recruiting and awarding a prize for an excellent thesis, they might have criteria with detailed descriptions for the awarding purpose. But for the normal process of examination, supervisors explained that different universities have different policies. Some provide an examiner's evaluation pack with a guideline or overarching criteria to assess the quality of theses, and some do not. If provided, the criteria are usually in the box-ticking format as a checklist for all examiners to check essential elements in each chapter. Or it can be a guideline with the description for each grade. Examiners are also encouraged to provide constructive comments at the end of the evaluation form for the revision purpose. 
What they do in those examiner packs is that they almost suggest to you what the grade would be, like... in order to achieve an A, a student must have done this and demonstrated this. But if it was a $\mathrm{C}$ they might have demonstrated that but only to a certain level. So yeah that's actually a good point I think that as a supervisor I guess you're very focused on the student doing the research, but I don't necessarily think along the lines of the examiner. But when I'm an examiner, I very much look at those criteria that I'm provided with because I've got a different role. (Supervisor-NZ-ELT-05)

In the interviews, the examiners noted that using experience does not mean that they use their own work as a benchmark to judge students' theses and push students to follow the approach the examiners prefer to use. It means that they use their experience from the extensive review of literature in the same or relevant areas to evaluate the clarity and coverage of content, appropriateness of selected methods to answer research questions as well as presenting arguments of a particular thesis.

In terms of impression, the examiners stated that after they have assessed a number of theses, they have a few excellent or most impressive theses in mind and possibly use these theses as a benchmark to assess other theses. If the theses being assessed do not meet that benchmark, scores or grades for the theses should not be as high as the previous outstanding ones. When they were asked to describe the qualifications of the impressive theses, they stated that excellent theses will give the readers a feeling of smoothness and joy and cause no suspicion either during or after reading.

\subsubsection{Rating criteria}

As presented in the previous section, in the actual practice of thesis examination, examiners do not have fixed criteria or detailed rating scale for assessing theses. However, basic elements that they automatically take into account when reading a thesis are the clarity of content, thesis organization, and the way the writers use language to present the content and develop a line of thesis argument.

In order to develop a rating scale for this study, the informants were asked to explain further about the characteristics of thesis discussion and conclusion chapters in four aspects: content, organization and presentation, language use, and genre knowledge. Even though these are basic elements of writing in any genre, the details of what the supervisor informants described for each aspect were different from those of writing in other genres. 


\section{(i) Content}

Sections 7.2.1 and 7.2.2 (Functional elements of the discussion and conclusion chapters) have provided a description of what informants felt about what and to which extent the content in the two chapters should be included. The focus of content in this section is on functional elements of the discussion and conclusion chapters presented in the two previous sections.

The most frequent mention by the informants in the two disciplines was on clarity and coverage of content. They suggested the content in good discussion and conclusion chapters must be clear and straightforward. The informants expect to see the ability of thesis writers to demonstrate critical interpretation and justification of significant findings in the discussion chapter. They explained that many of their students discuss the results superficially. They report whether the findings contradict or complement the findings in previous studies without answering the "so what" question. This indicates that supervisors expect their students to put more effort into providing a clear and logical explanation of the findings and comparing the findings to the reviewed literature or theories in the fields. Importantly, the discussion should reflect the writers' critical review of main theories and cover all the key findings or research questions. Even though they read and assess the theses holistically, experienced examiners can automatically identify what has been left out and which part requires more clarification.

Also as I said before, coming back to the question, sometimes you see a movie, you see a nice movie is going on and it stops...and so what? The "so what" factor is really important to me. (Supervisor-NZ-ELT-02)

Discussion should demonstrate critical thinking and be able to cover all research objectives and questions proposed. For example, students are proposing 3 or 4 objectives but discussing only 2 and ignoring the rest. Well, the problems I have commonly encountered are that students do not discuss every objective they have proposed, and some students just keep repeating their findings. And as I said earlier, they sometimes try to distort the findings as well. It is very clear that they should not do that. In the case of conclusion, they should describe what this study is about, which methods are used, how the results come out, and what suggestions are made. (Supervisor-TH-BA-21) 
A frequent comment on the conclusion chapter was a lack of concise summary of the whole research and concrete implications and suggestions for further research. The informants explained that most thesis writers actually have their own box-ticking guideline regarding what should be included in each chapter, and they tend to include all the elements stated in the guideline. The problem is they seem not to pay much attention to giving useful and concrete detail for each part (limitations, suggestions, etc.) because they think that it is the last chapter of their theses. They look at previous theses and provide suggestions and limitations similar to those in the previous theses. They may present only a perfect side of their research but not their problems. As shown in the excerpt below, Supervisor-TH-BA-20 stated that his student gave a very broad suggestion by saying that this research took a quantitative approach and future research should apply a qualitative approach. Supervisor-TH-ELT-17 mentioned that after reading some of her students' theses, she felt suspicious and came up with questions like "Where are these implications from? Are the implications and directions for future research based on this research or copied from other previous studies?"

From the supervisor/ examiner's point of view, students are expected to be honest and straightforward in acknowledging actual limitations and specifying further research suggestions in light of their own limitations rather than stating broad suggestions drawn from other previous studies.

They include everything: limitations and recommendations for future research. The problem is that they're not very practical... useless. Do you know why? Suppose that the current study uses the quantitative method, their recommendation for future studies is to use the qualitative or mixed method. Suppose that the current research study is conducted with a group of students, for the next study, they recommend trying other sample groups. They are not critical thinkers. Suppose that the current study describes percentages, for further research, their recommendation is to describe the effect size, use more complicated statistical tests, or use a wider range of samples and methods. (Supervisor-TH-BA-20) 
Most often, in the conclusion chapter, students just include a summary of their research without discussing implications and recommendations. If they include implications, the implications are not based on their current research. They are too general. Sometimes I feel like students just include the implication part as an element of the chapter but do not give much importance to that part. Maybe, for them, the conclusion is not much important. They just would like to finish it. In fact, the conclusion is important for the readers to understand why they study this and what the readers can benefit from the research. Recommendations or directions for further research are not solid enough... not based on the current research... not well-grounded... and no link to the literature. Also, they don't specify limitations they experienced and provide broad suggestions similar to those in other studies. (Supervisor-THELT-17)

\section{(ii) Organization and presentation}

Even though the informants did not explicitly mention organization and presentation as a criterion when examining theses, terms like "cohesion," "connectedness," and "threads" were frequently used in the description of a good thesis. This reflects supervisors' expectation that, apart from the clarity of content or ideas, good organization and presentation of a thesis argument are also important factors affecting the cohesion of the whole thesis.

Given that a thesis is like a long narrative, all the elements of the thesis are expected to be precisely organized and smoothly connected from the beginning to the end in order to support reading comprehension. Thesis writers should be able to organize their ideas and present the ideas to the readers in a logical way.

It is also about organizing ideas. The impression of readers when reading is that yes, there are these figures...then they read the descriptions of the figures. Students should be able to link all information together, so that they won't get lost and can reduce time in reading. (Supervisor-TH-ELT-16)

More than half of the supervisor informants mentioned flow and consistency in thesis writing. They said that a structural organization of theses varied across the nature of topics and disciplines or even individual styles of writers. Thesis writers should be able to see their theses in a big, well rounded picture and create threads from sentences to chapters and from the beginning to the end. These threads enable a sense of flow when reading and directly impact 
the reader's comprehension and impression at the end of reading the whole thesis.

So this reflects again what I was talking about the cohesion. So not only is it the cohesion between sections within the chapters, it's the cohesion of the whole thesis. (Supervisor-NZELT-05)

I think that when you're reading the thesis, when you get to the end of a chapter you have an idea of what's coming in the next chapter, and then the next chapter begins by briefly telling you what happened before and then moving on. So it's a very smooth, well-linked thesis. It makes it very easy for an examiner because it's very clear. (Supervisor-NZ-ELT-06)

As a thesis is a lengthy text, sometimes it is difficult for students, either native or non-native English speaking students, to look at their theses as a whole picture and make every part of their theses hold together. In the discussion chapter, when they have a large amount of analysis and several findings for discussion, the informants suggest their students look back at the research questions or hypotheses and think of main themes for the discussion. By this means, students can organize the chapter according to the research questions or themes, and the examiners can follow key points being pointed out more easily.

So it's quite often the best way to tackle that is to discuss the findings thematically. In the findings chapter, you should have identified themes, and the discussion chapter should be the place where you expand upon those themes... And at the same time you have to link particular themes to other themes that are going to emerge later. So what you're trying to do is to build up a picture. (Supervisor-NZ-ELT-07)

In terms of presentation, the informants suggested that theses should demonstrate consistency and appropriateness in formatting (e.g., font, headings, section numbers, table labels) throughout the theses. Consistency of using section numbers facilitates writers' and readers' understanding of the hierarchy of content and the overall pattern of the entire thesis. Moreover, the informants indicated that appropriate use of visual information (e.g., charts, tables, figures) is very important and useful in thesis writing because it makes the written information more illustrative to the readers. Visual presentations together with written description of data should be informative and effectively support the reader's comprehension. 
For research reports, using section numbers or hierarchy section numbers actually helps students to see the overall pattern of what they're doing. It actually helps them to make cross references as well to other parts of thesis text because they may not have page numbers at least not until they finalize it. Being able to use section numbers makes it easy for them to be specific and for cross-referencing. (Supervisor-NZ-ELT-03)

It is necessary to have informative graphs or tables to visualize the content...And importantly, I stress that students should avoid using colloquial language in academic texts like theses. (Supervisor-TH-BA-20)

\section{(iii) Language use}

Accuracy, appropriateness and consistency were frequently mentioned by most supervisors when they were asked about language use. Regarding a supervisor role, they carefully look at every aspect of their students' theses. This includes helping students check accuracy of grammatical structures and vocabulary and ensure consistency in writing theses in academic style.

Good writing here includes accuracy and academic writing style. This refers to formality in academic writing. We do not use colloquial language in writing. If you ask me whether students know of it, of course, they do. But sometimes they make mistakes. Because of their limited reading, they use spoken language in academic writing. They mix up everything. ... So consistency throughout the text is a key. (Supervisor-TH-ELT-18)

About writing styles, we expect a consistent, accurate writing. But I know that's not always easy for students... international students who need to manage their first language. Nonetheless, that's what readers are going to expect that. (Supervisor-NZ-ELT-03)

However, when playing an examiner role, the examiners do not focus much on language as long as it does not cause confusion or affect their comprehension. What they focus on is a clear expression of ideas through clear language, either complex or simple structures. Colloquial language should be avoided. In the interview, Supervisor-NZ-ELT-01 used an English expression that "Wooly thinking leads to wooly language" to illustrate her expectation about language use. She explained that if students are clear about what they are thinking and conveying, the language is likely to be clear and easy to understand. In contrast, if their thinking is not clear, the expression of the idea is likely to be scattered and more complicated for readers 
to understand. So the way students use language can reflect to which extent they understand what they are conveying.

\begin{abstract}
And we have an expression in English which is "Wooly thinking leads to wooly language." So if you are not clear about what you think, then your language probably is not going to be very clear either... And, as an examiner, I look for evidence of clear thinking that is being expressed well in writing. People could be using very complex language to do that or they could be using very simple language to do that. (Supervisor-NZ-ELT-01)

So for me that's not a huge thing. If there are small mistakes, I ignore them. They don't matter. If there are large mistakes...I should say this equally happens with native and nonnative speakers... so everyone, regardless of background, I always ask them to get their work proofread. So if there are any big things running throughout, they have a chance for a proofreader to help them spot that out first. Because any big errors running all the way throughout, it interferes with the ability to focus on the content. (Supervisor-NZ-ELT-04)
\end{abstract}

We know that language is only one thing in a thesis. You really need to look at the content...quality of the content. But quite often the content is placed through language. So

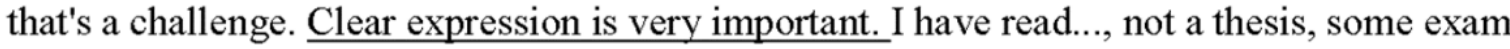
papers. We got Chinese students, for example, at all levels. Some are really good. Their logic is really good. They also know that they cannot express in a very colloquial way. (Supervisor-NZ-BA-10)

I'm just trying to think, of course I would expect a high standard of academic writing. And, I recently examined a master's thesis and sometimes the language was too conversational. And again, that's a learning curve because you want to appeal to the examiner... to make your writing interesting, but your writing style has to be academic. (Supervisor-NZ-ELT-05)

Thai supervisors especially in business administration stated that their students have limited ability in writing in English and presenting thesis arguments in a logical way. Some of them translate literally from Thai to English. Run-on sentences and comma splice errors frequently occur in their initial drafts because in Thai there is no use of full stop or comma. Some of them present everything without main thesis arguments. To improve their writing, students are encouraged to have their work proofread by native English speakers as an important process before thesis submission. 
If they are not international students, most often, they think in Thai. They then literally try to translate it into English. Because there is no use of punctuations such as period (full stop) in the Thai language, Thai students often write run-on sentences. No, that is unacceptable in English academic writing. Although they are language students, they need to be aware of this. That's why we encourage students to have their work proofread before submission. (Supervisor-TH-BA-22)

However, some informants admitted that accurate use of a wide variety of vocabulary and grammatical structures sometimes could impress them and make their reading more enjoyable. Examiners in business administration stated that thesis writers are expected to use appropriate technical terms in order to show their knowledge in the fields. If the terms are quite specific and known within the disciplinary groups, for example words used in finance, the writers need to make sure that definitions are provided, and in this case, repetition is acceptable.

They have learnt it and they should use it appropriately. They are not writing only for the public, but they are writing for the examiners as well. And the examiners normally know the field terms. They need to use the terms in their...diverse vocabulary. It makes reading enjoyable. (Supervisor-NZ-BA-10)

Right, there are some. As I said earlier, technical terms should be introduced in the first chapter where definitions of terms are provided. However, there are not many technical terms being used in my field as opposed to other subfields like finance. If the terms are used, the writers need to introduce them from the beginning and repeat them where necessary to remind the readers. (Supervisor-TH-BA-22)

\section{(iv) Genre knowledge}

As reported in the sections above, examiner informants expect to read content which covers essential elements in the thesis discussion and conclusion chapters. They expect to have a sense of flow when reading the lengthy theses through a logical and well-organized writing. They expect to see a high standard of academic writing in the theses through use of accurate and appropriate grammatical structures and vocabulary. All of these expectations reflect a need for thesis writers to have a clear understanding of writing in the thesis genre. In other words, students themselves need to demonstrate their understanding of what and to which extent content should be included in the chapters, how arguments should be developed and presented 
to create connectedness throughout the chapters and the entire thesis, and what kinds of grammatical structures and vocabulary should be used. These aspects are part of thesis genre knowledge. In the interviews, some informants also mentioned other aspects of genre knowledge, namely argument development, reader awareness, and tone in thesis writing.

At the beginning of this chapter, supervisors' perspectives of the similarities and differences between writing theses and research articles were reported. Supervisors suggested some differences (i.e., the scale of writing and target audience) between the types of texts and they expected their students to take those similarities and differences into account when writing theses. However, in the interviews they indicated that most master's students have a very limited knowledge of writing in the thesis genre because they have no experience in doing research and writing theses before. The supervisors, therefore, encourage students to look at previous theses as well as research articles as a research writing model, so that they can change their way of thinking and presenting thesis statements according to the conventions of the research writing genre.

So a big change for people is when thesis writing, I think. This is the first time they have ever written a research report. They have often written only essays before. So you are working with data. It is not an essay... I think that it is really important that the students understand that the level of detail that goes into the thesis is different from the level of detail that goes into an article. And I think it is really important that they read both the theses and articles in order to understand those different areas. How can you write an abstract if you do not read another's abstract? (Supervisor-NZ-ELT-01)

In the interviews, supervisors in both disciplines often mentioned that thesis students should have a clear understanding of the nature of research writing. In the research writing genre, a line of argument must be developed upon evidence and supportive literature, rather than the writers' intuition, and written in a formal tone. Some supervisors in the interviews suggested that to convince knowledgeable and skeptical scholar readers in the same field, students need to make sure that their statements in the discussion of findings, limitations, implications and so on are grounded on evidence of their own studies. And students need to have the ability to manage the strength of argument and professional tone of writing throughout. 
So the main key element, I think, is the ability of the students to convince their experienced readers that these are the key contributions and this is why this research is relevant. (Supervisor-NZ-BA-12)

In the discussion chapter, students should have statistical results to support their presentation and discussion of findings if their studies take a quantitative approach. After presenting the results, students have to explain what the results mean, what value is high, low or average. For qualitative research, students should use, for example, interview excerpts to support their claims. (Supervisor-TH-ELT-15)

New Zealand supervisors stated that students for whom English is a second language are more likely to make overly assertive claims despite a lack of sufficient evidence, whereas native English students were more cautious when making claims. Similarly, Thai supervisors mentioned that their Thai students sometimes wrote theses based on intuition rather than using statistical evidence or previous studies to warrant their claims. Students are often advised to soften their claims in order to avoid attracting negative feedback from readers. Maintaining a balance between cautious and confident claims was frequently mentioned when supervisors discussed building a thesis argument.

My students don't know how to discuss their research findings. They think they can freely discuss anything. There is no direction or theme in the discussion. They should find main points in their findings and discuss them thematically. In my opinion, the discussion should be based on their own data... You know, sometimes they make strong claims. I asked why? ...Any evidence to support this? They said they believed so. No, it shouldn't be based on your own opinions... Researchers should not have bias. If you want to express your own opinions, you need to say it in a different way. (Supervisor-TH-ELT-18)

I think the markers "they might suggest this" or "I argue that"... I think those are actually important components of a thesis because it is an argument. So I like to see that because students can't claim as if they knew or found everything. It's sometimes much better to suggest or argue in favour of because there may be differing opinions. I think that academic style is very important... I tend not to comment specifically on the words that a student uses to develop arguments... Sometimes it's just to give them an indication and just to give them an example of how something will read much better. (Supervisor-NZ-ELT-05) 
As a result of the interviews, there were four aspects that most disciplinary supervisors frequently referred to when they examined thesis discussion and conclusion chapters. The four main aspects were content, organization and presentation, language use, and genre knowledge. I used these four aspects as rating criteria in this study. The actual rating scale used in this study is presented in Section 7.5 at the end of this chapter.

\subsection{Supervisors' attitudes towards use of metadiscourse in theses}

When supervisor informants described language use in thesis writing, they were asked to share their attitudes towards students' use of metadiscourse markers. One might expect that supervisors who are not from applied linguistics may have a little difficulty in discussing language issues. However, in the interviews, I found that business supervisors in both New Zealand and Thai contexts were capable of talking about the issues, although they did not use exact terms that applied linguistics supervisors used. As mentioned earlier, performing either the thesis supervisor role or examiner role, the informants tend to focus more on content, but feedback in terms of grammatical accuracy and academic tone of writing are inevitably given to make sure that their students' theses attain a standard level of academic and postgraduate writing.

In the interviews, supervisors in the two disciplines agreed that metadiscourse markers play two important roles in thesis writing. The first role is to create explicit links (threads) between different discourse units in order to hold the long thesis story together and enable a sense of flow while reading. The second role is to enable academic tone when showing critical voice and making arguments in research writing. That is to say, the use of interpersonal markers (e.g., findings suggest, one possible reason is) reinforces the academic tone in the texts and reflects the ability of the writers in developing their argument to strengthen the conviction of expert readers.

Yes, I have. I do that when giving feedback on drafts. That is part of things holding a story together... so I think discourse markers are important across chapters or sections of a chapter. (Supervisor-NZ-ELT-02)

So, it's kind of a tricky genre. There has to be a slight element of conversation in it but academic conversation... If you use rhetorical structures like rhetorical questions, that engages the reader more in it too.

... So anytime that something feels like it either needs more of their voice, or if it feels like things are disjointed and things are not flowing then I encourage that. (Supervisor-NZ-ELT04) 
With regard to the actual use of metadiscourse markers in Thai and New Zealand students' theses, most of the informants stated that even though it is acknowledged that appropriate use of some metadiscourse markers can build the flow and facilitate reading, metadiscourse is not their main focus when they supervise students to write a thesis. This is because the inclusion or absence of markers does not affect the meaning of content or the accuracy of language use in theses.

The excerpts below indicate that supervisors focus more on content rather than language use or marker use. And it is certain that when they supervise students, they do not make an explicit indication to students about the use of metadiscourse markers. The informants explained when they read chapter drafts, comments on inserting or removing some markers are provided only when they think it is necessary, for example, to remind students to think more about framing the chapters and creating links between what is being presented and what has been already discussed in other chapters. When supervisors read their students' work, they are likely to be conscious that a certain part needs a metadiscourse marker to make an explicit link, soften a claim, and so on. But marker use is not a topic they emphasize when supervising thesis students.

Not the main thing to supervise but remind students to think of links between what they are talking about and what has been discussed in previous chapter in order to maintain the flow when the readers are reading... (Supervisor-TH-ELT-19)

But this (consideration of marker use) sort of comes naturally as I am reading the text. So I wouldn't comment on it at the beginning. But as I read the text, I would. And say you know... maybe you could rephrase this in a different way. So implicitly yes... (SupervisorNZ-BA-08)

Supervisor-TH-BA-22 shared her opinion on the significance of metadiscourse use in students' theses. She stated that her consideration of language use is prioritized in three levels: first accuracy and appropriateness in grammar and vocabulary, second, writing in an academic tone, and third smoothness of writing and reading. She indicated that with students who are not very good at English writing, she pays more attention to enhancing their accuracy and tone of writing first. But with students who have already demonstrated the accuracy and academic tone in their theses, she will further help the students to enhance smoothness in writing by suggesting that students use some linguistic markers within chapters and between chapters where necessary. 
Personally, I prioritize my consideration of students' writing in three levels. I feel like... linguistic markers help with smoothness of writing and reading and depend on writers' writing styles. Without them, the content or grammar is still correct. So I tend to focus more on the first two levels: accuracy and academic tone. If possible or when time permits, I will help students create links for smoothness when reading later. (Supervisor-TH-BA-22)

In the interviews, supervisor informants made comments on some types of metadiscourse, namely hedges and boosters, self-mentions, and evidentials (citations).

\subsubsection{Supervisors' comments on use of hedges and boosters}

During the interviews with supervisors, the issue about hedges and boosters was raised as a follow-up topic in the discussion about language use and genre knowledge. As mentioned in Section 7.3.2 (Rating criteria), thesis students are expected to have the ability to evaluate and manage the strength of claims as part of their thesis genre knowledge. Hedging and boosting claims are likely to be one of the writing strategies that students and supervisors use to denote their evaluation of content certainty and to signal to readers to which extent they are confident and assertive about the claims being made.

Supervisor-NZ-ELT-02 explained that in a thesis there is a line between certainty and uncertainty, involving proved facts and opinions. A thesis is not limited to certainty of proved facts. This suggests that students are not expected to provide only claims they are certain about but also to express the possibility and uncertainty of their own ideas by means of hedging.

As I said, it's a way of showing your honesty. The stronger the evidence, the more you can be certain about. You can never be certain about anything. Let's say you've got a line between doubt and certainty. And you can never reach certainty and the thesis shouldn't be full of doubts ...but the more you can be honest and the more you can push it towards certainty and be honest as you do it, it's better. (Supervisor-NZ-ELT-02)

When asked about making appropriate claims in theses, supervisors in the interviews indicated that some master's students still have difficulty in evaluating the strength of their own claims. That is, sometimes they over-claim and sometimes they are overcautious. Overclaiming happens when students do not have sufficient data or solid evidence but they try to draw a definite conclusion. Overcaution happens when students have clear evidence (e.g., statistical 
results) but they are overly humble and do not claim it explicitly and confidently. To make appropriate claims in theses, supervisors suggested that students need to consider the strength of evidence. When evidence is not sufficient or strong enough, claims need to be hedged.

Hedging is merely an expression of the fact that you realise the strength of your own claim. And that's the real problem. Students have a great difficulty judging the strength of their own claim...(Supervisor-NZ-ELT-07)

On one hand, they claim as if they found everything. This happens often. Overgeneralization. Overclaiming. ...On the other hand, overcautious. Sometimes they have quantitative evidence to support knowledge claims, but they are too humble to say that this is what they have found... This number shows what... (Supervisor-NZ-BA-09)

From the viewpoint of these supervisors, appropriate use of hedges and boosters is essential for thesis students for two reasons. First, it shows students' realization of limitations of their studies and intention to avoid overgeneralizing findings or weakening claims. Instead of drawing a definite conclusion such as "this is the opinion of Chinese people," students realize that they need to be mindful of the limited scale of their research and hedge the claim.

So saying that we have, you know, I've interviewed five people, doesn't mean that I can draw any definite conclusions. As an examiner, I've never seen that, but to see certainly...that would raise a red flag for me. I think that's part of the student being aware of the limitations of the study. (Supervisor-NZ-BA-11)

Second, use of hedging and boosting markers is an explicit way of showing honesty of interpretation. Either quantitative or qualitative research requires interpretation and plausible explanation after analyzing data. Supervisors stated that use of hedges and boosters is rich in the discussion chapter when compared to methodology and literature review chapters. The discussion chapter requires students to discuss current results and also propose possible reasons to explain the results. When students are not certain about reasons being proposed, hedging is then used to shield their arguments and indicate uncertainty of the propositional content to readers. This feature is less likely to be found in the literature review because the function of this chapter is to review the findings and claims of published research, which has gained acceptance by the research community in the sense that it is published. Hedges and boosters are sometimes used in the literature chapter when writers would like to show the readers where 
they are interpreting from reading and where they are reporting proved facts or claims of published research.

That is part of issues of the strength of evidence and being honest. For example, a positive relationship between two bits of information and when in fact there is a correlation so if you're not sure about the cause, you could say "this may be because." I actually encourage that. It's part of the honesty of interpretation and doesn't do you any harm at all. (SupervisorNZ-ELT-02)

Use of hedging markers (probably or maybe) in discussion is reasonable because you need to give possible reasons to explain your findings often. But use of hedging markers in the literature review might be a bit weird for me... you repeat what other people have done, found, and published. If you give comments on previous studies, that is different... the markers like maybe and probably can be used to indicate this part is your own understanding...your own recommendation. (Supervisor-TH-BA-21)

Supervisor informants further added that the presence or absence of hedges and boosters is not the main focus of their consideration and supervision in the first place. In early drafts of a thesis, supervisors tend to keep themselves focused on content and the overall picture of the thesis. The issues of hedging and boosting claims usually come through when they read and find claims not relevant to existing evidence. An explicit suggestion to use or remove hedges or boosters is only made when supervisors find it necessary for students to rephrase some claims which may cause suspicion and attract negative feedback from readers.

When asked to compare the use of hedges and boosters in students' theses based on their own observation, Thai supervisors stated that Thai students tend to use boosters more often than hedges. This is similar to New Zealand supervisors' response that L2 students are more likely to make assertive claims, whereas L1 students are more likely to make cautious claims through hedging. This is noticeable for the supervisors in the interviews because often they need to advise L2 students to soften claims and be more mindful of overgeneralization. Thai supervisors explained that it may be because most of their master's theses are quantitative research and rely heavily on statistical results without being cautious about research limitations. They make overly assertive claims based on evidence they have, without thinking of other possibilities. Another possible explanation for why Thai students tend to use a lot of boosters is that they would like to express their confidence and make strong claims to convince readers. 
They are reluctant to use less strong words and show uncertainty to the readers. In other words, their use of more powerful words like boosting markers is for persuasive purposes. This is why supervisors need to remind students that to convince the readers does not mean that students need to show confidence or certainty in propositions in their theses. Without sufficiency of evidence, it is possible for them to express some uncertainty or opinions when discussing findings.

I think they tend to make assertive claims students more often than hedging. It is possible that most of their master's theses are quantitative research and have clear statistical results to support their claims. They use the quantitative results to make a definite conclusion and overly assertive claims. They forgot that if they triangulate qualitative and quantitative data, they may find other possibilities or different results. (Supervisor-TH-ELT-14)

As I have seen, they have limited findings, but they try to explain them by using more powerful words. They misunderstand that using powerful words is the way to make strong claims and to show the readers their confidence. In fact, using too powerful words is putting them at risk. (Supervisor-TH-BA-22)

An interesting finding from the interviews is that a few supervisors do not encourage students to use boosting markers. They stated that if the claim is clear with solid evidence, the readers can see it by themselves. They do not think that putting boosting words in sentences makes arguments stronger. Thai supervisors explained that some students are not sensitive to understand the meanings of each marker. If supervisors encourage them to use some markers, they will superfluously use them without caution. It is probably better and easier for students to directly state claims without using boosters if they have clear evidence to present.

I don't really like it (boosting claims)... If you have presented your evidence well, you don't have to push it... your readers should see it for themselves that this is a good strong argument. And if it's not a good strong argument, saying that you strongly believe it actually doesn't make it any stronger. (Supervisor-NZ-ELT-07)

Students are not sensitive about using hedging and boosting markers to assist the way they manage claims. It's better to encourage them to directly state the claims without using any markers. (Supervisor-TH-BA-24) 
It's hard to tell where to use boosters or not to, depending on context. If you have clear evidence to support, you have two options... you use a booster to highlight the certainty, or you directly make the claims without using any marker. Let evidence speak for itself. (Supervisor-TH-ELT-14)

\subsubsection{Supervisors' comments on use of self-mentions}

In the interviews, supervisors mentioned that they expect to read theses written in an academic tone. Then they shared their attitudes towards use of active and passive forms as well as selfmention markers such as $I$, we, researcher, and author in thesis writing.

There is a controversy about whether it is appropriate for writers to use self-mention markers like $I$ and we in academic writing. New Zealand and Thai supervisors mentioned in the interviews that in the past it was not acceptable to use the first-person pronoun $I$ in thesis writing. At that time, there was a belief that using $I$ showed the writers' overt engagement and caused bias in the texts, whereas using the third person like this research and interview data helped distance the researchers or the writers from the texts and decrease the degree of subjectivity in thesis writing. Supervisor-NZ-ELT-07 explained that the use of first- and thirdperson pronouns is not the matter of making writing more or less biased.

One of the things that really irritates me is the belief that academics seem to have that if you write in the first person you're going to be biased. Why writing in the first person should make you biased? This belief that you're writing in the third person is good, unbiased, critical writing is just rubbish. Either it's good writing, as unbiased as we can be, or it isn't...putting it in the third person isn't going to make it less biased. (Supervisor-NZ-ELT-07)

At present, New Zealand and Thai supervisors agreed that there is flexibility to use either the first or third person and either active or passive voice. It is more about writing styles of individual writers. Supervisors only expect to see consistency in using a particular self-mention marker because switching identities of the writer back and forth in a lengthy thesis may cause confusion to readers. For example, at the beginning of a thesis, the self-mention marker $I$ is used and in other parts the researcher is used.

However, when New Zealand and Thai supervisors were asked to explain in detail about using self-mention markers (particularly the use of $I$ and the researcher) as well as using active and passive voice, their responses were somewhat different. 
Even though New Zealand and Thai supervisors agreed that now it is acceptable for writers to use the first-person pronoun $I$ in academic writing, New Zealand supervisors seem to be more flexible to allow students to use $I$ in their theses because it shows that students try to take ownership of their opinions and claims. Students just need to make sure that they do not use $I$ too often because a thesis is not a story about the researcher. Compared to the use of $I$ in theses, most New Zealand supervisors in the interviews do not encourage students to use the noun researcher because it makes writing artificial in that the readers actually know $I$ and the researcher are the same person. Also, it can be confusing for the readers whether the word researcher is a self-mention of the researcher of this current thesis or the researcher whose work is being cited.

I think it's fine to use "I", but sometimes people write "the researcher." And it strikes me somewhat artificial when everyone knows the person is writing. This is a bit old-fashioned to say "the researcher." Maybe it is supposed to create a sense of objectivity. On the other hand, you are talking about something... you would not expect many "I" ....I this... I that ... because it's not a story about you; it's a story about a context and then question. So mostly we are talking about third person situations but where your own voice comes in then "I" is fine. (Supervisor-NZ-ELT-02)

I'm very happy with students using personal pronoun. Anytime really it's their work. It goes with the fact that they are attributing ownership to their views and claims. They can claim their own conclusions as their own. There is no problem for me with using personal pronouns. ... Using "the researcher"? I have had students using that. I discourage that. As I said, they should take ownership. (Supervisor-NZ-ELT-03)

Some supervisors in the interviews indicated that the use of the self-mention marker $I$ is also related to the nature of research. Students doing qualitative research are likely to use the selfmention marker $I$ often because the nature of qualitative research is interpretative and narrative work. It is mainly based on interpretation and explanation of the research students themselves. Using the marker $I$ makes it clear that a certain proposition is based on the student's own understanding and interpretation. 
"I" is not what I prefer or not. I guess it's becoming more acceptable especially in qualitative research because qualitative research is interpretive or subjective understanding of particular research phenomenon...(Supervisor-NZ-BA-10)

I would normally say to them either is fine, as long as it is consistent. If they are on the interpretive end of the spectrum then I would probably encourage them to use first person. ....And if obviously you're doing something like narrative work, I would say you need to be using the first person....(Supervisor-NZ-BA-11)

Using either active or passive voice is not a problem for supervisor informants. But when asked for their preference, most New Zealand supervisors prefer active voice because they think it is straightforward and enables instantaneous understanding for readers. Depending on students' writing styles and thesis chapters, it is possible for them to use $I$ or the third person like this research and interview data as an agent in the active form. This means that if students feel uncomfortable to use $I$ because it sounds too personal, they can use active voice with the third person. Often, in findings, discussion, and conclusion chapters, students are likely to be encouraged to use the third person such as this research suggested that ... and interview data demonstrated that... to indicate to the readers that thesis arguments are presented based on facts or data rather than students' own feelings or thoughts. New Zealand supervisors seem not to encourage students to use passive voice often as a main structure. Concerning time and clarity, they explained that the readers will take a longer time to interpret the meaning of what is being conveyed in the passive structure throughout a lengthy thesis. Importantly, the supervisors would like to see students' confidence in expressing academic voice explicitly.

Very often some students use passive voice to sort of discount or not to take that much ownership particularly in the theoretical part. They are sometimes fearful of criticizing or showing some sort of disagreement particularly with definitions...I encouraged them and let them know it's ok that after you provide various definitions then you say "I would tend to agree with this authors because..." (Supervisor-NZ-BA-08)

In contrast to the New Zealand supervisors, Thai supervisors tend to encourage students to use passive voice when compared to active voice, especially with $I$ as an agent. Although they acknowledge that there are several factors (not only explicit use of $I$ ) affecting the degree of subjectivity, in practice they are likely to encourage students to use passive voice in order to increase a sense of objectivity in writing. In other words, for some Thai supervisors, it cannot 
be denied that explicit use of $I$ is one of the factors which make the tone of thesis writing personal and subjective. Regarding the use of the researcher and the first-person pronoun $I$, they are more likely to encourage students to use the researcher rather than $I$. Thai supervisors further indicated that the markers like I suggest and I assume are rarely used because students themselves seem to internalize that they are not supposed to use $I$ according to the traditional conventions of academic writing. Also, it is possible that Thai master's students may not be confident to take authority the way big scholars do, so they use the passive form to exclude themselves from the texts.

They mostly use passive voice and third-person. We know that every kind of research is subjective, but we try not to make it more subjective by using the pronoun "I". But if my students feel more comfortable to use "I", I have no problem with that. ...The markers like I suggest and I assume are rarely used because master's students prefer to follow the traditional style of writing with passive voice. And they are not confident to take the authority like big scholars. (Supervisor-TH-ELT-17)

Using the pronoun "I" makes the tone of writing non-academic. I don't know. It's just not $\underline{\text { my style of writing. It is not a personal issue. So I encourage students to use passive voice }}$ and exclude themselves from the text. (Supervisor-TH-ELT-16)

Two Thai supervisors provided an interesting reason for using the researcher and $I$ in Thai students' theses. They said that many of their previous students frequently used the researcher in their theses, and they asked the students for reasons. The students replied that "because I have read Thai articles and they used the word ผู้วัจิย (the researcher) and I have never seen คิฉัน (I) in the articles." The supervisors then realized that in the Thai language when it comes to academic writing, the active form with the agent $I$ is never used. The use of $I$ in the Thai language will make the tone of writing less academic.

Another interesting reason is that Thai supervisors tend to encourage their students to follow the same traditional practice as in previous theses. They explained that even though they are very open and have no problem with students' use of $I$ in academic writing, they tend to encourage students to use passive voice or the researcher rather than $I$ because this is the traditional practice that supervisors/ examiners and students in the Thai context have done for a long time. If they encourage students to change and use $I$, their students may have conflict with the readers/ examiners who take a more traditional approach to writing. 
It not only depends on my writing style. Sometimes students and I need to be aware of the expectations of examiners. We know that this examiner follows the traditional convention. He expects writing in passive voice. If I ask students to use $I$, for example in the methodology chapter I did this and I did that... but the examiner prefers something like The subjects were selected by..., I am afraid that my students will have conflict with the examiner. (SupervisorTH-ELT-15)

\subsubsection{Supervisors' comments on use of citations}

The topic of citations was raised in the interviews when supervisor informants discussed accuracy in language use which includes proper use of citations in thesis writing.

Supervisor informants suggested that citations do not only concern referencing or citing previous studies, but they are also related to intentional and unintentional plagiarism which supervisors as well as examiners take into serious consideration. Supervisors indicated that master's students do not have experience in research writing. When they paraphrase and use reported speech and direct quotes, they may fail to properly cite the original sources. Thesis students are then expected to show transparency in quoting other people's ideas with a proper citation format. Students cannot simply cut and paste a paragraph without using a proper citation format and punctuation for the direct quote. Supervisors also indicated that it is very important for students to ensure consistency of citation formats. A mix of citation formats, for example using p dot 53 in one place and colon 53 in another place, might distract examiners' attention from reading the content.

With regard to citation forms, both integral and non-integral citation are used in theses in the two disciplines. Supervisors mentioned that usually footnote citations are not used in their disciplines. The decision to use integral or non-integral citations depends on what the writers would like to focus on, either paraphrased information or giving credit to the original authors. In the interviews, supervisors suggested that when students cite a particular quote originally written by an influential scholar, integral or source-led citation (e.g., according to Cotler) should be used in order to explicitly give credit to the original author. If students integrate and paraphrase information from several sources and the focus is on the information, non-integral or parenthetical citation should be used, so that students can show responsibility for putting forward their own understanding of the information. 
Supervisors in business administration raised an interesting assumption that students in their field are more likely to use non-integral citation in the discussion and conclusion chapters. This assumption is grounded on the nature of their operation-based research which usually does not start from theories. When they need to review literature for the discussion of findings, they tend to review several studies and use information integrated from several sources rather than relying on a particular source. Another possible reason is that the writers have already discussed details of different studies and different viewpoints in the literature review chapter. In the discussion and conclusion chapters, they can refer to the literature to highlight the information relevant to their findings and put the citations in parentheses.

\subsection{Rating scale designed for thesis quality assessment in Study 2}

As presented in Section 7.3 about rating practices and criteria, in the actual examination process, informants reported that when they examine a thesis they read and assess the thesis holistically and have no fixed criteria or detailed rating scale for the assessment. They use experience and impressions as integral parts of their judgment. When examiners were asked in the interviews to describe what they expect to see in good discussion and conclusion chapters, most disciplinary examiners referred to content, organization and presentation, language use, and genre knowledge. Therefore, these four aspects were used as rating criteria in this study. It is important to note that the rating scale was designed to be generic for assessing theses in different disciplines.

After identifying the four criteria, I decided to apply a five-point rating scale format to this study because using more than five levels might make the task too demanding and impractical for raters to distinguish each level of criteria. To enable the same understanding of what each point means, I wrote descriptors for each point of the four criteria. The first criterion was content. Examiners in the interviews frequently mentioned key functions of discussion and conclusion chapters when they described their expectation of content in the two chapters. Therefore, when assessing content in the two chapters, raters in this study were required to focus on the coverage and clarity of the chapter functions as follows. To achieve Point 5 (highest), in terms of content, a thesis must fully cover and excellently describe key elements of discussion and conclusion chapters. It must include a highly critical interpretation and justification of significant findings and show strong reference to relevant literature. Significance of findings and contribution to the field must be clearly articulated. The conclusion part must include a concise, useful and impressive summary of the whole research 
and concrete implications to the field. Further research recommendations must be specified and aligned with actual limitations of current research rather than drawing from other previous studies. To achieve Point 1 (lowest), a thesis includes few key elements of discussion and conclusion chapters and keeps repeating research findings without offering a critical discussion. It hardly specifies the significance of the findings or contribution to the field. It provides very broad implications to the field. It acknowledges very broad limitations and recommendations for further research, but there is little or no connection between the two.

The second rating criterion was organization and presentation. Interview data suggest that when examiners assess the quality of organization and presentation of a thesis, they look at threads or connectedness of the entire thesis, effectiveness of visual presentation (e.g., charts, figures) and consistency of formatting (e.g., font, headings, section numbers, table labels). In this study, to achieve Point 5, a thesis must demonstrate systematic and logical organization which enables a clear sense of flow from the beginning to the end. It must show an excellent balance in terms of depth of discussion of each theme throughout (e.g., not too thick or too thin sections). Visual presentations and written description of data must be highly informative, appropriate and effective to support readers' comprehension. There must be a high level of consistency and appropriateness in terms of formatting throughout the chapters without any errors. To achieve Point 1 , a thesis has no theme in discussion and conclusion chapters. The organizational structure is choppy and loosely-connected. Visual presentations and written description of data are non-informative, inappropriate and ineffective. And there is no consistency or appropriateness in formatting.

The third criterion was language use, particularly grammatical structures and vocabulary. Examiners stated that usually the final draft of theses has been proofread before submission, so language is not their main focus when examining theses as long as it does not cause confusion or affect their comprehension. To achieve Point 5, a thesis must have excellent language control and high consistency in academic writing style. It must show highly accurate use of a wide variety of vocabulary and grammatical structures to make the reading more enjoyable. It shows highly appropriate use of technical terms with clear definitions and repetitions where necessary. To achieve Point 1, a thesis contains a lot of grammatical and word choice errors which seriously affect the clarity of core meaning and comprehension. It shows inappropriate use of technical terms in the field. And the writing style may be too conversational. 
The last criterion was genre knowledge. In the interviews, examiners in both disciplines often mentioned that thesis students should have a clear understanding of the nature of research writing. That is, students should be able to develop a line of argument based on evidence and present the argument in a formal tone in order to convince knowledgeable and skeptical scholar readers in the same field. So the term genre knowledge in this study covers argument development, reader awareness, and tone. To achieve Point 5 , in terms of genre knowledge, a thesis must show excellent management in terms of the strength of argument and tone of writing to convince the readers. It must show the writer's high awareness of limitations of research and sufficiency of evidence to warrant claims. Either cautious or assertive claims are logically and transparently developed on the basis of sufficiency of evidence throughout. It shows high consistency in formal tone of writing and has high strength of conviction. To achieve Point 1, a thesis shows that the writer has no awareness and makes little attempt to manage the strength of argument and tone of writing to convince the expected readers. It reflects that the writer has no awareness of research limitations and sufficiency of evidence to warrant claims. It contains many instances of overcautious, overconfident or unsupported claims. There is no consistency in writing tone (possibly using informal language) and no power of conviction.

Figure 7.1 presents the rating scale designed for thesis quality assessment. 


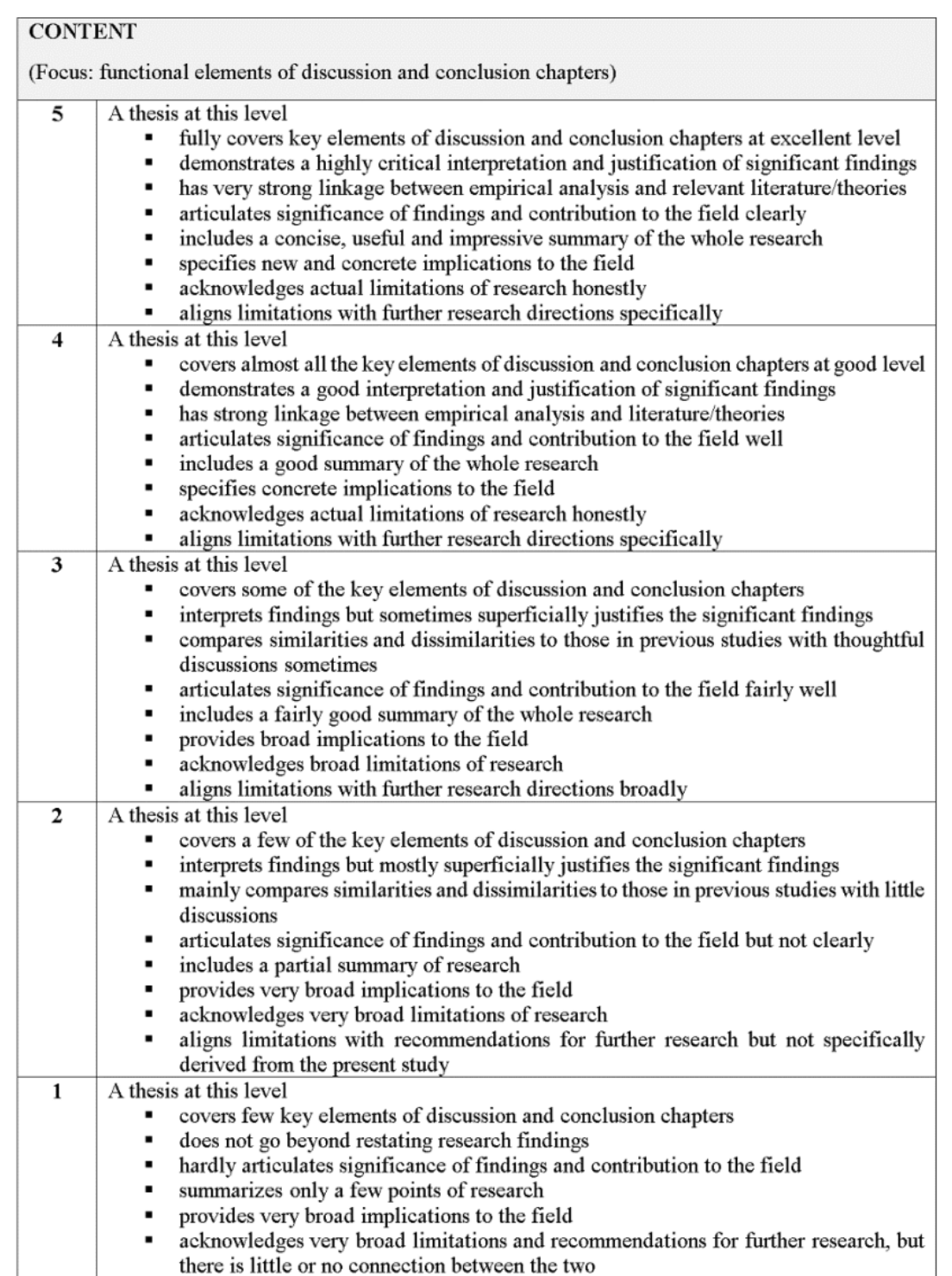

Figure 7.1. Rating scale for thesis quality assessment
ORGANIZATION AND PRESENTATION

(Focus: connectedness, visual presentation and formatting)

\begin{tabular}{|c|c|}
\hline 5 & $\begin{array}{l}\text { A thesis at this level shows } \\
\text { - an excellent, systematic and logical organization in discussion and conclusion } \\
\text { chapters } \\
\text { - an excellent balance in terms of depth of discussion of each theme throughout (e.g., } \\
\text { not too thick or too thin sections) } \\
\text { - threads between paragraphs, sections and chapters, enabling comprehension from the } \\
\text { beginning to the end with a clear sense of flow } \\
\text { - highly informative, appropriate and effective visual presentations (e.g., charts, } \\
\text { figures) and written description of data to support comprehension } \\
\text { - a high level of consistency and appropriateness in formatting (e.g., font, headings, } \\
\text { section numbers, table labels) throughout the chapters without any errors }\end{array}$ \\
\hline 4 & $\begin{array}{l}\text { A thesis at this level shows } \\
\text { - a good organization based on themes/research questions/hypotheses in discussion and } \\
\text { conclusion chapters } \\
\text { - a good balance in terms of depth of discussion of each theme throughout } \\
\text { - threads within and between chapters, enabling coherent understanding effortlessly } \\
\text { informative, appropriate and effective visual presentations (e.g., charts, figures) and } \\
\text { written description of data to support comprehension } \\
\text { - a good level of consistency and appropriateness in formatting (e.g., font, headings, } \\
\text { section numbers, table labels) throughout the chapters with a few errors }\end{array}$ \\
\hline 3 & $\begin{array}{l}\text { A thesis at this level shows } \\
\text { - a fairly good organization with certain themes in discussion and conclusion chapters } \\
\text { - eome balance in terms of depth of discussion of each theme } \\
\text { - fairly informative, appropriate and affective bisual presentations (e.g., charts, figures) } \\
\text { and written description of data } \\
\text { consistency and appropriateness in formatting (e.g., font, headings, section numbers, } \\
\text { table labels) with frequent errors }\end{array}$ \\
\hline 2 & $\begin{array}{l}\text { A thesis at this level shows } \\
\text { a poor organization with unclear themes in discussion and conclusion chapters } \\
\text { an imbalance in terms of depth of discussion of each theme (e.g., obviously too thick } \\
\text { and too thin sections) } \\
\text { - no connectedness within and between chapters, affecting smoothness of reading } \\
\text { fairly informative and appropriate visual presentations (e.g., charts, figures) but } \\
\text { sometimes not completely effective written description of data } \\
\text { - a poor level of consistency and appropriateness in formatting (e.g., font, headings, } \\
\text { section numbers, table labels) with frequent errors }\end{array}$ \\
\hline 1 & $\begin{array}{l}\text { A thesis at this level shows } \\
\text { - no themes in discussion and conclusion chapters } \\
\text { - hoppy and loosely-connected organizational structure, impeding comprehension } \\
\text { non-informative, inappropriate and ineffective visual presentations (e.g., charts, } \\
\text { figures) and written description of data } \\
\text { no consistency and appropriateness in formatting (e.g., font, headings, section } \\
\text { numbers, table labels) }\end{array}$ \\
\hline
\end{tabular}




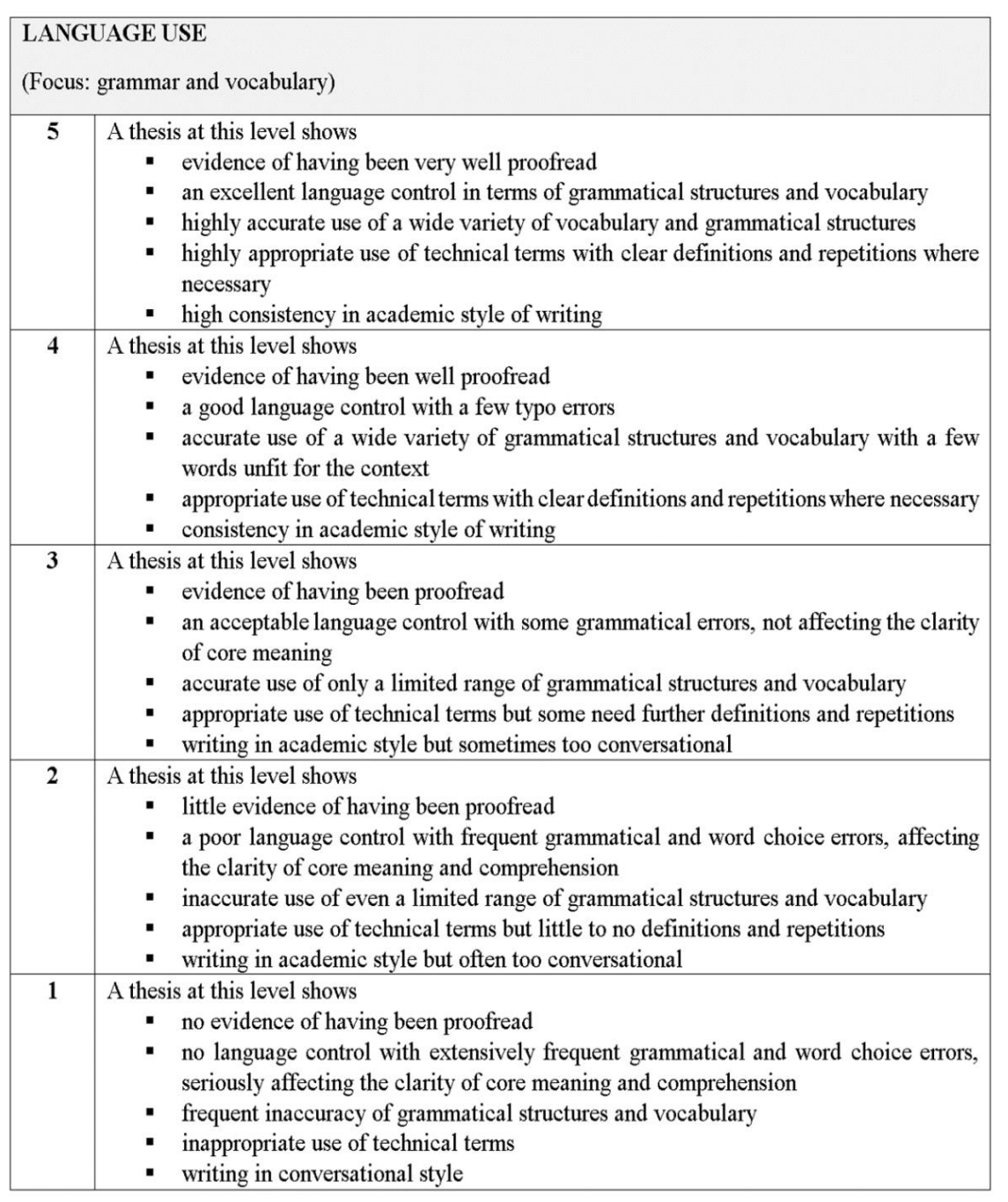

Figure 7.1. Rating scale for thesis quality assessment (continued)

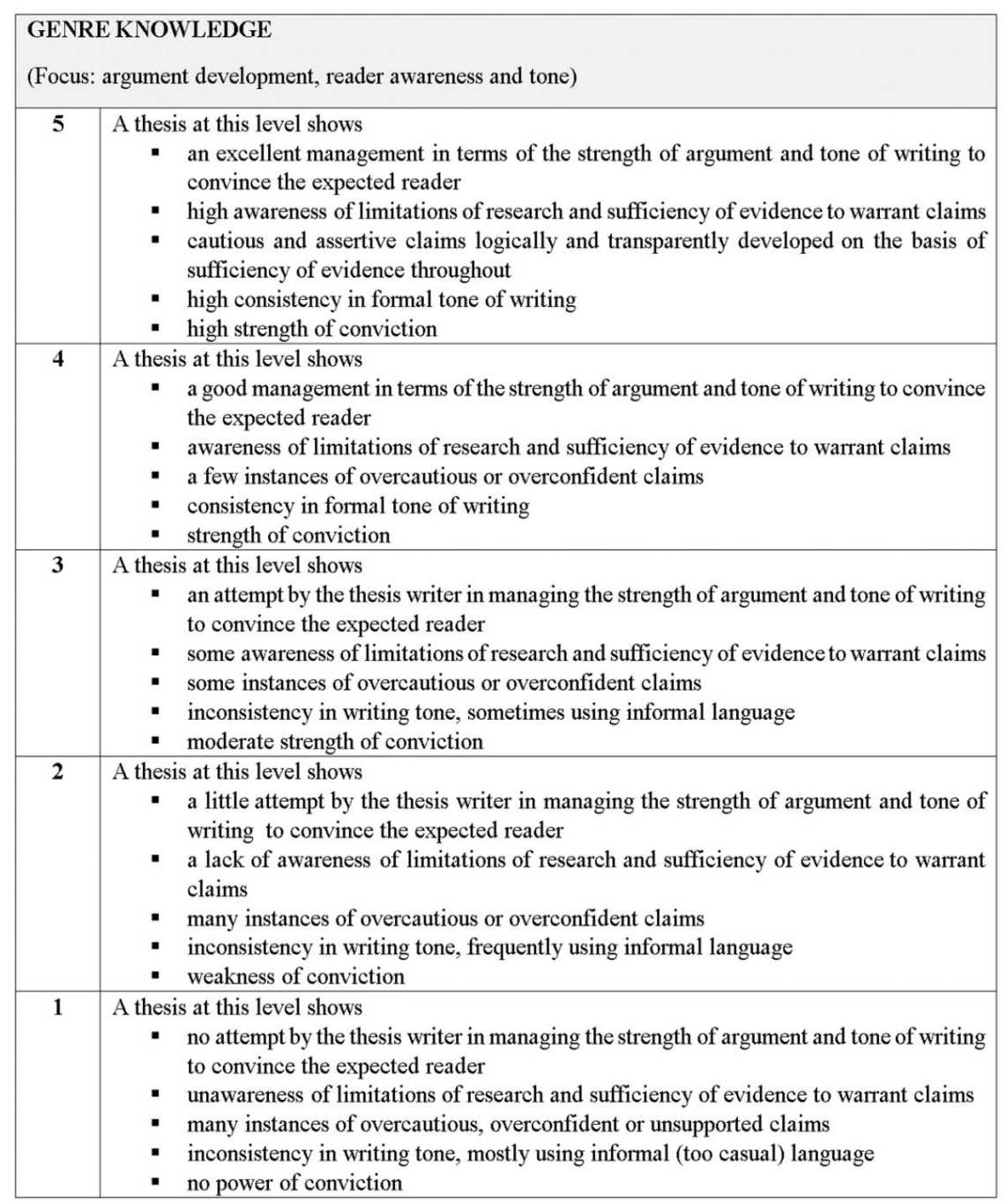




\subsection{Chapter summary}

This chapter has reported the results of disciplinary supervisor interviews in four areas: the overall structure of disciplinary theses in Thai and New Zealand contexts, writing discussion and conclusion chapters, rating practices and criteria for thesis quality assessment, and supervisors' attitudes towards use of metadiscourse in theses. This chapter has also contributed a five-point rating scale including four criteria (content, organization and presentation, language use, and genre knowledge) designed for thesis quality assessment. In the assessment phase, two raters in English language teaching and business administration used the same rating scale to assess twenty four discussion and conclusion chapters in their own disciplines. The next chapter will present the results of assessment and the relationship between metadiscourse frequencies and the quality scores of theses in each discipline. 


\section{CHAPTER 8 \\ STUDY 2: METADISCOURSE FREQUENCY AND THESIS QUALITY}

Study 2 corresponds to the last research question: How does metadiscourse affect the quality of postgraduate writing? What kinds of metadiscourse have the biggest impact? Theses in this study were written by New Zealand and Thai postgraduates from the disciplines of English language teaching and business administration (NZ-ELT, NZ-BA, TH-ELT and TH-BA subcorpora). Forty eight theses (twelve theses from each of the four subcorpora) were selected based on the findings of high and low frequencies of metadiscourse markers in Study 1.

In the quality assessment phase, divided by discipline, two raters in English language teaching rated twenty four discussion and conclusion chapters of theses in the language teaching discipline, and two raters in business administration rated twenty four discussion and conclusion chapters in the business discipline. All raters used the same rating scale to assess thesis quality in four aspects (i.e., content, organization and presentation, language use, and genre knowledge).

To align with statistical analyses divided by discipline, Section 8.1 presents findings about the relationship between metadiscourse frequencies and quality scores of English language teaching theses. Section 8.2 presents findings about the relationship between metadiscourse frequencies and quality scores of business administration theses. Section 8.3 presents a comparison of quality scores between high and low frequency groups in each discipline.

\subsection{Quality scores and metadiscourse frequencies in English language teaching theses}

This section includes analyses of (1) agreement between two raters in English language teaching, (2) correlations between frequencies in use of metadiscourse and scores awarded by raters for quality, (3) correlations between frequencies in use of textual and interpersonal metadiscourse and quality scores, and (4) correlations between frequencies in use of five textual metadiscourse subcategories and five interpersonal metadiscourse subcategories and quality scores.

\subsubsection{Interrater agreement in assessing English language teaching theses}

In order to test whether the scores awarded by the two raters met the assumptions of normal distribution and homogeneity of variance, a Shapiro-Wilk's normality test, Levene's 
homogeneity test and visual inspection were employed. They indicated that the quality scores were normally distributed and equal in terms of variances (both $p>.05$ ). Pearson's correlation coefficient was therefore used to measure the interrater agreement between twenty four individual scores assigned by the two raters in English language teaching. In Table 8.1, the average score assigned by the first rater is 13.77 out of $20(\mathrm{SD}=4.03)$, and the average score assigned by the second rater is $16.04(\mathrm{SD}=2.89)$. Although the Pearson's correlation result suggests a significant positive correlation between individual scores assigned by the two raters $(r(22)=.531, p<.01)$, the level of interrater agreement around .5 is considered low. The level of agreement should be .7 or higher (Salkind, 2010, p. 627).

With regard to the agreement in assessing each of the four quality aspects, the statistical results reveal significant positive correlations between individual scores assigned by the two raters in every criterion: content $(r(22)=.477, p<.05)$, organization and presentation $(r(22)=.525, p$ $<.01)$, language use $(r(22)=.465, p<.05)$, and genre knowledge $(r(22)=.496, p<.05)$.

Table 8.1. Interrater agreement in ELT

\begin{tabular}{|c|c|c|c|c|c|c|c|c|c|c|}
\hline \multirow{2}{*}{ Rating criterion } & \multicolumn{4}{|c|}{ Rater 1} & \multicolumn{4}{|c|}{ Rater 2} & \multirow{2}{*}{$r$} & \multirow{2}{*}{$p$-value } \\
\hline & Min. & Max. & Mean & SD & Min. & Max. & Mean & SD & & \\
\hline Content & 1.50 & 5.00 & 3.35 & 1.26 & 2.00 & 5.00 & 3.50 & 1.18 & $.477^{*}$ & .018 \\
\hline Organization and presentation & 2.50 & 5.00 & 3.67 & 0.93 & 2.50 & 5.00 & 4.02 & 0.84 & $.525^{* *}$ & .008 \\
\hline Language use & 1.50 & 5.00 & 3.42 & 0.95 & 3.50 & 5.00 & 4.75 & 0.44 & $.465^{*}$ & .022 \\
\hline Genre knowledge & 1.50 & 5.00 & 3.33 & 1.15 & 2.50 & 5.00 & 3.77 & 0.85 & $.496^{*}$ & .014 \\
\hline Overall quality scores & 8.00 & 20.00 & 13.77 & 4.03 & 12.00 & 20.00 & 16.04 & 2.89 & $.531^{* *}$ & .008 \\
\hline
\end{tabular}

\subsubsection{Correlations between quality scores and overall metadiscourse in English language} teaching theses

Table 8.2 and Table 8.3 display the descriptive statistics of quality scores and metadiscourse frequencies (normalized to 10,000 words) in English language teaching theses $(\mathrm{N}=24)$. The minimum, maximum, and mean of the normalized frequencies of the theses are also reported, allowing an investigation of the distributional pattern of metadiscourse subcategories and the overall characteristic of the theses being assessed. The mean score of the theses in this discipline is 14.91 out of 20 . The normalized frequency of overall metadiscourse in the language teaching theses is $434.8(\mathrm{M}=18.12)$. The normalized frequencies of textual and interpersonal metadiscourse are $223.4(\mathrm{M}=9.31)$ and $211.5(\mathrm{M}=8.81)$, respectively. 
As measured by the normalized frequencies, the theses in this discipline contain more textual metadiscourse (51.4\% of all metadiscourse occurrences) than interpersonal metadiscourse (48.6\% of all metadiscourse occurrences). Within the textual metadiscourse category, transition markers are the most frequently used, followed by evidentials. The frequencies of frame markers and code glosses are almost the same, ranking third and fourth. Endophoric markers are the least frequently used in this category. Within the interpersonal metadiscourse category, hedges are the most frequently used, followed by boosters, self-mentions, attitude markers, and engagement markers. When looking at the average frequencies across categories, the frequencies of transition markers and hedges are extremely high, while the frequencies of the eight other subcategories are much lower. The subcategory with the least frequent use of all is engagement markers.

Table 8.2. Descriptive statistics of quality scores in ELT theses

\begin{tabular}{lcccc}
\hline Quality aspect & Min. & Max. & Mean & SD \\
\hline Content & 1.75 & 5.00 & 3.43 & 1.05 \\
Organization and presentation & 2.75 & 5.00 & 3.84 & 0.77 \\
Language use & 3.00 & 5.00 & 4.08 & 0.61 \\
Genre knowledge & 2.25 & 5.00 & 3.55 & 0.87 \\
\hline Overall quality scores & 10.00 & 20.00 & 14.91 & 3.04 \\
\hline
\end{tabular}

Table 8.3. Descriptive statistics of metadiscourse frequencies in ELT theses

\begin{tabular}{lccccc}
\hline Category & Nf & Min. & Max. & Mean & SD \\
\hline Transition markers & 113.0 & 0.55 & 11.38 & $4.71(1)$ & 3.46 \\
Frame markers & 24.9 & 0.16 & 2.87 & $1.03(3-4)$ & 0.72 \\
Endophoric markers & 17.1 & 0.00 & 4.14 & $0.71(5)$ & 0.98 \\
Evidentials & 43.6 & 0.00 & 7.86 & $1.82(2)$ & 1.81 \\
Code glosses & 24.8 & 0.00 & 3.18 & $1.03(3-4)$ & 0.85 \\
Textual metadiscourse & 223.4 & 1.144 & 21.332 & 9.31 & 6.35 \\
\hline Hedges & 121.3 & 1.59 & 16.86 & $5.05(1)$ & 3.81 \\
Boosters & 36.4 & 0.30 & 3.98 & $1.52(2)$ & 1.07 \\
Attitude markers & 14.5 & 0.08 & 1.79 & $0.61(4)$ & 0.50 \\
Engagement markers & 10.7 & 0.00 & 2.69 & $0.44(5)$ & 0.71 \\
Self-mentions & 28.5 & 0.00 & 18.75 & $1.19(3)$ & 3.85 \\
Interpersonal metadiscourse & 211.5 & 2.31 & 25.26 & 8.81 & 6.69 \\
\hline Metadiscourse (overall) & 434.8 & 3.88 & 41.57 & 18.12 & 12.42 \\
\hline
\end{tabular}

The bracketed numbers indicate the ranks of each subcategory.

Because the distribution of frequencies in different metadiscourse types was not normal, 
Spearman's rank-order correlation between metadiscourse frequencies and quality scores was computed to explore this relationship. As presented in Table 8.4, the Spearman's test indicates that thesis quality scores are moderately correlated with frequencies of metadiscourse overall $\left(r_{s}(22)=.499, p<.05\right)$. Out of the four quality aspects, the metadiscourse frequencies are highly correlated with content scores $\left(r_{s}(22)=.695, p<.01\right)$ and organization and presentation scores $\left(r_{s}(22)=.547, p<.01\right)$. No significant correlations between metadiscourse frequencies and language use and genre knowledge scores are found.

Table 8.4. Correlations between quality scores and overall metadiscourse in ELT theses

\begin{tabular}{lcccccc}
\hline \multirow{2}{*}{ Quality aspect } & \multicolumn{2}{c}{ Textual metadiscourse } & \multicolumn{2}{c}{ Interpersonal metadiscourse } & \multicolumn{2}{c}{ All metadiscourse } \\
\cline { 2 - 7 } & \multicolumn{1}{c}{$r_{s}$} & $p$-value & $r_{s}$ & $p$-value & $r_{s}$ & $p$-value \\
\hline Content & $.586^{* *}$ & .003 & $.724^{* *}$ & $<.001$ & $.695^{* *}$ & $<.001$ \\
Organization and presentation & $.474 *$ & .019 & $.546^{* *}$ & .006 & $.547^{* *}$ & .006 \\
Language use & -.039 & .856 & .107 & .618 & .039 & .856 \\
Genre knowledge & .323 & .124 & $.424 *$ & .039 & .395 & .056 \\
\hline Overall quality scores & $.426^{*}$ & .038 & $.525^{* *}$ & .008 & $.499^{*}$ & .013 \\
\hline
\end{tabular}

**. Correlation is significant at the .01 level (2-tailed).

*. Correlation is significant at the .05 level (2-tailed).

In order to ascertain individual contribution of textual and interpersonal metadiscourse to quality scores, correlations between scores and frequencies of textual metadiscourse and interpersonal metadiscourse were examined using the values of Spearman's correlation coefficient. Prior to this analysis, it is worth noticing that there is a significant and strong positive correlation between frequencies of textual metadiscourse and interpersonal metadiscourse in the language teaching theses $\left(r_{s}(22)=.885, p<.01\right)$. In other words, theses with a high frequency of textual markers tend to have a high frequency of interpersonal markers, and theses with a low frequency of textual markers tend to have a low frequency of interpersonal markers.

With the significance of the correlation between frequencies of textual markers and interpersonal markers, the degree of collinearity of the two types of metadiscourse was further explored to ensure worthiness of comparing the individual contribution of textual and interpersonal frequencies to quality scores. Myers (1990 cited in Field, 2013, p. 324) suggests an inspection of Variance Inflation Factor (VIF) and Tolerance values from a multiple regression analysis to observe the degree of collinearity between two variables. The VIF value from the regression output in my study is $2.98(<10)$, and the Tolerance value is $.34(>.1)$. 
This means that, although the correlation value between textual and interpersonal metadiscourse frequencies is considerably high $\left(r_{s}=.885\right)$, the degree of collinearity in the regression analysis is still tenable, causing no concern about analyzing the individual contribution of textual and interpersonal frequencies to quality scores.

The statistical results indicate that frequencies of textual and interpersonal metadiscourse are significantly associated with overall quality scores $\left(r_{s}(22)=.426, p<.05\right.$ for textual markers, $r_{s}(22)=.525, p<.01$ for interpersonal markers). However, as measured by the strength of the correlation $(r s)$, interpersonal metadiscourse, compared to textual metadiscourse, is likely to be more closely related to the quality scores of theses in English language teaching.

Regarding the impact of textual and interpersonal metadiscourse frequencies on each thesis quality aspect, the correlation results in Table 8.4 above reveal that interpersonal metadiscourse frequencies are significantly correlated with scores in three quality aspects: content $\left(r_{s}(22)\right.$ $=.742, p<.01)$, organization and presentation $\left(r_{s}(22)=.546, p<.01\right)$, and genre knowledge $\left(r_{s}(22)=.424, p<.05\right)$. Textual metadiscourse frequencies are significantly correlated with content scores $\left(r_{s}(22)=.586, p<.01\right)$ and organization and presentation scores $\left(r_{s}(22)=.474\right.$, $p<.05)$, but not significantly correlated with genre knowledge scores $\left(r_{s}(22)=.323, p>.05\right)$. As measured by the correlation coefficient values $\left(r_{s}\right)$, interpersonal metadiscourse frequencies are more highly correlated with scores in these three quality aspects, when compared to textual metadiscourse. The results do not show any statistical significance of correlations between textual or interpersonal metadiscourse frequencies and language use scores $\left(r_{s}(22)=-.039, p\right.$ $>.05$ for textual metadiscourse, $r_{s}(22)=.107, p>.05$ for interpersonal metadiscourse). To sum up, interpersonal metadiscourse frequencies are related to content, organization and presentation, and genre knowledge scores, while textual metadiscourse frequencies are related to content and organization and presentation scores.

Since the Spearman's rank-order correlation test can only determine whether there are correlations between metadiscourse frequencies and quality scores, a simple linear regression was further conducted to explore whether metadiscourse frequencies are significant predictors for thesis quality scores. The average change in thesis quality scores resulting from one unit change in metadiscourse frequencies was also estimated from the regression. The regression results indicate that metadiscourse frequencies are statistically predictive of quality scores, $F(1$, $22)=5.150, p<.05, r_{2}=.190$. The $r 2$ value of .190 suggests that metadiscourse frequencies can account for $19 \%$ of the variance in the quality scores, whereas $81 \%$ of the variance cannot 
be explained by metadiscourse frequencies. The regression output in Table 8.5 shows an estimated quality score equal to $12.97+.11$ (point). This regression coefficient ( $b$-value) of .11 means for every one-unit increase in metadiscourse frequencies (one additional token per 10,000 words), quality scores are predicted to increase by .11 point (on average).

Table 8.5. Regression model for overall metadiscourse in ELT theses

\begin{tabular}{clccc}
\hline Model & & B & SE & $\beta$ \\
\hline 1 & $\begin{array}{l}\text { (Constant) } \\
\text { Metadiscourse frequencies } \\
(\text { overall })\end{array}$ & 12.97 & 1.03 & $.436^{*}$ \\
\hline
\end{tabular}

The simple linear regression assumes that the residuals are normally distributed. Figure 8.1 below illustrates that this is the case here.
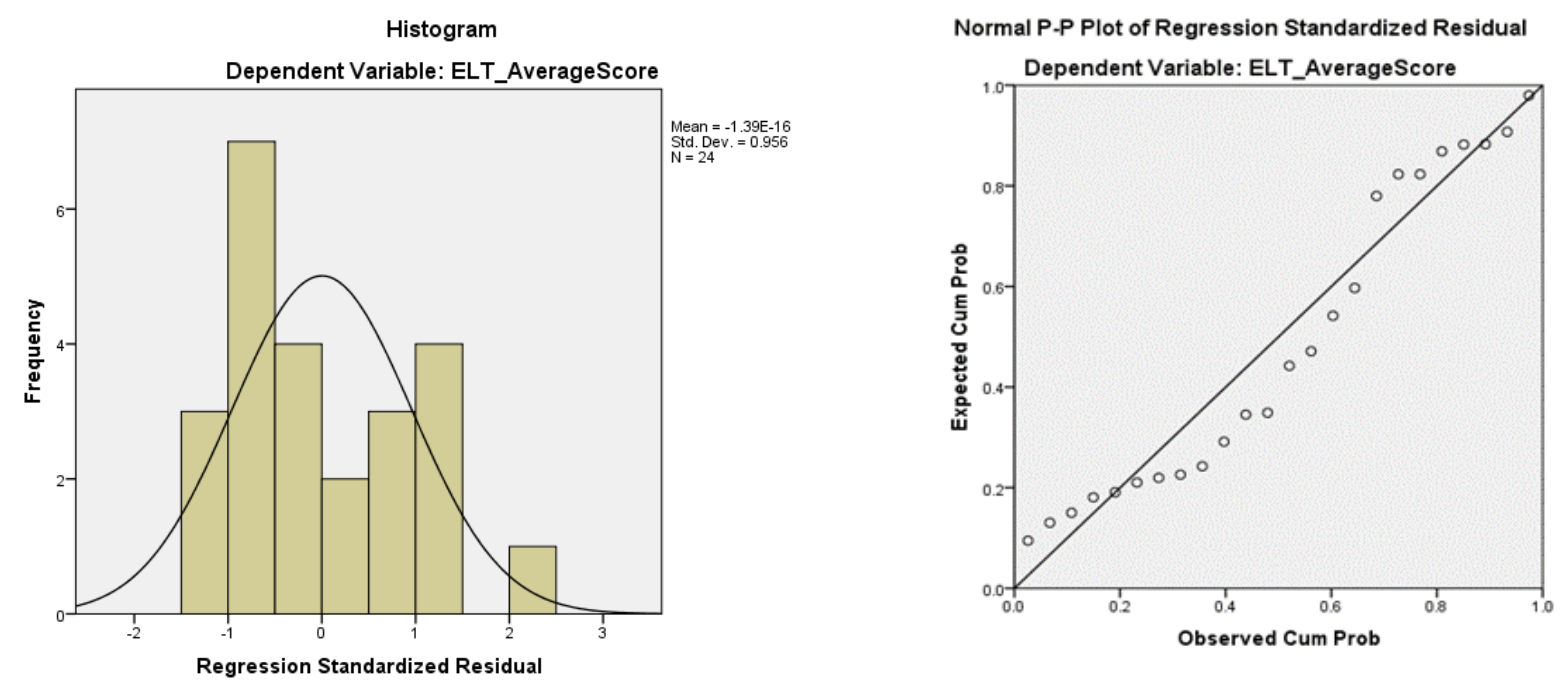

Figure 8.1. Histogram and normal P-P plot of quality score residual (ELT)

Subsequently, a multiple regression analysis was performed to predict quality scores based on the frequencies of textual and interpersonal metadiscourse. Because the correlation results presented earlier suggest a stronger relationship between interpersonal metadiscourse frequencies and thesis quality scores, the overall scores were regressed firstly on interpersonal metadiscourse (ModelıINT), then textual metadiscourse (Model2TEX), and interpersonal metadiscourse and textual metadiscourse (Model3INT+TEX), as demonstrated in Table 8.6. The regression in ModeliINT indicates that interpersonal metadiscourse frequencies are significantly predictive of the overall quality scores, $F(1,22)=6.070, p<.05, r 2=.216$. In Model2TEX, textual metadiscourse frequencies are not found to be significantly predictive of the scores, 
$F(1,22)=3.320, p>.05, r 2=.131$. As indicated by the $r 2$ values of .216 and .131 , the frequencies of interpersonal metadiscourse and textual metadiscourse account for $21.6 \%$ and $13.1 \%$ of the variance in the quality scores, respectively. In Model3INT+TEX, the regression for both interpersonal and textual metadiscourse is non-significant, $F(2,21)=2.911, p>.05$. When the frequencies of textual metadiscourse were included in Model3INT+TEX, the initial $r 2$ value (.216) of interpersonal metadiscourse increases to .217 or $21.7 \%$ of the variance, which means the frequencies of textual metadiscourse account for an additional $0.1 \%$. Therefore, the inclusion of textual metadiscourse frequencies as a predictor makes little difference to the third model and cannot improve the prediction of quality scores compared to using interpersonal metadiscourse alone.

Given that interpersonal metadiscourse frequencies play a more significant role in predicting quality scores, the $b$-value of .211 in Modelinst suggests a positive relationship between interpersonal metadiscourse frequencies and thesis quality scores. It can be observed from the $b$-value that as interpersonal metadiscourse frequencies increase by one unit, quality scores are likely to increase by .211 point (on average). When holding other variables constant (i.e., interpersonal metadiscourse), the $b$-value of .173 in Model2TEX also suggests a positive relationship between textual metadiscourse frequencies and thesis quality scores. It can be observed from the $b$-value that as textual metadiscourse frequencies increase by one unit, quality scores are likely to increase by .173 point (on average). However, it should be noted that textual metadiscourse is not a significant predictor for the quality scores.

Table 8.6. Regression model for textual and interpersonal metadiscourse in ELT theses

\begin{tabular}{clccc}
\hline Model & & B & SE & $\beta$ \\
\hline \multirow{2}{*}{ 1INT } & (Constant) & 13.043 & .942 & $.465^{*}$ \\
& Interpersonal metadiscourse & .211 & .086 & \multirow{2}{*}{.362} \\
\hline \multirow{2}{*}{ TEX } & (Constant) & 13.292 & 1.066 & .095 \\
& Textual metadiscourse & .173 & 1.043 & .506 \\
\hline \multirow{2}{*}{ INT+TEX } & (Constant) & 13.103 & .151 & -.050 \\
& Interpersonal metadiscourse & .230 & .160 & .020 \\
& Textual metadiscourse & -.024 &
\end{tabular}




\subsubsection{Correlations between quality scores and subcategories of textual and interpersonal metadiscourse in English language teaching theses}

This section provides a closer examination of correlations between quality scores and different subcategories of metadiscourse within textual and interpersonal metadiscourse categories. Spearman's correlation coefficient was computed to determine correlations of quality scores with five subcategories of textual metadiscourse (transition markers, frame markers, endophoric markers, evidentials, and code glosses) and five subcategories of interpersonal metadiscourse (hedges, boosters, attitude markers, engagement markers, and self-mentions).

Table 8.7 displays correlations between quality scores and the subcategories of textual and interpersonal metadiscourse. In the textual metadiscourse category, evidentials $\left(r_{s}(22)=.664\right.$, $p<.01)$ and code glosses $\left(r_{s}(22)=.503, p<.05\right)$ are significantly correlated with overall quality scores. Out of the four individual quality aspects, evidentials and code glosses are highly correlated with three aspects: content scores $\left(r_{s}(22)=.819, p<.01\right.$ for evidentials, $r_{s}(22)=.628$, $p<.01$ for code glosses), organization and presentation $\left(r_{s}(22)=.692, p<.01\right.$ for evidentials, $r_{s}(22)=.511, p<.05$ for code glosses $)$, and genre knowledge $\left(r_{s}(22)=.603, p<.01\right.$ for evidentials, $r_{s}(22)=.444, p<.05$ for code glosses). And, evidentials seem to be more highly related with the scores in these three aspects than code glosses, as indicated by the $r_{s}$ values. Transition markers $\left(r_{s}(22)=.509, p<.05\right)$ are significantly correlated with content scores only. Frame markers and endophoric markers are not correlated with scores in any quality aspect.

In the interpersonal metadiscourse category, all subcategories of interpersonal metadiscourse, except for boosters, are correlated with overall quality scores. Overall, attitude markers seem to have the greatest correlation with the overall scores, as measured by the strength of $r s$. Focusing on each quality aspect, all subcategories of interpersonal metadiscourse are significantly correlated with content scores, but none of them are correlated with language use scores. Attitude markers and engagement markers are more highly related with the content scores than hedges, self-mentions, and boosters, respectively. In terms of organization and presentation, attitude markers are also more closely related to the scores in this aspect, when compared to engagement markers, hedges, and self-mentions. And only attitude markers are significantly correlated with genre knowledge scores.

Referring back to the results of the correlations between textual and interpersonal metadiscourse and quality scores (Section 8.1.2), the frequencies of textual and interpersonal 
metadiscourse are significantly correlated with the quality scores. Out of the five subcategories for textual metadiscourse, only evidentials and code glosses are correlated with the overall quality scores. It is reasonable to assume that the significant correlation between textual metadiscourse and the quality scores results from the use of evidentials and code glosses. Interestingly, the average frequency in the use of transitions markers is highest $(\mathrm{Nf}=113, \mathrm{M}$ $=4.71$ ) (see Table 8.3), but it is not significantly correlated with the quality scores. In contrast, evidentials $(\mathrm{Nf}=43.6, \mathrm{M}=1.82)$ and code glosses $(\mathrm{Nf}=24.8, \mathrm{M}=1.03)$ are used less frequently, but they are significantly correlated with the quality scores in this discipline.

In the interpersonal metadiscourse category, only the use of boosters is not related to the overall quality scores. The four other subcategories (hedges, attitude markers, engagement markers, and self-mentions) are related to the quality scores and contribute to the strong correlation between interpersonal metadiscourse and the quality scores. Despite low frequency in the use of attitude markers $(\mathrm{Nf}=14.5, \mathrm{M}=0.61)$, this type of marker shows the highest correlation with the quality scores $\left(r_{s}(22)=.693, p<.01\right)$, whereas boosters with a higher frequency (Nf $=36.4, \mathrm{M}=1.52$ ) are not significantly correlated with the quality scores in this discipline $\left(r_{s}(22)=.343, p>.05\right)$. When looking at the most frequent interpersonal subcategory, hedges $(\mathrm{Nf}=121.3, \mathrm{M}=5.05)$ are significantly correlated with the quality scores $\left(r_{s}(22)=.442, p\right.$ $<.05)$, but the significant correlation is weaker than that of attitude markers. 
Table 8.7. Correlations between quality scores and subcategories of textual and interpersonal metadiscourse in ELT theses

\begin{tabular}{|c|c|c|c|c|c|c|c|c|c|c|}
\hline \multirow{3}{*}{ Quality aspect } & \multicolumn{5}{|c|}{ Textual metadiscourse } & \multicolumn{5}{|c|}{ Interpersonal metadiscourse } \\
\hline & $\begin{array}{c}\text { Transition } \\
\text { markers }\end{array}$ & $\begin{array}{c}\text { Frame } \\
\text { markers }\end{array}$ & $\begin{array}{c}\text { Endophoric } \\
\text { markers }\end{array}$ & Evidentials & $\begin{array}{l}\text { Code } \\
\text { glosses }\end{array}$ & Hedges & Boosters & $\begin{array}{l}\text { Attitude } \\
\text { markers } \\
\end{array}$ & $\begin{array}{c}\text { Engagement } \\
\text { markers }\end{array}$ & Self-mentions \\
\hline & $r_{s}$ & $r_{s}$ & $r_{s}$ & $r_{s}$ & $r_{s}$ & $r_{s}$ & $r_{s}$ & $r_{s}$ & $r_{s}$ & $r_{s}$ \\
\hline Content & $.509^{*}$ & .306 & .358 & $.819^{* *}$ & $.628^{* *}$ & $.596^{*}$ & $.464^{*}$ & $.822^{* *}$ & $.638^{* *}$ & $.554^{* *}$ \\
\hline$p$-value & .011 & .146 & .085 & $<.001$ & .001 & .002 & .222 & $<.001$ & .001 & .005 \\
\hline Organization and presentation & .384 & .274 & .355 & $.692^{* *}$ & $.511^{\circ}$ & $.476^{\circ}$ & .389 & $.676^{* *}$ & $.479^{*}$ & $.413^{*}$ \\
\hline$p$-value & .064 & .195 & .089 & $<.001$ & .011 & .019 & .060 & $<.001$ & .018 & .045 \\
\hline Language use & -.128 & -.204 & -.172 & .188 & .055 & .087 & -.114 & .282 & .139 & .215 \\
\hline$p$-value & .552 & .340 & .421 & .380 & .800 & .686 & .595 & .183 & .518 & .313 \\
\hline Genre knowledge & .202 & .100 & .233 & $.603^{* *}$ & $.444^{\circ}$ & .359 & .236 & $629^{* *}$ & .327 & .384 \\
\hline$p$-value & .344 & .641 & .273 & .002 & .030 & .085 & .266 & .001 & .119 & .064 \\
\hline Overall quality scores & .329 & .161 & .269 & $.664^{* *}$ & $.503^{\circ}$ & $.442^{\circ}$ & .343 & $.693^{* *}$ & $.456^{\circ}$ & $.415^{*}$ \\
\hline$p$-value & .117 & .453 & .203 & $<.001$ & .012 & .031 & .101 & $<.001$ & .025 & .044 \\
\hline
\end{tabular}

**. Correlation is significant at the .01 level (2-tailed).

*. Correlation is significant at the .05 level (2-tailed). 
Because evidentials and code glosses are significantly correlated with overall quality scores, a simple linear regression was performed to predict the average change in the overall scores resulting from one unit change in the frequencies of evidentials and code glosses. The regression in ModeliEvi shows that the frequency of evidentials is significantly predictive of the overall quality scores, $F(1,22)=13.304, p<.01$. The $r 2$ value of .377 in this model indicates that evidentials account for $37.7 \%$ of the variance in the quality scores. The regression output in Table 8.8 shows an estimated quality score equal to $13.031+1.033$ (point). The $b$-value of 1.033 means for every one-unit increase in evidential frequency, the quality score is estimated to increase by 1.033 point (on average). In Model2COD, the frequency of code glosses is also found to be significantly predictive of the quality scores, $F(1,22)=4.523, p<.05$. As determined by the $r 2$ value of .171, code glosses account for $17.1 \%$ of the variance in the scores. The regression output shows an estimated quality score equal to $13.371+1.483$ (point). The $b$-value of 1.483 suggests for every one-unit increase in code gloss frequency, the quality score is expected to increase by 1.483 point (on average).

Table 8.8. Regression model for evidentials and code glosses in ELT theses

\begin{tabular}{clccc}
\hline Model & & B & SE & $\beta$ \\
\hline \multirow{2}{*}{ 1EVI } & (Constant) & 13.031 & .718 & $.614^{* *}$ \\
& Evidentials & 1.033 & .283 & .925 \\
\hline \multirow{2}{*}{2 COD } & (Constant) & 13.371 & .697 & $.413^{*}$ \\
& Code glosses & 1.483 & \\
\hline
\end{tabular}

Within the interpersonal category, hedges, attitude markers, engagement markers, and selfmentions are significantly correlated with overall quality scores. So a simple linear regression was performed to predict the average change of scores based on a one-unit change in the frequencies of these four subcategories, as presented in Table 8.9.

The regression in Model ${ }_{1 \mathrm{HED}}$ and Model2ATt indicates that the frequencies of hedges and attitude markers are significant predictors for the quality scores: $F(1,22)=4.468, p<.05$ and $F(1,22)=17.926, p<.001$. The $r 2$ values of .169 and .449 indicate that hedges and attitude markers account for $16.9 \%$ and $44.9 \%$ of the variance in the quality scores, respectively. ModeliHED shows an estimated quality score equal to $13.248+0.328$ (point). As determined by the $b$-value of 0.328 , for every one-unit increase in hedging marker frequency, the quality score is expected to increase by 0.328 point (on average). Model2ATt shows an estimated quality score equal to $12.440+4.076$ (point). The $b$-value of 4.076 suggests that for every one- 
unit increase in attitude marker frequency, the quality score is likely to increase by 4.076 points (on average).

The regression in Model3ENG and Model4SEM reveals that the frequencies of engagement markers and self-mentions are non-significantly predictive of quality scores: $F(1,22)=2.566$, $p>.05$ and $F(1,22)=1.205, p>.05$. As indicated by the $r 2$ values of .104 and .052 , engagement markers and self-mentions only account for $10.4 \%$ and $5.2 \%$ of the variance in the quality scores, respectively. The regression output shows an estimated quality score equal to $14.290+$ 1.388 (point). It can be observed from the $b$-value that for every one-unit increase in engagement marker frequency, the quality score approximately increases by 1.388 points (on average). Similarly, it shows an estimated quality score equal to $14.692+0.180$ (point). For every one-unit increase in self-mention frequency, the quality score approximately increases by 0.180 point (on average). However, it must be noted that the regression in these two models is not statistically predictive of the overall scores.

Table 8.9. Regression model for hedges, attitude markers, engagement markers, and selfmentions in ELT theses

\begin{tabular}{clccc}
\hline Model & & B & SE & $\beta$ \\
\hline \multirow{2}{*}{ 1HED } & (Constant) & 13.248 & .975 & $.411^{*}$ \\
& Hedges & .328 & .155 & $.670^{* *}$ \\
\hline \multirow{2}{*}{ ATT } & (Constant) & 12.440 & .749 & .323 \\
& Attitude markers & 4.076 & .963 & .714 \\
\hline \multirow{2}{*}{ EENG } & (Constant) & 14.290 & .866 & .228 \\
& Engagement markers & 1.388 & .648 & .164 \\
\hline \multirow{2}{*}{ 4SEM } & (Constant) & 14.692 & .180 & .164 \\
& Self-mentions & &
\end{tabular}

\subsection{Quality scores and metadiscourse frequencies in business administration theses}

This section includes analyses of (1) agreement between two raters in business administration, (2) correlations between frequencies in use of metadiscourse and scores awarded by raters for quality, (3) correlations between frequencies in use of textual and interpersonal metadiscourse and quality scores, and (4) correlations between frequencies in use of five textual metadiscourse subcategories and five interpersonal metadiscourse subcategories and quality scores. 


\subsubsection{Interrater agreement in assessing business administration theses}

A pair of raters in business administration assessed the quality of twenty four discussion and conclusion chapters in their discipline. To test whether the scores awarded by the two raters met the assumptions of normal distribution and homogeneity of variance, a Shapiro-Wilk's test, Levene's test and visual inspection were employed. They indicated that the quality scores were normally distributed and equal in terms of variances (both $p>.05$ ). Pearson's correlation coefficient was therefore used to measure the interrater agreement between the two raters. In Table 8.10, the average score assigned by the first rater is 11.21 out of 20 ( $\mathrm{SD}=4.67)$, and the average score assigned by the second rater is $15.58(\mathrm{SD}=2.82)$. Although there is a significant positive correlation between individual scores assigned by the two raters $(r(22)=.452, p<.05)$, the level of interrater agreement around .4 is considered low as it is less than the acceptable level of agreement at .7 (Salkind, 2010, p. 627).

With regard to the agreement in assessing the four quality aspects, the statistical results reveal significant positive correlations between individual scores assigned by the two raters in three quality aspects: content $(r(22)=.442, p<.05)$, organization and presentation $(r(22)=.432, p$ $<.05)$, and language use $(r(22)=.471, p<.05)$. Although the agreement between the two raters in assessing genre knowledge is not statistically significant $(r(22)=.392, p>.05)$, it is worth noticing that the $r$-value indicates a moderate correlation and the exact $p$-value of .058 is very close to the significance level of .05.

Table 8.10. Interrater agreement in BA

\begin{tabular}{|c|c|c|c|c|c|c|c|c|c|c|}
\hline \multirow{2}{*}{ Rating criterion } & \multicolumn{4}{|c|}{ Rater 1} & \multicolumn{4}{|c|}{ Rater 2} & \multirow{2}{*}{$r$} & \multirow{2}{*}{$p$-value } \\
\hline & Min. & Max. & Mean & SD & Min. & Max. & Mean & SD & & \\
\hline Content & 1.00 & 5.00 & 2.50 & 1.44 & 2.50 & 5.00 & 3.94 & 0.68 & $.442^{*}$ & .031 \\
\hline Organization and presentation & 1.00 & 5.00 & 2.81 & 1.31 & 2.50 & 5.00 & 3.92 & 0.82 & $.432 *$ & .035 \\
\hline Language use & 2.00 & 5.00 & 3.15 & 1.04 & 1.50 & 5.00 & 3.77 & 0.87 & $.471^{*}$ & .020 \\
\hline Genre knowledge & 1.00 & 5.00 & 2.75 & 1.19 & 2.00 & 5.00 & 3.96 & 0.79 & .392 & .058 \\
\hline Overall quality scores & 5.00 & 20.00 & 11.21 & 4.67 & 9.00 & 20.00 & 15.58 & 2.82 & $.452^{*}$ & .027 \\
\hline
\end{tabular}

*. Correlation is significant at the .05 level (2-tailed). 


\subsubsection{Correlations between quality scores and overall metadiscourse in business administration theses}

The descriptive statistics of quality scores and metadiscourse frequencies (normalized to 10,000 words) in business administration theses are presented in Table 8.11 and Table 8.12. The minimum, maximum, and mean of the normalized frequencies of the twenty four theses are provided, allowing an investigation of the distributional pattern of metadiscourse subcategories and the overall characteristic of the business theses. The mean score of the theses in this discipline is 13.40 out of 20 . The normalized frequency of metadiscourse in the business theses is $412.3(\mathrm{M}=17.18)$. The normalized frequencies of textual and interpersonal metadiscourse are $233.7(\mathrm{M}=9.74)$ and $178.6(\mathrm{M}=7.44)$, respectively.

Table 8.11. Descriptive statistics of quality scores in BA theses

\begin{tabular}{lcccc}
\hline Quality aspect & Min. & Max. & Mean & SD \\
\hline Content & 1.75 & 5.00 & 3.22 & 0.92 \\
Organization and presentation & 2.00 & 5.00 & 3.36 & 0.91 \\
Language use & 1.75 & 5.00 & 3.46 & 0.82 \\
Genre knowledge & 2.00 & 4.75 & 3.35 & 0.83 \\
\hline Overall quality scores & 8.00 & 18.50 & 13.40 & 3.23 \\
\hline
\end{tabular}

Table 8.12. Descriptive statistics of metadiscourse frequencies in BA theses

\begin{tabular}{lccccc}
\hline Category & Nf & Min. & Max. & Mean & SD \\
\hline Transition markers & 125.4 & 0.00 & 17.41 & $5.23(1)$ & 4.74 \\
Frame markers & 24.9 & 0.00 & 3.40 & $1.04(4)$ & 0.91 \\
Endophoric markers & 12.3 & 0.00 & 3.05 & $0.51(5)$ & 0.81 \\
Evidentials & 40.0 & 0.00 & 7.77 & $1.67(2)$ & 2.24 \\
Code glosses & 31.0 & 0.07 & 4.65 & $1.29(3)$ & 1.44 \\
Textual metadiscourse & 233.7 & 0.35 & 34.82 & 9.74 & 9.21 \\
\hline Hedges & 123.2 & 0.69 & 20.32 & $5.13(1)$ & 4.63 \\
Boosters & 26.9 & 0.07 & 2.72 & $1.12(2)$ & 0.86 \\
Attitude markers & 15.9 & 0.00 & 3.88 & $0.66(3)$ & 0.86 \\
Engagement markers & 6.1 & 0.00 & 1.39 & $0.26(5)$ & 0.35 \\
Self-mentions & 6.5 & 0.00 & 1.32 & $0.27(4)$ & 0.35 \\
Interpersonal metadiscourse & 178.6 & 0.83 & 27.60 & 7.44 & 6.26 \\
\hline Metadiscourse (overall) & 412.3 & 1.18 & 62.42 & 17.18 & 15.13 \\
\hline
\end{tabular}

The bracketed numbers indicate the ranks of each subcategory. 
Similar to the English language teaching discipline, the twenty four theses in business administration include more textual metadiscourse (56.7\% of all metadiscourse occurrences) than interpersonal metadiscourse (43.3\% of all metadiscourse occurrences). As shown in Table 8.12 , the frequency of transition markers is highest in the textual category, followed by evidentials, code glosses, frame markers, and endophoric markers, respectively. In the interpersonal category, the frequency of hedges is highest, followed by boosters, attitude markers, self-mentions, and engagement markers, respectively. When looking at the average frequencies across categories, transition markers and hedges are most frequently used. The frequencies of these two subcategories are extremely high, while the frequencies of the eight other subcategories are much lower. Engagement markers are the subcategory with the least frequent use. Theses in English language teaching also exhibit this trend.

Because the frequencies in different metadiscourse types were not normally distributed, Spearman's rank-order correlation was used to examine the relationship between metadiscourse frequencies and quality scores. The results reveal a highly positive correlation between metadiscourse frequencies and overall quality scores $\left(r_{s}(22)=.559, p<.01\right)$. And the metadiscourse frequencies are significantly correlated with all four quality aspects: content $\left(r_{s}(22)=.541, p<.01\right)$, organization and presentation $\left(r_{s}(22)=.500, p<.05\right)$, language use $\left(r_{s}(22)=.436, p<.05\right)$, and genre knowledge $\left(r_{s}(22)=.520, p<.01\right)$.

Table 8.13. Correlations between quality scores and overall metadiscourse in BA theses

\begin{tabular}{lcccccc}
\hline \multirow{2}{*}{ Quality aspect } & \multicolumn{2}{c}{ Textual metadiscourse } & \multicolumn{2}{c}{ Interpersonal metadiscourse } & \multicolumn{2}{c}{ All metadiscourse } \\
\cline { 2 - 7 } & $r_{s}$ & $p$-value & $r_{s}$ & $p$-value & $r_{s}$ & $p$-value \\
\hline Content & $.545^{* *}$ & .006 & $.458^{*}$ & .024 & $.541 * *$ & .006 \\
Organization and presentation & $.498^{*}$ & .013 & $.469 *$ & .021 & $.500^{*}$ & .013 \\
Language use & $.453^{*}$ & .026 & .369 & .076 & $.436^{*}$ & .033 \\
Genre knowledge & $.552^{* *}$ & .005 & $.470^{*}$ & .020 & $.520^{* *}$ & .009 \\
\hline Overall quality scores & $.572 * *$ & .003 & $.507 *$ & .011 & $.559 * *$ & .004 \\
\hline
\end{tabular}

**. Correlation is significant at the .01 level (2-tailed).

*. Correlation is significant at the .05 level (2-tailed).

Individual contribution of textual and interpersonal metadiscourse to quality scores was further explored using Spearman's correlation coefficient. Similar to English language teaching theses, the statistical results reveal a very strong positive correlation between frequencies of textual and interpersonal metadiscourse in business administration theses $\left(r_{s}(22)=.873, p<.01\right)$. 
With the significance of the correlation between frequencies of textual markers and interpersonal markers in this discipline, the degree of collinearity of the two types of metadiscourse was further examined to ensure the worthiness of analyzing the impact of textual and interpersonal frequencies. The VIF value from the multiple regression output is 5.674 (< 10), and the Tolerance value is .176 (>.1). This means that although the correlation value between textual and interpersonal frequencies is considerably high $\left(r_{s}=.873\right)$, the degree of collinearity in the regression analysis is still acceptable, causing no concern about analyzing the individual contribution of textual and interpersonal frequencies to quality scores.

The statistical results shown in Table 8.13 suggest that frequencies of textual and interpersonal metadiscourse are strongly associated with quality scores $\left(r_{s}(22)=.572, p<.01\right.$ for textual metadiscourse, $r_{s}(22)=.507, p<.05$ for interpersonal metadiscourse). The strength of the correlation $\left(r_{s}\right)$ indicates that in business administration theses, textual metadiscourse frequencies seem to be more highly related to the overall quality scores, when compared to interpersonal metadiscourse.

With regard to the impact of textual and interpersonal metadiscourse frequencies on each quality aspect, the Spearman's test reveals significant correlations between textual metadiscourse frequencies and scores in all quality aspects. Interpersonal metadiscourse frequencies are significantly correlated with scores in three aspects (i.e., content, organization and presentation, and genre knowledge) but non-significantly correlated with language use. As determined by the coefficient values, the frequencies of textual metadiscourse are more highly correlated with scores in all the quality aspects when compared to interpersonal metadiscourse: content $\left(r_{s}(22)=.545, p<.01\right.$ for textual metadiscourse, $r_{s}(22)=.458, p<.05$ for interpersonal metadiscourse), organization and presentation $\left(r_{s}(22)=.498, p<.05\right.$ for textual metadiscourse, $r_{s}(22)=.469, p<.05$ for interpersonal metadiscourse $)$, language use $\left(r_{s}(22)=.453, p<.05\right.$ for textual metadiscourse, $r_{s}(22)=.369, p>.05$ for interpersonal metadiscourse), and genre knowledge $\left(r_{s}(22)=.552, p<.01\right.$ for textual metadiscourse, $r_{s}(22)=.470, p<.05$ for interpersonal metadiscourse).

A simple linear regression was carried out to examine whether metadiscourse frequencies are significantly predictive of thesis quality scores in the business discipline. The regression results suggest that metadiscourse frequencies are significantly predictive of the quality scores, $F(1$, $22)=16.553, p<.001, r 2=.429$. As indicated by the $r 2$ value of .429 , metadiscourse frequencies can account for $42.9 \%$ of the variance in the quality scores and $57.1 \%$ of the variance cannot 
be explained by metadiscourse frequencies. From the regression output, an estimated score is equal to $10.993+.140$ (point). So it can be observed by the $b$-value that as metadiscourse frequencies increase by one unit, quality scores are likely to increase by .140 point (on average).

Table 8.14. Regression model for overall metadiscourse in BA theses

\begin{tabular}{clccc}
\hline Model & & B & SE & $\beta$ \\
\hline 1 & $\begin{array}{l}\text { (Constant) } \\
\text { Metadiscourse frequencies } \\
\text { (overall) }\end{array}$ & 10.993 & .780 & $.655^{* *}$ \\
& & .140 & .034 & \\
\hline
\end{tabular}

The simple linear regression assumes that the residuals are normally distributed. Figure 8.2 below illustrates that this is the case here.
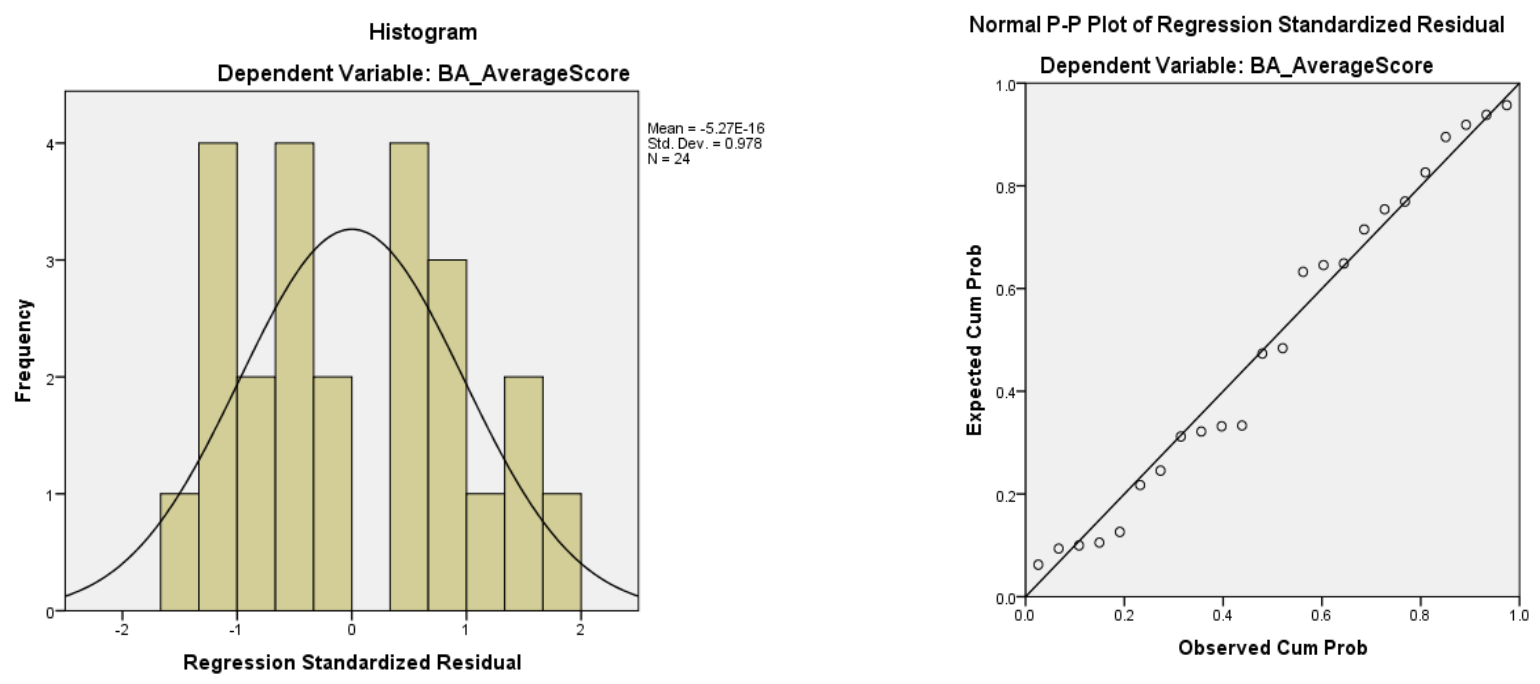

Figure 8.2. Histogram and normal P-P plot of quality score residual (BA)

A multiple regression analysis was performed to predict the average change of quality scores based on a one-unit increase in the frequencies of textual and interpersonal metadiscourse. As the correlation results indicate a stronger correlation between textual metadiscourse and overall scores compared to interpersonal metadiscourse, the thesis quality scores were firstly regressed on textual metadiscourse (Model1TEX), then interpersonal metadiscourse (Model2INT), and textual metadiscourse and interpersonal metadiscourse (Model3TEX+INT), as presented in Table 8.15. The regression in the three models is significant: $F(1,22)=17.163, p<.01 ; F(1,22)=$ $12.961, p<.01$; and $F(1,22)=8.204, p<.01$. This means that the frequencies of textual and interpersonal metadiscourse are significant predictors for the thesis quality scores in this discipline. As indicated by the $r 2$ values of .438 and .371 , the frequencies of textual 
metadiscourse and interpersonal metadiscourse account for $43.8 \%$ and $37.1 \%$ of the variance in the quality scores, respectively. When the frequencies of textual metadiscourse were included in Model 3 TEX+INT, the initial $r 2$ value (.438) of textual metadiscourse increases to .439 or $43.9 \%$ of the variance, which means the frequencies of interpersonal metadiscourse account for an additional $0.1 \%$. Generally, the regression results indicate that frequencies of textual and interpersonal metadiscourse are significantly predictive of the quality scores in this discipline.

The $b$-values of .232 and .314 indicate positive relationships between thesis quality scores and textual metadiscourse as well as interpersonal metadiscourse, respectively. It can be observed by the $b$-values that as textual metadiscourse frequencies increase by one unit, quality scores are likely to increase by .232 point (on average). Similarly, as interpersonal metadiscourse frequencies increase by one unit, quality scores are predicted to increase by .314 point (on average).

Table 8.15. Regression model for textual and interpersonal metadiscourse in BA theses

\begin{tabular}{clccc}
\hline Model & & B & SE & $\beta$ \\
\hline \multirow{2}{*}{1 TEX } & (Constant) & 11.136 & .743 & $.662^{* *}$ \\
& Textual metadiscourse & .232 & .056 & $.609 * *$ \\
\hline \multirow{2}{*}{$2 \mathrm{INT}$} & (Constant) & 11.060 & .841 & .087 \\
& Interpersonal metadiscourse & .314 & .813 & .621 \\
\hline \multirow{2}{*}{3 TEX+INT } & (Constant) & 11.103 & .137 & .046 \\
& Textual metadiscourse & .218 & .201 & .023 \\
& Interpersonal metadiscourse & .023 & & .6 \\
\hline
\end{tabular}

\subsubsection{Correlations between quality scores and subcategories of textual and interpersonal metadiscourse in business administration theses}

To provide a closer examination within textual and interpersonal metadiscourse categories, Spearman's correlation coefficient was used to determine correlations between quality scores and the frequencies of five textual metadiscourse subcategories (transition markers, frame markers, endophoric markers, evidentials, and code glosses) and five interpersonal metadiscourse subcategories (hedges, boosters, attitude markers, engagement markers, and self-mentions).

Table 8.16 below shows significant correlations between frequencies of the five textual metadiscourse subcategories and overall quality scores at moderate and strong levels. Within the textual category, transition markers have the strongest correlation with overall quality 
scores at a high level of significance, followed by endophoric markers and frame markers. The correlations of evidentials and code glosses are significant at a moderate level.

When looking specifically at each quality aspect, transition markers, endophoric markers, and evidentials are significantly correlated with the four quality aspects. Frame markers are significantly correlated with content, organization and presentation, and genre knowledge scores, but not significantly correlated with language use scores. Code glosses are significantly correlated with language use scores only.

In the interpersonal metadiscourse category, attitude markers, engagement markers, and selfmentions are not significantly correlated with overall quality scores or scores in each of the four aspects. Hedges and boosters are correlated with overall scores at a high level of significance. Between these two subcategories, hedges are more highly related to content and language use scores, while boosters are more highly related to organization and presentation and genre knowledge scores, as demonstrated by the correlation values.

Referring back to the results of correlations between textual and interpersonal metadiscourse and overall quality scores (Section 8.2.2), in business administration theses, textual metadiscourse frequencies are more highly correlated with the overall quality scores, when compared to interpersonal metadiscourse frequencies. In this discipline, the five subcategories of textual metadiscourse are significantly related to the quality scores, whereas only two subcategories of interpersonal metadiscourse (i.e., hedges and boosters) are related. For textual metadiscourse, both high and low frequency subcategories are correlated with the scores. For interpersonal metadiscourse, only the two highest frequency subcategories $(\mathrm{Nf}=123.2, \mathrm{M}=$ 5.13 for hedges, $\mathrm{Nf}=26.9, \mathrm{M}=1.12$ for boosters) are correlated with the scores (see Table $8.12)$. 
Table 8.16. Correlations between quality scores and subcategories of textual and interpersonal metadiscourse in BA theses

\begin{tabular}{|c|c|c|c|c|c|c|c|c|c|c|}
\hline \multirow{3}{*}{ Quality aspect } & \multicolumn{5}{|c|}{ Textual metadiscourse } & \multicolumn{5}{|c|}{ Interpersonal metadiscourse } \\
\hline & $\begin{array}{c}\text { Transition } \\
\text { markers }\end{array}$ & $\begin{array}{c}\text { Frame } \\
\text { markers }\end{array}$ & $\begin{array}{c}\text { Endophoric } \\
\text { markers }\end{array}$ & Evidentials & $\begin{array}{c}\text { Code } \\
\text { glosses }\end{array}$ & Hedges & Boosters & $\begin{array}{l}\text { Attitude } \\
\text { markers }\end{array}$ & $\begin{array}{c}\text { Engagement } \\
\text { markers }\end{array}$ & $\begin{array}{c}\text { Self- } \\
\text { mentions }\end{array}$ \\
\hline & $r_{s}$ & $r_{s}$ & $r_{s}$ & $r_{s}$ & $r_{s}$ & $r_{s}$ & $r_{s}$ & $r_{s}$ & $r_{s}$ & $r_{s}$ \\
\hline Content & $.557^{* *}$ & $.534^{* *}$ & $.450^{\circ}$ & $.441^{*}$ & .346 & $.486^{\circ}$ & $.466^{\circ}$ & .260 & .224 & .155 \\
\hline$p$-value & .005 & .007 & .027 & .031 & .098 & .016 & .022 & .220 & .293 & .470 \\
\hline Organization and presentation & $.510^{*}$ & $.433^{\circ}$ & $.497^{*}$ & $.501^{*}$ & .361 & $.465^{\circ}$ & $.527^{* *}$ & .246 & .207 & .256 \\
\hline$p$-value & .011 & .035 & .013 & .013 & .083 & .022 & .008 & .246 & .332 & .228 \\
\hline Language use & $.478^{*}$ & .343 & $.562^{* *}$ & $.499^{*}$ & $.439^{*}$ & $.435^{\circ}$ & .318 & .333 & .184 & .063 \\
\hline$\underline{p \text {-value }}$ & .018 & .101 & .004 & .013 & .032 & .033 & .131 & .112 & .391 & .771 \\
\hline Genre knowledge & $.550^{* *}$ & $.542^{* *}$ & $.503^{\circ}$ & $.501^{*}$ & .384 & $.466^{\circ}$ & $.498^{*}$ & .315 & .306 & .230 \\
\hline$p$-value & .005 & .006 & .012 & .013 & .064 & .022 & .013 & .134 & .146 & .279 \\
\hline Overall quality scores & $.579^{* *}$ & $.522^{* *}$ & $.565^{* *}$ & $.504^{*}$ & $.419^{*}$ & $.524^{* *}$ & $.515^{* *}$ & .328 & .280 & .213 \\
\hline$p$-value & .003 & .009 & .004 & .012 & .042 & .009 & .010 & .117 & .185 & .317 \\
\hline
\end{tabular}

**. Correlation is significant at the .01 level (2-tailed).

*. Correlation is significant at the .05 level (2-tailed). 
As frequencies of the five subcategories within the textual metadiscourse category are correlated with overall quality scores, a simple linear regression was further conducted to determine whether all the frequencies are statistically significant predictors for the quality scores. As presented in Table 8.17, the overall quality scores were regressed on the frequencies of transition markers (Model1TRA), frame markers (Model2FRA), endophoric markers (Model3END), evidentials (Model4EvI), and code glosses (Model5CoD). The regression results suggest that the frequencies of the five types are significantly predictive of the quality scores: transition markers, $F(1,22)=14.850, p<.001, r 2=.403$; frame markers, $F(1,22)=11.657, p$ $<.002, r_{2}=.346$; endophoric markers, $F(1,22)=9.088, p<.006, r 2=.292$; evidentials, $F(1$, $22)=14.283, p<.001, r_{2}=.394$; and code glosses, $F(1,22)=7.227, p<.013, r_{2}=.247$.

The regression in ModelıtRA shows an estimated quality score equal to $11.135+0.433$ (point). This means for every one-unit increase in transition marker frequency, the quality score is estimated to increase by 0.433 point (on average). In Model2FRA, an estimated quality score is equal to $11.220+2.094$ (point), which means for every one-unit increase in frame marker frequency, the quality score is estimated to increase by 2.094 points (on average). In Model3END, an estimated quality score is equal to $12.289+2.163$ (point), which means for every one-unit increase in endophoric marker frequency, the quality score is estimated to increase by 2.163 points (on average). In Model4EVI, an estimated quality score is equal to $11.887+0.905$ (point), which means for every one-unit increase in evidential frequency, the quality score is estimated to increase by 0.905 point (on average). In Model5CoD, an estimated quality score is equal to $11.951+1.118$ (point), which means for every one-unit increase in code gloss frequency, the quality score is estimated to increase by 1.118 points (on average).

Table 8.17. Regression model for the five types of textual metadiscourse in BA theses

\begin{tabular}{|c|c|c|c|c|}
\hline Model & & B & SE & $\beta$ \\
\hline \multirow[t]{2}{*}{ 1TRA } & (Constant) & 11.135 & .784 & \\
\hline & Transition markers & .433 & .112 & $.635 * *$ \\
\hline \multirow[t]{2}{*}{ 2FRA } & (Constant) & 11.220 & .839 & \\
\hline & Frame markers & 2.094 & .613 & $.589^{* *}$ \\
\hline \multirow[t]{2}{*}{ 3END } & (Constant) & 12.289 & .675 & \\
\hline & Endophoric markers & 2.163 & .718 & $.541 * *$ \\
\hline \multirow[t]{2}{*}{$4 \mathrm{EVI}$} & (Constant) & 11.887 & .659 & \\
\hline & Evidentials & .905 & .239 & $.627^{* *}$ \\
\hline \multirow[t]{2}{*}{$5 \mathrm{COD}$} & (Constant) & 11.951 & .794 & \\
\hline & Code glosses & 1.118 & .416 & $.497 * *$ \\
\hline
\end{tabular}


In the interpersonal metadiscourse category, only hedges and boosters show significant correlations with overall quality scores. Therefore, the regression for these two subcategories was used to test whether they are statistically significant predictors for the quality scores and estimate the average change in the scores for every one-unit increase in frequency. As shown in Table 8.18, the regression results suggest that the frequencies of hedges and boosters are significantly predictive of the overall quality scores in the business discipline: $F(1,22)=$ $13.515, p<.001, r_{2}=.381$ and $F(1,22)=9.793, p<.005, r_{2}=.308$. The $r 2$ values indicate that hedges and boosters account for $38.1 \%$ and $30.8 \%$ of the variance in the quality scores, respectively. To estimate the average change of scores, Model1HED shows an estimated quality score equal to $11.189+0.430$ (point). This means for every one-unit increase in hedging marker frequency, the quality score is predicted to increase by 0.430 point (on average). Model2воО shows an estimated quality score equal to $11.052+2.094$ (point). This means for every oneunit increase in booster frequency, the quality score is predicted to increase by 2.094 points (on average).

Table 8.18. Regression model for hedges and boosters in BA theses

\begin{tabular}{clccc}
\hline Model & & B & SE & $\beta$ \\
\hline 1HED & (Constant) & 11.189 & .801 & \\
& Hedges & .430 & .117 & $.617^{* *}$ \\
\hline 2BOO & (Constant) & 11.052 & .936 & \\
& Boosters & 2.094 & .669 & $.555^{* *}$ \\
\hline
\end{tabular}

\subsection{Comparison of quality scores in high and low frequency groups in English language teaching and business administration}

Sections 8.1 and 8.2 discuss whether there are correlations between metadiscourse frequencies and quality scores. The overall finding from the previous sections is that metadiscourse frequencies are correlated with the quality scores in both English language teaching and business administration disciplines. Accordingly, this section compares quality scores of theses with high and low frequencies of metadiscourse markers in the two disciplines.

\subsubsection{Comparison of quality scores in high and low frequency groups in English language teaching}

Twenty four theses in English language teaching comprised twelve theses with a high frequency of metadiscourse (HFG) and twelve theses with a low frequency of metadiscourse 
(LFG). To examine the difference in quality scores between high and low frequency groups, regardless of educational contexts, an independent samples $t$-test was performed. As shown in Table 8.19, the average score in the high frequency group $(\mathrm{M}=15.96, \mathrm{SD}=2.55)$ is higher than the score in the low frequency group $(\mathrm{M}=13.85, \mathrm{SD}=3.23)$. The $t$-test output suggests that the difference in scores between the two groups is not statistically significant, $t(22)=$ $1.771, p=.09$. The difference between means is 2.11 , and the $95 \%$ confidence interval ranges from -0.21 to 4.44 . The bootstrap confidence interval ranging from a negative value to a positive one confirms that the higher frequency of metadiscourse seems not to affect the quality scores in this discipline.

Table 8.19. Quality scores in high and low frequency groups in ELT theses

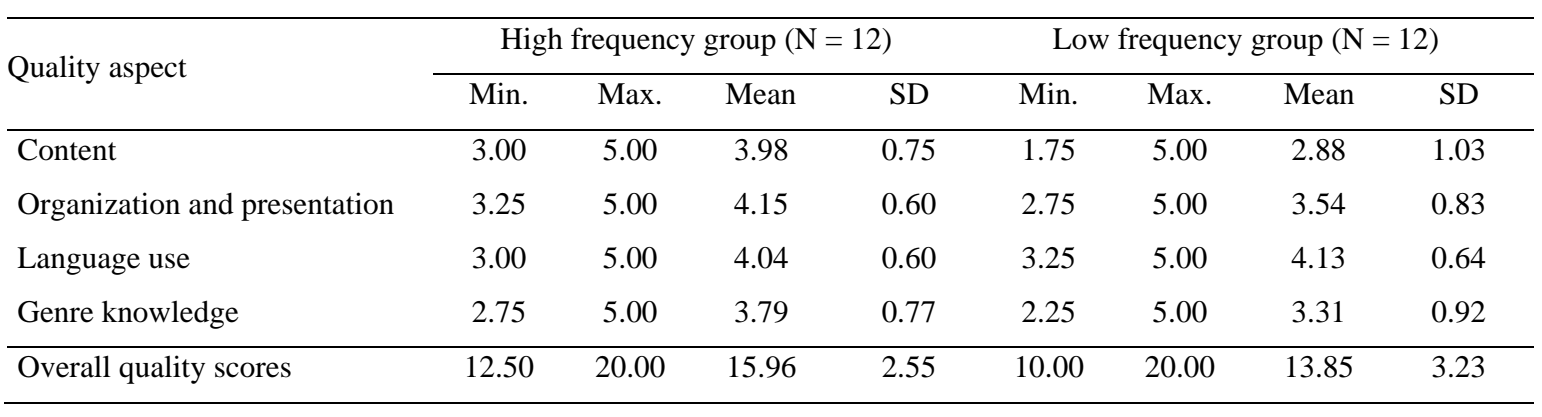

In order to gain more insight into differences and similarities between theses in high and low frequency groups, this section further explores metadiscourse distribution and ranges of types of markers within each subcategory between the two groups. Figure 8.3 offers a visual inspection of metadiscourse distribution patterns in high and low frequency groups. When comparing the frequencies of each subcategory, it is clear that the high frequency group has more metadiscourse occurrences than does the low frequency group in all subcategories. However, gaps in frequencies between the two groups illustrate that not all the subcategories make a great difference between the two groups. As shown in the graph below, only frequencies of transition markers $(\mathrm{Nf}=90.8$ for $\mathrm{HFG}, \mathrm{Nf}=22.2$ for $\mathrm{LFG})$ and hedges $(\mathrm{Nf}=93.6$ for $\mathrm{HFG}$, $\mathrm{Nf}=27.7$ for $\mathrm{LFG}$ ) are extremely different between the two groups, while frequencies in the remaining subcategories are not very different. Frequencies of attitude markers $(\mathrm{Nf}=11.6$ for $\mathrm{HFG}, \mathrm{Nf}=3.0$ for $\mathrm{LFG}$ ) and engagement markers ( $\mathrm{Nf}=9.5$ for $\mathrm{HFG}, \mathrm{Nf}=1.2$ for $\mathrm{LFG}$ ) show the least difference between the two groups.

Moreover, the shape of lines reveals similarities in the ranks of textual subcategories but a slight difference in the ranks of interpersonal subcategories between high and low frequency groups. For the textual metadiscourse subcategories, the two groups contain the highest 
frequency of transition markers and evidentials and the lowest frequency of endophoric markers. Frame markers and code glosses rank third and fourth, and vice versa between the two groups. For the interpersonal metadiscourse subcategories, the two groups show the highest frequency of hedges and lower frequencies of boosters, attitude markers, and engagement markers. A considerable difference between the two groups is the frequency of self-mention markers. The self-mention markers obtain the second highest use after hedges in the high frequency group, but they obtain the lowest use after other subcategories in the low frequency group.

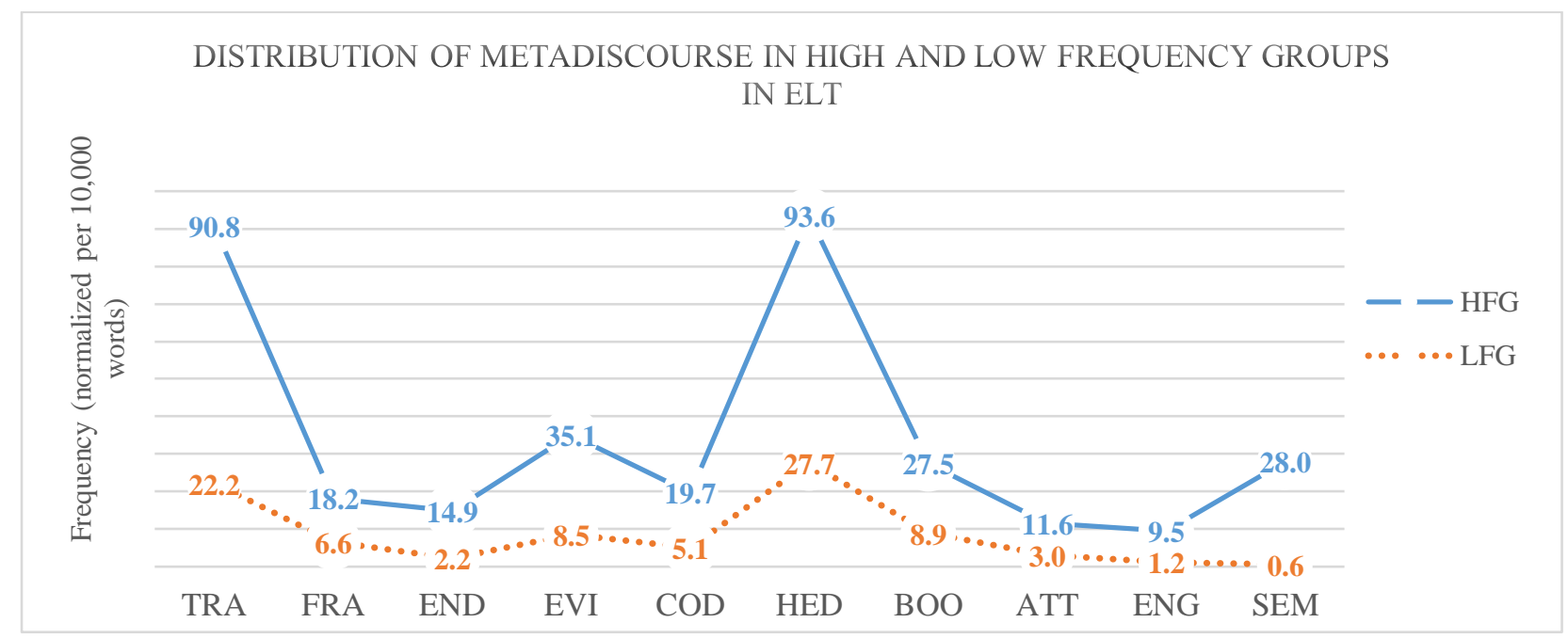

Figure 8.3. Distribution of metadiscourse in high and low frequency groups in ELT

When taking types of markers into consideration, the high frequency group contains more types of markers in every subcategory than does the low frequency group. This means that the theses in the high frequency group do not only have higher occurrences of markers but also have a greater variety in terms of individual items. However, when looking at the types of markers shared between the two frequency groups, it is worth noting that most of the types identified in the low frequency group are also found in the high frequency group.

Similarities and differences between the two groups were also investigated based on percentages of shared types. As can be seen in Table 8.20 below, transition markers, code glosses, and self-mentions are found to have higher percentages of shared types between the two groups. In high and low frequency groups, respectively, there are 40 and 32 types of transition markers (with 32 types shared), 17 and 15 types of code glosses (with 14 types shared), and 5 and 4 types of self-mentions (with 4 types shared). The shared types in each of these subcategories account for approximately $80 \%$ of all types found in the high frequency 
group. This means that $20 \%$ of the types in the high frequency group are different from the ones in the low frequency group. There are 57 and 43 types of hedges found in high and low frequency groups (with 42 types shared). The shared types account for approximately $74 \%$ of all the hedging markers found in the high frequency group, which means $26 \%$ of all the hedging markers in the high frequency group are different from those in the low frequency group. There are 27 and 19 types of evidentials (with 16 types shared) and 25 and 16 types of boosters (with 15 types shared) in high and low frequency groups. The shared types in these subcategories account for approximately $60 \%$ of all types found in the high frequency group. This means that $40 \%$ of the types in the high frequency group are different from the ones in the low frequency group. There are 40 and 24 types of frame markers (with 22 types shared), 14 and 7 types of endophoric markers (with 7 types shared), and 18 and 11 types of engagement markers (with 9 types shared), identified in high and low frequency groups. The shared types in each of these subcategories account for approximately $50 \%$ of all types found in the high frequency group. This means that half of the types found in the high frequency group are the same as the ones in low frequency group, and half are different. Lastly, there are 25 and 15 types of attitude markers found in high and low frequency groups (with 10 types shared). The shared types account for $40 \%$ of all types of attitude markers in the high frequency group. This means that $60 \%$ of the attitude markers in the high frequency group are different from those in the low frequency group. To summarize, the percentages of shared markers indicate that attitude markers contribute the largest difference between the two groups in terms of types. In other subcategories (especially transition markers, code glosses, self-mentions, and hedges), most of the types between high and low frequency groups are the same.

Focusing on the top ten markers in high and low frequency groups, most of the top ten markers in every subcategory overlap between the two groups, as presented in Table 8.20. Also, percentages in the use of the top ten markers (compared to other lower frequency markers) are considerably high (more than 60\% in all subcategories). This indicates that the ten high frequency markers in each subcategory occupy more than $60 \%$ of the total occurrences in high and low frequency theses, while a range of lower frequency markers outside the list occupies approximately $40 \%$ only.

However, a comparison of the percentages between high and low frequency groups suggests that theses in the low frequency group not only have fewer occurrences of markers but also rely more heavily on a small cluster of high frequency markers for seven out of ten 
subcategories. These subcategories are frame markers (60.3\% for HFG, $72.7 \%$ for LFG), endophoric markers (94.7\% for HFG, 100\% for LFG), code glosses (94.4\% for HFG, $94.6 \%$ for LFG), hedges (75.4\% for HFG, $80.0 \%$ for LFG), boosters (90.7\% for HFG, $94.8 \%$ for LFG), attitude markers (79.4\% for HFG, $90.5 \%$ for LFG), and engagement markers $(93.6 \%$ for HFG, 95.3\% for LFG). In contrast, theses in the high frequency group have a slightly greater reliance on the use of the top ten markers for two subcategories, namely transition markers (74.2\% for HFG, $72.5 \%$ for LFG) and evidentials (92.2\% for HFG, 90.8\% for LFG). Because theses in high and low frequency groups do not contain many types of self-mention markers, the markers present on the list account for $100 \%$ of the total self-mentions in the two groups. 
Table 8.20. Top ten marker list in high and low frequency groups in ELT

\begin{tabular}{|c|c|c|c|c|c|c|c|c|c|c|}
\hline & \multicolumn{2}{|c|}{ Transition markers } & \multicolumn{2}{|c|}{ Frame markers } & \multicolumn{2}{|c|}{ Endophoric markers } & \multicolumn{2}{|c|}{ Evidentials } & \multicolumn{2}{|c|}{ Code glosses } \\
\hline & HFG & LFG & HFG & LFG & HFG & LFG & HFG & LFG & HFG & LFG \\
\hline 1 & also & also & regarding & numbering & Table X & $\mathbf{X}$ above & $\begin{array}{l}\text { Non-integral } \\
\text { citation }\end{array}$ & $\begin{array}{l}\text { Non-integral } \\
\text { citation }\end{array}$ & & such as \\
\hline 2 & however & however & numbering & first & $\mathbf{X}$ below & Table X & $X$ find & $X$ find & for example & for example \\
\hline 3 & because & while & firstly & second & Example X & (In) Chapter X & according to & X support & & e.g. \\
\hline 4 & although & and & first & firstly & $\mathbf{X}$ above & $\mathbf{X}$ below & X support & X state & that is & i.e. \\
\hline 5 & but & because & (in) this chapter & on the whole & (In) Section $\mathbf{X}$ & (In) Section $\mathbf{X}$ & $\mathrm{X}$ assert & according to $X$ & $(\ldots)$ & $(\ldots)$ \\
\hline 6 & thus & & secondly & (in) this section & Page X & (In) the $X$ chapter & cited & $\mathrm{X}$ show & - & in other words \\
\hline 7 & while & although & (in) this section & regarding & P. $X$ & $\mathbf{X}$ earlier & $\mathrm{X}$ suggest & $\mathrm{X}$ indicate & in other words & namely \\
\hline 8 & and & in addition & second & (in) this chapter & (In) the $X$ chapter & - & $\mathrm{X}$ report & $\mathrm{X}$ propose & for instance & called \\
\hline 9 & so & since & now & secondly & (In) Chapter X & - & X state & $\mathrm{X}$ demonstrate & in fact & indeed \\
\hline \multirow[t]{5}{*}{10} & therefore & therefore & finally & finally & $\mathbf{X}$ earlier & - & X show & $\mathrm{X}$ identify & called & specifically \\
\hline & $(74.2 \%)^{*}$ & $(72.5 \%)$ & $(60.3 \%)$ & $(72.7 \%)$ & $(94.7 \%)$ & $(100 \%)$ & $(92.2 \%)$ & $(90.8 \%)$ & $(94.4 \%)$ & $(94.6 \%)$ \\
\hline & \multicolumn{2}{|c|}{$\begin{array}{l}\text { Types found: } 40,32 \\
\text { Types shared: } 32\end{array}$} & \multicolumn{2}{|c|}{$\begin{array}{l}\text { Types found: } 40,24 \\
\text { Types shared: } 22\end{array}$} & \multicolumn{2}{|l|}{$\begin{array}{l}\text { Types found: } 14,7 \\
\text { Types shared: } 7\end{array}$} & \multicolumn{2}{|c|}{$\begin{array}{l}\text { Types found: } 27,19 \\
\text { Types shared: } 16\end{array}$} & \multicolumn{2}{|c|}{$\begin{array}{l}\text { Types found: } 17,15 \\
\text { Types shared: } 14\end{array}$} \\
\hline & \multicolumn{2}{|c|}{ Hedges } & \multicolumn{2}{|c|}{ Boosters } & \multicolumn{2}{|c|}{ Attitude markers } & \multicolumn{2}{|c|}{ Engagement markers } & \multicolumn{2}{|c|}{ Self-mentions } \\
\hline & HFG & LFG & HFG & LFG & HFG & LFG & HFG & LFG & HFG & LFG \\
\hline 1 & may & could & find & show & important & important & see & our & $\mathbf{I}$ & researcher \\
\hline 2 & might & would & show & find & necessarily & crucial & we & note & my & my \\
\hline 3 & should & should & demonstrate & believe & interesting & interesting & our & see & me & $\mathbf{I}$ \\
\hline 4 & suggest & may & believe & demonstrate & significant & valuable & us & should & researcher & me \\
\hline 5 & could & indicate & must & indeed & interestingly & significant & ? & we & our & - \\
\hline 6 & would & might & always & evident & expected & essential & let's & explore & - & - \\
\hline 7 & likely & suggest & evident & always & importantly & interestingly & investigate & (personal asides) & - & - \\
\hline 8 & appear & tend to & clear & clear & valuable & unique & note & $?$ & - & - \\
\hline 9 & perhaps & likely & prove & clearly & unique & necessarily & assume & consider & - & - \\
\hline \multirow[t]{3}{*}{10} & possible & possible & really & considerable & fundamental & importantly & look at & refer & - & - \\
\hline & $(75.4 \%)$ & $(80.0 \%)$ & $(90.7 \%)$ & $(94.8 \%)$ & $(79.4 \%)$ & $(90.5 \%)$ & $(93.6 \%)$ & $(95.3 \%)$ & $(100 \%)$ & $(100 \%)$ \\
\hline & $\begin{array}{l}\text { Types four } \\
\text { Types shar }\end{array}$ & $\begin{array}{l}57,43 \\
: 42\end{array}$ & $\begin{array}{l}\text { Types found: } 2 \\
\text { Types shared: }\end{array}$ & 16 & $\begin{array}{l}\text { Types found: } 25,15 \\
\text { Types shared: } 10\end{array}$ & & $\begin{array}{l}\text { Types found } \\
\text { Types share }\end{array}$ & & $\begin{array}{l}\text { Types found: } 5 \\
\text { Types shared: }\end{array}$ & \\
\hline
\end{tabular}

**Bolded markers represent the markers shared between high and low frequency groups.

*Ratio of ten higher frequency markers on the list and other lower frequency markers in the same subcategory 


\subsubsection{Comparison of quality scores in high and low frequency groups in business administration}

There were twenty four theses in business administration for the comparison in this section. These comprised twelve theses with a high frequency of metadiscourse and twelve theses with a low frequency of metadiscourse. To examine the difference in quality scores between high and low frequency groups in the business discipline, regardless of educational contexts, an independent samples $t$-test was performed. As shown in Table 8.21, the average score in the high frequency group $(\mathrm{M}=15.31, \mathrm{SD}=3.06)$ is higher than the score in the low frequency group $(\mathrm{M}=11.48, \mathrm{SD}=2.10)$. The $t$-test output shows that the difference in scores between the two groups is statistically significant, $t(22)=3.576, p=.002$. The difference between means is 3.83 , and the $95 \%$ confidence interval ranges from 1.60 to 5.75 . The bootstrap confidence interval ranging between positive values confirms that the higher frequency of metadiscourse is likely to affect the quality scores in this discipline.

Table 8.21. Quality scores in high and low frequency groups in BA theses

\begin{tabular}{lcccccccc}
\hline \multirow{2}{*}{ Quality aspect } & \multicolumn{3}{c}{ High frequency group $(\mathrm{N}=12)$} & \multicolumn{3}{c}{ Low frequency group $(\mathrm{N}=12)$} \\
\cline { 2 - 9 } & Min. & Max. & Mean & SD & Min. & Max. & Mean & SD \\
\hline Content & 2.50 & 5.00 & 3.75 & 0.94 & 1.75 & 3.50 & 2.69 & 0.53 \\
Organization and presentation & 2.25 & 5.00 & 3.85 & 0.97 & 2.00 & 3.50 & 2.88 & 0.51 \\
Language use & 3.00 & 5.00 & 3.90 & 0.74 & 1.75 & 4.00 & 3.02 & 0.66 \\
Genre knowledge & 2.75 & 4.75 & 3.81 & 0.72 & 2.00 & 4.25 & 2.90 & 0.69 \\
\hline Overall quality scores & 10.75 & 18.50 & 15.31 & 3.06 & 8.00 & 15.25 & 11.48 & 2.10 \\
\hline
\end{tabular}

Similarities and differences between business theses in high and low frequency groups were further explored in terms of metadiscourse distribution and ranges of types of markers between the two groups. When comparing the frequencies of each subcategory in Figure 8.4, it is apparent that the high frequency group has higher counts of metadiscourse than the low frequency group in all subcategories. However, gaps in the frequencies between the two groups indicate that frequencies in the high frequency group are very much higher than those in the low frequency group in the subcategories of transition markers $(\mathrm{Nf}=108.6$ for $\mathrm{HFG}, \mathrm{Nf}=16.8$ for $\mathrm{LFG}$ ) and hedges $(\mathrm{Nf}=103.8$ for $\mathrm{HFG}, \mathrm{Nf}=19.4$ for $\mathrm{LFG})$, while frequencies in other subcategories are not very different. Transition markers and hedges, therefore, are the biggest contributors to the difference between the two groups, and frequencies of engagement markers 
$(\mathrm{Nf}=5.0$ for $\mathrm{HFG}, \mathrm{Nf}=1.2$ for $\mathrm{LFG})$ and self-mentions $(\mathrm{Nf}=4.8$ for $\mathrm{HFG}, \mathrm{Nf}=1.7$ for $\mathrm{LFG})$ between the two groups contribute the least difference.

Regarding metadiscourse distribution patterns, the shape of lines reveals considerable differences in the ranks of textual metadiscourse subcategories and similarities in the ranks of interpersonal metadiscourse subcategories between the two groups. For the textual metadiscourse subcategories, the two groups contain the highest frequency of transition markers and the lowest frequency of endophoric markers. In the high frequency group, evidentials obtain the second highest use, followed by code glosses and frame markers. In the low frequency group, frame markers obtain the second highest use followed by evidentials and code glosses. For the interpersonal metadiscourse subcategories, the two groups contain the highest frequency of hedges, followed by boosters and attitude markers. Engagement markers and self-mentions obtain the lowest use in this category. A slight difference is that the high frequency group contains slightly more engagement markers than self-mentions, whereas the low frequency group contains more self-mentions than engagement markers.

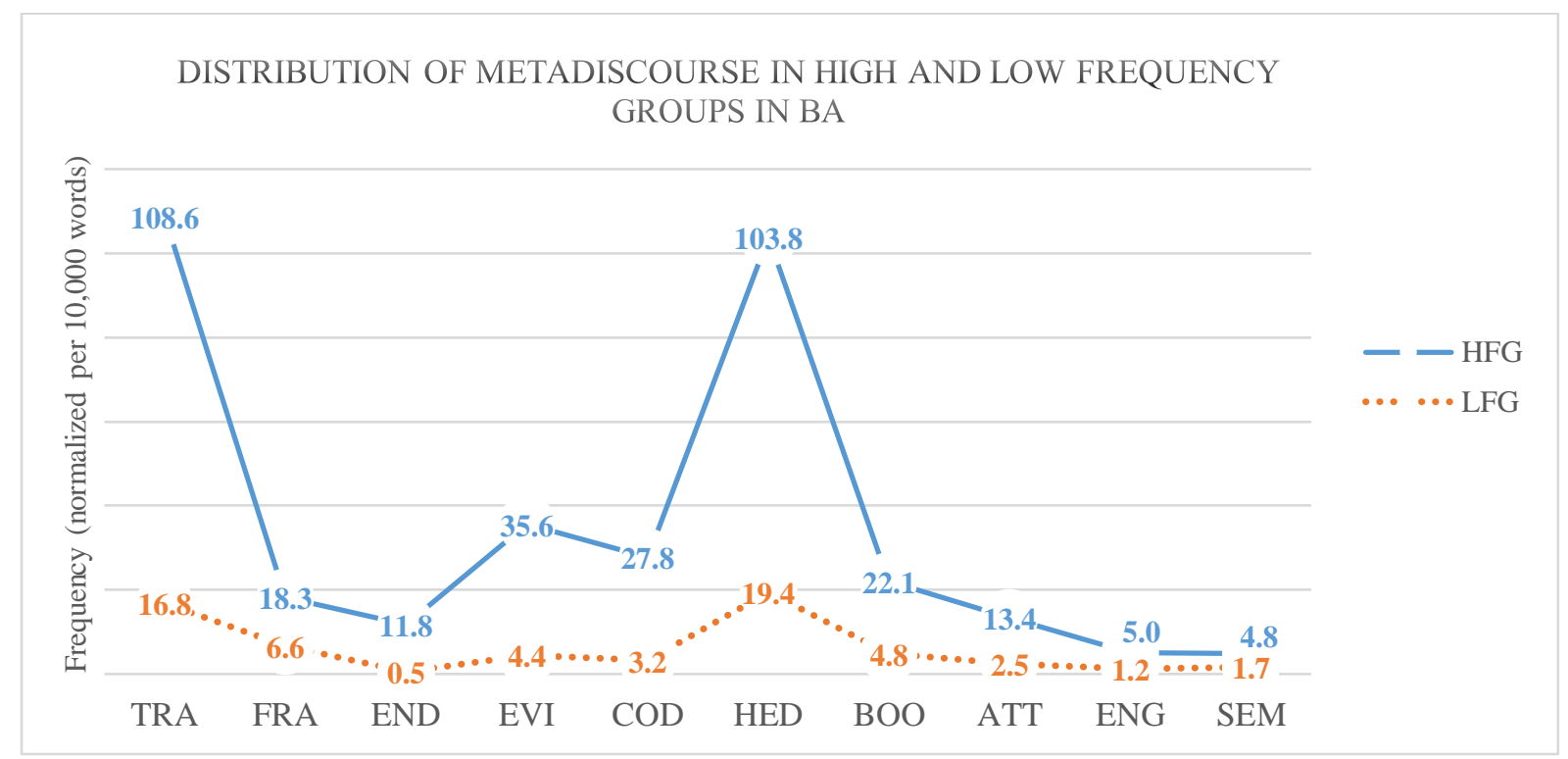

Figure 8.4. Distribution of metadiscourse in high and low frequency groups in BA

When taking types of markers into consideration, the high frequency group contains more types of markers in every subcategory than does the low frequency group. This means that the theses in the high frequency group not only have higher occurrences of markers but also a greater variety in terms of individual items. When looking at the types of markers shared between the two frequency groups, it is important to note that percentages of shared types are not as high as those in the English language teaching discipline. As we have seen in the results of English 
language teaching (Section 8.3.1), most types of markers (approximately 70-80\%), especially in the subcategories of transition markers, code glosses, self-mentions, and hedges, are the same between the two groups (with only $20-30 \%$ of different types in these subcategories). But in the business discipline, out of ten subcategories, the highest percentage of shared types is approximately $60 \%$ of all types found in the subcategories of frame markers and hedges. In high and low frequency groups, respectively, there are 39 and 25 types of frame markers (with 24 types shared) and 55 and 33 types of hedges (with 33 types shared). The shared types account for approximately $60 \%$ of all frame markers and of all hedges in the high frequency group. This indicates that the high frequency group contains about $40 \%$ of types different from the low frequency group. Following this, there are 40 and 23 types of transition markers (with 23 types shared) and 7 and 4 types of self-mentions (with 4 types shared) in high and low frequency groups. The shared types account for approximately $57 \%$ of all transition markers and of all self-mentions in the high frequency group. This means that the high frequency group contains about $43 \%$ of types in the two subcategories different from the low frequency group. There are 24 and 13 types of boosters (with 12 types shared), 23 and 15 types of attitude markers (with 12 types shared), and 10 and 7 types of engagement markers (with 5 types shared) in high and low frequency groups. The shared types account for approximately $50 \%$ or half of all types identified in each of the three subcategories in the high frequency group. This means that the high frequency group contains $50 \%$ of types in the subcategories different from the low frequency group. There are 12 and 4 types of endophoric markers (with 4 types shared), 23 and 8 types of evidentials (with 8 types shared), and 20 and 9 types of code glosses (with 9 types shared) in high and low frequency groups. The shared types account for approximately $33 \%$ of all endophoric markers, $35 \%$ of all evidentials, and $45 \%$ of all code glosses found in the high frequency group. This means that the high frequency group contains approximately $55-70 \%$ of types in the last three subcategories different from the low frequency group. To summarize, percentages of shared types between high and low frequency groups in business theses are not very high, when compared to the theses in English language teaching. The high frequency group contains at least $40 \%$ of types in each subcategory different from the low frequency group. Types of markers in the subcategories of endophoric markers, evidentials, and code glosses are the most different (about 60\%) between the two groups. It can be argued that high and low frequency groups in business administration have a large difference in terms of types of markers. 
Focusing on the top ten markers in each subcategory, the higher frequency markers on the list either in high or low frequency groups account for more than $65 \%$ of all the markers identified in each subcategory. This suggests that theses in the two groups greatly rely on the higher frequency markers on the list and scantly use lower frequency markers below the list. In particular, theses in the low frequency group are limited to a very small cluster of endophoric markers (4 types identified), evidentials ( 8 types identified), code glosses ( 9 types identified), engagement markers ( 7 types identified), and self-mentions (4 types identified). As displayed in Table 8.22, most of the high frequency markers in every subcategory (except attitude markers) overlap between the two groups. Only four of the top ten attitude markers are shared, indicating that different types of high frequency attitude markers are used in high and low frequency groups.

A comparison of percentages in the use of the ten markers between the two groups suggests that theses in the low frequency group have fewer occurrences of markers and rely more heavily on the top ten markers for eight out of ten subcategories. These are transition markers $(75.1 \%$ for $\mathrm{HFG}, 82.9 \%$ for $\mathrm{LFG}$ ), frame markers (66.5\% for HFG, $69.3 \%$ for LFG), endophoric markers ( $96.6 \%$ for HFG, $100 \%$ for LFG), evidentials (91.5\% for HFG, $100 \%$ for LFG), code glosses (91.8\% for HFG, 100\% for LFG), hedges (74.7\% for HFG, 83.8\% for LFG), boosters (88.4\% for HFG, $95.8 \%$ for LFG), and attitude markers (85.3\% for HFG, $86.1 \%$ for LFG). Because the two groups contain fewer than ten types of engagement markers and self-mention markers, the markers present on the list account for $100 \%$ of the total use of the markers in both groups. 
Table 8.22. Top ten marker list in high and low frequency groups in BA

\begin{tabular}{|c|c|c|c|c|c|c|c|c|c|c|}
\hline & \multicolumn{2}{|c|}{ Transition markers } & \multicolumn{2}{|c|}{ Frame markers } & \multicolumn{2}{|c|}{ Endophoric markers } & \multicolumn{2}{|c|}{ Evidentials } & \multicolumn{2}{|c|}{ Code glosses } \\
\hline & HFG & LFG & HFG & LFG & HFG & LFG & HFG & LFG & HFG & LFG \\
\hline 1 & also & also & firstly & first & Table X & $\mathbf{X}$ below & $\begin{array}{l}\text { Non-integral } \\
\text { citation }\end{array}$ & $\begin{array}{l}\text { Non-integral } \\
\text { citation }\end{array}$ & such as & such as \\
\hline 2 & however & however & secondly & second & (In) Section X & Figure $\mathbf{X}$ & X support & $\mathrm{X}$ find & e.g. & for example \\
\hline 3 & therefore & therefore & lastly & finally & Figure X & X above & $X$ find & X support & for example & for instance \\
\hline 4 & because & because & finally & numbering & $\mathbf{X}$ above & Page $X$ & $\mathrm{X}$ suggest & X state & i.e. & this means \\
\hline 5 & while & and & (in) this chapter & purpose & (In) the $\mathrm{X}$ section & - & $\mathrm{X}$ assert & according to $\mathrm{X}$ & for instance & e.g. \\
\hline 6 & although & moreover & numbering & listing & (In) Chapter X & - & $\mathrm{X}$ identify & $X$ note & $(\ldots)$ & in fact \\
\hline 7 & and & while & (in) this section & fourth & $\mathrm{X}$ below & - & $\mathrm{X}$ argue & $\mathrm{X}$ show & in fact & - \\
\hline 8 & moreover & but & thirdly & (in) this chapter & (In) the $\mathrm{X}$ chapter & - & $X$ note & $\mathrm{X}$ report & that is & i.e. \\
\hline 9 & but & so & in conclusion & firstly & $\mathrm{X}$ earlier & - & cited & - & in other words & specifically \\
\hline \multirow[t]{3}{*}{10} & consequently & furthermore & listing & secondly & Page X & - & X state & - & this means & - \\
\hline & $(75.1 \%)^{*}$ & $(82.9 \%)$ & $(66.5 \%)$ & $(69.3 \%)$ & $(96.6 \%)$ & $(100.0 \%)$ & $(91.5 \%)$ & $(100.0 \%)$ & $(91.8 \%)$ & $(100.0 \%)$ \\
\hline & $\begin{array}{l}\text { Types found: } \\
\text { Types shared: }\end{array}$ & & $\begin{array}{l}\text { Types found: } 39,2 \\
\text { Types shared: } 24\end{array}$ & & $\begin{array}{l}\text { Types found: } 12,4 \\
\text { Types shared: } 4\end{array}$ & & $\begin{array}{l}\text { Types found: } 23,8 \\
\text { Types shared: } 8\end{array}$ & & $\begin{array}{l}\text { Types found: } 2 \\
\text { Types shared: } 9\end{array}$ & \\
\hline
\end{tabular}

\begin{tabular}{|c|c|c|c|c|c|c|c|c|c|c|}
\hline & \multicolumn{2}{|c|}{ Hedges } & \multicolumn{2}{|c|}{ Boosters } & \multicolumn{2}{|c|}{ Attitude markers } & \multicolumn{2}{|c|}{ Engagement markers } & \multicolumn{2}{|c|}{ Self-mentions } \\
\hline & HFG & LFG & HFG & LFG & HFG & LFG & HFG & LFG & HFG & LFG \\
\hline 1 & should & should & show & show & important & important & see & our & researcher & researcher \\
\hline 2 & could & could & find & find & interesting & essential & we & we & the researcher's & $\mathbf{I}$ \\
\hline 3 & may & would & must & must & unique & valuable & us & see & my & my \\
\hline 4 & would & may & believe & believe & interestingly & significant & $?$ & note/ be noted & me & our \\
\hline 5 & suggest & indicate & evident & clear & essentially & interesting & note/ be noted & us & we & - \\
\hline 6 & appear & might & clearly & always & significant & crucial & one's & should & our & - \\
\hline 7 & might & suggest & always & demonstrate & surprising & agrees & assume & (personal asides) & $\mathbf{I}$ & - \\
\hline 8 & indicate & likely & demonstrate & of course & prominent & expected & keep in mind & - & - & - \\
\hline 9 & often & relatively & clear & actually & valuable & remarkable & (the) reader's & - & - & - \\
\hline \multirow[t]{3}{*}{10} & possible & often & certainly & no doubt & necessarily & surprisingly & our & - & - & - \\
\hline & $(74.7 \%)$ & $(83.8 \%)$ & $(88.4 \%)$ & $(95.8 \%)$ & $(85.3 \%)$ & $(86.1 \%)$ & $(100.0 \%)$ & $(100.0 \%)$ & $(100.0 \%)$ & $(100.0 \%)$ \\
\hline & \multicolumn{2}{|c|}{ Types found: 55,33} & \multicolumn{2}{|c|}{ Types found: 24,13} & \multicolumn{2}{|c|}{ Types found: 23,15} & \multicolumn{2}{|l|}{ Types found: 10,7} & \multicolumn{2}{|l|}{$\begin{array}{l}\text { Types found: } 7,4 \\
\text { Types shared: } 4\end{array}$} \\
\hline
\end{tabular}

**Bolded markers represent the markers shared between high and low frequency groups.

*Ratio of ten higher frequency markers on the list and other lower frequency markers in the same subcategory 


\subsection{Chapter summary}

This chapter has provided evidence of the positive correlation between metadiscourse frequencies and overall quality of thesis writing in both English language teaching and business administration disciplines. In English language teaching, interpersonal metadiscourse, compared to textual metadiscourse, seems to be more closely related to the overall quality scores. Only some subcategories are correlated with the quality scores, namely evidentials and code glosses within the textual category and all subcategories within the interpersonal category except for boosters. In business administration, the frequency of textual metadiscourse seems to be more highly related to the overall quality scores, compared to interpersonal metadiscourse. In this discipline, all five textual metadiscourse subcategories are correlated with the quality scores, but only hedges and boosters in the interpersonal category are correlated with the quality scores. Moreover, the comparisons of quality scores in high and low frequency groups in each discipline indicate that the scores between two groups are significantly different in business administration, but not in English language teaching. 


\section{CHAPTER 9}

\section{DISCUSSION}

The findings of Study 1 (Metadiscourse analysis) and Study 2 (Metadiscourse frequency and thesis quality) are discussed under four themes. Section 9.1 discusses variation of metadiscourse frequency across educational contexts and disciplines. Section 9.2 discusses variation of metadiscourse types. Section 9.3 discusses variation of metadiscourse functions. Section 9.4 discusses the relationship between the use of metadiscourse and quality of postgraduate writing.

\subsection{Variation of metadiscourse frequency}

A comparative analysis of metadiscourse frequency in master's thesis discussion and conclusion chapters written by New Zealand and Thai postgraduates in English language teaching and business administration reveals both similarities and differences in the use of metadiscourse between the two educational contexts and between the two disciplines.

\subsubsection{Textual and interpersonal metadiscourse in New Zealand and Thai theses}

Comparisons of textual and interpersonal metadiscourse categories and subcategories between educational contexts and between disciplines are summarized in Table 9.1. The first column of the table displays results of contextual comparisons, i.e., whether New Zealand students (NZ) or Thai students (TH) employ more metadiscourse. The second column displays results of disciplinary comparisons, i.e., whether English language teaching students (ELT) or business administration students (BA) employ more metadiscourse. The group with significantly more frequent use is specified in the table. 
Table 9.1. Summary of comparisons of textual and interpersonal metadiscourse categories and subcategories between educational contexts and disciplines

\begin{tabular}{lcc}
\hline Category & $\begin{array}{c}\text { Between educational contexts } \\
\text { NZ vs. TH }\end{array}$ & $\begin{array}{c}\text { Between disciplines } \\
\text { ELT vs. BA }\end{array}$ \\
\hline Transition markers & $\mathrm{TH}$ & BA \\
Frame markers & $\mathrm{TH}$ & $\mathrm{X}$ \\
Endophoric markers & $\mathrm{X}$ & ELT \\
Evidentials & $\mathrm{NZ}$ & ELT \\
Code glosses & $\mathrm{NZ}$ & $\mathrm{X}$ \\
Textual metadiscourse & $\mathrm{TH}$ & ELT \\
\hline Hedges & $\mathrm{NZ}$ & ELT \\
Boosters & $\mathrm{TH}$ & $\mathrm{X}$ \\
Attitude markers & $\mathrm{NZ}$ & $\mathrm{X}$ \\
Engagement markers & $\mathrm{NZ}$ & ELT \\
Self-mentions & $\mathrm{NZ}$ & ELT \\
Interpersonal metadiscourse & $\mathrm{NZ}$ & ELT \\
\hline Metadiscourse (overall) & $\mathrm{NZ}$ & ELT \\
\hline
\end{tabular}

$X$ denotes no significant difference between the two groups.

This part focuses on the extent to which New Zealand and Thai postgraduates use metadiscourse in their master's theses. On the whole, this study found significantly more occurrences of metadiscourse in New Zealand theses than in Thai theses. This finding is in line with previous cross-cultural studies of research writing (e.g., Alshahrani, 2015; Mauranen, 1993; Mirshamsi \& Allami, 2013; Ozdemir \& Longo, 2014), in which a higher incidence of metadiscourse is found in the native English speaking student (L1) corpus compared to the non-native English speaking student (L2) corpus. However, some studies, for instance, Burneikaitè's (2008) analysis of British and Lithuanian theses and Gholami and Ilghami's (2016) analysis of American and Iranian research articles, found no difference in the frequency of using metadiscourse between the L1 and L2 groups.

Interestingly, the finding of the present study is different from Li's (2016) study which examined four-word bundles of metadiscourse (e.g., on the other hand, as can be seen, it is important to, it should be noted) in New Zealand and Chinese theses. In Li's study, the higher incidence of metadiscourse is found in the Chinese thesis corpus rather than in the New Zealand thesis corpus. There are four factors which may explain this difference: disciplines, academic competence (master's/ doctoral degree), units of analysis (four-word bundles vs. a full range of metadiscourse from punctuation to sentences), and language backgrounds of L2 writers (Chinese vs. Thai). Despite the difference in the overall result, the comparison of Li's study and my study shows that there is no decisive answer as to whether New Zealand students use 
more metadiscourse than non-native English speaking student groups because of their status as native English speakers. Some groups of L2 students such as Chinese may use more metadiscourse than New Zealand students, as indicated in Li's study. Nevertheless, the present study found that Thai students use metadiscourse less frequently than New Zealand students.

Regardless of other underlying factors contributing to different results, the previous studies mentioned above and the present study acknowledge the fact that there may be wide variations among the L1 student groups (i.e., American, British, and New Zealand students). Not all groups of L1 students use metadiscourse extensively nor are more reader-oriented than all groups of L2 students. Therefore, it might be too crude and incautious to put all groups of L1 students together and conclude that L1 students in inner-circle English speaking countries are more inclined to use metadiscourse in their research writing and have more awareness of providing readers a textual guidance and promoting writer-reader interactions in the texts. Given that L1 students in different contexts also exhibit a variety of rhetorical preferences and writing styles, future research should consider similarities and differences in the use of metadiscourse by native English speaking students in different countries in order to gain more insight into variation of rhetorical strategies and writing styles of English speaking students in different contexts.

Earlier cross-cultural research offers some possible reasons to shed light on why L2 students may use metadiscourse less than L1 students. For example, Mirshamsi and Allami (2013) state that L1 students are writing in their own language and might be more familiar with the norms and conventions of rhetorical structure in that language. Alshahrani (2015) and Burneikaite (2008) suggest that L2 students might have an insufficient awareness and knowledge of metadiscourse functions in academic discourse due to an implicit instruction on metadiscourse as well as the influence of local institutional culture in each country. These reasons might be applicable to the case of Thai and New Zealand contexts where universities even in the same country may have somewhat different conventions and practices of academic writing.

Taking the discussion with supervisor informants into account, one possible explanation for why Thai students make less frequent use of metadiscourse when compared to New Zealand students may be related to the novelty of the metadiscourse concept in the Thai context. Thai supervisor informants suggested that the notion of metadiscourse concerning writer-reader interactions is very new and not central to discussion in academic writing classes in the Thai context. The academic writing instruction in this context only focuses on textual features, 
coherence and cohesion, leading to Thai teachers' and students' greater familiarity with the concept of coherence and cohesion than interpersonal features in academic writing. Moreover, Thai students have been taught to write academic texts like research articles and theses in a very formal and impersonal way but are rarely taught to politely engage with readers in the texts (Getkham, 2014). The Thai informants mentioned that even though some students are conscious that it is more acceptable than in the past to include interpersonal features such as self-mentions and engagement markers in academic texts, they still favour the traditional style of academic writing because they are concerned that other readers who take a traditional approach to writing may find such interpersonal markers inappropriate to be included in the theses. Their use of metadiscourse in academic writing is then limited to certain textual types such as connectors and sequencers.

A closer consideration of textual and interpersonal features in this study shows that New Zealand and Thai students employ more textual metadiscourse than interpersonal metadiscourse. However, the degree of reliance on either textual or interpersonal metadiscourse between the two groups is different. Thai students exhibit a greater reliance on the use of textual metadiscourse than New Zealand students $(\mathrm{Nf}=225.3$ in $\mathrm{NZ}, \mathrm{Nf}=238.3$ in $\mathrm{TH})$. New Zealand students exhibit a greater reliance on the use of interpersonal metadiscourse than Thai students $(\mathrm{Nf}=221.4$ in $\mathrm{NZ}, \mathrm{Nf}=187.6$ in $\mathrm{TH})$. These findings are in line with several cross-cultural studies of metadiscourse (e.g., Alshahrani, 2015; Burneikaitè, 2008; Gholami \& Ilghami, 2016; Mestre-Mestre, 2017; Mu et al., 2015; Ozdemir \& Longo, 2014), showing a greater reliance by L2 students on textual features and a greater reliance by L1 students on interpersonal features.

Focusing attention to the distribution or ranks of textual and interpersonal subcategories (see Table 5.1 and Table 6.1), findings reveal that the high incidence of textual and interpersonal metadiscourse in either New Zealand or Thai theses is derived mainly from the same frequent subcategories. That is, in the textual subcategories, New Zealand and Thai students have the highest use of transition markers (however, because) in their theses, moderate use of evidentials ( $X$ find, $X$ suggest), frame markers (firstly, in conclusion) and code glosses (for example, such as), and the lowest use of endophoric markers (table $X$, in chapter $X$ ). Thus, the preponderance of textual metadiscourse in New Zealand and Thai theses is largely due to the high frequency of transition markers which constitute approximately half of all occurrences of textual metadiscourse in both New Zealand theses (48.2\%) and Thai theses (59.4\%). The four other 
textual subcategories, especially endophoric markers, are used far less frequently by students in the two contexts, accounting for a smaller proportion of total textual metadiscourse.

As for the distribution of interpersonal subcategories, the two groups of students have the highest use of hedges (may, likely), moderate use of boosters (show, certainly), attitude markers (important, interesting) and self-mentions (I, researcher), and the lowest use of engagement markers (we, rhetorical questions). The most frequent interpersonal subcategory is hedges which account for more than half of all occurrences of interpersonal metadiscourse in New Zealand theses (60.2\%) and Thai theses (64.7\%). The four other interpersonal subcategories, especially engagement markers, are far less frequently used in New Zealand and Thai theses, accounting for a smaller proportion of total interpersonal metadiscourse.

The analysis of textual and interpersonal subcategories demonstrates that transition markers and hedges are the most predominant metadiscourse features in New Zealand and Thai theses and make the largest contribution to the density of textual and interpersonal metadiscourse in this study. The heavy use of the two subcategories in thesis writing is similar to Mirshamsi and Allami's (2013) study of metadiscourse in thesis discussion and conlusion chapters. This can be explained in relation to the main functions of discussion and conclusion chapters. The chapters are important parts of theses in which students need to offer critical justification of research findings and provide a summary of the whole study. When writing these critical chapters, students need to ensure that their justification and what they intend to communicate to the readers are convincing and unlikely to be misinterpreted. This possibly motivates them to put great emphasis on facilitating readers' interpretation of relations between different segments through the use of additive, adversative, and causative transition markers. The infrequent use of endophoric markers in the chapters suggests students' attempt to reduce readers' effort and time by clearly providing details and illustrations about the current discussion rather than referring readers to other sections or chapters, as partly indicated by the greater use of code glosses. The preponderance of hedges reflects students' genre-related knowledge that research writing, particularly in discussion and conclusion parts, is more than presenting certain facts but also opinions or unproved justification towards key findings (Ädel \& Erman, 2012; Getkham 2014; Hyland, 2004). The hedging strategy can be seen as a cautious way in which novice research students show their attempt to give plausible reasons for their findings and also their awareness of some limitations restraining them not to overstate the findings and reasoning. 
Given the similarities in the distribution of textual and interpersonal subcategories in New Zealand and Thai theses, it is worth observing differences in the degree of preference for particular textual and interpersonal subcategories.

As shown in Table 9.1 above, New Zealand students make significantly more frequent use of evidentials and code glosses than Thai students. By contrast, Thai students make significantly more frequent use of transition markers and frame markers than New Zealand students. The two groups are not different in the frequency of using endophoric markers. These findings suggest that New Zealand students, compared to Thai students, put more emphasis on clarifying their thoughts by including examples and aside information and on providing justification for their arguments by referring to previous studies. Their use of evidentials not only indicates their intention to enhance the credibility of the arguments but also their intention to demonstrate their knowledge of literature in the field, which is an important ethos in research writing (Hyland, 2004).

The greater use of transition markers and frame markers in the Thai corpus supports my contention that Thai students have a high concern for creating coherent and cohesive texts through sequencing and presenting their arguments in a refined structure. This finding is consistent with Alshahrani (2015), Burneikaite (2008), and Ozdemir and Longo (2014), indicating a higher density of transition markers and frame markers in L2 student corpora.

When comparing the use of each interpersonal metadiscourse subcategory between New Zealand and Thai groups, it is interesting that New Zealand students make significantly greater use of hedges, attitude markers, engagement markers, and self-mentions than Thai students. This means the only interpersonal metadiscourse subcategory that Thai students use more often than New Zealand students is boosters. This result aligns with Gholami and Ilghami (2016), Li (2016), and Nguyen Thi Thuy (2018), indicating a higher frequency of boosters in L2 writers' texts.

It is not surprising that New Zealand students make greater use of interpersonal metadiscourse in almost all subcategories than Thai students. Based on the findings of higher frequencies of interpersonal metadiscourse in this study, New Zealand students' theses, especially in English language teaching, are prominent in terms of interpersonal features and writing in a more personal style to create rapport with readers. In addition to the fact that hedges are the most frequent interpersonal subcategory in New Zealand and Thai theses, the significantly higher 
frequency of boosters in Thai theses compared to New Zealand theses indicates that Thai students not only make substantial use of the cautious strategy (hedges) but also the assertive strategy (boosters) to reinforce their power of conviction and gain acceptance for their work from disciplinary expert readers. To do so, they emphasize the strength of their commitment to specific findings with strong words (certainly, evidently) and use the logical force of the argument together with supporting evidence to convince readers (Hyland, 1998a).

Some studies (e.g., Hyland, 2005; Mauranen, 1993; Tarrayo, 2011) refer to writer-responsible and reader-responsible writing cultures, based on the use of textual metadiscourse. To recall these cultures from Chapter 2, according to Hinds (1987), writer-responsible and readerresponsible cultures refer to characteristics of writing and preconceptions of writers in different communities. In writer-responsible cultures such as English, writers play an important role in producing well-organized texts through explicit textual-organizing devices, with an awareness and evaluation of readers' need for elaboration and engagement. In reader-responsible cultures such as Japanese and Chinese (Mok, 1993; Qi \& Liu, 2007), writers tend not to make explicit the textual organization and rhetorical acts. The readers are therefore more responsible for interpreting the writers' argument. Given that the definitions of the writing cultures in previous literature are provided on a basis of textual features only, the present study has proposed explicit and implicit use of interpersonal metadiscourse as further descriptions of the two writing styles (see Section 2.2). In writer-responsible cultures, writers explicitly engage themselves and readers into the texts and indicate to readers whether propositions are certain facts or tentative opinions, so that the readers can interpret the propositions with more careful consideration. In reader-responsible cultures, writers are likely to be implicit in projecting themselves on the texts and addressing the readers.

Drawing upon the concept of writer-responsible and reader-responsible writing styles given above, regardless of gradations in between, the analysis of metadiscourse in this study reflects different characteristics of thesis writing in New Zealand and Thai contexts based on the frequency of using either textual or interpersonal metadiscourse. With far greater use of textual metadiscourse, Thai students' thesis writing is more likely to be explicit, impersonal and writerresponsible in terms of textual organization and expressions. Apart from propositional content, Thai students tend to maintain impersonality in their thesis writing and focus on making readers' interpretative task less demanding with more explicit textual guidance. However, their writing is quite implicit in terms of writer-reader engagement and seems to be reader- 
responsible in terms of interactional features. With more frequent use of interpersonal metadiscourse, New Zealand students' thesis writing seems to be much more personalized and put more emphasis on interactional features in order to build rapport between (student) writers and (supervisor/ examiner) readers. This means that New Zealand theses, compared to Thai theses, seem to be more reader-responsible in terms of textual organization but tend to be more writer-responsible in terms of maintaining interactions with readers. It is possible that New Zealand students would like to explicitly guide readers in terms of what they think about the content, which also makes it easier for readers to follow the writers' argument.

\subsubsection{Textual and interpersonal metadiscourse in English language teaching and business administration theses}

As most of the previous research paid attention to differences between soft and hard knowledge domains (e.g., Chan, 2015; Dahl, 2004; Hyland, 2004), disciplinary variation within the soft knowledge domain has been less well-defined in literature. This study therefore focused on two disciplines in the soft knowledge branch (English language teaching and business administration in humanities and social sciences).

As anticipated, this study found the use of metadiscourse not only varies across educational contexts but also across disciplines within the soft knowledge domain. In terms of similarities, master's students in the two disciplines have the same inclination to use more textual metadiscourse than interpersonal metadiscourse. This is consistent with previous crossdisciplinary research (Hyland, 1998b, 1999, 2004; Li \& Wharton, 2012), showing more frequent use of textual markers than interpersonal ones. This finding suggests a primary concern of master's students in the two disciplines about overall textual features in their theses and an emphasis on coherence and cohesion in the texts over interactional features.

The frequency comparison of each category between the two disciplinary groups indicates a significantly higher frequency in the use of metadiscourse in English language teaching theses than business administration theses, in both textual metadiscourse $(\mathrm{Nf}=234.8$ in ELT, $\mathrm{Nf}=226$ in BA) and interpersonal metadiscourse categories ( $\mathrm{Nf}=221$ in ELT, $\mathrm{Nf}=190.3$ in BA).

Transition markers and hedges are the most frequent textual and interpersonal metadiscourse subcategories in the two disciplines. This finding agrees with the trend reported in Hyland's (1998b, 2004) cross-disciplinary studies, showing the highest frequencies of transition markers and hedges in both his research article corpus and thesis corpus. A considerable difference 
between the two disciplines is that English language teaching students tend to use self-mentions in the theses more often than business administration students. The less frequent use of selfmentions in business administration theses aligns with Hyland's (2004) study of hard and soft knowledge disciplines, reporting a higher incidence of self-mentions in applied linguistics (a related discipline to English language teaching) than in business studies. He argues that the infrequent use of self-mention features such as first-person pronouns is more evident in disciplines which do not rely on writers' personal interpretation but rather on objectivity of interpretation or facts. As discussed later, the nature of the two disciplines may play a crucial part in the difference.

When looking at the degree of preference for particular textual and interpersonal subcategories of students in the two disciplines, as presented in Table 9.1, in the textual subcategories, endophoric markers and evidentials occur slightly more in English language teaching theses, whereas transition markers occur slightly more in business administration theses. The two disciplinary groups do not differ in the use of frame markers and code glosses.

In the five interpersonal subcategories, language teaching students make more frequent use of hedges, engagement markers, and self-mentions than business students. The two groups do not show any difference in the use of boosters or attitude markers.

Hyland (1998a) suggests that disciplinary requirements play a part in the use of metadiscourse markers. In light of this idea, variation between English language teaching and business administration can be explained in relation to the nature of research or research paradigms in each discipline (Hu \& Cao, 2015). As discussed in the interview results section (Chapter 7), supervisor informants suggested that business administration theses are likely to be operationbased research. Generally, the purpose of theses in this discipline is to report and discuss a business administration plan and its outcome, for instance, whether the plan succeeds or fails and whether customers are satisfied with company services. Also, business administration theses normally take a quantitative approach, dealing with numeric results or facts emerging from current studies and not relying much on theories and previous studies. They have fewer opportunities to have conflicting views because they do not require a lot of interpretations or negotiation with the readers and do not need to make a lot of reference to previous studies. In contrast, English language teaching theses are more likely to be theory-based research which requires students to extensively review different theories and form their line of argument in relation to the literature. English language teaching theses typically mix quantitative and 
qualitative approaches, relying on non-numeric data such as classroom observation. They require research students' effort to interpret qualitative data, present opinions, and negotiate their ideas with expert readers in order to gain acceptance. Based on the interview data, because of these disciplinary requirements, theses in the language teaching discipline are more abstract, subjective, and open to alternative interpretations than theses in the business discipline. Students in English language teaching, therefore, are more motivated than business students to show a writer-responsible attitude and use an array of textual and interpersonal devices to precisely structure their argument and to shield their claims from conflicting views as well as establish solidarity with their expert readers.

Another reason for why English language teaching students make more frequent use of both textual and interpersonal metadiscourse than business administration students is possibly related to their anticipation of whom they are communicating to and of what expectations those people might have. As indicated in Koutsantoni's (2006) study of engineering theses and RAs, thesis students' awareness of disciplinary gatekeepers' expectations seems to govern their choice of rhetorical strategies. Thesis students tend to present their claims in ways that adhere to the expectations of supervisors and examiners in their fields and satisfy their requirements. In English language teaching, students need to present and negotiate their ideas with respective experts in the language teaching or linguistics field. Matters of language use and rhetorical features seem to be part of their content. They are more likely to value language use and selection of appropriate rhetorical features than business administration students. Making appropriate use of metadiscourse and other rhetorical strategies may allow the language teaching students to display their mastery of language and professional style of writing to their expert readers. Focusing more on the business subject matter, students in business administration may have less pressure and concern about language use and rhetorical conventions insofar as overall thesis features meet academic writing standards.

The findings of more and less frequent metadiscourse subcategories between the two disciplines support my discussion above in terms of the nature of research in each discipline and the anticipation of readership. The slightly greater use of evidentials in the English language teaching discipline, which is theory-based and more subjective, reflects students' need to form their arguments in reference to theories and previous studies in order to make thesis arguments more credible and their negotiation with expert readers more successful. The slightly more frequent use of endophoric markers in the English language teaching discipline 
is partly because the analyses and discussions of research findings in this discipline are often based on a large amount of quantitative and qualitative data and may be divided into several sections. Students in this discipline thus have more need to make sure preview and review markers are sufficiently provided to readers when they switch between written and visual presentations and refer to preceding and forthcoming statements, examples, and excerpts in other parts of the texts compared to students in business administration.

Drawing on the interview data, business theses are more operation-based and less likely to be viewed as subjective by readers and writers. Students in this discipline can draw conclusions based on emerge ng facts rather than theories and previous studies, so they can focus more on presenting content and making their arguments easily interpreted and thoroughly comprehensible by explicitly using transition markers. In the business discipline, research gaps or research questions tend to emerge on the back of earlier or current problems in a particular context (e.g., company, industrial section) and so literature is not as dispersed when compared to the language teaching discipline. The discussions of findings are mainly based on the analysis of the specific context rather than referring to literature more broadly. Students in this discipline do not have to take account of any theoretical framework and therefore have less need to make extensive reference to literature. With regard to the business students' infrequent use of interpersonal metadiscourse, Hyland (1998a) argues that some disciplines like linguistics have a broader and heterogeneous readership with less of a shared background. In some disciplines like business, readers are more restricted to a specific group with a shared background. Thus, there is a need for students in English language teaching to present findings and possible reasoning in ways that allow for alternative meanings and viewpoints and to put in more effort to engage themselves and readers in discourse in order to gain solidarity.

With respect to the overall characteristics of theses between the two disciplines, writerresponsible or reader-responsible culture (regardless of graduations in between), the greater use of textual and interpersonal metadiscourse in English language teaching theses reflects a more writer-responsible culture in the field of English language teaching, while business administration seems to represent a more reader-responsible culture in terms of textual organization and writer-reader interactions. This indicates that despite the uniformity of academic genre and soft knowledge branch, rhetorical features in theses of the two disciplines are considerably different. 


\subsubsection{Textual and interpersonal metadiscourse in the four subcorpora}

Comparisons between subcorpora offer a more detailed picture of metadiscourse variation between different disciplines within the same educational contexts (NZ-ELT vs. NZ-BA; THELT vs. TH-BA) and between different educational contexts within the same disciplines (NZELT vs. TH-ELT; NZ-BA vs. TH-BA). The previous sections have suggested that contextual and disciplinary factors are likely to play a crucial role in variation in the use of metadiscourse. One important finding that emerges from this study is that in some contexts like Thailand, disciplinary requirements may be less influential than contextual factors.

Taking disciplinary variation within the New Zealand context into account (NZ-ELT vs. NZBA), NZ-ELT students include more metadiscourse in their theses than NZ-BA students $(\mathrm{Nf}=473.1$ in $\mathrm{NZ}-\mathrm{ELT}, \mathrm{Nf}=409.9$ in $\mathrm{NZ}-\mathrm{BA})$. Comparing frequencies of textual and interpersonal metadiscourse between the two groups, the NZ-ELT group makes significantly more frequent use of interpersonal metadiscourse than the NZ-BA group (Nf=243.8 in NZELT, Nf=190.2 in NZ-BA), but they do not differ significantly in the frequency of using textual metadiscourse ( $\mathrm{Nf}=229.3$ in NZ-ELT, $\mathrm{Nf}=219.7$ in NZ-BA).

In the Thai context (TH-ELT vs. TH-BA), students in the two disciplines share the same trend in using textual metadiscourse more often than interpersonal metadiscourse. Frequencies in the use of metadiscourse between the two groups are also not significantly different, neither the incidence of textual metadiscourse $(\mathrm{Nf}=243.7$ in $\mathrm{TH}-\mathrm{ELT}, \mathrm{Nf}=233$ in $\mathrm{TH}-\mathrm{BA})$ nor interpersonal metadiscourse ( $\mathrm{Nf}=184.6$ in $\mathrm{TH}-\mathrm{ELT}, \mathrm{Nf}=190.5$ in TH-BA). The findings show a noticeable difference in the use of interpersonal metadiscourse by New Zealand students in English language teaching and business administration and show no significant difference between students in the two disciplines in the Thai context.

In accordance with my earlier discussion about variation between English language teaching and business administration, it is understandable why the use of metadiscourse in the two disciplines is different in the New Zealand context. However, the result of disciplinary comparison in the Thai context is quite surprising. The two disciplines in the Thai context do not display significant differences in the use of metadiscourse. This reflects that disciplinary requirements are less influential on thesis writing in the Thai context, but more influential in the New Zealand context. This finding coincides with Li and Wharton's (2012) study. They argue that sometimes contextual factors such as local institutional culture within a particular 
context have a stronger effect than disciplinary ones.

More precisely, rhetorical preferences and academic writing styles of Thai students are not predominantly shaped by disciplinary culture. Thai students in the two disciplines share a similarity in depending heavily on textual metadiscourse to structure their ideas and argument but making sparse use of interpersonal metadiscourse. This similarity can be explained by referring to Thai students' familiarity with or repertoire of interpersonal features in academic writing. As discussed earlier, Thai students either in English language teaching or business administration tend to focus more on the issue of creating coherent and cohesive texts. As indicated in Getkham's (2014) politeness strategy study, Thai students make infrequent use of some politeness strategies (e.g., certainty markers, engagement markers (rhetorical questions) and attitude markers) which are helpful in presenting their personal views and interacting with the readers. They are only aware of certain rhetorical devices for presenting a series of facts. Thai students' limited repertoire of interpersonal metadiscourse suggests a need for language and writing instruction in EFL contexts like Thailand to expand focus from only distinct textorganizing devices to other interactional devices.

Another reason behind the lack of interpersonal features in Thai students' theses in both disciplines might be related to the conventions of Thai academic writing. In the interviews with disciplinary supervisors, Thai supervisors in English language teaching raised an interesting point based on their own observation that Thai students' English writing is very much influenced by their Thai writing culture. Explicit interpersonal features of expressing writers' personal opinions and making self-reference are rarely present in advanced academic writing in the Thai language. Such features are considered appropriate in spoken language and excluded from written language.

In regard to the comparisons of metadiscourse in the same disciplines but from different educational contexts, in the English language teaching discipline (NZ-ELT vs. TH-ELT), NZELT students include metadiscourse significantly more often than TH-ELT students $(\mathrm{Nf}=473.1$ in NZ-ELT, $\mathrm{Nf}=428.3$ in TH-ELT). Comparing frequencies of each category between the two groups, the NZ-ELT group uses significantly more interpersonal metadiscourse than the THELT group ( $\mathrm{Nf}=243.8$ in NZ-ELT, $\mathrm{Nf}=184.6$ in TH-ELT). In contrast, the TH-ELT group uses significantly more textual metadiscourse than the NZ-ELT group $(\mathrm{Nf}=229.3$ in NZ-ELT, $\mathrm{Nf}=243.7$ in TH-ELT). Within the business administration discipline (NZ-BA vs. TH-BA), New Zealand and Thai students in this discipline are not significantly different in the frequency 
of using metadiscourse markers in their theses $(\mathrm{Nf}=409.9$ in NZ-BA, $\mathrm{Nf}=423.5$ in $\mathrm{TH}-\mathrm{BA})$. Both groups share the same trend in using textual metadiscourse more often than interpersonal metadiscourse. Comparing frequencies of each category between the two groups, the TH-BA group makes significantly more frequent use of textual metadiscourse than the NZ-BA group $(\mathrm{Nf}=219.7$ in NZ-BA, $\mathrm{Nf}=233$ in TH-BA). There is no significant difference between the two groups in the use of interpersonal metadiscourse ( $\mathrm{Nf}=190.2$ in NZ-BA, $\mathrm{Nf}=190.5$ in $\mathrm{TH}-\mathrm{BA})$.

From these comparisons, NZ-ELT theses are distinctive from the other three subcorpora (NZBA, TH-ELT, and TH-BA) in the more substantial use of interpersonal metadiscourse markers than textual markers. Theses in the three subcorpora are similar in the higher incidence of textual metadiscourse markers than interpersonal markers. This means that students in NZ-BA, TH-ELT, and TH-BA put a great deal of effort into accommodating supervisors and general readers in comprehending their lengthy theses by showing explicit links of ideas in different segments with transition markers, for example. This aligns with findings from the interviews with disciplinary supervisors about their expectations and focus when reading students' theses. As presented in Chapter 7, one primary expectation of the supervisors is to see elaborate arguments and good thesis organization enabling smooth connection and flow when reading from the beginning to the end of the thesis. It is possible that when students bear these expectations in mind, they try to precisely organize the theses and employ some textual metadiscourse markers.

The distinctive use of interpersonal metadiscourse in NZ-ELT theses indicates that NZ-ELT students are not only concerned with the textual features but also try to create rapport with their disciplinary readers. Hyland (2004) argues that the greater use of metadiscourse of more competent students (e.g., PhD vs. master's students) can be seen as a sophisticated approach to language because these competent students need to show not only the ability to handle disciplinary research but also the ability to craft more scholarly and reader-friendly texts in order to project their language competency and ideology to expert readers in their fields. In my study, I consider NZ-ELT students as a more competent group of students based on their linguistic repertoire and familiarity with English academic writing conventions and interpersonal features when compared to Thai students with little exposure to English. Although NZ-ELT and NZ-BA students are similar in terms of ethnicity or status as native English speakers, NZ-BA students seem to have less pressure and motivation to demonstrate their ability in using language and rhetorical strategies to advance their thesis writing. Their 
concentration seems to be much more on presenting the subject content and ensuring that their disciplinary readers thoroughly understand the content.

\subsection{Variation of metadiscourse types}

The analysis of individual types in each of the ten subcategories yields two important findings. First, although New Zealand and Thai students in the two disciplines are different in the frequency of using metadiscourse markers, the relatively high number of shared markers across the four subcorpora indicates their similarity in using similar individual markers in their disciplinary theses. Second, both New Zealand and Thai students in the two disciplines rely heavily on a very small cluster of high frequency markers and make scarce use of lower frequency ones in all subcategories. Importantly, the high frequency markers in each subcategory overlap across the four subcorpora. Some previous studies (e.g., Ädel \& Erman, 2012; Hyland \& Milton, 1997) indicate the general trend that L2 writers are likely to rely on a more limited range of items when compared to L1 writers who have a tendency to use a wider range of items. The findings of the present study, however, vary from the previous studies in relation to this trend. Both New Zealand and Thai students rely on a narrow range of markers in all subcategories and display a number of shared markers in their theses. To a great extent, using a wider range of markers may help render the writing more academic and appealing to the readers. However, in some sense, the reoccurrence of the same high frequency markers may be useful for long-text readers in that it helps readers rapidly realize meanings and achieve comprehension of the overall content in lengthy texts like theses. To recall, high frequency markers here refer to top ten markers in each subcategory presented in Chapters 5 and 6 , and low frequency markers refer to the identified markers below the top ten marker list.

\subsubsection{Types of textual markers}

Starting with transition markers, New Zealand and Thai students in both disciplines have a greater proportion in the use of high frequency transition markers and very sparse use of lower frequency markers. The ten high frequency markers account for approximately $80 \%$ of all transition markers, meaning that only $20 \%$ is accounted for by lower frequency transition markers. However, among the four groups, TH-ELT students show a relatively wider range of higher and lower frequency transition markers in their theses.

Also, however, because, while, and, and therefore are the most prominent markers shared over the four subcorpora. Thus, single-word transition markers are the most prominent feature which 
New Zealand and Thai students use to express relations of their arguments in different segments. This finding is similar to Li and Wharton's (2012) finding of however, therefore, but, and so as the most salient transition markers for Chinese students in their study. Parkinson (2011) also found because is the most frequent marker for the expression of cause in students' laboratory reports, with other frequent markers like therefore and since. Conjunctions, regarded as more spoken features, occur more in students' laboratory reports than in research articles with more adverbial phrases such as due to. Overall, New Zealand and Thai students in the two disciplines are likely to employ the same chunk of simple transition markers and avoid using more complex markers to signal meanings or relations of different segments in their theses. Looking at the lower frequency transition markers outside the top ten marker list, this study found a few markers which occur only in the Thai corpus: in the same way and by the same token in TH-ELT and thereby in TH-BA. These markers are completely omitted from the New Zealand corpus. Despite the infrequent incidence of these "more academic" markers in the Thai corpus, their presence shows the attempt of Thai students, especially in the English language teaching discipline, to enrich their own expression and refine their academic writing through the use of more complex and lower frequency markers.

Next is frame markers. According to the small number of shared types across the four subcorpora (approximately 21 of 45 identified frame markers), New Zealand and Thai students in the two disciplines include different types of markers in their theses. Firstly and finally are found as the most salient sequencers to mark the first and last propositional content in a topic across the four subcorpora. Often, NZ-ELT and NZ-BA students use the letters $a, b$, $c$, etc., but this textual feature is not frequently found in the Thai thesis corpus. TH-ELT, TH-BA, and NZBA students often use a list of Arabic numbers $(1,2,3)$ or Roman numbers $(i, i i$, iii) to order units of arguments. This indicates that master's students in this study tend to structure their arguments in sequences with explicit enumerative and alphabetical features. The predominant use of sequencers reflects students' concern about the density of information in discussion and conclusion chapters which comprise different themes and subsections. A considerable difference between New Zealand and Thai students is the use of frame markers to signpost topic shifts. Thai students give importance to using signposting markers for major shifts to new topics, with heavy use of regarding, with regard to, and concerning. Bruce (2010) found that frame markers such as I will now focus on ... and [new topic] shall now be discussed are used to signal major rhetorical shifts in the body section of British students' sociology essays. These topic shift features are not predominant in New Zealand theses, with a greater emphasis on 
announcing major goals at section and chapter levels through the markers like this section discusses... and the purpose of this chapter is.... Mestre-Mestre (2017) reports the same trend that native English speaking students make substantial use of the marker my purpose is... to announce major discourse goals in thesis discussion and conclusion chapters, whereas Spanish students show greater emphasis on sequencing arguments with heavy use of finally and to conclude.

The third textual subcategory is endophoric markers. There are not many types nor tokens of endophoric markers used in the four subcorpora. Eight high frequency markers on the top ten marker list are the same in the four subcorpora. These are Table $X$, (In) Chapter $X, X$ above, Figure X, X below, X earlier, (In) the X section, and (In) the X chapter. This indicates that New Zealand and Thai students, though to a limited extent, refer readers to statements and related illustrations both in adjacent parts and in other sections and chapters. The findings align with Burneikaite's (2008) work which shows the use of endophoric markers is very limited in British and Lithuanian students' master's theses. $X$ above and $X$ below are salient endophoric markers employed by both British and Lithuanian students to relate current statements to adjacent preceding and following parts. However, her study is different from the present study in that explicit reference to larger units at section and chapter levels (e.g., In Section X, In Chapter X) rarely occurs in her study. In Hyland's (1999) comparison of metadiscourse between textbooks and research articles, endophoric markers in research articles are found to be used quite considerably to refer to tables and graphs rather than referring to explanatory and related materials more broadly as in textbooks.

As other subcategories, the four groups of students show great reliance on high frequency evidential markers. Ranking second in frequency after transition markers in the textual category, this study shows that evidentials, either in integral or non-integral citation form, are principal features in discussion and conclusion chapters. Non-integral citations, $X$ find, $X$ suggest, and $X$ support are high frequency evidential markers shared over the four subcorpora. In addition to these markers, $X$ note, $X$ describe, and $X$ assert frequently occur in New Zealand theses in both disciplines, while $X$ state, $X$ show, and $X$ indicate frequently occur in Thai theses in both disciplines. These findings suggest that reporting verbs play a vital role in citation and that high frequency reporting verbs in New Zealand and Thai theses are quite varied. Hyland (2009) suggests that it is common that research writers in different disciplines employ very different sets of reporting verbs to refer to literature. For instance, high frequency reporting 
verbs identified in his study are $X$ suggest and $X$ argue in the soft disciplines like marketing and applied linguistics and $X$ report and $X$ show in the hard disciplines like biology and physics. The predominance of non-integral citations across the four subcorpora in this study shows the intention of New Zealand and Thai students in both disciplines to reduce emphasis on authors or sources (Hyland, 2005) and to encourage the readers to focus more on propositional content which has been paraphrased from a single or several sources and which has been integrated with their own ideas. Also, as discussed in Section 7.4.3 (Supervisors' comments on use of citations), it could be that in the literature review chapter, writers have already discussed work of others at greater length and are more likely to use integral citations in this chapter and use non-integral citations in discussion and conclusion chapters.

The fifth textual metadiscourse subcategory is code glosses. There are five types of high frequency code glosses shared over the four subcorpora, namely such as, for example, parenthetical gloss (...), e.g., and for instance. Based on these instances of code glosses, it is evident that New Zealand and Thai students in the two disciplines similarly employ code glosses in the discussion and conclusion chapters mainly for the purpose of exemplification rather than reformulation. Code glosses for rephrasing such as in other words and put it in another way occur far less frequently. This supports my contention that New Zealand and Thai theses are likely to be written in a less formal tone, using simpler markers, when compared to writing in research articles which are targeted at a wider audience and have greater expectations of omission of colloquial features (Hyland, 2005). Kobayashi (2016) reveals that Thai students are likely to employ more code glosses than other groups of Asian students (e.g., Japanese students), and high frequency code glosses used to provide supporting examples are such as and for example. Alyousef (2015) indicates that accounting students frequently employ colons and i.e. as instances of code glosses and that much of the reformulation and exemplification is implemented through these visual markers. Likewise, the frequent code glosses found in Kawase's (2015) research are colons, abbreviations in parentheses, and is referred to as, indicating genre-related factors such as writing space between research articles and $\mathrm{PhD}$ theses. Kawase claims that the introduction section of research articles contains a number of code glosses for describing methodological information from the beginning so as to downsize the method section as the narrowest part of research articles, whereas it is less necessary for thesis writers to downsize the method chapter as there is more space and the expectation of greater elaboration in justifying the chosen approach. 


\subsubsection{Types of interpersonal markers}

The first interpersonal metadiscourse subcategory is hedges. Although the incidence of hedges in the New Zealand corpus is considerably higher than in the Thai corpus, New Zealand and Thai students in the two disciplines nevertheless include similar hedging markers in their theses (approximately 40 of 50 hedging markers are shared). Six high frequency hedging markers overlapping on the top ten list across all subcorpora are may, would, could, should, suggest, and indicate. These are also the most frequent hedging items in Hyland's (1998a) crossdisciplinary study. When classifying all the hedging markers found in the data sets according to four grammatical forms (modal verbs, verbs, adjectives, and adverbs) and comparing frequencies, an interesting finding is that New Zealand and Thai students show the same tendency to hedge their arguments mostly through modal verbs (may, should), but their preferences for other forms are different. Besides modal verbs, New Zealand students in the two disciplines prefer hedging through the verb form (suggest, indicate) to adverbs (often, mostly) and adjectives (likely, possible). In contrast, Thai students in the two disciplines prefer to hedge using adverbs compared to verbs and adjectives. The greater use of the modal verb forms over other grammatical forms is consistent with other studies (e.g., Getkham, 2014; Hyland \& Milton, 1997), but this finding is different from Nguyen Thi Thuy's (2018) recent finding, indicating the same inclination of Vietnamese and English research article authors to use epistemic verb forms (indicate, seem, suggest) for hedging arguments. In Nguyen Thi Thuy's study, modal verbs (may, would, could, might, should) account for the second highest proportion, followed by epistemic adverbs (possibly, often, usually) and adjectives (possible, likely, unlikely). It is interesting that modal expressions are said to be complex and problematic for novice writers because they can convey a range of different meanings (Hyland, 2000b; Hyland \& Milton, 1997), but a number of earlier studies (e.g., Alshahrani, 2015; Hyland \& Milton, 1997) and the present study found L2 students still make frequent use of modal verbs to express their evaluative stance towards propositions being conveyed. Previous researchers (Holmes, 1988; Hyland \& Milton, 1997) explain that this may be because students are not taught sufficient expressions as alternatives to categorical assertion, and pedagogical materials seem to place a higher emphasis on teaching modal verbs as principal ways of expressing either tentative or certain propositions. Another interesting point is that despite the same tendency to use modal verbs as hedging markers, there is a distinction between New Zealand and Thai students in their selection of individual modal verbs. While may is the most frequent hedging marker in New Zealand theses in both disciplines, should is the most frequent one in Thai 
theses in both disciplines. As discussed in the Methodology Chapter, although should has both epistemic and deontic modal meanings (Coates, 1987), this study included only the one denoting epistemic necessity of a proposition. The high incidence of should in the Thai corpus can be explained by its pragmatic function; it not only literally expresses students' evaluation of necessity of propositions but also shows their politeness to mitigate confrontation with readers (Getkham, 2014). May appears to be the most prominent hedging marker in many studies (Hardjanto, 2016; Nguyen Thi Thuy, 2018) because of its overt epistemic meaning of tentativeness and possibility and its frequent appearance in the academic genre rather than other genres (Coates, 1987). Apart from modal verbs, the high incidence of reporting verbs (indicate, suggest) in the New Zealand corpus shows another crucial means frequently used by New Zealand students to construct more impersonal and objective propositions in their theses, not only by explicit means of avoiding personal pronouns (self-mentions) and attitudinal expressions. The frequent use of verb+that reporting structure may be attributable to the idea that reporting verbs open an evaluative space to comment on the that-clause or the evaluated entity (Hyland \& Jiang, 2018b), and epistemic verbs identify "both the mode of knowing and its attributing source and carry implications about the reliability of the knowledge itself" (Hyland, 1998c cited in Nguyen Thi Thuy, 2018). In the Thai corpus, the higher incidence of adverbs (often, mostly) which are used for expressing degrees of definiteness (Hyland \& Milton, 1997) can be explained by their positional flexibility. Adverbs are easier for novice writers to manipulate with assurance because they are more common in speech and syntactically mobile in clause structure. This important property of adverbs enables students to use the adverbial markers without grammatical and lexical complications when hedging or even boosting their research claims (Hyland \& Milton, 1997).

Similar to hedges, high frequency boosters can be realized in the grammatical form of modal verbs, verbs, adjectives, and adverbs. Show, find, must, certainly, clearly and always are six high frequency boosters shared over the four subcorpora. New Zealand and Thai students in the two disciplines seem to express their certain views and degree of commitment to research propositions mostly through the use of verbs (show, find) and adverbs (certainly, clearly, always). This is in line with Hinkel's assertion (2002, cited in Hyland, 2005) that academic writers, particularly L2 writers in some cultures, overtly strengthen their claims by means of amplification such as gradable adverbs and verbs. The less frequent use of modal verbs and some other boosting markers aligns with Hyland and Jiang's (2018a) indication that there has been a substantial decrease of boosters in research articles over the past 50 years, particularly 
the modal verb must and cognitive verbs such as recognize, believe, and know. Relating their finding to the high frequency of the verbs show and find in my study, it is possible that the verbs show and find appear to replace those cognitive verbs, indicating a rhetorical change from commitments expressed as personal beliefs to more objective, data-supported assertions (Hu \& Cao, 2015; Hyland \& Jiang, 2018a, 2018b). Most often, strong verbs such as show, prove, and confirm are used to express strong claims of proof which actually refer to a result already published and accepted as fact by the research community in the literature (Parkinson, 2011). Similar to hedges, these reporting verbs commonly occur in the that-clause pattern where agency is attributed to human sources (other scholars, research participants) and abstract or inanimate sources (this analysis, research data, table) rather than the writers themselves. Although must is still the main modal verb of inferential certainty in this study, far fewer occurrences of must when compared to may and should (in the hedging subcategory) suggest thesis students' trend to soften their statements and state the probability objectively rather than making categorical judgments and stating the probability subjectively.

As for attitude markers, New Zealand students are more likely to make greater use of lower frequency attitude markers when compared to Thai students. Thai students have a heavy reliance on a small cluster of attitude markers and do not make frequent use of the attitude markers to express their personal sentiments in theses (Getkham, 2014). Important, interesting, valuable, and significant are the most salient attitude markers which are shared across the four subcorpora. The infrequent use of attitude markers can be explained in relation to an academic writing trend that writers are likely to project a more objective, less personal stance towards the value of their research materials and findings (Hyland \& Jiang, 2018a; Mu et al., 2015). This is evident in the more extensive use of evidential markers than attitude markers in academic writing. In order to manipulate the degree of personality and impersonality and create a greater sense of objectivity in their theses, they avoid explicit expressions of their own stance towards evaluated entities (research materials, findings, reasoning, etc.) by making reference to views or claims of other scholars (Hyland \& Jiang, 2018b; Kawase, 2015). In discussion and conclusion chapters, thesis students seem to use the evaluative expressions (it is interesting..., the finding is valuable...) to direct readers' attention to significance and interestingness of research findings and their interpretations and thereby solicit solidarity with readers.

The fourth interpersonal metadiscourse subcategory is engagement markers. Not many types of engagement markers are employed by New Zealand and Thai students, and Thai students in 
English language teaching employ the smallest cluster of engagement markers when compared to other groups of students. See, we (inclusive), our (inclusive), us (inclusive), and note (be noted) are most prominent engagement markers overlapping across the four subcorpora. In addition to the five markers shared over the four subcorpora, divided by context, New Zealand students in the two disciplines share two other types of engagement markers, namely interrogative markers (rhetorical questions) and personal asides in parentheses/ dashes. The pronouns you and your are found only in NZ-BA. Although Kobayashi (2016) reveals that Thai students use engagement markers, especially second-person pronouns (you, your), significantly more than other groups of Asian students (e.g., Japanese students), second-person pronouns are not found in the Thai thesis corpus in the present study. This may be because second-person pronouns are linguistic features which are prominent in a more informal writing style and spoken language. Because of this, Thai students may find addressing the readers directly in thesis writing inappropriate as the pronouns you and yours give too much sense of confrontation with readers. In Hu and Cao's (2015) study, reader references are most frequently realized by inclusive we, followed by the indefinite pronoun one, and the inclusive determiner our, with the pronoun you occurring occasionally.

The last interpersonal metadiscourse subcategory is self-mentions. New Zealand theses in both disciplines contain more types of self-mentions when compared to Thai theses. The noun researcher is frequently used by New Zealand and Thai students in both disciplines. NZ-ELT students are distinctive from the other three groups in that they more extensively use $I$ rather than researcher. TH-BA students completely avoid the marker $I$ in their theses. TH-ELT students completely avoid exclusive we, while the other three groups sometimes use we in their theses. Taking the authorship of theses into account, it is surprising that NZ-ELT, NZ-BA, and TH-BA students sometimes refer to themselves by using the first-person plural pronoun we, which usually occurs in multiple-authored research articles (Mur Dueñas, 2007). This case is also found in Mur Dueñas' (2007) study, in which first-person plural self-references like exclusive we, us, and our are frequently used in single-authored research articles in Spanish. Hyland (2001) argues that the use of the first-person plural pronoun in single-authored texts indicates "how writers can simultaneously reduce their personal intrusion and yet emphasize the importance that should be given to their unique procedural choices or views." Likewise, the use of researcher rather than $I$ in NZ-BA, TH-ELT, and TH-BA theses can be explained in terms of the avoidance of face-threatening acts. As Mur Dueñas (2007) argues, the use of $I$ seems to be a stronger face-threatening act than the exclusive we and researcher. Thus, the 
greater use of we and researcher in NZ-ELT, NZ-BA, and TH-BA theses suggests students' intention to reduce the strong face-threatening act of personal attributions. However, the frequent use of $I$ rather than we and researcher in NZ-ELT theses can be explained by the fact that NZ-ELT students tend to display an authoritative professional persona as a way to establish solidarity with the members of their disciplinary community (Hyland, 2001; Mur Dueñas, 2007).

\subsection{Variation of metadiscourse functions}

According to the functional analysis of metadiscourse in Chapters 5 and 6, functions of metadiscourse in each subcategory do not vary across the four subcorpora. However, an interesting finding from the functional analysis in this study is the extent to which New Zealand and Thai students in the two disciplines employ markers for each function. Key functions of the ten metadiscourse subcategories are summarized in Table 9.2. Six subcategories whose functions or features contribute to differences between New Zealand and Thai theses are transition markers, frame markers, evidentials, attitude markers, engagement markers, and selfmentions. These six subcategories are discussed in detail below.

Transition markers perform three main functions: adding arguments (also, and), marking contrast of ideas (however, while), and specifying causes and results of actions (because, therefore). The functions of transition markers in the four subcorpora are the same, but the ratios of using transition markers to represent each function are interestingly different. New Zealand students in the two disciplines most frequently use transition markers to denote adversative relations, followed by additive relations, and causative and resultative relations, respectively. In contrast, Thai students in the two disciplines tend to include transition markers mostly for the additive function, with a slight difference between adversative and causative functions. This suggests Thai students' preference for a progressive style of writing, which is adding arguments in the same direction. As similarly reported in Alsharani's (2015) study, English and Arab doctoral students show the same preference for a progressive style over a retrogressive style with greater use of additive markers than comparative and consequential markers. In Lee and Casal's (2014) cross-linguistic study, Spanish writers favor a retrogressive style with greater use of comparative and consequential markers, whereas English writers prefer a progressive style with greater use of additive markers. Nonetheless, in the present study, New Zealand (L1) students are different from those English writers reported in the two 
previous studies. They show a retrogressive style of writing through frequent use of adversative markers.

Table 9.2. Summary of key functions of metadiscourse subcategories

\begin{tabular}{|c|c|}
\hline Subcategory & Key functions and features of metadiscourse in master's theses \\
\hline Transition markers & $\begin{array}{l}\text { (1) adding arguments } \\
\text { (2) marking contrasting ideas } \\
\text { (3) specifying causes and results of actions }\end{array}$ \\
\hline Frame markers & $\begin{array}{l}\text { (1) sequencing arguments } \\
\text { (2) labelling discourse acts } \\
\text { (3) announcing discourse goals } \\
\text { (4) signposting topic shifts }\end{array}$ \\
\hline Endophoric markers & $\begin{array}{l}\text { (1) linear text references } \\
\text { (2) non-linear text references }\end{array}$ \\
\hline Evidentials & (1) providing a source attribution for arguments \\
\hline Code glosses & $\begin{array}{l}\text { (1) exemplifying } \\
\text { (2) rephrasing }\end{array}$ \\
\hline Hedges & $\begin{array}{l}\text { (1) expressing tentativeness of research findings } \\
\text { (2) making possible justifications } \\
\text { (3) reducing frankness of assertions } \\
\text { (4) discussing theoretical and practical implications } \\
\text { (5) commenting on research limitations } \\
\text { (6) suggesting alternative methods for further research }\end{array}$ \\
\hline Boosters & $\begin{array}{l}\text { (1) warranting certainty of research findings } \\
\text { (2) adding persuasion } \\
\text { (3) indicating necessity of an action }\end{array}$ \\
\hline Attitude markers & $\begin{array}{l}\text { (1) claiming the value of research } \\
\text { (2) indicating interestingness in different findings } \\
\text { (3) commenting on research methods and findings } \\
\text { (4) emphasizing (un)expected outcome } \\
\text { (5) projecting (un)acceptance of claims }\end{array}$ \\
\hline Engagement markers & $\begin{array}{l}\text { (1) reader references } \\
\text { (2) directives } \\
\text { (3) interrogatives (asking rhetorical questions) } \\
\text { (4) personal asides }\end{array}$ \\
\hline Self-mentions & $\begin{array}{l}\text { (1) labelling discourse acts } \\
\text { (2) expressing attitudes } \\
\text { (3) making arguments } \\
\text { (4) describing research procedures }\end{array}$ \\
\hline
\end{tabular}


Frame markers have four main functions: sequencing arguments, labelling discourse acts, announcing discourse goals, and signposting topic shifts (Hyland, 1998b, 2005). The similarity across the four subcorpora was that identified frame markers are employed mainly for sequencing arguments and structuring the thesis discussion and conclusion chapters. However, a clear difference between New Zealand and Thai students is that Thai students in both disciplines exhibit considerable use of frame markers for signposting topic shifts, but this feature is rarely used in NZ-ELT theses and completely omitted from NZ-BA theses. Hyland (1999) also found that frame markers identified in his study are used mainly for sequencing lists of points in the discussion part of research articles and announcing goals in the introduction part. The substantial use of signposting markers in the Thai corpus indicates the greater concern of Thai students about the readers' processing needs in following the dense chapters. In contrast, assuming that expert readers have sensitivity to be aware of the shifts, it is possible that New Zealand students may see the provision of signposting markers as an option but not highly necessary since relations or connections between arguments are already there by virture of meanings, and writers can choose to or not to make the connections explicit (Mauranen, 1993).

Another interesting subcategory showing a great difference between New Zealand and Thai theses is evidentials. A primary function of evidential markers is to provide a source attribution for arguments which are not originally derived from the writer of the current text. When writing discussion and conclusion chapters, thesis students refer to literature not only to build support for their justification and interpretation of findings in the chapters (Hyland, 2005) but also to highlight where new knowledge as contributions of their studies is added to prior literature in the fields. Generally, the evidential function can be expressed in two forms: integral citations and non-integral citations. A combination of all the integral citation occurrences reveals inverse proportions of integral citation and non-integral citation between New Zealand and Thai theses, indicating different practices in the use of evidentials between students in the two contexts. Thai students in both disciplines prefer integral citations to non-integral citations. The use of reporting verbs preceded with cited authors in the subject position illustrates that Thai students in the two disciplines tend to present comments and statements from scholars in the fields in the narrative feature and give a great emphasis on the original attributors. By contrast, New Zealand students in the two disciplines have a greater preference for non-integral citations than integral citations. This pattern is very evident in hard disciplines (Hyland \& Tse, 2004). The predominant use of non-integral citations in New Zealand theses reflects students' intention 
and writing style not to give much weight to who originally owns ideas. This is an effective means to reduce human intervention (Hyland, 2005) and increase a sense of objectivity in research writing. It also reflects New Zealand students' preference and practice of building arguments based on information generalized from several sources rather than information summarized from one single source, which encourages them to put the names of cited authors in parentheses (Hyland \& Jiang, 2018a).

The use of attitude markers also displays a difference in New Zealand and Thai theses. In this study, attitude markers are employed to express thesis writers' perceptions on propositional content in five aspects, namely importance (important, essential), interestingness (interesting, interestingly), quality (unique, salient), predictability (expected, unfortunately), and acceptability (agree, acceptable). Among five aspects, New Zealand and Thai students show the same tendency in making less frequent use of attitude markers to demonstrate their personal viewpoints in terms of quality (of research methods), predictability (of findings) and acceptability (of propositional content). In particular, TH-ELT students do not use markers of acceptability (agree, acceptable, understandable) to project their evaluative judgement about propositions from previous studies or show their acceptance of present findings. Most of the attitude markers identified in this study (it is important, it is interesting) are used by New Zealand and Thai students to emphasize the value of their research in the section of research contributions. Moreover, they are used for the explicit expression of importance and interestingness of some research findings and topics or actions which cannot be addressed in current studies as a suggestion for general readers who may be interested in making practical use of the research. This coincides with Hyland and Jiang's (2018b) contention that "in academic contexts, attitude is typically expressed in terms of judgments of importance, novelty and interest" (p. 157). They indicate a change of stance expressions that academics do not tend to express attitudinal meanings such as affect (like and dislike, expectation, etc.), or obligation (what they think should be done), but they tend to use attitude markers to express common accepted knowledge (it is true that).

Next is engagement markers. As the frequencies of engagement markers in all four subcorpora are very low, I adopted Hyland's (2005) analytical framework to identify distinctive features of types of engagement markers found in this study. The finding is that engagement markers in New Zealand and Thai theses are used to have readers engage in their theses through the four following features: reader references, interrogatives, directives (imperatives), and 
personal asides. Similar to Hu and Cao's (2015) finding, engagement markers identified in this study mostly occur in the form of reader references (inclusive we) and directives (see, let's, it is important to notel consider). Regarding a considerable difference between the two disciplines, NZ-ELT and TH-ELT students show more frequent use of the imperatives in their theses, while NZ-BA and TH-BA students tend to make more direct references to the readers (we). As for interrogatives and personal asides, it is interesting that these two features are substantially used by New Zealand students in the two disciplines but almost completely avoided by Thai students. Although these features remain relatively infrequent, Hyland and Jiang (2018a) report a slight increase of engagement markers in science disciplines over decades, i.e., biologists have doubled their use of rhetorical questions and electrical engineers have substantially increased their use of directives and reference to readers through the marker inclusive we. A decrease in the frequency of using asides (personal comments in parentheses and dashes) and explicit references to shared knowledge such as of course in disciplinary writing indicates "less confidence in what can be reliably called up as shared or the common knowledge which can be referred to with an aside" (p. 27). This may be in response to the trend of interdisciplinary research and the need to communicate with other non-specialist outsiders.

The incidence of self-mentions reveals variation in thesis-writing practices across different educational contexts. New Zealand students are more likely to present themselves in their theses and overtly take personal responsibility for their assertions. New Zealand students especially in the language teaching discipline make extensive use of the first-person pronoun $I$ pointing to the thesis writers themselves. In contrast, Thai students in both English language teaching and business administration disciplines make very sparse use of the first-person pronoun $I$ (and other first-person pronouns me and mine), indicating their avoidance of selfmentioning and personalizing their theses with the use of first-person pronouns. The noun researcher and the first-person plural pronoun we are the markers Thai students sometimes use for authorial presence. Even though it is acknowledged that theses individually have single writers, Thai writers are likely to use the plural pronoun form to present their own theses in a more impersonal and inclusive way. Pronouns ( $I$, we) and nouns (writer, researcher) which refer to the writers are found to collocate with other types of markers like the hedging markers suggest and argue as well as the boosting markers believe and found. Self-mentions focus on the writers' involvement in theses with four main purposes depending on types of markers being collocated: self-mentions collocated with frame markers for labelling discourse acts (Following this, I will discuss ...); self-mentions collocated with attitude markers for expressing 
attitudes towards evaluated entities (The researcher agrees...); self-mentions collocated with hedges/boosters for making tentative and assertive arguments (I would argue...); and selfmentions collocated with action verbs/nouns for describing research procedures (the researcher designed..., the researcher's observation). These four rhetorical functions are relevant to the functions of exclusive we in Mur Dueñas' (2007) study. In her business text corpus, exclusive we appears to perform eight different rhetorical functions: explaining a procedure (we used); making a claim or statement, elaborating on an argument (we suggest); stating a hypothesis, an expectation or a wish (we predicted); stating a goal or purpose (we focus); showing results or findings (we found); assessing the limitations of their research (we were unable to); assessing the strengths of their research (we report); and outlining the steps followed in the research articles (we develop).

\subsection{Relationship between the use of metadiscourse and quality of thesis writing}

As mentioned in Chapter 2, there have been a few studies investigating the association of metadiscourse with writing quality. All of these studies which focused on essay writing reveal the same robust trend that high scoring essays demonstrate a higher frequency and a broader range of metadiscourse markers than low scoring essays (Chang, 2014; Intaraprawat \& Steffensen, 1995; Noble, 2010; Sanford, 2012). However, there has been very little information about the relationship between metadiscourse frequencies and quality of thesis writing. Discussing thesis quality in reference to findings of essays seems not sensible as some metadiscourse features, e.g., citations and certainty markers, are less likely to be found in essays (Crismore et al., 1993; Mohamed \& Rashid, 2017), but the present study and other previous studies of research writing (Hyland, 2004) have discovered that the two features are found to be predominant in thesis and research article writing.

Divided by discipline, two raters in English language teaching rated twenty four discussion and conclusion chapters of theses in the language teaching discipline, and two raters in business administration rated twenty four discussion and conclusion chapters in the business discipline. All raters used the same rating scale to assess thesis quality in four aspects (i.e., content, organization and presentation, language use, and genre knowledge). Overall, the Spearman results reveal significant correlations between metadiscourse frequencies and quality of theses in both English language teaching and business administration disciplines. Theses in the two disciplines show similarity in containing more textual metadiscourse than interpersonal metadiscourse. When looking at the average frequencies across textual and interpersonal 
categories, theses in the two disciplines also exhibit the same pattern that the frequencies of transition markers and hedges are extremely high and very different from the frequencies of other subcategories. The subcategory with the least frequent use of all is engagement markers. The following sections discuss correlations between metadiscourse and quality of theses in each discipline.

\subsubsection{English language teaching theses}

English language teaching thesis quality scores are moderately correlated with frequencies in the use of metadiscourse overall. Out of the four quality aspects, metadiscourse frequencies are highly correlated with content scores and organization and presentation scores. No significant correlations are found between metadiscourse frequencies and language use and genre knowledge scores. In other words, the use of metadiscourse in English language teaching theses seems to be associated with the communication of content as well as textual organization and presentation rather than language use and genre knowledge. Frequencies of textual and interpersonal metadiscourse are significantly associated with the quality scores. However, interpersonal metadiscourse, compared to textual metadiscourse, is more closely related to the quality scores of theses in English language teaching.

A closer examination of textual and interpersonal subcategories suggests that not all subcategories are related to the overall quality scores. In the textual metadiscourse category, only evidentials and code glosses (i.e., making extensive comparison with prior findings and clarifying meanings of propositions) are significantly correlated with the overall quality scores. Surprisingly, transition markers, the type that has the highest frequency, are unlikely to contribute to the overall quality of thesis writing. These findings suggest that evidentials and code glosses, although with moderate to low frequencies, are important features of the quality of thesis writing in the language teaching discipline. This may be because the two features reflect students' concern about linking current studies with existing knowledge or literature in their field and making elaborate arguments for readers' clear and effortless comprehension. As Hyland and Jiang (2018a) suggest, there has been a marked increase of evidentials and code glosses in research articles, given that research writers use the two features in order to make their ideas more transparent and their texts more persuasive to the readers, especially less specialized readers outside their specialist area. 
As for interpersonal metadiscourse, all subcategories of interpersonal metadiscourse, except for boosters, are correlated with the overall quality scores. Attitude markers seem to have the greatest correlation with the overall scores. This implies that interpersonal metadiscourse features are crucial to the quality of thesis writing in English language teaching. Making appropriate claims with hedging markers, engaging readers and writers themselves in theses with engagement markers and self-mentions, and expressing evaluative stance towards research findings and literature are likely to be the features expected by the raters which might affect the quality scores of English language teaching theses.

\subsubsection{Business administration theses}

In business administration, there is a highly positive correlation between metadiscourse frequencies and the overall quality scores. Metadiscourse frequencies are significantly correlated with all four quality aspects: content, organization and presentation, language use, and genre knowledge. A major difference between the two disciplines is that in business administration, the frequency of textual metadiscourse is more highly related to the quality scores when compared to interpersonal metadiscourse, but in English language teaching, the frequency of interpersonal metadiscourse is more closely related to the quality scores.

With respect to the textual metadiscourse category, transition markers have the strongest correlation with overall scores at a high level of significance, followed by endophoric markers and frame markers. The correlations of evidentials and code glosses are significant at a moderate level. While evidentials and code glosses are the only two textual subcategories whose correlations with the quality scores are statistically significant in English language teaching, they are less significant features in business administration. This means that transition markers, endophoric markers, and frame markers play a more vital role in the quality of theses in business administration.

In the interpersonal metadiscourse category, attitude markers, engagement markers, and selfmentions are not significantly correlated with overall quality scores or scores in any of the four aspects. Only hedges and boosters are correlated with the quality scores at a high level of significance. This is rather opposite to the pattern in English language teaching in which all interpersonal subcategories, except for boosters, are correlated with the quality scores.

These findings reveal a striking difference in the effect of using metadiscourse on thesis quality scores between the two disciplines. All textual metadiscourse subcategories are more crucial 
and positively related to the quality score of theses in business administration than interpersonal features. Only hedging and boosting features in the interpersonal category show significant correlations with the quality scores. In English language teaching, on the other hand, all interpersonal features, except for making assertive claims with boosters, are more important and likely to be correlated with the quality scores of theses than textual features. Only evidentials and code glosses show significant correlations with the quality scores.

The difference reflects that expert raters or readers in each discipline place a greater emphasis on different aspects, either textual or interpersonal features, in students' theses. Business administration raters might focus more on the potential of textual features which directly affect readers' comprehension and impression of the whole theses such as clarity and connectedness of ideas (content) from smaller to larger units within and across chapters. In this discipline, raters might focus on students' ability to evaluate and manage the strength of claims, with less concern about explicit authorial presence and reader involvement. In English language teaching, raters not only show their primary concern about textual features but also have more expectations of the interactional features reflecting students' care about readers and their authorial position. The overt use of some textual features such as transition markers might be considered less important than the explicit expression of students' attitudes towards their own research propositions.

\subsubsection{Quality scores in high and low frequency groups}

The comparison of quality scores between high and low frequency groups yields different results between English language teaching and business administration disciplines. A difference in scores between high and low frequency groups is found to be statistically significant only in business administration, but not in English language teaching. This means that the higher frequency of metadiscourse is likely to significantly affect the scores of theses solely in business administration. The different results between the two disciplines raise the issue of whether the results can be explained simply by the fact the higher frequency of metadiscourse is likely to affect the higher scores of theses. If this were the case, the result in the English language teaching discipline would have shown a significant difference in scores between high and low frequency groups.

To find out why the difference in scores between high and low frequency groups is significant in business administration but not significant in English language teaching, gaps in frequencies 
in each subcategory, ranks of textual and interpersonal subcategories, and percentages of individual markers shared between high and low frequency groups were taken into consideration.

When comparing the frequencies of each subcategory, it is clear that the high frequency group has more metadiscourse occurrences than does the low frequency group in all subcategories. However, in English language teaching and business administration disciplines, gaps in frequencies between high and low frequency groups suggest that frequencies of transition markers and hedges contribute mainly to a distinctive difference between the two groups. Frequencies of the remaining subcategories between the two groups are not very different. This means that making relationships of segments explicit (e.g., cause and effect) and showing subtlety in argument and due caution in reporting and discussing results are important to quality.

When considering metadiscourse distribution and ranges of types of markers in English language teaching, high and low frequency groups show similarities in the ranks of textual subcategories and individual markers but a slight difference in the ranks of interpersonal subcategories.

For the textual metadiscourse subcategories, the two groups contain the highest frequency of transition markers and evidentials and the lowest frequency of endophoric markers. Frame markers and code glosses rank third and fourth, and vice versa between the two groups. For the interpersonal metadiscourse subcategories, the two groups show the highest frequency of hedges and lower frequencies of boosters, attitude markers, and engagement markers. A difference between the two groups is self-mentions. The self-mention markers obtain the second highest use after hedges in the high frequency group, but they obtain the lowest use in the low frequency group.

In terms of types of markers, the high frequency group contains more types of markers in every subcategory than does the low frequency group. However, when looking at the types of markers shared between the two frequency groups, it is worth noting that most of the markers identified in the low frequency group are also found in the high frequency group (approximately $70-80 \%$ of markers shared, especially in the subcategories of transition markers, code glosses, selfmentions, and hedges). 
Despite the difference in frequencies, high and low frequency groups are not largely different from each other in terms of the distribution (ranks) of textual subcategories and individual markers identified. Although the ranks of interpersonal subcategories are slightly different due to the higher tokens of self-mentions in the high frequency group, this difference might not be influential enough to affect the scores between high and low frequency groups in English language teaching.

To find out why there is a significant difference in scores between high and low frequency groups in business administration, gaps in frequencies in each subcategory, ranks of textual and interpersonal subcategories, and percentages of markers shared between high and low frequency groups were taken into consideration. Frequencies of transition markers and hedges contribute mainly to a distinctive difference between high and low frequency groups in business administration, whereas frequencies of the remaining subcategories between the two groups are not very different.

In this discipline, high and low frequency groups show similarities in the ranks of interpersonal subcategories but a slight difference in the ranks of textual subcategories and types of markers. For the textual subcategories, the two groups contain the highest frequency of transition markers and the lowest frequency of endophoric markers. In the high frequency group, evidentials obtain the second highest use, followed by code glosses and frame markers. In the low frequency group, frame markers obtain the second highest use, followed by evidentials and code glosses. For the interpersonal subcategories, the two groups contain the highest frequency of hedges, followed by boosters and attitude markers. Engagement markers and self-mentions obtain the lowest use.

When taking types of markers into consideration, the theses in the high frequency group not only have higher occurrences of markers but also a greater variety in terms of individual items. As presented in the result section of business administration (Chapter 8), percentages of shared types between high and low frequency groups in business theses are not very high, when compared to theses in English language teaching discipline. In English language teaching, most markers (approximately 70-80\%), especially in the subcategories of transition markers, code glosses, self-mentions, and hedges, are the same in the two groups (with only $20-30 \%$ of different types of markers in these subcategories). In business administration, the high frequency group contains at least $40 \%$ of markers in each subcategory different from the low frequency group. Types in endophoric markers, evidentials, and code glosses are the most 
different (about 60\%) between the two groups. It can be argued that high and low frequency groups in business administration have a great difference in terms of types of markers.

These findings indicate that apart from the difference in frequencies between high and low frequency groups, the considerable differences in terms of the ranks of textual subcategories and types of markers may contribute to the significant difference in scores between the two groups. To associate these findings with the correlations between frequencies of metadiscourse subcategories and quality scores, all textual metadiscourse subcategories and hedging and boosting subcategories are positively correlated with the quality scores of theses in business administration. When high and low frequency groups show differences in terms of gaps in frequencies of transition markers and hedges (the significantly larger number of transition markers and hedges in the high frequency group) and even overall ranks of textual subcategories, these differences are likely to affect the quality scores between the two groups. In English language teaching, although the larger number of transition markers and hedges is also found in the high frequency group, the frequencies of transition markers are not correlated with the quality scores in this discipline. Thus, the higher frequency of markers in certain subcategories (e.g., making explicit links between segments with transition markers or making claims with caution by hedging) may have a big impact on the quality scores in one discipline but may not have any impact in another discipline given that the features may not be crucial or highly expected by raters in the discipline. Moreover, the raters may not only take into considation the frequency of use but also appropriate use of a wider range of markers.

\subsection{Chapter summary}

This chapter has explicated plausible reasons for similarities and differences in metadiscourse frequencies, types, and functions across educational contexts and disciplines in regard to the insufficient discussion of metadiscourse (especially the notion of writer-reader interaction in academic texts) in L2 writing classes, the anticipation of readership, and the nature or requirements of English language teaching and business administration disciplines. The discussion of more or less frequent use of metadiscourse also reflects different thesis writing styles of New Zealand and Thai students in the two disciplines. In addition, this chapter has discussed the findings of Study 2 regarding certain types of metadiscourse which are correlated with thesis writing quality in each discipline as well as factors apart from frequencies (i.e., distribution ranks of metadiscourse subcategories and ranges of markers) which might affect the quality scores. 


\section{CHAPTER 10 \\ CONCLUSION AND IMPLICATIONS}

This thesis has explored variation of metadiscourse across educational contexts and disciplines and investigated the widely held assumption that metadiscourse frequencies are likely to affect quality of writing. This chapter summarizes findings of Study 1 focusing on metadiscourse frequencies, types, and functions (Section 10.1) and findings of Study 2 regarding the relationship between metadiscourse frequencies and quality of thesis writing (Section 10.2). In light of the two studies, this chapter also discusses the theoretical, methodological, and pedagogical implications (Sections 10.3-10.5) as well as limitations and recommendations for further research (Section 10.6).

\subsection{Summary of Study 1}

Study 1 sought to reveal similarities and differences in the use of metadiscourse (i.e., frequencies, types, and functions) in master's thesis discussion and conclusion chapters. The chapters were written in English by New Zealand and Thai postgraduates in the disciplines of English language teaching and business administration. Four subcorpora with a total of 116 thesis samples were compiled: 26 NZ-ELT theses, 30 NZ-BA theses, 30 TH-ELT theses, and 30 TH-BA theses. This study adopted Hyland's (2005) metadiscourse taxonomy to investigate both textual and interpersonal metadiscourse in thesis writing. Textual metadiscourse includes transition markers, frame markers, endophoric markers, evidentials, and code glosses. Interpersonal metadiscourse includes hedges, boosters, attitude markers, engagement markers, and self-mentions. The following are the key findings of Study 1.

\subsubsection{Frequencies of metadiscourse}

This section discusses contextual and disciplinary variation of metadiscourse frequencies. Overall, the present study found a higher incidence of metadiscourse in New Zealand theses than in Thai theses. While both New Zealand and Thai students show a higher use of textual metadiscourse than interpersonal metadiscourse, New Zealand students show a significantly greater reliance on the use of interpersonal metadiscourse than Thai students. Thai students place a significantly greater reliance on the use of textual metadiscourse than New Zealand students. 
Out of the ten subcategories of textual and interpersonal metadiscourse, transition markers and hedges are the most prominent metadiscourse features in both New Zealand and Thai theses. These two subcategories respectively contribute the preponderance of textual and interpersonal metadiscourse in this study.

Comparing the degree of preference for each textual subcategory between New Zealand and Thai thesis corpora (see Table 9.1) reveals the different focus of New Zealand and Thai students when dealing with textual features in their theses. The higher incidence of evidentials and code glosses in New Zealand theses than in Thai theses suggests a greater emphasis of New Zealand students on clarifying their thoughts by providing examples and aside information and on supporting the credentials of research claims by using published work to support them. In contrast, the higher incidence of transition markers and frame markers in Thai theses than in New Zealand theses indicates the greater concern of Thai students for sequencing and making explicit links between arguments.

Comparing the use of each interpersonal subcategory between the New Zealand and Thai thesis corpora emphasizes the salience of interpersonal features in New Zealand theses. The higher incidence of hedges, attitude markers, engagement markers, and self-mentions in New Zealand theses than in Thai theses indicates the difference in the rhetorical preference of New Zealand students for expressing personal stance and arguments explicitly with due circumspection in thesis writing. Boosters are the only interpersonal metadiscourse subcategory that Thai students use more often than New Zealand students to emphasize the strength of their commitment to research claims and reinforce their power of conviction.

With regard to variation between English language teaching and business administration disciplines, a higher incidence of metadiscourse, both textual and interpersonal metadiscourse, is found in English language teaching theses. Comparing each textual subcategory between the two disciplines, English language teaching students use endophoric markers and evidentials more often than business administration students. Given the nature of research as theory-based and more subjective, students in English language teaching have more need to form their arguments in reference to prior work and provide sufficient previewing and reviewing markers when referring the readers to other parts of theses than students in business administration. The business students show a higher use of transition markers than the language teaching students, indicating their greater emphasis on facilitating the readers' comprehension of arguments. 
As for the interpersonal subcategories, business students do not make more frequent use of any interpersonal subcategories, whereas language teaching students make more frequent use of hedges, engagement markers, and self-mentions than business students. This means that out of the ten textual and interpersonal metadiscourse subcategories, transition markers are the only subcategory that business administration students use more often than English language teaching students. Taking the anticipation of readership into consideration, the finding suggests that students in business administration may have less pressure and concern about language use and rhetorical conventions than English language teaching students.

\subsubsection{Types of metadiscourse}

The analysis of individual types in each of the ten subcategories yields two important findings. First, despite differences in frequencies, New Zealand and Thai students in the two disciplines use similar markers in their theses, as indicated by the relatively high number of shared markers across the four subcorpora. Second, both New Zealand and Thai students in the two disciplines rely heavily on a very small cluster of high frequency markers and make scarce use of lower frequency ones in all subcategories. Importantly, high frequency markers in each subcategory overlap across the four subcorpora. The following section recapitulates salient individual markers in the ten subcategories found in the present study.

In the transition marker subcategory, also, however, because, while, and, and therefore are the most frequent markers shared over the four subcorpora. Single-word transition markers are the most prominent feature which New Zealand and Thai students use to express relationships between segments of their arguments, rather than using more complex transition markers (consequently, as a result).

In the frame marker subcategory, firstly and finally are the most salient sequencers in the four subcorpora. NZ-ELT and NZ-BA students use the alphabetical sequencers $(a, b, c)$, but this textual feature is rarely found in the Thai thesis corpus. TH-ELT, TH-BA, and NZ-BA students often use the enumerative feature $(1,2,3$ or $i, i$, iii). TH-ELT and TH-BA students often use signposting markers (regarding, with regard to, concerning) for major shifts to new topics, but this textual feature is not frequently found in the New Zealand thesis corpus

In the endophoric marker subcategory, Table X, (In) Chapter X, X above, Figure X, X below, $X$ earlier, (In) the $X$ section, and (In) the $X$ chapter are the high frequency endophoric markers shared in the four subcorpora. New Zealand and Thai students, though to a limited extent, 
refer readers to statements and related illustrations both in adjacent parts and in other sections and chapters.

In the evidential subcategory, either integral or non-integral citation forms are principal features in discussion and conclusion chapters. Non-integral citations, $X$ find, $X$ suggest, and $X$ support are the high frequency evidential markers shared over the four subcorpora. Reporting verbs play a vital role in citation.

In the code gloss subcategory, the high frequency code glosses shared over the four subcorpora are such as, for example, parenthetical gloss (...), e.g., and for instance. New Zealand and Thai students in the two disciplines tend to employ simpler code glosses mainly for the purpose of exemplification rather than reformulation (in other words, put another way).

In the hedging subcategory, may, would, could, should, suggest, and indicate are the high frequency hedging markers common over the four subcorpora. Based on four grammatical forms (modal verbs, verbs, adjectives, and adverbs), New Zealand and Thai students show the same tendency to hedge their arguments mostly through modal verbs (may, should).

In the boosting subcategory, show, find, must, certainly, clearly, and always are six high frequency boosters common over the four subcorpora. Based on the grammatical forms, New Zealand and Thai students in the two disciplines make assertive claims mostly through the use of verbs (show, find) and adverbs (certainly, clearly, always). Similar to hedges, reporting verbs commonly occur in the that-clause pattern where agency is attributed to human sources (other scholars, research participants) and abstract or inanimate sources (this analysis, research data, table) rather than the writers themselves.

In the attitude marker subcategory, important, interesting, valuable, and significant are the most salient attitude markers shared across the four subcorpora. Rather than using these markers to express their own stance towards evaluated entities (research materials, findings, reasoning, etc.), they are more likely to refer to views or published claims of other scholars.

In the engagement marker subcategory, see, we (inclusive), our (inclusive), us (inclusive), and note (be noted) are the most prominent engagement markers overlapping across the four subcorpora. Apart from the five markers, NZ-ELT and NZ-BA students share two other types of engagement markers, namely interrogative markers (asking rhetorical questions) and 
personal asides. The second-person pronouns you and your are absent from the Thai corpus but present in the New Zealand corpus.

In the self-mention subcategory, New Zealand theses in the two disciplines contain more types of self-mentions when compared to Thai theses. The noun researcher is frequently used by New Zealand and Thai students in the two disciplines. NZ-ELT students are distinctive from the other three groups in that they more extensively use I rather than researcher. The use of we is not found in TH-ELT theses.

\subsubsection{Functions of metadiscourse}

In this study, functions of metadiscourse in each subcategory do not vary across the four subcorpora, but the extent to which New Zealand and Thai students in the two disciplines employ markers for each function is different. Key functions of the ten metadiscourse subcategories are summarized in Table 9.2. The section below reviews six subcategories whose functions or features contribute to differences between New Zealand and Thai theses, namely transition markers, frame markers, evidentials, attitude markers, engagement markers, and selfmentions.

New Zealand students in both disciplines most frequently use transition markers to denote adversative relations, followed by additive relations and causative and resultative relations, respectively. This shows New Zealand students' preference for a retrogressive style of writing. In contrast, Thai students in both disciplines tend to include transition markers mostly for the additive function, suggesting their preference for a progressive style of writing.

New Zealand and Thai students tend to use identified frame markers mainly to sequence arguments and structure the thesis discussion and conclusion chapters. A clear difference between New Zealand and Thai students is that Thai students in both disciplines show considerable use of frame markers for signposting topic shifts, but this feature is rarely used in NZ-ELT theses and completely omitted from NZ-BA theses.

A combination of all the integral citation occurrences reveals inverse proportions that Thai students in both disciplines prefer integral citations to non-integral citations, whereas New Zealand students in both disciplines have a greater preference for non-integral citations than integral citations. 
Most of the attitude markers identified in this study (it is important, it is interesting) are used by New Zealand and Thai students to emphasize the value of their research in the section of research contributions. They are mainly used to express common accepted knowledge and to highlight importance and interestingness of topics or actions which should be addressed in future research.

Engagement markers identified in this study mostly occur in the features of reader references (inclusive we) and directives (see, let's, it is important to note/ consider). A marked difference between the two disciplines is that NZ-ELT and TH-ELT students show more frequent use of the directive or imperative feature in their theses, while NZ-BA and TH-BA students tend to make more direct references to the readers. In regard to interrogative and personal aside features, these two features are substantially used by New Zealand students in the two disciplines but almost completely avoided by Thai students.

Last, Thai students tend to take a more traditional approach to thesis writing by making less frequent use of self-mentions $(I, w e)$, whereas New Zealand students focus more on selfreferencing and taking ownership of their claims than Thai students. Main purposes of using self-mention markers in New Zealand and Thai theses depend on types of markers being collocated: self-mentions collocated with frame markers for labelling discourse acts; selfmentions collocated with attitude markers for expressing attitudes towards research findings; self-mentions collocated with hedges/ boosters for making tentative and assertive arguments; and self-mentions collocated with action verbs/ nouns for describing research procedures.

\subsection{Summary of Study 2}

Study 2 addressed the issue of the relationship between metadiscourse frequencies and quality of thesis writing. Forty eight theses (twelve theses with highest and lowest frequencies of metadiscourse markers in each of the four subcorpora in Study 1) were selected for this study. Semi-structured interviews were conducted with twenty four disciplinary supervisors in New Zealand and Thailand in order to investigate supervisors' attitudes towards and expectations of good thesis writing in their disciplines. This information was used to design a rating scale specifically for thesis quality assessment. Two New Zealand and Thai raters in English language teaching and business administration, four raters altogether, rated twenty four discussion and conclusion chapters in their own disciplines. They used the same rating scale to assess thesis quality in four aspects: content, organization and presentation, language use, and 
genre knowledge.

The findings of Study 2 reveal a positive correlation between metadiscourse frequencies and thesis quality scores in both English language teaching and business administration disciplines. However, a major difference between the two disciplines is that in business administration, the frequency of textual metadiscourse is more highly related to the quality scores when compared to interpersonal metadiscourse. In English language teaching, the frequency of interpersonal metadiscourse is more highly related to the quality scores.

A closer examination of textual and interpersonal subcategories suggests that not all subcategories are related to the overall quality scores. With regard to English language teaching theses, in the textual metadiscourse category, only evidentials (making extensive comparison with prior findings) and code glosses (clarifying meanings) are significantly correlated with the overall quality scores. Transition markers are unlikely to contribute to the overall quality of thesis writing in the language teaching discipline. In the interpersonal metadiscourse category, all subcategories of interpersonal metadiscourse, except for boosters, are correlated with the overall quality scores.

As for business administration theses, all textual metadiscourse subcategories are correlated with the overall quality scores. Transition markers have the strongest correlation with the quality scores at a high level of significance, followed by endophoric markers and frame markers. Comparing between the two disciplines, transition markers, endophoric markers, and frame markers seem to play a more vital role in the quality of theses in business administration. In the interpersonal metadiscourse category, only hedges and boosters are significantly correlated with the quality scores. This is rather opposite to the pattern in English language teaching in which all interpersonal subcategories, except for boosters, are correlated with the quality scores.

In comparing quality scores between high and low frequency groups, a statistically significant difference is found only in business administration, but not in English language teaching. This means that the higher frequency of metadiscourse is likely to affect the scores of theses solely in business administration.

To associate these findings with the correlations between frequencies of metadiscourse subcategories and quality scores as mentioned above, all textual metadiscourse subcategories and hedging and boosting subcategories are positively correlated with the quality scores of 
theses in business administration. When high and low frequency groups show differences in terms of gaps in frequencies of transition markers and hedges (the significantly larger number of transition markers and hedges in the high frequency group) and even overall ranks of textual subcategories, these differences are likely to affect the quality scores between the two groups. In English language teaching, high and low frequency groups also have a distinctive difference in the use of transition markers and hedges, but the correlation results indicate that the high frequency of transition markers is not correlated with the quality scores in this discipline.

\subsection{Theoretical implications}

The present thesis has made three main theoretical contributions to metadiscourse and postgraduate writing assessment fields.

\subsubsection{Providing more rigorous criteria for identifying some ambiguous metadiscourse markers}

Even though this study took a top-down approach with a set of pre-identified metadiscourse markers and adopted Hyland's (2005) taxonomy as an analytical framework, identifying metadiscourse in a large amount of data is still a demanding task. This is because metadiscourse broadly includes a wide range of linguistic devices which can be realized in different grammatical forms and perform different functions. The list of pre-identified markers accommodates analysts in terms of searching and tracking potential items, but determining whether each particular item is metadiscourse or not and which function it performs is sometimes unclear and requires a lot of careful justification. This may cause conflicting views in identifying metadiscourse across different studies.

As I have presented in Chapter 3 (Research methodology), during the data analysis process, I had four unclear points related to transition markers (linking adverbials, coordinators and subordinators), hedges, and boosters. As a novice metadiscourse analyst, I reviewed previous metadiscourse studies to find detailed explanations of how they decided to include or exclude ambiguous items, but I found little information addressing the difficulties in the studies. Most of the studies provided only categories of metadiscourse markers in general. Therefore, in order to minimize the subjectivity and ensure a coding consistency within this study, I gave a full account for setting criteria in assigning linguistic items as metadiscourse. The criteria benefit from my preliminary analysis of my authentic data (four thesis subcorpora) and revisiting relevant theories, e.g., Hyland's (2005) Metadiscourse Theory, Halliday and Hasan's (1976) 
Cohesion Theory, and Coates and Leech's (1980) The Meanings of the Modals Theory. The following section summarizes my answers for the four unclear points (see detail in Chapter 3):

(1) whether prepositional phrases followed by a noun (in contrast to + noun, as a result of + noun) should be metadiscourse

Answer: The present study included prepositional phrases followed by a noun (in contrast to, as a result of) insofar as they mark a reference to a link between information in the previous segment and the current one.

(2) whether coordinators linking main clauses (and, but, or, so) should be metadiscourse

Answer: This study included coordinators linking between main clauses. This clearly excluded items connecting a group of nouns and verbs (cable TV and audio-visual aids).

(3) whether subordinators (because, although) should be metadiscourse

Answer: Focusing on functions, subordinators were counted as transition markers if they mark a logical relation between "ideas" or "arguments" of the text writer. As in "Another participant (S11) said that although she had expected them weekly, she ...," the subordinator although was excluded.

(4) whether all meanings of modal verbs in hedge and booster categories should be metadiscourse

Answer: This study included only epistemic modals and excluded deontic ones. Epistemic modals which convey tentativeness, possibility, uncertainty, and cautious commitment were counted in the hedging subcategory. Epistemic modals which convey the writer's confidence in making claims and evaluation of certainty and necessity of a proposition were counted in the booster subcategory. Modal verbs which concern obligation, permission and ability were omitted. As in "The subjects in their study could use the concordances for error-correction...," the modal verb could was excluded.

In addition to frameworks given by respective scholars in the metadiscourse field, this information might help other metadiscourse analysts, especially novice ones, clarify their confusion when analyzing the ambiguous markers. 


\subsubsection{Proposing further description of writer-responsible and reader-responsible writing cultures based on metadiscourse perspectives}

A number of contrastive studies seek to classify writing characteristics of L1 and L2 writers' academic texts based on Hinds' (1987) notion of writer-responsible and reader-responsible writing culture. Put simply, texts with more explicit use of textual-organizing devices are characterized as writer-responsible writing style, as opposed to reader-responsible texts. As often mentioned in this study, Mauranen (1993) reveals a more reader-responsible culture in Finnish writers' texts and a more writer-responsible culture in American writers' texts with more extensive use of metatext. However, when I tried to identify characteristics of thesis writing produced by New Zealand (L1) and Thai (L2) students, I found that Hinds' notion is premised on textual features in a text. This is to say, interpersonal features have not been taken into account and placed on the writer-responsible and reader-responsible styles of writing. A question arose when I discovered that the two groups of students in my study have different degrees of using textual and interpersonal markers in their texts, reflecting different degrees of writer responsibility for textual organization and writer-reader interaction. If students make more explicit use of textual markers but make less frequent use of interpersonal markers, should their texts be characterized as writer-responsible or reader-responsible writing, regardless of graduations between?

As seen in Section 2.2 (Contrastive rhetoric), this study proposed use of interpersonal metadiscourse markers as a further description of writer-responsible and reader-responsible cultures, in addition to use of textual metadiscourse markers as a criterion. In writer-responsible cultures, writers produce their writing with an orientation to readers. They explicitly engage themselves and readers in the texts and indicate to the readers whether propositions are certain facts or tentative opinions, so that the readers can interpret the propositions with more careful consideration. In reader-responsible cultures, writers are likely to be implicit in participating in the text and addressing the readers. When considering the writers' use of textual and interpersonal markers, it is possible that texts may indicate the writers' high responsibility for giving explicit textual guidance but less responsibility for building writer-reader interaction in the texts, or vice versa. Thus, this thesis has provided descriptions of the two writing cultures based on metadiscourse perspectives, which might be beneficial to further contrastive research on metadiscourse. To characterize academic writing styles, focus should not be on the writers' responsibility for textual features only but also their responsibility for interactional features. 


\subsubsection{Proposing rating criteria for thesis quality assessment}

Considering the lack of rating scales for thesis quality assessment, this research has provided a significant contribution to the existing literature in assessment. This study included interviews with supervisors and examiners in English language teaching and business administration with regard to their rating practices and criteria when they examine theses. The interview information was utilized as a basis for designing a rating scale for thesis quality assessment in Study 2.

With regard to the rating practices, almost all of Thai and New Zealand informants indicated that they view thesis assessment as a holistic process. They consider all aspects in the theses as a big picture and mark the theses holistically rather than focusing on one single aspect and criticizing it. They do not have fixed criteria or detailed rating scales for assessing theses. Nevertheless, basic elements that they automatically take into account when reading a thesis are the clarity of content, thesis organization, and the way the writers use language to present the content and develop a line of argument.

During the interviews, there were four aspects that most disciplinary supervisors frequently referred to when they examined thesis discussion and conclusion chapters. The four main aspects were content, organization and presentation, language use, and genre knowledge. These four aspects were used as rating criteria for assessing writing quality of discussion and conclusion chapters. The innovative rating scale with score descriptions used in this study is presented in Chapter 7. In brief, the provision of rating practice information and the thesis rating scale may be beneficial to supervisors, postgraduate students, and researchers in the area of assessment.

\subsection{Methodological implications}

This thesis has four main methodological implications which will be discussed in this section.

\subsubsection{Taking into account both contextual and disciplinary factors}

This study took into account both contextual and disciplinary factors. To begin with the contextual part, most previous cross-cultural studies use the writers' first language as the grouping criteria. In this study, L1 students' theses were selected not only based on their first language but also their educational contexts because L1 students (American, British, and New 
Zealand students) are likely to have a variety of rhetorical preferences and writing styles. This can be inferred from the contradictory results reported in prior cross-cultural work on metadiscourse. Therefore, this study included only theses written by New Zealand and Australian writers who had studied at New Zealand universities.

In addition to the issue of selecting L1 writers' theses, this cross-contextual study also took into account variation of disciplines within each context, instead of focusing on contexts or disciplines separately. As expected, the comparisons between the two different disciplines within each context and the same disciplines in different contexts yield valuable results showing that the use of metadiscourse between the two disciplines is not different in the Thai context, where there is not much variation in use of textual metadiscourse nor interpersonal metadiscourse. In contrast, in the New Zealand context, the two disciplines display a significant difference in the use of interpersonal metadiscourse. This indicates that disciplinary requirements are more influential on thesis writing in the New Zealand context, but less influential in the Thai context where some contextual factors such as local institutional culture may have a stronger effect than disciplinary ones. In brief, this thesis highlights the value of examining two relevant factors in the same study.

\subsubsection{Developing a list of markers from different sources}

Metadiscourse studies taking a top-down approach typically adopt only one model or source of pre-identified markers. However, this thesis makes a methodological contribution by way of creating a list of markers based on three sources before actual identification:

(1) Hyland's (2005) list of metadiscourse markers

(2) List of common words extracted from the theses in my corpus

(3) The Academic Word List (AWL) (https://www.victoria.ac.nz/lals/resources/ academicwordlist/most-frequent) (Coxhead, 2000)

First, I used Hyland's (2005) list of metadiscourse markers as a starting point of creating a marker list and data coding for this study. Then I expanded Hyland's list by finding potential markers from my own data by using the tool "WordList" in WordSmith to create a list of common words extracted from the theses in my corpus and find some potential markers which are not present on Hyland's list. Finally, I looked for other items in the AWL, a valuable resource of academic words used at tertiary level across a wide range of disciplines. It is important to note that although this study used the pre-identified marker list, the searching was 
not limited to the markers on the prepared list. In the actual identification process, I also read annotations line by line in order to look for other markers in sentential context. Apart from using this methodology, future researchers can include the additional items identified in this study in their analyses (see Appendix 1).

\subsubsection{Conducting interviews with disciplinary supervisors}

Prior work on metadiscourse often includes follow-up interviews with text producers (writers) as part of metadiscourse analysis in order to provide reasons behind their use of metadiscourse. However, this study changed the direction from interviewing student writers to interviewing thesis supervisors or examiners for two main reasons. First, they are the target readers of theses who play a very important role in guiding students in terms of content or even style of writing and in evaluating the quality of theses to ensure the theses meet the standard at postgraduate level. Second, their expectations of thesis content and style of writing are likely to influence or shape how students write and use metadiscourse to a great extent.

Therefore, semi-structured interviews with disciplinary supervisors in Thailand and New Zealand were included as a bridge between Study 1 and Study 2 for two main purposes. Interview data were used to supplement the discussion of metadiscourse findings in Study 1 and to design a rating scale for thesis quality assessment in Study 2. In addition to these main purposes, the supervisor interviews have also contributed to a better understanding of (1) disciplinary practices in terms of structuring master's theses and research articles in Thai and New Zealand educational contexts, (2) important elements of discussion and conclusion chapters, (3) and rating practices and criteria for examining master's thesis discussion and conclusion chapters, as presented in Chapter 7. Interviewing disciplinary supervisors provides useful information to enlighten postgraduate students as to what supervisors in their disciplines expect to see in their theses.

\subsubsection{Assessing quality of thesis writing and use of metadiscourse}

The fourth methodological contribution of the thesis is the way in which the relationship between metadiscourse frequencies and thesis quality scores was examined. In addition to metadiscourse analysis in Study 1, Study 2 was designed to investigate the widely held assumption that metadiscourse frequencies are likely to affect quality of writing. There have been some previous studies investigating the correlation between the two variables, but the investigations have focused on undergraduate writing only. The findings from this study, 
therefore, provide grounds for further research on metadiscourse and postgraduate writing assessment. Moreover, the rating scale which has been designed for assessing thesis quality based on supervisors and examiners' expectations might be useful for further work on thesis quality assessment.

\subsection{Pedagogical implications}

This thesis has shown some variation in the use of metadiscourse in master's theses across two educational contexts and disciplines. This means that, to a greater or lesser extent, the use of metadiscourse and thesis writing conventions are influenced by genre-specific requirements, rhetorical practices in different contexts, and disciplinary communities. Therefore, the following section addresses pedagogical implications with an emphasis on the application of genre analysis, contrastive analysis, and metadiscourse analysis to postgraduate writing instruction.

\subsubsection{Developing postgraduate students' genre, intercultural, and interdisciplinary knowledge through authentic materials from different sources}

The first pedagogical recommendation of the present study is to develop postgraduate students' genre, intercultural, and interdisciplinary knowledge by means of genre analysis and contrastive analysis using authentic materials from different sources. As indicated in research on postgraduate writing, master's students are novice researchers and writers who often seek advice on researching the subject matter and writing their initial theses. From my own observation, although there are thesis writing advice books available for students' self-learning, those published books mainly concern the macro-structure of theses. The topic of rhetorical options like metadiscourse features for thesis writing seems to be neglected or inadequately discussed in the materials. Thus, it is necessary to give students specific knowledge of writing in the thesis genre from their early stage of postgraduate study, for instance, providing a presessional course of English for Postgraduate Writing.

In the writing course, postgraduate writing instructors may start from introducing the overall macro-structure or chapters of a thesis and then proceed with highlighting communicative functions of each chapter. The supervisor interviews in this study suggest that with the partgenre knowledge, students will better understand what kind of content (discourse moves and steps) should be included in each chapter and what kind of rhetorical strategies are essential for rendering their writing more effective. 
As frequently mentioned in the supervisor interviews, one important strategy that supervisors use when supervising thesis students is asking them to consult previous theses. This suggests that, apart from lecturing or providing theoretical knowledge, it is important to provide students the opportunity to learn from reading and analyzing authentic materials such as research articles and previous theses in their disciplines. However, given that not all previous work is very well written, students should not be left with the decision what to read as a model. Supervisors may need to provide guidance or discuss with students which previous work is well written. Moreover, students should be encouraged to explicitly analyze such texts rather than just ask them to read the texts and assume that they will pick up on such language features. By this means, students can internalize what good theses in the disciplines look like and familiarize themselves with academic language use and rhetorical conventions in research-based writing. Besides gaining better knowledge of the genre, through analyzing authentic thesis samples, students can anticipate expectations of readers and rhetorical practices in their disciplinary communities. In consequence, it is likely that their theses will meet the expectations of the readers and obtain acceptance by members in their communities.

However, sources of the materials should not be limited to only their own institutional repositories. Instructors and supervisors, especially in non-English speaking contexts like Thailand, should encourage students to read more English research papers from different sources and written by either advanced L1 or L2 students in different contexts, so that students in the same disciplines can observe how their peers in other educational contexts write theses and thus draw on a variety of professional writing styles and rhetorical strategies in their own writing.

Alternatively, postgraduate instructors and students can also consult the findings of this study addressing the issues of writing theses in the two contexts and disciplines and using metadiscourse as rhetorical devices to improve thesis writing quality. Thus, the findings from this study highlight the importance of engaging novice thesis students with authentic research texts so as to enhance their awareness and knowledge of postgraduate writing conventions in different educational contexts and disciplines. 


\subsubsection{Developing postgraduate students and instructors' awareness and knowledge of metadiscourse}

The second pedagogical recommendation is to enhance students' awareness and knowledge of both textual and interpersonal metadiscourse by means of metadiscourse analysis using a concordance tool.

The discussion chapter indicates that both New Zealand and Thai students have a relatively high concern in regard to textual metadiscourse features. However, Thai students have more limited use of rhetorical features like self-authorial reference, reader engagement and seem to have much less concern about interpersonal features in thesis writing, when compared to New Zealand students.

The findings above clearly contribute to a pedagogical implication, especially in the Thai context, other L2 contexts, and even L1 contexts with a number of L2 students. Postgraduate writing instructors may need to help raise students' awareness of using interactional features in academic texts on a par with textual features. Not only in terms of frequency of use, knowledge of metadiscourse types, functions, and grammatical patterns should be brought into discussion in postgraduate writing classes.

In postgraduate writing classes, instructors should highlight frequent metadiscourse features that postgraduate students need to master when writing theses. That is to say, some sessions in writing classes should be designed to address the topics of managing research claims through hedges and boosters, creating explicit links and flow throughout the theses through transition markers, making appropriate citations, engaging the writers themselves and readers into the theses through self-mentions, asking rhetorical questions, and so forth.

One learning activity that has been suggested in several studies is to incorporate a concordance tool into writing classes. The instructors and students can utilize either the list of all markers identified in this thesis corpus (Appendix 1) or the higher frequency marker list for each metadiscourse subcategory presented in the findings chapters (e.g., Table 5.9, Table 6.9, etc.) as teaching and learning materials when identifying markers and learning the functions and patterns of use from the concordance lines. Using the tool to analyze metadiscourse in previous thesis samples and published articles, students can better understand how each marker is used in sentences and learn to use academic words more appropriately from the authentic thesis samples. 


\subsection{Limitations and recommendations for future research}

This section discusses five major limitations and suggestions for further research drawn from Study 1 and Study 2. Each limitation and suggestion is presented in turn below.

The first limitation is related to the ethical issue of utilizing copyrighted theses in Study 1 . After I had consulted copyright guidelines provided by universities in New Zealand and Thailand and made initial contact with their librarians, I found that different universities have different systems of granting permission to outsiders to make use of theses even for academic purposes. In New Zealand, thesis authors hold the copyright to their own work, whereas in Thailand, universities hold the copyright. This means that even though the theses are openaccess, I needed to contact each individual thesis author in New Zealand and contacted Thai universities for consent. As a result of this constraint, I needed to exclude theses for which authors were not able to be contacted for consent and for which Thai universities did not grant permission to use their theses for my research purpose. Despite a large collection of New Zealand and Thai theses available online, the dataset in this study was limited to 116 thesis samples from six universities in New Zealand and only from two universities in Thailand because of these constraints. Therefore, the findings may not represent the rhetorical conventions of theses in all universities in New Zealand and Thailand.

From my own observation, most previous contrastive studies used thesis authors' names as an indicator and assumed that the theses were written by native speakers of English. However, the outcome of contacting individual authors whose names sound English indicated that not all of them speak English as their first language. This suggests that using names as an indicator to determine authors' ethnicity and language backgrounds might not be effective in comparative research. A recommendation for further research dealing with L1 writers is to find different ways to confirm text authors' identities and obtain their consent in order to ensure the accuracy of findings and also avoid the ethical malpractice.

The second issue relates to the need to focus on discussion and conclusion chapters rather than the whole theses. As this study compared a wide range of metadiscourse markers between two contexts and two disciplines, a careful analysis of only the chapters where a number of metadiscourse markers are likely to be found was more manageable and less time consuming for the coder than analyzing the whole theses. Given that different chapters have different communicative purposes, the findings of this study may not be generalizable beyond discussion 
and conclusion chapters. Thus, a recommendation for further research is to examine metadiscourse features in other chapters of theses. The findings of such investigations may provide more specific recommendations of language features for other chapters, which can be used as teaching materials about salient metadiscourse in each individual chapter.

The third limitation is that this study did not undertake a further analysis of research paradigms in each discipline. The findings of this study indicate significant variation of metadiscourse frequencies and types between English language teaching and business administration, and the possibility of differences was discussed in relation to the nature of research or research paradigms in each discipline (e.g., theory-based research in ELT vs. operation-based research in BA). However, the discussion was drawn mainly on the information from the interviews with supervisors in the fields only. As a deeper analysis of the paradigmatic factor is outside the scope of this study, a further analysis of research paradigms between the two disciplines in future research may be beneficial to understand the nature of research and use of rhetorical strategies in the two disciplines better.

The fourth limitation is related to the lack of accepted rating scales for thesis writing assessment in Study 2. There was a need for this study to set rating criteria and design a generic rating scale to assess thesis quality. Although I ensured the validity of the scale through a pilot study with two supervisors before the actual assessment, the scale may need some improvement. A recommendation from this limitation is that further research on thesis quality assessment should treat the scale from this study as a model and refine the score descriptions for assessing other chapters, the whole theses, or even the discussion and conclusion chapters themselves.

The fifth limitation concerns low interrater agreement in Study 2. Although Pearson's correlation results indicated significant positive correlations between individual scores assigned by the two raters in both disciplines, the level of interrater agreement is considered low (Salkind, 2010). This may undermine the quality rating results in Study 2. It is possible that although a detailed rating scale was provided for analytic assessment in this study, raters from two different educational contexts may have taken a holistic process as they do in the actual practice of thesis examination. As Lumley (2002) suggests, in the actual rating process, while raters try to remain close to the scale provided, they are inevitably influenced by their impression of the text obtained when they first read it. The findings of this study, hence, may be authentic in terms of the raters' rating process and differences between the scores assigned to theses in the two contexts. Since reasons for the differences in assigning scores in this study 
are not obvious, future research may need to account for this issue and improve the agreement level, for example, by (1) providing raters additional guidelines to assist their scoring decisions, (2) administrating a more proper training in rating and implementing the rating scale, so that all raters can rate in a similar manner (Lumley, 2002), and (3) including a session for raters to describe their rating process to understand their scoring decisions better.

The last limitation is about statistical analyses in Study 1 and Study 2. Log-likelihood was used in Study 1 to support significance of frequency differences when comparing each pair of subcorpora, and the Spearman's correlation test was used in Study 2 to indicate significance of correlations between frequencies of each metadiscourse subcategory and the quality scores. Although the two tests are very common and widely used in corpus-based research dealing with uneven distributions of frequency data and aiming to indicate trends in corpora, they might not be powerful enough for multiple tests such as in experimental research which requires a strict control of a familywise error-rate by means of a $p$-value adjustment before drawing firm conclusions based on statistical figures (Larson-Hall, 2009; Pallant, 2001). Given that the focus of the present study was on providing evidence of trends rather than trying to improve the correlations, this study set alpha levels at .05 and .01 to detect correlations which may exist between quality of thesis writing and frequencies of metadiscourse and indicate the potential correlations for future research to work on. It may be of great value for future research to replicate the study for more robust measurement of association strengths.

\subsection{Final remarks}

This thesis has provided valuable insight into how postgraduate students across educational contexts and disciplines organize their theses and manage knowledge claims and what kind of rhetorical strategies are essential for students to master when writing disciplinary theses. Such information may be useful for English for Academic Purposes instruction at postgraduate level. It also sheds light for postgraduate students on their supervisors' attitudes towards and expectations of good thesis writing in their disciplines. Finally, this thesis has documented the impacts of certain metadiscourse features on quality of theses in different disciplines. 


\section{REFERENCES}

Ädel, A. (2006). Metadiscourse in L1 and L2 English. Amsterdam: John Benjamins.

Ädel, A. (2010). Just to give you kind of a map of where we are going: A taxonomy of metadiscourse in spoken and written academic English. Nordic Journal of English Studies, 9(2), 69-97.

Ädel, A., \& Erman, B. (2012). Recurrent word combinations in academic writing by native and non-native speakers of English: A lexical bundles approach. English for Specific Purposes, 31(2), 81-92. https://doi.org/10.1016/j.esp.2011.08.004

Ädel, A., \& Mauranen, A. (2010). Metadiscourse: Diverse and Divided Perspectives. Nordic Journal of English Studies, 9, 1-11.

Akbas, E. (2012). Interactional Metadiscourse in Turkish Postgraduates Academic Texts: A Comparative Study of How They Introduce and Conclude. I-Manager's Journal on English Language Teaching, 2(3), 35-44.

Akbas, E., \& Hardman, J. (2018). Strengthening or Weakening Claims in Academic Knowledge Construction: A Comparative Study of Hedges and Boosters in Postgraduate Academic Writing. Educational Sciences: Theory \& Practice, 18(4). https://doi.org/10.12738/estp.2018.4.0260

Alshahrani, A. A. S. (2015). A Cross-linguistic Analysis of Interactive Metadiscourse Devices Employment in Native English and Arab ESL Academic Writings. Theory and Practice in Language Studies, 5(8), 1535-1542. https://doi.org/10.17507/tpls.0508.01

Alyousef, H. S. (2015). An Investigation of Metadiscourse Features in International Postgraduate Business Students' Texts: The Use of Interactive and Interactional Markers in Tertiary Multimodal Finance Texts. SAGE Open, 5(4), 1-10.

Biber, D., Johansson, S., Leech, G., Conrad, S., \& Finegan, E. (1999). Longman grammar of spoken and written English. Essex: Pearson Education, Limited. 
Bitchener, J., \& Basturkmen, H. (2006). Perceptions of the difficulties of postgraduate L2 thesis students writing the discussion section. Journal of English for Academic Purposes, 5(1), 4-18. https://doi.org/10.1016/j.jeap.2005.10.002

Blagojevic, S. (2004). Metadiscourse in academic prose: A contrastive study of academic articles written in English by English and Norwegian native speakers. Kalbu Studijos, (5), 60-67.

Bruce, I. (2009). Results sections in sociology and organic chemistry articles: A genre analysis. English for Specific Purposes, 28(2), 105-124. https://doi.org/10.1016/j.esp.2008.12.005

Bruce, I. (2010). Textual and discoursal resources used in the essay genre in sociology and English. Journal of English for Academic Purposes, 9(3), 153-166. https://doi.org/10.1016/j.jeap.2010.02.011

Bunton, D. (1999). The use of higher level metatext in Ph.D theses. English for Specific Purposes, 18, 41-56.

Bunton, D. (2005). The structure of PhD conclusion chapters. Journal of English for Academic Purposes, 4(3), 207-224. https://doi.org/10.1016/j.jeap.2005.03.004

Burneikaite, N. (2008). Metadiscourse in Linguistics Master's Theses in English L1 and L2. KALBOTYRA, 59(3), 38-47.

Chan, T. H. T. (2015). A corpus-based study of the expression of stance in dissertation acknowledgements. Journal of English for Academic Purposes, 20, 176-191. https://doi.org/10.1016/j.jeap.2015.09.005

Chang, L. (2014). The Relationship between Metatext and College Students' Writing Quality. Proceedings of the 2014 2nd International Conference on Advances in Social Science, Humanities and Management. https://doi.org/10.2991/asshm-14.2014.30

Cheng, X., \& Steffensen, M. S. (1996). Metadiscourse: A technique for improving student writing. Research in the Teaching of English, 30(2), 149-181.

Coates, J. (1987). Epistemic modality and spoken discourse. Transactions of the Philological Society, 85(1), 110-131. 
Coates, J., \& Leech, G. (1980). The Meanings of the Modals in British and American English. York Papers in Linguistics, 8, 23-34.

Cohen, A. D. (1994). Assessing language ability in the classroom (2nd ed.). Boston, MA: Heinle and Heinle Publishers.

Connor, U. (1998). Contrastive rhetoric: Developments and challenges. Studia Anglica Posnaniensia: International Review of English Studies, 105-116.

Connor, U. (2002). New Directions in Contrastive Rhetoric. TESOL Quarterly, 36(4), 493510. https://doi.org/10.2307/3588238

Coxhead, A. (2000). A New Academic Word List. TESOL Quarterly, 34(2), 213-238. https://doi.org/10.2307/3587951

Crismore, A., Markkanen, R., \& Steffensen, M. S. (1993). Metadiscourse in Persuasive Writing. Written Communication, 10(1), 39-71.

Dafouz-Milne, E. (2008). The pragmatic role of textual and interpersonal metadiscourse markers in the construction and attainment of persuasion: A cross-linguistic study of newspaper discourse. Journal of Pragmatics, 40(1), 95-113. https://doi.org/10.1016/j.pragma.2007.10.003

Dahl, T. (2004). Textual metadiscourse in research articles: A marker of national culture or of academic discipline? Journal of Pragmatics, 36(10), 1807-1825. https://doi.org/10.1016/j.pragma.2004.05.004

Field, A. (2013). Discovering statistics using SPSS (4th ed.). London: Sage.

Fulcher, G. (2003). Testing second language speaking. London: Pearson Longman.

Gardezi, S. A., \& Nesi, H. (2009). In M. Charles, S. Hunston, \& D. Pecorari (Eds.) Academic Writing: At the Interface of Corpus and Discourse (pp. 236-250). London: Continuum.

Getkham, K. (2014). Politeness Strategies in Thai Graduate Research Paper Discussions: Implications for Second/Foreign Language Academic Writing. English Language Teaching, 7(11), 159-167. https://doi.org/10.5539/elt.v7n11p159 
Gholami, J., \& Ilghami, R. (2016). Metadiscourse markers in biological research articles and journal impact factor: Non-native writers vs. native writers: Metadiscourse Markers in Biological Research Articles. Biochemistry and Molecular Biology Education, 44(4), 349-360. https://doi.org/10.1002/bmb.20961

Grabe, W., \& Kaplan, R. B. (1996). Theory and practice of writing. New York: Longman.

Gries, S. T. (2010). Useful statistics for corpus linguistics. A Mosaic of Corpus Linguistics: Selected Approaches, 66, 269-291.

Halliday, M. A. K. (1973). Explorations in the functions of language. London: Edward Arnold.

Halliday, M. A. K. (2014). Halliday's Introduction to Functional Grammar (4th ed.). London: Routledge.

Halliday, M. A. K, \& Hasan, R. (1976). Cohesion in English. London: Longman.

Hardjanto, T. D. (2016). Hedging through the Use of Modal Auxiliaries in English Academic Discourse. Humaniora, 28(1), 37-50.

Hewings, M., \& Hewings, A. (2002). "It is interesting to note that...": A comparative study of anticipatory 'it' in student and published writing. English for Specific Purposes, 21(4), 367-383.

Hinds, J. (1987). Reader versus writer responsibility: A new typology. In U. Connor \& R. B. Kaplan (Eds.), Writing across languages: Analysis of L2 Text (pp. 141-152). Reading, MA: Addison-Wesley.

Hinkel, E. (2002). Second language writer's text: Linguistic and rhetorical features. Mahwah, NJ: Lawrence Erlbaum Associates.

Holmes, J. (1988). 'Doubt and certainty in ESL textbooks'. Applied Linguistics, 91, 20-44.

Hu, G., \& Cao, F. (2015). Disciplinary and paradigmatic influences on interactional metadiscourse in research articles. English for Specific Purposes, 39, 12-25. https://doi.org/10.1016/j.esp.2015.03.002 
Huddleston, R., \& Pullum, G.K. (2002). The Cambridge grammar of the English language. Cambridge: Cambridge University Press.

Hyland, K. (1998a). Boosting, hedging and the negotiation of academic knowledge. TextInterdisciplinary Journal for the Study of Discourse, 18(3), 349-382.

Hyland, K. (1998b). Persuasion and context: The pragmatics of academic metadiscourse. Journal of Pragmatics, 30, 437-455.

Hyland, K. (1998c). Hedging in Scientific Research Articles. Amsterdam: John Benjamins.

Hyland, K. (1999). Talking to Students: Metadiscourse in Introductory Coursebooks. English for Specific Purposes, 18(1), 3-26.

Hyland, K. (2000a). Hedges, boosters and lexical invisibility: Noticing modifiers in academic texts. Language Awareness, 9(4), 179-197.

Hyland, K. (2000b). 'It might be suggested that...': Academic hedging and student writing. 'It Might Be Suggested That... ': Academic Hedging and Student Writing, 16(1), 8397. https://doi.org/10.1075/aralss.16.06hyl

Hyland, K. (2001). Humble servants of the discipline? Self-mention in research articles. English for Specific Purposes, 20, 207-226.

Hyland, K. (2004). Disciplinary interactions: Metadiscourse in L2 postgraduate writing. Journal of Second Language Writing, 13(2), 133-151. https://doi.org/10.1016/j.jslw.2004.02.001

Hyland, K. (2005). Metadiscourse: Exploring interaction in writing. London: Continuum.

Hyland, K. (2009). Writing in the disciplines: Research evidence for specificity. Taiwan International ESP Journal, 1(1), 5-22.

Hyland, K. (2017). Metadiscourse: What is it and where is it going? Journal of Pragmatics, 113, 16-29. https://doi.org/10.1016/j.pragma.2017.03.007

Hyland, K., \& Jiang, F. (2016). Change of attitude? A diachronic study of stance. Written Communication, 33(3), 251-274. 
Hyland, K., \& Jiang, F. (2018a). "In this paper we suggest”: Changing patterns of disciplinary metadiscourse. English for Specific Purposes, 51, 18-30. https://doi.org/10.1016/j.esp.2018.02.001

Hyland, K., \& Jiang, F. (2018b). 'We Believe That ... ': Changes in an Academic Stance Marker. Australian Journal of Linguistics, 38(2), 139-161. https://doi.org/10.1080/07268602.2018.1400498

Hyland, K., \& Milton, J. (1997). Qualification and certainty in L1 and L2 students' writing. Journal of Second Language Writing, 6(2), 183-205. https://doi.org/10.1016/S10603743(97)90033-3

Hyland, K., \& Tse, P. (2004). Metadiscourse in Academic Writing: A Reappraisal. Applied Linguistics, 25(2), 156-177.

Intaraprawat, P., \& Steffensen, M. S. (1995). The use of metadiscourse in good and poor ESL essays. Journal of Second Language Writing, 4(3), 253-272. https://doi.org/10.1016/1060-3743(95)90012-8

Jacoby, S., \& McNamara, T. (1999). Locating Competence. English for Specific Purposes, 18(3), 213-241. https://doi.org/10.1016/S0889-4906(97)00053-7

Jakobson, R. (1998). On Language: Roman Jakobson. L. R. Waugh \& M. Monville-Burston (Eds.). Cambridge, MA and London: Harvard University Press.

Jiang, F., \& Hyland, K. (2017). Metadiscursive nouns: Interaction and cohesion in abstract moves. English for Specific Purposes, 46, 1-14. https://doi.org/10.1016/j.esp.2016.11.001

Johns, A. M., \& Swales, J. M. (2002). Literacy and disciplinary practices: Opening and closing perspectives. Journal of English for Academic Purposes, 1(1), 13-28. https://doi.org/10.1016/S1475-1585(02)00003-6

Kaplan, R. B. (1966). Cultural thoughts patterns in international education. Language Learning, 16(1), 1-20. 
Kawase, T. (2015). Metadiscourse in the introductions of $\mathrm{PhD}$ theses and research articles. Journal of English for Academic Purposes, 20, 114-124. https://doi.org/10.1016/j.jeap.2015.08.006

Knoch, U. (2009). Diagnostic assessment of writing: The development and validation of a rating scale. Frankfurt: Peter Lang.

Knoch, U. (2011). Rating scales for diagnostic assessment of writing: What should they look like and where should the criteria come from? Assessing Writing, 16(2), 81-96. https://doi.org/10.1016/j.asw.2011.02.003

Knoch, U., \& Macqueen, S. (2016). Language assessment for the workplace. In D. Tsagari \& J. Banerjee (Eds.), Handbook of Second Language Assessment (pp. 291-308). De Gruyter Mouton. https://doi.org/10.1515/9781614513827-020

Kobayashi, Y. (2016). Investigating Metadiscourse Markers in Asian Englishes: A CorpusBased Approach. Language in Focus, 2(1), 19-35. https://doi.org/10.1515/lifijsal2016-0002

Koutsantoni, D. (2006). Rhetorical strategies in engineering research articles and research theses: Advanced academic literacy and relations of power. Journal of English for Academic Purposes, 5(1), 19-36. https://doi.org/10.1016/j.jeap.2005.11.002

Larson-Hall, J. (2009). A Guide to Doing Statistics in Second Language Research Using SPSS (1st ed.). Routledge. https://doi.org/10.4324/9780203875964

Lee, J. J., \& Casal, J. E. (2014). Metadiscourse in results and discussion chapters: A crosslinguistic analysis of English and Spanish thesis writers in engineering. System, 46, 39-54. https://doi.org/10.1016/j.system.2014.07.009

Leki, I. (1991). Twenty-Five Years of Contrastive Rhetoric: Text Analysis and Writing Pedagogies. TESOL Quarterly, 25(1), 123-143. https://doi.org/10.2307/3587031

Li, L. (2016). Sentence initial bundles in L2 thesis writing: A comparative study of Chinese L2 and New Zealand L1 postgraduates' writing (Doctoral dissertation, The University of Waikato, Hamilton, New Zealand). https://doi.org/10.13140/rg.2.2.21287.14245 
Li, T., \& Wharton, S. (2012). Metadiscourse repertoire of L1 Mandarin undergraduates writing in English: A cross-contextual, cross-disciplinary study. Journal of English for Academic Purposes, 11(4), 345-356. https://doi.org/10.1016/j.jeap.2012.07.004

Lumley, T. (2002). Assessment criteria in a large-scale writing test: What do they really mean to the raters? Language Testing, 19(3), 246-276. https://doi.org/10.1191/02655322021t230oa

Markkanen, R., Steffensen, M. S., \& Crismore, A. (1993). Quantitative Contrastive Study of Metadiscourse: Problems in Design and Analysis of Data. Papers and Studies in Contrastive Linguistics, 28, 137-152.

Mauranen, A. (1993). Contrastive ESP Rhetoric: Metatext in Finnish-English Economics Texts. English for Specific Purposes, 12, 3-22.

Mestre-Mestre, E. M. (2017). An analysis of interactive and interactional strategies in Conclusions and Discussion sections in Masters Theses. Pragmalingüística, 25, 416438.

Mirshamsi, A., \& Allami, H. (2013). Metadiscourse Markers in the Discussion/Conclusion Section of Persian and English Master's Theses. The Journal of Teaching Language Skills. 5(3), 23-40.

Mohamed, A. F. B., \& Rashid, R. B. A. (2017). The Metadiscourse Markers in Good Undergraduate Writers' Essays Corpus. International Journal of English Linguistics, 7(6), 213-220. https://doi.org/10.5539/ijel.v7n6p213

Mok, W. E. (1993). Contrastive Rhetoric and the Japanese Writer of EFL. JALT Journal. $15(2), 151-161$.

Moreno, A. I. (2008). The importance of comparable corpora in cross-cultural studies. In U. Connor, E. Nagelhout, \& W. Rozycki (Eds.), Pragmatics \& Beyond New Series (pp. 25-41). https://doi.org/10.1075/pbns.169.04mor

Mu, C., Zhang, L. J., Ehrich, J., \& Hong, H. (2015). The use of metadiscourse for knowledge construction in Chinese and English research articles. Journal of English for Academic Purposes, 20, 135-148. https://doi.org/10.1016/j.jeap.2015.09.003 
Mur Dueñas, P. (2007). 'I/we focus on...': A cross-cultural analysis of self-mentions in business management research articles. Journal of English for Academic Purposes, 6(2), 143-162. https://doi.org/10.1016/j.jeap.2007.05.002

Myers, G. (1989). The pragmatics of politeness in scientific articles. Applied Linguistics, 10(1), 1-35. http://dx.doi.org/10.1093/applin/10.1.1

Myers, R. (1990). Classical and modern regression with applications (2nd ed.). Boston, MA: Duxbury.

Myford, C. M. (2002). Investigating design features of descriptive graphic rating scales. Applied Measurement in Education, 15(2), 187-215.

Nguyen Thi Thuy, T. (2018). A Corpus-Based Study on Cross-Cultural Divergence in the Use of Hedges in Academic Research Articles Written by Vietnamese and Native English-Speaking Authors. Social Sciences, 7(4), 1-13. https://doi.org/10.3390/socsci7040070

Noble, W. (2010). Understanding Metadiscoursal Use: Lessons from a Local Corpus of Learner Academic Writing. Nordic Journal of English Studies, 9(2), 145-169.

Ozdemir, N. O., \& Longo, B. (2014). Metadiscourse Use in Thesis Abstracts: A Crosscultural Study. Procedia - Social and Behavioral Sciences, 141, 59-63. https://doi.org/10.1016/j.sbspro.2014.05.011

Pallant, J. (2001). SPSS survival manual: A step-by-step guide to data analysis using SPSS for Windows (Versions 10 and 11). Open University Press.

Parkinson, J. (2011). The Discussion section as argument: The language used to prove knowledge claims. English for Specific Purposes, 30(3), 164-175. https://doi.org/10.1016/j.esp.2011.03.001

Qi, X., \& Liu, L. (2007). Differences between Reader/Writer Responsible Languages Reflected in EFL Learners' Writing. Intercultural Communication Studies, 16(3), $148-159$.

Rayson, P. (2009). Log-likelihood and effect size calculator. Retrieved November 1, 2017, from http://ucrel.lancs.ac.uk/llwizard.html 
Rustipa, K. (2014). Metadiscourse in Indonesian EFL Learners' Persuasive Texts: A Case Study at English Department, UNISBANK. International Journal of English Linguistics, 4(1), 44-52. https://doi.org/10.5539/ijel.v4n1p44

Sanford, S. G. (2012). A comparison of metadiscourse markers and writing quality in adolescent written narratives (Master's thesis, The University of Montana, Missoula, United States). Retrieved from http://scholarworks.umt.edu/etd/1366/

Swales, J. M. (1990). Genre analysis: English in academic and research settings. Cambridge: Cambridge University Press.

Tarrayo, V. (2011). Metatext in results-and-discussion sections of ESL-EFL research: A contrastive analysis of Philippine English, Taiwanese English, and Iranian English. IManager's Journal of English Language Teaching, 1(3), 39-52.

Thompson, G. (2001). Interaction in Academic Writing: Learning to Argue with the Reader. Applied Linguistics, 22(1), 58-78.

Thompson, P. (2013). Thesis and dissertation writing. In B. Paltridge, \& S. Starfield (Eds.), The handbook of English for specific purposes (pp. 283-299). West Essex, UK: Wiley- Blackwell.

Uysal, H. H. (2010). A critical review of the IELTS writing test. ELT Journal, 64(3), 314320. https://doi.org/10.1093/elt/ccp026

Vande Kopple, W. J. (1985). Some Exploratory Discourse on Metadiscourse. College Composition and Communication, 36(1), 82-93. https://doi.org/10.2307/357609

Vande Kopple, W. J. (1997). Refining and Applying Views of Metadiscourse. Presented at the the Annual Meeting of the Conference on College Composition and Communication (48th, Phoenix, AZ, March 12-15, 1997). Retrieved from https://eric.ed.gov/?id=ED411539

Vande Kopple, W. J. (2012). The importance of studying metadiscourse. Applied Research in English, 1(2), 37-44. 
Vázquez Orta, I., \& Giner, D. (2008). Beyond mood and modality: Epistemic modality markers as hedges in research articles. A cross-disciplinary study. Revista Alicantina de Estudios Ingleses, 21, 171-190.

Weigle, S. C. (2002). Assessing writing. Cambridge: Cambridge University Press.

Weir, C. J. (1990). Communicative language testing. London: Prentice Hall.

Williams, J. M. (1981). Style: Ten lessons in clarity and grace. Glenview, IL: Scott, Foresman and Company. 


\section{APPENDICES}

\section{Appendix 1. Complete list of pre-identified metadiscourse markers}

Note:

1. The list was mainly adapted from Hyland's (2005) metadiscourse taxonomy.

2. Additional markers apart from Hyland's list are in the grey area. 


\begin{tabular}{|c|c|c|c|}
\hline \multicolumn{4}{|c|}{ 1. TRANSITION MARKERS } \\
\hline accordingly & additionally & again & also \\
\hline alternatively & although & and & as a consequence \\
\hline as a result & at the same time & because & besides \\
\hline but & by contrast & by the same token & consequently \\
\hline conversely & equally & even though & further \\
\hline furthermore & hence & however & in addition \\
\hline in contrast & in the same way & leads to & likewise \\
\hline moreover & nevertheless & nonetheless & on the contrary \\
\hline on the other hand & rather & result in & similarly \\
\hline since & so & so as to & still \\
\hline the result is & thereby & therefore & though \\
\hline thus & whereas & while & yet \\
\hline \multicolumn{4}{|c|}{ 2. FRAME MARKERS } \\
\hline \multicolumn{4}{|l|}{ SEQUENCING } \\
\hline (in) chapter X & (in) part $\mathrm{X}$ & (in) section $X$ & (in) the $\mathrm{X}$ chapter \\
\hline (in) the $\mathrm{X}$ part & (in) the $\mathrm{X}$ section & (in) this chapter & (in) this part \\
\hline (in) this section & finally & first & first of all \\
\hline firstly & last & lastly & listing $(\mathrm{a}, \mathrm{b}, \mathrm{c})$ \\
\hline next & numbering $(1,2,3)$ & second & secondly \\
\hline subsequently & then & third & thirdly \\
\hline to begin & to start with & & \\
\hline \multicolumn{4}{|c|}{ LABELING DISCOURSE ACTS } \\
\hline all in all & at this point & at this stage & by far \\
\hline for the moment & in brief & in conclusion & in short \\
\hline in sum & in summary & now & on the whole \\
\hline overall & so far & thus far & to conclude \\
\hline to repeat & to sum up & to summarize & \\
\hline \multicolumn{4}{|c|}{ ANNOUNCING GOALS } \\
\hline (in) this chapter & (in) this part & (in) this section & aim \\
\hline desire to & focus & goal & intend to \\
\hline intention & objective & purpose & seek to \\
\hline want to & wish to & would like to & \\
\hline \multicolumn{4}{|c|}{ SHIFTING TOPICS } \\
\hline back to & digress & in regard to & move on \\
\hline now & resume & return to & revisit \\
\hline shift to & so & to look more closely & turn to \\
\hline well & with regard to & & \\
\hline \multicolumn{4}{|c|}{ ADDITIONAL TYPES } \\
\hline as for & concerning & fifth & fourth \\
\hline in connection with & in the matter of & last but not least & regarding \\
\hline \multicolumn{4}{|c|}{ 3. ENDOPHORIC MARKERS } \\
\hline (In) Chapter X & (In) Part X & (In) Section X & (In) the $\mathrm{X}$ chapter \\
\hline (In) the X part & (In) the $\mathrm{X}$ section & (In) This chapter & (In) This part \\
\hline (In) This section & Example X & Fig. X & Figure $\mathrm{X}$ \\
\hline P. X & Page X & Table X & $\mathrm{X}$ above \\
\hline
\end{tabular}




\begin{tabular}{|c|c|c|c|}
\hline $\mathrm{X}$ before & $\mathrm{X}$ below & $\mathrm{X}$ earlier & $\mathrm{X}$ later \\
\hline \multicolumn{4}{|c|}{ ADDITIONAL TYPES } \\
\hline As I noted in ... & As we saw in ... & As we shall see in ... & \\
\hline \multicolumn{4}{|c|}{ 4. EVIDENTIALS } \\
\hline (date)/(name) & (to) cite $\mathrm{X}$ & (to) quote $\mathrm{X}$ & [ref.no] / [name] \\
\hline according to $\mathrm{X}$ & cited & quoted & \\
\hline \multicolumn{4}{|c|}{ ADDITIONAL TYPES } \\
\hline non-integral citation & following $\mathrm{X}, \ldots$ & is determined & is noticed \\
\hline is seen & $\mathrm{X}$ acknowledge & $\mathrm{X}$ argue & $\mathrm{X}$ assert \\
\hline $\mathrm{X}$ claim & $\mathrm{X}$ conclude & $\mathrm{X}$ contend & $\mathrm{X}$ demonstrate \\
\hline $\mathrm{X}$ describe & $\mathrm{X}$ discover & $\mathrm{X}$ emphasize & X establish \\
\hline $\mathrm{X}$ find & X identify & $\mathrm{X}$ indicate & $\mathrm{X}$ mention \\
\hline X note & $\mathrm{X}$ point out & $\mathrm{X}$ propose & $\mathrm{X}$ provide \\
\hline $\mathrm{X}$ recommend & $\mathrm{X}$ reiterate & $\mathrm{X}$ report & $\mathrm{X}$ show \\
\hline X state & $\mathrm{X}$ suggest & X support & \\
\hline \multicolumn{4}{|c|}{ 5. CODE GLOSSES } \\
\hline- & (...) & as a matter of fact & called \\
\hline defined as & e.g. & for example & for instance \\
\hline I mean & i.e. & in fact & in other words \\
\hline indeed & known as & namely & or $\mathrm{X}$ \\
\hline put another way & say & specifically & such as \\
\hline that is & that is to say & that means & this means \\
\hline viz & which means & & \\
\hline \multicolumn{4}{|c|}{ ADDITIONAL TYPES } \\
\hline I will put it this way & what I mean to say is... & & \\
\hline \multicolumn{4}{|c|}{ 6. HEDGES } \\
\hline about & almost & apparent & apparently \\
\hline appear & approximately & argue & around \\
\hline assume & broadly & certain amount & certain extent \\
\hline certain level & claim & could & couldn't \\
\hline doubt & doubtful & essentially & estimate \\
\hline fairly & feel & frequently & from my perspective \\
\hline from our perspective & from this perspective & generally & guess \\
\hline in general & in most cases & in most instances & in my opinion \\
\hline in my view & in our opinion & in our view & in this view \\
\hline indicate & largely & likely & mainly \\
\hline may & maybe & might & mostly \\
\hline often & on the whole & ought & perhaps \\
\hline plausible & plausibly & possible & possibly \\
\hline postulate & presumable & presumably & probable \\
\hline probably & quite & rather $\mathrm{x}$ & relatively \\
\hline roughly & seems & should & sometimes \\
\hline somewhat & suggest & suppose & suspect \\
\hline tend to & to my knowledge & typical & typically \\
\hline uncertain & uncertainly & unclear & unclearly \\
\hline unlikely & usually & would & wouldn't \\
\hline
\end{tabular}




\begin{tabular}{|c|c|c|c|}
\hline \multicolumn{4}{|c|}{ ADDITIONAL TYPES } \\
\hline basically & if I am not mistaken, ... & imply & inclined \\
\hline normally & potentially & sort of & they are thought to be... \\
\hline \multicolumn{4}{|c|}{ 7. BOOSTERS } \\
\hline actually & always & believe & beyond doubt \\
\hline certain & certainly & clear & clearly \\
\hline conclusively & decidedly & definite & definitely \\
\hline demonstrate & doubtless & establish & evident \\
\hline evidently & find & in fact & incontestable \\
\hline incontestably & incontrovertible & incontrovertibly & indeed \\
\hline indisputable & indisputably & know & must \\
\hline never & no doubt & obvious & obviously \\
\hline of course & prove & realize & really \\
\hline show & sure & surely & think \\
\hline true & truly & undeniable & undeniably \\
\hline undisputedly & undoubtedly & without doubt & \\
\hline \multicolumn{4}{|c|}{ ADDITIONAL TYPES } \\
\hline considerable & the fact is ... & & \\
\hline \multicolumn{4}{|c|}{ 8. ATTITUDE MARKERS } \\
\hline$!$ & admittedly & agree & amazed \\
\hline amazing & amazingly & appropriate & appropriately \\
\hline astonished & astonishing & astonishingly & correctly \\
\hline curious & curiously & desirable & desirably \\
\hline disagree & disappointed & disappointing & disappointingly \\
\hline dramatic & dramatically & essential & essentially \\
\hline even $\mathrm{X}$ & expected & expectedly & fortunate \\
\hline fortunately & hopeful & hopefully & important \\
\hline importantly & inappropriate & inappropriately & interesting \\
\hline interestingly & prefer & preferable & preferably \\
\hline remarkable & shocked & shocking & shockingly \\
\hline striking & strikingly & surprised & surprising \\
\hline surprisingly & unbelievable & unbelievably & understandable \\
\hline understandably & unexpected & unexpectedly & unfortunate \\
\hline unfortunately & unusual & unusually & usual \\
\hline \multicolumn{4}{|c|}{ ADDITIONAL TYPES } \\
\hline accept & accurately & ambiguous & crucial \\
\hline do not agree & fundamental & ideal & ideally \\
\hline necessarily & odd & outstanding & prominent \\
\hline salient & significant & unique & valuable \\
\hline \multicolumn{4}{|c|}{ 9. ENGAGEMENT MARKERS } \\
\hline (...) (personal asides) & (the) reader & ? (rhetorical questions) & add \\
\hline allow & analyze & apply & arrange \\
\hline assess & assume & by the way & calculate \\
\hline choose & classify & compare & connect \\
\hline consider & consult & contrast & define \\
\hline demonstrate & determine & develop & do not \\
\hline
\end{tabular}




\begin{tabular}{|c|c|c|c|}
\hline employ & ensure & estimate & evaluate \\
\hline find & follow & go & have to \\
\hline imagine & incidentally & increase & input \\
\hline insert & integrate & key & let us \\
\hline let $x=y$ & let's & look at & mark \\
\hline measure & mount & must & need to \\
\hline note/ be noted & notice & observe & one \\
\hline order & ought & our (inclusive) & pay \\
\hline picture & prepare & recall & recover \\
\hline refer & regard & remember & remove \\
\hline review & see & select & set \\
\hline should & show & state & suppose \\
\hline take (a look/as example) & think about & think of & turn \\
\hline us (inclusive) & use & we (inclusive) & you \\
\hline \multicolumn{4}{|l|}{ your } \\
\hline \multicolumn{4}{|l|}{ ADDITIONAL TYPES } \\
\hline bear in mind & explore & investigate & keep in mind \\
\hline \multicolumn{4}{|l|}{ recognize } \\
\hline \multicolumn{4}{|c|}{ 10. SELF-MENTIONS } \\
\hline I & my & me & we \\
\hline our & mine & us & the author \\
\hline the author's & the writer & the writer's & \\
\hline \multicolumn{4}{|l|}{ ADDITIONAL TYPES } \\
\hline researcher & the researcher's & & \\
\hline
\end{tabular}


Appendix 2. Complete list of metadiscourse markers identified in the corpus

Note:

1. Markers are arranged by their number of occurrences in each corpus.

2. Top ten markers in each subcategory are bolded.

3. Markers in the grey area are not found in the corpus. 


\begin{tabular}{|c|c|c|c|}
\hline \multicolumn{4}{|c|}{ 1. TRANSITION MARKERS } \\
\hline NZ-ELT & NZ-BA & TH-ELT & TH-BA \\
\hline also & also & also & also \\
\hline however & however & however & because \\
\hline because & while & because & however \\
\hline although & therefore & moreover & therefore \\
\hline while & because & therefore & but \\
\hline but & although & while & moreover \\
\hline and & and & so & and \\
\hline therefore & furthermore & thus & thus \\
\hline so & but & although & while \\
\hline thus & consequently & and & in addition \\
\hline in addition & additionally & since & although \\
\hline since & further & in addition & furthermore \\
\hline similarly & so & but & so \\
\hline furthermore & yet & furthermore & since \\
\hline on the other hand & nonetheless & even though & additionally \\
\hline yet & whereas & hence & on the other hand \\
\hline even though & in addition & whereas & further \\
\hline whereas & similarly & on the other hand & in contrast \\
\hline further & as a result & additionally & similarly \\
\hline as a result & thus & as a result & hence \\
\hline again & though & similarly & nevertheless \\
\hline nonetheless & nevertheless & besides & whereas \\
\hline additionally & rather & nevertheless & even though \\
\hline consequently & in contrast & accordingly & so as to \\
\hline nevertheless & accordingly & so as to & at the same time \\
\hline though & again & in contrast & as a result \\
\hline likewise & conversely & on the contrary & besides \\
\hline in contrast & likewise & though & on the contrary \\
\hline rather & moreover & conversely & though \\
\hline conversely & even though & further & accordingly \\
\hline hence & on the other hand & likewise & likewise \\
\hline alternatively & alternatively & nonetheless & again \\
\hline at the same time & at the same time & as a consequence & still \\
\hline moreover & hence & by contrast & alternatively \\
\hline so as to & since & consequently & consequently \\
\hline equally & on the contrary & rather & conversely \\
\hline accordingly & so as to & in the same way & equally \\
\hline as a consequence & as a consequence & by the same token & nonetheless \\
\hline besides & by contrast & equally & thereby \\
\hline by contrast & equally & still & yet \\
\hline on the contrary & still & yet & as a consequence \\
\hline the result is & besides & again & the result is \\
\hline by the same token & by the same token & alternatively & by contrast \\
\hline in the same way & in the same way & at the same time & by the same token \\
\hline
\end{tabular}




\begin{tabular}{|c|c|c|c|}
\hline leads to & leads to & leads to & in the same way \\
\hline result in & result in & result in & leads to \\
\hline still & the result is & the result is & rather \\
\hline thereby & thereby & thereby & result in \\
\hline \multicolumn{4}{|c|}{ 2. FRAME MARKERS } \\
\hline NZ-ELT & NZ-BA & TH-ELT & TH-BA \\
\hline first & firstly & numbering $(1,2,3)$ & numbering $(1,2,3)$ \\
\hline firstly & finally & regarding & lastly \\
\hline $\begin{array}{l}\text { (in) this chapter } \\
\text { (announcing goals) }\end{array}$ & secondly & $\begin{array}{l}\text { (in) this chapter } \\
\text { (announcing goals) }\end{array}$ & finally \\
\hline $\begin{array}{l}\text { (in) this section } \\
\text { (announcing goals) }\end{array}$ & $\begin{array}{l}\text { (in) this chapter } \\
\text { (announcing goals) }\end{array}$ & firstly & first \\
\hline second & numbering $(1,2,3)$ & secondly & secondly \\
\hline then & overall & $\begin{array}{l}\text { (in) this section } \\
\text { (announcing goals) }\end{array}$ & in conclusion \\
\hline $\begin{array}{l}\text { now } \\
\text { (labeling discourse acts) }\end{array}$ & listing $(\mathbf{a}, \mathbf{b}, \mathbf{c})$ & finally & second \\
\hline overall & $\begin{array}{l}\text { (in) this section } \\
\text { (announcing goals) }\end{array}$ & second & regarding \\
\hline finally & purpose & with regard to & $\begin{array}{l}\text { (in) this chapter } \\
\text { (announcing goals) }\end{array}$ \\
\hline listing (a, b, c) & lastly & lastly & firstly \\
\hline secondly & second & first & listing $(\mathrm{a}, \mathrm{b}, \mathrm{c})$ \\
\hline numbering $(1,2,3)$ & then & in conclusion & overall \\
\hline aim & first & then & third \\
\hline $\begin{array}{l}\text { (in) this part } \\
\text { (announcing goals) }\end{array}$ & thirdly & thirdly & fourth \\
\hline purpose & in conclusion & concerning & aim \\
\hline lastly & $\begin{array}{l}\text { (in) chapter } \mathrm{X} \\
\text { (sequencing) }\end{array}$ & next & as for \\
\hline $\begin{array}{l}\text { (in) this chapter } \\
\text { (sequencing) }\end{array}$ & $\begin{array}{l}\text { now } \\
\text { (labeling discourse acts) }\end{array}$ & third & $\begin{array}{l}\text { (in) this chapter } \\
\text { (announcing goals) }\end{array}$ \\
\hline thirdly & aim & to conclude & next \\
\hline in summary & $\begin{array}{l}\text { (in) this chapter } \\
\text { (sequencing) }\end{array}$ & aim & $\begin{array}{l}\text { (in) this section } \\
\text { (sequencing) }\end{array}$ \\
\hline $\begin{array}{l}\text { (in) the } \mathrm{X} \text { section } \\
\text { (sequencing) }\end{array}$ & $\begin{array}{l}\text { (in) the } \mathrm{X} \text { section } \\
\text { (sequencing) }\end{array}$ & as for & purpose \\
\hline third & subsequently & last but not least & would like to \\
\hline $\begin{array}{l}\text { (in) the X chapter } \\
\text { (sequencing) }\end{array}$ & third & in sum & first of all \\
\hline subsequently & $\begin{array}{l}\text { (in) the } \mathrm{X} \text { chapter } \\
\text { (sequencing) }\end{array}$ & on the whole & thirdly \\
\hline in conclusion & next & in summary & $\begin{array}{l}\text { (in) this part } \\
\text { (announcing goals) }\end{array}$ \\
\hline $\begin{array}{l}\text { (in) chapter X } \\
\text { (sequencing) }\end{array}$ & in summary & overall & focus \\
\hline $\begin{array}{l}\text { (in) part } \mathrm{X} \\
\text { (sequencing) }\end{array}$ & objective & $\begin{array}{l}\text { (in) the X chapter } \\
\text { (sequencing) }\end{array}$ & objective \\
\hline next & focus & $\begin{array}{l}\text { (in) this chapter } \\
\text { (sequencing) }\end{array}$ & then \\
\hline so far & at this point & first of all & fifth \\
\hline goal & in short & $\begin{array}{l}\text { (in) this part } \\
\text { (announcing goals) }\end{array}$ & in summary \\
\hline $\begin{array}{l}\text { (in) the X part } \\
\text { (sequencing) }\end{array}$ & in sum & objective & to conclude \\
\hline to begin & to conclude & fourth & with regard to \\
\hline fourth & seek to & fifth & concerning \\
\hline
\end{tabular}




\begin{tabular}{|c|c|c|c|}
\hline at this point & $\begin{array}{l}\text { (in) part X } \\
\text { (sequencing) }\end{array}$ & all in all & last \\
\hline at this stage & $\begin{array}{l}\text { (in) section } \mathrm{X} \\
\text { (sequencing) }\end{array}$ & in brief & at this point \\
\hline on the whole & $\begin{array}{l}\text { (in) the } \mathrm{X} \text { part } \\
\text { (sequencing) }\end{array}$ & purpose & in short \\
\hline wish to & $\begin{array}{l}\text { (in) this part } \\
\text { (announcing goals) }\end{array}$ & $\begin{array}{l}\text { (in) chapter } \mathrm{X} \\
\text { (sequencing) }\end{array}$ & in sum \\
\hline would like to & $\begin{array}{l}\text { (in) this section } \\
\text { (sequencing) }\end{array}$ & listing $(\mathrm{a}, \mathrm{b}, \mathrm{c})$ & on the whole \\
\hline as for & first of all & to start with & to sum up \\
\hline $\begin{array}{l}\text { (in) section } \mathrm{X} \\
\text { (sequencing) }\end{array}$ & last & at this point & $\begin{array}{l}\text { (in) chapter } \mathrm{X} \\
\text { (sequencing) }\end{array}$ \\
\hline $\begin{array}{l}\text { (in) this part } \\
\text { (sequencing) }\end{array}$ & to begin & in short & $\begin{array}{l}\text { (in) part } \mathrm{X} \\
\text { (sequencing) }\end{array}$ \\
\hline $\begin{array}{l}\text { (in) this section } \\
\text { (sequencing) }\end{array}$ & to start with & $\begin{array}{l}\text { now } \\
\text { (labeling discourse acts) }\end{array}$ & $\begin{array}{l}\text { (in) section } \mathrm{X} \\
\text { (sequencing) }\end{array}$ \\
\hline first of all & fourth & to sum up & $\begin{array}{l}\text { (in) the } \mathrm{X} \text { chapter } \\
\text { (sequencing) }\end{array}$ \\
\hline fifth & fifth & to summarize & $\begin{array}{l}\text { (in) the } \mathrm{X} \text { part } \\
\text { (sequencing) }\end{array}$ \\
\hline by far & last but not least & goal & $\begin{array}{l}\text { (in) the } \mathrm{X} \text { section } \\
\text { (sequencing) }\end{array}$ \\
\hline in short & all in all & in regard to & $\begin{array}{l}\text { (in) this part } \\
\text { (sequencing) }\end{array}$ \\
\hline in sum & at this stage & $\begin{array}{l}\text { now } \\
\text { (shifting topics) }\end{array}$ & $\begin{array}{l}\text { (in) this section } \\
\text { (sequencing) }\end{array}$ \\
\hline to conclude & by far & $\begin{array}{l}\text { (in) part X } \\
\text { (sequencing) }\end{array}$ & subsequently \\
\hline to sum up & for the moment & $\begin{array}{l}\text { (in) section } \mathrm{X} \\
\text { (sequencing) }\end{array}$ & to begin \\
\hline objective & in brief & $\begin{array}{l}\text { (in) the } \mathrm{X} \text { part } \\
\text { (sequencing) }\end{array}$ & to start with \\
\hline back to & on the whole & $\begin{array}{l}\text { (in) the X section } \\
\text { (sequencing) }\end{array}$ & last but not least \\
\hline $\begin{array}{l}\text { now } \\
\text { (shifting topics) }\end{array}$ & so far & $\begin{array}{l}\text { (in) this part } \\
\text { (sequencing) }\end{array}$ & all in all \\
\hline revisit & thus far & $\begin{array}{l}\text { (in) this section } \\
\text { (sequencing) }\end{array}$ & at this stage \\
\hline last & to repeat & last & by far \\
\hline to start with & to sum up & subsequently & for the moment \\
\hline last but not least & to summarize & to begin & in brief \\
\hline all in all & $\begin{array}{l}\text { (in) this part } \\
\text { (sequencing) }\end{array}$ & at this stage & $\begin{array}{l}\text { now } \\
\text { (labeling discourse acts) }\end{array}$ \\
\hline for the moment & desire to & by far & so far \\
\hline in brief & goal & for the moment & thus far \\
\hline thus far & intend to & so far & to repeat \\
\hline to repeat & intention & thus far & to summarize \\
\hline to summarize & want to & to repeat & desire to \\
\hline desire to & wish to & desire to & goal \\
\hline focus & would like to & focus & intend to \\
\hline intend to & back to & intend to & intention \\
\hline intention & digress & intention & seek to \\
\hline seek to & in regard to & seek to & want to \\
\hline want to & move on & want to & wish to \\
\hline digress & $\begin{array}{l}\text { now } \\
\text { (shifting topics) }\end{array}$ & wish to & back to \\
\hline in regard to & resume & would like to & digress \\
\hline
\end{tabular}




\begin{tabular}{|c|c|c|c|}
\hline move on & return to & back to & in regard to \\
\hline resume & revisit & digress & move on \\
\hline return to & shift to & move on & $\begin{array}{l}\text { now } \\
\text { (shifting topics) }\end{array}$ \\
\hline shift to & so & resume & resume \\
\hline so & to look more closely & return to & return to \\
\hline to look more closely & turn to & revisit & revisit \\
\hline turn to & well & shift to & shift to \\
\hline well & with regard to & so & so \\
\hline with regard to & regarding & to look more closely & to look more closely \\
\hline regarding & concerning & turn to & turn to \\
\hline concerning & in the matter of & well & well \\
\hline in the matter of & as for & in the matter of & in the matter of \\
\hline in connection with & in connection with & in connection with & in connection with \\
\hline \multicolumn{4}{|c|}{ 3. ENDOPHORIC MARKERS } \\
\hline NZ-ELT & NZ-BA & TH-ELT & TH-BA \\
\hline Table X & Figure $\mathrm{X}$ & Table X & Table X \\
\hline (In) Chapter X & (In) Section X & $\mathrm{X}$ below & $\mathrm{X}$ above \\
\hline (In) Section $\mathrm{X}$ & $\mathrm{X}$ below & $\mathrm{X}$ above & $\mathrm{X}$ below \\
\hline $\mathrm{X}$ above & Table X & P. $X$ & Figure $\mathrm{X}$ \\
\hline Figure $\mathrm{X}$ & (In) the $\mathrm{X}$ section & Example X & (In) Chapter X \\
\hline Page $X$ & X earlier & (In) Chapter X & X earlier \\
\hline $\mathrm{X}$ below & (In) Chapter X & (In) the $X$ chapter & (In) the $X$ chapter \\
\hline X earlier & (In) the $X$ chapter & $\mathbf{X}$ earlier & (In) the $\mathrm{X}$ section \\
\hline (In) the $\mathrm{X}$ section & $\mathrm{X}$ above & (In) the $\mathrm{X}$ section & (In) Part X \\
\hline (In) the $X$ chapter & Page X & Figure $\mathrm{X}$ & (In) Section X \\
\hline As we saw in... & $\mathrm{X}$ later & $\mathrm{X}$ later & (In) the X part \\
\hline $\mathrm{X}$ later & (In) This chapter & (In) the X part & (In) This chapter \\
\hline (In) the X part & Example X & (In) Part X & (In) This part \\
\hline (In) This chapter & (In) Part X & (In) Section $\mathrm{X}$ & (In) This section \\
\hline Example X & (In) the X part & (In) This chapter & Example X \\
\hline (In) Part X & (In) This part & (In) This part & Fig. X \\
\hline (In) This part & (In) This section & (In) This section & P. X \\
\hline (In) This section & Fig. X & Fig. $X$ & Page X \\
\hline Fig. X & P. X & Page X & $\mathrm{X}$ before \\
\hline P. $\mathrm{X}$ & $\mathrm{X}$ before & $\mathrm{X}$ before & X later \\
\hline $\mathrm{X}$ before & As I noted in ... & As I noted in ... & As I noted in ... \\
\hline As I noted in ... & As we shall see in ... & As we shall see in ... & As we shall see in ... \\
\hline As we shall see in ... & As we saw in ... & As we saw in ... & As we saw in ... \\
\hline \multicolumn{4}{|c|}{ 4. EVIDENTIALS } \\
\hline NZ-ELT & NZ-BA & TH-ELT & TH-BA \\
\hline non-integral citation & non-integral citation & non-integral citation & non-integral citation \\
\hline$X$ find & $\mathrm{X}$ suggest & $\mathrm{X}$ find & X support \\
\hline $\mathrm{X}$ suggest & $\mathrm{X}$ note & according to $X$ & $\mathrm{X}$ find \\
\hline according to $X$ & $\mathrm{X}$ support & X state & X state \\
\hline $\mathrm{X}$ support & $\mathrm{X}$ find & X support & cited \\
\hline cited & $X$ assert & cited & $\mathrm{X}$ indicate \\
\hline
\end{tabular}




\begin{tabular}{|c|c|c|c|}
\hline $\mathrm{X}$ note & $\mathrm{X}$ argue & $\mathrm{X}$ suggest & $\mathrm{X}$ mention \\
\hline $\mathrm{X}$ describe & $\mathrm{X}$ identify & X show & according to $\mathrm{X}$ \\
\hline $\mathrm{X}$ assert & is determined & $\mathrm{X}$ report & X show \\
\hline X state & $\mathrm{X}$ describe & $\mathrm{X}$ indicate & $\mathrm{X}$ suggest \\
\hline X claim & according to $\mathrm{X}$ & $\mathrm{X}$ recommend & $\mathrm{X}$ note \\
\hline X show & cited & $\mathrm{X}$ mention & Xidentify \\
\hline $\mathrm{X}$ recommend & $\mathrm{X}$ point out & X claim & $\mathrm{X}$ propose \\
\hline $\mathrm{X}$ point out & $\mathrm{X}$ state & $\mathrm{X}$ propose & $\mathrm{X}$ argue \\
\hline $\mathrm{X}$ emphasize & $\mathrm{X}$ indicate & $\mathrm{X}$ discover & $\mathrm{X}$ report \\
\hline $\mathrm{X}$ report & $\mathrm{X}$ show & is determined & is determined \\
\hline is determined & $\mathrm{X}$ propose & $\mathrm{X}$ conclude & $\mathrm{X}$ describe \\
\hline $\mathrm{X}$ identify & X claim & $\mathrm{X}$ demonstrate & $\mathrm{X}$ assert \\
\hline $\mathrm{X}$ mention & X establish & $\mathrm{X}$ assert & $\mathrm{X}$ point out \\
\hline $\mathrm{X}$ argue & $\mathrm{X}$ acknowledge & $\mathrm{X}$ point out & $\mathrm{X}$ discover \\
\hline $\mathrm{X}$ demonstrate & $\mathrm{X}$ contend & X note & (date)/(name) \\
\hline $\mathrm{X}$ contend & $\mathrm{X}$ emphasize & $\mathrm{X}$ describe & (to) cite $\mathrm{X}$ \\
\hline $\mathrm{X}$ propose & $\mathrm{X}$ provide & X emphasize & (to) quote $\mathrm{X}$ \\
\hline $\mathrm{X}$ provide & $\mathrm{X}$ mention & $\mathrm{X}$ reiterate & [ref.no] / [name] \\
\hline $\mathrm{X}$ conclude & (date)/(name) & Xidentify & quoted \\
\hline is seen & (to) cite $\mathrm{X}$ & (date)/(name) & $\mathrm{X}$ conclude \\
\hline $\mathrm{X}$ indicate & (to) quote $\mathrm{X}$ & (to) cite X & is seen \\
\hline following $X, \ldots$ & [ref.no] / [name] & (to) quote $\mathrm{X}$ & is noticed \\
\hline $\mathrm{X}$ reiterate & quoted & [ref.no]/[name] & $\mathrm{X}$ claim \\
\hline $\mathrm{X}$ acknowledge & $\mathrm{X}$ conclude & quoted & $\mathrm{X}$ demonstrate \\
\hline (date)/(name) & is seen & is seen & $\mathrm{X}$ establish \\
\hline (to) cite $\mathrm{X}$ & is noticed & is noticed & $\mathrm{X}$ acknowledge \\
\hline (to) quote $\mathrm{X}$ & $\mathrm{X}$ demonstrate & $\mathrm{X}$ argue & $\mathrm{X}$ recommend \\
\hline [ref.no] / [name] & $\mathrm{X}$ recommend & X establish & $\mathrm{X}$ contend \\
\hline quoted & X report & $\mathrm{X}$ acknowledge & X emphasize \\
\hline is noticed & $\mathrm{X}$ reiterate & $\mathrm{X}$ contend & $\mathrm{X}$ reiterate \\
\hline $\mathrm{X}$ establish & following $\mathrm{X}, \ldots$ & following $X, \ldots$ & following $\mathrm{X}, \ldots$ \\
\hline $\mathrm{X}$ discover & $\mathrm{X}$ discover & $\mathrm{X}$ provide & $\mathrm{X}$ provide \\
\hline \multicolumn{4}{|c|}{ 5. CODE GLOSSES } \\
\hline NZ-ELT & NZ-BA & TH-ELT & TH-BA \\
\hline such as & such as & such as & such as \\
\hline for example & for example & for example & for example \\
\hline$(\ldots)$ & i.e. & that is & e.g. \\
\hline e.g. & e.g. & e.g. & $(\ldots)$ \\
\hline i.e. & $(\ldots)$ & in other words & i.e. \\
\hline- & for instance & for instance & for instance \\
\hline for instance & indeed & $(\ldots)$ & in other words \\
\hline in fact & in fact & - & this means \\
\hline in other words & specifically & namely & namely \\
\hline indeed & that is & called & in fact \\
\hline specifically & - & i.e. & defined as \\
\hline or $\mathrm{X}$ & this means & in fact & specifically \\
\hline
\end{tabular}




\begin{tabular}{|c|c|c|c|}
\hline that is & namely & this means & that is to say \\
\hline namely & known as & specifically & known as \\
\hline this means & in other words & as a matter of fact & or $\mathrm{X}$ \\
\hline called & which means & defined as & which means \\
\hline known as & called & that is to say & indeed \\
\hline defined as & defined as & that means & that is \\
\hline that is to say & put another way & I mean & that means \\
\hline which means & as a matter of fact & indeed & - \\
\hline as a matter of fact & I mean & known as & as a matter of fact \\
\hline I mean & or $\mathrm{X}$ & or $\mathrm{X}$ & called \\
\hline put another way & say & put another way & I mean \\
\hline say & that is to say & say & put another way \\
\hline that means & that means & viz & say \\
\hline viz & viz & which means & viz \\
\hline what I mean to say is ... & what I mean to say is ... & what I mean to say is ... & what I mean to say is ... \\
\hline I will put it this way & I will put it this way & I will put it this way & I will put it this way \\
\hline \multicolumn{4}{|c|}{ 6. HEDGES } \\
\hline NZ-ELT & NZ-BA & TH-ELT & TH-BA \\
\hline may & may & should & should \\
\hline would & could & may & could \\
\hline could & would & might & may \\
\hline suggest & suggest & could & would \\
\hline might & should & indicate & might \\
\hline likely & appear & suggest & indicate \\
\hline appear & indicate & would & tend to \\
\hline should & likely & possible & mostly \\
\hline indicate & often & frequently & suggest \\
\hline often & possible & mostly & likely \\
\hline perhaps & potentially & possibly & quite \\
\hline possible & might & assume & often \\
\hline seem & largely & tend to & wouldn't \\
\hline tend to & argue & likely & almost \\
\hline apparent & generally & appear & generally \\
\hline relatively & relatively & usually & in general \\
\hline generally & perhaps & probably & possible \\
\hline argue & tend to & seem & relatively \\
\hline potentially & typically & quite & usually \\
\hline quite & seem & mainly & seem \\
\hline usually & essentially & often & maybe \\
\hline typically & somewhat & generally & appear \\
\hline sometimes & apparent & almost & mainly \\
\hline possibly & possibly & sometimes & around \\
\hline in general & wouldn't & perhaps & imply \\
\hline probably & assume & relatively & suppose \\
\hline largely & almost & claim & perhaps \\
\hline feel & in general & in general & assume \\
\hline
\end{tabular}




\begin{tabular}{|c|c|c|c|}
\hline assume & sometimes & rather $\mathrm{x}$ & normally \\
\hline somewhat & usually & imply & approximately \\
\hline approximately & feel & approximately & about \\
\hline almost & quite & normally & sometimes \\
\hline on the whole & frequently & wouldn't & argue \\
\hline mostly & probably & on the whole & largely \\
\hline plausible & mainly & plausible & probably \\
\hline unclear & claim & about & unlikely \\
\hline mainly & mostly & argue & frequently \\
\hline unclearly & approximately & largely & typically \\
\hline frequently & suppose & apparent & essentially \\
\hline wouldn't & unlikely & typically & feel \\
\hline maybe & rather $\mathrm{x}$ & somewhat & on the whole \\
\hline around & unclear & suppose & plausibly \\
\hline unlikely & maybe & around & basically \\
\hline presumably & plausible & fairly & potentially \\
\hline claim & fairly & essentially & possibly \\
\hline certain level & certain level & feel & apparent \\
\hline essentially & certain amount & unlikely & somewhat \\
\hline about & couldn't & plausibly & claim \\
\hline probable & doubt & apparently & fairly \\
\hline inclined & presumable & certain extent & probable \\
\hline imply & inclined & estimate & inclined \\
\hline fairly & normally & potentially & plausible \\
\hline from this perspective & around & maybe & rather $\mathrm{x}$ \\
\hline in most cases & on the whole & unclear & unclear \\
\hline in my view & about & unclearly & unclearly \\
\hline to my knowledge & unclearly & certain level & certain level \\
\hline uncertain & presumably & presumably & presumably \\
\hline basically & probable & probable & apparently \\
\hline suppose & plausibly & certain amount & certain amount \\
\hline rather $\mathrm{x}$ & apparently & couldn't & certain extent \\
\hline plausibly & certain extent & doubt & couldn't \\
\hline apparently & estimate & from this perspective & doubt \\
\hline certain amount & from this perspective & in most cases & estimate \\
\hline certain extent & in most cases & in my view & from this perspective \\
\hline couldn't & in my view & presumable & in most cases \\
\hline doubt & to my knowledge & to my knowledge & in my view \\
\hline estimate & uncertain & uncertain & presumable \\
\hline presumable & broadly & broadly & to my knowledge \\
\hline broadly & doubtful & doubtful & uncertain \\
\hline doubtful & from my perspective & from my perspective & broadly \\
\hline from my perspective & from our perspective & from our perspective & doubtful \\
\hline from our perspective & guess & guess & from my perspective \\
\hline guess & in most instances & in most instances & from our perspective \\
\hline in most instances & in my opinion & in my opinion & guess \\
\hline
\end{tabular}




\begin{tabular}{|c|c|c|c|}
\hline in my opinion & in this view & in this view & in most instances \\
\hline in this view & in our opinion & in our opinion & in my opinion \\
\hline in our opinion & in our view & in our view & in this view \\
\hline in our view & ought & ought & in our opinion \\
\hline ought & postulate & postulate & in our view \\
\hline postulate & roughly & roughly & ought \\
\hline roughly & suspect & suspect & postulate \\
\hline suspect & typical & typical & roughly \\
\hline typical & uncertainly & uncertainly & suspect \\
\hline uncertainly & sort of & sort of & typical \\
\hline sort of & they are thought to be ... & they are thought to be ... & uncertainly \\
\hline they are thought to be ... & if I am not mistaken, ... & if I am not mistaken, ... & sort of \\
\hline if I am not mistaken, ... & basically & inclined & they are thought to be .. \\
\hline normally & imply & basically & if I am not mistaken, ... \\
\hline \multicolumn{4}{|c|}{ 7. BOOSTERS } \\
\hline NZ-ELT & NZ-BA & TH-ELT & TH-BA \\
\hline show & find & find & show \\
\hline find & show & show & find \\
\hline certainly & must & certainly & must \\
\hline demonstrate & evident & demonstrate & always \\
\hline must & certainly & must & certainly \\
\hline evident & clear & always & clear \\
\hline clearly & demonstrate & obvious & think \\
\hline always & always & evident & clearly \\
\hline clear & clearly & prove & obviously \\
\hline indeed & in fact & clearly & actually \\
\hline in fact & of course & realize & realize \\
\hline believe & believe & in fact & believe \\
\hline of course & considerable & obviously & demonstrate \\
\hline never & actually & think & evident \\
\hline true & obviously & clear & of course \\
\hline considerable & never & of course & obvious \\
\hline really & realize & no doubt & definitely \\
\hline actually & establish & considerable & in fact \\
\hline prove & decidedly & never & never \\
\hline surely & indeed & evidently & really \\
\hline undoubtedly & think & know & undoubtedly \\
\hline establish & obvious & believe & indeed \\
\hline evidently & prove & indeed & prove \\
\hline obviously & undoubtedly & actually & true \\
\hline realize & definitely & true & no doubt \\
\hline definitely & surely & undeniably & know \\
\hline no doubt & true & without doubt & surely \\
\hline indisputable & really & really & establish \\
\hline think & no doubt & undoubtedly & evidently \\
\hline obvious & evidently & definitely & decidedly \\
\hline
\end{tabular}




\begin{tabular}{|c|c|c|c|}
\hline know & know & surely & indisputable \\
\hline decidedly & indisputable & establish & undeniably \\
\hline undeniably & undeniably & decidedly & without doubt \\
\hline without doubt & without doubt & indisputable & beyond doubt \\
\hline beyond doubt & beyond doubt & beyond doubt & certain \\
\hline certain & certain & certain & conclusively \\
\hline conclusively & conclusively & conclusively & definite \\
\hline definite & definite & definite & doubtless \\
\hline doubtless & doubtless & doubtless & incontestable \\
\hline incontestable & incontestable & incontestable & incontestably \\
\hline incontestably & incontestably & incontestably & incontrovertible \\
\hline incontrovertible & incontrovertible & incontrovertible & incontrovertibly \\
\hline incontrovertibly & incontrovertibly & incontrovertibly & indisputably \\
\hline indisputably & indisputably & indisputably & sure \\
\hline sure & sure & sure & truly \\
\hline truly & truly & truly & undeniable \\
\hline undeniable & undeniable & undeniable & undisputedly \\
\hline undisputedly & undisputedly & undisputedly & the fact is ... \\
\hline the fact is ... & the fact is ... & the fact is ... & considerable \\
\hline \multicolumn{4}{|c|}{ 8. ATTITUDE MARKERS } \\
\hline NZ-ELT & NZ-BA & TH-ELT & TH-BA \\
\hline important & important & important & important \\
\hline necessarily & interesting & interestingly & interesting \\
\hline interesting & valuable & interesting & essential \\
\hline significant & significant & significant & unique \\
\hline valuable & unique & essential & necessarily \\
\hline crucial & necessarily & importantly & expected \\
\hline interestingly & interestingly & crucial & crucial \\
\hline unique & essentially & salient & unfortunately \\
\hline expected & prominent & valuable & significant \\
\hline importantly & essential & outstanding & valuable \\
\hline surprising & surprising & fundamental & fundamental \\
\hline essential & crucial & surprising & interestingly \\
\hline salient & importantly & essentially & importantly \\
\hline ideally & fundamental & expected & appropriate \\
\hline fundamental & ideal & remarkable & understandable \\
\hline unfortunately & appropriate & unique & surprisingly \\
\hline prominent & agree & prominent & outstanding \\
\hline appropriate & unexpected & preferable & ideal \\
\hline understandable & understandable & necessarily & surprising \\
\hline essentially & surprisingly & unfortunately & essentially \\
\hline unusual & disappointing & appropriate & remarkable \\
\hline desirable & ambiguous & understandable & agree \\
\hline striking & ideally & surprisingly & do not agree \\
\hline surprisingly & unfortunately & unusual & hopefully \\
\hline ambiguous & unusual & agree & fortunately \\
\hline
\end{tabular}




\begin{tabular}{|c|c|c|c|}
\hline accept & desirably & desirable & ideally \\
\hline accurately & unexpectedly & striking & unusual \\
\hline remarkable & odd & unexpected & desirable \\
\hline agree & expected & do not agree & striking \\
\hline do not agree & remarkable & disappointing & unexpected \\
\hline hopefully & desirable & hopefully & disappointing \\
\hline preferable & striking & curious & preferable \\
\hline curious & do not agree & desirably & curious \\
\hline dramatically & hopefully & dramatically & desirably \\
\hline inappropriate & preferable & fortunately & dramatically \\
\hline prefer & curious & inappropriate & inappropriate \\
\hline surprised & dramatically & prefer & prefer \\
\hline unfortunate & fortunately & surprised & surprised \\
\hline unexpected & inappropriate & unexpectedly & unexpectedly \\
\hline disappointing & prefer & unfortunate & unfortunate \\
\hline desirably & surprised & $!$ & $!$ \\
\hline fortunately & unfortunate & admittedly & admittedly \\
\hline unexpectedly & $!$ & amazed & amazed \\
\hline$!$ & admittedly & amazing & amazing \\
\hline admittedly & amazed & amazingly & amazingly \\
\hline amazed & amazing & appropriately & appropriately \\
\hline amazing & amazingly & astonished & astonished \\
\hline amazingly & appropriately & astonishing & astonishing \\
\hline appropriately & astonished & astonishingly & astonishingly \\
\hline astonished & astonishing & correctly & correctly \\
\hline astonishing & astonishingly & curiously & curiously \\
\hline astonishingly & correctly & disappointed & disappointed \\
\hline correctly & curiously & disappointingly & disappointingly \\
\hline curiously & disappointed & disagree & disagree \\
\hline disappointed & disappointingly & dramatic & dramatic \\
\hline disappointingly & disagree & even X & even $\mathrm{X}$ \\
\hline disagree & dramatic & expectedly & expectedly \\
\hline dramatic & even X & fortunate & fortunate \\
\hline even X & expectedly & hopeful & hopeful \\
\hline expectedly & fortunate & inappropriately & inappropriately \\
\hline fortunate & hopeful & preferably & preferably \\
\hline hopeful & inappropriately & shocked & shocked \\
\hline inappropriately & preferably & shocking & shocking \\
\hline preferably & shocked & shockingly & shockingly \\
\hline shocked & shocking & strikingly & strikingly \\
\hline shocking & shockingly & unbelievable & unbelievable \\
\hline shockingly & strikingly & unbelievably & unbelievably \\
\hline strikingly & unbelievable & understandably & understandably \\
\hline unbelievable & unbelievably & unusually & unusually \\
\hline unbelievably & understandably & usual & usual \\
\hline understandably & unusually & ambiguous & salient \\
\hline
\end{tabular}




\begin{tabular}{|c|c|c|c|}
\hline unusually & usual & accept & prominent \\
\hline usual & salient & ideal & ambiguous \\
\hline outstanding & outstanding & ideally & accept \\
\hline ideal & accept & accurately & accurately \\
\hline odd & accurately & odd & odd \\
\hline \multicolumn{4}{|c|}{ 9. ENGAGEMENT MARKERS } \\
\hline NZ-ELT & NZ-BA & TH-ELT & TH-BA \\
\hline see & we (inclusive) & see & we (inclusive) \\
\hline we (inclusive) & see & we (inclusive) & see \\
\hline our (inclusive) & our (inclusive) & should & us (inclusive) \\
\hline ? (rhetorical questions) & ? (rhetorical questions) & our (inclusive) & note/ be noted \\
\hline us (inclusive) & (...) (personal asides) & note/ be noted & assume \\
\hline (...) (personal asides) & note/ be noted & investigate & should \\
\hline note/ be noted & us (inclusive) & bear in mind & our (inclusive) \\
\hline consider & assume & integrate & consider \\
\hline let's & your & assume & keep in mind \\
\hline (the) reader & you & us (inclusive) & notice \\
\hline explore & recognize & (...) (personal asides) & your \\
\hline should & take (a look/as example) & one's & explore \\
\hline bear in mind & should & consider & refer \\
\hline assume & imagine & (the) reader's & investigate \\
\hline look at & show & let's & one's \\
\hline investigate & consider & your & (the) reader's \\
\hline recognize & one & explore & let's \\
\hline keep in mind & investigate & recognize & bear in mind \\
\hline need to & (the) reader & look at & recognize \\
\hline imagine & let's & you & look at \\
\hline refer & bear in mind & keep in mind & you \\
\hline compare & explore & imagine & imagine \\
\hline determine & look at & need to & integrate \\
\hline find & keep in mind & refer & need to \\
\hline follow & integrate & by the way & by the way \\
\hline have to & need to & compare & compare \\
\hline picture & refer & determine & determine \\
\hline review & by the way & find & find \\
\hline one & compare & follow & follow \\
\hline your & determine & have to & have to \\
\hline you & find & incidentally & incidentally \\
\hline integrate & follow & notice & picture \\
\hline by the way & have to & picture & review \\
\hline incidentally & incidentally & review & show \\
\hline notice & notice & show & take (a look/as example) \\
\hline show & picture & take (a look/as example) & (...) (personal asides) \\
\hline take (a look/as example) & review & ? (rhetorical questions) & ? (rhetorical questions) \\
\hline add & add & add & add \\
\hline allow & allow & allow & allow \\
\hline
\end{tabular}




\begin{tabular}{|c|c|c|c|}
\hline analyze & analyze & analyze & analyze \\
\hline apply & apply & apply & apply \\
\hline arrange & arrange & arrange & arrange \\
\hline assess & assess & assess & assess \\
\hline calculate & calculate & calculate & calculate \\
\hline choose & choose & choose & choose \\
\hline classify & classify & classify & classify \\
\hline connect & connect & connect & connect \\
\hline consult & consult & consult & consult \\
\hline contrast & contrast & contrast & contrast \\
\hline define & define & define & define \\
\hline demonstrate & demonstrate & demonstrate & demonstrate \\
\hline do not & do not & do not & do not \\
\hline develop & develop & develop & develop \\
\hline employ & employ & employ & employ \\
\hline ensure & ensure & ensure & ensure \\
\hline estimate & estimate & estimate & estimate \\
\hline evaluate & evaluate & evaluate & evaluate \\
\hline go & go & go & go \\
\hline increase & increase & increase & increase \\
\hline input & input & input & input \\
\hline insert & insert & insert & insert \\
\hline key & key & key & key \\
\hline let $x=y$ & let $x=y$ & let $x=y$ & let $x=y$ \\
\hline let us & let us & let us & let us \\
\hline mark & mark & mark & mark \\
\hline measure & measure & measure & measure \\
\hline mount & mount & mount & mount \\
\hline must & must & must & must \\
\hline observe & observe & observe & observe \\
\hline order & order & order & order \\
\hline ought & ought & ought & ought \\
\hline pay & pay & pay & pay \\
\hline prepare & prepare & prepare & prepare \\
\hline recall & recall & recall & recall \\
\hline recover & recover & recover & recover \\
\hline regard & regard & regard & regard \\
\hline remember & remember & remember & remember \\
\hline remove & remove & remove & remove \\
\hline select & select & select & select \\
\hline set & set & set & set \\
\hline suppose & suppose & suppose & suppose \\
\hline state & state & state & state \\
\hline think about & think about & think about & think about \\
\hline think of & think of & think of & think of \\
\hline turn & turn & turn & turn \\
\hline
\end{tabular}




\begin{tabular}{|c|c|c|c|}
\hline use & use & use & use \\
\hline \multicolumn{4}{|c|}{ 10. SELF-MENTIONS } \\
\hline NZ-ELT & NZ-BA & TH-ELT & TH-BA \\
\hline I & researcher & researcher & researcher \\
\hline my & $\mathbf{I}$ & $\mathbf{I}$ & we \\
\hline me & my & the researcher's & our \\
\hline researcher & the researcher's & we & the author's \\
\hline we & me & me & I \\
\hline the researcher's & we & my & me \\
\hline our & the writer & our & my \\
\hline mine & our & mine & mine \\
\hline us & mine & us & us \\
\hline the author & us & the author & the author \\
\hline the author's & the author & the author's & the writer \\
\hline the writer & the author's & the writer & the writer's \\
\hline the writer's & the writer's & the writer's & the researcher's \\
\hline
\end{tabular}




\section{Appendix 3. Rating template}

\section{Thesis Quality Assessment}

Assessor:

Please score each rubric following the rating scales attached (from $5=$ highest to $1=$ lowest).

\begin{tabular}{|c|c|c|c|c|c|}
\hline Thesis ID & $\begin{array}{l}\text { Content } \\
\text { (5 points) }\end{array}$ & $\begin{array}{c}\text { Organization } \\
\text { and } \\
\text { presentation } \\
\text { (5 points) }\end{array}$ & $\begin{array}{c}\text { Language } \\
\text { Use } \\
\text { (5 points) }\end{array}$ & $\begin{array}{c}\text { Genre } \\
\text { knowledge } \\
\text { (5 points) }\end{array}$ & Total \\
\hline Example & 4 & 3.5 & 4 & 2 & 13.5 \\
\hline BA-01 & & & & & \\
\hline BA-02 & & & & & \\
\hline BA-03 & & & & & \\
\hline BA-04 & & & & & \\
\hline BA-05 & & & & & \\
\hline BA-06 & & & & & \\
\hline BA-07 & & & & & \\
\hline BA- 08 & & & & & \\
\hline BA-09 & & & & & \\
\hline BA-10 & & & & & \\
\hline BA-11 & & & & & \\
\hline BA-12 & & & & & \\
\hline BA-13 & & & & & \\
\hline BA-14 & & & & & \\
\hline BA-15 & & & & & \\
\hline BA-16 & & & & & \\
\hline BA-17 & & & & & \\
\hline BA-18 & & & & & \\
\hline BA-19 & & & & & \\
\hline BA-20 & & & & & \\
\hline BA-21 & & & & & \\
\hline BA-22 & & & & & \\
\hline BA-23 & & & & & \\
\hline BA-24 & & & & & \\
\hline
\end{tabular}

Note: 0.5 point can be given in case that some aspects are overlapping between two levels. For example, overall content of Thesis-BA-01 is mostly adhered to the description at Level 4, but also there are a few aspects achieving Level 5 . In this case, it is possiblefor the raters to assign 4.5 for the content of Thesis-BA01. Other decimal points (e.g., 0.1, 3.2, 4.9) are not counted. 


\section{CONTENT}

(Focus: functional elements of discussion and conclusion chapters)

\begin{tabular}{|c|c|}
\hline 5 & $\begin{array}{l}\text { A thesis at this level } \\
\text { - fully covers key elements of discussion and conclusion chapters at excellent level } \\
\text { - has verystrates a highly critical interpretation and justification of significant findings } \\
\text { - articulates significance of findings and contribution to the field clearly } \\
\text { - includes a concise, useful and impressive summary of the whole research } \\
\text { - } \text { specifies new and concrete implications to the field } \\
\text { - acknowledges actual limitations of research honestly } \\
\text { aligns limitations with further research directions specifically }\end{array}$ \\
\hline 4 & $\begin{array}{l}\text { A thesis at this level } \\
\text { - covers almost all the key elements of discussion and conclusion chapters at good level } \\
\text { - has strong linkage between empirical analysis and literature/theories } \\
\text { - } \text { articulates significance of findings and contribution to the field well } \\
\text { includes a good summary of the whole research } \\
\text { - } \text { ackecifies concrete implications to the field } \\
\text { - aligns limitations with further research directions specifically }\end{array}$ \\
\hline 3 & $\begin{array}{l}\text { A thesis at this level } \\
\text { - covers some of the key elements of discussion and conclusion chapters } \\
\text { interprets findings but sometimes superficially justifies the significant findings } \\
\text { compares similarities and dissimilarities to those in previous studies with thoughtful } \\
\text { discussions sometimes } \\
\text { - } \text { articulates significance of findings and contribution to the field fairly well } \\
\text { - } \text { provides broad implications to the field } \\
\text { - acknowledges broad limitations of research }\end{array}$ \\
\hline 2 & $\begin{array}{l}\text { A thesis at this level } \\
\text { - covers a few of the key elements of discussion and conclusion chapters } \\
\text { interprets findings but mostly superficially justifies the significant findings } \\
\text { discussions } \\
\text { - } \text { articulates significance of findings and contribution to the field but not clearly } \\
\text { includes a partial summary of research } \\
\text { - acknowides very broad implications to the field } \\
\text { aligns limitations with recommendations for further research but not specifically } \\
\text { derived from the present study }\end{array}$ \\
\hline 1 & $\begin{array}{l}\text { A thesis at this level } \\
\text { - covers few key elements of discussion and conclusion chapters } \\
\text { does not go beyond restating research findings } \\
\text { - } \text { summardly articulates significance of findings and contribution to the field } \\
\text { provides very broad implications to the field } \\
\text { acknowledges very broad limitations and recommendations for further research, but } \\
\text { there is little or no connection between the two }\end{array}$ \\
\hline
\end{tabular}




\section{ORGANIZATION AND PRESENTATION}

(Focus: connectedness, visual presentation and formatting)

\begin{tabular}{|c|c|}
\hline 5 & $\begin{array}{l}\text { A thesis at this level shows } \\
\text { - an excellent, systematic and logical organization in discussion and conclusion } \\
\text { chapters } \\
\text { - an excellent balance in terms of depth of discussion of each theme throughout (e.g., } \\
\text { not too thick or too thin sections) } \\
\text { - threads between paragraphs, sections and chapters, enabling comprehension from the } \\
\text { beginning to the end with a clear sense of flow } \\
\text { - highly informative, appropriate and effective visual presentations (e.g., charts, } \\
\text { figures) and written description of data to support comprehension } \\
\text { - a high level of consistency and appropriateness in formatting (e.g., font, headings, } \\
\text { section numbers, table labels) throughout the chapters without any errors }\end{array}$ \\
\hline 4 & $\begin{array}{l}\text { A thesis at this level shows } \\
\text { - a good organization based on themes/research questions/hypotheses in discussion and } \\
\text { conclusion chapters } \\
\text { - a good balance in terms of depth of discussion of each theme throughout } \\
\text { - threads within and between chapters, enabling coherent understanding effortlessly } \\
\text { informative, appropriate and effective visual presentations (e.g., charts, figures) and } \\
\text { written description of data to support comprehension } \\
\text { a good level of consistency and appropriateness in formatting (e.g., font, headings, } \\
\text { section numbers, table labels) throughout the chapters with a few errors }\end{array}$ \\
\hline 3 & $\begin{array}{l}\text { A thesis at this level shows } \\
\text { - a fairly good organization with certain themes in discussion and conclusion chapters } \\
\text { - } \text { some balance in terms of depth of discussion of each theme } \\
\text { - fairly informative, appropriate and effective visual presentations (e.g., charts, figures) } \\
\text { and written description of data } \\
\text { - consistency and appropriateness in formatting (e.g., font, headings, section numbers, } \\
\text { table labels) with frequent errors }\end{array}$ \\
\hline 2 & $\begin{array}{l}\text { A thesis at this level shows } \\
\text { - a poor organization with unclear themes in discussion and conclusion chapters } \\
\text { - an imbalance in terms of depth of discussion of each theme (e.g., obviously too thick } \\
\text { and too thin sections) } \\
\text { - no connectedness within and between chapters, affecting smoothness of reading } \\
\text { - fairly informative and appropriate visual presentations (e.g., charts, figures) but } \\
\text { sometimes not completely effective written description of data } \\
\text { - a poor level of consistency and appropriateness in formatting (e.g., font, headings, } \\
\text { section numbers, table labels) with frequent errors }\end{array}$ \\
\hline 1 & $\begin{array}{l}\text { A thesis at this level shows } \\
\text { - no themes in discussion and conclusion chapters } \\
\text { - choppy and loosely-connected organizational structure, impeding comprehension } \\
\text { non-informative, inappropriate and ineffective visual presentations (e.g., charts, } \\
\text { figures) and written description of data } \\
\text { no consistency and appropriateness in formatting (e.g., font, headings, section } \\
\text { numbers, table labels) }\end{array}$ \\
\hline
\end{tabular}




\begin{tabular}{|c|c|}
\hline \multicolumn{2}{|c|}{$\begin{array}{l}\text { LANGUAGE USE } \\
\text { (Focus: grammar and vocabulary) }\end{array}$} \\
\hline 5 & $\begin{array}{l}\text { A thesis at this level shows } \\
\text { - evidence of having been very well proofread } \\
\text { - an excellent language control in terms of grammatical structures and vocabulary } \\
\text { - highly accurate use of a wide variety of vocabulary and grammatical structures } \\
\text { necessary } \\
\text { - high consistency in academic style of writing }\end{array}$ \\
\hline 4 & $\begin{array}{l}\text { A thesis at this level shows } \\
\text { - evidence of having been well proofread } \\
\text { - a good language control with a few typo errors } \\
\text { - words unfit for the context } \\
\text { - } \text { appropriate use of technical terms with clear definitions and repetitions where necessary } \\
\text { - consistency in academic style of writing }\end{array}$ \\
\hline 3 & $\begin{array}{l}\text { A thesis at this level shows } \\
\text { - evidence of having been proofread } \\
\text { - an acceptable language control with some grammatical errors, not affecting the clarity } \\
\text { - accurate meaning } \\
\text { - appropriate of only a limited range of grammatical structures and vocabulary } \\
\text { - writing in academic style but sometimes too conversational }\end{array}$ \\
\hline 2 & $\begin{array}{l}\text { A thesis at this level shows } \\
\text { - little evidence of having been proofread } \\
\text { - a poor language control with frequent grammatical and word choice errors, affecting } \\
\text { the clarity of core meaning and comprehension } \\
\text { - inaccurate use of even a limited range of grammatical structures and vocabulary } \\
\text { - } \text { appropriate use of technical terms but little to no definitions and repetitions } \\
\text { - writing in academic style but often too conversational }\end{array}$ \\
\hline 1 & $\begin{array}{l}\text { A thesis at this level shows } \\
\text { - no evidence of having been proofread } \\
\text { no language control with extensively frequent grammatical and word choice errors, } \\
\text { - seriously affecting the clarity of core meaning and comprehension } \\
\text { - } \text { inappropriate use of technical terms } \\
\text { - writing in conversational style }\end{array}$ \\
\hline
\end{tabular}




\section{GENRE KNOWLEDGE}

(Focus: argument development, reader awareness and tone)

\begin{tabular}{|c|c|}
\hline 5 & $\begin{array}{l}\text { A thesis at this level shows } \\
\text { - an excellent management in terms of the strength of argument and tone of writing to } \\
\text { convince the expected reader } \\
\text { - high awareness of limitations of research and sufficiency of evidence to warrant claims } \\
\text { sufficiens and assertive claims logically and transparently developed on the basis of } \\
\text { - high consistency in formal tone of writing } \\
\text { - high strength of conviction }\end{array}$ \\
\hline 4 & $\begin{array}{l}\text { A thesis at this level shows } \\
\text { - a good management in terms of the strength of argument and tone of writing to convince } \\
\text { the expected reader } \\
\text { - awareness of limitations of research and sufficiency of evidence to warrant claims } \\
\text { - consistency in formal tone of writing } \\
\text { - strength of conviction }\end{array}$ \\
\hline 3 & $\begin{array}{l}\text { A thesis at this level shows } \\
\text { - an attempt by the thesis writer in managing the strength of argument and tone of writing } \\
\text { to convince the expected reader } \\
\text { - some awareness of limitations of research and sufficiency of evidence to warrant claims } \\
\text { - } \text { inconsinstances of overcautious or overconfident claims } \\
\text { - moderate strength of conviction }\end{array}$ \\
\hline 2 & $\begin{array}{l}\text { A thesis at this level shows } \\
\text { - a little attempt by the thesis writer in managing the strength of argument and tone of } \\
\text { writing to convince the expected reader } \\
\text { - a lack of awareness of limitations of research and sufficiency of evidence to warrant } \\
\text { claims } \\
\text { - many instances of overcautious or overconfident claims } \\
\text { - inconsistency in writing tone, frequently using informal language }\end{array}$ \\
\hline 1 & $\begin{array}{l}\text { A thesis at this level shows } \\
\text { - no attempt by the thesis writer in managing the strength of argument and tone of writing } \\
\text { to convince the expected reader } \\
\text { - unawareness of limitations of research and sufficiency of evidence to warrant claims } \\
\text { - many instances of overcautious, overconfident or unsupported claims } \\
\text { - no powsistency in writing tone, mostly using informal (too casual) language } \\
\text { - no conviction }\end{array}$ \\
\hline
\end{tabular}


Additional comments (optional) 
Appendix 4. Ethics approval memorandum

TE WHARE WĀNANGA O TE UPOKO O TE IKA A MĀUI

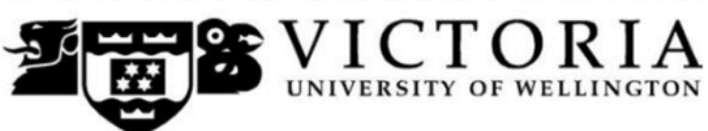

MEMORANDUM

Phone $\quad 0-4-4635480$

Email susan.corbett@vuw.ac.nz

\begin{tabular}{l|l}
\hline TO & Pansa Prommas \\
\hline COPY TO & Jean Parkinson \\
\hline FROM & AProf Susan Corbett, Convener, Human Ethics Committee \\
\hline DATE & 9 May 2017 \\
\hline PAGES & 1 \\
\hline \multicolumn{2}{|l}{} \\
\hline SUBJECT & $\begin{array}{l}\text { Ethics Approval: } \mathbf{2 4 6 0 0} \\
\text { Metadiscourse in Postgraduate Writing }\end{array}$ \\
\hline
\end{tabular}

Thank you for your application for ethical approval, which has now been considered by the Standing Committee of the Human Ethics Committee.

Your application has been approved from the above date and this approval continues until 9 May 2020. If your data collection is not completed by this date you should apply to the Human Ethics Committee for an extension to this approval.

Best wishes with the research.

Kind regards

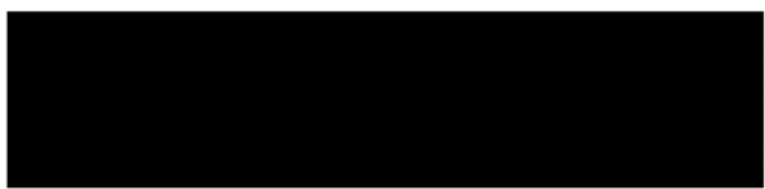

Susan Corbett

Convener, Victoria University Human Ethics Committee 


\section{Appendix 5. Information sheet for supervisor interview participation}

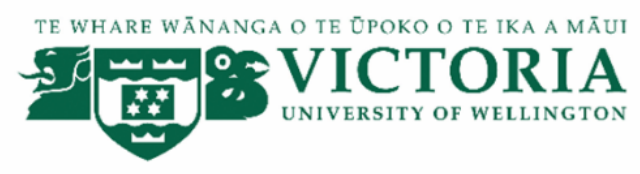

Quality of Thesis Writing

Information sheet for supervisor participation in a semi-structured interview

My name is Pansa Prommas. I am a PhD student in Applied Linguistics at Victoria University of Wellington, New Zealand. As you are recognized as an experienced lecturer/supervisor and likely to have dealt with a substantial amount of postgraduate writing, I am writing to invite you to participate in a semi-structured interview regarding your supervision experience, the written language use of your postgraduate students and rating criteria for assessment of quality of master's theses in your discipline.

\section{RESEARCH DETAILS}

The purpose of this project is to investigate how supervisors in different disciplines assess the quality of thesis writing, especially discussion and conclusion chapters. It is anticipated that this project will be beneficial to all thesis-writing students by providing information about supervisors' expectations and criteria used to assess theses. This research has been approved by the Victoria University of Wellington Human Ethics Committee (Application 24600).

\section{PARTICIPATION AND PROCEDURES}

If you agree to take part in this research, your participation will involve a semi-structured interview of approximately one hour in length. It will take place in a mutually agreed time and venue. With your permission, the interview will be audio-recorded to facilitate collection of data and later transcribed for analysis. During the interview, you can decline to answer questions at any time. After the interview has been completed, I will send you a copy of the transcript to give you an opportunity to confirm the accuracy of our conversation and to add or clarify any points that you wish.

\section{CONFIDENTIALITY AND WITHDRAWAL}

All the data you provide will be completely confidential. Your identity will not be disclosed in any dissertation and publications resulting from this research. Access to the data will be restricted to me and my supervisors. In addition to the use of aggregate data in my doctoral dissertation which will be publicly available, the aggregate data may also be used in conference presentations and research publications. The interview transcript and recording will be securely retained and destroyed three years after the completion of the research.

Participation in this research is entirely voluntary. If you would like to withdraw your data, you can do so within one week after the interview without giving a reason, and any data you have provided will be destroyed.

\section{QUESTIONS AND CONCERNS}

Should you have any concerns about the conduct of my research or would like to receive further information, please do not hesitate to contact me, my supervisors, or the Victoria University Human Ethics Committee Convener. Contact details are given below. 


\section{CONTACT DETAILS}

\section{Researcher:}

Pansa Prommas

E-mail: pansa.prommas@vuw.ac.nz

Telephone: +64-4-463 5233 (ext. 8705)

\section{Supervisors:}

Dr. Jean Parkinson

E-mail: jean.parkinson@vuw.ac.nz

Telephone: +64-4-463 5233 (ext. 8009)

Dr. Rachael Ruegg

E-mail: rachael.ruegg@vuw.ac.nz

Telephone: +64-4-463 5233 (ext. 5628)

Victoria University HEC Convener:

Dr. Judith Loveridge

E-mail: judith.loveridge@vuw.ac.nz

Telephone: +64-4-463 6028
School of Linguistics and Applied Language Studies P0 Box 600, von Zedlitz Building, Office 414

Wellington 6140

New Zealand

School of Linguistics and Applied Language Studies P0 Box 600, von Zedlitz Building, Office 417

Wellington 6140

New Zealand

School of Linguistics and Applied Language Studies P0 Box 600, von Zedlitz Building, Office 411

Wellington 6140

New Zealand 


\section{Appendix 6. Consent form for supervisor interview participation}

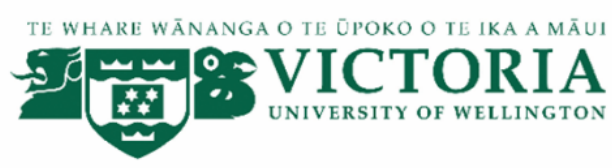

Quality of Thesis Writing

Consent form for supervisor participation in a semi-structured interview

Full name (please print clearly):

- I confirm that I have read and understood the information sheet for the above project and the researcher has answered any queries to my satisfaction.

- I understand that I may ask any questions about the research at any time during participation.

- I understand that the interview transcript will be returned to me to verify its accuracy.

- I understand that all the data I provide will be kept confidential and that my identity will not be disclosed in any dissertation and publications resulting from this research.

- I understand that I may withdraw any data provided for this project within one week after the interview, without giving a reason and without any consequences.

- I understand that the interview transcript and audio-recording will be kept secure and destroyed three years after the completion of the research.

- I understand that the results will be published as a Victoria University of Wellington doctoral dissertation and may also be published in journals and presented at conferences.

- I agree to participate in this phase of the research.

Please tick $\sqrt{ }$ here if you would like to receive:

a copy of the interview transcript

a summary report of this research

Signed:

Date:

E-mail: 


\section{Appendix 7. Interview questions}

\section{General questions}

1. Would you mind telling me about your areas of specific interest and the areas in which you supervise students?

2. Can you describe the common structure of theses in your field? What are main thesis chapters?

\section{Specific questions about writing discussion and conclusion chapters}

3. As some theses combine discussion and conclusion chapters and in some theses they are separate, what about theses in your field? Are the two chapters usually separate or combined? Or, are there any other options like combining results and discussion?

4. What are functions/ crucial elements of a good discussion chapter? What are crucial elements of a good conclusion chapter?

\section{More specific questions about rating practice and criteria}

5. Can you describe the process when you examine or read a thesis, especially discussion and conclusion chapters?

6. What do you consider or focus on when you read and evaluate a thesis? What do you expect to see in the discussion and conclusion chapters?

7. Just now you mentioned about ... (e.g., content). Can you share your experience how you evaluate content of a thesis, particularly the two chapters? What are the indicators to evaluate whether the content is good or not good enough?

8. As you mentioned briefly about ... (e.g., connectedness, language use), can you say a bit more about ... (e.g., connectedness, language use) in a thesis? How would you describe ... (e.g., connectedness, language use) in a thesis?

9. From your experience, what sorts of problems do master's students have when writing discussion and conclusion chapters?

10. Do you think that master's students have sufficient genre knowledge (knowledge of writing different types of texts for different purposes and target readers, for example, theses and research articles)?

11. Is there anything else you would like to add on the assessment or the quality of theses?

\section{Additional questions about metadiscourse}

12. Have you ever explicitly encouraged students to use metadiscourse markers (i.e., however, as mentioned in Chapter 3, I suggest that, I believe that)? Do you think metadiscourse markers play a role in thesis writing and in determining the quality of theses?

13. Do you think that hedging (expressing caution through the markers like maybe, it is likely that, the findings suggested that) is essential for making claims in theses? How would you advise your students to express caution or make strong claims with confidence when writing their theses?

14. What are common citation practices in your field? Is there any specific preference for citation form in your field?

15. What advice would you give to a student who asked you whether they should use the first person pronouns $I$ or $w e$ in their theses?

16. Have you noticed whether students have difficulties in establishing their own voice/ attitude in their theses? How would you advise students about this? 


\section{Appendix 8. Information sheet for rater participation}

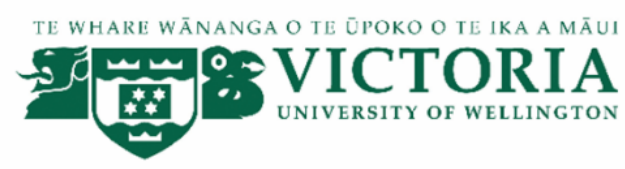

Quality of Thesis Writing

Information sheet for rater participation in thesis writing assessment

My name is Pansa Prommas. I am a PhD student in Applied Linguistics at Victoria University of Wellington, New Zealand. I am writing to invite you to participate as a rater in my doctoral research since you are recognized as an experienced lecturer/supervisor and likely to have dealt with a substantial amount of postgraduate writing in (DISCIPLINE).

\section{RESEARCH DETAILS}

The purpose of this project is to examine quality of thesis writing produced by Thai and New Zealand students in different disciplines and investigate its relationship with the use of linguistic features to form textual connectedness and reader engagement in writing. This research has been approved by the Victoria University of Wellington Human Ethics Committee (Application 24600).

\section{PARTICIPATION AND PROCEDURES}

If you agree to take part in this research, you will be required to assess quality of twenty-four master's thesis discussion and conclusion chapters written by Thai and New Zealand students in (DISCIPLINE) within one month, starting from 1 November 2018. It may take approximately two hours to read and rate the chapters of a thesis. You will be given a rating scale template in order to rate the theses based on the given criteria, your own expectations and general impression. After the assessment task has been completed, you will be invited to participate in a follow-up interview via Skype, lasting no longer than thirty minutes, to discuss the assessment of thesis quality and disciplinary students' writing problems.

\section{CONFIDENTIALITY AND WITHDRAWAL}

Scoring and interview data will be completely confidential. Your identity will not be disclosed in any dissertation and publications resulting from this research. Access to the data will be restricted to me and my supervisors. In addition to the use of aggregate data in my doctoral dissertation which will be publicly available, the aggregate data may also be used in conference presentations and research publications. All the data (i.e., scores, interview transcripts and recordings) will be securely retained and destroyed three years after the completion of the research.

Participation in this research is entirely voluntary. If you would like to withdraw yourself from the assessment task, you may do so before 15 November 2018 without giving a reason, and any data you have provided will be destroyed.

\section{QUESTIONS AND CONCERNS}

Should you have any concerns about the conduct of my research or would like to receive further information, please do not hesitate to contact me, my supervisors, or the Victoria University Human Ethics Committee Convener. Contact details are given below. 


\section{CONTACT DETAILS}

\section{Researcher:}

Pansa Prommas

School of Linguistics and Applied Language Studies

E-mail: pansa.prommas@vuw.ac.nz

Telephone: +64-4-463 5233 (ext. 8705) P0 Box 600, von Zedlitz Building, Office 414

Wellington 6140

New Zealand

\section{Supervisors:}

Dr. Jean Parkinson

School of Linguistics and Applied Language Studies

E-mail: jean.parkinson@vuw.ac.nz

Telephone: +64-4-463 5233 (ext. 8009) P0 Box 600, von Zedlitz Building, Office 417

Wellington 6140

New Zealand

Dr. Rachael Ruegg

E-mail: rachael.ruegg@vuw.ac.nz

Telephone: +64-4-463 5233 (ext. 5612)

School of Linguistics and Applied Language Studies P0 Box 600, von Zedlitz Building, Office 411

Wellington 6140

New Zealand

Victoria University HEC Convener:

Dr. Judith Loveridge

E-mail: judith.loveridge@vuw.ac.nz

Telephone: +64-4-463 6028 


\section{Appendix 9. Consent form for rater participation}

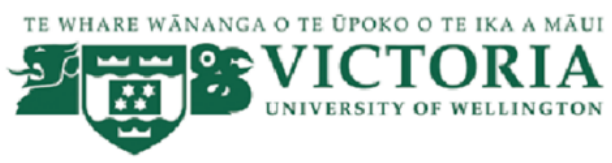

Quality of Thesis Writing

Consent form for rater participation in thesis writing assessment

Full name (please print clearly):

- I confirm that I have read and understood the information sheet for the above project and the researcher has answered any queries to my satisfaction.

- I understand that I may ask any questions about the research at any time during participation.

- I understand that after I have done the assessment task, I will be required to participate in a follow-up interview.

- I understand that I may withdraw myself from the assessment task before 15 November 2018, without giving a reason and without any consequences.

- I understand that the interview transcript will be returned to me to verify its accuracy.

- I understand that all the data provided will be kept confidential and that my identity will not be disclosed in any dissertation and publications resulting from this research.

- I understand that all the data (i.e., scores, interview transcripts and recordings) will be kept secure and destroyed three years after the completion of the research.

- I understand that the results will be published as a Victoria University of Wellington doctoral dissertation and may also be published in journals and presented at conferences.

- I agree to participate as a rater in this phase of the research.

Please tick $\sqrt{ }$ here if you would like to receive:

a copy of the follow-up interview transcript

$\square$ a summary report of this research

Signed:

Date:

E-mail: 


\section{Appendix 10. Request letter to thesis authors for permission to use theses}

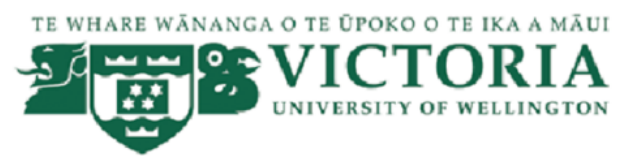

School of Linguistics and Applied Language Studies

PO Box 600

Wellington 6140

New Zealand

Dear Sir or Madam,

My name is Pansa Prommas. I am a PhD student in Applied Linguistics at Victoria University of Wellington, New Zealand. I am writing to request permission to use your master's thesis in my doctoral research.

The research project is entitled "Metadiscourse in Postgraduate Writing." It aims to analyze linguistic features like metadiscourse markers (e.g., according to, in other words, as you can see), which native Thai and English postgraduates use to interact with readers in their theses. This research has been approved by the Victoria University of Wellington Human Ethics Committee (Application 24600). A print copy of my completed dissertation will be deposited in the Victoria University of Wellington Library, and a digital copy will also be made available on open access via the University's digital repository ResearchArchive for research and study purposes only.

Hereby, I am requesting you to grant me permission to use your thesis for my research and to include excerpts from your thesis of a maximum length of 200 words in the print and electronic copies of my dissertation as well as any publications resulting from the research.

Please be assured that the data will not be reported at an individual level, and your identity will not be disclosed to anyone else outside the research team. If you agree to grant me permission, kindly return the attached consent form to me at the e-mail address given below. Should you have any queries about the conduct of my research, please do not hesitate to contact me, my supervisors, or the Victoria University Human Ethics Committee Convener. Contact details are given below.

Thank you for your consideration.

Yours sincerely,

Pansa Prommas 


\section{CONTACT DETAILS}

\section{Researcher:}

Pansa Prommas

E-mail: pansa.prommas@vuw.ac.nz

Telephone: +64-4-463 5233 (ext. 8705)

\section{Supervisors:}

Dr. Jean Parkinson

E-mail: jean.parkinson@vuw.ac.nz

Telephone: +64-4-463 5233 (ext. 8009)

Dr. Rachael Ruegg

E-mail: rachael.ruegg@vuw.ac.nz

Telephone: +64-4-463 5233 (ext. 5612)

Victoria University HEC Convener:

Associate Professor Susan Corbett

E-mail: susan.corbett@vuw.ac.nz

Telephone: +64-4-4635480
School of Linguistics and Applied Language Studies P0 Box 600, von Zedlitz Building, Office 414

Wellington 6140

New Zealand

School of Linguistics and Applied Language Studies PO Box 600, von Zedlitz Building, Office 417 Wellington 6140

New Zealand

School of Linguistics and Applied Language Studies PO Box 600, von Zedlitz Building, Office 411

Wellington 6140

New Zealand 


\section{Appendix 11. Consent form from authors for electronic thesis use}

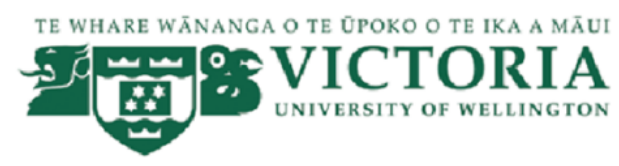

Metadiscourse in Postgraduate Writing

Consent form for electronic thesis use (Author)

Master's thesis title:

Full name (please print clearly):

- I confirm that I have read and understood the information sheet for the above project.

- I have had an opportunity to ask questions, and the researcher has answered them to my satisfaction.

- I understand that the data I provide will be stored securely (in a password protected computer). My identity will be confidential and a pseudonym will be used.

- I understand that the data I provide will be aggregated and not be reported at an individual level.

- I understand that the results will be published as a Victoria University of Wellington doctoral dissertation and may also be published in journals and presented at conferences.

- I agree to grant you an irrevocable and perpetual license to include excerpts from my thesis of a maximum length of 200 words in the print and electronic copies of your dissertation as well as any publications resulting from this research.

Please indicate whether you would like to receive a summary report of this research at the end of the project:

$\square$ Yes E-mail address :

No

Signed:

Date: 


\section{Appendix 12. Request letter to Thammasat University for permission to use theses}

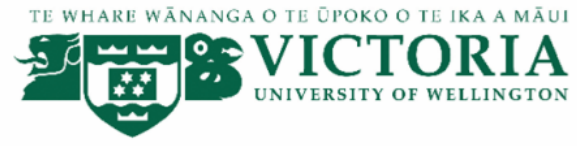

วันที่ 1 มิถุนายน 2560

เรื่อง ขออนุญาตใช้วิทยานิพนธ์เพื่อการวิจัยทางภาษา

เรียน รองอธิการบดีฝ่ายวิชาการ

ด้วยข้าพเจ้านางสาวพรรษา พรหมมาศ อาจารย์ประจำภาควิชาภาษาต่างประเทศ คณะพาณิชยศาสตร์และการจัดการ มหาวิทยาลัยสงขลานครินทร์ วิทยาเขตตรัง ปัจจุบันกำลังศึกษาต่อระดับปริญญาเอก สาขาภาษาศาสตร์ประยุกต์ ณ Victoria University of Wellington ประเทศนิวซีแลนด์ มีความประสงค์ขอใช้วิทยานิพนธ์ของมหาวิทยาลัยธรรมศาสตร์เพื่อการวิจัยทาง ภาษาระดับปริญญาเอก

หัวข้อโครงการวิจัยของข้าพเจ้าคือ Metadiscourse in Postgraduate Writing งานวิจัยชิ้นนี้มุ่งเน้นการวิเคราะห์การใช้ ภาษาของนักศึกษาระดับปริญญาโทชาวไทยและเจ้าของภาษาอังกฤษในการสื่อสารกับผู้อ่านวิทยานิพนธ์ เช่นการใช้คำเชื่อม according to, in other words และ as you can see เป็นต้น งานวิจัยดังกล่าวได้รับการตรวจสอบและอนุมัติจาก Victoria University of Wellington Human Ethics Committee (งานวิจัยเลขที่ 24600)

ในการนี้ ข้าพเจ้าจึงเรียนมาเพื่อขอความอนุเคราะห์จากท่านในการลงนามอนุญาตให้ข้าพเจ้าใช้วิทยานิพนธ์ที่เผยแพร์ใน ฐานข้อมูลวิทยานิพนธ์ฉบับอิเล็กทรอนิกส์ (E-theses) ของมหาวิทยาลัยธรรมศาสตร์จำนวน 60 ฉบับ เพื่อเป็นข้อมูลในการ วิเคราะห์ภาษาของผู้เรียนระดับปริญญาโทสาขาบริหารธุรกิจและการสอนภาษาอังกฤษเป็นภาษาต่างประเทศ โดยข้าพเจ้าจะ รายงานผลการวิจัยเป็นแบบองค์รวม เช่น นักศึกษาไทยสาขาบริหารธุรกิจใช้คำเชื่อม according to จำนวน 460 ครั้ง เป็นต้น หากมีการยกตัวอย่างประกอบการวิเคราะห์โครงสร้างของภาษา ข้าพเจ้าจะยกตัวอย่างข้อความหรือรูปแบบประโยคที่พบใน วิทยานิพนธ์ไม่เกิน 200 คำต่อครั้ง ข้าพเจ้าขอยืนยันว่าการตีพิมพ์ผลการวิจัยทั้งในวิทยานิพนธ์ของข้าพเจ้าหรือวารสารวิชาการ ต่างๆจะไม่มีการระบุตัวตนของผู้เขียนวิทยานิพนธ์ ข้อมูลที่เกี่ยวข้องกับผู้เขียนวิทยานิพนธ์จะถือเป็นข้อมูลลับ จะมีเพียงข้าพเจ้า และอาจารย์ที่ปรึกษาเท่านั้นที่สามารถเข้าถึงข้อมูลดังกล่าวได้

ข้าพเจ้าหวังเป็นอย่างยิ่งว่าท่านจะอนุเคราะห์ให้ข้าพเจ้าใช้วิทยานิพนธ์ของมหาวิทยาลัยธรรมศาสตร์ เพื่อวัตถุประสงค์ ทางการวิจัยตามรายละเอียดข้างต้น หากท่านมีข้อสงสัยใดๆเกี่ยวกับโครงการวิจัยหรีอตัวข้าพเจ้าท่านสามารถสอบถามข้อมูล เพิ่มเติมได้ทั้งจากตัวข้าพเจ้า อาจารย์ที่ปรึกษา หรือ ประธานคณะกรรมการพิจารณาจริยธรรมการวิจัยในมนุษย์ของ Victoria University ตามรายละเอียดการติดต่อที่แนบมา

ขอแสดงความนับถือ

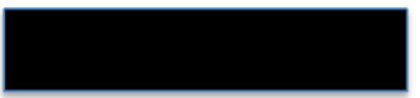

พรรษา พรหมมาศ

เอกสารแนบ: 1. หนังสือขออนุญาตใช้วิทยานิพนธ์ฉบับภาษาอังกฤษ (Permission request letter/ information sheet)

2. แบบฟอร์มอนุญาตให้ใช้วิทยานิพนธ์ (Consent form)

3. หนังสือรับรองผู้วิจัย (Verification letter from the Head of School) 
School of Linguistics and Applied Language Studies

PO Box 600

Wellington 6140

New Zealand

1 June 2017

Dear Vice President for Academic Affairs,

My name is Pansa Prommas. I am currently a PhD student in Applied Linguistics at Victoria University of Wellington, New Zealand. I am writing to request permission to use digital copies of master's theses of Thammasat University in my doctoral research.

The research project is entitled "Metadiscourse in Postgraduate Writing." It aims to analyze linguistic features like metadiscourse markers (e.g., according to, in other words, as you can see), which native Thai and English postgraduates use to form textual connectedness and reader engagement in their theses. This research has been approved by the Victoria University of Wellington Human Ethics Committee (Application 24600). A print copy of my completed dissertation will be deposited in the Victoria University of Wellington Library, and a digital copy will also be made available on open access via the University's digital repository ResearchArchive for research and study purposes only.

I intend to collect 60 digital copies of master's theses in two disciplines-Business Administration and Teaching English as a Foreign Language (maybe under other titles such as Teaching English as a Second and Other Language (TESOL), Applied Linguistics, etc.). With an awareness of author's copyright, I am requesting to collect only theses which authors have given consent to your university to publish their work online and to utilize them for research and scholarly purposes. However, authors' identities will be confidential and not be disclosed to anyone else outside the research team.

I am also requesting that you grant an irrevocable and perpetual license to include excerpts from the theses of a maximum length of 200 words in the print and electronic copies of my dissertation as well as any publications resulting from this research. Proper acknowledgement to your university holding the copyright of theses will be given in my dissertation.

If these arrangements meet with your approval, kindly return the attached consent form to me at the e-mail address given below. Should you have any queries about the conduct of my research, please do not hesitate to contact me, my supervisors, or the Victoria University Human Ethics Committee Convener. Contact details are given below.

Thank you for your consideration.

Yours sincerely,

Pansa Prommas 


\section{CONTACT DETAILS}

Researcher:

Pansa Prommas

E-mail: pansa.prommas@vuw.ac.nz

Telephone: +64-4-463 5233 (ext. 8705)

\section{Supervisors:}

Dr. Jean Parkinson

E-mail: jean.parkinson@vuw.ac.nz

Telephone: +64-4-463 5233 (ext. 8009)

Dr. Rachael Ruegg

E-mail: rachael.ruegg@vuw.ac.nz

Telephone: +64-4-463 5233 (ext. 5612)

Victoria University HEC Convener:

Associate Professor Susan Corbett

E-mail: susan.corbett@vuw.ac.nz

Telephone: +64-4-463 5480
School of Linguistics and Applied Language Studies P0 Box 600, von Zedlitz Building, Office 414

Wellington 6140

New Zealand

School of Linguistics and Applied Language Studies P0 Box 600, von Zedlitz Building, Office 417

Wellington 6140

New Zealand

School of Linguistics and Applied Language Studies P0 Box 600, von Zedlitz Building, Office 411

Wellington 6140

New Zealand 


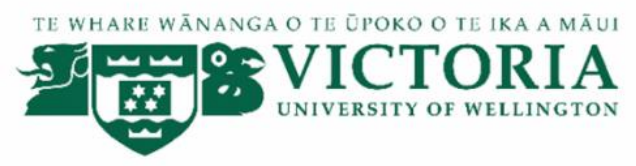

Metadiscourse in Postgraduate Writing

Consent form for electronic thesis collection and use

Full name (please print clearly):

- I confirm that I have read and understood the information sheet for the above project.

- I have had an opportunity to ask questions, and the researcher has answered them to my satisfaction.

- I understand that the data I provide will be stored securely (in a password protected computer). Identities of thesis authors will be confidential and pseudonyms will be used.

- I understand that the data I provide will be aggregated and not be reported at an individual level.

- I understand that the results will be published as a Victoria University of Wellington doctoral dissertation and may also be published in journals and presented at conferences.

- I agree to permit you to collect electronic theses of Thammasat University and grant you an irrevocable and perpetual license to include excerpts from the theses of a maximum length of 200 words in the print and electronic copies of your dissertation as well as any publications resulting from this research.

Please indicate whether you would like to receive a summary report of this research at the end of the project:

$\square$ Yes E-mail address :

$\square$ No

Signed:

Position:

Date: 


\section{Appendix 13. Consent letter from Thammasat University}
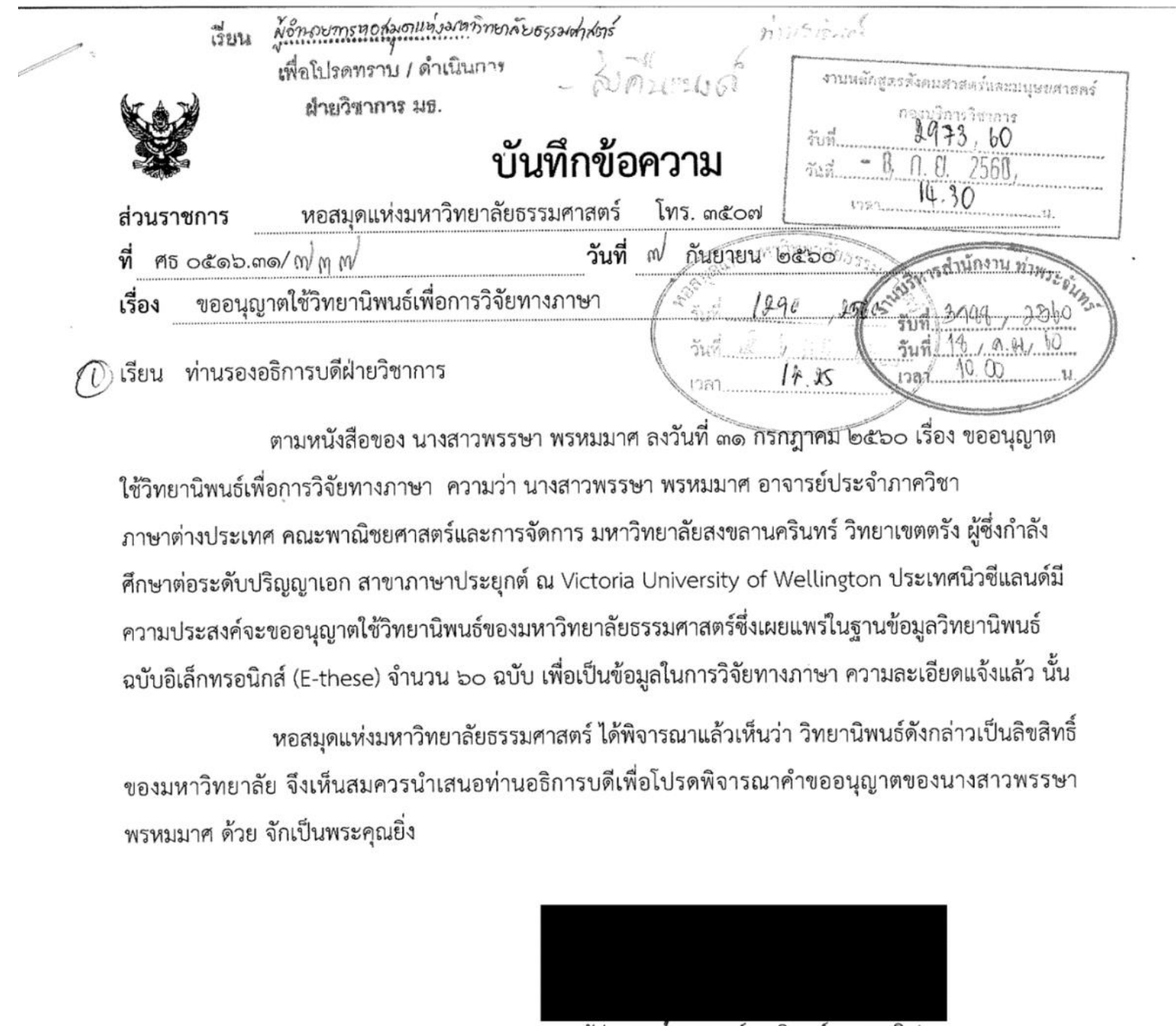

(ผู้ช่วยศาสตราจารย์เอกรินทร์ ยลระบิล)

ผู้อำนวยการหอสมุดแห่งมหาวิทยาลัยธรรมศาสตร์

(2) เรียน ท่านอธิการบดี

สืบเนื่องจากข้อบังคับมหาวิทยาลัยธรรมศาสตร์ ว่าด้วยการศึกษาระดับบัณฑิตศึกษา พ.ศ. 2553 ข้อ 26 กำหนดไว้ว่า “ลิขสิทธิ์วิทยานิพนธ์ สารนิพนธ์ หรือการค้นคว้าอิสระเป็นของมหาวิทยาลัย" และที่ผ่านมาจะมีการ ขออนุญาตเฉพาะกรณีขอนำผลงานวิทยานิพนธ์/สารนิพนธ์ ไปเผยแพร่เท่านั้น กรณีนี้เป็นการขออนุญาตใช้วิทยานิพนธ์ ที่เผยแพร่ในฐานข้อมูลวิทยานิพนธ์ฉบับอิเล็กทรอนิกส์ (E-thesis) ของมหาวิทยาลัยธรรมศาสตร์ จำนวน 60 ฉบับ เพื่อเป็นข้อมูลในการวิจัยทางภาษาระดับปริญญาเอกของ นางสาวพรรษา พรหมมาศ ซึ่งฝ่ายวิชาการพิจารณาแล้ว เห็นควรอนุญาตตามที่หอสมุดมหาวิทยาลัยธรรมศาสตร์เสนอขอมา

(4) รैominas. จึงเรียนมาเพื่อโปรดพิจารณา
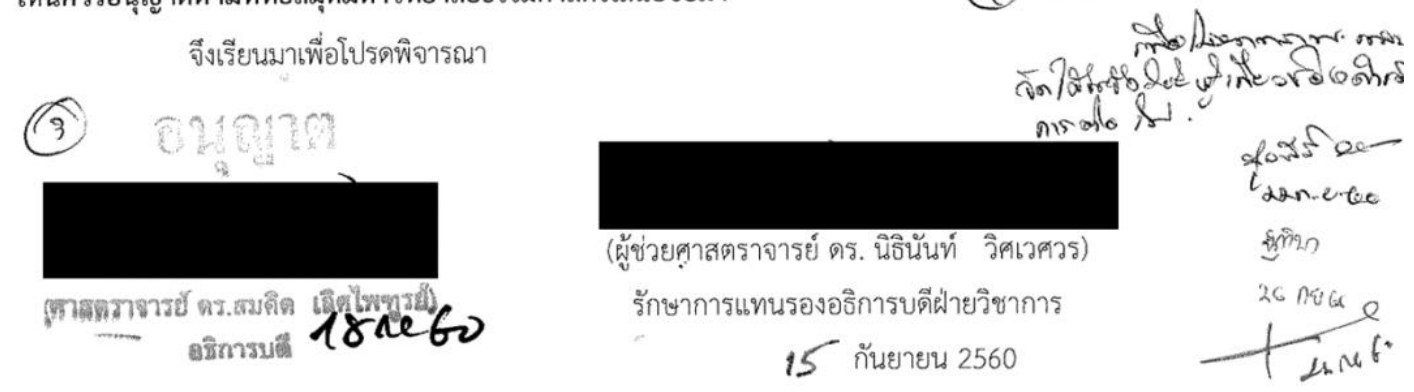


\title{
Appendix 14. Request letter to Prince of Songkla University for permission to use theses
}

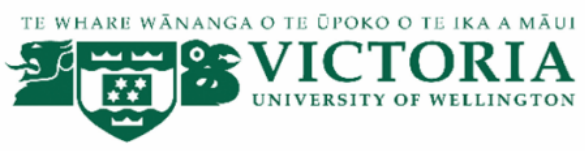

\author{
วันที่ 1 มิถุนายน 2560 \\ เรื่อง ขออนุญาตใช้วิทยานิพนธ์เพื่อการวิจัยทางภาษา \\ เรียน คณบดีบัณฑิตวิทยาลัย
}

ด้วยข้าพเจ้านางสาวพรรษา พรหมมาศ อาจารย์ประจำภาควิชาภาษาต่างประเทศ คณะพาณิชยศาสตร์และการจัดการ มหาวิทยาลัยสงขลานครินทร์ วิทยาเขตตรัง ปัจจุบันกำลังศึกษาต่อระดับปริญญาเอก สาขาภาษาศาสตร์ประยุกต์ ณ Victoria University of Wellington ประเทศนิวซีแลนด์ มีความประสงค์ขอใช้วิทยานิพนธ์ของมหาวิทยาลัยสงขลานครินทร์ เพื่อการวิจัย ทางภาษาระดับปริญญาเอก

หัวข้อโครงการวิจัยของข้าพเจ้าคือ Metadiscourse in Postgraduate Writing งานวิจัยชิ้นนี้มุ่งเน้นการวิเคราะห์การใช้ ภาษาของนักศึกษาระดับปริญญาโทชาวไทยและเจ้าของภาษาอังกฤษในการสื่อสารกับผู้อ่านวิทยานิพนธ์ เช่นการใช้คำเชื่อม according to, in other words และ as you can see เป็นต้น งานวิจัยดังกล่าวได้รับการตรวจสอบและอนุมัติจาก Victoria University of Wellington Human Ethics Committee (งานวิจัยเลขที่ 24600)

ในการนี้ ข้าพเจ้าจึงเรียนมาเพื่อขอความอนุเคราะห์จากท่านในการลงนามอนุญาตให้ข้าพเจ้าใช้วิทยานิพนธ์ที่เผยแพร์ใน ฐานข้อมูลวิทยานิพนธ์ฉบับอิเล็กทรอนิกส์ (E-theses) ของมหาวิทยาลัยสงขลานครินทร์จำนวน 60 ฉบับ เพื่อเป็นข้อมูลในการ วิเคราะห์ภาษาของผู้เรียนระดับปริญญาโทสาขาบริหารธุรกิจและการสอนภาษาอังกฤษเป็นภาษานานาชาติ โดยข้าพเจ้าจะ รายงานผลการวิจัยเป็นแบบองค์รวม เช่น นักศึกษาไทยสาขาบริหารธุรกิจใช้คำเชื่อม according to จำนวน 460 ครั้ง เป็นต้น หากมีการยกตัวอย่างประกอบการวิเคราะห์โครงสร้างของภาษา ข้าพเจ้าจะยกตัวอย่างข้อความหรือรูปแบบประโยคที่พบใน วิทยานิพนธ์ไม่เกิน 200 คำต่อครั้ง ข้าพเจ้าขอยืนยันว่าการตีพิมพ์ผลการวิจัยทั้งในวิทยานิพนธ์ของข้าพเจ้าหรือวารสารวิชาการ ต่างๆจะไม่มีการระบุตัวตนของผู้เขียนวิทยานิพนธ์ ข้อมูลที่เกี่ยวข้องกับผู้เขียนวิทยานิพนธ์จะถือเป็นข้อมูลลับ จะมีเพียงข้าพเจ้า และอาจารย์ที่ปรึกษาเท่านั้นที่สามารถเข้าถึงข้อมูลดังกล่าวได้

ข้าพเจ้าหวังเป็นอย่างยิ่งว่าท่านจะอนุเคราะห์ให้ข้าพเจ้าใช้วิทยานิพนธ์ของมหาวิทยาลัยสงขลานครินทร์เพื่อ วัตถุประสงค์ทางการวิจัยตามรายละเอียดข้างต้น หากท่านมีข้อสงสัยใดๆเกี่ยวกับโครงการวิจัยหรือตัวข้าพเจ้าท่านสามารถ สอบถามข้อมูลเพิ่มเติมได้ทั้งจากตัวข้าพเจ้า อาจารย์ที่ปรีกษา หรือ ประธานคณะกรรมการพิจารณาจริยธรรมการวิจัยในมนุษย์ ของ Victoria University ตามรายละเอียดการติดต่อที่แนบมา

ขอแสดงความนับถือ

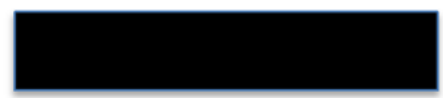

พรรษา พรหมมาศ

เอกสารแนบ: 1. หนังสือขออนุญาตใช้วิทยานิพนธ์ฉบับภาษาอังกฤษ (Permission request letter/ information sheet)

2. แบบฟอร์มอนุญาตให้ใช้วิทยานิพนธ์ (Consent form)

3. หนังสือรับรองผู้วิจัย (Verification letter from the Head of School) 
School of Linguistics and Applied Language Studies

P0 Box 600

Wellington 6140

New Zealand

1 June 2017

Dear Dean of the Graduate School,

My name is Pansa Prommas. I am currently a $\mathrm{PhD}$ student in Applied Linguistics at Victoria University of Wellington, New Zealand. I am writing to request permission to use digital copies of master's theses of Prince of Songkla University in my doctoral research.

The research project is entitled "Metadiscourse in Postgraduate Writing." It aims to analyze linguistic features like metadiscourse markers (e.g., according to, in other words, as you can see), which native Thai and English postgraduates use to form textual connectedness and reader engagement in their theses. This research has been approved by the Victoria University of Wellington Human Ethics Committee (Application 24600). A print copy of my completed dissertation will be deposited in the Victoria University of Wellington Library, and a digital copy will also be made available on open access via the University's digital repository ResearchArchive for research and study purposes only.

I intend to collect 60 digital copies of master's theses in two disciplines-Business Administration and Teaching English as an International Language (maybe under other titles such as Teaching English as a Second and Other Language (TESOL), Applied Linguistics, etc.). With an awareness of author's copyright, I am requesting to collect only theses which authors have given consent to your university to publish their work online and to utilize them for research and scholarly purposes. However, authors' identities will be confidential and not be disclosed to anyone else outside the research team.

I am also requesting that you grant an irrevocable and perpetual license to include excerpts from the theses of a maximum length of 200 words in the print and electronic copies of my dissertation as well as any publications resulting from this research. Proper acknowledgement to your university holding the copyright of theses will be given in my dissertation.

If these arrangements meet with your approval, kindly return the attached consent form to me at the e-mail address given below. Should you have any queries about the conduct of my research, please do not hesitate to contact me, my supervisors, or the Victoria University Human Ethics Committee Convener. Contact details are given below.

Thank you for your consideration.

Yours sincerely,

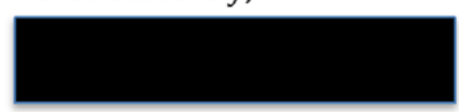

Pansa Prommas 


\section{CONTACT DETAILS}

\section{Researcher:}

Pansa Prommas

E-mail: pansa.prommas@vuw.ac.nz

Telephone: +64-4-463 5233 (ext. 8705)

\section{Supervisors:}

Dr. Jean Parkinson

E-mail: jean.parkinson@vuw.ac.nz

Telephone: +64-4-463 5233 (ext. 8009)

Dr. Rachael Ruegg

E-mail: rachael.ruegg@vuw.ac.nz

Telephone: +64-4-463 5233 (ext. 5612)

Victoria University HEC Convener:

Associate Professor Susan Corbett

E-mail: susan.corbett@vuw.ac.nz

Telephone: +64-4-4635480
School of Linguistics and Applied Language Studies P0 Box 600, von Zedlitz Building, Office 414

Wellington 6140

New Zealand

School of Linguistics and Applied Language Studies P0 Box 600, von Zedlitz Building, Office 417 Wellington 6140

New Zealand

School of Linguistics and Applied Language Studies P0 Box 600, von Zedlitz Building, Office 411

Wellington 6140

New Zealand 


\section{Metadiscourse in Postgraduate Writing \\ Consent form for electronic thesis collection and use}

Full name (please print clearly):

- I confirm that I have read and understood the information sheet for the above project.

- I have had an opportunity to ask questions, and the researcher has answered them to my satisfaction.

- I understand that the data I provide will be stored securely (in a password protected computer). Identities of thesis authors will be confidential and pseudonyms will be used.

- I understand that the data I provide will be aggregated and not be reported at an individual level.

- I understand that the results will be published as a Victoria University of Wellington doctoral dissertation and may also be published in journals and presented at conferences.

- I agree to permit you to collect electronic theses of Prince of Songkla University and grant you an irrevocable and perpetual license to include excerpts from the theses of a maximum length of 200 words in the print and electronic copies of your dissertation as well as any publications resulting from this research.

Please indicate whether you would like to receive a summary report of this research at the end of the project:

$\square$ Yes E-mail address:

$\square$ No

Signed:

Position:

Date: 


\section{Appendix 15. Consent letter from Prince of Songkla University}

\section{บันทึกข้อความ}

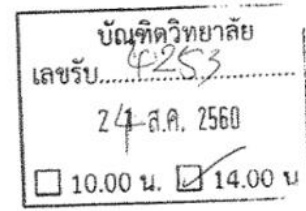

ส่วนราชการ ศูนย์ทรัพย์สินทางปัญญา อุทยานวิทยาศาสตร์ มหาวิทยาลัยสงขลานครินทร์ โทร. 9335

ที่ มอ $164.3 / 335$

วันที่ 24 สิงหาคม 2560

เรื่อง อนุญาตให้ใช้ลิขสิทธิ์ในวิทยานิพนธ์

เรียน คณบดีบัณฑิตวิทยาลัย

ตามที่ อาจารย์พรรษา พรหมมาศ สังกัดคณะพาณิชยศาสตร์และการจัดการ มหาวิทยาลัยสงขลานครินทร์ วข.ตรัง มีความประสงค์ขออนุญาตใช้วิทยานิพนธ์ของนักศึกษาบัณฑิตศึกษา มหาวิทยาลัยสงขลานครินทร์เพื่อการทำงานวิจัยในการศึกษาต่อระดับ ปริญญาเอก ณ Victoria University of Wellington โดยมีข้อมูลดังนี้

1. ประสงค์ใช้ข้อมูลจากวิทยานิพนธ์ระดับปริญญาโท ในสาขาวิชาบริหารธุรกิจและสาขาวิชา การสอนภาษาอังกฤษเป็นภาษานานาชาติที่เผยแพร่ออนไลน์จาก

https://opac.psu.ac.th/Search_Basic.aspx จำนวน 60 ฉบับ ตามเอกสารแนบ

2. งานวิจัยมุ่งเน้นการวิเคราะห์การใช้ภาษาของ นักศึกษาปริญญาโท ชาวไทยและเจ้าของ ภาษาในการสื่อสารกับผู้อ่านวิทยานิพนธ์

โดยงานวิทยานิพนธ์ ดังกล่าวข้างต้น เป็นลิขสิทธิ์ของมหาวิทยาลัยสงขลานครินทร์

ในการนี้ มหาวิทยาลัยสงขลานครินทร์ได้พิจารณาแล้วมีความเห็นว่าควรอนุญาตให้ทาง อาจารย์พรรษา พรหมมาศ ใช้ผลงานลิขสิทธิ์ดังกล่าวโดยไม่มีค่าตอบแทนและใช้สิทธิได้เฉพาะ เพื่อการทำงานวิจัยในการศึกษาต่อระดับ ปริญญาเอก ณ Victoria University of Wellington เท่านั้น ทั้งนี้ จะต้องมีการอ้างถึงมหาวิทยาลัยสงขลานครินทร์และซื่อผู้สร้างสรรค์ผลงานให้เป็นที่ประจักษ์ในการใช้ผลงาน ดังกล่าวด้วย หากมีผู้ประสงค์จะใช้งานในผลงานอันมีลิขสิทธิ์ดังกล่าวนอกเหนือจากที่ได้อนุญาตไว้ จักต้องมี การขออนุญาตและได้รับการอนุญาตจากมหาวิทยาลัยสงขลานครินทร์ก่อนทุกครั้ง

จึงเรียนมาเพื่อโปรดทราบ

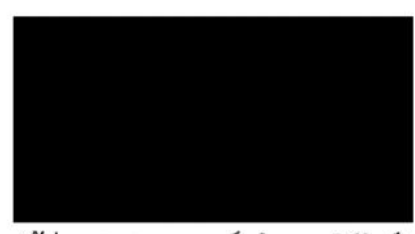

(ผู้ช่วยศาสตราจารย์ คำรณ พิทักษ์)

ผู้อำนวยการอุทยานวิทยาศาสตร์

มหาวิทยาลัยสงขลานครินทร์ 


\section{Appendix 16. List of theses from Prince of Songkla University}

PRINCE OF SONGKLA UNIVERSITY THESES

\begin{tabular}{|c|c|c|}
\hline & Master of Arts in Teaching English as an International Language & \\
\hline No. & Thesis title & Author \\
\hline 1 & Problems and Needs in English Teaching and Learning at the Institutes of Physical Education, Thailand & Supaporn Klaichim \\
\hline 2 & $\begin{array}{l}\text { Communication Strategies: A Study of Students with High and Low English Proficiency in the M.3 English Program at } \\
\text { Attarkiah Islamiah School }\end{array}$ & Thipakorn Binhayeearong \\
\hline 3 & Reciprocal Teaching Procedure and Regular Reading Instruction: Their Effects on Students' Reading Development & Wanpavee Panmanee \\
\hline 4 & Effects of Using Concordances on EFL Learners' Ability to Self-Correct Grammatical Errors & Asama Tasanameelarp \\
\hline 5 & Effects of Cooperative Learning on Writing Ability of Thai Secondary School Students & Nakamol Nudee \\
\hline 6 & An Attitudinal Study of Varieties of English: Voices from Thai University English Learners & Naratip Jindapitak \\
\hline 7 & $\begin{array}{l}\text { Effectiveness of Explicit Instruction in Pronunciation of English Unfamiliar Sounds: A Case Study of M.5 Students } \\
\text { at Darussalam School, Narathiwat Province }\end{array}$ & Nurhaswanee Boto \\
\hline 8 & $\begin{array}{l}\text { Effectiveness of Inductive Approach to Grammar Learning for Writing Course: A Case Study of 2nd Year English Major } \\
\text { Students, } \\
\text { Suratthani Rajabhat University }\end{array}$ & Prisna Putthasupa \\
\hline 9 & $\begin{array}{l}\text { Teaching Questioning and Answering Skills Through Information-Gap Activities: } \\
\text { A Case Study of Thai EFL Students }\end{array}$ & Rongdara Rochanahasadin \\
\hline 10 & Pragmatic Competence in Requests: A Case of Thai English Teachers & Suratchawadee Pinyo \\
\hline 11 & Reading and Writing Skills Development: The Use of SQ5R Technique & Tanomchit Sangcharoon \\
\hline 12 & $\begin{array}{l}\text { Thai EFL Learners' Use of Discourse Markers in English Conversation: A Study of Business English Students at Didyasarin } \\
\text { International College }\end{array}$ & Wipawanna Nookam \\
\hline 13 & The Relationship between Vocabulary Learning Strategies and Vocabulary Knowledge of Thai Undergraduate Students & Tinutda Komol \\
\hline 14 & Effects of Processing Strategies on Listening Comprehension & Jaruwan Nufai \\
\hline 15 & Pragmatic Features in English Course Materials Used at a Thai University & Sirion Wichien \\
\hline 16 & Relationships between Vocabulary Learning Strategies and Vocabulary Knowledge and Reading Comprehension & Sukanlaya Thavornpon \\
\hline 17 & Learners' Knowledge of Grammar and Vocabulary in Relation to Pragmatic Competence: A Case of 1st Year Medical Students & Tawan Rattanaprasert \\
\hline 18 & The Investigation of the Perception of the Listening Strategies and Listening Difficulties of Undergraduate Students & Thitipat Wattajarukiat \\
\hline 19 & Impact of Journal Writing with Peer Feedback on EFL Students' Writing Ability & Watcharee Kulprasit \\
\hline 20 & Incidental Vocabulary Acquisition through Newspaper Reading: The Impact of Content Familiarity & Wilaiwan Lebkatem \\
\hline 21 & $\begin{array}{l}\text { Using Scripted Role-play to Improve Oral English Performance: A Study of Grade Six Students at Chariyathamsuksa } \\
\text { Foundation School, Songkhla }\end{array}$ & Ardae Makeh \\
\hline 22 & A Comparative Study of Language Use in Oral Presentations of Thai EFL Learners and English-native Students & Cherdsak Yeereem \\
\hline 23 & Effectiveness of a Computer-Assisted Vocabulary Learning Package for Nursing Students and Their Learning Attitude & Gyanandra Dewan \\
\hline 24 & Developing Ability to Translate Homonyms and Homographs via Training in Part of Speech Identification and Dictionary Use & Jitsuda Laongphol \\
\hline
\end{tabular}




\begin{tabular}{|c|c|c|}
\hline 25 & $\begin{array}{l}\text { Effects of Using Online Dictionary and Intensive Involvement Tasks in Developing EFL Learners' Receptive and Productive } \\
\text { Knowledge of Verb-Noun Collocations }\end{array}$ & Muhammadsorlaeh Hamad \\
\hline 26 & $\begin{array}{l}\text { Using Non-Scripted Role-Play to Teach Speaking Skills: A Study of English Conversation of Thai College Students at Yala } \\
\text { Rajabhat University }\end{array}$ & Nuchanan Naksevee \\
\hline 27 & The Effects of Two Types of Direct Corrective Feedbackon EFL Writing & Piyanut Kaewkasi \\
\hline 28 & $\begin{array}{l}\text { Conversation Proficiency Assessment: A Comparative Study of Two-Party Peer Interaction and Interview Interaction } \\
\text { Implemented with Thai EFL Learners }\end{array}$ & Ratchawan Ussama \\
\hline 29 & Using Scripted and Non-Scripted Role-Plays to Improve Speaking Performance of Hotel Engineering Staff & Sawinee Rodpradit \\
\hline 30 & $\begin{array}{l}\text { Cultural Contents in Fundamental English Coursebooks: A Study of New Headway and Teachers' Perceptions and } \\
\text { Expectations }\end{array}$ & Wanvisa Angsutara \\
\hline 31 & Students' Attitudes and Behaviors towards the Use of Google Translate & Arissara Sukkhwan \\
\hline 32 & Speech Acts Knowledge of Thai University Students Majoring in Tourism Industry in Southern Thailand & Jirayu Songkhro \\
\hline 33 & $\begin{array}{l}\text { Teacher Perceptions of and Confidence in Teaching Cultural Content in English Courses: A Study of Islamic Private Schools } \\
\text { in } \\
\text { Five Southern Border Provinces of Thailand }\end{array}$ & Noorulhooda Ding \\
\hline 34 & $\begin{array}{l}\text { Receptive and Productive Knowledge of Verb+Noun and Adjective+Noun Collocations of International Program and English } \\
\text { Major Students of Prince of Songkla University }\end{array}$ & Nuramal Bueraheng \\
\hline 35 & $\begin{array}{l}\text { A Comparative Study of Multiple-choice and Error Recognition Tests: Its Effects on Grammar Knowledge Development and } \\
\text { Test anxiety on Test Performance }\end{array}$ & Nur-ihsaan Nihae \\
\hline 36 & Language Learning Strategies Used by First Year Students at Thaksin University, Songkhla Campus, Thailand & Orawee Pannak \\
\hline 37 & Vocabulary Size and Vocabulary Learning Strategies of Thai University Students & Supika Nirattisai \\
\hline 38 & Improving Thai Undergraduates' English Conversation through Explicit CA- Informed Instruction & Bunthan Teng \\
\hline 39 & The Validity of and the Test Anxiety Produced by Rational Cloze Test as a Test of Vocabulary & Nurhuda Benjama \\
\hline
\end{tabular}


PRINCE OF SONGKLA UNIVERSITY THESES

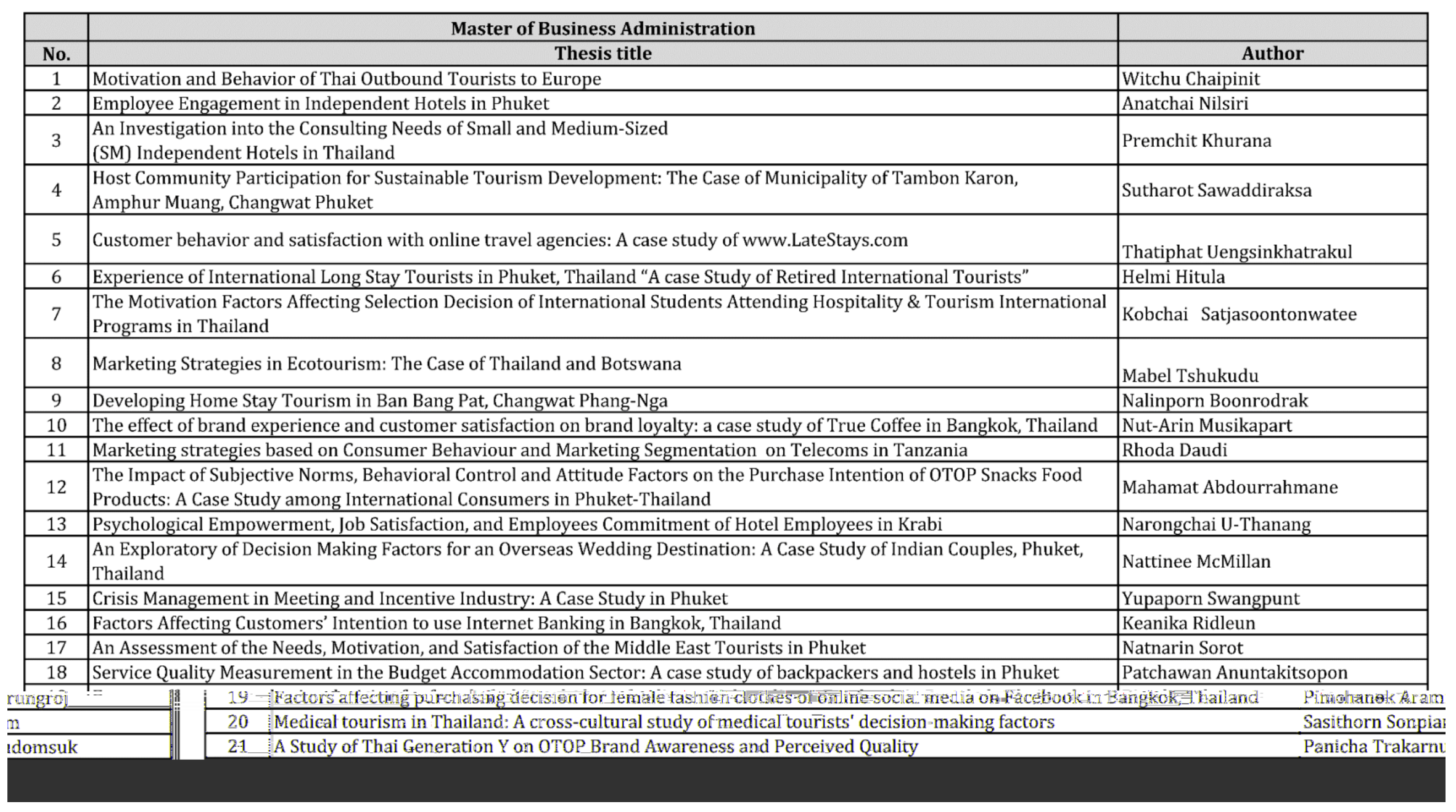

